PNL-5669

UC-98

\title{
State Energy Price System: 1983 Update Overview and Documentation
}
K. L. Imhoff
J. M. Fang
L. G. McWethy

December 1985

Prepared for the U.S. Department of Energy under Contract DE-AC06-76RLO 1830

Pacific Northwest Laboratory Operated for the U.S. Department of Energy by Battelle Memorial Institute 


\title{
DISCLAIMER
}

This report was prepared as an account of work sponsored by an agency of the United States Government. Neither the United States Government nor any agency thereof, nor any of their employees, makes any warranty, express or implied, or assumes any legal liability or responsibility for the accuracy, completeness, or usefuiness of any information, apparatus, product, or process disclosed, or represents that its use would not infringe privately owned rights. Reference herein to any specific commercial product, process, or service by trade name, trademark, manufacturer, or otherwise, does not necessarily constitute or imply its endorsement, recommendation, or favoring by the United States Government or any agency thereof. The views and opinions of authors expressed herein do not necessarily state or reflect those of the United States Government or any agency thereof.

\author{
PACIFIC NORTHWEST LABORATORY \\ operated by \\ BATTELLE \\ for the \\ UNITED STATES DEPARTMENT OF ENERGY \\ under Contract DE-AC06-76RLO 1830
}

\begin{tabular}{|c|c|}
\hline \multicolumn{2}{|c|}{ Printed in the United States of America } \\
\hline \multicolumn{2}{|c|}{ Available from } \\
\hline \multicolumn{2}{|c|}{ National Technical Information Service } \\
\hline \multicolumn{2}{|c|}{ United States Department of Commerce } \\
\hline \multicolumn{2}{|c|}{5285 Port Royal Road } \\
\hline \multicolumn{2}{|c|}{ Springfield, Virginia 22161} \\
\hline \multicolumn{2}{|c|}{$\begin{array}{l}\text { NTIS Price Codes } \\
\text { Microfiche } A 01\end{array}$} \\
\hline & \\
\hline \multicolumn{2}{|c|}{ Printed Copy } \\
\hline & Price \\
\hline Pages & Codes \\
\hline 001-025 & A02 \\
\hline 026-050 & $\mathrm{A} 03$ \\
\hline 051-075 & AO4 \\
\hline $076-100$ & A05 \\
\hline $101-125$ & A06 \\
\hline $126-150$ & A07 \\
\hline $151-175$ & $\mathrm{~A} 08$ \\
\hline $176-200$ & A09 \\
\hline 201-225 & A010 \\
\hline $226-250$ & A011 \\
\hline $251-275$ & A012 \\
\hline $276-300$ & $A 013$ \\
\hline
\end{tabular}



X. L. Imhoff
J. M. Fang
L. G. McWethy

December 1985

Prepared for the U.S. Department of Energy under contract DE-ACO6-76RLO 1830 


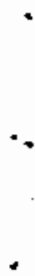




\section{EXECUTIVE SUMMARY}

This report documents the update of the State Energy Price System (STEPS) for the 1970-1983 period. The STEPS data base, developed by the Pacific Northwest Laboratory (PNL) under contract to the Office of Energy Markets and End Use, Energy Information Administration, contains national and state-leve? energy price data for ten fuels and five end-use sectors. STEPS is intended to provide energy price information for Federal, state, and local government and private sector applications. The primary objective of this study is to document the update of the price series to include data for 1983. Concurrent with the 1983 update, PNL also began verifying the reproducibility of individual prices in the data base for the 1970-1982 period. While the reproducibility check work is completed for six of the ten fuels and is integrated in the documentation for those fuels, the findings from this task are not discussed in detail in this report.

The 1983 update and the partially completed task to verify and revise STEPS prices for 1970-1982 are aimed at improving both the accuracy of reported prices, and the documentation describing computational procedures. These improvements should enhance the useability of the STEPS data base in all of its applications. The six fuel price series in STEPS that have been both verified (1970-1982) and updated (1983) are electricity, natural gas, coking coal. steam coal, distillate fuel, and diesel fuel. For motor gasoline, kerosene/jet fuel, residual fuel, and liquefied petroleum gas, the 1983 update is complete, and verification of prices for 1970-1982 is scheduled for completion in early 1986. The differences between the STEPS prices for electricity, steam coa?, and distillate fuel contained in this report and prices contained in previous STEPS reports are more pronounced. The natural gas, coking coal, and diesel fuel prices have remained similar to prices previously reported for those fuels. Because they have not yet been verified, the 1970-1982 prices for motor gasoline, kerosene/jet fuel, residual fuel, and LPG are identical to those published in the 1982 STEPS Update. 
One of the major problems with previous STEPS update documentation was the "piggy-backing" of the update reports on the original report documenting the original development of the data base. The original report contained documentation for 1970-1980, while each of the update reports contained information only about changes for 1981 or 1982. In addition, much of the original documentation was incomplete, particularly in regard to the imputation of prices for missing states. This report marks the transition to documentation that describes STEPS procedures for the entire time period covered by the price series (1970-1983 for this update). Other significant improvements in documentation have also accompanied the 1983 update; for example, all variables and computer files are coded using an established naming convention that is similar to the naming convention used by the EIA in other state-level energy data bases. Equations have been rewritten to more accurately reflect the data as reported by the source documents, and the computational procedures are more completely described. Some problems encountered in the previous versions of the STEPS documentation are not within the scope of this study; in particular, the uncertainty as to whether or not taxes are included in many of the price series is a problem that should be addressed in future revisions of STEPS. 


\section{CONTENTS}

Page

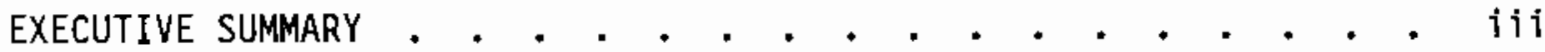

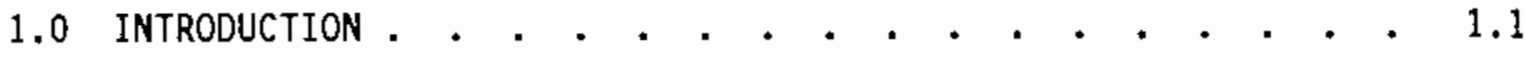

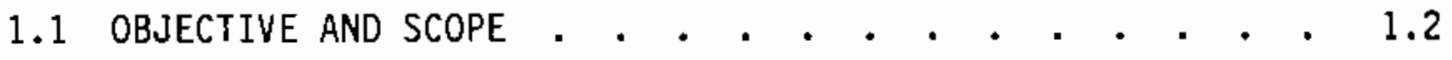

1.2 REPORT STRUCTURE . . . . . . . . . . . . . . . 1.4

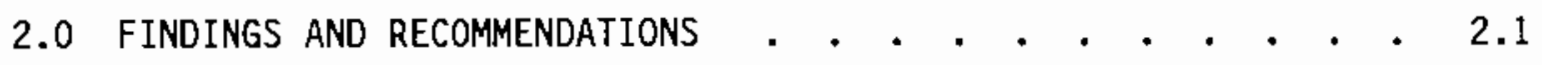

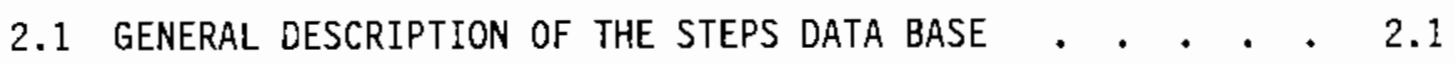

2.1 .1 Sources of Data . . . . . . . . . . . . 2.2

2.1.2 Hierarchy of Price Imputation . • . . . . . 2.4

2.2 GENERAL FINDINGS • • • • • • • • • • • • • • 2.5

2.2.1 Documentation . • . • . . • . • . . . . 2.7

2.2 .2 Computational Procedures . . . . • . . . 2.7

2.2.3 Implementation of Computational Procedures . • 2.8

2.3 SPECIFIC FINDINGS BY FUEL • • • • • • • • • • • • • 2.9

2.3.1 Electricity • • • • . • . • • • . • 2.9

2.3 .2 Natural Gas . . . . . . . . . . . 2.10

2.3 .3 Coking Coal . . . . . . . . . . . . . 2.11

2.3 .4 Steam Coal. . . . . . . . . . . . . 2.11

2.3.5 Distillate Fuel . . . . . . . . . . . 2.13

2.3.6 Motor Gasoline . . . . . . . . . . . . 2.14

2.3.7 Diesel Fuel . . . . . . . . . . . . 2.15

2.3 .8 Kerosene and Jet Fuel . . . . . . . . . . 2.15

2.3 .9 Residual Fuel . . . . . . . . . . . . 2.16

2.3.10 Liquefied Petroleum Gas . • . . • . • . 2.17

2.4 RECOMMENDATIONS • . • . . . . • . • . . . . . 2.17

3.0 METHODOLOGICAL OVERVIEW . • • • • • • • • • • • . • . 3.1

3.1 CRITERIA FOR DATA BASE DEVELOPMENT • • • • • • • • 3.1

3.2 DEFINITIONS • • • • • • • . • • • • . • • . 3.2

3.2 .1 Price Definitions . . . . . . • . • . 3.2

3.2.2 Fuel Definitions . . . . . . . . . . 3.4

3.2.3 End-Use Sector Definitions . . . . . . . . 3.6 
Page

3.3 GENERAL METHODOLOGY • • • • • • • • • • • . • • • 3.7

3.3 .1 Data Source Review . . . . . . . . . . 3.7

3.3.2 Analysis of Imputation Options . . . . . . 3.9

3.3.3 Initial Documentation . . . • . • . . . . 3.9

3.3.4 Calculation and Verification of Prices . . . 3.10

3.3.5 Final Documentation . . . . . . . . . . . 3.10

3.4 DATA AND METHODOLOGICAL ISSUES . • • . • • . • . 3.11

3.4.1 Uses of State-Level Energy Price Data . . . . . 3.11

3.4.2 Imputation and the Nature of Imputed Data . . 3.12

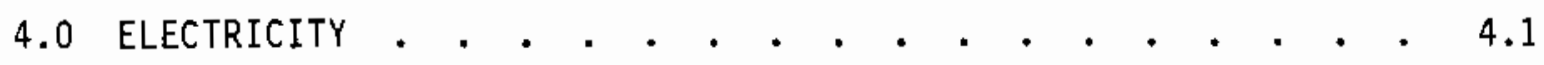

4.1 DATA SOURCES • • • • • . • . • • • • • . 4.1

4.2 CONVERSION FACTOR . . . . . . . . . . . . . . . 4.1

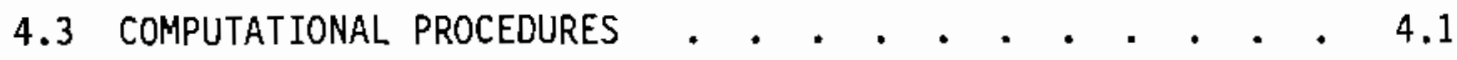

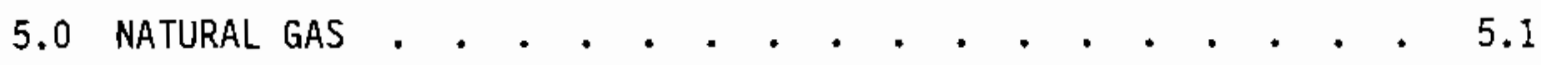

5.1 RESIDENTIAL, COMMERCIAL, AND INDUSTRIAL SECTORS . • . 5.1

5.1 .1 Data Sources . . . . . . . . . . . . . 5.1

5.1 .2 Conversion Factors . . . . . . . . . . . 5.1

5.1 .3 Computational Procedures . . . . . . . . 5.6

5.2 ELECTRIC UTILITY SECTOR • • • • • • • • • • • • 5.8

5.2 .1 Data Sources . . . . . . . . . . . . 5.8

5.2 .2 Conversion Factors . . . . . . . . . . . 5.8

5.2.3 Computational Procedures: 1970-1972 • • • • . 5.9

5.2.4 Computational Procedures: $1973-1974,1983$ • . 5.9

5.2.5 Computational Procedures: 1975-1979 • . • . . 5.11

5.2.6 Computational Procedures: 1980-1982 . . • . . 5.11

5.2.7 Imputation of Alaska Prices: 1973-1983 • • . 5.12

6.0 COKING COAL • . . . . . . . . . . . . . . . . . 6.1

6.1 DATA SOURCES . . . . . . . . . . . . . . . . 6.1

6.2 CONVERSION FACTOR • • • . • • • • • • • • . . 6.2

6.3 COMPUTATIONAL PROCEDURES: $1970-1983$. . . . . . . 6.2

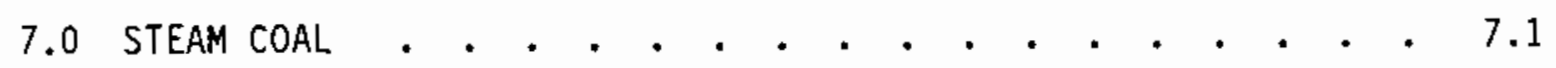

7.1 ELECTRIC UTILITY SECTOR • • • • • • • • • • • • • 7.1

7.1 .1 Data Sources . • . • . • . • • • • • • 7.1

7.1 .2 Conversion Factors . . . • . • • • . . . 7.1

7.1.3 Computational Procedures: 1970-1972 • • . . . 7.1 
Page

7.1.4 Computational Procedures: 1973-1983 . . . . . 7.2

7.1.5 Imputation of Alaska Prices . . . . . . . . 7.3

7.2 RESIDENTIAL SECTOR . . . . . . . . . . . . . 7.5

7.2.1 Data Sources . . . . . . . . . . . . 7.5

7.2 .2 Conversion Factors . . . . . . . . . . 7.7

7.2.3 Computational Procedures: Btu State Prices,

1971-1978 . . . . . . . . . . . . . 7.7

7.2.4 Computational Procedures: Btu State Prices,

7.2.5 Computational Procedures: Btu State Prices, 1970 . 7.10

7.2.6 Computational Procedures: Btu U.S. Prices, 1970-1983 . . . . . . . . . . . . . 7.14

7.2.7 Computational Procedures: Physical Unit Prices, 1970-1983 . . . . . . . . . . . . . 7.14

7.3 INDUSTRIAL SECTOR . . . . . . . . . . . . . . . 7.15

7.3.1 Data Sources . . . . . . . . . . . . . 7.15

7.3 .2 Conversion Factors . . . . . . . . . . . 7.15

7.3.3 Computational Procedures: Physical Unit Prices, 1970-1979 . . . . . . . . . . . . 7.15

7.3.4 Computational Procedures: Physical Unit Prices, 1980-1983 . . . . . . . . . . . . . 7.21

7.3.5 Computational Procedures: Btu Prices, 1970-1983 . 7.23

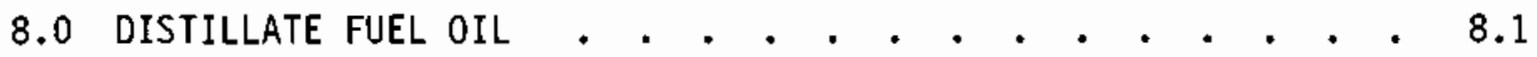

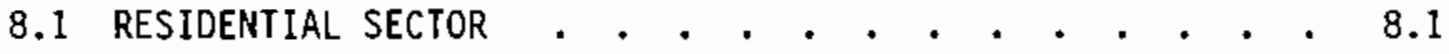

8.1 .1 Data Sources . . . . . . . . . . . . 8.1

8.1 .2 Conversion Factor . . . . . . . . . . . 8.2

8.1.3 Computational Procedures: Physical Unit State

8.1.4 Computational Procedures: Physical Unit State Prices, 1978-1982 . . . . . . . . . 8.7

8.1.5 Computational Procedures: Physical Unit State Prices, 1983 . . . . . . . . . . . . 8.10

8.1.6 Computational Procedures: Physical Unit State Prices, 1970-1974 . . . . . . . . . . 8.12

8.1.7 Computational Procedures: Physical Unit U.S. Prices, 1970-1983 . . . . . . . . . . 8.14

8.1.8 Computationa] Procedures: Btu Prices, 1970-1983 .8 .15 
Page

8.2 COMMERCIAL SECTOR . • • . • • • • • • . • . • 8.15

8.2.1 Data Sources . . . . . . . . . . . . 8.15

8.2.2 Conversion Factor . . . . . . . . . . 8.16

8.2.3 Computational Procedures: Physical Unit State

8.2.4 Computational Procedures: Physical Unit State

8.2.5 Computational Procedures: Physical Unit U.S.
Prices, $1970-1983$. . . . . . . . . 8.22

8.2.6 Computational Procedures: Btu Prices, 1970-1983 . 8.22

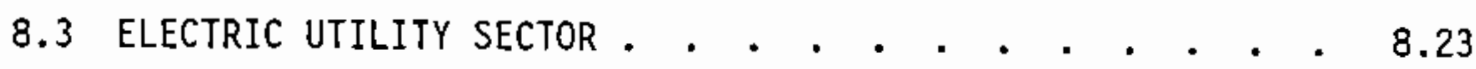

8.3.1 Data Sources . . . . . . . . . . . . 8.23

8.3.2 Conversion Factors . . . . . . . . . . . 8.23

8.3.3 Computational Procedures: 1973-1983 . . . . . 8.23

8.3.4 Computational Procedures: 1970-1973 . . . . 8.26

8.4 INDUSTRIAL SECTOR . . . . . . . . . . . . . . 8.29

8.4.1 Data Sources . . . . . . . . . . . . . 8.29

8.4.2 Conversion Factor . . . . . . . . . . 8.30

8.4.3 Computational Procedures: Physical Unit State

8.4.4 Computational Procedures: Physical Unit State Prices, 1982 . . . . . . . . . 8.32

8.4.5 Computational Procedures: Physical Unit State Prices, 1983 . . . . . . . . . . . 8.33

8.4.6 Computational Procedures: Physical Unit U.S.
Prices, $1970-1983$. .

8.4.7 Computational Procedures: Btu Prices, 1970-1983 • 8.36

9.0 MOTOR GASOLINE . . . . . . . . . . . . . . . . . . 9.1

9.1 DATA SOURCES • . • . . . . . . . . . . . . . 9.1

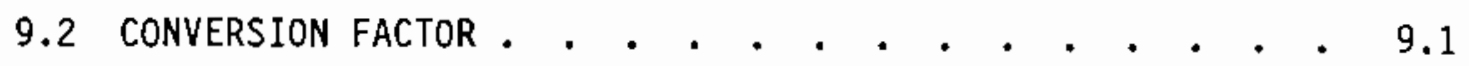

9.3 COMPUTATIONAL PROCEDURES . . . . . . . . . . . . . 9.2

10.0 DIESEL FUEL • • • • • • • • • • • • • • . . . . 10.1

10.1 DATA SOURCES . . . . . . . . . . . . . . . 10.1

10.2 CONVERSION FACTOR . . . . . . . . . . . . . . 10.1

10.3 COMPUTATIONAL PROCEDURES . . • . • . • . . . . . . 10.1

10.3.1 Physical Unit Prices, 1970-1976 • . • . . . 10.2

10.3.2 Physical Unit Prices, 1977-1983 • • • • • . 10.3

10.3.3 Btu Prices, 1970-1983 . . . . . . . . . . 10.4 


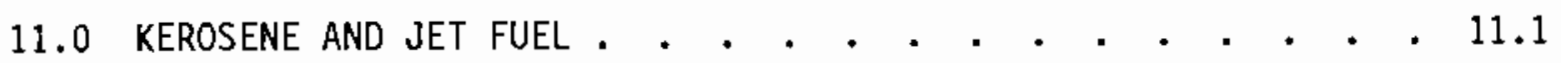

11.1 RESIDENTIAL SECTOR . . . . . . . . . . . . . . . 11.1

11.1.1 Data Sources . . . . . . . . . . . . . 11.1

11.1 .2 Conversion Factor . . . . . . . . . . . 11.2

11.1.3 Computational Procedures . . . . . . . . . 11.2

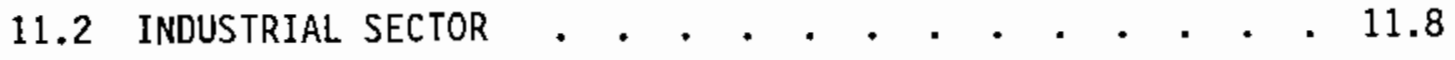

11.2.1 Data Sources . . . . . . . . . . . . . 11.8

11.2.2 Conversion Factor . . . . . . . . . . . 11.8

11.2.3 Computational Procedures . . . . . . . . . 11.8

11.3 TRANSPORTATION SECTOR . . . . . . . . . . . . 11.10

11.3.1 Data Sources . . . . . . . . . . . . . 11.10

11.3.2 Conversion Factor . . . . . . . . . . . 11.10

11.3.3 Computational Procedures . . . . . . . . . 11.10

12.0 RESIDUAL FUEL . • . . . . . . . . • • . . . . 12.1

12.1 ELECTRIC UTILITY SECTOR . . . . . . . . . . . 12.1

12.1.1 Data Source . . . . . . . . . . . . . 12.1

12.1.2 Conversion Factors . . . . . . . . . . 12.1

12.1.3 Computational Procedures . . . . . . . . . 12.2

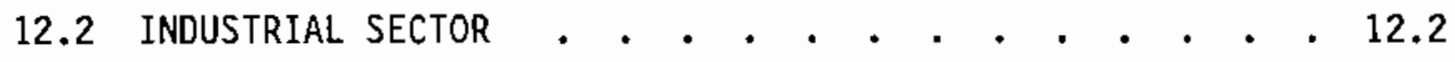

12.2.1 Data Sources . . . . . . . . . . . . . 12.3

12.2.2 Conversion Factor . . . . . . . . . . 12.3

12.2.3 Computational Procedures . . . . . . . . 12.3

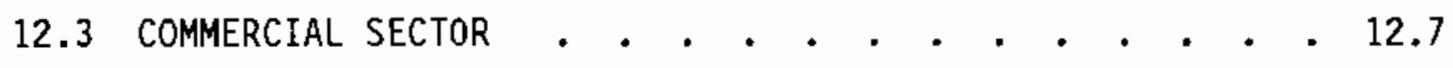

12.3.1 Data Sources . . . . . . . . . . . . . 12.7

12.3.2 Conversion Factor . . . . . . . . . . 12.8

12.3.3 Computational Procedures . . . . . . . . . 12.8

12.4 TRANSPORTATION SECTOR . . . . . . . . . . . . 12.10

12.4.1 Data Sources. . . . . . . . . . . . . 12.10

12.4.2 Conversion Factor . . . . . . . . . . . 12.11

12.4.3 Computational Procedures . . . . . . . . . 12.11

13.0 LIQUEFIED PETROLEUM GAS • • . . . . . . . . . . . . . 13.1

13.1 RESIDENTIAL SECTOR

13.1.1 Data Sources. . . . . . . . . . . . . 13.1

13.1.2 Conversion Factor . . . . . . . . . . . 13.1

13.1.3 Computational Procedures . . . . . . . . . 13.1 
Page

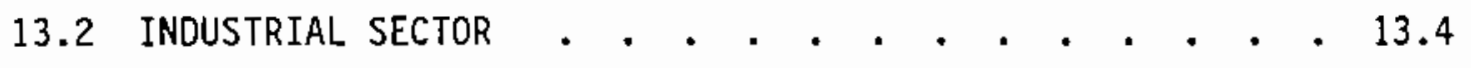

13.2.1 Data Sources . . . . . . . . . . . . . 13.4

13.2.2 Conversion Factor . . . . . . . . . . 13.4

13.2.3 Computational Procedures. . . . . . . . . 13.4

REFERENCES • . . . • . . . . . . . . . • . . . . R.1

APPENDIX A - STEPS VARIABLE NAMING CONVENTION . . . . . . . . A.1

APPENOIX B - FINAL PHYSICAL UNIT PRICES . . . . . . . . . . B.1

APPENDIX C - FINAL BTU PRICES . . . . . . . . . . . . . C.1 


\section{IABLES}

Page

1.1 STEPS End-Use Sector Coverage by Fuel, 1970-1983 . . . . . 1.3

2.1 Sources of STEPS Price Data by Fuel and End-Use Sector . . . 2.3

2.2 Hierarchy of Imputation in the STEPS Data Base . . . . . 2.6

4.1 States Without Reported STEPS Transportation Sector Electricity Prices, 1970-1983 . . . . . . . . . . 4.4

5.1 Btu Conversion Factors for Natural Gas, by State, 1970-1983 . 5.2

5.2 Tables from cost and Quality of Fuels Used to Calculate Electric Utility Sector Natural Gas Prices . . . . . 5.8

5.3 States With No Electric Utility Sector Prices Reported by STEPS, 1973-1983 . . . . . . . . . . . . . 5.10

6.1 Numbers of Coke and Coal Chemicals Tables Used for Price Data, 1970-1980 . . . . . . . . . . . . 6.1

6.2 Coking Coal Price Assignments, 1970-1983 . . . . . . . 6.3

7.1 Imputation of Steam Coal Electric Utility Alaska Btu Prices for 1971, 1973, 1975, and 1978 . . . . . . . 7.4

7.2 Imputation of Steam Coal Electric Utility Alaska Physical Unit Prices for 1971, 1973, 1975, and 1978 . . 7.6

7.3 Steam Coal Residential Sector Conversion Factors . • • . 7.7

7.4 Imputation of Missing State Prices: Steam Coal Residential Sector, 1971-1978 . . . . . . . . . . 7.9

7.5 Estimated Values of Dummy Variable Coefficients: Residential Sector Steam Coal (Equation 7.12) . . . . . . . . 7.11

7.6 Assignment of Prices for States Missing Cost and Quality Average Spot Coal Prices, 1974-1983 . . . . . . . . 7.12

7.7 Estimated Values of Dummy Variable Coefficients: Steam Coal Residential Sector (Equation 7.13) . . . . . . . . 7.13

7.8 Steam Coal Industrial Sector Conversion Factors . . . . . 7.16

7.9 Imputation of Missing ASM/CM Steam Coal Industrial Sector Data for 1971 and 1974-1979 . . . . . . . . . . 7.17

7.10 Steam Coal Electric Utility Sector Price Assignments Used to Estimate and Implement Equation 7.20, 1970-1977 . . . 7.19

7.11 Estimated Values of Dummy Variable Coefficients: Steam Coal Industrial Sector (Equation 7.18) . . . . . . . . 7.20

7.12 Industrial Sector Steam Coal Imputations for 1980-1983 . . 7.22

8.1 Platt's Prices for No. 2 Fuel, Assigned to States: 1970-1983 
Page

8.2 Estimated Values for the Federal Region Dummy Variables: Distillate Residential Sector, 1970-1974 . . . . . 8.13

8.3 Assignment of Energy Prices Commercial Sector Markups to States, 1970-1982. . . . . . . . . . . . . 8.18

8.4 Imputation of Missing Monthly PMM Commercial/Institutional Distillate Prices, 1983 . . . . . . . . . . . . 8.20

8.5 States with No Distillate Electric Utility Sector Prices Reported by STEPS, 1970-1983 . . . . . . . . . . 8.24

8.6 Estimated Values for State Dummy Coefficients: Distillate Electric Utility Sector Physical Unit Prices

(Equation 8.52) . . . . . . . . . . . . . . 8.27

8.7 Estimated Values for State Dummy Coefficients: Distillate Electric Utility Sector Btu Prices (Equation 8.53) . . . 8.28

8.8 Adjacent State Assignments for the Imputation of Missing Data: Distillate Industrial Sector, 1974-1981 . . 8.31

8.9 Imputation of Missing Monthly Prices: Distillate

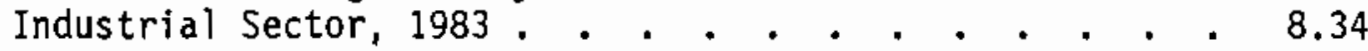

9.1 Assignments for Missing Monthly Gasoline Price Data from Petroleum Marketing Monthly, 1983 . . . . . . . . 9.2

11.1 Other Distillate Sales by PAD Districts and Monthiy Average Sales

12.1 Assignment of Adjacent States to be Used in the Imputation of Missing ASM/CM Prices: Residual Fuel Industrial Sector, 1978-1981 . . . . . . . . . . . . . . 12.4

12.2 No. 6 Fuel $0 i 1$ Price Assignments from Platt's: 1978-1983 . 12.5

12.3 Adjacent State Assignments for Imputing Missing Prices: Residual Electric Utility Sector, 1983 . . . . . . 12.9

12.4 Transportation Sector End-Uses for Residual Fue1, by State, 1983 . . . . . . . . . . . . . . . 12.12

13.1 Price Assignments for States Missing ASM/CM Prices, 1978-1981

B.1 Electricity Prices: Residential Sector $(\$ / \mathrm{kWh})$. . . . . B.3

B.2 Electricity Prices: Commercial Sector $(\$ / k$ Wh $)$. . . . . B.5

B.3 Electricity Prices: Industrial Sector $(\$ / \mathrm{kWh})$. . . . . B.7

B.4 Electricity Prices: Transportation Sector $(\$ / \mathrm{kWh})$. . . . B.9

B.5 Natural Gas Prices: Residential Sector $(\$ / 1000 \mathrm{cu} \mathrm{ft})$. . B.11

B.6 Natural Gas Prices: Commercial Sector $(\$ / 1000 \mathrm{cu} \mathrm{ft})$. . . B.13

B.7 Natural Gas Prices: Industrial Sector $(\$ / 1000 \mathrm{cu} \mathrm{ft})$. . B.15

B.8 Natural Gas Prices: Electric Utility Sector $(\$ / 1000 \mathrm{cu} \mathrm{ft})$. B.17

B.9 Coking Coal Prices: Industrial Sector (\$/ton) . . . . . B.19

B.10 Stean Coal Prices: Residential Sector $(\$ /$ ton $)$. . . . . B.21 
Page

B.11 Steam Coal Prices: Industrial Sector (\$/ton) . . . . . B.23

B.12 Steam Coal Prices: Electric Utility Sector (\$/ton) • . . B.25

B.13 Distillate Fuel Prices: Residential Sector (\$/gal) • • • B.27

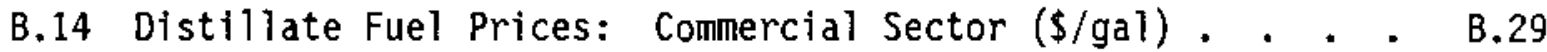

B.15 Distillate Fuel Prices: Industrial Sector (\$/gal) . . . . B.31

B.16 Distillate Fuel Prices: Electric Utility Sector (\$/gal) • • B.33

B.17 Motor Gasoline Prices: Transportation Sector (\$/gal) . • • B.35

B.18 Diesel Fuel Prices: Transportation Sector (\$/gal) . . . . B.37

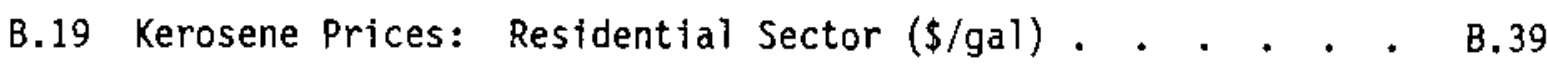

B.20 Kerosene Prices: Industrial Sector (\$/gal) . . . . . . B.41

B.21 Jet Fuel Prices: Transportation Sector $(\$ / g a 1)$. . . . . B.43

B.22 Residual Fuel Prices: Commercial Sector $(\$ / b b l)$. . . . B.45

B.23 Residual Fuel Prices: Industrial Sector $(\$ / b b])$. . . B.47

B.24 Residual Fuel Prices: Transportation Sector $(\$ / b b l)$. . . B.49

B.25 Residual Fuel Prices: Electric Utility Sector $(\$ / b b l)$. . B.51

B.26 LPG Prices: Residential Sector (\$/gal) . . . . . . . 8.53

B.27 LPG Prices: Industrial Sector (\$/gal) . . . . . . . . 8.55

C.1 Electricity Prices: Residential Sector (\$/MMBtu) . . . . C.3

C.2 Electricity Prices: Commercial Sector (\$/MMBtu) . . . . . c.5

C.3 Electricity Prices: Industrial Sector (\$/MMBtu) . . . . . C.7

C.4 Electricity Prices: Transportation Sector (\$/MMBtu) . . . C.9

C.5 Natural Gas Prices: Residential Sector (\$/MMBtu) . . . . C.I1

C.6 Natural Gas Prices: Commercial Sector (\$/MMBtu) . . . . . C.13

C.7 Natural Gas Prices: Industrial Sector (\$/MMBtu) . . . . . c.15

C.8 Natural Gas Prices: Electric Utility Sector (\$/MMBtu) . . . c.17

C.9 Coking Coal Prices: Industrial Sector (\$/MMBtu) . . . . . c.19

C.10 Steam Coal Prices: Residential Sector (\$/MMBtu) . . . . C.21

C.11 Steam Coal Prices: Industrial Sector (\$/MMBtu) . . . . . C.23

C.12 Steam Coal Prices: Electric Utility Sector (\$/MMBtu) . . . C.25

C.13 Distillate Fuel Prices: Residential Sector (\$/MMBtu) • • • C.27

C.14 Distillate Fuel Prices: Commercial Sector (\$/MMBtu) . . . c.29

C.15 Distillate Fuel Prices: Industrial Sector (\$/MMBtu) . . . c.31

C.16 Distillate Fuel Prices: Electric Utility Sector (\$/MMBtu) . C.33

C.17 Motor Gasoline Prices: Transportation Sector (\$/MMBtu) . . C.35

C.18 Diesel Fuel Prices: Transportation Sector (\$/MMBtu) . . . C.37 
C.19 Kerosene Prices: Residential Sector (\$/MMBtu) . . . . . C.39

C.20 Kerosene Prices: Industrial Sector (\$/MMBtu) . . . . . C.41

C.21 Jet Fuel Prices: Transportation Sector (\$/MMBtu) . . . . C.43

C.22 Residual Fuel Prices: Commercial Sector (\$/MMBtu) . . . C.45

C.23 Residual fuel Prices: Industrial Sector (\$/MMBtu) . . . . C.47

C.24 Residual fuel Prices: Transportation Sector (\$/MMBtu) . . C.49

C.25 Residual Fuel Prices: Electric Utility Sector (\$/MMBtu) . . C.51

C.26 LPG Prices: Residential Sector (\$/MMBtu) . . . . . . C.53

C.27 LPG Prices: Industrial Sector (\$/MMBtu) . . . . . . . C.55 


\subsection{INTRODUCLION}

The mission of the Energy Information Administration (EIA) is to carry out "a central, comprehensive, and unified energy data and information program which will collect, evaluate, assemble, analyze, and disseminate data and information."(a) To fulfill this mission, the Division of Economics and Statistics, Office of Energy Markets and End Use has the responsibility to maintain and improve existing energy data series and to conduct sector surveys of energy consumption. One data series being maintained and updated by the Division of Economics and Statistics is the series of state-level energy prices by end-use sectors known as the State Energy Price System (STEPS).

The Pacific Northwest Laboratory (PNL) began assisting EIA with the development and evaluation of the STEPS data base in August 1980. The initial data base construction was conducted on a fuel-by-fuel basis, where potential data sources for each price series were reviewed and screened. Imputation strategies were developed for cases where price data were not directly available from a published data source. The resulting state-level prices and the corresponding documentation of this first effort were published as State Energy Price System (Volume I--overview and Technial Documentation and Volume II-Data Base Development). (b) PNL later published State Energy Price System: 1981 Update (Fang, Imhoff, and Hood 1983) and State Energy Price System: 1982 Update (Imhoff and Fang 1984). These latter reports contained the 1981 and 1982 updated versions of the STEPS price series and a description of the changes in computational procedures needed to incorporate 1981 and 1982 prices into the data base.

Currently, the STEPS data base is a key input to the EIA's State Energy Price and Expenditure Report (SEPER), which combines energy prices with energy consumption data from State Energy Data System (SEDS) to compute national and

(a) The Department of Energy Organization Act, Public Law 95-91, Section 205, a(2).

(b)Fang, et al (1982); also published as Pacific Northwest Laboratory (1982). 
state-level energy expenditures. The continuing use of STEPS in Federal and state policy analyses, as well as its growing use by the private sector, called for improvements to the computation and reporting of the price series. In addition, changes in available energy price data sources suggested that a review of data sources and computational procedures would be advisable to ensure that the STEPS price series are reasonable, consistent, and welldocumented.

In response to this need, PNL began two tasks: 1) updating the STEPS price series to 1983 ; and 2 ) verifying the reproducibility of previously calculated prices for 1970-1982. This report documents the 1983 update for all ten fuels covered by STEPS. The need for the second task, the reproducibility check of prices for 1970-1982, became apparent when users were not able to recreate some prices in the data base. The purpose of this task was to verify the input data and computational procedures used to generate the STEPS price series. The results of the verification of prices for 1970-1982 for the six completed fuels are reflected in the revised documentation and final prices contained in this report. For the remaining four fuels (motor gasoline, kerosene/jet fuel, residual fuel, and liquefied petroleum gas), only documentation for the 1983 update is inciuded in this report. Unti] the verification task is completed for these fuels, documentation for the 1970-1982 period can be found in the documents State Energy Price System (Volume I) and State. Energy Price System: 1982 Update.

\subsection{OBJECTIVE AND SCOPE}

The primary objective of this study is to improve and update the existing STEPS data base to include energy prices for 1983 using reasonable, consistent, and well-documented published data sources. This objective includes promoting consistency within the STEPS data base and between STEPS and other energy prices published by EIA. As part of this effort, PNL was asked to investigate the incorporation of petroleum price data from the EIA's Petroleum Marketing Monthly into STEPS for 1983 and future years. The desired end result of this effort continues to be a state-level energy price series by fuel type and by end-use sector. 
The energy types included in STEPS are four nonpetroleum fuels or energy forms (electricity, natural gas, coking coal, and steam coal), and six petroleum products: distillate fuel, motor gasoline, diesel fuel, kerosene/jet fuel, residual fuel, and liquefied petroleum gas (LPG). The end-use sectors covered by the data base are the residential, commercial, industrial, transportation, and electric utflity sectors. Price series are developed only for the sectors with reported use of the specific fuel in question (generally as reported in SEDS); see Table 1.1 for the sector coverage offered by STEPS. All 50 states, the District of Columbia, and the United States as a whole are covered. Generally, if no or very little consumption is reported by SEDS for a state, no STEPS energy prices are developed. Both Btu and physical unit prices are developed for all fuels.

IABLE 1.1. STEPS End-Use Sector Coverage by Fuel, 1970-1983

End-Use Sector

Fuel/Energy Type_ dential $\begin{gathered}\text { Commer- Indus- } \\ \text { cial transpor- Electric } \\ \text { trial tation Utility }\end{gathered}$

Nonpetroleum Fuels

Electricity

Natural Gas

Coking Coal

Steam Coal

Petroleum Fuels

Distillate Fuel

Motor Gasoline

Diesel Fuel

Kerosene/Jet Fuel

Residual Fuel

LPG

$\star$
$\star$
-
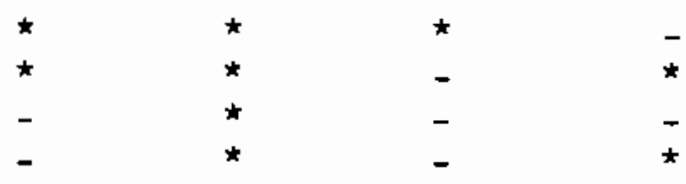

Key: "*" = contained in STEPS; "-" = not contained in STEPS.

Source: Pacific Northwest Laboratory 


\subsection{REPORT STRUCTURE}

The remainder of this report contains the findings, methodology, and final documentation for the 1983 STEPS update work. Chapter 2.0 contains the findings and recommendations associated with the completed update work. Chapter 3.0 discusses the general approach used for developing the original STEPS data base, for verifying the reproducibility of the data base, and for updating the data base for 1983 . Chapters 4.0, 5.0,6.0, 7.0, 8.0, and 10.0 contain the complete STEPS documentation (1970-1983) for electricity, natural gas, coking coal, steam coal, distillate fuel, and diesel fuel, respectively. Chapters $9.0,11.0,12.0$, and 13.0 contain documentation for the 1983 update for motor gasoline, kerosene/jet fuel, residual fuel, and LPG, respectively. Since the reproducibility work for these latter four fuels is currently underway, documentation for 1970-1982 for these fuels can be found in state Energy Price System (Volume I) and State Energy Price System: 1982 Update.

Following the references section, Appendix A contains the key to the variable naming convention used in STEPS equations and computer files. Appendix $B$ contains the final calculated STEPS prices in physical units, while Appendix $C$ contains the final calculated STEPS prices in dollars per mitlion Btu, 


\subsection{EINDINGS AND RECOMMENDATIONS}

This chapter contains a summary of the findings and recommendations associated with the 1983 update of the STEPS data base. Some of the major findings from the development of the original STEPS price series are also discussed. Since the STEPS data base itself is the primary "finding, "Section 2.1 gives a general description of the data base. Section 2.2 discusses general findings and Section 2.3 discusses specific findings by fuel. Section 2.4 contains recommendations formulated for future improvements to the STEPS data base.

\subsection{GENERAL DESCRIPIION OF THE STEPS DATA BASE}

The State Energy Price System contains time series price data for energy and fuels by end-use sector for states and the United States as a whole. Prices per million Btu and physical unit prices are developed for each of the following ten fuels: electricity, natural gas, coking coal, steam coal, distillate fuel, motor gasoline, diesel fuel, kerosene/jet fuel, residual fuel, and liquefied petroleum gas (LPG). The end-use sectors covered are residential, commercial, industrial, transportation, and electric utility. The individual price series, cross-classified by fuel and end-use sector, are shown in Table 1.1 of Chapter 1.0. Note that the 1983 updated version of STEPS no longer contains transportation sector prices for natural gas. The 1983 version of the STEPS data base contains prices covering the period 1970-1983. Previous versions of STEPS contained prices from 1960 through 1982 for electricity and natural gas.

The STEPS data base is compiled from various data sources, including those published by the EIA and other Federal agencies, as well as those published by private groups. To the extent possible, price data are taken directly from source documents. In many cases, however, prices are calculated using revenue (cost) and sales (volume) data. If a data source does not cover all the states for which consumption of a fuel is reported by SEDS, missing state prices are developed using an imputation strategy. Data sources are 
briefly summarized below; detailed information about data sources and computational procedures by fuel can be found in Chapters 4.0 through 13.0 .

\subsubsection{Sources of Data}

The various published data sources used to compile the STEPS data base originate with the Energy Information Administration, other Federal agencies, and other non-Federal groups. Table 2.1 shows the distribution of price data sources by end-use sector and fuel. The bulk of the data used by STEPS are published by the EIA and other Federal agencies. A brief discussion of each type of data source is presented below.

EIA Sources. Since the EIA is the primary Federal agency charged with the collection and publication of objective and validated energy data, and since consistency with other published EIA prices is an important criteria in the development of STEPS, many EIA series are used in STEPS. Data from the EIA's Natural Gas Annual and Cost and Quality of Fuels for Electric Utility Plants provided the data for the natural gas price series. Cost and Quality of Fuels also provided electric utility sector data for 1973-1983 for steam coal, distillate fuel, kerosene/jet fuel (1973-1982), and residual fuel. coking coal prices are taken exclusively from coke and coal chemicals and Quarterly Coa_ Report. Data from forms EIA-3 and EIA-9A are used for the steam coal and distillate fuel series, respectively. Several of the petroleum series have 1983 prices based on EIA's Petroleum Marketing Monthly. Other EIA sources used include Annual Energy Review, Monthly Energy Review, State Energy Data System (SEDS), Monthly Petroleum Product Price Report, Monthly Petroleum Supply Annual, Retail Sales and Inventories of Fuel $0 i l$, and Deliveries of Fuel $0 i l$ and Kerosene.

It should be noted that predecessor documents to the EIA publications, such as the 8ureau of Mines Natural Gas Production and Consumption: Annual (predecessor to Natural Gas Annual), are treated as an EIA data source. The electricity and LPG price series are the only STEPS series that do not use any EIA publications for basic price data; the electricity series uses EIA data only to adjust state-level prices taken from Edison Electric Institute's Statistical Year Book of the Electric Uti]ity Industry. 


\section{TABLE 2.1. Sources of STEPS Price Data by Fuel and End-Use Sector}

\begin{tabular}{|c|c|c|c|c|c|}
\hline \multirow[b]{2}{*}{ Energy/Fuel } & \multicolumn{5}{|c|}{ End-Use Sector } \\
\hline & Residential & Commercial & Industrial & Transportation & Electric Jtility \\
\hline Electricity & $\begin{array}{l}\frac{\text { Statistical Year }}{\text { Sook }} \\
\text { Annual Energy } \\
\text { Review }\end{array}$ & $\begin{array}{l}\frac{\text { Statistical Year }}{\text { Book }} \\
\frac{\text { Annual Energy }}{\text { Review }}\end{array}$ & $\begin{array}{l}\frac{\text { Statistical Year }}{\text { Book }} \\
\frac{\text { Annual Energy }}{\text { Review }}\end{array}$ & $\frac{\text { Stațistical Year }}{\underline{\text { Book }}}$ & --- \\
\hline ilatural Gas & Haturai Gas Annual & Naturai Gas Annual & Natural Gas Annual & --- & $\frac{\frac{\text { Jatural Gas }}{\text { annual }}}{\frac{\text { Gost and }}{\text { Euality of }}}$ \\
\hline Coking Cod 1 & $\cdots$ & --- & $\begin{array}{l}\text { Coke and Coal } \\
\frac{\frac{\text { Chemicals }}{\text { Qurterly Coul }}}{\text { Report }}\end{array}$ & $--\infty$ & $\rightarrow$ \\
\hline Steam Codl & $\begin{array}{l}\text { Gas Househeating } \\
\text { Survey } \\
\text { Statisticat Year } \\
\text { Book }\end{array}$ & - & $\frac{\text { Annual Survey/Census }}{0 \text { of Manufactures }}$ & --- & $\begin{array}{l}\frac{\text { Statistical year }}{\text { Book }} \\
\frac{\text { Cost and Qudity }}{\text { uf Futis }}\end{array}$ \\
\hline Distillate Fuel & $\begin{array}{l}\frac{\text { Monthly Energy }}{\text { Review }} \\
\frac{\text { platt's oil Price }}{\text { Handbook }}\end{array}$ & $\begin{array}{l}\frac{\text { Energy Prices: }}{1960-73} \\
\frac{\text { Platt's } 0 \text { il Price }}{\text { Handbook }}\end{array}$ & $\begin{array}{l}\frac{\text { Annual Survey/Census }}{\text { of Manufactures }} \\
\frac{\text { Platts oil Price }}{\text { Handbook }}\end{array}$ & $\cdots$ & $\begin{array}{l}\frac{\text { Statistical Fear }}{\text { book }} \\
\frac{\text { Cost and Quality }}{\text { of Fuels }}\end{array}$ \\
\hline $\begin{array}{l}\text { Motor Gasoline } \\
(1983 \text { on } 1 y)\end{array}$ & -- & --- & --- & $\begin{array}{l}\frac{\text { Petroleut }}{\text { Marketing }} \\
\frac{\text { Monthly }}{\text { consumer Prices: }} \\
\frac{\text { Energy }}{\text { Mong }}\end{array}$ & -- \\
\hline Qiesel Fuel & --- & --- & -- & Agricultural Prices & --- \\
\hline $\begin{array}{l}\text { Kerosene/Jet fuel } \\
(1983 \text { only) }\end{array}$ & $\frac{\text { Agricultural Prices }}{\frac{\text { Producer Prices }}{\text { and Price }}}$ & -- & $\begin{array}{l}\text { Producer Prices and } \\
\text { Price Indexes } \\
\text { STESS Industridi } \\
\text { Distillate Prices }\end{array}$ & $\frac{\text { Petroleum Marketing }}{\text { Monthly }}$ & -- \\
\hline $\begin{array}{c}\text { Residual Fuel } \\
(1983 \text {. on ly) }\end{array}$ & -- & $\begin{array}{l}\text { STEPS Electric } \\
\text { Utility } \\
\text { Residual Prices } \\
\text { Monthly Energy } \\
\text { Review }\end{array}$ & $\begin{array}{l}\frac{\text { Annual Survey/Census }}{\text { of Manufactures }} \\
\text { Platts 0il Price } \\
\text { Hardbook }\end{array}$ & $\begin{array}{l}\text { Month 1y Energy } \\
\text { Review } \\
\text { STEPS Cornmercial } \\
\text { Residual Prices }\end{array}$ & $\frac{\text { Cost arid Quality }}{\text { of ruels }}$ \\
\hline $\begin{array}{l}\text { LPG } \\
(1983 \text { on } 1 y)\end{array}$ & $\frac{\text { Gas Howseheat ing }}{\text { Survey }}$ & --- & $\frac{\text { Agriculturd Prices }}{\text { Annudl Surveyl }}$ & --- & $-2-$ \\
\hline
\end{tabular}

Source: Pacific Morthwest Laboratory 
Other Federal Sources. Several non-EIA Federal data sources are used in the construction of STEPS. Data from the Bureau of the Census are taken from Annual Survey of Manufactures, Census of Manufactures, and Statistical

Abstract. The Bureau of Labor Statistics' Consumer Prices: Energy and Producer Prices and Price Indexes are used for the motor gasoline and kerosene/jet fuel price series, respectively. The diesel, kerosene residential, and LPG industrial price series are based on price data from Agricultural Prices, published by the Crop Reporting Board, U.S. Department of Agriculture. The state-level diesel and gasoline monthly consumption volumes published by the Federal Highway Administration in Highway Statistics are also used.

Non-Federal Sources. Four non-EIA, non-Federal publications representing industry or quasi-industry sources are used to construct the electricity, steam coal, distillate, motor gasoline, residual fuel, and LPG price series. Edison Electric Institute's Statistical Year Book of the Electric Utility Industry is used for all sectors in the electricity price series, and for the electric utility sector in the steam coal, distillate and residual fuel price series. Platt's Oil Price Handbook and Oilmanac, published by McGraw-Hill, provides wholesale distillate and residual fuel prices which are used to estimate retail prices. Platt's also is a source for motor gasoline retail prices. The third and fourth non-Federal data sources are the American Gas Association's Gas Househeating Survey and Gas Facts. The former publication is used for residential sector steam coal and LPG prices, while the latter is the source for natural gas conversion factors for 1970-1979.

\subsubsection{Hierarchy of Price Imputation}

The use of diverse data sources in the construction of the STEPS data base resulted in gaps and discrepancies which have to be filled through imputation procedures. Several different imputation strategies are used throughout the data base, depending on what data are available. These procedures include mapping, linking, and price assignments. The data points derived from some procedures are "imputed data" or "synthetic data." The documentation of computational procedures for each fuel indicate which prices have been imputed and describe the imputation strategy used. The different 
procedures used can be generally ordered as follows in terms of their "imputedness: "

\begin{abstract}
No Imputation. Except for combining some of the originally reported categories to be consistent with the end-use sector definitions established for STEPS, no imputation is made in the data base development process. However, more than one data source may be used.

Mapping. Two or more data series with similar or comparable definitions and coverage are mapped or spliced together using regression analysis.

Linking. Data points outside the period covered by original source data ar generated by assumed relationship or regression equations, linking the available data to an ongoing series.

Price Assignments. The price data for a fuel in a specific state or region are assigned to a neighboring state or region, with or without a constraint, or prices of one fuel are assigned to another fuel.
\end{abstract}

Table 2.2 provides a summary of the STEPS price series in terms of this hierarchy of imputation. This table is intended to provide an overview of the types of imputation techniques used to develop each data series. The electricity, natural gas, coking coal, motor gasoline (1983 only), and diesel fuel price series have very little imputation. The steam coal and distillate fuel price series have moderate amounts of imputation, while the kerosene/jet fuel, residual fuel, and LPG price series (all 1983 only) are almost entirely imputed. Details about the imputation strategies used for each fuel can be found in Chapters 4.0 through 13.0 .

\title{
2.2 GENERAL FINDINGS
}

As a result of the 1983 update of the data base, several observations can be made about the differences in data sources and computational procedures between the prices for 1970-1982 published in the 1982 STEPS Update and the 1983 prices published in this report. Virtually all of the 1983 fuel price series differ from the 1982 versions in the following ways: 1) more complete documentation; 2) additional verification of input data and computational procedures; 3 ) change in the calculation of Btu prices (or physical unit prices, in some cases): and 4) increased use of computer programining. Highlights of 
IABLE 2.2. Hierarchy of Imputation in the STEPS Data Base

\begin{tabular}{|c|c|c|c|c|c|}
\hline _Energy/Fuel_ & End-Use Sector & $\begin{array}{c}\text { No } \\
\text { Imputation }\end{array}$ & Mapping & Linking & $\begin{array}{c}\text { Price } \\
\text { Assignment }\end{array}$ \\
\hline Electricity & $\begin{array}{l}\text { Residential } \\
\text { Commercial } \\
\text { Industrial } \\
\text { Transportation }\end{array}$ & $\begin{array}{l}A / D \\
A / D \\
A / D \\
A / D\end{array}$ & & & \\
\hline Natural Gas & $\begin{array}{l}\text { Residential } \\
\text { Commercial } \\
\text { Industrial } \\
\text { Electric Utility }\end{array}$ & $\begin{array}{l}B / D \\
B / D \\
B / D \\
B / D\end{array}$ & & & $\begin{array}{l}C / E \\
C / E \\
C / E \\
C / F\end{array}$ \\
\hline Coking Coal & Industrial & $B / D$ & & & $C / D$ \\
\hline Steam Coal & $\begin{array}{l}\text { Residential } \\
\text { Industrial } \\
\text { Electric Utility }\end{array}$ & $\begin{array}{l}B / E \\
B / E \\
B / D\end{array}$ & $\begin{array}{l}A / F \\
A / F\end{array}$ & $C / F$ & $\begin{array}{l}C / E \\
C / E \\
C / F\end{array}$ \\
\hline $\begin{array}{l}\text { Distillate } \\
\text { Fuel }\end{array}$ & $\begin{array}{l}\text { Residential } \\
\text { Commercial } \\
\text { Industrial } \\
\text { Electric Utility }\end{array}$ & $\begin{array}{l}C / F \\
C / F \\
B / E \\
A / E\end{array}$ & $A / F$ & $\begin{array}{l}B / D \\
A / E \\
A / F \\
C / E\end{array}$ & $\begin{array}{l}B / D \\
C / E\end{array}$ \\
\hline $\begin{array}{l}\text { Motor Gasoline } \\
(1983 \text { only) }\end{array}$ & Transportation & $A / D$ & & & \\
\hline Diesel Fuel & Transportation & $A / E$ & & & $C / F$ \\
\hline $\begin{array}{l}\text { Kerosene/ } \\
\text { Jet Fuel } \\
\text { (1983 only) }\end{array}$ & $\begin{array}{l}\text { Residential } \\
\text { Industrial } \\
\text { Transportation }\end{array}$ & & & $\begin{array}{l}A / D \\
A / D\end{array}$ & $A / D$ \\
\hline $\begin{array}{c}\text { Residual Fuel } \\
\text { (1983 on } 1 \text { y) }\end{array}$ & $\begin{array}{l}\text { Commercial } \\
\text { Industrial } \\
\text { Transportation } \\
\text { Electric Utility }\end{array}$ & $A / D$ & & $\begin{array}{l}A / D \\
A / D \\
A / D\end{array}$ & \\
\hline $\begin{array}{l}\text { LPG } \\
\text { (1983 only) }\end{array}$ & $\begin{array}{l}\text { Residential } \\
\text { Industrial }\end{array}$ & $B / D$ & & $\begin{array}{l}C / D \\
A / D\end{array}$ & \\
\hline
\end{tabular}

KEY: $A=$ all states; $B=$ most states; $C=$ some states;

$D=$ all years; $E=$ most years; $F=$ some years .

Source: Pacific Northwest Laboratory 
the findings for specific fuels will be described after the following discussion on these general findings.

\subsubsection{Documentation}

The documentation contained in Chapters 4.0 through 13.0 represents a significant improvement over previous versions of STEPS documentation. In the latter, many discrepancies and omissions of pertinent information made it very difficult to reproduce individual prices in the data base. Procedures for imputing missing states were often vague or were missing altogether. The documentation reported by fuel in Chapters 4.0 through 13.0 is much more detailed and uses a consistent naming convention for labelling variables and computer files. Considerable effort has been made to include all the detajls about the type of data (units, and price, fuel, and end-use sector definitions) and computational procedures in this documentation. Whether or not taxes are included in the final STEPS prices is explicitly stated.

Another problem with earlier documentation was the "piggy-backing" of update documentation with the original documentation, State Energy Price system (Volume I). The update documentation referred readers back to the original documentation, noting any changes in data sources or procedures necessary to develop prices for 1981 or 1982. This dispersion of documentation decreased the useability of the data base. This report and future STEPS documentation will include in one volume all information about data sources and computational procedures for all years covered by the data base.

\subsubsection{Computational Procedures}

The review and verification of the input data and computational procedures used in the 1983 update are the same as the practice adopted for the reproducibility check work. Input data are thoroughly reviewed and corrected as needed. Computer programs are documented and run with trial data to verify that they are correctly performing the desired calculations. Many input and procedural errors have been found through the reproducibility effort, so increased emphasis has been placed on one-over-one review of all development 
work. In addition, computer checks have been made of non-price data by checking monthly and U.S. totals where appropriate.

Several users of the STEPS data base complained that the Btu prices reported in the published documentation could not be reproduced exactly using the physical unit prices and the conversion factors as stated in documentation. This problem was the result of rounding error generated by the number of decimal places carried by the computer. To resolve the discrepancy due to rounding error, physical unit prices (Btu prices) are first calculated to several decimal places. These prices are then rounded to three places after the decimal and Btu prices (physical unit prices) are calculated from the conversion factor and the rounded physical unit prices. All the revised and updated fuei prices, except electric utility price series based on data from the EIA's cost and Quality of Fuels, are calculated using this procedure.

\subsubsection{Implementation of Computational Procedures}

The final general difference between earlier versions of STEPS and the current version is the increased use of computer programming in all stages of the computational procedures. This improvement offers accuracy and consistency in price calculations and a good method for tracking the actual computer development of the data base. The transition from hand calculations to computer calculations is made easier for some fuels (such as motor gasoline) by the availability of new data sources for 1983 (such as EIA's Petroleum Marketing Monthly). The documentation contained in Chapters 4.0 through 13.0 describes the development of STEPS in a clear and concise manner so that data base users can reproduce individual prices. However, in the actual construction of the data base there are more efficient ways of performing these calculations, particularly in terms of the order of calculation. While the computer programs do strongly resemble the written documentation, there are some differences that are effectively recorded with the use of established programs. Another benefit of established programming is the simplification of the update process. 


\subsection{SPECIFIC FINDINGS BY FUEL}

In addition to the general findings described above, there are severat important findings specific to each fuel series in the STEPS data base. These findings are presented below.

\subsubsection{Electricity}

The STEPS electricity price series cover the residential, commercial, industrial, and transportation sectors. Both the reproducibility check and update work are complete for this fuel, so the documentation contained in chapter 4.0 covers the entire period 1970-1983. The procedures for calculating 1983 electricity prices remain basically the same as for previous years, as amended by the reproducibility work. One difference is the change in temporal coverage from 1960-1983 to 1970-1983 requested by EIA.

One change in the 1983 and future update procedures is the substitution of final Statistical Year Book data for the preliminary data previously used. In 1980, Edison Electric Institute (EEI) started publishing preliminary data in each edition of Statistica] Year Book, then updating that information in the following year. No effort was made in previous STEPS updates to revise the electricity prices once the revised EEI data were available. It is intended that the substitution of final prices for preliminary prices will continue as the former become available. The EIA requested that conversion factors be taken from the State Energy Data Report (SEDR) instead of from Annual Energy Review; this change had no affect as the factors reported in the two documents are identical.

Another change from the reproducibility effort that affects the 1983 electricity update is the added step to reconcile state-level prices from Statistical Year Book with U.S. prices from Annual Energy Review. Previously, U.S. prices were calculated directly from Statistical Year Book data in the same way as state prices. In the revised procedure, the U.S. prices are taken directly from $A E R$ and the ratios of $A E B$ prices to the U.S. prices published in Statistical Year Book are used as adjustment factors. Virtually all the 
electricity prices now reported in STEPS are affected by this procedural change which brings the STEPS U.S. electricity prices into agreement with the U.S. electricity prices published in other EIA publications. This change also serves as a check on the prices collected by EEI, a non-Federal government source.

\subsubsection{Natural Gas}

The 1983 STEPS natural gas price series cover the residential, commercial, industrial, and electric utility sectors. The 1982 STEPS Update for this series also included prices for the transportation sector, but since the pipeline prices previously used for this sector really represent intermediate transactions, they have been dropped from the data base. As for electricity, the EIA also requested that the natural gas price series cover the period 1970-1983 instead of the period 1960-1983. Both the reproducibility check and the 1983 update are complete for the natural gas price series. Since the data sources and procedures vary significantly between the residential, commercial, and industrial sectors, and the electric utility sector, the discussion of findings is separated below. Detalled documentation for natural gas for 1970-1983 can be found in Chapter 5.0.

Besidential, Commercial, and Industrial Sectors. For the residential and commercial sectors, data sources and computational procedures for 1983 are the same as those for 1970-1982. For the industrial sector, the use of lease and plant fuel data is discontinued for all years, including 1983. These data had been added to the Natural Gas Annual industrial sector data to construct the STEPS industrial sector price series. This change means that all of the reported prices for the natural gas industrial sector series differ from those reported in the 1982 version of STEPS. A few states continue to have outlying prices that appear to be the result of errors in the source documents: Oklahoma (1979, commercial); Utah (1980-1982, commercial); and Wyoming (1974, industrial).

Electric Utility Sector. The data source for natural gas electric utility sector prices continues to be the EIA's cost and Quality of Fuels in 1983. However, instead of using data from a computer tape, EIA has requested that 
data be taken from published hard copies of the data source. For this fue] series as a whole, reported prices are very similar to previous versions of STEPS, with a few exceptions for states that are missing prices for years where prices were reported before. Alaska (1980-1981) and West Virginia (1973-1974) continue to have prices that stand out from general trends.

\subsubsection{Coking Coal}

The STEPS coking coal price series cover the industrial sector only. Both the reproducibility check and the .1983 update are complete for this fuel. There are no differences in data sources or procedures from 1982, and reported physical unit coking coal prices for 1970-1982 are virtually identical in the 1982 and 1983 versions of STEPS. A few prices are modified due to corrections in data input errors, and all the Btu prices are modified by the EIA request to use conversion factors from SEDR. Since the physical unit prices did not extend beyond three places after the decimal point in the source documents, there never was a rounding error problem for this price series. Chapter 6.0 contains the detajled STEPS documentation for coking coal.

\subsubsection{Steam_coal}

The STEPS steam coal price series cover three end-use sectors: electric utility, residential, and industrial. Both the reproducibility check and the 1983 update are complete for this fuel. Since the data sources and procedures vary significantly between the electric utility, residential, and industrial sectors, the discussion of findings is separated below. The detailed STEPS documentation for steam coal can be found in Chapter 7.0.

Electric Utility Sector. The data source for steam coal electric utility sector Btu and physical unit prices continues to be cost and Quality of Fuels in 1983. There is a change from cost and Quality computer tape data to published hard copy data, made at the request of EIA. For this fuel series as a whole, the prices for 1970-1972 reported in this document are identical to the 1982 update report while prices for 1973-1983 differ somewhat from the 1982 report in both the physical unit and Btu series. One reason for the differences is the change from computer tape to published hard copy data sources 
which took place during the reproducibility check; another possible contributing factor could be an error in the calculation of previously reported prices. Inadequacies in the 1970-1982 documentation do not allow verification of the procedures previously used.

Residential sector. There is no change in basic computational procedures for this sector but there is a change in data sources for the data year 1983. The regression equation used to impute residential steam coal prices for 1979-1983 was revised during the reproducibility check. The 1979-1982 prices reported in the 1982 STEPS Update were estimated using two separate equations: one for states with bituminous coal use and one for states that do not use bituminous coal. The equation for the former group of states was estimated with cost and Quality bituminous spot prices, while the equation for states without bituminous use was estimated with all coal spot prices. Since EIA has decided to use only published hard copy cost and Quality data in STEPS, the distinction between types of spot coal prices can no longer be maintained. To solve this problem, separate regression runs were made with all coal spot prices and with all coal spot and contract prices. Since the best results were obtained with the spot prices alone, the equation using spot prices is used to calculate 1979-1983 prices for all states. In addition to the change in input data for the regression equation, EIA also requested a change in data sources for conversion factors from Monthly Energy Review to SEDR. As a result, the entire physical unit price series is affected.

Industrial Sector. The final steam coal industrial prices calculated included in this update report are calculated similarly to those for 1982 . The imputation of data for states missing EIA-3 data follows the procedure established during the reproducibility check for 1980-1982. Missing states prices are imputed using averages of only published prices from adjacent states instead of using the old procedure of averaging published and unpublished data from adjacent states. Btu prices are affected by the change, made at the request of the EIA, to SEDR as the conversion factor data source. 


\subsubsection{Distillate Fue]}

STEPS distillate fuel prices are developed for the residential, commercial, industrial, and electric utility sectors. Both the reproducibility check and the 1983 update are complete for this fuel. Detailed information about the data sources and computational procedures used to construct these price series for the period 1970-1983 is given in Chapter 8.0. Since the data sources and computational procedures vary significantly between the sectors, the findings are discussed separately for each sector below.

Residential Sector. For the 24 states that had state-level residential sector heating oil prices reported for 1978-1982, no changes in data source or procedures took place for the 1983 update. Annual average prices for these states are taken from EIA's Monthly Energy Review, following procedures developed for 1978-1982 in the reproducibility check. For the other 27 states, however, the 1983 data source is EIA's Petroleum Marketing Monthly (PMM), an EIA report that began publication with 1983 data. While the procedures for estimating state-level prices for these states from the published monthly regional data are basically unchanged, the regional definitions themselves do change from Federal Regions to PAD Districts. Prices for the U.S. are still taken from Annual Energy Review. The distillate residential sector (and commercial and industrial sector) prices are not changed by EIA's request to take conversion factors from SEDR.

Commercial Sector. The distillate commercial prices for 1983 are calculated similarly to those for the residential sector using data from $\mathrm{PMM}$, except that monthly state-level prices are available for the 24 states instead of annual average prices. These monthly prices are weighted into annual averages using monthly heating degree data from the National Oceanic and Atmospheric Administration (NOAA). This change in data source offers significant improvements to the quality of distillate commercial prices over the markup-based estimation procedures used for 1970-1982.

Industrial Sector. The distillate industrial sector prices for 1983 are also computed from PMM data, using procedures similar to those for the 
residential and commercial sectors. The monthly state-level prices for 24 states are combined into annual prices with simple averaging techniques. The PMM data fill the gap left by the lack of Annual Survey of Manufactures (ASM) data after 1981. Since there are no sources of distillate industrial sector prices for 1982, the preliminary prices estimated during the 1982 Update are replaced with prices estimated based on the relationship between ASM data and the completed STEPS distillate electric utility prices for 1978-1981. The procedures for 1982 and 1983 are different than those for previous years.

Electric Utility sector. The data source for distillate electric utility sector Btu and physical unit prices continues to be cost and Quality of Fuels in 1983. There is, however, a change from computer tape sources to published hard copy sources, as for the natural gas and steam coal electric utility price series. This change is made at the request of the EIA, and affects all distillate electric utility sector prices for 1973-1983.

\subsubsection{Motor Gasoline}

The STEPS motor gasoline price series cover the transportation sector only. Only the 1983 update is complete for this fuel; the reproducibility check work is scheduled for completion in early 1986. Chapter 9.0 only contains documentation for the development of the 1983 prices. Information about the development of the 1970-1982 prices can be found in State Energy Price System (Volume I) and State Energy Price System: 1982 update.

The 1983 motor gasoline price series in the STEPS data base are based on monthly state-level prices taken from the EIA's publication Petroleum Marketing Monthly. Composite "all types" prices for finished gasoline are available for all states except Alaska, Hawai, and the District of Columbia. Prices for these three states are taken from consumer Prices: Energy as in previous years. Monthly gasoline consumption volumes from Highway Statistics continue to be used to calculated annual prices. With sharp decline in the availability of monthly, state-level gasoline prices from Platt's 0il. Price Handbook and Qilmanac, the PMM provides the best available data for use in constructing the STEPS series. When the reproducibility work is completed, the impacts of the change in procedures between 1982 and 1983 can be evaluated. 


\subsubsection{Diesel Fuel}

Like motor gasoline, the diesel prices series cover only the transportation sector. Both the reproducibility check and the 1983 update are complete for the STEPS diesel price series. Other than the general differences mentioned in Section 2.2, there are no differences in data sources or computational procedures for the calculation of 1983 prices. The change to SEDR as the source of diesel conversion factors, made at the request of the EIA, does not affect the final reported prices. Detailed diesel documentation for 1970-1983 can be found in Chapter 10.0.

\subsubsection{Kerosene and Jet Fuel}

The STEPS kerosene/jet fuel price series cover the residential, industrial, transportation, and electric utility sectors. For 1983, however, no electric utility sector data are available, so no prices are developed for this year. Only the 1983 update is complete for this fuel; the reproducibility work is scheduled for completion in early 1986. Chapter 11.0 contains documentation only for the development of 1983 prices. Information about the development of the 1970-1982 prices can be found in State Energy Price System (Volume I) and State Energy Price System: 1982 Update.

Residential and Industrial Sectors. Other than the general changes mentioned in Section 2.2, kerosene prices for the residential and industrial sectors are calculated using the same data sources and procedures as 1982. The Bureau of Labor Statistics' Producer Prices and Price Indexes is the basis for the series, with sector adjustments from Agricultural Prices in the residential sector and the STEPS distillate industrial price series for the industrial sector. EIA's request to use the conversion factors found in SEDR does not affect either the residential sector or industrial sector final kerosene prices.

Iransportation Sector. Transportation sector jet fuel prices for 1983 are computed from Petroleum Marketing Monthly data for PAD Districts. The 1983 jet fuel prices are different from those developed for previous years in 
several respects. First, PMM provides retail price data, while Producer Prices provides wholesale data. Since no retail jet fuel data were previously available to adjust the wholesale data, STEPS jet fuel prices for 1970-1982 are wholesale. The PMM data are also reported for PAD Districts instead of the Census Divisions reported by Producer Prices. The procedure of assigning regional prices directly to states is continued for 1983, so the 1983 price series are based on slightly more aggregated prices (seven PAD Districts as opposed to nine Census Divisions). When the reproducibility check is completed, the impacts of these differences on the continuity of the series can be evaluated.

\subsubsection{Residual Fuel}

The STEPS residual fuel price series cover the commerciat, industrial, transportation, and electric utility sectors. Only the 1983 update has been completed for residual fuel; the reproducibility check is scheduled for completion in early 1986. Chapter 12.0 contains documentation only for the development of 1983 prices. Information about the development of residual prices for 1970-1982 can be found in State Energy Price System (Volume I) and State Energy Price System: 1982 Update. Due the significant differences in data sources and computational procedures among sectors, the discussion of findings is separated below.

Electric Utility Sector. Like the electric utility sector price series for natural gas, steam coal, and distillate fuel, the residual fuel series for 1983 is based on the EIA's cost and Quality of Fuels published hard copy data. No imputation is needed for any states in 1983.

Industrial Sector. The 1983 update of the STEPS residual price series consists of two steps: 1) finalizing prices for 1982, and 2) generating prices for 1983. Prior to 1982, industrial residual prices are computed from Annual Survey of Manufactures (ASM) and Census of Manufactures (CM) data. Since ASM/CM ceased publication of state-level residual data after 1981, prices for 1982 and 1983 are imputed based on the relationship between Platt's prices for No. 6 fuel oil and ASM/CM-based residual STEPS prices for 1978-1981. The residual conversion factors are taken from SEDR, at the request of the EIA. 
Commercial and Transportation Sectors. Other than the general changes mentioned in Section 2.2, the data sources and procedures for calculating 1983 residual fuel commercial and transportation sector prices are basically the same as for 1982. The one exception to this is the substitution of the price for residual fuel oil with sulfur content greater than one percent, for the Bunker $C$ price in the transportation sector; this change is necessary because Bunker $C$ prices are no longer available for EIA sources. Both of these sectors use the conversion factors from SEDR.

\subsubsection{Liquefied Petroleum Gas}

The STEPS liquefied petroleum gas (LPG) price series cover the residential and industrial sectors. Only the 1983 update is complete for this fuel; the reproducibility check for LPG is scheduled for completion in early 1986 . Chapter 13.0 contains the detafled documentation for this fuel for 1983 oniy. The documentation for the 1970-1982 prices can be found in State Energy Price System (Volume I) and State Energy Price System: 1982 Update.

The 1983 LPG prices for the residential sector are calculated using the same data sources and procedures as for previous years. With the suspension of publication of $A S M / C M$ after 1981, the procedures for the industrial sector LPG price series for 1983 had to be changed from those of previous years. The 1983 LPG industrial prices are calculated based on the relationship between ASM/CM prices and Agricultural Prices data for 1978-1981. The procedures involved are similar to those used for the residual fuel industrial sector price series. It is anticipated that this same procedure will be used during the reproducibility check to estimate prices for 1982 .

\subsection{RECOMMENDATIONS}

The 1983 update of the STEPS and the reproducibility check completed for six fuels have resulted in significant improvements to the 1982 version of STEPS. To extend this improvement for the remaining four fuels, it is recommended that the reproducibility work currently underway for motor gasoline, kerosene/jet fuel, residual fuel, and $L P G$ be completed and included in the 
1984 STEPS Update report. The continuation of STEPS updates in accordance with the standards for accuracy and consistency established during the reproducibility check will give users more confidence in the state energy price data base for many applications.

One major issue that surfaced during the 1983 update and the reproducibility check is the question of whether or not taxes are included in the reported prices. Many of the original data sources do not explicitly state whether or not taxes are included in their data, and many of the data collection forms issued by either Federal or non-Federal agencies do not include instructions on how taxes should be treated. It is relatively important to be able to identify the tax status of prices, particularly in data series such as the distillate residential series, that are pieced together from several different data sources. Users of STEPS need to be advised about any potential differences in the nature of prices reported in the data base. Resolution of this question may involve interviews with the agencies or groups responsible for the different publications. Once the tax status has been ascertained, it may make sense to revise fuel price series that have inconsistent tax reporting.

Another general recommendation is to continue to utilize computer programing as much as possible in the data base. For some fuel price series, fiand calculations are still used in the development process. The accuracy and efficiency of the update process will be enhanced by the further use of computer programming.

The following two recommendations are fuel-specific. First, the natural gas price series has several reported prices that do not follow the apparent trends. Since input data or procedural errors do not explain these odd prices, it appears likely that there may be errors in the value or quantity data published in the source documents. It is recommended that an effort be made to double check the source values with the originating agency. Second, consideration should be given to either discontinuing prices or developing another imputation strategy for the steam coal residential sector. As the update years get further away from 1978 (the last year of coal data from a published source), the less accurate estimates of actual prices are likely to 
be. With the 1984 update, the years of estimated prices will nearly equal the years used as the basis for the series. 


\subsection{METHOOOLOGICAL OVERVIEW}

This chapter presents an overview of the approach and methodology adopted for the development of STEPS. This discussion includes an explanation of the original criteria for the data base; definitions of prices, fuels, and sectors; and the methodology itself. The methodology and approach discussed reflect any changes made to the original methodology during the reproducibility check, and are directly related to the prices reported in the 1983 STEPS data base.

\subsection{CRITERIA FOR DATA BASE DEVELOPMENT}

When PNL first began work on the development of a state-level energy price data base in 1980, the EIA outlined several criteria that were to be met by the final data base. For the most part these criteria have remained constant through the various updates, but a few changes have been made as STEPS has progressed through the various update and reproducibility check tasks. The basic criteria upon which the 1983 update price series are based, are as follows:

1. The energy price series to be developed are electricity, natural gas, coking coal, steam coal, distillate fuel, motor gasoline, diesel fuel, kerosene/jet fuel, residual fuel, and LPG.

2. The applicable end-use sectors are residential, commercial, industrial, transportation, and electric utility.

3. The state is the smallest unit of disaggregation for each energy price series. Each price series must be able to stand independently from similar data and be reaggregated.

4. The time period to be covered is 1970 through 1983.

5. The price series developed should be consistent with prices published in other EIA documents.

6. Where possible, the variables included in the prices (i.e. taxes, transportation costs, etc.) should be identified.

7. The definitions used for fuels and sectors should be the same as those found in State Energy Data Report. 
8. It should be noted if any price series segments share data elements across state boundaries.

9. EIA data sources should be carefully considered in the evaluation of alternative data sources. If an EIA series is considered to be inadequate, a discussion of the inadequacy should be provided.

10. Complete documentation must be provided for implementation of the state energy price series and for subsequent annual updates.

\subsection{DEFINITIONS}

With the variety of original data sources used in the development of STEPS, there are some differences in the definitions of price, fuel, and end-use sector. Inconsistencies of definitions generally follow changes in data sources; however, over time definitions may change within a particular data source. While it would be ideal to have uniform definitions of price, fuel, and end-use sector in STEPS, it should be noted that this data base is not the result of a primary data collection effort. To improve the useability of the data base despite some inconsistencies, an effort has been made to document the definitions used by the various original data sources. This information is included in detail in the discussion of individual fuel computational procedures (Chapters 4.0 through 13.0), and is summarized below.

\subsubsection{Price Definitions}

Price is a basic economic concept. Generally, price represents the amount of money that is transferred to effect a transaction of a unit of product or service. There are many dimensions of a transaction that may affect the price, including: the quality of the product or service, terms of payment, the timing and location of the transaction, the inclusion or exclusion of transportation and distribution costs, quantity discounts, and the nature of customer classes. Examples of how each of these dimensions affects energy prices are shown below:

Quality of a Product. Coal and residual fuel prices vary with sulfur content; electricity and natural gas prices may be lower if service is interruptible. 
Terms of Payment. Prices may vary depending on whether a transaction is a cash sale, charge sale, or installment sale. The spot price for a fuel is likely to be different from the long-term contract price.

Lime and Location. The price of gasoline during the summer travel months may be different from the price in winter. The price of natural gas in Texas may be different from the price of natural gas in washington. Prices may change hourly, daily, weekly, monthly, quarterly, seasonally, or yearly.

Iransportation/Distribution costs. The delivered price of crude oil may be different from the FOB price; the city-gate price of natural gas is different from the delivered price to households.

Quantity Discounts. The volume of a transaction may affect the unit price in the form of a discount for large volumes. This price difference may actually reflect some of the reduced cost of effecting the transaction.

customer classes. The prices to residential, commercial, industrial, and electric utilities differ, partly because of differences in transaction and transportation costs. Similarly, wholesale prices differ from retail prices.

The types of prices found in the STEPS data base include average price, wholesale price, retail price, spot price, contract price, and delivered price. Average price may refer to "average" revenue per unit of product, a population-weighted average price, or the average of price quotes over a period such as a day, a week, a month, or a year. Retail prices are prices paid by consumers of a product who intend to use the product for final consumption or production purposes, not for resale to others. Wholesale prices are charged to buyers who purchase the product for the purpose of reselling at a profit. The spot price is the price quoted for "on the spot" transactions, as opposed to the long-term contract price which is intended to be in effect for a long period of time (usually with some mechanism for changing the price quotes if necessary). Delivered prices include the cost of delivering the product from the seller's location to that of the purchaser. The cost of delivery may include transportation, insurance, and customs taxes.

The major objective of the work to develop the State Energy Price System is to develop an energy price data base that can be used by the EIA in its regional energy analysis activities, in developing state energy expenditures 
accounts, and in general monitoring and information activities. With these intended uses, the prices sought for the STEPS data base are the average retajl price per unit of fuel. In general, average prices should be quantity-weighted if quantity data are available; in some cases, however, proportional and other linear relationships are used in the imputation of prices, so that quantity-weighting cannot be done. The use of imputation strategies to estimate missing prices sometimes makes an exact definition of the resulting price difficult to state, particularly if two different sources with different definitions of price are involved. With several of the data sources, including EIA, other Federal, and non-Federal sources, it is not clear whether or not taxes are included in the reported prices. The inclusion or exclusion of taxes, or the uncertainty as to inclusion or exclusion, is explicitly stated in the fuel-by-fuel documentation given in Chapters 4.0 through 13.0 .

\subsubsection{Euel Definitions}

Ten major fuels are covered by STEPS: electricity, natural gas, coking coal, steam coal, distillate fuel, motor gasoline, diesel fuel, kerosene/jet fuel, residual fuel, and LPG. Prices for other fuels for which consumption data are available in SEDS (such as lubricant, road oils, asphalt, wood, etc.) are beyond the scope of STEPS development. The definitions of the covered fuels used in STEPS are consistent with those included in the EIA's Annual.

Energy Review. (a) Because of data source limitations, however, there are some discrepancies. While the fuel definitions used by each data source are documented in Chapters 4.0 through 13.0 , the following definitions are used for general purposes:

Electricity. Electricity sales to ultimate consumers.

Natural Gas. A mixture of hydrocarbons and small quantities of various non-hydrocarbons existing in the gaseous phase or in solution with crude oil in underground reservoirs.

Coking Coal. Bituminous coal from which constituents have been driven off by heat so that the fixed carbon and the ash are fused together.

(a) Energy Information Administration, U.S. Department of Energy. Annual Energy Review 1983. D0E/EIA-0384(83), pp. 229-237, Washington, D. C. 
Steam Coal. Includes all ranks of coal--anthracite, bituminous coal (including subbituminous coal), and lignite.

Anthracite. A hard, black, lustrous coal containing a high percentage of fixed carbon and a low percentage of volatile matter. It is often referred to as hard coal.

Bituminous. A coal that is high in carbonaceous matter having a volatility greater than anthracite and calorific value greater than lignite. Often referred to in the United States as soft coal.

Lignite. A brownish-black coal of low rank with high inherent moisture and volatile matter. It is also referred to as brown coal.

Subbituminous. A dull, black coal of rank intermediate between lignite and bituminous coal.

Distillate Fuel. A general classification for one of the petroleum fractions produced in conventional distillation operations, Included are products known as No. 1 and No. 2 heating oils, diesel fuels, and No. 4 fuel oil.

Motor Gasoline. A complex mixture of relatively volatile hydrocarbons, with or without small quantities of additives, that have been blended to form a fuel suitable for use in spark-ignition engines. Included are finished leaded gasoline, finished unleaded gasoline, and gasohol.

Diesel Fuel. A type of distillate fuel oil.

Kerosene. A petroleum middle distillate having burning properties suitable for use as an illuminant when burned in wick lamps. Included are No. 1-K and No. 2-K and grades of kerosene called range oil having properties similar to No. 1 fuel oil.

Jet Fuel. Includes both naphtha-type and kerosene-type jet fuel meeting standards for use in aircraft turbine engines.

Residual Fuel. The topped crude of refinery operations that includes No. 5 and No. 6 fuel oils, Navy Special fuel oil, and Bunker $C$ fuel $0 i 1$.

Liquefied Petroleum Gas ( $L P G)$. Included are propane, propylene, butane, butylene, ethane-propane mixtures, propane-butane mixtures, and isobutane produced at refineries or natural gas processing plants, including plants that fractionate raw natural gas plant liquids. Ethane and ethylene are excluded. 


\subsubsection{End-Use Sector Definitions}

The classification of end-use sectors used in STEPS is in accordance with SEDS and the EIA's Annual Energy Review. There are five end-use sectors covered by STEPS: residential, commercial, industrial, transportation, and electric utility. The residential sector consists of households occupying single family homes, multiple family dwellings, and mobile homes. The commercial sector includes retail and wholesale establishments, office buildings, warehouses, educational facilities, hospitals and health care buildings, commercial lodging, recreational, other assembly buildings, and utilities except electric utilities. The industrial sector includes manufacturing, agriculture, construction, and mining. The transportation sector covers common carrier air, ground, and water transportation for passengers and freight. Common practice also includes gasoline and diesel use by private automobiles in the transportation sector. The electric utility sector covers power plants which consume primary energy sources such as coal, oil, natural gas, and nuclear fuels to generate electricity.

The STEPS data base sector definitions resemble the above EIA definitions as closely as the source data publications allow. There are several difficulties in assigning actual data to sectors, partly due to the differences between the EIA sector definitions and the definitions used by the original data source. For the electricity and natural gas STEPS price series, the division between the industrial and commercial sectors is sometimes blurred. Collection of data on electricity kilowatt-hour sales and revenues is generally based on the specific rate schedules in use by individual utilities. Historical data on sales of electricity to both businesses and industries are generally grouped into two categories: "small power and light," requiring less than 1000 kilowatts of service, and "large power and light," requiring more than 1000 kilowatts of service. Generaliy, the assumption is made that the former category approximates the commercial sector, while the latter approximates the industrial sector. However, there may be small manufacturing establishments which are included in the industrial sector but which are also included in the "small power and light" category. Similarly, there may be large commercial businesses which are included in "large power and light." 


\subsection{GENERAL METHODOLOGY}

The fuel price series contained in the 1983 STEPS are developed from the original STEPS data base for 1970-1980, the 1981 and 1982 updates, and the reproducibility check work (for electricity, natural gas, coking coal, steam coal, distillate fuel, and diesel fuel). While this data base has evolved through the updating and reproducibility check tasks, the basic methodology used in its construction has remained relatively unchanged. The discussion of methodology in this section does not reflect all the iterations of the data base, but rather focuses on the procedures actually used to generate the prices found in this report.

The development of the STEPS data base has been carried out in a fuel-by-fuel fashion, where each fuel has its own documentation, programs, and data file library. The construction of each fuel series can be broken into several major steps: 1) data source review; 2) analysis of imputation options: 3) initial documentation; 4) calculation and verification of prices; and 6) finat documentation. Each of these steps is discussed below.

\subsubsection{Data Source Review}

The first step in the development of STEPS fuel price series is to review the available, published data sources from which prices or other relevant data may be taken. To screen potential data sources, a set of review criteria are established in accordance with requirements of the STEPS (see Section 3.1), the intended uses of the final data base, and the data accessibility and quality requirements of EIA. The set of review criteria established and used for all fuels for the 1983 update are as follows:

1. The source must provide data that is the result of primary data collection. It is at the level of actual data collection and aggregation that the reliability of the data can be assessed. This criterion eliminates data that are a compilation or re-presentation of data from secondary sources.

2. The data must be published and be available from 1970, and must be collected on a consistent basis at fixed time intervais of one year or less. Since the EIA must, by law, make public any data which it 
uses, (a) the STEPS cannot contain proprietary data. Consistency in the method and timing of data collection is desired because the EIA data base development must be on a continuing basis. Collection intervals of one year or less are necessary to allow for calculation of annual prices. This criterion rules out the use of data which do not form a comprehensive and consistent series, such as the data collected by individual state agencies.

3. The data must be reported at the company, utility, city, or state level. This criterion is designed to identify data sources that contain state-level price estimates or data sources from which state-level price estimates can be generated. Sources whose price data have a lowest aggregation level greater than the state level, are, therefore, generally excluded from possible use in the data development process.

4. The data must cover the entire United States. This criterion is included in the review both to minimize the number of states for which prices have to be imputed, and to exclude data sources in which the accuracy of the data varies considerably across states. It is recognized, however, that some gaps in coverage of Alaska, Hawai $i$, and the District of Columbia may be unavoidable.

5. The data must be reported by end-use sector. This criterion screens out those data bases that aggregate all end-use consumption and those that categorize consumption by source or type of supply, rather than by demand sector. As noted, the five end-use sectors considered in this study are the residential, commercial, industrial, transportation, and electric utility sectors; however, not all five sectors are required for each of the fuels considered.

6. Data collection and aggregation procedures must be documented by the source organization. In order to evaluate the accuracy of the data and its suitability for EIA purposes, factors such as sample design, product definitions, and price imputation methods must be known. This criterion rules out possible use of data bases whose source organization refuses to reveal the methodology used.

7. The data for a calendar year must be avajlable before the end of the following calendar year. This is required because the price series data are needed to prepare the EIA's Annual Energy Review and other documents that must be produced in a timely manner.

8. The data must permit calculation of a volume-weighted cost per million Btu. This is required by the EIA. With this measure of energy price, the price data can be multiplied by consumption volume data to yield an estimate of total fuel expenditures. A price per million 8 tu consumed also ensures consistent measurement of end-use consumption across physical units that may vary in Btu content.

(a)Department of Energy Organization Act, P. L. 95-91, Section 205, g. 
In order evaluate potential data sources against these criteria, telephone and personal interviews are conducted with the publishing organization for candidate series. An initial screening of the available data series is then conducted to eliminate those data sources with gross deficiencies. A detajled comparison and review of the remaining data sources is then conducted, where the performance of each data source with regard to the review criteria is evaluated. This comparative analysis determined whether a single data source or a combination of data sources is needed to construct state-level prices for a particular fuel and end-use sector.

\subsubsection{Analysis of Imputation Options}

The analysis of imputation options, the next step in the development of the STEPS data base, is contingent upon the findings during the data base review. For some fuel/sector price series, no prices need to be imputed. For other series, a great deal of imputation may be required. Prices are generally considered to be "missing" if consumption data for a state are reported by SEDS. Almost all of the ten fuels have some prices generated using imputation methods.

The choice of imputation strategies is made by PNL and EIA after the following three elements have been identified: 1) the sectoral, geographical, and time coverage of the usable data sources; 2) alternative logic and data requirements for different imputation strategies; and 3 ) the costs and benefits associated with the different proposed strategies. A variety of imputation strategies are used throughout STEPS including adjacent state averages or price assignments, average ratios, trend analysis, simple regression analysis, and multiple regression analysis and pooling techniques.

\subsubsection{Initial Documentation}

After data sources and imputation strategies have been selected and approved by EIA, the initial documentation for each fuel is prepared. This documentation is used as the basis for the preparation of input data, the naming of data files, and computer programming. All data sources are specifically mentioned, and all computational procedures are described both 
in prose and by mathematical equations. As data entry to the computer and computer programming are done, any needed changes to this documentation are noted. The feedback that occurs during the next step in the process, calculation and verification, is an important part of finalizing the documentation.

\subsubsection{Calculation and Verification of Prices}

The amount of work involved in the calculation and verification of the final STEPS prices varies considerably from fuel to fuel. In the simplest case, data are transferred from the origina! source documents to the EIA computer, simple calculations are performed to generate physical unit prices, and Btu prices are generated using a conversion factor. In most cases, however, the many complexities associated with combining data from different sources and imputing missing prices make the calculation step more involved. Data verification takes place throughout the data input and computational process. At least two iterations are performed in the verification of input data, and test cases are run to verify computer programming. Once the final STEPS prices have been completed, the series is checked again to look for prices that do not fit apparent trends. Any outlying prices are rechecked to ensure that no data input or computational errors are involved.

\subsubsection{Einal Documentation}

The preparation of the final documentation is the last step in the construction of the STEPS price series. The initial documentation is revised to incorporate any improvements identified during the calculation and verification of prices. Other comments designed to improve the clarity or accuracy of the procedures actually used in the data base development process are also included. In addition to the final documentation report, all computer data files and program files are finalized and saved. 


\subsection{DATA AND METHODOLOGICAL ISSUES}

Several data and methodological issues arise in the development of the kind of data base documented in this report. The issues of potential uses of state-level energy price data, and the need for imputation and the nature of the imputed data are discussed below.

\subsubsection{Uses of State-Level Energy Price Data}

There are primarily four major uses of the energy price series developed as STEPS: policy analysis, information and comparison, market assessment and program evaluation, and short-term analysis and forecasting. These four uses are necessarily interrelated and are somewhat overlapping. As explained below, the main differences among the four uses are a matter of emphasis.

Policy Analysis. State-level energy price data are used for making decisions in both the public and private sectors. With the rapid increase in fuel prices since the 1973-1974 011 embargo, industries and businesses are incorporating energy prices into their location and investment decisions. Consumers are becoming accustomed to basing their purchases of durable goods on energy efficiency and prices. Federal, state, and local governments are also basing their research, development, and other decisions on energy price information.

Information and Comparison. Energy price data provide information for understanding past trends and monitoring current developments in the relative prices of different fuels, as well as between fuels and other commodities, services, and factor inputs. These data are components of general price indicators such as the Consumer Price Index and the Producer Price Index. From the prices of the same energy source or fuel for different states, comparisons can be made in the cost of energy and fuels among states. Energy price data are also useful in constructing state-level energy expenditure accounts. This type of information can be used in comparing impacts of changing energy prices on households, businesses, and industries in the states and regions of the United States. 
Market Assessment and Program Evaluation. The assessment of market potential for new sources of energy supply, as well as for new conservation and renewable resource technologies, requires information on current and expected future prices of competing energy sources. Similarly, the benefit/cost analysis of proposed programs to encourage energy conservation and utilization of renewable resources requires projections of future energy prices. Development of current and historical price data bases is a necessary first step in projecting future prices of competing fuels.

Short-Term Analysis and Forecasting. Energy price data are essential in the analysis, modelling, and forecasting of energy use, production, and energy market performance. Data are needed to establish the relationship between production, costs, prices, and consumption, such as in the estimation of price elasticities and cross elasticities. They are essential in the application of historical observations or forecasting of future developments.

\subsubsection{Imputation and the Nature of Imputed Data}

One important constraint on the development of the STEPS data base is the requirement that existing data sources be used; no primary data collection is included as part of this project. This means that the quality of the resulting data base is limited by the quality of existing data sources. In addition, where more than one data base met the data source review criteria, Federal data sources are to be used over non-Federal sources.

Given the constraints of available data sources and the EIA requirements, many prices have to be imputed either because the original data source did not distinguish between end-use sectors, or because data for certain years or states are missing. For the purpose of this report, the term "imputed" is used to refer to any of the following:

1. Utilization of two or more data sources to derive a single sector-specific price series for a fuel. This often involves splicing of the data series involved using simple ratios or empirically estimated regression equations. 
2. Extrapolation of a single data source to cover an earlier or later period than that for which the source data are collected, or when interpolation is required to fill in some of the missing data points within the data period covered by source data.

3. Assignment of a price series for one fuel to represent a closely related fuel, or when a fuel-and sector-specific price series from a state or region is used to represent the same price series for other states or regions.

The hierarchy of imputation for the 1983 STEPS is given in Section 2.1.2 of the previous chapter. Because the STEPS data base is constructed from a wide range of data sources collected for different purposes, and because of the necessity to impute some data points, it is not possible to give a degree of confidence, in the statistical sense, for the data included in the data base. The discussion of the hierarchy of "imputedness" is intended to give users of STEPS an indication of the relative accuracy of specific data points. Detailed documentation about the imputation for each fuel can be found in the respective Chapter 4.0 through 13.0 . 
, 


\subsection{ELECTRICITY}

The STEPS electricity price series are developed for the residential, commercial, industrial, and transportation sectors. Prices given are retail prices for sales of electricity to ultimate users. It is unclear whether or not these prices include taxes. For all four sectors, physical unit prices are calculated from source data, then prices per million Btu are computed using a conversion factor. Since the computational procedures are similar for all four sectors covered by electricity prices, the following discussion is not broken down by sectors.

\subsection{DATA SOURCES}

1970-1983 Edison Electric Institute. Statistical Year Book of the Electric Utility Industry. Table titled, "Revenues: Total Electric Utility Industry," and "Energy Sales: Total Electric Utility Industry."

1970-1983 Energy Information Administration, U.S. Department of Energy. Annual Energy Review 1984. Table 82, "Average Price of Electricity Sold by the Electric Utility Industry to End-Use Sector, 1960-1984."

\subsection{CONVERSION FACTOR}

1970-1983 Energy Information Administration, U.S. Department of Energy. State Energy Data Report. Appendix C, p. 670.

3412 Btu per kilowatt-hour

\subsection{COMPUTATIONAL PROCEDURES}

1. Physical unit prices for states and the U.S. are calculated for all four sectors as average revenue per unit of sales for all the electric utilities reporting in a state. The calculation of physical unit prices is done with the revenues and sales data from Statistical Year Book for each year in the series. For the years 1980 and on, prices are based on preliminary revenues and sales data in the update year and are replaced with revised data in the following year. For example, the 1983 STEPS update involves calculating preliminary 1983 prices and replacing the 1982 preliminary prices developed in the 1982 update with prices based on the revised 1982 sales and revenues available in the 1983 edition of Statistical 
Year Book. The only exception to this rule is the revenues data for Arkansas for 1981; preliminary data are used in this case because of an apparent error in the revised data.

\section{Residential Sector: 1970-1983}

$$
\text { ESRCNZZ }=(\text { ESRCCZZ } / \text { ESRCVZZ }) / 1000
$$

where:

ESRCNZZ = residential sector electricity price for state $Z Z$ or the U.S. ( $\$ / \mathrm{kWh}$ )

ESRCCZZ = residential revenues for State $Z Z$ or the U.S. from Statistical Year Book $(\$ 1000)$

ESRCVZZ = residential energy sales for State $Z Z$ or the U.S. from Statistical Year 8ook (mil1ion kwh)

Commercial Sector: 1970-1983

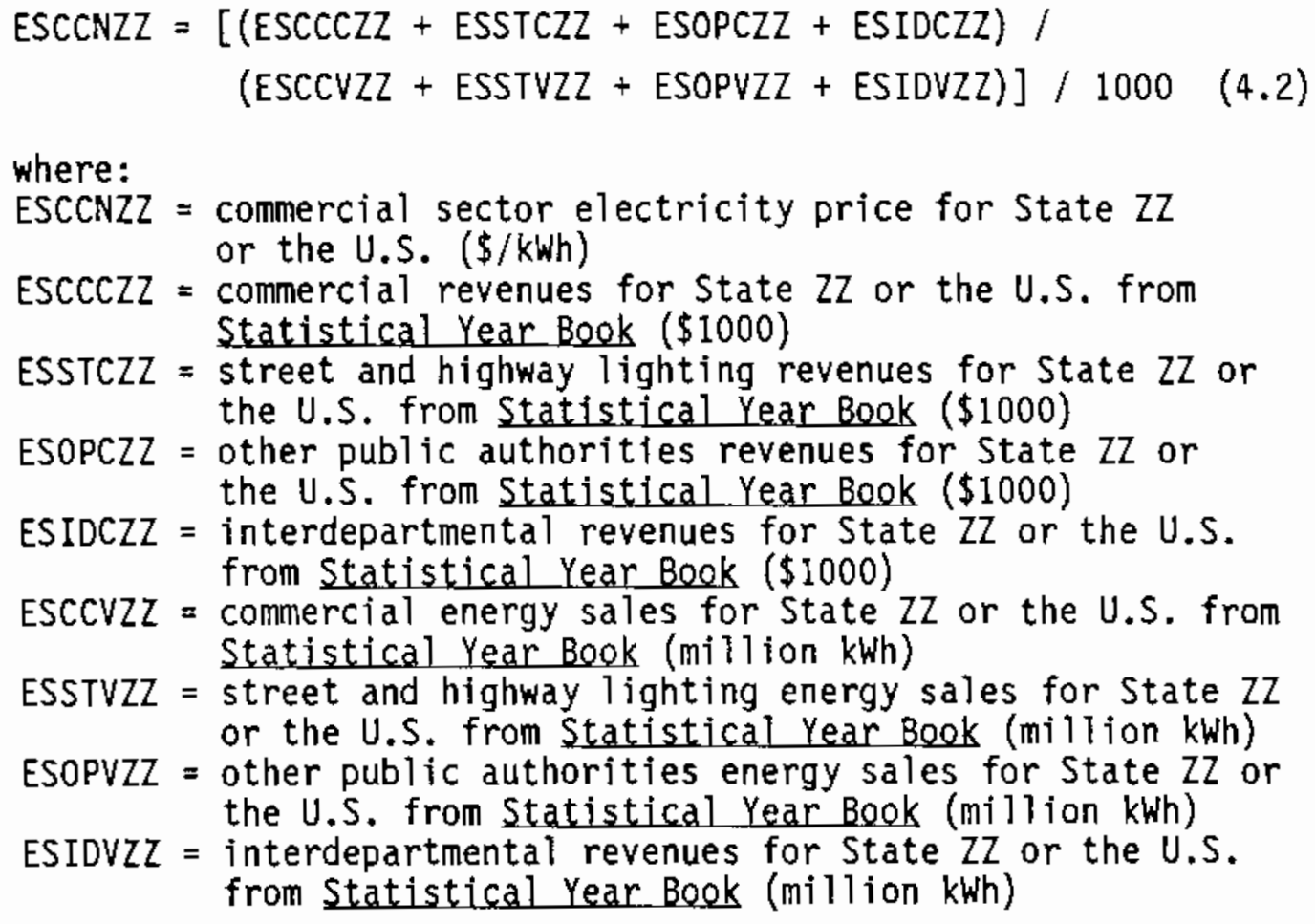

Industrial Sector: 1970-1983

$$
\text { ESICNZZ }=(\text { ESICCZZ } / \text { ESICVZZ }) / 1000
$$




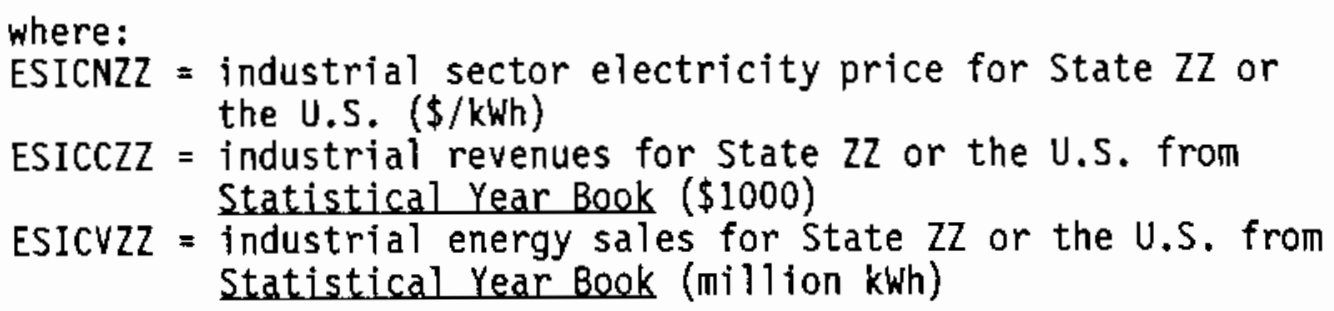

Iransportation Sector: 1970-1983

$$
\text { ESACUZZ }=(\text { ESRRCZZ } / \text { ESRRVZZ }) / 1000
$$

where:
ESACUZZ = STEPS final transportation sector electricity price for State $2 Z$ or the U.S. $(\$ / \mathrm{kWh})$
ESRRCZZ = rail roads and railways revenues for State $Z Z$ or the U.S. from Statistical Year Book $(\$ 1000)$
ESRRVZZ = rail roads and railways energy sales for State $Z Z$ or the U.S. from Statistical Year Book (million $\mathrm{kWh}$ )

2. There are no revenues and/or energy sales data for some states in the transportation sector. If energy sales or revenues or both are reported by Statistical Year Book as zero (0) for a state, then no STEPS transportation sector price is reported for that state. States without reported prices during the 1970-1983 period are given in Table 4.1.

3. Maryland prices are assigned for missing District of Columbia prices. There are no other missing prices for the residential, commercial, and industrial sectors.

4. In order to reconcile the STEPS electricity series (based on Statistical Year Book data) with the EIA electricity prices published in Annual Energy Review (AER), yearly adjustment factors are calculated for the residential, commercial, and industrial sectors from U.S. prices from the Statistical Year Book and AER. Since no transportation sector prices are published in $A E R$, no adjustments are made to that sector.

$$
\begin{aligned}
& \text { ESRCSUS = ESRCUUS / ESRCNUS } \\
& \text { ESCCSUS }=\text { ESCCUUS } / \text { ESCCNUS } \\
& \text { ESICSUS = ESICUUS / ESICNUS }
\end{aligned}
$$


IABLE 4.1. States Without Reported STEPS Transportation Sector Electricity Prices, 1970-1983

\begin{tabular}{ll} 
State & \multicolumn{1}{c}{ Year(s) } \\
\cline { 2 - 2 } AK & $1970-1971$ \\
AL & $1970-1983$ \\
AZ & $1970-1980$ \\
CO & $1970-1983$ \\
CT & $1970-1982$ \\
DE & $1970-1983$ \\
FL & $1970-1983$ \\
GA & $1970-1978$ \\
HI & $1970-1983$ \\
IA & $1970-1983$ \\
ID & $1970-1983$ \\
KS & $1970-1983$ \\
KY & $1970-1983$ \\
LA & 1971 \\
ME & $1974-1983$ \\
MI & $1970-1983$ \\
MN & $1970-1983$ \\
MS & $1970-1983$ \\
MT & $1970-1983$ \\
NC & $1975-1983$ \\
ND & $1970-1983$ \\
NH & $1970-1983$ \\
NM & $1970-1983$ \\
NV & $1970-1983$ \\
OK & $1970-1983$ \\
OR & $1970-1983$ \\
RI & $1970-1983$ \\
SC & $1970-1983$ \\
SD & $1970-1983$ \\
TN & $1970-1983$ \\
TX & $1970-1983$ \\
UT & $1970-1983$ \\
VA & $1970-1983$ \\
VT & $1970-1977$ \\
WI & $1970-1983$ \\
WV & $1970-1983$ \\
WY & $1970-1983$ \\
& $1970-1983$ \\
& \\
\hline
\end{tabular}

Source: Pacific Northwest Laboratory 


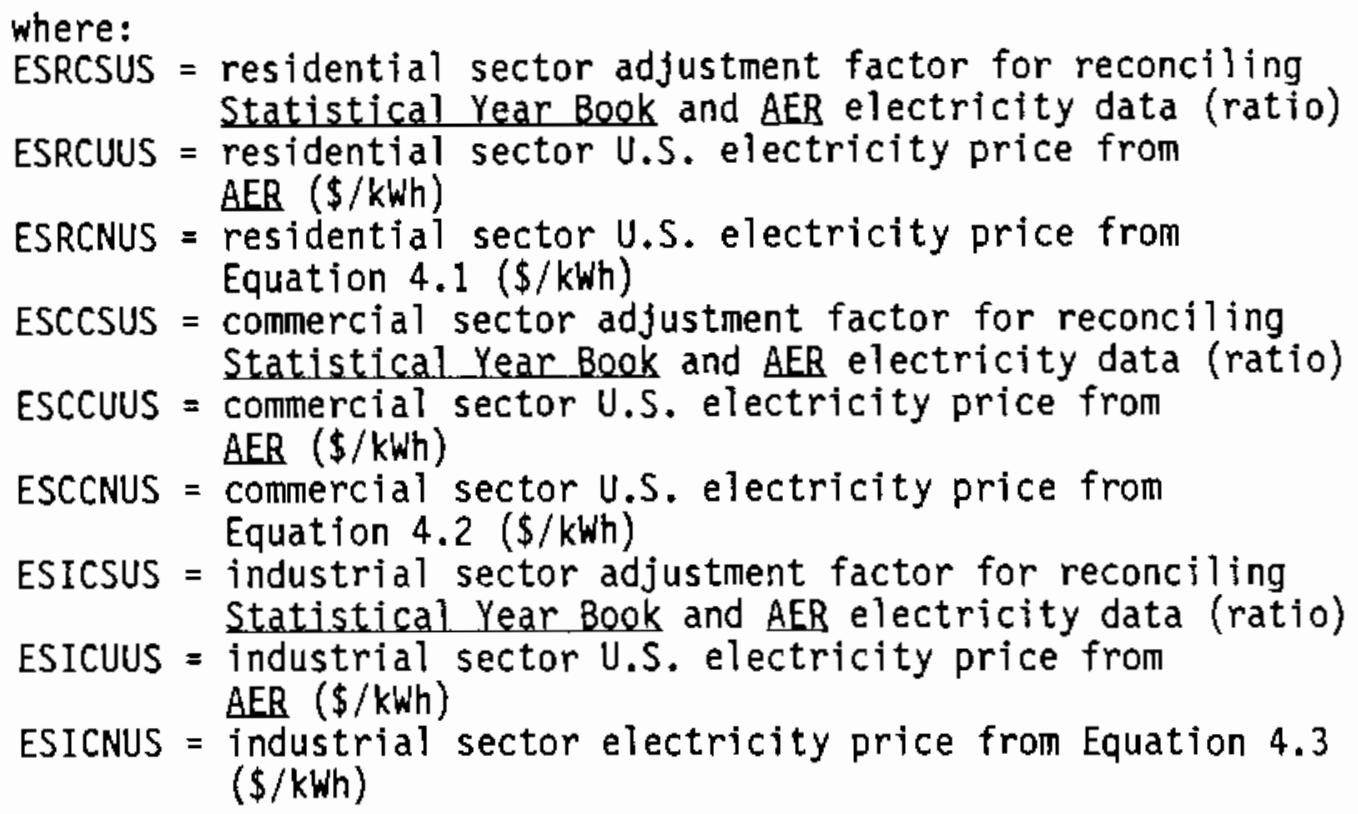

5. To calculate final STEPS physical unit prices for the residential, commercial, and industrial sectors, the state and U.S. prices calculated from the Statistical Year Book sales and revenues data are multiplied by the appropriate yearly sector adjustment factors:

$$
\begin{aligned}
& \text { ESRCUZZ }=\text { ESRCNZZ } * \text { ESRCSUS } \\
& \text { ESCCUZZ }=\text { ESCCNZZ } * \text { ESCCSUS } \\
& \text { ESICUZZ }=\text { ESICNZZ } * \text { ESICSUS }
\end{aligned}
$$

where:

ESRCUZZ = STEPS final residential sector electricity price for State $\mathrm{ZZ}$ or the U.S. $(\$ / \mathrm{kWh})$

ESCCUZZ = STEPS final commercial sector electricity price for State $Z Z$ or the U.S. ( $\$ / \mathrm{kWh})$

ESICUZZ = STEPS final industrial sector electricity price for State $2 Z$ or the U.S. ( $\$ / \mathrm{kWh})$

6. Btu prices for states and the U.S. are calculated using the completed physical unit price series and the conversion factor as illustrated in the following equations:

$$
\begin{aligned}
& \text { ESRCDZZ }=\text { ESRCUZZ } /(3412 / 1,000,000) \\
& \text { ESCCDZZ }=\text { ESCCUZZ } /(3412 / 1,000,000) \\
& \text { ESICDZZ }=\text { ESICUZZ } /(3412 / 1,000,000) \\
& \text { ESACDZZ }=\text { ESACUZZ } /(3412 / 1,000,000)
\end{aligned}
$$


where:

ESRCDZZ = STEPS final residential sector electricity price for State ZZ or the U.S. (\$/MMBtu)

ESCCDZZ = STEPS final commercial sector electricity price for State ZZ or the U.S. (\$/MMBtu)

ESICDZZ = STEPS final industrial sector electricity price for State $Z Z$ or the U.S. ( $\$ /$ MMBtu)

ESACDZZ = STEPS final transportation sector electricity price for State $Z Z$ or the U.S. (\$/MMBtu) 


\subsection{NATURAL GAS}

The STEPS natural gas price series are developed for four end-use sectors: residential, commercial, industrial, and electric utility. No prices are reported for the transportation sector because natural gas used for transportation is almost solely consumed in natural gas pipeline operations. As such, it is an intermediate transaction (process fuel). Prices reported in STEPS are retail prices for sales of natural gas to ultimate users. It is not clear whether or not any taxes are included in these prices. For all four sectors, physical unit prices for states and the U.S. are calculated directly from the data sources, then Btu prices are computed using a conversion factor.

Since there is a major difference in computational procedures for the electric utility sector price series, the documentation is divided into two parts. The procedures for the residential, commercial, and industrial sectors are explained together, followed by the procedures for the electric utility sector.

\subsection{RESIDENIIAL, COMMERCIAL, ANO_INOUSTRIAL SECTORS}

\subsubsection{Data Sources}

1980-1983 Energy Information Administration, U.S. Department of Energy. Natural Gas Annual. Table 11 (1980); and Table 14 (1981-1983).

1970-1979 Bureau of Mines, U.S. Department of the Interior. Natural Gas Production and consumption. Table 6 (1970, 1979); and Table 7 (1971-1978).

\subsubsection{Conversion Factors}

1969-1979 American Gas Association. Gas Facts. Table titled, "Gas Utility Industry Sales, by State and Class of Service." Values used are given in Table 5.1. Conversion factors for 1970 and 1971, which are not available, are imputed as the average of the 1969 and 1972 factors; factors for Hawai for 1970 and 1971 are assumed to be equal to the 1972 factor. 
IABLE 5.1. Btu Conversion Factors for Natural Gas, by State, 1970-1983

\begin{tabular}{|c|c|c|c|c|c|c|c|}
\hline Year & $A K$ & - AL & $\mathrm{AR}$ & $A Z$ & $-C A$ & $C O$ & $\mathrm{CJ}$ \\
\hline 1970 & 1005 & 1032 & 1002 & 1068 & 1062 & 981 & 1016 \\
\hline 1971 & 1005 & 1032 & 1002 & 1068 & 1062 & 981 & 1016 \\
\hline 1972 & 1005 & 1031 & 1004 & 1059 & 1054 & 974 & 1016 \\
\hline 1973 & 1010 & 1029 & 999 & 1056 & 1053 & 962 & 1015 \\
\hline 1974 & 1005 & 1028 & 999 & 1065 & 1056 & 967 & 1012 \\
\hline 1975 & 1005 & 1029 & 997 & 1052 & 1057 & 913 & 1005 \\
\hline 1976 & 1005 & 1030 & 997 & 1052 & 1053 & 914 & 1008 \\
\hline 1977 & 1005 & 1031 & 1021 & 1056 & 1052 & 900 & 1010 \\
\hline 1978 & 1000.0 & 1032.5 & 1000.9 & 1064.7 & 1053.2 & 875.9 & 1013.0 \\
\hline 1979 & 1000.0 & 1028.4 & 1017.0 & 1045.4 & 1049.7 & $892.4^{\circ}$ & 1011.7 \\
\hline 1980 & 1003 & 1034 & 1001 & 1049 & 1046 & 993 & 1022 \\
\hline 1981 & 1004 & 1036 & 1001 & 1053 & 1048 & 994 & 1025 \\
\hline 1982 & 1000 & 1052 & 1002 & 1054 & 1049 & 1000 & 1027 \\
\hline 1983 & 1002 & 1038 & 1023 & 1045 & 1043 & 1006 & 1029 \\
\hline Year & DC & DE & $\mathrm{FL}$ & $\mathrm{GA}$ & HI & IA & ID \\
\hline 1970 & 1019 & 1031 & 1045 & 1037 & 962 & 1015 & 1042 \\
\hline 1971 & 1019 & 1031 & 1045 & 1037 & 962 & 1015 & 1042 \\
\hline 1972 & 1016 & 1020 & 1041 & 1031 & 962 & 1009 & 1061 \\
\hline 1973 & 1013 & 1020 & 1043 & 1030 & 935 & 1012 & 1058 \\
\hline 1974 & 1012 & 1020 & 1043 & 1028 & 921 & 1011 & 1042 \\
\hline 1975 & 1012 & 1020 & 1043 & 1027 & 947 & 1008 & 1055 \\
\hline 1976 & 1012 & 1025 & 1041 & 1027 & 911 & 1008 & 1057 \\
\hline 1977 & 1016 & 1030 & 1045 & 1027 & 949 & 1004 & 1060 \\
\hline 1978 & 1016.0 & 1030.9 & 1047.0 & 1027.9 & 958.0 & 1002.2 & 1053.4 \\
\hline 1979 & 1016.0 & 1031.1 & 1037.3 & 1039.0 & 950.0 & 1002.3 & 1047.1 \\
\hline 1980 & 1003 & 1035 & 1041 & 1032 & 963 & 1003 & 1053 \\
\hline 1981 & 1014 & 1035 & 1059 & 1027 & 959 & 1003 & 1070 \\
\hline 1982 & 1017 & 1033 & 1044 & 1030 & 989 & 1008 & 1072 \\
\hline 1983 & 1010 & 1018 & 1048 & 1026 & 1023 & 1014 & 1047 \\
\hline
\end{tabular}


IABLE 5.1 (CONT). Btu Conversion Factors for Natural Gas, by State, 1970-1983

\begin{tabular}{|c|c|c|c|c|c|c|c|}
\hline Year & IL & IN & KS & KY & $-L A$ & $M A$ & $M O$ \\
\hline 1970 & 1029 & 1004 & 993 & 1020 & 1021 & 1012 & 1023 \\
\hline 1971 & 1029 & 1004 & 993 & 1020 & 1021 & 1012 & 1023 \\
\hline 1972 & 1025 & 1006 & 998 & 1017 & 1029 & 1012 & 1022 \\
\hline 1973 & 1023 & 998 & 988 & 1019 & 1031 & 1011 & 1020 \\
\hline 1974 & 1023 & 997 & 986 & 1015 & 1030 & 1009 & 1020 \\
\hline 1975 & 1026 & 990 & 984 & 1008 & 1037 & 1004 & 1013 \\
\hline 1976 & 1025 & 990 & 981 & 1011 & 1038 & 1006 & 1014 \\
\hline 1977 & 1028 & 990 & 981 & 1011 & 1038 & 1007 & 1016 \\
\hline 1978 & 1018.3 & 989.1 & 978.1 & 1009.9 & 1044.7 & 1009.1 & 1030.1 \\
\hline 1979 & 1024.4 & 990.4 & 977.8 & 1009.9 & 1036.9 & 1009.1 & 1044.8 \\
\hline 1980 & 1022 & 989 & 987 & 1009 & 1038 & 1016 & 1020 \\
\hline 1981 & 1020 & 993 & 987 & 1014 & 1037 & 1016 & 1014 \\
\hline 1982 & 1022 & 1016 & 999 & 1014 & 1047 & 1024 & 1018 \\
\hline 1983 & 1041 & 1006 & 999 & 1020 & 1042 & 1025 & 1021 \\
\hline Year & ME & $M I$ & $M N$ & $-M D$ & MS & MI & $N C$ \\
\hline 1970 & 1021 & 1015 & 1006 & 1014 & 1025 & 1016 & 1025 \\
\hline 1971 & 1021 & 1015 & 1006 & 1014 & 1025 & 1016 & 1025 \\
\hline 1972 & 1012 & 1015 & 1002 & 1007 & 1025 & 1032 & 1024 \\
\hline 1973 & 1011 & 1010 & 999 & 995 & 1024 & 1032 & 1027 \\
\hline 1974 & 1011 & 1007 & 1001 & 1005 & 1025 & 1022 & 1025 \\
\hline 1975 & 1024 & 1012 & 1001 & 1006 & 1023 & 1021 & 1018 \\
\hline 1976 & 1024 & 1008 & 998 & 1003 & 1023 & 1014 & 1018 \\
\hline 1977 & 1024 & 1006 & 997 & 1002 & 1025 & 1009 & 1019 \\
\hline 1978 & 1024.0 & 1005.5 & 996.7 & 1003.8 & 1021.2 & 1000.5 & 1020.8 \\
\hline 1979 & 1000.0 & 1005.3 & 995.3 & 979.5 & 1024.3 & 990.1 & 1021.9 \\
\hline 1980 & 1024 & 1011 & 997 & 1014 & 1028 & 1012 & 1012 \\
\hline 1981 & 1025 & 1017 & 995 & 1015 & 1025 & 1011 & 1012 \\
\hline 198 & 1025 & 1022 & 1005 & 1018 & 1028 & 1011 & 1033 \\
\hline 198 & 1026 & 1024 & 1023 & 1027 & 1027 & 1008 & 1033 \\
\hline
\end{tabular}


IABLE 5.1 (CONT). Btu Conversion Factors for Natural Gas, by State, 1970-1983

\begin{tabular}{|c|c|c|c|c|c|c|c|}
\hline Year & $\mathrm{ND}$ & NE & $\mathrm{NH}$ & $\mathrm{NJ}$ & NM & NV & NY \\
\hline 1970 & 1020 & 1003 & 1010 & 1032 & 1091 & 1070 & 1021 \\
\hline 1971 & 1020 & 1003 & 1010 & 1032 & 1091 & 1070 & 1021 \\
\hline 1972 & 1031 & 1008 & 1010 & 1026 & 1083 & 1082 & 1021 \\
\hline 1973 & 1024 & 1005 & 1008 & 1027 & 1067 & 1067 & 1030 \\
\hline 1974 & 1002 & 1002 & 1007 & 1026 & 1062 & 1067 & 1023 \\
\hline 1975 & 1001 & 994 & 1010 & 1031 & 1064 & 1067 & 1015 \\
\hline 1976 & 1000 & 994 & 1010 & 1034 & 1057 & 1066 & 1014 \\
\hline 1977 & 1000 & 998 & 1000 & 1034 & 1057 & 1049 & 1011 \\
\hline 1978 & 1000.0 & 997.8 & 1007.3 & 1035.0 & 1055.0 & 1027.9 & 1011.9 \\
\hline 1979 & 1000.0 & 993.8 & 1040.0 & 1035.9 & 1056.4 & 1013.1 & 1015.5 \\
\hline 1980 & 1052 & 978 & 1020 & 1033 & 1043 & 1061 & 1025 \\
\hline 1981 & 1042 & 978 & 1022 & 1034 & 1047 & 1076 & 1020 \\
\hline 1982 & 1026 & 981 & 1020 & 1031 & 1045 & 1070 & 1023 \\
\hline 1983 & 1045 & 982 & 1021 & 1031 & 1033 & 1066 & 1027 \\
\hline Year & $-\mathrm{OH}$ & OK & $Q R$ & $P A$ & RI & $S C$ & SO \\
\hline 1970 & 1027 & 1028 & 1050 & 1033 & 1032 & 1032 & 1005 \\
\hline 1971 & 1027 & 1028 & 1050 & 1033 & 1032 & 1032 & 1005 \\
\hline 1972 & 1023 & 1032 & 1045 & 1033 & 1021 & 1028 & 1004 \\
\hline 1973 & 1025 & 1023 & 1059 & 1036 & 1016 & 1026 & 1002 \\
\hline 1974 & 1026 & 1032 & 1044 & 1024 & 1013 & 1025 & 999 \\
\hline 1975 & 1023 & 1015 & 1039 & 1025 & 1014 & 1024 & 1000 \\
\hline 1976 & 1025 & 1014 & 1036 & 1025 & 1013 & 1023 & 999 \\
\hline 1977 & 1024 & 1027 & 1042 & 1021 & 1013 & 1022 & 1000 \\
\hline 1978 & 1023.0 & 1023.9 & 1045.1 & 1021.5 & 1012.9 & 1032.0 & 999.2 \\
\hline 1979 & 1024.9 & 1023.5 & 1044.8 & 1020.6 & 1011.3 & 1018.1 & 995.6 \\
\hline 1980 & 1016 & 1023 & 1046 & 1022 & 1021 & 1033 & 998 \\
\hline 1981 & 1023 & 1035 & 1044 & 1022 & 1022 & 1023 & 1002 \\
\hline 1982 & 1029 & 1023 & 1044 & 1028 & 1036 & 1030 & 999 \\
\hline 1983 & 1034 & 1042 & 1041 & 1029 & 1035 & 1027 & 1011 \\
\hline
\end{tabular}


IABLE 5.1 (CONT). Btu Conversion Factors for Natural Gas, by State, 1970-1983

\begin{tabular}{|c|c|c|c|c|c|c|c|}
\hline Year & IN & $T X$ & UT & VA & VI & WA & $W I$ \\
\hline $\begin{array}{l}1970 \\
1971 \\
1972 \\
1973 \\
1974 \\
1975 \\
1976 \\
1977 \\
1978 \\
1979 \\
1980 \\
1981 \\
1982 \\
1983\end{array}$ & $\begin{array}{l}1031 \\
1031 \\
1022 \\
1022 \\
1020 \\
1031 \\
1029 \\
1031 \\
1028.0 \\
1032.6 \\
1016 \\
1016 \\
1024 \\
1023\end{array}$ & $\begin{array}{l}1033 \\
1033 \\
1027 \\
1027 \\
1027 \\
1026 \\
1025 \\
1027 \\
1028.1 \\
1032.5 \\
1033 \\
1032 \\
1032 \\
1029\end{array}$ & $\begin{array}{c}932 \\
932 \\
938 \\
945 \\
952 \\
950 \\
948 \\
950 \\
956.2 \\
959.8 \\
1086 \\
1073 \\
939 \\
1075\end{array}$ & $\begin{array}{l}1029 \\
1029 \\
1026 \\
1025 \\
1022 \\
1019 \\
1019 \\
1023 \\
1020.8 \\
1021.4 \\
1016 \\
1024 \\
1027 \\
1030\end{array}$ & $\begin{array}{l}1020 \\
1020 \\
1006 \\
1006 \\
1008 \\
1008 \\
1008 \\
1008 \\
1010.5 \\
1010.1 \\
990 \\
993 \\
993 \\
992\end{array}$ & $\begin{array}{l}1059 \\
1059 \\
1055 \\
1051 \\
1047 \\
1042 \\
1041 \\
1045 \\
1047.6 \\
1046.9 \\
1052 \\
1050 \\
1053 \\
1043\end{array}$ & $\begin{array}{l}1022 \\
1022 \\
1019 \\
1015 \\
1015 \\
1020 \\
1017 \\
1015 \\
1012.3 \\
1012.9 \\
1008 \\
1009 \\
1012 \\
1009\end{array}$ \\
\hline Year & WV & WY & US. & & & & \\
\hline $\begin{array}{l}1970 \\
1971 \\
1972 \\
1973 \\
1974 \\
1975 \\
1976 \\
1977 \\
1978 \\
1979 \\
1980 \\
1981 \\
1982 \\
1983\end{array}$ & $\begin{array}{l}1034 \\
1034 \\
1029 \\
1030 \\
1023 \\
1037 \\
1043 \\
1042 \\
1031.4 \\
1023.7 \\
1032 \\
1040 \\
1047 \\
1038\end{array}$ & $\begin{array}{c}992 \\
992 \\
1023 \\
1017 \\
996 \\
934 \\
950 \\
937 \\
913.7 \\
929.2 \\
1060 \\
1059 \\
1002 \\
1059\end{array}$ & $\begin{array}{l}1029 \\
1029 \\
1027 \\
1021 \\
1024 \\
1021 \\
1020 \\
1021 \\
1019.0 \\
1020.8 \\
1026 \\
1027 \\
1028 \\
1031\end{array}$ & & & & \\
\hline
\end{tabular}

Source: Pacific Northwest Laboratory 
1980-1983 Energy Information Administration, U.S. Department of Energy. Natural Gas Annual. Table 11 (1980), and Table 14 (1981-1983). Values used are given in Table 5.1.

\title{
5.1.3 Computational Procedures
}

1. All natural gas physical unit prices for the residential, commercial, and industrial sectors are calculated from value and quantity of sales data from Natural Gas Annual or $i$ \&s predecessor report Natural Gas Production and Consumption (NGA). ${ }^{\text {S }}$ State and U.S. prices are calculated directly from the data sources as average revenue per unit of sales by natural gas utilities. Prices for each of the three sectors are computed as discussed below.

\section{Residential Sector: 1970-1983.}

$$
\text { NGRCUZZ = NGRCCZZ / NGRCVZZ }
$$

where:

NGRCCZZ = residential value of gas reported for State $Z Z$ or the U.S. from NGA $(\$ 1000)$

NGRCVZZ = residential quantity of gas sold reported for State $Z Z$ or the U.S. from NGA (million cu ft)

\author{
Commercial Sector: 1970-1981. \\ NGCCUZZ $=($ NGCCCZZ + NGOCCZZ) $/$ (NGCCVZZ + NGOCVZZ) \\ where: \\ NGCCUZZ = STEPS final commercial sector natural gas price for \\ State $\mathrm{ZZ}$ or the U.S. ( $\$ / 1000 \mathrm{cu} \mathrm{ft})$ \\ NGCCCZZ = commercial value of gas for State ZZ or the U.S. from \\ NGA $(\$ 1000)$ \\ NGCCVZZ = commercial volume of gas sold for State ZZ or the U.S. \\ from NGA (million cu $\mathrm{ft}$ ) \\ NGOCCZZ = other consumers value of gas reported for State ZZ \\ or the U.S. from NGA $(\$ 1000)$ \\ NGOCVZZ = other consumers volume of gas sold reported for \\ State $\mathrm{ZZ}$ or the U.S. from NGA (million cu ft)
}

(a) Both of these EIA publications will be abbreviated NGA, since the data contained in each is similar. 
Commercial Sector: 1982-1983.

NGCCUZZ $=$ NGCCCZZ / NGCCVZZ

where:

NGCCUZZ = STEPS final commercial sector natural gas price for State $Z Z$ or the U.S. ( $\$ / 1000 \mathrm{cu} \mathrm{ft})$

$N G C C C Z Z$ = commercial value of gas reported for state $Z Z$ or the U.S. from NGA $(\$ 1000)$

NGCCVZZ = commercial volume of gas sold reported for state $Z Z$ or the U.S. from NGA (million cu ft)

Industrial Sector: $1970-1983$.

NGICUZZ = NGICCZZ / NGICVZZ

where:

NGICUZZ = STEPS final industrial sector natural gas price for State $Z Z$ or the U.S. ( $\$ / 1000 \mathrm{cu} \mathrm{ft})$

NGICCZZ = industrial value of gas reported for state ZZ or the U.S. from $N G A(\$ 1000)$

NGICVZZ = industrial volume of gas sold reported for state ZZ or the U.S. from NGA (million cu ft)

2. For 1970-1979, both the value and quantity of sales data from NGA are reported as composites for Maryland/District of Columbia and Maine/New Hampshire/Vermont. In each case, the combined prices are assigned equally and identically to each of the states in the composite. Hawai i has no reported natural gas use for 1970-1979 in the residential and commercial sectors and for 1970-1983 in the industrial sector, so no STEPS prices are reported for these years.

3. Btu prices for states and the U.S. for all years are calculated using the completed physical unit price series and the state-level conversion factors:

$$
\begin{aligned}
& \text { NGRCDZZ }=(\text { NGRCUZZ / NGNCKZZ) } \star 1000 \\
& \text { NGCCDZZ }=(\text { NGCCUZZ / NGNCKZZ) } * 1000 \\
& \text { NGICDZZ }=(\text { NGICUZZ / NGNCKZZ) } * 1000
\end{aligned}
$$

where:

NGRCDZZ = STEPS final residential sector natural gas price for State $Z Z$ or the U.S. ( $\$ / M M B t u)$

NGCCDZZ = STEPS final commercial sector natural gas price for State $Z Z$ or the U.S. ( $\$ / M M B t u)$

NGICDZZ = STEPS final industrial sector natural gas price for State $Z Z$ or the U.S. ( $\$ / M M B t u)$

NGNCKZZ = conversion factor for natural gas for State $Z Z$ or the U.S. from Table 5.1 (8tu/cu ft) 


\subsection{ELECTRIC UTILITY SECTOR}

\subsubsection{Data Sources}

1980-1983 Energy Information Administration, U.S. Department of Energy. Natural Gas Annual. Table 11 (1980); and Table 14 (1981-1983).

1970-1979 Bureau of Mines, U.S. Department of the Interior. Natural Gas Production and Consumption. Table 6 (1970, 1979); and Table 7 (1971-1978).

1973-1983 Energy Information Administration, U.S. Department of Energy. cost and Quality of Fuels for Electric Utility Plants. Tables numbered as shown in Table 5.2 .

\subsubsection{Conversion Factors}

1970-1972 American Gas Association. Gas Facts. Table titled, "Gas Utility Industry Sales, by State and Class of Service." Values used are listed in Table 5.1. Conversion factors for 1970 and 1971, which are not available, are imputed as the average of the 1969 and 1972 factors.

1973-1983 No conversion factors are required; Btu and physical unit prices are calculated directly from data sources.

IABLE 5.2. Tables from Cost and Quality of Fuels Used to Calculate Electric Utility Sector Natural Gas Prices

\begin{tabular}{lcc} 
C\&O Table(s) & $\begin{array}{c}\text { C\&Q Table(s) } \\
\text { Containing } \\
\text { Price Data }\end{array}$ & $\begin{array}{r}\text { Containing } \\
\text { Volume Data }\end{array}$ \\
\cline { 2 - 3 } 1973 & 10 & 9 \\
1974 & 10 & 9 \\
1975 & 10,16 & 9,15 \\
1976 & 10,16 & 9,15 \\
1977 & 10,16 & 9,15 \\
1978 & 10,16 & 9,15 \\
1979 & 10,16 & 9,15 \\
1980 & 48 & -- \\
1981 & 48 & -- \\
1982 & 48 & -- \\
1983 & 53 & --
\end{tabular}

Source: Pacific Northwest Laboratory 


\subsubsection{Computational Procedures: $1970-1972$}

1. State and U.S. prices for 1970-1972 are taken from Natural Gas Production and Consumption and are calculated similarly to prices for the residential, commercial, industrial, and transportation sectors. Prices, as average revenues of per unt of sales, are computed from value and quantity of sales data from the source reports.

$$
\text { NGEUUZZ = NGEUCZZ / NGEUVZZ }
$$

$$
\begin{aligned}
\text { where: } & \\
\text { NGEUUZZ = } & \text { STEPS final electric utility sector natural gas price } \\
& \text { for State } Z Z \text { or the U.S. ( } \$ / 1000 \mathrm{cu} \mathrm{ft}) \\
\text { NGEUCZZ = } & \text { electric utilities value reported for State } Z Z \text { or } \\
& \text { the U.S. from NGA }(\$ 1000) \\
\text { NGEUVZZ = } & \text { electric utilities volume reported for State } Z Z \\
& \text { or the U.S. from NGA (million cu } \mathrm{ft})
\end{aligned}
$$

2. The Hawaii, Idaho, and Washington value and consumption data are both equal to zero (0) throughout the period 1970-1972, so no STEPS prices are developed for these three states. A combined price is reported for Maine, New Hampshire, and Vermont for 1971 and 1972; each of these states is assigned the combined price equally and identically. The combined Maryland/District of Columbia prices are assigned equally and identically to these two states.

3. Btu prices for states and the U.S. are calculated from the completed physical unit price series using the state-level conversion factors.

$$
\text { NGEUDZZ }=(\text { NGEUUZZ } / \text { NGNCKZZ }) \star 1000
$$

where:

$$
\begin{aligned}
\text { NGEUDZZ = } & \text { STEPS final electric utility sector natural gas price } \\
& \text { for State } Z Z \text { or the U.S. ( } \$ / M M B t u) \\
\text { NGNCKZZ = } & \text { conversion factor for natural gas for State } Z Z \text { or the } \\
& \text { U.S. from Table } 5.1 \text { (Btu/cu ft) }
\end{aligned}
$$

\subsubsection{Computational Procedures: 1973-1974, 1983}

1. Btu and physical unit prices for states and the U.S. are reported by cost and Quality of Fuels (c\&O) for gas consumed at steam-electric plants only. Prices are taken directly from cost and Quality for the physical unit price series, while prices per million Btu are converted from cents to dollars.

$$
\begin{aligned}
& \text { NGEUUZZ }=\text { NGSENZZ } \\
& \text { NGEUDZZ }=\text { NGSEFZZ } / 100
\end{aligned}
$$




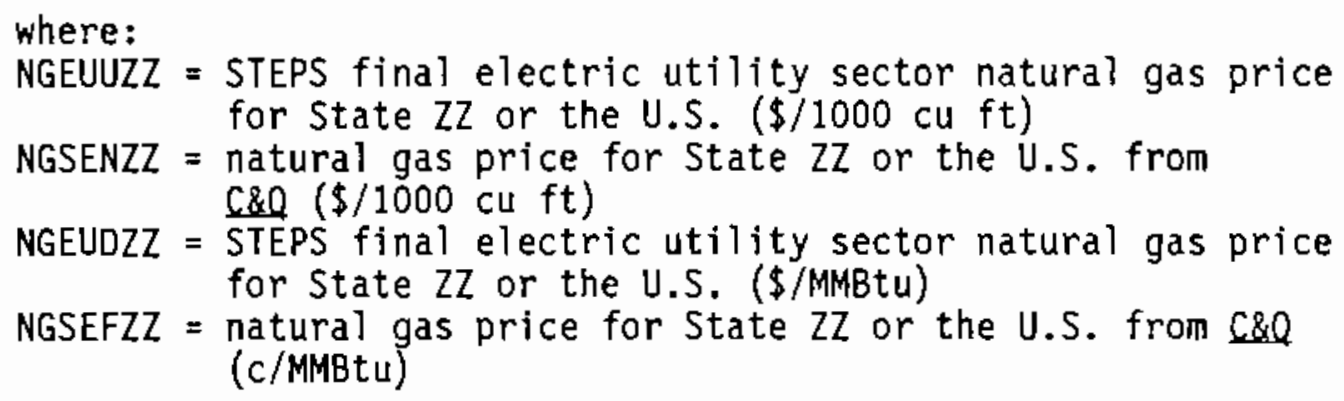

2. Alaska is the only state missing Cost and Quality price data for which prices are imputed. The imputation of Alaska prices for all the years 1973-1983 is discussed later. States with no prices reported by STEPS for 1973, 1974, and 1983 are listed in Table 5.3.

TABLE 5.3. States With No Electric Utility Sector Prices Reported by STEPS, 1973-1983

\begin{tabular}{ll} 
State & \multicolumn{1}{c}{ Years With_No Reported Prices } \\
CT & $1973-1983$ \\
DC & $1973-1983$ \\
HI & $1973-1983$ \\
ID & $1973-1974,1983$ \\
MD & $1973-1974,1983$ \\
ME & $1973-1983$ \\
NC & 1983 \\
ND & $1973-1974,1976-1983$ \\
NH & $1973-1974,1977-1978,1980,1982-1983$ \\
OR & 1983 \\
PA & 1973 \\
RI & $1976-1978,1980$ \\
SC & 1977 \\
SD & 1983 \\
TN & $1974-1983$ \\
VT & 1983 \\
WA & $1973-1978,1983$ \\
WY & 1973,1975
\end{tabular}

Source: Pacific Northwest Laboratory 


\subsubsection{Computational Procedures: 1975-1979}

1. Btu and physical unit prices for states and the U.S. are reported separately by cost and Quality for gas consumed at steam-electric plants and gas consumed at combustion turbine and internal combustion units. Weighted-average Btu and physical unit prices are calculated using the two Cost and Quality prices and the respective gas deliveries for steam-electric and combustion use.

$$
\begin{gathered}
\text { NGEUUZZ = }[(\text { NGSENZZ * NGSEVZZ })+(\text { NGCTNZZ * NGCTVZZ })] / \\
(N G S E V Z Z+N G C T V Z Z) \\
\text { NGEUDZZ = }[(\text { NGSEFZZ / 100)*NGSEVZZ }]+ \\
{[(N G C T F Z Z / 100) * \text { NGCTVZZ }] /} \\
(N G S E V Z Z+\text { NGCTVZZ) }
\end{gathered}
$$

where:

NGEUUZZ = STEPS final electric utility sector natural gas price for State $Z Z$ or the U.S. ( $\$ / 1000 \mathrm{cu} \mathrm{ft}$ )

NGSENZZ = steam-electric gas price for State $Z Z$ or the U.S. from $\mathrm{c \& O}(\$ / 1000 \mathrm{cu} \mathrm{ft})$

NGSEVZZ = deliveries of gas to steam-electric plants as reported for State $Z Z$ or the U.S. from $\mathrm{C \& Q}$ (million cu ft)

NGCTNZZ = combustion turbine gas price for State $Z Z$ or the U.S. from $\mathrm{c} \& \mathrm{Q}(\$ / 1000 \mathrm{cu} \mathrm{ft})$

NGCTVZZ = deliveries of gas to combustion turbine units as reported for State $Z Z$ or the U.S. from C\&O (million cu ft)

NGEUDZZ = STEPS final electric utility sector natural gas price for State ZZ or the U.S. (\$/MMBtu)

NGSEFZZ = steam-electric gas price for State ZZ or the U.S. from C\&O (c/MMBtu)

NGCTFZZ = combustion turbine gas price for State ZZ or the U.S. from C\&Q (c/MMBtu)

2. The imputation of Alaska prices is discussed below. No other state prices are imputed for the $1975-1979$ period. Table 5.3 lists the states with no reported STEPS prices for the 1975-1979 period.

\subsubsection{Computational Procedures: 1980-1982}

1. Btu and physical unit prices for states and the U.S. for 1980-1982 are taken from cost and Quality for all reporting plants. Physical unit prices are taken directly from the data source, while Btu prices are converted from cents to dollars per million 8 tu.

$$
\begin{aligned}
& \text { NGEUUZZ }=\text { NGEUNZZ } \\
& \text { NGEUDZZ }=\text { NGEUFZZ } / 100
\end{aligned}
$$




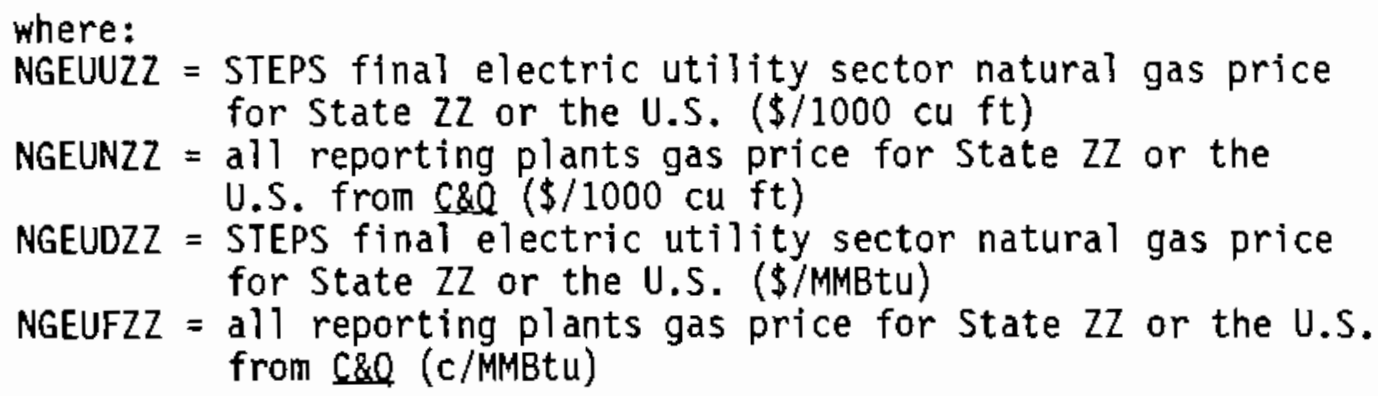

2. The imputation of Alaska prices is described below. No other missing state prices are imputed for the 1980-1982 period. States with no reported prices for these years are listed in Table 5.3.

\subsubsection{Imputation of Alaska. Prices: 1973-1983}

1. Since cost and Quality does not cover Alaska prices and since SEDS does report natural gas usage in the electric utility sector, Alaska prices are imputed from other data sources. $N G A$ does have quantity and value data from which physical unit prices are calculated:

$$
\text { NGEUUAK = NGEUCAK / NGEUVAK }
$$

where:

NGEUUAK = STEPS final electric utility sector natural gas price for Alaska ( $\$ / 1000 \mathrm{cu} \mathrm{ft})$

NGEUCAK = electric utility value of gas for Alaska from NGA $(\$ 1000)$

NGEUVAK = electric utility quantity of gas consumed in Alaska from $N G A$ (million $\mathrm{cu} f \mathrm{t}$ )

2. Btu prices are calculated using the Alaska physical unit prices and the Btu conversion factors for Alaska:

$$
\text { NGEUDAK }=(\text { NGEUUAK / NGNCKAK }) * 1000
$$

where:

NGEUDAK = STEPS final electrlc utility sector natural gas price for Alaska (\$/MMBtu)

NGNCKAK = conversion factor for Alaska from Table 5.1 


\subsection{COKING COAL}

The coking coal price series in STEPS cover only the industrial sector. Prices are those paid at coke plants for coal received, and probably include any taxes paid (although this is not clear from the data collection form). Physical unit prices for states and the U.S. are taken directly from the data sources, then Btu prices are computed using a conversion factor.

\subsection{DATA SOURCES}

1970-1980 Energy Information Administration, U.S. Department of Energy. coke and coal Chemicals. Tables numbered as shown in Table6.1.

1981-1983 Energy Information Administration, U.S. Department of Energy. Quarterly Coal Report. Table A3.

IABLE 6.1. Numbers of Coke and Coal Chemicals Tables Used for Price Data, 1970-1980

Year(s)
1970
1971
$1972-1973$
$1974-1976$
1977
1978
$1979-1980$

Source: Pacific Northwest Laboratory
Iable Number

8

16

19

22

19

15 


\subsection{CONVERSION FACTOR}

1970-1983 Energy Information Administration, U.S. Department of Energy. State Energy Data Report. Table titled, "Conversion Factors in the State Energy Data System." Average bituminous coal and lignite consumption in coke plants.

26.8 Million Btu per short ton

\subsection{COMPUTATIONAL PROCEDURES: $1970-1983$}

1. Individual state and U.S. physical unit prices are assigned to their respective states. Group prices are assigned equally and identically to each state within the group. Table 6.2 shows these price assignments by state.

$$
\text { CCICUZZ }=\text { CCICNZZ }
$$

where:

CCICUZZ = STEPS final industrial sector coking coal price for State $\mathrm{ZZ}$ or the U.S. (\$/ton)

CCICNZZ = price of coal coke reported for State ZZ or the U.S. in Coke and coal Chemicals or Quarterly Coal Report $(\$ /$ ton $)$

2. Btu prices are calculated for states and the U.S. using the completed physical unit price series and the conversion factor:

$$
\text { CCICOZZ = CCICUZZ } / 26.8
$$

where:

CCICDZZ = STEPS final industrial sector coking coal price for State $Z Z$ or the U.S. (\$/MMBtU) 
IABLE 6.2. Coking Coal Price Assignments, 1970-1983

\begin{tabular}{lll} 
State & Year(s) & \\
\cline { 2 - 3 } AL & $1970-1983$ & Alabama \\
CA & $1970-1982$ & California, Colorado, Utah \\
CO & $1970-1982$ & California, Colorado, Utah \\
IL & $1970-1983$ & Illinois \\
IN & $1970-1983$ & Indiana \\
KY & $1970-1983$ & Kentucky, Missouri, Tennessee, Texas \\
MD & $1970-1971$ & Maryland, New Jersey, New York \\
& $1972-1982$ & Maryland, New York \\
MI & $1970-1978$ & Michigan \\
& 1979 & Michigan, Minnesota, Wisconsin \\
MN & $1980-1983$ & Michigan, Wisconsin \\
& $1970-1978$ & Minnesota, Wisconsin \\
MO & 1979 & Michigan, Minnesota, Wisconsin \\
NJ & $1970-1983$ & Kentucky, Missouri, Tennessee, Texas \\
NY & $1970-1971$ & Maryland, New Jersey, New York \\
& $1970-1971$ & Maryland, New Jersey, New York \\
OH & $1972-1982$ & Maryland, New York \\
PA & $1970-1983$ & Ohio \\
TN & $1970-1983$ & Pennsylvania \\
TX & $1970-1983$ & Kentucky, Missouri, Tennessee, Texas \\
UT & $1970-1983$ & Kentucky, Missouri, Tennessee, Texas \\
VA & $1970-1982$ & California, Colorado, Utah \\
WI & $1978-1982$ & Virginia, West Virginia \\
& $1970-1978$ & Minnesota, Wisconsin \\
WV & 1979 & Michigan, Minnesota, Wisconsin \\
US & $1980-1983$ & Michigan, Wisconsin \\
& $1970-1977$ & West Virginia \\
& $1978-1982$ & Virginia, West Virginia \\
$1970-1983$ & United States \\
& &
\end{tabular}

Source: Pacific Northwest Laboratory 
, 


\subsection{SIEAM COAL}

STEPS steam coal price series are developed for the residential, industrial, and electric utility sectors. While some commercial and transportation sector coal use is reported in the State Energy Data Report, no commercial or transportation price data are available. The industrial sector steam coal prices reported in STEPS can be used as estimates of prices for these two sectors. The types of prices and computational procedures for the steam coal price series are discussed separately below.

\subsection{ELECTRIC UTILIIY SECTOR}

For all years, Btu and physical unit retail prices for states and the U.S. are taken directly from the data sources. For 1970-1972, prices are the average for coal burned under boilers or by internal combustion engines for the electric utility industry. For 1973-1983, prices are the average cost per ton of coal purchased by electric utility plants within each state. It is not clear whether or not taxes are included in any of the steam coal electric utility prices.

\subsubsection{Data Sources}

1970-1983 Edison Electric Institute. Statistical Year Book of the Electric Utility Industry. Table titled, "Analys is of Fuel for Electric Generation: Total Electric Utility Industry."

1973-1983 Energy Information Administration, U.S. Department of Energy. Cost and Quality of Euels for Electric Utility Plants. Table 3 (1973-1979), Table 51 (1980-1982) and Table 50 (1983). Average of all coal spot and contract prices.

\subsubsection{Conversion Factors}

1970-1983 Both 8tu and physical unit prices are taken directly from the data sources, so no explicit conversion factors are used.

\subsubsection{Computational_Procedures: $1970-1972$}

Physical unit and Btu prices for steam coal in the electric utility sector are taken from the Edison Electric Institute's Statistical Year Book. Btu prices are converted from cents to dollars per million Btu, and a few states are assigned combined prices. The 1971 electric utility prices for Alaska are imputed using an average ratio technique. 
1. Btu and physical unit prices for states and the U.S. are taken from the Statjstical Year Book. Physical unit prices in dollars per ton are used directly from the data source, while prices per million Btu are converted from cents to dollars.

$$
\begin{aligned}
& \text { BCEUUZZ }=\text { CLEUNZZ } \\
& \text { BCEUDZZ }=\text { CLEUFZZ } / 100
\end{aligned}
$$

where:

$$
\begin{aligned}
\text { BCEUUZZ = } & \text { STEPS final electric utility sector steam coal price } \\
& \text { for State ZZ or the U.S. ( } \$ / \text { ton) } \\
\text { CLEUNZZ = } & \text { cost of coal burned in the electric utility sector for } \\
& \text { State ZZ or the U.S. from Statistical Year Book }(\$ / \text { ton) } \\
\text { BCEUDZZ = } & \text { STEPS final electric utility sector steam coal price } \\
& \text { for State ZZ or the U.S. ( } \$ / M M B t u) \\
\text { CLEUFZZ = } & \text { cost of coal burned in the electric utility sector for } \\
& \text { State ZZ or the U.S. from Statistical Year Book (c/MMBtu) }
\end{aligned}
$$

2. Delaware, the District of Columbia, and Maryland are each assigned the combined price for those three states.

3. The California price reported in Statistical Year Book in 1970, and the Oregon and Rhode Island prices reported for 1970-1972 are not used; no prices are reported in STEPS for these states, due to a lack of coal consumption as reported in SEDS.

4. The steam coal electric utility sector Alaska price for 1971 is imputed as discussed in section 7.1.5.

\subsubsection{Computational Procedures: $1973-1983$}

Steam coal electric utility prices (both physical unit and Btu) are taken from the EIA's Cost and Quality of Fuels for Electric Utility Plants (C\&O). All available physical unit prices and Btu prices are used. Physical unit prices are used directly, while Btu prices are converted from cents to dollars per million Btu. Except for the imputation of Alaska prices that is discussed below, there is no imputation of prices for states without C\&O data.

1. Btu and physical unit prices for states and the U.S. are taken from Cost and Quality for 1973-1983. Physical unit prices are used as reported in the data sources, while Btu prices are converted from cents to dollars per million Btu:

$$
\begin{aligned}
& \text { BCEUUZZ }=\text { BCSENZZ } \\
& \text { BCEUDZZ }=\text { BCSEFZZ } / 100
\end{aligned}
$$


where:

BCEUUZZ = STEPS final electric utility sector steam coal price for State $Z Z$ or the U.S. (\$/ton)

BCSENZZ = steam-electric steam coal price for State $Z Z$ or the U.S. from C\&O (\$/ton)

BCEUDZZ = STEPS final electric utility sector steam coal price for State $Z Z$ or the U.S. (\$/MMBtu)

$B C S E F Z Z$ = steam-electric stean coal price for State ZZ or the U.S. from C\&O (c/MMBtu)

2. Hawaii, which is not covered by cost and Ouality, does not have prices reported by STEPS for any years in the 1973-19B3 period. No prices are reported for the following states: Louisiana (1980); Oregon (1979); Rhode Island (1974); and Vermont (1977-1978).

\subsubsection{Computational Procedures: Imputation of Alaska. Prices}

Since Cost and Quality data do not cover Alaska, Btu and physical unit prices for Alaska are taken from other sources or imputed for 1973-1983 and for 1971.

1. For the years $1974,1976,1977$, and 1979-1983, prices are taken directly from Statistical Year Book and entered into the data base; this involves converting prices per million Btu from cents to dollars as shown in Equation 7.6:

$$
\begin{aligned}
& \text { BCEUUAK }=\text { CLEUNAK } \\
& \text { BCEUDAK }=\text { CLEUFAK } / 100
\end{aligned}
$$

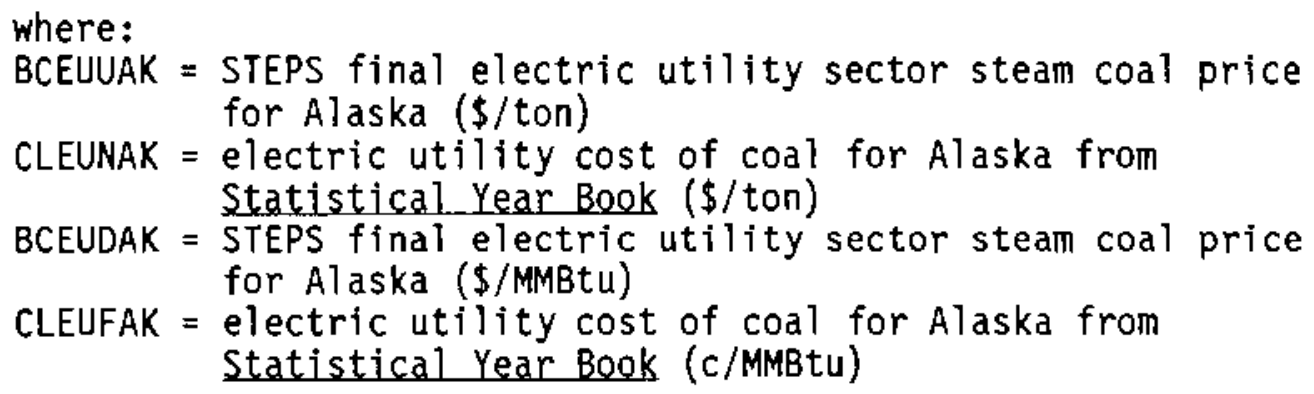

2. Alaska prices for $1971,1973,1975$, and 1978 are imputed from statistical Year Book prices for the U.S. and the average ratio of Alaska to U.S. prices for the years when Alaska prices are avajlable. The 1971 and 1973 imputed prices (both physical unit and Btu) are based on the average ratio for 1970 and 1972, while the 1975 and 1978 imputed prices are based on the average ratio for 1974, 1976, 1977, and 1979. The Btu price calculations are shown as Equations 7.7 and 7.8 ; the actual calculations are done by hand as shown in Table 7.1 . 
IABLE 7.1. Imputation of Steam Coal Electric Utility Alaska Btu Prices for 1971, 1973, 1975, and 1978

1971,1973

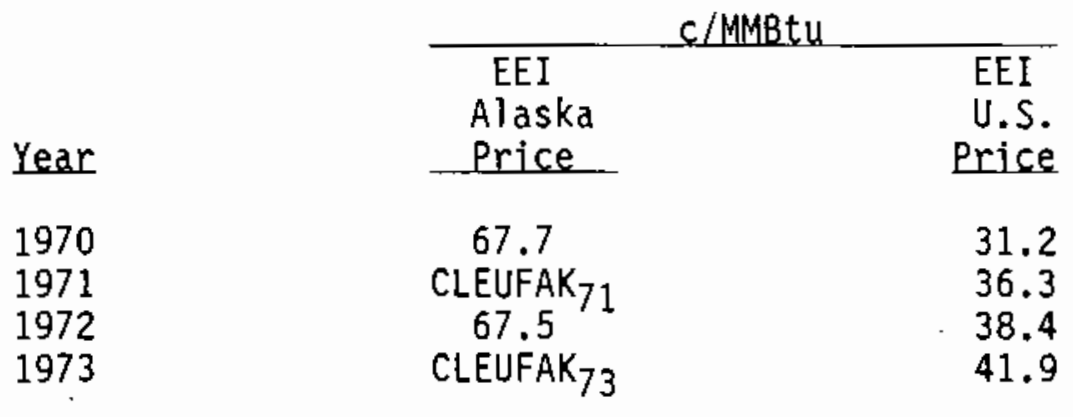

Using Equation 7.7:

$$
\begin{aligned}
& \text { BCEUDAK }_{71}=\frac{1}{2}\left(\frac{67.7}{31.2}+\frac{67.5}{38.4}\right) * 36.3=71.287 \\
& \text { BCEUDAK }_{73}=\frac{1}{2}\left(\frac{67.7}{31.2}+\frac{67.5}{38.4}\right) * 41.9=82.285
\end{aligned}
$$

1975,1978

\begin{tabular}{lcr} 
& \multicolumn{2}{c}{ c/MMBtu } \\
\cline { 2 - 3 } Year & EEI & EEI \\
& Alaska & U.S. \\
Price & \\
1974 & & \\
1975 & 81.6 & 67.8 \\
1976 & CLEUFAK & 86.4 \\
1977 & 97.7 & 88.7 \\
1978 & 108.0 & 97.5 \\
1979 & CLEUFAK & 116.1 \\
& 131.0 & 126.7
\end{tabular}

Using Equation 7.8:

$$
\begin{aligned}
& \text { BCEUDAK }_{75}=\frac{1}{4}\left(\frac{81.6}{67.8}+\frac{97.7}{88.7}+\frac{108.0}{97.5}+\frac{131.0}{126.7}\right) * 86.4=96.047 \\
& \text { BCEUDAK }_{78}=\frac{1}{4}\left(\frac{81.6}{67.8}+\frac{97.7}{88.7}+\frac{108.0}{97.5}+\frac{131.0}{126.7}\right) * 116.1=129.064
\end{aligned}
$$

Source: Pacific Northwest Laboratory 


$$
\begin{aligned}
& \text { BCEUDAK }_{t}=1 / 2 \sum_{j=1}^{2}\left(\left(\text { CLEUFAK }_{i} / \text { CLEUFUS }_{j}\right) * \text { CLEUFUS }_{t}\right) \\
& \text { BCEUDAK }_{r}=1 / 4 \sum_{j=1}^{4}\left(\left(\text { CLEUFAK }_{j} / \text { CLEUFUS }_{j}\right) * \text { CLEUFUS }_{r}\right)
\end{aligned}
$$

where:

$$
\begin{aligned}
\text { BCEUDAK }= & \text { STEPS final electric utility sector steam coal price for } \\
& \text { Alaska (c/MMBtu) } \\
\text { CLEUFAK }= & \text { electric utility cost of coal for Alaska from } \\
\text { CLEUFUS }= & \text { Statistical Year Book (c/MMBtu) } \\
& \text { electric utility cost of coal for the U.S. from } \\
t & =1971 \text { or } 1973 \\
i & =1970,1972 \\
r & =1975 \text { or } 1978 \\
j & =1974,1976,1977,1979
\end{aligned}
$$

3. The physical unit price imputation calculations are done for the same years as the Btu calculations, using Equations 7.7 and 7.8 but substituting the Statistical Year Book physical unit prices (dollars per ton) for the Btu price data inputs. The hand calculation of these Alaska prices is shown in Table 7.2 .

\subsection{RESIDENIIAL SECTOR}

Residential sector steam coal prices are the average delivered prices for coal purchased by residential customers. It is not clear whether or not these prices include any taxes. For all the years 1970-1983, Btu prices are calculated first, then physical unit prices are calculated using the completed Btu price series and the conversion factors.

\subsubsection{Data Sources}

1971-1978 American Gas Association. Gas Househeating Survey. Table titled, "Competitive Fuel Prices."

1970-1978 Edison Electric Institute. Statistical Year Book of the Electric Utility Industry. Table $43 \mathrm{~s}$.

1974-1983 Energy Information Administration, U.S. Department of Energy. Cost and Quality of Fuels for Electric Plants. Average spot coal prices. Table 2 (1974-1979); Table 44 (1980-1982); and Table 49 (1983).

1970-1983 Energy Information Administration, U.S. Department of Energy. State Energy Data System. Residential sector coal consumption. 
IABLE 7.2. Imputation of Steam Coal Electric Utility Alaska

Physical Unit Prices for 1971, 1973, 1975, and 1978

1971,1973

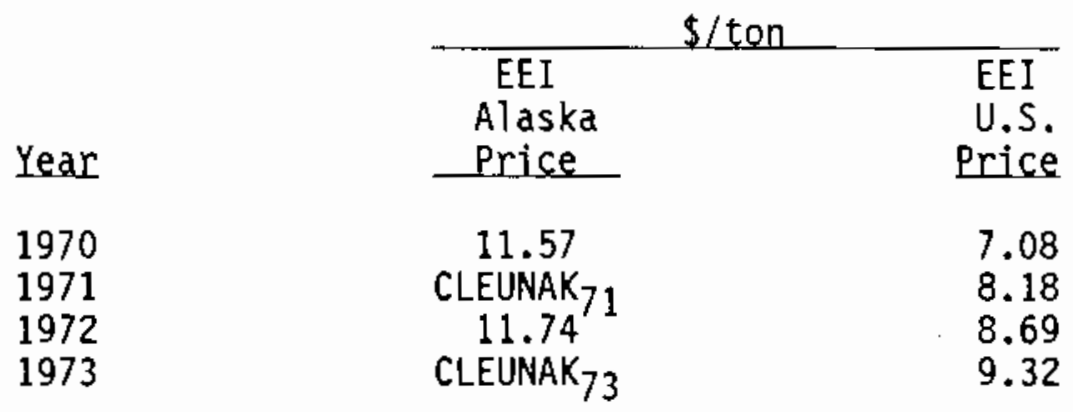

Using Equation 7.7:

$$
\begin{aligned}
& \text { BCEUUAK }_{71}=\frac{1}{2}\left(\frac{11.57}{7.08}+\frac{11.74}{8.69}\right) * 8.18=12.213 \\
& \text { BCEUUAK }_{73}=\frac{1}{2}\left(\frac{11.57}{7.08}+\frac{11.74}{8.69}\right) * 9.32=13.915
\end{aligned}
$$

$1975, \quad 1978$

\begin{tabular}{ccc} 
& \multicolumn{2}{c}{$\$ /$ ton } \\
\cline { 2 - 3 } Year & $\begin{array}{c}\text { EEI } \\
\text { Alaska } \\
\text { Price }\end{array}$ & $\begin{array}{r}\text { EEI } \\
\text { U.S. } \\
\end{array}$ \\
\cline { 2 - 3 } 1974 & & Price \\
1975 & 14.20 & \\
1976 & CLEUNAK $_{75}$ & 14.81 \\
1977 & 16.94 & 18.71 \\
1978 & 18.83 & 19.29 \\
1979 & CLEUNAK $_{78}$ & 20.97 \\
& 22.77 & 24.70 \\
& & 27.13
\end{tabular}

Using Equation 7.8:

$$
\begin{aligned}
& \text { BCEUUAK }_{75}=\frac{1}{4}\left(\frac{14.20}{14.81}+\frac{16.94}{19.29}+\frac{18.83}{20.97}+\frac{22.77}{27.13}\right) * 18.71=16.727 \\
& \text { BCEUUAK }_{78}=\frac{1}{4}\left(\frac{14.20}{14.81}+\frac{16.94}{19.29}+\frac{18.83}{20.97}+\frac{22.77}{27.13}\right) * 24.70=22.082
\end{aligned}
$$

Source: Pacific Northwest Laboratory 


\subsubsection{Conversion_Factors}

1970-1983 Energy Information Administration, U.S. Department of Energy. Annual Energy Review_1984. Table titled," Thermal Conversion Factors: Coal and Coal Coke, 1949-1984." Bituminous coal and lignite consumption in the residential/commercial sector. values used are shown in Table 7.3.

\subsubsection{Computational Procedures: Btu State Prices, 1971-1978}

For 1971-1978, Btu steam coal prices are calculated first, based on data from Gas Househeating Survey (GHS). Since GHS reports data in physical units for 1971 and 1972, this means that these prices must be converted to prices per milition Btu. Simple averages of adjacent state prices are used to impute missing prices throughout the 1971-1978 period. The GHS prices are the average delivered prices to residential consumers as reported by competitive natural gas distributors; it is not clear whether or not the prices include any taxes.

1. Because they have no residential coal consumption reported in SEDS, the following states are not covered by STEPS prices for the entire period (even though a few have some prices reported by GHS): Alaska, Arkansas, Arizona, California, Florida, Hawaii, Louisiana, Mississippi, New Mexico, Oklahoma, Oregon, and Texas.

IABLE 7.3. Steam Coal Residential Sector Conversion Factors (Million Btu per Short Ton)

Year

1970

1971

1972

1973

1974

1975

1976

1977

1978

1979

1980

1981

1982

1983

\section{Conversion Factor}

23.111

22.927

22.861

22.887

22.523

22.258

22.819

22.594

22.078

21.884

22.488

22.191

22.373

22.934

Source: Annual_Energy Review 1984. 
2. For 1971 and 1972, GHS reports physical unit rather than the Btu prices published from 1973 to 1978 . For either type of data, the price for a state is equal to the simple average of the city/utility price observations for that state. Equation 7.9 shows the calculation for 1971 and 1972, and Equation 7.10 shows the calculation for 1973-1978. Both of these equations are hand calculated.

$$
\begin{aligned}
& \text { BCRCUZZ }=1 / N \sum_{i=1}^{N} \text { BCRCNKK }_{j} \\
& \text { BCRCDZZ }=1 / N \sum_{i=1}^{N} \text { BCRCFKK }_{j}
\end{aligned}
$$

where:

BCRCUZZ = STEPS final residential coal price for State $Z Z(\$ /$ ton $)$

BCRCNKK = coal price observed in State $Z Z$ and reported by GHS ( $\$ /$ ton)

BCRCDZZ = STEPS final residential sector steam coal price for State ZZ (\$/MMBtu)

BCRCFKK = coal price observed in State $Z Z$ and reported by GHS (\$/MMBtu)

$N=$ number of city/utility observations in State $Z Z$

$i=$ index for a city/utility observation

3. Maryland prices are substituted for missing District of Columbia and Delaware prices.

4. A simple average of price observations in Connecticut, Massachusetts, Maine, New Hampshire, Rhode Island, and Vermont is assigned equally and identically to each of these states.

5. To impute other missing prices in the 1971-1978 period, simple averages of adjacent state prices are used as shown in Table 7.4. Only adjacent state prices from GHS and the assigned prices for the District of Columbia, Delaware, and the New England states are used in the imputations (that is, no imputed data are used to impute data for another state).

6. At this point, STEPS Btu prices have been calculated for all states for 1973-1978, and physical unit prices have been calculated for 1971 and 1972. The next step is to convert the prices for 1971-1972 into Btu prices using the conversion factors from Table 7.3:

$$
\text { BCRCDZZ }=\text { BCRCUZZ } / \text { BCRCKUS }
$$

where:

BCRCKUS = coal conversion factor of 22.927 in 1971 and 22.861 in 1972 (MMBtu/ton) 
IABLE 7.4. Imputation of Missing State Prices: Steam Coal Residential Sector, 1971-1978

\begin{tabular}{|c|c|c|}
\hline Missing State & Year (s) & $\begin{array}{c}\text { Adjacent States Used } \\
\text { in Imputation }\end{array}$ \\
\hline AL & 1971 & TN \\
\hline GA & 1971 & NC, TN \\
\hline & $\begin{array}{l}1972 \\
1077\end{array}$ & $A L, N C, T N$ \\
\hline ID & 1977 & MT, UT, WY \\
\hline $\begin{array}{l}\text { KS } \\
\text { MN }\end{array}$ & $\begin{array}{l}1971,1972 \\
1971\end{array}$ & $\begin{array}{l}\text { CO, MO } \\
I A, N D, W I\end{array}$ \\
\hline & 1972 & $I A, W 1$ \\
\hline MT & 1971 & ID， ND, WY \\
\hline & 1972,1973 & ID, WY \\
\hline ND & $\begin{array}{l}1972 \\
1973\end{array}$ & $\begin{array}{l}\text { IA, WI } \\
M N, S D\end{array}$ \\
\hline & 1974 & MN, MT, SD \\
\hline NE & 1971,1972 & $\begin{array}{l}\text { CO, } 1 A, M O, W Y \\
C O, I A, K S, M O, S D, W Y\end{array}$ \\
\hline NJ & $\begin{array}{l}1971,1972 \\
1974,1977,\end{array}$ & \\
\hline NV & $\begin{array}{c}1978 \\
1971,1972, \\
1975\end{array}$ & $\begin{array}{l}D E, N Y, P A \\
I D, U T\end{array}$ \\
\hline & 1973 & ID, OR, UT \\
\hline SC & 1971,1972 & NC \\
\hline SD & $\begin{array}{l}1971 \\
1972\end{array}$ & $\begin{array}{l}\text { IA, ND, WY } \\
\text { IA, WY }\end{array}$ \\
\hline UT & 1974,1978 & CO, ID, NV, WY \\
\hline WA & $\begin{array}{l}1971,1972, \\
1974 \\
1977\end{array}$ & $\begin{array}{l}\text { ID } \\
\text { MT, UT, WY }\end{array}$ \\
\hline WV & 1971,1972 & $K Y, M D, O H, P A, V A$ \\
\hline
\end{tabular}

Source: Pacific Northwest Laboratory 


\subsubsection{Computational Procedures: Btu State Prices, 1979-1983}

1. Residential steam coal Btu prices for 1979 and subsequent years are computed using an equation estimated by regressing the residential steam coal prices generated for 1974-197B (from GHS) and average spot coal Btu prices from cost and Quality of Fuels. The resulting equation is as follows (the estimated coefficients for the state dummy variables are shown in Table 7.5). Note that the cost and Quality prices in cents per million Btu must be changed to dollars per million Btu before they are used to estimate the 1979-19B3 prices. Since the tax status of the GHS data used to estimate this equation is uncertain, it is unclear whether or not taxes are included in the imputed 1979-19B3 prices.

$$
\begin{aligned}
\text { BCRCDZZ }= & \frac{0.2703+1.7568 \text { (BCEUFZZ } / 100)+C_{Z Z} \text { * DUMZZ }}{(3.736)} \\
& \text { R-square }=0.7691
\end{aligned}
$$

where:

$$
\begin{aligned}
& B C R C D Z Z=\text { STEPS final residential steam coal price for state } Z Z \\
& \text { (\$/MMBtu) } \\
& \text { BCEUFZZ = spot coal price for state } Z Z \text { from C\&Q (c/MMBtu) } \\
& D U M Z Z \text { = dummy variable for State } Z Z ; A l \text { abama is the reference } \\
& \text { state }
\end{aligned}
$$

2. States with very little or no reported coal use in SEDS from 1979-1983 (therefore no dummy variable in Equation 7.12) are: Alaska, Arkansas, Arizona, California, Florida, Hawaij, Louisiana, Mississippi, New Mexico, Oklahoma, Oregon, and Texas.

3. Several states are missing cost and Quality coal spot prices, both in the 1974-1978 data used to estimate Equation 7.12 and in the 1979-1983 data that is used to calculate STEPS prices. For these missing data, cost and Quality prices are substituted from other states as described in Table 7.6 .

\subsubsection{Computational Procedures: Btu State Prices, 1970}

1. Since state-level coal price data for 1970 are not available from either Gas Househeating Survey or cost and Quality of Fuels, the 1970 residential sector coal prices are calculated using the equation below. Equation 7.13 was estimated using the 1971-1978 data from the Statistical Year Book for the 39 states wi th some reported coal use from 1971-1983 and regression analysis. The estimated coefficients for the state dummy variable are given in Table 7.7. It is unclear whether or not taxes are included in the imputed prices for 1970 . 
IABLE 7.5. Estimated Values of Dumny Variable Coefficients: Residential Sector Steam Coal (Equation 7.12)

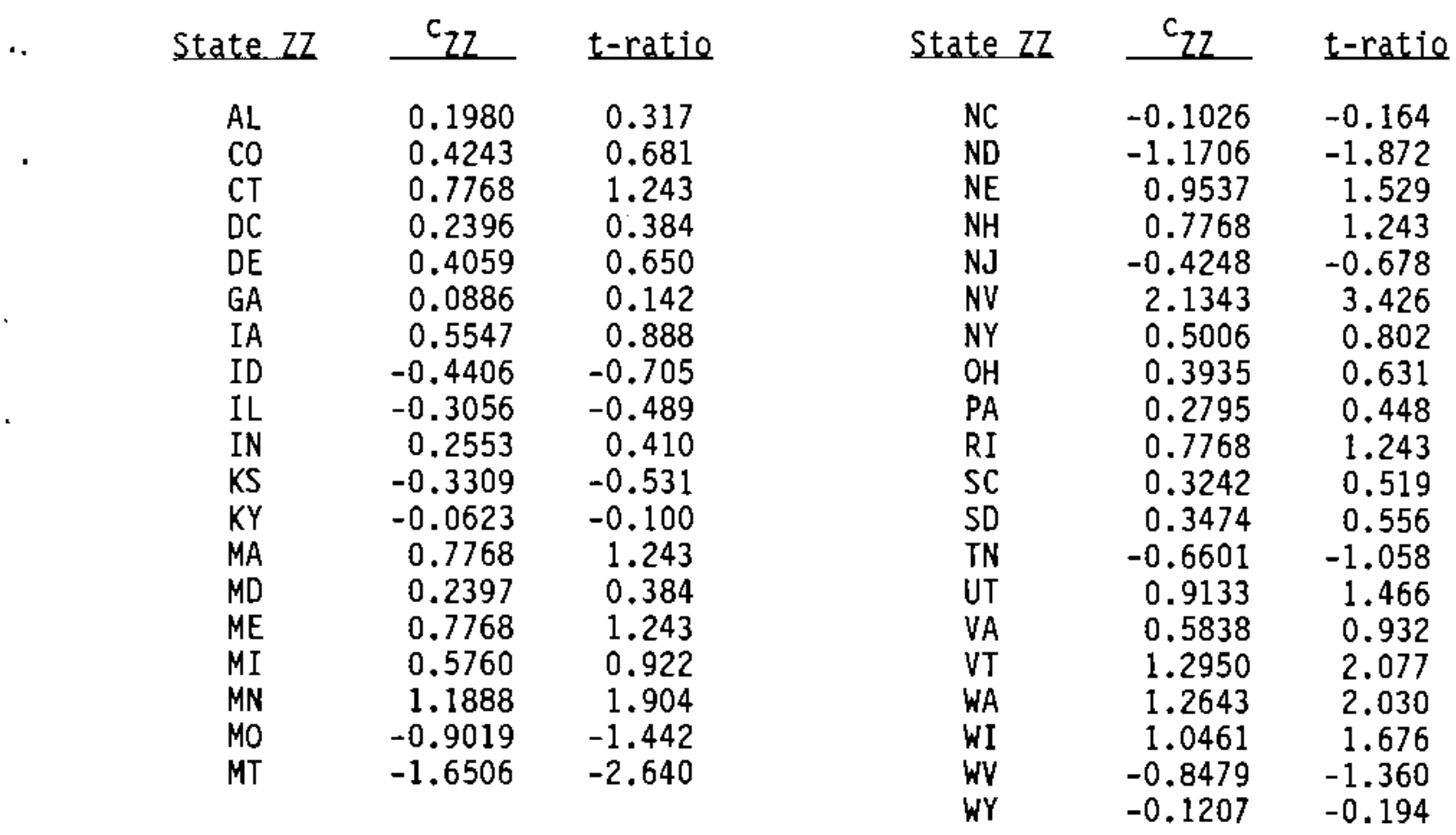

Source: Pacific Northwest Laboratory 
IABLE 7.6. Assignment of Prices for States Missing cost and Quality Average Spot Coal Prices, 1974-1983

\begin{tabular}{|c|c|c|}
\hline Missing State & $\operatorname{Year}(\mathrm{s})$ & $\begin{array}{l}\text { State Price } \\
\text { Assigned }\end{array}$ \\
\hline $\mathrm{CO}$ & 1979,1981 & KS \\
\hline CT & $1975^{\circ}$ & NY \\
\hline & $\begin{array}{l}1976-1979 \\
1980-1983\end{array}$ & $\begin{array}{l}\text { NH } \\
\text { MA }\end{array}$ \\
\hline$D C$ & $1976-1983$ & MD \\
\hline ID & $\begin{array}{l}1974,1979-1982 \\
1975-1977\end{array}$ & $\begin{array}{l}\text { NV } \\
\text { SD }\end{array}$ \\
\hline & 1978 & ND \\
\hline & 1983 & $\mathrm{CO}$ \\
\hline MA & 1975 & VT \\
\hline & $1976-1979$ & NH \\
\hline ME & $1974-1975,1981,1983$ & VT \\
\hline & $1976-1980,1982$ & NH \\
\hline MT & $1974-1975,1978$ & ND \\
\hline & $\begin{array}{l}1976-1977 \\
1979-1982\end{array}$ & SO \\
\hline ND & $1976-1977$ & SD \\
\hline & $1979-1983$ & MN \\
\hline NH & $1974-1975,1981,1983$ & VT \\
\hline NV & $1975-1978,1983$ & CO \\
\hline RI & 1974 & CT \\
\hline & 1975 & VT \\
\hline & $1976-1979$ & $\mathrm{NH}$ \\
\hline & $1980-1983$ & MA \\
\hline SD & 1978 & ND \\
\hline & $1979-1983$ & MN \\
\hline UT & $1975-1978,1980,1983$ & $\mathrm{CO}$ \\
\hline & 1979 & NV \\
\hline VT & 1976,1980 & $\mathrm{NH}$ \\
\hline WA & $1974-1978,1983$ & $\mathrm{CO}$ \\
\hline & $1979-1982$ & NV \\
\hline$W Y$ & $1974-1976,1978,1982-1983$ & $\mathrm{co}$ \\
\hline
\end{tabular}

Source: Pacific Northwest Laboratory 
IABLE 7.7. Estimated Values of Dummy Variable Coefficients: Steam Coal Residential Sector (Equation 7.13)

\begin{tabular}{|c|c|c|c|c|c|}
\hline State IZ & $\mathrm{d}_{z z}$ & t-ratio & State $2 Z$ & $\mathrm{~d}_{z 2}$ & t-ratio \\
\hline$A L$ & (a) & -- & ND & 0.6783 & 6.1401 \\
\hline $\mathrm{CO}$ & 0.1046 & 0.9554 & NE & 0.0752 & 0.6917 \\
\hline CT & 0.0943 & 0.8628 & $\mathrm{NH}$ & 0.2367 & 2.1765 \\
\hline $\mathrm{DC}$ & -0.0305 & -0.2802 & NJ & -0.0511 & -0.4675 \\
\hline $\mathrm{DE}$ & 0.0434 & 0.3990 & NV & 0.3682 & 3.3576 \\
\hline GA & -0.0537 & -0.4944 & NY & 0.1661 & 1.5259 \\
\hline IA & 0.3036 & 2.7943 & $\mathrm{OH}$ & 0.1844 & 1.6972 \\
\hline ID & 0.3933 & 3.5444 & PA & 0.1047 & 0.9636 \\
\hline IL & 0.1418 & 1.3049 & RI & 0.1157 & 1.0597 \\
\hline IN & 0.3328 & 3.0547 & SC & 0.0412 & 0.3786 \\
\hline KS & -0.0080 & -0.0730 & SD & 0.5579 & 5.1165 \\
\hline KY & 0.1943 & 1.7829 & TN & -0.0128 & -0.1177 \\
\hline MA & 0.1309 & 1.2000 & UT & 0.0084 & 0.0770 \\
\hline MD & -0.0305 & -0.2802 & VA & 0.2295 & 2.1090 \\
\hline ME & 0.2367 & 2.1765 & VT & 0.0879 & 0.8046 \\
\hline MI & 0.3453 & 3.1780 & WA & 0.2418 & 2.2001 \\
\hline MN & 0.4517 & 4.1478 & $W I$ & 0.4197 & 3.8632 \\
\hline MO & 0.0757 & 0.6936 & WV & -0.1880 & -1.7306 \\
\hline MT & 0.1863 & 1.6788 & WY & 0.2149 & 1.9043 \\
\hline $\mathrm{NC}$ & 0.0295 & 0.2714 & & & \\
\hline
\end{tabular}

(a) Alabama is the reference state. Source: Pacific Northwest Laboratory 


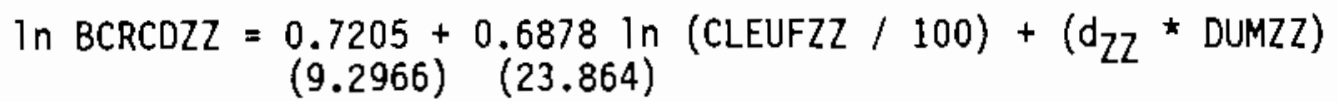

$$
\text { R-square }=0.7771
$$

where:

BCRCDZZ = STEPS final residential sector steam coal price for State ZZ (\$/MMBtu)

CLEUFZZ = coal price for State ZZ from Statistical Year Book (c/MMBtu)

DUMZZ = duminy variable for State ZZ: Alabama is the reference state

2. The same 12 states have no reported STEPS steam coal prices in 1970 as in the other years.

3. For estimating Equation 7.13, states missing Statistical Year Book data are assigned prices as follows: Maine is assigned the New Hampshire price (1970-1978); Rhode Island is assigned the Connecticut price (1973, 1975-1978): Massachusetts is assigned the Connecticut price (1976-1978); Idaho is assigned the Montana price (1970-1978); and Washington is assigned the Oregon price (1970-1972). Delaware, the District of Columbia, and Maryland are all assigned the combined Statistical Year Book price for those states.

\subsubsection{Computational Procedures: Btu U.S. Prices, 1970-1983}

Btu prices for the U.S. are calculated from the state-level Btu prices, using the following equation and steam coal residential sector consumption data from SEDS:

$$
\begin{aligned}
\text { BCRCDUS }= & \left(\sum_{Z Z=1}^{51}(B C R C D Z Z * B C R C P Z Z)\right) / \sum_{Z Z=1}^{51} B C R C P Z Z \\
\text { Where: } & \text { BCRCDUS = } \\
\text { STEPS final residential sector steam coal price for } & \text { the U.S. (\$/MMBtu) } \\
\text { BCRCPZZ = } & \text { volume of residential coal consumed as reported for } \\
& \text { State } Z Z \text { from SEDS (1000 short tons) }
\end{aligned}
$$

\subsubsection{Computational Procedures: Physical Unit Prices, 1970-1983}

Btu prices for 1970-1983 are converted to physical unit prices using the completed Btu price series for states and the U.S. and the coal conversion factors from Table 7.3.

$$
B C R C U Z Z=B C R C D Z Z * B C R C K U S
$$




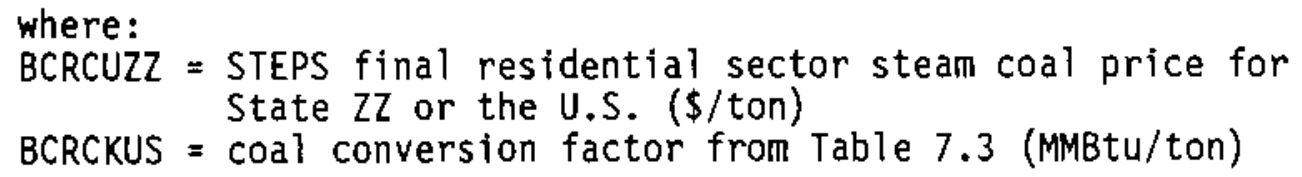

\subsection{INDUSTRIAL SECTOR}

The industrial sector steam coal prices in the STEPS data base are developed using different data sources and computational procedures, depending on the years involved. For 1970-1979, prices reported in STEPS are the average cost of coal sold to manufacturing firms. For 1980-1983, prices are average price of coal receipts at manufacturing plants. It is not clear whether or not any of the prices for 1970-1983 include any taxes. Physical unit prices are calculated first, then Btu prices are computed using the conversion factors.

\subsubsection{Data Sources}

1971, 8ureau of the Census, U.S. Department of Commerce. Annual

1974-1979 Survey of Manufactures, and Census of Manufactures. Table 4 (1971) and Table 3 (1974-1979).

1980-1983 Energy Information Administration, U.S. Department of Energy. "Quarterly Coal Consumption Report: Manufacturing Plants," (EIA-3). Only published data are used.

1970,1972, STEPS steam coal electric utility physical unit price series. 1973

\subsubsection{Conversion Factors}

1970-1983 Energy Information Administration, U.S. Department of Energy. Annual Energy Review 1984. Table titled, "Thermal Conversion Factors: Coal and Coal Coke, 1949-1984." Bituminous coal and lignite consumption in the other/Industrial Sector. Values used are given in Table 7.8 .

\subsubsection{Computational Procedures: Physical Unit Prices, 1970-1979}

For 1970-1979, physical unit industrial steam coal prices are based either directly on manufacturing cost and quantity data from the Annual Survey of Manufactures (ASM) and Census of Manufactures (CM), or on imputation strategies that depend indirectly on the $A S M / C M$ data. These prices represent the average cost of steam coal per ton to manufacturing firms; it is not clear whether or not these prices include any taxes. 
IABLE_Z2. Steam Coal Industrial Sector Conversion Factors (Million Btu per Short Ton)

Year

1970

1971

1972

1973

1974

1975

1976

1977

1978

1979

1980

1981

1982

1983
Conversion Factor

22.973

22.653

22.539

22.585

22.420

22.439

22.528

22.290

22.175

22.436

22.690

22.572

22.694

22.679

Source: Annual_Energy Review 1984.

1. For 1971 and 1974-1979, available cost and quantity of bituminous coal, lignite, and anthracite from ASM or CM are used to calculate prices as average cost per unit of sales for covered states and the U.S. (states with undisclosed data are not considered covered).

$$
\text { BCICUZZ }=(8 C M F C Z Z / B C M F V Z Z) * 1000
$$

where:

BCICUZZ = STEPS final industrial sector steam coal price for State ZZ or the U.S. ( $\$ /$ ton)

$B C M F C Z Z$ = manufacturing cost of coal for State ZZ or the U.S. from $\mathrm{ASM} / \mathrm{CM}$ (\$million)

BCMFVZZ = manufacturing quantity of coal sold for State ZZ or the U.S. from ASM/CM (1000 short tons)

2. For states with industrial steam coal use and for which ASM and CM data are not available in 1971 and 1974-1979, adjacent state averages of available ASM/CM data are used to impute prices. The assigned adjacent states are given in Table 7.9.

$$
\text { BCICUZZ }_{m}=1 / N \sum_{a=1}^{N} \text { BCICUZZ }_{a}
$$


IABLE 7.9. Imputation of Missing ASM/CM Steam Coal Industrial Sector Data for 1971, and 1974-1979

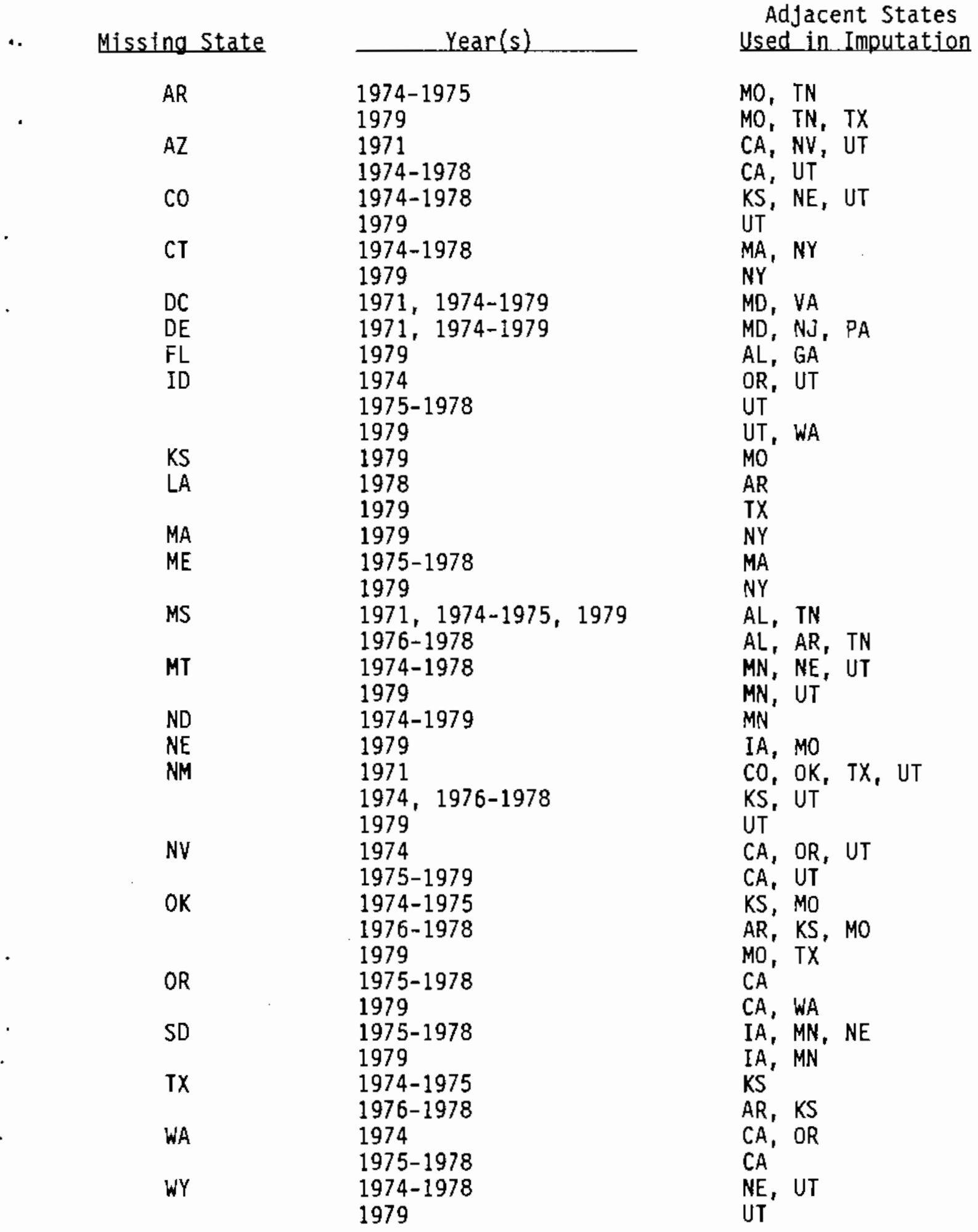

Source: Pacific Northwest Laboratory 
where:
BCICUZZ = STEPS final industrial sector steam coal price for State $\mathrm{ZZ}(\$ /$ ton $)$
$m=$ state with missing data for 1971, 1974-1977
$a=$ index for adjacent state with data
$N=$ number of states adjacent to missing State $Z Z$

3. State and U.S. steam coal industrial sector prices for 1970, 1972, and 1973 (years for which no ASM/CM prices are available) are imputed using the following equation. This equation was estimated using regression techniques where values for the independent variable are STEPS steam coal electric utility sector physical unit prices and values for the dependent variable are the steam coal industrial physical unit prices (from ASM or imputed as described above) for 1971, and 1974-1977. A few states are assigned utility sector data because no utility prices are available; these assignments are given in Table 7.10. Because they have no reported industrial coal use for 1970, 1972, and 1973, the following states do not have prices imputed with Equation 7.18: Florida, Hawai i, Louisiana, New Hampshire, Rhode Island, and Vermont. Alaska prices are imputed as described later. The estimated coefficients for dumny variable are listed in Table 7.11.

$$
\begin{aligned}
\text { BCICUZZ }= & 12.2473+0.7330 \text { BCEUUZZ }-7.8391 \text { TIME } \\
& (5.5309) \quad(10.0754) \\
& +e_{Z Z} * \text { DUMZZ } \\
& \text { R-square }=0.8734
\end{aligned}
$$

where:

BCICUZZ = STEPS final industrial sector steam coal price for State ZZ or the U.S. ( $\$ /$ ton)

BCEUUZZ = STEPS electric utility stean coal price for State $Z Z$ $(\$ /$ ton $)$

DUMZZ = dummy variable for State $Z Z$; Ohio is the reference state

TIME = time dummy variable; equals 1.0 for $1970-1973$ and 0.0 for $1974-1977$

4. The following states do not have reported STEPS steam coal industrial prices for years in the 1970-1979 time period: Arkansas (1970-1972); Florida (1970-1974); Hawai i (1970-1979); Louisiana (1970-1976); New Hampshire (1970-1979); New Mexico (1975); Oklahoma (1970); Rhode Island (1970-1979); South Dakota (1970-1974); and Vermont (1970-1979).

5. Steam coal industrial sector prices are imputed for the state of Alaska based on the assumption that the ratio of the state price to the U.S. price for the industrial sector is the same as the ratio found in the electric utility sector for each respective year from 1970-1979:

$$
\text { BCICUAK = (BCEUUAK / BCEUUUS }) * \text { BCICUUS }
$$

where: 
IABLE 7.10. Steam Coal Electric Utility Sector Price Assignments Used to Estimate and Implement Equation 7.20, 1970-1977

$\begin{array}{clc}\text { Missing State } & \text { Missing Year(s) } & \begin{array}{c}\text { State } \\ \text { Assign }\end{array} \\ \text { AR } & 1973-1977 & \text { MO } \\ \text { CA } & 1970-1977 & \text { NV } \\ \text { CT } & 1975-1977 & \text { NY } \\ \text { DC } & 1976-1977 & \text { MD } \\ \text { ID } & 1970-1977 & \text { MT } \\ \text { MA } & 1976-1977 & \text { NH } \\ \text { ME } & 1970-1977 & \text { NH } \\ \text { OK } & 1973-1975 & \text { KS } \\ \text { OR } & 1973-1977 & \text { WA } \\ \text { TX } & 1970 & \text { NM } \\ \text { WA } & 1970-1972 & \text { OR }\end{array}$

Source: Pacific Northwest Laboratory 
IABLE 7.11. Estimated Values of Dummy Variable Coefficients: Steam Coal Industrial Sector (Equation 7.18)

\begin{tabular}{|c|c|c|c|c|c|}
\hline State $Z Z$ & ${ }^{e_{Z Z}}$ & t-ratio & State ZZZ & ${ }^{e} z z$ & t-ratio \\
\hline$A L$ & -2.3399 & -0.9976 & $\mathrm{NC}$ & 1.0588 & 0.4453 \\
\hline$A R$ & 5.2366 & 2.0551 & ND & 3.3254 & 1.2945 \\
\hline$A Z$ & 5.4667 & 2.1719 & NE & -7.2280 & -3.0791 \\
\hline $\mathrm{CA}$ & 5.1889 & 2.1282 & $\mathrm{NJ}$ & -7.0239 & -2.7423 \\
\hline $\mathrm{CO}$ & 0.1566 & 0.0643 & NM & 5.8262 & 2.1771 \\
\hline CT & 6.9254 & 2.8939 & NV & 2.7732 & 1.1374 \\
\hline DC & -8.7746 & -3.5061 & NY & -1.3483 & -0.5644 \\
\hline $\mathrm{DE}$ & -4.8691 & -2.0439 & $\mathrm{OH}$ & (a) & - \\
\hline GA & 0.7788 & 0.3316 & OK & 2.6432 & 1.1076 \\
\hline IA & -0.2156 & -0.0916 & $O R$ & 3.1060 & 1.1942 \\
\hline ID & 3.9712 & 1.5586 & $P A$ & -2.0366 & -0.8681 \\
\hline IL & 1.2728 & 0.5394 & SC & 0.3771 & 0.1572 \\
\hline IN & 3.2796 & 1.3753 & SD & 5.1595 & 1.7898 \\
\hline KS & 0.1760 & 0.0736 & TN & -0.0244 & -0.0104 \\
\hline KY & 2.4424 & 1.0288 & $T X$ & 7.0541 & 2.7629 \\
\hline MA & 10.8275 & 4.4004 & UT & -1.6081 & -0.6737 \\
\hline$M D$ & -9.8336 & -4.0756 & VA & -1.3264 & -0.5510 \\
\hline ME & 11.9965 & 4.9388 & WA & 4.4751 & 1.8322 \\
\hline MI & 1.6057 & 0.6834 & WI & 4.3602 & 1.8583 \\
\hline MN & -0.8192 & -0.3400 & WV & -0.3571 & -0.1523 \\
\hline MO & 2.3030 & 0.9615 & $W Y$ & 1.0650 & 0.7707 \\
\hline MS & -0.9100 & -0.3881 & US & 1.6574 & 0.7055 \\
\hline MT & 3.7178 & 1.4592 & & & \\
\hline
\end{tabular}

(a) Ohio is the reference state. Source: Pacific Northwest Laboratory 


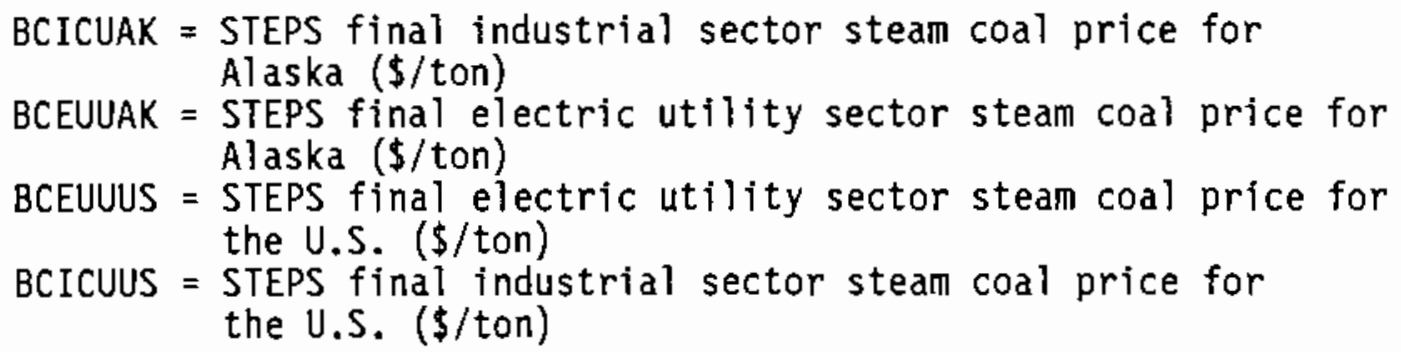

\subsubsection{Computational Procedures: Physical Unit Prices, 1980-1983}

For 1980-1983, physical unit steam coal prices for states and the U.S. are taken from EIA-3 data. Published prices as average cost per ton are used directly when available, while missing prices are imputed using simple averages or price assignments from adjacent states. It is not clear whether or not these prices include taxes.

1. State and U.S. physical unit prices where available are taken directly from the EIA-3 data.

$$
B C I C U Z Z=B C M F N Z Z
$$

where:

BCICUZZ = STEPS final industrial sector steam coal price for State $\mathrm{ZZ}$ or the U.S. ( $\$ /$ ton)

BCMFNZZ = average price of coal at manufacturing plants for State ZZ or the U.S. from EIA-3 ( $\$ /$ ton)

2. Missing state data are imputed using simple averages of the published data for adjacent states. In some cases, a single adjacent state price is available for the imputation. The adjacent states used for imputations are given in Table 7.12 .

$$
\text { BCICUZZ }=1 / N \sum_{a=1}^{N} B C M F N Z Z_{a}
$$

where:

BCICUZZ = STEPS final industrial sector steam coal price for State $\mathrm{ZZ}$ (\$/ton)

$a=$ index for adjacent states

$\mathbf{N}=$ number of states adjacent to State $Z Z$ with published data

3. No steam coal industrial prices are reported by STEPS for 1980-1983 for the following states: Alaska, Connecticut, the District of Columbia, Hawaii, New Hampshire, Rhode Island, and Vermont. 
IABLE 7.12. Industrial Sector Steam Coal Imputations for 1980-1983

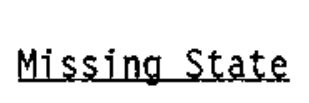

$A Z$

CO

DE

$\mathrm{FL}$

LA

MA

MS

MT

ND

NE

$\mathrm{NJ}$

NM

NV

OK

$O R$

SD

WV

WY

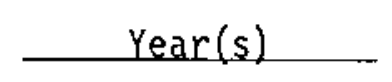

1980

1981

1980

1980-1983

1980

1980-1983

1980-1983

1980-1983

1980-1983

1983

1980-1982

1983

1980

1982-1983

1980-1983

1980

1981

1982-1983

1980-1981

1983

1980

$1980,1981,1983$

1982

1980

1981

1982

1983

1980

1980

1981
Adjacent States

Used in Imputations

CA, UT

CA, CO, UT

$\mathrm{KS}$, UT

MD

$A L, G A$

$A R, T X$

NY

NY

$A L, A R, T N$

ID, WY

MN, MT

MN

IA, KS, MO

CO, IA, KS, MO, WY

$N Y, P A$

$T X$, UT

CO, OK, TX

$A Z, C O, O K, T X$

CA, ID, UT

$A Z, C A, I D, U T$

$A R, K S, M O, T X$

$C A$, ID, WA

$C A, I D, N V, W A$

IA, MN, MT

IA, MN, MT, NE

IA, MN, MT, WY

IA, MN, WY

$K Y, M D, O H, P A, V A$

ID, MT, UT

CO, ID, MT, NE, UT

Source: Pacific Northwest Laboratory 


\subsubsection{Computational Procedures: Btu Prices, 1970-1983}

Btu prices for states and the U.S. for all the years 1970-1983 are computed using the completed physical unit price series and the conversion factors given in Table 7.8:

$$
\text { BCICDZZ = BCICUZZ / BCICKUS }
$$

\section{where:}

$B C I C D Z Z=$ STEPS final industrial sector steam coal price for State $Z Z$ or the U.S. (\$/MMBtu)

BCICKUS = industrial sector coal conversion factor from Table 7.8 (MMBtu/ton) 


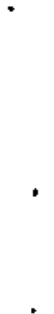




\subsection{DISIILLATE FUEL OIL}

The STEPS distillate price series cover the residential, commercial, industrial, and electric utility sectors with physical unit prices in dollars per gallon and prices per million Btu. Distillate transportation sector use is covered by the STEPS price series for motor gasoline and diesel. Since the types of prices and the computational procedures vary significantly for each sector, the sectors are described separately below.

\subsection{RESIDENTIAL SECTOR}

The STEPS distillate residential price series is developed from a variety of data sources, depending on the years involved. In all cases, physical unit prices for states and the U.S. are deveioped first, then 8tu prices are calculated using the completed physical unit price series and the conversion factor. The prices contained in this series are the retail prices paid by consumers for residential heating oil. Except for 1983, it is not clear whether or not these prices include any taxes; in 1983 taxes are excluded.

\subsubsection{Data Sources}

1970-1983 McGraw-Hill, Inc. Platt's Oil Price Handbook and Oilmanac. Refinery and terminal prices for No. 2 fuel oil.

1975-1983 Energy Information Administration, U.S. Department of Energy. Monthly Energy Review. Table titled, "Residential Heating $0 i 1$ Prices by Region," (1975-1982); and "Sales Prices of No. 2 Distillate to Residences for Selected States," (1983).

1983

1975-1983 National Oceanic and Atmospheric Administration, U. S. Department of Commerce. State, Regional, and National Monthly and Seasonal Heating Degree Days Weighted by Population (1980 Census). Historical Climatology Series 5-1, table titled, "1951-80 State Pop. Wgt'd Heating Degree Days."

1970-1983 Energy Information Administration, U.S. Department of Energy. Annual Energy Review 1984. Table 58.

1970-1983 Energy Information Administration, U.S. Department of Energy. State Energy Data System. Computer tape. Residential sector distillate consumption. 


\subsubsection{Conversion Factor}

1970-1983 Energy Information Adminstration, U.S. Department of Energy. State Energy Data Report. Appendix C, p. 667.

\subsection{Million Btu per Barrel}

\subsubsection{Computational Procedures: Physical Unit State Prices, 1975-1977}

For the years 1975-1977, no state-level data are available. Regional data from the Monthly Energy Review (MER) are available at the Census Division level, except for Federal Region prices for November and December of 1977. These price data are collected on Form EIA-9 (formerly Form FEA-P112-M-1). The Census Division prices from MER are allocated to states based on their relationship to comparable Census Division prices estimated from state-level prices from Platt's 0il Price Handbook and Oilmanac (Platt's) and state-level residential distillate consumption volumes from SEDS. Adjustment factors are calculated at the regional level and applied to Platt's price data assigned to states. This procedure is described step-by-step below.

1. Monthly regional price data for 1975 and 1976 are reported in MER only for Census Divisions. In 1977, however, monthly price data are reported for Census Divisions for January through October and for Federal Regions for November and December. The Federal Region prices for November and December are assigned to their respective states and reaggregated into Census Divisions in order to create a consistent set of monthly Census Division prices for 1977 . Annual residential sector distillate consumption volumes from SEDS are used to do the reaggregation:

$$
\mathrm{DFRCMZZ}_{\mathrm{m}}=\mathrm{DFRCMYY}_{\mathrm{m}}
$$

$$
\operatorname{DFRCMXX}_{m}=\sum_{Z Z=1}^{N_{X X}} \text { (DFRCMZZ } * \text { DFRCPZZ) / } \sum_{Z Z=1}^{N_{X X}} D F R C P Z Z
$$

where:

DFRCMZZ = residential sector monthly distillate price for state $Z Z$ (c/gal)

DFRCMYY = residential sector monthly distillate price for Federal Region $Y Y$ from MER (c/gal)

DFRCMXX = residential sector distillate price in Census Division $X X$ (c/gal)

DFRCPZZ = residential sector distillate consumption for State $Z Z$ from SEDS (1000 bbls)

$N_{X X}=$ number of States $Z Z$ in Census Division $X X$

$\mathrm{m}=$ index for November or December 1977 
2. The Census Division monthly price data from MER for 1975, 1976, and the first 10 months of 1977 are used with the estimated Census Division price data for November and December 1977 (DFRCMXX above) to estimate state-level prices for STEPS.

a. Missing monthly prices in the East South Central Division for June and November 1975, and the Mountain Division for March and July 1975 are imputed using an average of the prices for the month preceding and the month following the missing month. Missing November and December West South Central Division prices in 1977 are imputed with the assignment of the October price to both months. No monthly price data are avajlable for the west South Central Region in 1975; part (f) below discusses how the calculations are handled for this region.

b. The monthly state-level heating degree day normal data are averaged for the states within each Census Division to estimate regional monthly heating degree days. Alaska, the District of Columbia, and Hawaii are assigned the monthly heating degree days from Minnesota, Maryland, and Florida, respectively.

$$
H D X X_{m}=1 / N_{X X} \sum_{Z Z=1}^{N_{X X}} H Z_{m}
$$

where:

$H D X X=$ average heating degree day normal for Census Division $X X$ (base 65 degrees $F$ )

$\mathrm{HDZZ}$ = average heating degree day normal for State $Z Z$ (base 65 degrees F)

$m=$ index for months

$N_{X X}=$ number of States $Z Z$ in Census Division $X X$

c. Average annual distillate prices for Census Divisions are calculated using the monthly Census Division price data from MEB and the heating degree day normals estimated for Census Divisions:

$$
\text { DFRCNXX }=\left(\sum_{m=1}^{12}\left(\text { DFRCMXX }_{m} * \operatorname{HDXX}_{m}\right) / \sum_{m=1}^{12} \operatorname{HDXX}_{\mathrm{m}}\right) / 100
$$

where:

DFRCNXX = residential sector distillate price for Census Region XX (\$/gal)

DFRCMXX = residential sector distillate price for Census Division XX from MER (1975, 1976, and January - October 1977) or the imputed prices (DFRCMXX $x_{m}$ ) calculated above for November and December 1977 (c/gal) 
d. City-level No. 2 fuel oil refinery and terminal prices from Platt's for 1975-1977 are assigned to states as shown in Table 8.1. The assigned Platt's prices for states are volume-weighted into Census Divisions using residential sector consumption volumes from SEDS:

$$
\begin{aligned}
& \text { DFNRNXX }=\left(\sum_{Z Z=1}^{N_{X X}}\left[\left(\text { DFNCNZZ }_{X X} / 100\right) * \text { DFRCPZZ }_{X X}\right]\right) / \\
& \sum_{Z Z=1}^{N X X X} D^{X F C P Z Z} X X
\end{aligned}
$$

where:

DFNRNXX = estimated distillate price based on Platt's for Census Division XX ( $\$ / g a l)$

DFNCNZZ = No. 2 fuel oil price assigned to State $Z Z$ from Platt's (c/gal)

DFRCPZZ = residential sector distillate consumption for State $Z Z$ from SEDS (1000 bbls)

$N_{X X}=$ number of States $Z Z$ in Census Division $X X$

e. An adjustment factor relating the MER Census Division prices with the Census Division prices estimated from Platt's is calculated as follows:

$$
\text { DFRCAXX }=\text { DFRCNXX / DFNRNXX }
$$

where:

DFRCAXX = residential sector adjustment factor equal to the ratio of MER to Platt's distillate prices for Census Division XX (ratio)

f. Since there are no 1975 MER price data for the west South Central Region from which to calculate an adjustment factor, the adjustment factor for this region for 1975 is assumed to be equal to the average of the west South Central adjustment factors (DFRCAWS) for 1976 and 1977 , or 1.1313 .

g. The STEPS residential sector distillate state prices for all 51 states are calculated using the regional adjustment factors for each year and the state-level assigned Platt's prices:

$$
\text { DFRCUZZ }=\text { DFRCAXX * (DFNCNZZ XX } / 100)
$$

where:

DFRCUZZ = STEPS final residential sector distillate price for State $\mathrm{ZZ}(\$ /$ gal) 
IABLE 8.1. Platt's Prices for No. 2 Fuel, Assigned to States: 1970-1983

State

AK

$\mathrm{AL}$

AR

$A Z$

$C A$

$\mathrm{CO}$

$\mathrm{CT}$

DC

DE

FL

GA

HI

IA

ID

IL

IN

KS

KY

LA

MA

$M D$

ME

MI

MN

MO

MS

MT

NC

ND

NE

$\mathrm{NH}$

NJ

NM

NV

Assigned City Prices

Los Angeles/San Francisco, CA, 1970-1976; Portland, OR, 1977-1978; Seattle, WA, 1979-1980; Seattle-Tacoma/Spokane, WA, 1981-1983 Birmingham/Mobile/Montgomery, 1970-1974; Mobile/Birmingham, 1975-1977; Birmingham, 1978-1983

Arkansas, $1970-1983$

Los Angeles/San Francisco, CA, 1970-1978; Phoenix, 1979-1983

Los Angeles/San Francisco, 1970-1983

Minneapolis-St. Paul, MN, 1970-1976; Denver, 1977-1983

New Haven, 1970-1983

Baltimore, MD, 1970-1983

Baltimore, MD, 1970-1983

Jacksonville/Miami/Tampa/Pensacola/Panama City/Port Everglades, 1970-1972; Miami/Tampa/Pensacola, 1973; Miami/Tampa, 1974-1975, 1981-1983; Miami, 1976-1980

At lanta/Savannah/Albany/Athens/Bainbridge/Columbus/Macon, 19701973; Atlanta/Savannah, 1974-1983

Los Angeles/San Francisco, CA, 1970-1983

Chicago, IL, 1970-1981; Des Moines, 1982-1983

Los Angeles/San Francisco, CA, 1970-1976; Portland, OR, 1977-1982;

Boise, 1983

Chicago, 1970-1983

Chicago, 1970-1983

Los Angeles/San Francisco, CA, 1970-1973; St. Louis, MO, 1974-1983

Baton Rouge/New Orleans, LA, 1970; New Orleans, LA, 1971-1983

Baton Rouge/New Orleans, 1970; New Orleans, 1971-1983

Boston, 1970-1983

Baltimore, 1970-1983

Portland, 1970-1983

Detroit, 1970-1983

Minneapolis-St. Paul, 1970-1983

Baton Rouge/New Orleans, LA, 1970; New Orleans, LA, 1971-1973;

St. Louis, 1974-1983

Greenville/Meridian, 1970-1973; New Orleans, LA, 1974-1983

Minneapolis-St. Paul, MN, 1970-1976; Billings, 1977-1983

Greensboro/Wi lmington/Charlotte/Sal i sbury/Selma, 1970-1973; Greensboro/Wilmington/Charlotte, 1974-1975; Greensboro/Wilmington, 1976-1983

Minneapolis-St. Paul, MN, 1970-1983

Baton Rouge/New Orleans, LA, 1970; New Orleans, 1971-1973;

St. Louis, MO, 1974-1983

Portland, ME, 1970-1983

New York/Albany/Buffalo, NY, 1970-1975; New York/Albany, NY, 1976-1982; North Jersey, 1983

New Mexico-West Texas, 1970-1972; Los Angeles/San Francisco, CA, 1973-1976; Albuquerque, 1977-1980, 1983;

Albuquerque/Farmington, 1981-1982

Los Angeles/San Francisco, CA, 1970-1983 
IABLE 8.2 (CONI). Platt's Prices for No. 2 Fuel 011 Assigned to States: 1970-1983

state

NY

$\mathrm{OH}$

$\mathrm{OK}$

$O R$

$P A$

RI

$\mathrm{SC}$

$S D$

TN

TX

UT

VA

VT

WA

WI

WV

WY

\section{Assigned city Prices}

New York/Albany/Buffalo, 1970-1975; New York/AIbany, 1976-1983

Toledo/Clevel and/Zanesville/Columbus/Dayton, 1970-1972;

Detroit, MI, 1973-1982; Columbus, 1983

Oklahoma (Group 3), 1970-1983

Los Angeles/San Francisco, CA, 1970-1976; Portland, 1977-1983

Philadelphia, 1970-1978; Philadelphia/Pittsburgh, 1979-1983

Providence, 1970-1975; New Haven, CT, 1976-1983

Charleston/Spartanburg/Belton, 1970-1975: Charleston/Spartanburg, 1976-1983

Minneapolis-St. Paul, MN, 1970-1983

Chat tanooga, 1970-1973; New Orleans, LA, 1974-1983

New Mexico-West Texas, 1970-1972; New Orleans, LA, 1973-1978;

Houston, 1979-1980; Oallas-Ft. Worth/Houston, 1981; Amari110/

Corpus Christi/Dalias-Ft. Worth/Houston, 1982-1983

Minneapolis-St. Paul, 1970-1976; Salt Lake City, 1977-1983

Norfolk/Roanoke, 1970-1973; Norfolk, 1974-1983

Portland, ME, 1970-1983

Los Angeles/San Francisco, CA, 1970-1976; Seattle, 1977, 1979-1980,

Portland, OR, 1978; Seatt1e-Tacoma/Spokane, 1981-1983

Chicago, IL, 1970-1983

Norfolk/Roanoke, VA, 1970-1973; Norfolk, VA, 1974-1983

Minneapolis-St. Paul, MN, 1970-1976; Cheyenne, 1977-1982;

Casper, 1983

Source: Pacific Northwest Laboratory 


\subsubsection{Computational Procedures: Physical Unit State Prices, 1978-1982}

For 1978-1982, annual physical unit distillate prices for states are either taken directly from Monthly Energy Review or are calculated from monthly Federal Region price data, also from Monthly Energy Review. These data are collected on Form EIA-9A (formerly Form EIA-9 and Form FEA-P112-M-1). The Platt's price data and SEDS consumption data for 1978-1982 are used to compute state prices when only regional data are available. These calculations are described step-by-step below.

1. Annual state physical unit prices are available from MER for the following 24 states: Alaska, Connecticut, District of Columbia, Delaware, Idaho, Illinois, Indiana, Massachusetts, Maryland, Maine, Pennsylvania, Rhode Island, Virginia, Vermont, Washington, Wisconsin, and West Virginia. The 24 covered states compose all of Federal Regions $1,2,3,5$, and 10 . Prices for these states exclude taxes and are converted to dollars per gallon for reporting in STEPS.

$$
\text { DFRCUZZ }=\text { DFRCNZZ } / 100
$$

$$
\begin{aligned}
& \text { DFRCUZZ = STEPS final residential sector distillate price for } \\
& \text { State ZZ (\$/gal) } \\
& \text { DFRCNZZ = residential sector distillate price for State } Z Z \\
& \text { from MEB (c/gal) }
\end{aligned}
$$

2. Of the remaining 27 states, the 22 in Federal Regions $4,7,8$, and 9 have annual prices imputed from the monthly Federal Region prices published in MER. No regional prices are available for Federal Region 6 for the 1978-1982 period, and some monthly prices are missing in Regions 7, 8, and 9 in 1980, 1981, and 1982.

a. Missing monthly prices for Federal Regions are imputed with assigned prices as follows: the Region 9 November 1980 price is assigned for December 1980; an average of the Region 7 July and October 1982 prices is assigned to August and September 1982; an average of Region 8 June and September 1982 prices is assigned to July and August 1982; and an average of Region 3 August and October 1982 prices is assigned for the missing September 1982 price. Imputation of missing Region 6 prices for 1978-1982 and missing Region 9 prices for 1981-1982 is discussed later.

b. Monthly state-level heating degree day normal data are averaged for all the states within each of the ten Federal Regions to estimate average Federal Region heating degree days. Alaska, the District of Columbia, and Hawaij are assigned the monthly heating degree days from Minnesota, Maryland, and Florida, respectively.

$$
H_{\text {DYY }}=1 / N_{Y Y} \sum_{Z Z=1}^{N_{Y Y}} H^{\prime} Z_{m}
$$


where:

HDYY = average heating degree day monthly normal for Federal Region YY (base 65 degrees $F$ )

HDZZ = average heating degree day monthly normal for State ZZ (base 65 degrees F)

$m=$ index for months

$N_{Y Y}=$ number of States $Z Z$ in Federal Region $Y Y$

c. Average annual physical unit distillate prices for the residential sector are calculated for Federal Regions 4, 7, 8, and 9 (except for Region 9 in 1981 and 1982) using the regional heating degree day normals and the monthly regionai prices from MER:

DFRCNYY $=\left(\sum_{m=1}^{12}\left[\right.\right.$ DFRCMYY $\left.\left.\left._{m} / 100\right) \star \mathrm{HDYY}_{\mathrm{m}}\right]\right) / \sum_{m=1}^{12} \mathrm{HDYY}_{\mathrm{m}}$

where:

DFRCNYY = annual residential sector distillate price in Federal Region $Y Y$ (\$/gal)

DFRCMYY = monthly residential sector distillate price for Federal Region YY from MER (c/gal)

$m=$ index for months

d. In 1981, only March and May prices are available for Federal Region 9. To estimate the average annual price for this Region, the relationship between the U.S. annual heating oil price (from MER) and the U.S. March and May prices is expressed as a ratio and used with the Region 9 March and May prices to estimate the 1981 annual Region 9 price:

$$
\begin{gathered}
\text { DFRCSO9 }_{\mathrm{m}}=\text { DFRCNUS } / \text { DFRCMUS }_{\mathrm{m}} \\
\text { DFRCNO9 } \left.=\left(1 / 2 \sum_{\mathrm{m}=1}^{2}\left[\text { (DFRCSO9 }_{\mathrm{m}} \text { DFRCMO9 }_{\mathrm{m}}\right)\right]\right) / 100
\end{gathered}
$$

where:

DFRCS09 = ratio of the annual 1981 distillate U.S. price to the U.S. price (ratio)

DFRCNUS = annual U.S. distillate price for 1981 from $M E R(c / g a l)$

DFRCMUS = monthiy U.S. distillate price for 1981 from MER (c/gal)

DFRCNO9 = estimated annual Federal Region 9 distillate price for 1981 ( $\$ / g a 1)$

DFRCM09 $=$ Region 9 monthly distillate price in 1981 from MER (c/gal)

$m$ = index for March or May 
e. City-level prices from Platt's are assigned to states as shown in Table 8.1. The assigned state-level Platt's prices for states are volume-weighted into Federal Regions using residential sector consumption volume data from SEDS:

$$
\text { DFNRNYY }=\left(\sum_{Z Z=1}^{N_{Y Y}}\left[\left(D_{\left.Z Z N C N Z Z_{Y Y} / 100\right) * D_{Y Y}}^{N_{Y Y}}{ }_{\text {DFRCPZZZZZY }}\right]\right) /\right.
$$

where:

DFNRNYY = estimated distillate price for Federal Region YY based on Platt's and SEDS data (\$/gal)

DFNCNZZ = No. 2 fuel oil price assigned to State $Z Z$ from Platt's (c/gal)

DFRCPZZ = residential sector distillate consumption volume for State ZZ from SEDS (1000 bbls)

f. An adjustment factor relating the regional MER prices with the regional Platt's-based prices is calculated for Federal Regions 4, 7, 8, and 9 (except for 1982) as follows:

$$
\text { DFRCAYY = DFRCNYY / DFNRNYY }
$$

where:

DFRCAYY = residential sector distillate adjustment factor equal to the ratio of MER to Platt's data for Federal Region YY (ratio)

g. Since there are no monthly regional distillate prices from Monthly Energy Reveiw for Federal Region 6 for 1978-1982 and Federal Region 9 for 1982, the adjustment factors for these regions are based on the adjustment factors for previous time periods. The Region 6 adjustment factor (DFRCA06) for each of the years in the 1978-1982 period is equal to 1.1313 , which is the average of the adjustment factor for the West South Central Census Division for 1976 and 1977 (calculation of this factor is described in the procedures for 1975-1977 above). The Region 9 adjustment factor for 1982 is equal to 1.1995 , which is the average adjustment factor for Region 9 from 1978 to 1981 . 
h. The STEPS residential sector distillate state prices for the 27 states in Federal Regions 4, 6, 7, 8, and 9 are calculated using the regional adjustment factors for each year and the state-level assigned Platt's prices:

$$
\text { DFRCUZZ }=\text { DFRCAYY } \star\left(\text { DFNCNZZYY }_{Y} / 100\right)
$$

where:

DFRCUZZ = STEPS final residential sector distillate price for State $\mathrm{ZZ}(\$ / \mathrm{ga}])$

\subsubsection{Computational Procedures: Physical Unit State Prices, 1983}

For 1983, physical unit distillate prices in cents per gallon (excluding taxes) are available for 24 states and 7 PAD Districts from MER and Petroleum Marketing Monthly (PMM), EIA publications that take their distillate prices from Form EIA-782. Platt's 0il Price Handbook and Oilmanac price data assigned to states and state-level SEDS data are used to impute state prices from the PAD District prices for the 27 states that do not have prices in MER. This procedure is described step-by-step below.

1. Annual state physical unit prices from Monthly Energy Review are available for the same 24 states covered for 1978-1982. Prices for these states are taken from MER and converted to dollars per gallon:

$$
\text { DFRCUZZ }=\text { DFRCNZZ } / 100
$$

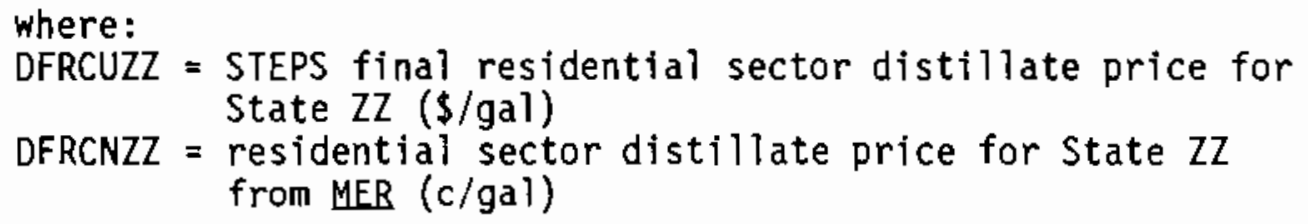

where:

DFRCUZZ = STEPS final residential sector distillate price for State ZZ (\$/gal)

DFRCNZZ = residential sector distillate price for State $Z Z$ from MER (c/gal)

2. The remaining 27 states have annual prices imputed from monthly PAD District prices in PMM for seven districts: Ia, Ib, Ic, II, III, IV, and $V$.

a. PAD Districts IC and IV are missing January prices and PAD District III is missing prices for January, February, March, and April. PAD Districts Ia and Ib have no states needing imputation of annual prices because these two districts are completely covered in the 24 states for which state-level data are available (see above). The respective February prices are assigned for the missing January prices in Districts Ic and IV, while the District III May price is assigned for each of the missing months January, February, March, and April. 
b. Monthly state-level heating degree day normal data are averaged for all states within each of the 7 PAD Districts to estimate PAD District heating degree days. Alaska, the District of Columbia, and Hawai $i$ are assigned the heating degree day normals from Minnesota, Maryland, and Florida, respectively.

$$
H_{D W}=1 / N_{W W} \sum_{Z Z=1}^{N} H_{m} H_{m}
$$

where:

HDWW = average heating degree day monthly normal for PAD District WW (base 65 degrees F)

$H D Z Z$ = average heating degree day monthly normal for State $Z Z$ (base 65 degrees F)

$m=$ index for months

$N_{W W}=$ number of States $Z Z$ in PAD District WW

c. Average annual physical unit distillate prices for the residential sector are calculated for PAD Districts IC, II, III, IV, and V using the monthiy PAD District price data and the PAD District estimated monthly heating degree day normals:

DFRCNWW $=\left(\sum_{m=1}^{12}\left[\right.\right.$ (DFRCMWW $\left._{m} / 100\right) *$ HDWW $\left.\left._{m}\right]\right) / \sum_{m=1}^{12}$ HDWW $_{m}$

where:

DFRCNWW = annual residential sector distillate price for PAD District WW (\$/gal)

DFRCMWW = monthly residential sector distillate price for PAD District WW from PMM (c/gal)

$m$ = index for months

d. City-level No. 2 fuel oil refinery and terminal prices from Platt's 0il Price Handbook and Oilmanac are assigned to States as shown in Table 8.1. The assigned state-level Platt's prices are volume-weighted into PAD District prices using state-level residential sector consumption volume data from SEDS:

$$
\text { DFNRNWW }=\left(\sum_{Z Z=1}^{N_{W W}}\left[\left(\text { DFNCNZZ }_{W W} / 100\right) * \text { DFRCPZZ }_{W W}\right]\right) /
$$


where:
DFNRNWW = estimated distillate price based on Platt's for PAD District WW (\$/gal)
DFNCNZZ = distillate price assigned to State $Z Z$ from Platt's (c/gal)
DFRCPZZ = residential sector distillate consumption volume for State ZZ from SEDS (1000 bbls)

e. An adjustment factor relating the PMM PAD District prices to the Platt's-based PAD District prices is calculated for PAD Districts IC, II, III, IV, and V:

DFRCAWW = DFRCNWW $/$ DFNRNWW

where:

DFRCAWW = residential sector adjustment factor equal to the ratio of PMM to Platt's distillate prices for PAD District WW (ratjo)

f. Annual physical unit distillate prices for the 27 states not explicitly covered by PMM state-level data are calculated using the assigned Platt's prices for each state and the PAD District-level adjustment factors:

$$
\text { DFRCUZZ }=\text { DFRCAWW } *\left(\text { DFNCNZZ WW }_{W} / 100\right)
$$

where:

DFRCUZZ = STEPS final residential sector distillate price for State ZZ (\$/gal)

\subsubsection{Computational Procedures: Physical Unit State Prices, 1970-1974}

There are no regional or state-level distillate price data directly avajlable for the 1970-1974 period. To estimate state prices, regional average prices are first derived from the relationship between U.S. prices and Federal Region prices for 1975 to 1980 . State prices are then estimated from the regional prices using a methodology similar to that described above for 1978-1982.

1. The first step in the estimation of residential distillate prices for the 1970-1974 time period, is to develop an equation that uses U.S. prices to estimate prices for Federal Regions. Regression techniques are used for this purpose. U.S. prices for 1975-1980 are taken from the Annual Energy Review and used as the independent variable for estimating the equation; annual Federal Region prices are used as the dependent variable. Federal Region prices for 1978-1980 are calculated above (DFRCNYY), but MER prices for 1975-1977 are for Census Divisions. To convert these annual Census Division prices into Federal Region prices, the estimated STEPS state prices for 1975-1977 (DFRCUZZ) are aggregated using SEDS volumes into Federal Regions: 
DFRCNYY $=\left(\sum_{Z Z=1}^{N_{Y Y}}\left(\right.\right.$ DFRCUZZ $_{Y Y} *$ DFRCPZZ $\left.\left._{Y Y}\right)\right) / \sum_{Z Z=1}^{N_{Y Y}}$ DFRCPZZZY $_{Y}$

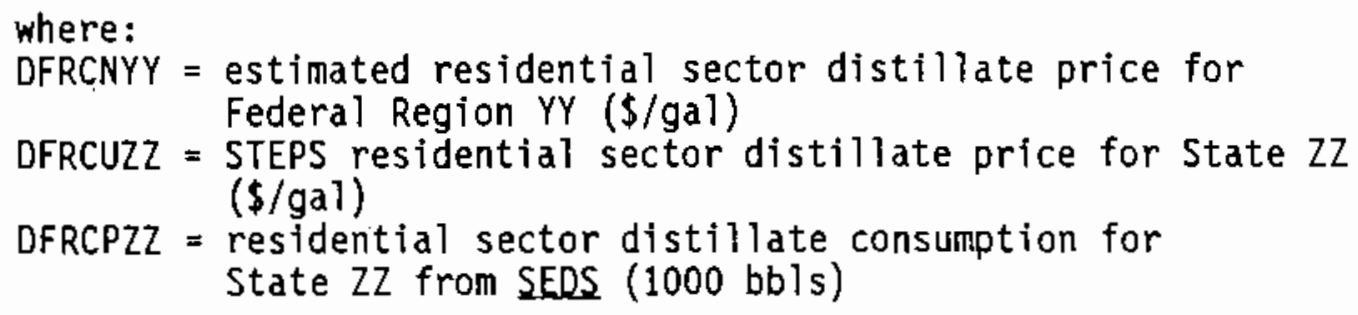

2. Regression techniques are applied to the pooled Federal Region price data (dependent variable) and the U.S. prices from $A E B$ (independent variable) for 1975-1980 and the following equation is estimated. U.S. prices for 1970-1974 are input to this equation to estimate annual Federal Region prices for 1970-1974. The estimated coefficients on the dummy variable are give in Table 8.2.

$$
\begin{aligned}
\text { DFRCNYY }= & 0.0270+0.9733 \text { (DFRCUUS / 100) }+C_{Y Y} \text { * DUMYY } \\
& (2.6191)(82.435) \\
& \text { R-square }=0.9929
\end{aligned}
$$

where:

DFRCNYY = estimated residential sector distillate price for Federal Region YY (\$/gal)

DFRCUUS = residential sector distillate price for the U.S. from AER (c/gal)

IABLE 8.2. Estimated Values for the Federal Region Dummy Variables: Distillate Residential Sector, 1970-1974 (Equation 8.23)

Eedera]
2
3
4
5
6
7
8
9
10

$$
\begin{gathered}
c_{Y Y} \\
\hline-0.0085 \\
-0.0175 \\
-0.0276 \\
-0.0340 \\
-0.0735 \\
-0.0400 \\
-0.0297 \\
-0.0314 \\
-0.0123
\end{gathered}
$$$$
\text { t_Ratio }
$$

$-1.5839$

$-2.4911$

$-3.0743$

$-6.6346$

$-3.6124$

$-2.6850$

$-2.8381$

$-1.1149$

Source: Pacific Northwest Laboratory 
3. City-level prices from Platt's for 1970-1974 are assigned to states as shown in Table 8.1. The assigned state-ievel Platt's prices are volume-weighted into Federal Regions using residential sector distillate consumption volumes from SEDS:

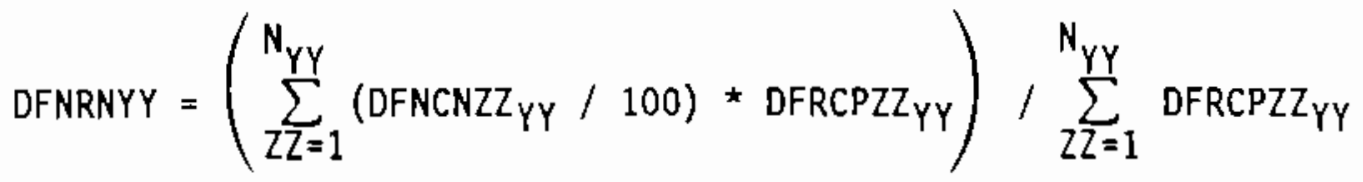

where:

DFNRNYY = estimated distillate price based on Platt's for Federal Region YY (\$/gal)

DFNCNZZ = No. 2 fuel oil price assigned to State $Z 2$ from Platt's (c/gal)

DFRCPZZ = residential sector distillate consumption for State $Z 2$ from SEDS (1000 bbls)

4. An adjustment factor relating the regional MER Federal Region prices with the Platt's-based Federal Region prices is calculated as follows:

DFRCAYY = DFRCNYY / DFNRNYY

where:

DFRCAYY = residential sector distillate adjustment factor equal to the ratio of MER to Platt's distillate prices for Federal Region YY

5. The STEPS residential sector distillate prices for all 51 states are calculated using the regional adjustment factors for each year and the state-level assigned Platt's prices:

$$
\text { DFRCUZZ }=\text { OFRCAYY * (DFNCNZZ }
$$

where:

DFRCUZZ = STEPS final residential sector distillate price for State $2 Z$ ( $\$ / g a l)$

\subsubsection{Computational Procedures: Physical Unit U.S. Prices, 1970-1983}

Residential sector distillate physical unit prices for the U.S. are taken from the Annual Energy Review for 1970-1983.

DFRCUUS $=$ DFRCNUS $/ 100$

where:

OFRCUUS = STEPS final residential sector distillate price for the U.S. (\$/gal)

DFRCNUS = residential sector U.S. distillate price from $A E R$ (c/gal) 


\subsubsection{Computational Procedures: Btu Prices, 1970-1983}

Btu prices for states and the U.S. are calculated using the completed physical unit price series and the conversion factor:

$$
\text { DFRCDZZ }=(\text { DFRCUZZ * 42) } / 5.825
$$

where:

DFRCDZZ = STEPS final residential sector distillate price for State $Z Z$ or the U.S. (\$/MMBtu)

\subsection{COMMERCIAL SECTOR}

The data sources and computational procedures for the STEPS commercial sector distillate price series are basically split between 1970-1982 and 1983. For 1970-1982, commercial distillate prices are based on markups calculated from Energy Prices: $1960-73$ and refinery and terminal (wholesale) prices from Platt's. It is not clear whether or not these prices include any taxes. For 1983, retail prices paid by commercial/institutional establishments (excluding taxes) are taken from PMM. Throughout the 1970-1983 period, physical unit prices are calculated from the data sources and Btu prices are computed using the physical unit price series and the conversion factor.

\section{B.2.1 Data Sources}

1970-1972 Foster Associates, Inc. 1974. Energy Prices 1960-73. Tables 4-c and 5-b.

1970-19B3 McGraw-Hill, Inc. Platt's Oil Price Handbook and 0ilmanac. Refinery and terminal prices for No. 2 fuel oil.

1983

Energy Information Administration, U.S. Department of Energy. Petroleum Marketing Monthly. Table titled, "Sales Prices of No. 2 Fuel 0il, by PAD District and Selected States."

National Oceanic and Atmospheric Administration, U.S. Department of Commerce. State, Regional, and National Monthly and Seasonal Heating Degree Days Weighted by Population (1980 Census). Historical Climatology Series 5-1, table titled, "1951-80 State Population Wgt'd Heating Degree Days."

1970-1983 Energy Information Administration, U.S. Department of Energy. State Energy Data System. Computer tape. Commercial sector distillate consumption. 


\subsubsection{Conversion Factor}

1970-1983 Energy Information Administration, U.S. Department of Energy. State Energy Data Report. Appendix C, p. 667.

\subsection{Million Btu per Barrel}

\subsubsection{Computational Procedures: Physical Unit State Prices, 1970-1982}

Commercial sector distillate physical unit prices for 1970-1982 are calculated using Platt's prices assigned to states and commercial sector markups estimated from Energy Prices: 1960-73.

1. The first step is to compute the markups. Energy Prices contains single price estimates for small commercial users and two price estimates for large commercial users for 10 cities: Boston, MA; Albany, NY; New York, NY; Charlotte, NC; Washington, DC; Chicago, IL; Detroit MI;

Minneapolis/St. Paul, MN; St. Louis, MO; and Seattle, WA. Before Equation 8.29 is executed, a simple average of the two large commercial prices is calculated for each city except for Albany and New York. In this case, all four large commercial prices will be averaged together, since cities are assigned to their respective states in Equation 8.29.

$$
\text { DFCCNZZ }=1 / 2(\text { DFSCNZZ }+ \text { DFLCNZZ })
$$

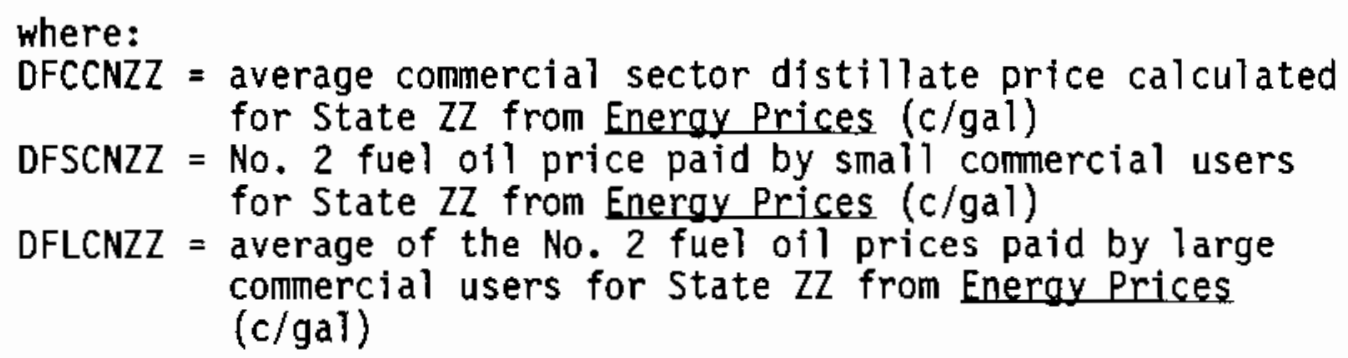

2. For the 9 states covered by the Energy Prices data, the markup of the reported Energy Prices prices over the assigned Platt's prices (see Table 8.1) and the markup of the STEPS residential prices calculated above for 1970-1972 over the Platt's prices are calculated. The nine states involved are: District of Columbia, Illinois, Massachusetts, Michigan, Minnesota, Missouri, North Carolina, New York, and Washington.

$$
\begin{aligned}
& \text { DFCCTZZ }=(\text { DFCCNZZ } / \text { DFNCNZZ })-1 \\
& \text { DFRCTZZ }=[\text { DFRCUZZ } /(\text { DFNCNZZ } / 100)]-1
\end{aligned}
$$




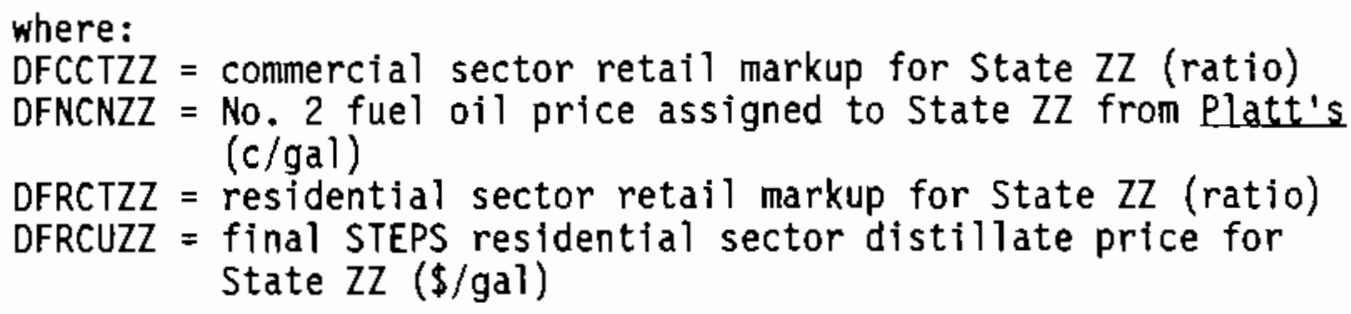

3. At this point, residential and commercial sector retail markups have been computed for 9 states for each of the years 1970-1972. The next step is to calculate the average retail markup for the three year period for each sector. A simple average of the markup ratios is calculated:

$$
\begin{aligned}
& \text { DFCCRZZ }=1 / 3 \sum_{t=70}^{72} \text { DFCCTZZ } \\
& \text { DFRCRZZ }=1 / 3 \sum_{t=70}^{72} \text { DFRCTZZ }
\end{aligned}
$$

where:

DFCCRZZ = average commercial sector retail markup for 1970-1972 for State $\mathrm{ZZ}$ (ratio)

DFRCRZZ = average residential sector retail markup for 1970-1972 for State $Z Z$ (ratio)

4. The average commercial and residential sector retail markups for the nine available states (District of Columbia, Illinois, Massachusetts, Michigan, Minnesota, Missouri, North Carolina, New York, and Washington) are assigned to the other 42 states as shown in Table 8.3.

5. To translate the average commercial and residential markups for 1970-1972 into the estimated commercial sector retail markups to be used in STEPS for 1970-1982, the relationship between these two markups is used with the residential markups calculated for all 51 states for each year. The calculation of the residential markups is the same procedure used in Equation 8.31:

$$
\begin{aligned}
& \text { DFRCTZZ }=[\text { DFRCUZZ } /(\text { DFNCNZZ } / 100)]-1 \\
& \text { DFCCAZZ }=(\text { DFCCRZZ } / \text { DFRCRZZ }) * \text { DFRCTZZ }
\end{aligned}
$$

where:

$D F R C T Z Z$ = residential sector retail markup for State $Z Z$ (ratio)

DFCCAZZ = commercial sector markup adjustment factor for State ZZ (ratio) 
IABLE 8.3. Assignment of Energy Prices Commercial Sector Distillate Markups to States, 1970-1982

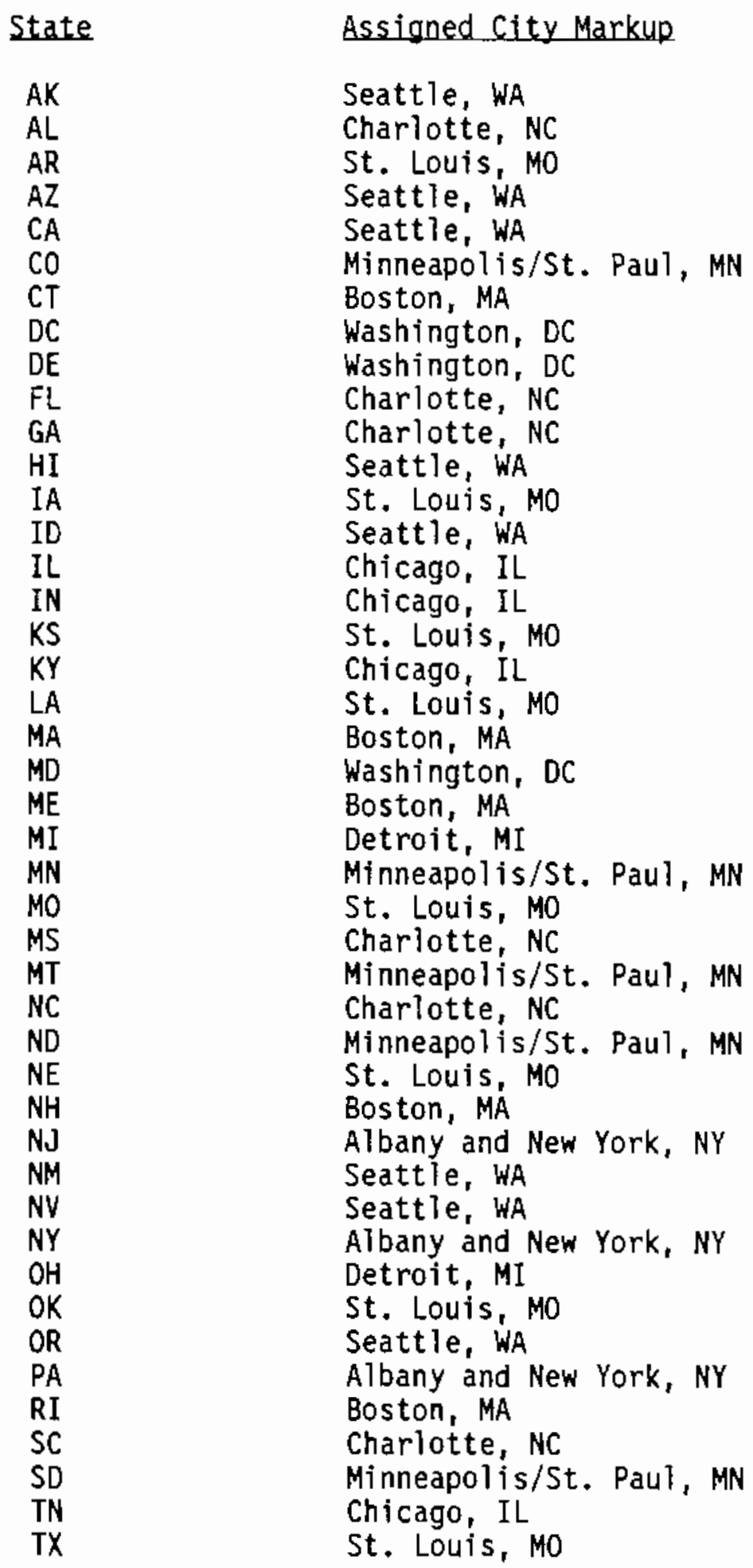




\section{IABLE 8.3 (CONI). Assignment of Energy Prices Commercial Sector} Distillate Markups to States, $1970-1982$

$\begin{array}{ll}\text { State } & \text { Assigned City Markup } \\ \text { UT } & \text { Minneapolis/St, Paul, MN } \\ \text { VA } & \text { Washington, DC } \\ \text { VT } & \text { Boston, MA } \\ \text { WA } & \text { Seattle, WA } \\ \text { WI } & \text { Chicago, IL } \\ \text { WV } & \text { Washington, DC } \\ \text { WY } & \text { Minneapolis/St. Paul, MN }\end{array}$

Source: Pacific Northwest Laboratory

6. The commercial sector adjustment factors for each state for each of the years 1970-1982 are used with the corresponding Platt's prices for 1970-1982 to calculate the final STEPS commercial sector physical unit prices :

$$
\text { DFCCUZZ }=(1+\text { DFCCAZZ }) *(\text { DFNCNZZ } / 100)
$$

where:

DFCCUZZ = STEPS final commercial sector distillate price for State $Z Z(\$ /$ gal)

\subsubsection{Computational Procedures: Physical Unit State Prices, 1983}

For 1983, physical conmercial sector distillate prices in cents per gallon (excluding taxes) are available for 24 states and 7 PAD Districts from Petroleum Marketing Monthly (PMM) under the heading "Sales to End-Users: Commercial/Institutional Consumers." Platt's distillate price data assigned to states and state-level SEDS data are used to impute state prices from the PAD District prices for the 27 states that do not have prices in PMM. This procedure is described step-by-step below.

1. Monthly state physical unit prices from PMM are available for the following 24 states: Alaska, Connecticut, District of Columbia, Delaware, Idaho, Illinois, Indiana, Massachusetts, Maryland, Maine, Michigan, Minnesota, New Hampshire, New Jersey, New York, Ohjo, Oregon, Pennsylvania, Rhode Island, Virginia, Vermont, Washington, Wisconsin, and West Virginia.

a. Several states are missing some monthly PMM commercial price data. The missing monthly prices are assigned prices or averages of prices for adjacent months as shown in Table 8.4 . 
IABLE 8.4. Imputation of Missing Monthly PMM Commercial/Institutional Distillate Prices, 1983

$\begin{array}{cll}\text { State } & \text { Missing Month } & \begin{array}{l}\text { Assigned Monthly } \\ \text { Price (or_Average) }\end{array} \\ \text { AK } & \text { January } & \text { February } \\ \text { DC } & \text { January } & \text { February } \\ \text { DE } & \text { January, February } & \text { March } \\ \text { ID } & \text { January } & \text { February } \\ & \text { May } & \text { April/June } \\ \text { ME } & \text { July } & \text { June/August } \\ \text { MI } & \text { January } & \text { February } \\ \text { MN } & \text { January, February } & \text { March } \\ \text { NH } & \text { January } & \text { February } \\ \text { NJ } & \text { January } & \text { February } \\ \text { OH } & \text { January } & \text { February } \\ \text { OR } & \text { January } & \text { February } \\ \text { RI } & \text { January } & \text { February } \\ \text { VA } & \text { January } & \text { February } \\ \text { WI } & \text { February } & \text { January/March } \\ \text { WV } & \text { January } & \text { February }\end{array}$

Source: Pacific Northwest Laboratory

b. Annual physical unit prices are calculated for the 24 states from the monthly prices and state-level heating degree day monthly normals Alaska, the District of Columbia, and Hawaji are assigned the monthiy heating degree day normals for Minnesota, Maryland, and Florida, respectively.

$$
\begin{aligned}
& \operatorname{DFCCUZZ}=\left(\sum_{m=1}^{12}\left[\left(\text { DFCIMZZ }_{m} / 100\right) * \mathrm{HDZZ}_{m}\right]\right) / \sum_{m=1}^{12} \mathrm{HDZZ}_{\mathrm{m}} \\
& \text { where: } \\
& \text { DFCCUZZ = STEPS final commercial sector distillate price for } \\
& \text { State } Z Z(\$ / \text { gal) } \\
& \text { DFCIMZZ = commercial/institutional sector distillate price } \\
& \text { for State ZZ from PMM (c/gal) } \\
& \text { HDZZ = monthly heating degree day normal for State } Z Z \\
& \text { (base } 65 \text { degrees } F \text { ) } \\
& \mathrm{m}=\text { index for months }
\end{aligned}
$$


2. Physical unit state prices for the remaining 27 states are imputed from monthly PAD District prices from PMM for seven districts: Ia, Ib, IC, II, III, IV, and V.

a. PAD District IV is missing prices for January and Juiy; the average price for June and August is assigned to July and the February price is assigned for January. Because the 24 states covered directly by PMM data completely encompass PAD Districts Ia and Ib, the missing January prices for these two regions do not have to be imputed.

b. Average annual physical unit distillate prices for the commercial sector are calculated for PAD Districts IC, II, III, IV, and V using the monthly PAD District price data from PMM and the PAD District estimated monthly heating degree day normals:

DFCCNWW $=\left(\sum_{m=1}^{12}\left[\left(\right.\right.\right.$ DFCIMWW $\left._{m} / 100\right) *$ HDWW $\left.\left._{m}\right]\right) / \sum_{m=1}^{12} H^{2} W_{m}$

where:

DFCCNWW = annual commercial sector distillate price for PAD District WW $(\$ /$ gal $)$

DFCIMWW = monthly commercial/institutional sector distillate price for PAD District WW from PMM (c/gal)

HDWW = average heating degree day monthly normal for PAD District WW from Equation 8.17 (base 65 degrees $F$ ) $m=$ index for months

c. City-level distillate refinery and terminal prices from Platt's are assigned to states as shown in Table 8.1. The assigned state-level Platt's prices are volume-weighted into PAD District prices using state-level commercial sector consumption volume data from SEDS:

DFNCNWW $=\left(\sum_{Z Z=1}^{N_{W W}}\left[\left(\right.\right.\right.$ DFNCNZZ $\left._{W W} / 100\right) *$ DFCCPZZ $\left.\left._{W W}\right]\right)$,

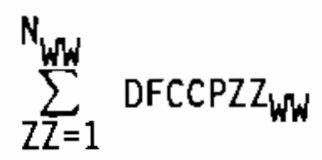

where:

DFNCNWW = estimated commercial sector distillate price based on Platt's for PAD District WW (\$/gal)

DFNCNZZ = No. 2 fuel ofl price assigned to State $Z Z$ from Platt's (c/gal)

DFCCPZZ = commercial sector distillate consumption volume for State ZZ from SEDS (1000 bbls)

$\mathrm{N}_{W W}=$ number of States $Z Z$ in PAD District WW 
d. An adjustment factor relating the PMM PAD District prices to the Platt's-based PAD District prices is calculated for PAD Districts IC, II, III, IV, and V:

$$
\text { DFCCAWW = DFCCNWW } / \text { DFNCNWW }
$$

where:

DFCCAWW = commercial sector adjustment factor equal to the ratio of PMM to Platt's distillate prices for PAD District WW

e. Annual physical unit distillate prices for the 27 states not explicitly covered by $\mathrm{PMM}$ state-level data are calculated using the assigned Platt's prices for each state and the PAD District-level adjustment factors:

$$
\text { DFCCUZZ }=\text { DFCCAWW * }\left(\text { DFNCNZZ }_{W W} / 100\right)
$$

where:

DFCCUZZ = STEPS final commercial sector distillate price for State $Z Z$ (\$/gal)

\subsubsection{Computational Procedures: Physical Unit U.S. Prices, 1970-1983}

Commercial sector physical unit prices for the U.S. are calculated from the completed state-level physical unit prices and commercial sector distillate consumption data from SEDS:

$$
\begin{aligned}
\text { DFCCUUS }= & \left(\sum_{Z Z=1}^{51}(\text { DFCCUZZ *DFCCPZZ) }) / \sum_{Z Z=1}^{51}\right. \text { DFCCPZZ } \\
\text { where: } & \\
\text { DFCCUUS }= & \text { STEPS final commercial sector distillate price for } \\
\text { the U.S. ( } \$ / \text { gal) } & \\
\text { DFCCPZZ }= & \begin{array}{l}
\text { commercial sector distillate consumption for state } Z Z \\
\text { from SEDS (1000 bbls) }
\end{array}
\end{aligned}
$$

\subsubsection{Computational Procedures: Btu Prices, 1970-1983}

Btu prices for states and the U.S. are calculated using the completed physical unit price series and the conversion factor:

$$
\text { DFCCDZZ }=(\text { DFCCUZZ *42)/5.825 }
$$

where:

DFCCDZZ = STEPS final commercial sector distillate price for state $Z Z$ or the U.S. (\$/MMBtu) 


\subsection{ELECTRIC UTILITY SECTOR}

The STEPS electric utility price series for distillate contain prices equal to the average delivered cost of receipts at electric utilities. For 1973-1983, these prices are taken from cost and Quality of Fuels for Electric Utility Plants, and for 1970-1972 prices from Statistical Year Book of the Electric Utility Industry are used with regression analysis. It is not clear whether or not these prices include any taxes. Both physical unit and Btu prices are developed directly from the data sources.

\subsubsection{Data Sources}

1970-1983 Edison Electric Institute. Statistical Yearbook of the Electric Utility Industry. Table titled, "Analysis of Fuel for Electric Generation -- Total Electric Utility Industry."

1973-1983 Energy Information Administration, U.S. Department of Energy. Cost and Quality of Fuels for Electric Utjlity Plants.

Table 6 (1973 and 1974); Tables 5, 6, 12, 13 (1975-1979);

Table 45 (1980-1982); Table 51 (1983).

1970-1973 Energy Information Administration, U.S. Department of Energy. State Energy Data System. Computer tape. Electric utility sector distillate consumption.

\subsubsection{Conversion Factors}

Both Btu and physical unit prices are calculated directly from data sources, so no explicit conversion factors are needed for any years for the electric utility sector.

\subsubsection{Computational Procedures: 1973-1983}

Physical unit and Btu prices for the years 1973-1982 are based directly on the physical unit and Btu prices reported in cost and Quality of Fuels (C\&Q). For 1973, 1974 and 1980-1983, both physical unit and Btu prices are taken directly from the data source and converted to STEPS units. For 1975-1979, weighted average physical unit and Btu prices are calculated from prices and consumption volumes reported separately for steam-electric plants and for combustion turbine and internal combustion units. Except for 1973, U.S. prices are also taken from cost and Quality and changed to the appropriate units for STEPS. Because 1973 was the first year cost and Quality was published, there are many states with missing data for this year. The imputation of these missing prices follows the same procedure as prices for 1970-1972 and is discussed below. The calculation of 1973 U.S. prices also follows the 1970-1972 procedure. No prices are imputed for 1974-1983, except for Hawai i (1974-1982). or for Alaska for 1970-1973; states with no distillate electric utility sector prices in STEPS are summarized by year in Table 8.5 . 
IABLE 8.5. States with No Distillate Electric Utility Sector

Prices Reported by STEPS, 1970-1983

$\begin{array}{ll}\text { State } & \text { Years with No Reported Prices } \\ \text { AK } & 1970-1983 \\ \text { CA } & 1983 \\ \text { ID } & 1970-1974,1976,1980-1983 \\ \text { ME } & 1974 \\ \text { MT } & 1974-1975,1977,1983 \\ \text { NH } & 1974 \\ \text { NJ } & 1974 \\ \text { RI } & 1976-1983 \\ \text { SD } & 1974 \\ \text { VT } & 1974,1978,1983 \\ \text { WA } & 1970-1971,1974-1977\end{array}$

Source: Pacific Northwest Laboratory

$1973-1974,1983$.

Btu prices in cents per million Btu and physical unit prices in dollars per barrel are taken directly from cost and Quality and converted to dollars per million Btu and dollars per gallon, respectively. For 1974 and 1983, the calculations include the U.S., while for 1973 they do not.

$$
\begin{aligned}
& \text { DFEUUZZ }=\text { DFSENZZ } / 42 \\
& \text { DFEUDZZ }=\text { DFSEFZZ } / 100
\end{aligned}
$$

where:

DFEUUZZ = STEPS final electric utility sector distillate price for State ZZ or $(1974,1983)$ the U.S. (\$/gal)

DFSENZZ = physical price of fuel oil No. 2 delivered to steam electric plants from C\&Q $(\$ / b b l)$

DFEUDZZ = STEPS final electric utility sector distillate price for State $Z Z$ or $(1974,1983)$ the U.S. (\$/MMBtu)

DFSEFZZ = Btu price of fuel oil No. 2 delivered to steam electric plants from C\&Q (c/million Btu)

1975-1979.

Btu prices in cents per million Btu and physical unit prices in dollars per barrel are taken from cost and Quality with their corresponding delivered quantities, weighted into overall prices, and converted to the appropriate STEPS units. These calculations apply equaliy to states and the U.S. 


$$
\begin{gathered}
\text { DFEUUZZ = }[(\text { DFSENZZ } / 42) * \text { DFSEVZZ }]+[(\text { DFCTNZZ } / 42) * \text { DFCTVZZ }] \\
/(\text { DFSEVZZ }+ \text { DFCTVZZ }) \\
\text { DFEUDZZ = [(DFSEFZZ } / 100) * \text { DFSEVZZ }]+[(\text { DFCTFZZ } / 100) * \text { DFCTVZZ }] \\
/(\text { DFSEVZZ }+ \text { DFCTVZZ })
\end{gathered}
$$

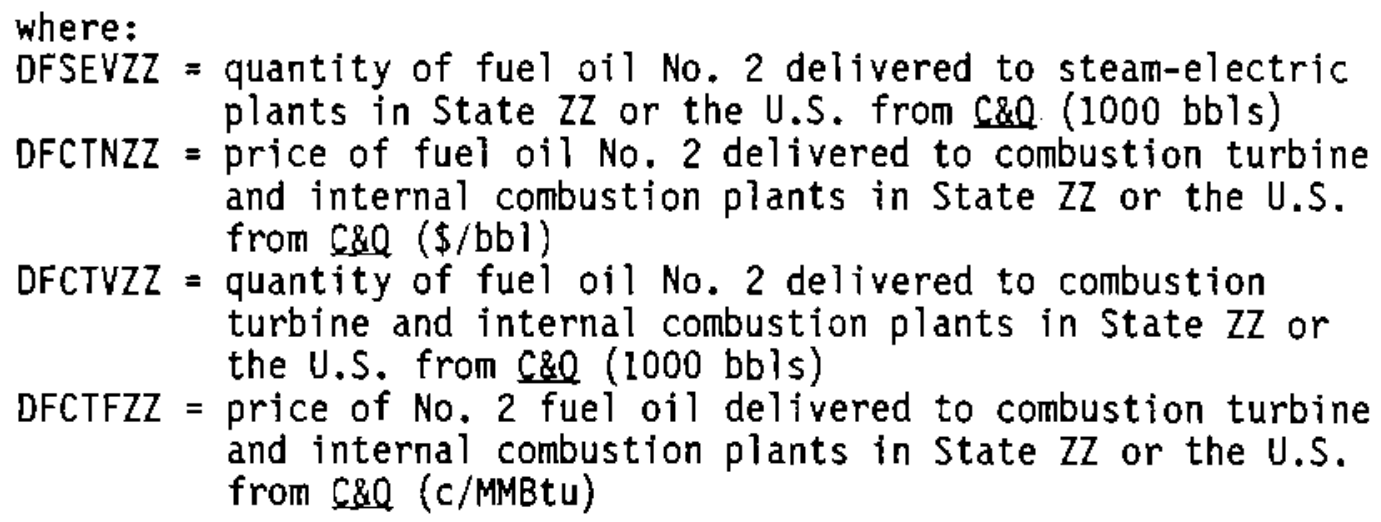

1980-1982.

For the 1980-1982 period, Btu and physical unit prices are reported in Cost and Quality for all reporting plants. These prices are changed to dollars per million Btu and to dollars per gallon for use in the STEPS series.

$$
\begin{aligned}
& \text { DFEUUZZ }=\text { DFEUNZZ } / 42 \\
& \text { DFEUDZZ }=\text { DFEUFZZ } / 100
\end{aligned}
$$

where:

$$
\begin{aligned}
& \text { DFEUNZZ }= \text { price of No. } 2 \text { fuel oil delivered to all reporting } \\
& \text { plants in State ZZ or the U.S. from } 6 \& Q(\$ / b b 1) \\
& \text { DFEUFZZ }= \text { price of No. } 2 \text { fuel oil delivered to all reporting } \\
& \text { plants in State ZZ or the U.S. from C\&Q (c/MMBtu) }
\end{aligned}
$$

\section{Imputation of Hawaji Prices: 1974-1982.}

Since cost and Quality does not cover the State of Hawaij (which does have distillate fuel usage in the electric utility sector reported in SEDS), prices for this state are imputed. The ratio of the reported cost and Quality U.S. price and the Statistical Year Book U.S. price is multiplied by the Statistical Year Book Hawaji price for each year to estimate the Hawaij price reported in STEPS. Separate equations are used for physical unit and Btu prices.

$$
\begin{aligned}
& \text { DFEUUHI }=\text { [DFEUUUS } /(\text { OLEUNUS } / 42)] * \text { (OLEUNHI / 42) } \\
& \text { DFEUDHI }=\text { [DFEUDUS } /(\text { OLEUFUS } / 100)] *(\text { OLEUFHI } / 100)
\end{aligned}
$$




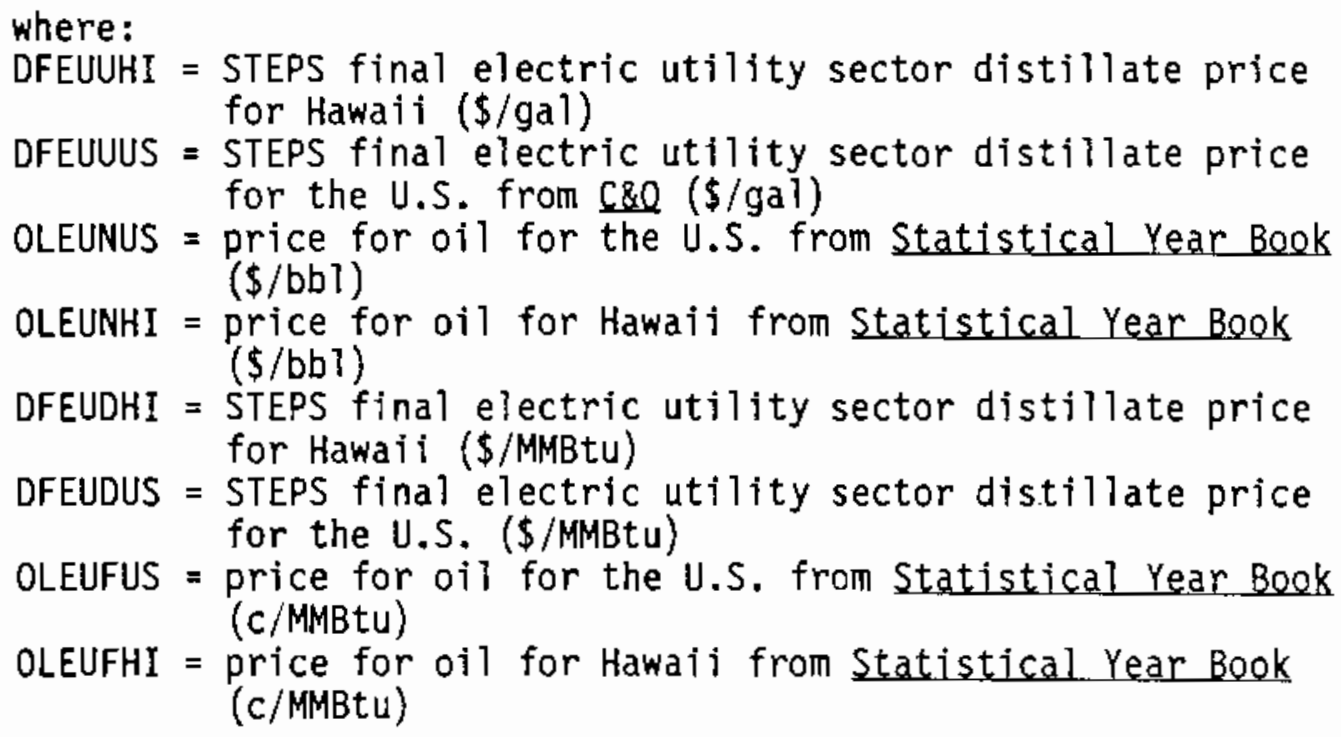

\subsubsection{Computational Procedures: 1970-1973}

Both Btu and physical unit prices for 1970-1972 and for states missing Cost and Quality data for 1973 (Connecticut, District of Columbia, Delaware, Maryland, Maine, Montana, New Hampshire, New Jersey, South Dakota, Tennessee, Vermont, Washington, West Virginia, and Wyoming) are estimated using data from Statistical Year Book of the Electric Utility Industry. U.S. prices are then computed using the completed state-level price series and electric utility distillate consumption data from SEDS.

1. Regression techniques are used to estimate the equations for estimating utility sector distillate prices for the 1970-1973 period. Separate equations are estimated for the calculation of Btu and physical unit prices, with each equation treating Alabama as a reference state. The regression equation uses Statistical Year Book state-level prices for 1974-1980 as the independent variable and the state-level STEPS prices calculated above for 1974-1980 as the dependent variable. Substituting physical unit and Btu prices for 1970-1973 from Statistical Yearbook into the following two equations yields the utility sector state-level distillate prices reported in STEPS. The coefficients for the state dunmy variables are given in Tables 8.6 and 8.7.

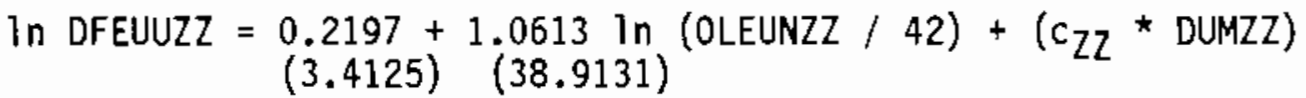

$$
\begin{aligned}
& \text { R-square }=0.8520
\end{aligned}
$$

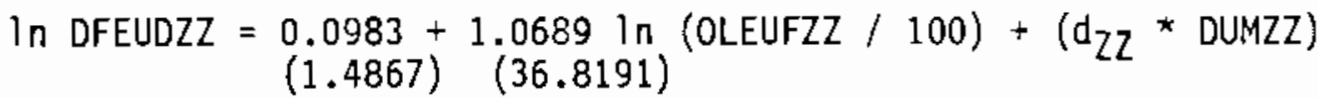

$$
\begin{aligned}
& \text { R-square }=0.8381
\end{aligned}
$$


IABLE 8.6. Estimated Values for State Dummy Coefficients: Distillate Electric Utility Sector Physical Unit Prices (Equation 8.52)

\begin{tabular}{|c|c|c|c|c|c|}
\hline State & $\mathrm{c}_{Z Z}$ & t Ratio & State & $c_{Z Z}$ & t Ratio \\
\hline $\mathrm{AL}$ & (a) & (a) & HT & 0.1347 & 1.4089 \\
\hline AR & -0.0424 & -0.5199 & $N C$ & -0.0439 & -0.5377 \\
\hline$A Z$ & 0.0158 & 0.1940 & ND & 0.1748 & 2.1408 \\
\hline CA & -0.1666 & -2.0409 & NE & 0.1083 & 1.3264 \\
\hline $\mathrm{CO}$ & -0.0200 & -0.2456 & $\mathrm{NH}$ & 0.1235 & 1.4552 \\
\hline CT & -0.0573 & -0.7028 & $\mathrm{NJ}$ & -0.0609 & -0.7172 \\
\hline$D C$ & -0.0290 & -0.3352 & NM & -0.0080 & -0.0985 \\
\hline $\mathrm{DE}$ & -0.0067 & -0.0822 & NV & 0.1272 & 1.5597 \\
\hline $\mathrm{FL}$ & 0.0645 & 0.7911 & NY & -0.0072 & -0.0882 \\
\hline GA & 0.0486 & 0.5961 & $\mathrm{OH}$ & -0.1257 & -1.5404 \\
\hline HI & 0.0046 & 0.0557 & OK & 0.0610 & 0.7481 \\
\hline IA & -0.0345 & -0.4231 & $\mathrm{OR}$ & -0.0859 & -1.0524 \\
\hline ID & 0.1642 & 1.7146 & $\mathrm{PA}$ & -0.0435 & -0.5338 \\
\hline IL & -0.0876 & -1.0739 & RI & -0.0803 & -0.6556 \\
\hline IN & -0.0857 & -1.0508 & SC & 0.3343 & 4.0797 \\
\hline KS & 0.1723 & 2.1070 & SD & 0.1257 & 1.4814 \\
\hline$K Y$ & 0.0863 & 1.0582 & TN & 0.0206 & 0.2527 \\
\hline LA & 0.0018 & 0.0225 & TX & 0.1174 & 1.4369 \\
\hline MA & 0.0752 & 0.9222 & UT & 0.2026 & 2.4817 \\
\hline MD & 0.0072 & 0.0884 & VA & 0.0748 & 0.9166 \\
\hline ME & 0.1984 & 2.3375 & VT & -0.0411 & -0.4592 \\
\hline MI & -0.0151 & -0.1857 & WA & -0.0229 & -0.2170 \\
\hline MN & 0.0501 & 0.6138 & $W I$ & -0.0674 & -0.8270 \\
\hline MO & 0.0468 & 0.5735 & WV & -0.1202 & -1.4714 \\
\hline MS & 0.1 & 1.4744 & $W Y$ & 0.1733 & 2.1255 \\
\hline
\end{tabular}

Source: Pacific Northwest Laboratory 
IABLE 8.7. Estimated Values for State Dummy Coefficients: Distillate Electric Utility Sector Btu Prices (Equation 8.53)

\begin{tabular}{|c|c|c|c|c|c|}
\hline State & $\mathrm{d}_{72}$ & t Ratio & State & $\mathrm{d}_{72}$ & tratio \\
\hline $\mathrm{AL}$ & (a) & (a) & MT & -0.0298 & -0.2973 \\
\hline AR & 0.0217 & 0.2532 & NC & -0.0318 & -0.3716 \\
\hline$A Z$ & 0.0569 & 0.6657 & ND & 0.1780 & 2.0774 \\
\hline $\mathrm{CA}$ & -0.1080 & -1.2623 & NE & 0.1558 & 1.8169 \\
\hline $\mathrm{CO}$ & 0.0169 & 0.1973 & NH & 0.1918 & 2.1534 \\
\hline CT & -0.0058 & -0.0684 & NJ & -0.0233 & -0.2619 \\
\hline DC & 0.0272 & 0.3182 & NM & 0.0265 & 0.3098 \\
\hline $\mathrm{DE}$ & 0.0454 & 0.5306 & NV & 0.1724 & 2.0137 \\
\hline $\mathrm{FL}$ & 0.1331 & 1.5540 & NY & 0.0477 & 0.5574 \\
\hline GA & 0.0982 & 1.1475 & $\mathrm{OH}$ & -0.1065 & -1.2446 \\
\hline HI & 0.0615 & 0.7158 & OK & 0.0652 & 0.7613 \\
\hline IA & -0.0504 & -0.5891 & $O R$ & -0.0901 & -1.0522 \\
\hline ID & 0.1333 & 1.3277 & PA & -0.0036 & -0.0423 \\
\hline IL & -0.0478 & -0.5590 & RI & -0.0302 & -0.2352 \\
\hline IN & -0.0898 & -1.0500 & SC & 0.3970 & 4.6083 \\
\hline KS & 0.2354 & 2.7405 & SD & 0.2556 & 2.8694 \\
\hline KY & 0.1131 & 1.3224 & TN & 0.0207 & 0.2416 \\
\hline LA & 0.0573 & 0.6696 & $T X$ & 0.1487 & 1.7334 \\
\hline MA & 0.1384 & 1.6170 & UT & 0.2332 & 2.7209 \\
\hline MD & 0.0619 & 0.7239 & VA & 0.1283 & 1.4983 \\
\hline ME & 0.2574 & 2.8896 & VT & -0.0561 & -0.5975 \\
\hline MI & 0.0207 & 0.2420 & WA & 0.0245 & 0.2207 \\
\hline MN & 0.1102 & 1.2869 & WI & -0.0707 & -0.8262 \\
\hline MO & 0.0627 & 0.7335 & WV & -0.1471 & -1.7164 \\
\hline MS & 0.1881 & 2.1916 & WY & 0.1666 & 1.9475 \\
\hline
\end{tabular}

Source: Pacific Northwest Laboratory 


\begin{abstract}
where:
OLEUNZZ = price of oil purchased for electric generation in State $Z Z$ from Statistical Year Book (\$/bbl)

OLEUFZZ = price of oil purchased for electric generation in State ZZ from Statistical Year Book (c/MMBtu)
\end{abstract}

2. U.S. prices are computed for both the Btu and physical unit price series using the respective state-level prices and distillate electric utility sector consumption data from SEDS for weights:

$$
\begin{aligned}
& \text { DFEUUUS }=\left(\sum_{Z Z=1}^{51} \text { (DFEUUZZ *DFEUPZZ) }\right) / \sum_{Z Z=1}^{51} \text { DFEUPZZ } \\
& \text { DFEUDUS }=\left(\sum_{Z Z=1}^{51} \text { (DFEUDZZ *DFEUPZZ) }\right) / \sum_{Z Z=1}^{51} \text { DFEUPZZ }
\end{aligned}
$$

where:

DFEUUUS = STEPS final electric utility sector distillate price for the U.S. (\$/gal)

DFEUDUS = STEPS final electric utility sector distillate price for the U.S. (\$/MMBtu)

DFEUPZZ = electric utility sector distillate consumption for State ZZ from SEDS (1000 bbls)

\title{
8.4 INDUSIRIAL SECTOR
}

The STEPS industrial sector distillate price series are developed using several different data sources and computational procedures, depending on the years involved. For 1970-1982, prices reported in STEPS are the average cost of distillate to manufacturing firms; it is not clear whether or not these prices contain any taxes. For 1983, sales prices of No. 2 fuel oil to industrial consumers (excluding taxes) are taken from Petroleum Marketing Monthly. Regardless of data source, physical unit prices for states and the U.S. are calculated first, then Btu prices are computed using the physical unit prices and the conversion factor.

\subsubsection{Data Sources}

1971, 1977 Bureau of the Census, U.S. Department of Commerce. Census 1981 of Manufactures. Table 4 (1971), and Table 3 (1977 and 1981).

1974-1976, Bureau of the Census, U.S. Department of Commerce. Annual 1978-1980 Survey of Manufactures. Table 3.

1970-1983 McGraw-Hill, Inc. Platt's Oil Price Handbook and 0ilmanac. Refinery and terminal prices for No. 2 fuel oil. 
1983

Energy Information Administration, U.S. Department of Energy. Petroleum Marketing Monthly. Table titled, "Sales Prices of No. 2 Fuel 0il, by PAD District and Selected States."

$1970-1983$

Energy Information Administration, U.S. Department of Energy. State Energy Data System. Computer tape. Industrial sector distillate consumption.

\subsubsection{Conversion Factor}

1970-1983 Energy Information Administration, U.S. Department of Energy. State Energy Data Report. Appendix C, p. 667.

5.825 Mi1lion Btu per Barrel

\subsubsection{Computational Procedures: Physical Unit State Prices, 1970-1981}

For the years 1970-1981, industrial sector distillate prices are either calculated directly from cost and quantity data from Annual survey of Manufactures (ASM) or Census of Manufactures (CM), or are imputed using the relationship of ASM/CM data to No. 2 fuel oil price data from Platt's.

1. For 1971 and 1974-1981, industrial sector physical unit prices are calculated as average cost per unit of sales from cost and quantity data from ASM or CM. It is not clear whether or not these prices include any taxes.

$$
\text { DFICUZZ }=(\text { DFMFCZZ } / \text { DFMFVZZ }) * 1000 / 42
$$

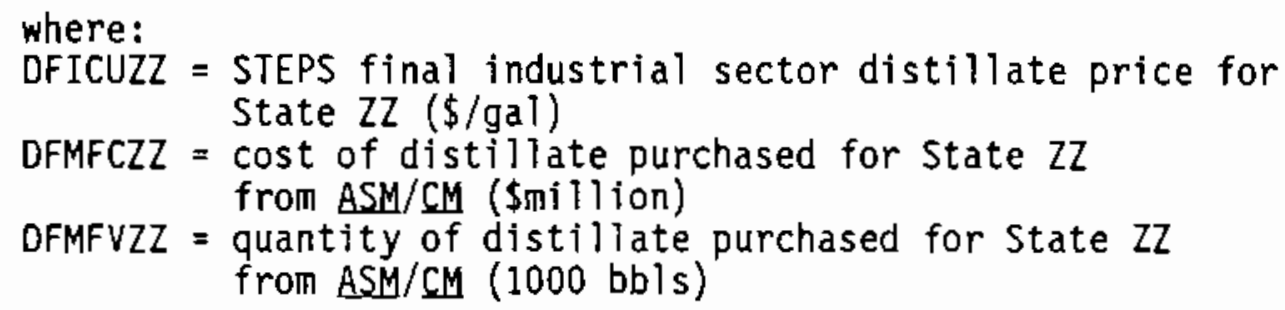

2. Six states are missing some ASM cost and quantity data for the 1974-1981 period. Cost and quantity data for these states are estimated as the simple average of the cost and quantity data for their adjacent states. The states, the years for which data are imputed, and the adjacent states used to make the estimation are all shown in Table 8.8. There are no missing prices for 1971. The estimated cost and quantity data are used in Equation 8.56 to estimate final STEPS prices.

$$
\operatorname{DFMFCZZ}_{b}=1 / N \sum_{a=1}^{N} \operatorname{DFMFCZZ}_{a}
$$


IABLE 8.8. Adjacent State Assignments for the Imputation of Missing Data: Distillate Industrial Sector, 1974-1981

$\begin{array}{lll}\text { Missing State } & \text { Years } & \text { Adjacent States Assigned } \\ \begin{array}{l}\text { Hawaii } \\ \text { North Dakota }\end{array} & \begin{array}{l}1979-1981 \\ 1979-1981\end{array} & \begin{array}{l}\text { California } \\ \text { Minnesota, Montana, South } \\ \text { Dakota }\end{array} \\ \begin{array}{l}\text { New Mexico } \\ \text { Nevada }\end{array} & 1974-1979 & \begin{array}{l}\text { Arizona, Colorado, Texas } \\ \text { Arizona, California, Idaho, } \\ \text { Oregon, Utah }\end{array} \\ \text { OkTahoma } & 1974-1981 & \begin{array}{l}\text { Arkansas, Colorado, Kansas, } \\ \text { Missouri, Texas }\end{array} \\ \text { Wyoming } & 1974-1978 & \begin{array}{l}\text { Colorado, Idaho, Montana, } \\ \text { Nebraska, South Dakota, } \\ \text { Utah }\end{array} \\ & 1974-1981 & \end{array}$

Source: Pacific Northwest Laboratory

$$
\text { DFMFVZZ }_{b}=1 / N \sum_{a=1}^{N} \text { DFMFVZZ }_{a}
$$

where:

$\mathrm{b}=$ index for State $Z Z$ with missing data for 1971, 1974-1981

$a=$ index for State $Z Z$ with data and adjacent to the State $Z Z$ with missing data

$N=$ number of states adjacent to State $Z Z$ with missing data

3. Since ASM and CM data are not available for 1970, 1972, or 1973, prices for these years must be estimated. Physical unit prices are based on the ratio of $1971 \mathrm{CM}$ prices to the 1971 assigned Platt's prices (see Table 8.1). The resulting ratios for each state are used with the Platt's assigned prices for 1970, 1972, and 1973 to estimate STEPS prices.

a. The first step in the estimation of industrial sector distillate STEPS prices is to calculate state-level ratios between STEPS prices calculated from the $1971 \mathrm{CM}$ cost and quantity data and the 1971 assigned Platt's prices. There are no missing states in either of these two sets of prices.

$$
\text { DFICSZZ }=\text { DFICUZZ } /(\text { DFNCNZZ } / 100)
$$

where:

DFICSZZ = ratio of the STEPS 1971 price to the assigned Platt's 1971 price for State $Z Z$

DFNCNZZ = No. 2 fuel oil price assigned to State ZZ from Platt's (c/gal) 
b. State-level physical unit prices for 1970, 1972, and 1973 are estimated using the 1971 ratio and the assigned state-level Platt's prices for each respective year:

$$
\text { DFICUZZ }=\text { DFICSZZ * (DFNCNZZ } / 100)
$$

where:

DFICUZZ = STEPS final industrial sector distillate price for State ZZ (\$/gal)

\subsubsection{Computational Procedures: Physical Unit State Prices, 1982}

In 1984, the Bureau of the Census announced that detailed fuel cost and quantity information would no longer be published in the Annual Survey of Manufactures and probably not in the Census of Manufactures. In addition, Petroleum Marketing Monthly, the source for 1983 industrial sector distillate price data, does not contain 1982 prices. Because of this lack of price data, the 1982 STEPS industrial sector distillate prices are imputed based on the relationship of industrial sector prices to electric utility sector prices for 1978-1981. The 1983 prices are not used in the imputation because they exclude taxes, while the 1978-1981 prices may include taxes.

1. The states of Alaska (1978-1982), Idaho (1980-1982), Rhode Island (1978-1982), and Vermont (1978) are missing electric utility data for 1978-1982 period. To calculate the average ratios in Equation 8.61, Idaho is assigned Montana electric utility prices, Rhode Island is assigned Connecticut prices, Alaska is assigned Washington prices, and Vermont is assigned the Maine price.

2. The average 1978-1981 ratios of industrial to electric utility sector distillate prices are calculated for each state:

$$
\text { DFICRZZ }=1 / 4 \sum_{t=78}^{81}\left(\text { DFICUZZ }_{t} / \text { DMEUUZZ }_{t}\right)
$$

where:

$$
\begin{aligned}
\text { DFICRZZ = } & \text { average ratio of STEPS industrial sector distillate } \\
& \text { prices to STEPS electric utility sector distillate } \\
& \text { prices for State ZZ (ratio) } \\
\text { DFICUZZ = } & \text { STEPS final industrial sector distillate price for } \\
& \text { State } Z Z \text { ( } \$ / \text { gal) } \\
\text { DMEUUZZ = } & \text { STEPS final electric utility sector distillate price for } \\
& \text { State ZZ with imputations for missing states ( } \$ / g a l) \\
\mathrm{t}= & \text { index for years (1978-1981) }
\end{aligned}
$$


3. Prices for 1982 are computed using the average ratios and STEPS electric utility data for 1982. The imputed prices for Alaska, Idaho, and Rhode Island for 1982 are described in (1) above.

$$
\text { DFICUZZ }=\text { DFICRZZ } \star \text { DFEUUZZ }
$$

where:

DFICUZZ = STEPS final industrial sector distillate price for State $\mathrm{ZZ}$ in 1982

\subsubsection{Computational Procedures: Physical Unit State Prices, 1983}

For 1983, physical unit industrial sector distillate prices in cents per gallon (excluding taxes) are avilable for 24 states and 7 PAD Districts from Petroleum Marketing Monthly (PMM) under the heading "Sales to End-Users: Industrial Consumers." Platt's distillate price data assigned to states and state-level SEDS consumption data are used to impute state prices from the PAD District prices for the 27 states that do not have prices in PMM. This procedure is described step-by-step below.

1. Monthly state physical unit prices from PMM are available for the following 24 states: Alaska, Connecticut, District of Columbia, Delaware, Idaho, Illinois, Indiana, Massachusetts, Maryland, Maine, Michigan, Minnesota, New Hampshire, New Jersey, New York, Ohio, Oregon, Pennsylvania, Rhode Island, Virginia, Vermont, Washington, Wisconsin, and West Virginia.

a. Several of these states are missing some monthly PMM industrial price data. The missing monthly prices are assigned prices or averages of prices for adjacent months as shown in Table 8.9.

b. Annual physical unit prices are calculated for the 24 states covered directly by PMM as simple averages of the monthly prices:

$$
\text { DFICUZZ }=1 / 12 \sum_{m=1}^{12}\left(\text { DFICMZZ }_{m} / 100\right)
$$

where:

DFICUZZ = STEPS final industrial sector distillate price for State $2 Z$ ( $\$ /$ gal)

DFICMZZ = monthly industrial sector distillate price for state $Z Z$ from PMM (c/gal)

$m=$ index for months 
IABLE 8.9. Imputation of Missing PMM Monthly Prices:

Distillate Industrial Sector, 1983

\begin{tabular}{cll} 
State & \multicolumn{1}{c}{ Missing Month } & Assigned Month. (or Average) \\
\cline { 2 - 3 } AK & January-March & April \\
DC & January-October & MD January-October \\
DE & January & February \\
& December & November \\
ID & January-October, & [Calculated as for other \\
& December & PAD IV States] \\
IL & January & February \\
MD & January, February & March \\
ME & January & February \\
& March, April & February/May Average \\
MI & January & February \\
NH & January, February & March \\
& June, July & May/August Average \\
NJ & January & February \\
NY & January & February \\
DH & January & February \\
OR & January & February \\
& August-November & WA August-November \\
RI & January & February \\
VA & January & February \\
VT & January, February & March \\
WA & January & February \\
WI & January & February \\
WV & January, February & March \\
& &
\end{tabular}

Source: Pacific Northwest Laboratory 
2. Physical unit state prices for the remaining 27 states are imputed from monthly PAD District prices from PMM for seven districts: Ia, Ib, Ic, II, III, IV, and V.

a. PAD Districts IC and IV are both assigned the average of their respective January and March prices for their missing February prices. Although some monthly prices are missing for Districts Ia and $\mathrm{Ib}$, these are completely covered state-level data, so no imputation is needed.

b. Average annual physical unit distillate prices for the industrial sector are calculated for PAD Districts IC, II, III, IV, and V using simple averages of the monthly PAD District price data from PMM:

$$
\text { DFICNWW }=1 / 12 \sum_{m=1}^{12}\left(\text { DFICMWW }_{m} / 100\right)
$$

where:

DFICNWW = annual industrial sector distillate price for PAD District WW $(\$ / g a l)$

DFICMWW = monthly industrial sector distillate price for PAD District WW from PMM (c/gal)

$\mathrm{m}=$ index for months

c. City-level distillate refinery and terminal prices from Platt's are assigned to states as shown in Table 8.1. The assigned state-level Platt's prices are volume-weighted into PAD District prices using state-level industrial sector consumption volume data from SEDS:

DFNINWW $=\sum_{Z Z=1}^{N W W}\left[\left(\right.\right.$ DFNCNZZ $\left._{W W} / 100\right) *$ DFICPZZ $\left._{W W}\right] /$

$$
\sum_{Z Z=1}^{N W W} D_{W I C P Z Z} W W
$$

where:

DFNINWW = estimated industrial sector distillate price based on Platt's for PAD District WW (\$/gal)

DFNCNZZ = distillate price assigned to State ZZ from Platt's (c/gal)

DFICPZZ = industrial sector distillate consumption volume for State $Z Z$ from SEDS (1000 bbls)

$N_{W W}=$ number of States ZZ in PAD District WW 
d. An adjustment factor relating the PMM PAD District prices to the Platt's-based PAD District prices is calculated for PAD Districts IC, II, III, IV, and V:

$$
\text { DFICAWW = DFICNWW / DFNINWW }
$$

where:

DFICAWW = industrial sector adjustment factor equal to the ratio of PMM to Platt's distillate prices for PAD District WW

e. Annual physical unit prices for the 27 states not explicitly covered by PMM state-level data are calculated using the assigned Platt's prices for each state and the PAD District-level adjustment factors:

$$
\text { DFICUZZ }=\text { DFICAWW } *\left(\text { DFNCNZZ }_{W W} / 100\right)
$$

where:

DFICUZZ = STEPS final industrial sector distillate price for State ZZ (\$/gal)

\subsubsection{Computational Procedures: Physical Unit U.S. Prices, 1970-1983}

Physical unit prices for the U.S. are computed using the completed state physical unit prices and the distillate industrial consumption data from SEDS:

$$
\text { DFICUUS }=\left(\sum_{Z Z=1}^{51}(\text { DFICUZZ * DFICPZZ) }) / \sum_{Z Z=1}^{51}\right. \text { DFICPZZ }
$$

where:

DFICUUS = STEPS final industrial sector distillate price for the U.S. ( $\$ /$ gal)

DFICPZZ = industrial sector distillate consumption for State $Z Z$ from SEDS (1000 bbls)

\subsubsection{Computational Procedures: Btu Prices, 1970-1983}

Btu prices for states and the U.S. are calculated using the completed STEPS physical unit price series and the conversion factor:

$$
\text { DFICDZZ }=(\text { DFICUZZ * 42) } / 5.825
$$

where:

DFICDZZ = STEPS final industrial sector distillate price for State $Z Z$ or the U.S. (\$/MMBtu) 


\subsection{MOTOR GASOLINE}

The STEPS motor gasoline price series cover the transportation sector with prices in dollars per gallon and dollars per million Btu. The prices in this series are retail prices (usually service station prices) including taxes. Physical unit prices are calculated from the data sources, while Btu prices are computed using the completed physical unit price series and the conversion factor. The development of the STEPS motor gasoline price series is described below only for the year 1983; this is the only year for which data sources and calculations have been verified. For information about the development of the STEPS motor gasoTine price series for 1970-1982, the reader should see State Energy Price System (Volume I) and State Energy Price System: 1982 Update.

\subsection{DATA SOURCES}

1983 Energy Information Administration, U.S. Department of Energy. Petroleum Marketing Monthly. Table titled, "Refiner and Gas Plant Operator Sales Prices of Finished Motor Gasoline, by Type of Seller and PAD District and State."

1983 Federal Highway Administration, U.S. Department of Transportation. Highway Statistics. Tables MF-26 (monthly consumption volumes) and MF-121T (taxes).

1983 Bureau of Labor Statistics, U.S. Department of Labor. Consumer Prices: Energy. Computer printouts of gasoline prices (obtained directly from BLS).

1983 Energy Information Administration, U.S. Department of Energy. State Energy Data System. Computer tape. Transportation sector motor gasoline consumption data.

\subsection{CONVERSION FACTOR}

1983 Energy Information Administration, U.S. Department of Energy. State Energy Data Report. Appendix C, p. 667.

5.253 Million Btu per Barrel 


\subsection{COMPUTATIONAL PROCEDURES}

Motor gasoline physical unit prices are based on monthly state-level price data available from Petroleum Marketing Monthly (PMM) or from Consumer Prices:

Energy (CPI). Where necessary, state taxes are added to the monthly prices. Monthiy gasoline consumption volumes from Highway Statistics are then used to combine monthly prices into annual prices for each state. The U.S. physical unit price is calculated using the completed physical unit state prices and annual state-level consumption volumes from SEDS. Btu prices are calculated using the completed physical unit price series and the conversion factor.

1. Monthly state-level gasoline prices are available for all states except Alaska, the District of Columbia, and Hawai from PMM. The average sales price (excluding taxes) of finished motor gasoline to end-users through company outlets is used, based on the assumption that these prices approximate retail gasoline prices. Finished motor gasoline in this case includes leaded, unleaded, and gasohol.

a. A few states are missing monthly prices for specific months. Price assignments for missing months are given in Table 9.1.

IABLE 9.1. Assignments for Missing Monthly Gasoline Price Data from Petroleum Marketing Monthly, 1983

Missing
State

AR

MD

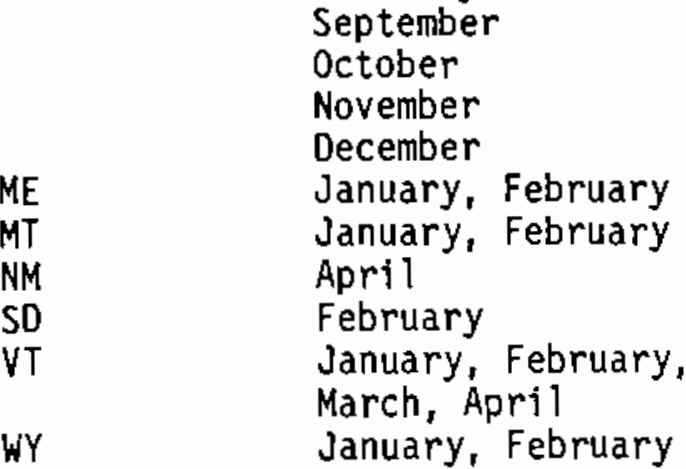

February

January

February

September

ctober

November

January, February

January, February

April

February

March, April

WY January, February
Price Assigned

AR January

DE January

DE February

DE September

DE October

DE November

DE December

ME March

MT March

NM May

SD January

VT May

WY March

Source: Pacjfic Northwest Laboratory 
b. Because the PMM prices exclude taxes, taxes must be added to the reported prices. Monthly state-level tax information is taken from Highway Statistics and is added to the PMM prices as follows:

$$
\text { MGACGZZ }_{m}=\left(M G[M O N] Z Z_{m}+M G T A X Z Z_{m}\right] / 100
$$

where:

MGACGZZ = monthly motor gasoline price, including taxes, for State ZZ (\$/gai)

MG[MON]ZZ = monthly motor gasoline price, excluding taxes, for State ZZ from PMM (c/gal)

MGTAXZZ = monthly tax on motor gasoline for State $Z Z$ from Highway Statistics (c/gal)

$m$ = index for months

2. Monthly motor gasoline prices for Alaska, the District of Columbia, and Hawaij are taken directly from CPI, since these prices already include taxes.

$$
\operatorname{MGACGZZ}_{m}=\text { MGACMZZ }_{m}
$$

where:

MGACGZZ = monthly motor gasoline price, including taxes, for State ZZ (\$/gal)

MGACMZZ = monthly motor gasoline price, including taxes, for State $Z Z$ from CPI $(\$ / g a l)$

$m$ = index for months

3. Annual physical unit prices for all 51 states are calculated from the monthly gasoline prices calculated above and monthly gasoline consumption volumes for states from Highway Statistics:

$$
\begin{aligned}
& \text { MGACUZZ }=\left(\sum_{m=1}^{12}\left(\text { MGACGZZ }_{m} * M_{M G W Y Z Z}\right)\right) / \sum_{m=1}^{12} M_{m} G W Y Z Z_{m} \\
& \text { where: } \\
& \text { MGACUZZ = STEPS final transportation sector motor gasoline price } \\
& \text { MGHWYZZ = highway use gasoline consumption volume for State ZZ } \\
& \text { from Highway Statistics (1000 gal) } \\
& m=\text { index for months }
\end{aligned}
$$

4. The physical unit U.S. price is computed using the completed physical unit state prices and annual state-level motor gasoline consumption data for the transportation sector from SEDS:

$$
\text { MGACUUS }=\left(\sum_{Z Z=1}^{51} \text { (MGACUZZ * MGACPZZ) }\right), \sum_{Z Z=1}^{51} \text { MGACPZZ }
$$


where:

MGACUUS = STEPS final transportation sector motor gasoline price for the U.S. ( $\$ / \mathrm{gal})$

MGACPZZ = transportation sector motor gasoline consumption for State ZZ from SEDS (1000 bbls)

5. Btu prices for states and the U.S. are computed using the completed STEPS physical unit price series and the conversion factor:

$$
\text { MGACDZZ }=(\text { MGACUZZ * 42) } / 5.253
$$

where:

MGACDZZ = STEPS final transportation sector motor gasoline price for State $Z Z$ or the U.S. (\$/MMBtu) 


\subsection{DIESEL FUEL}

The STEPS diesel price series cover the transportation sector only. The prices reported are the retail prices paid by farmers in both dollars per gallon and dollars per million Btu. No information about whether or not these prices include taxes is available from the data sources. For all the years in the 1970-1983 period, physical unit prices are calculated from the data sources, while Btu prices are computed using the completed physical unit price series and the conversion factor.

\subsection{DATA SOURCES}

1970-1983 Crop Reporting Board, U.S. Department of Agriculture. Agricultural Prices. Table generally titled, "Motor Supplies: Average Price Pajd by Farmers for Motor Fuel," for 1970-1979, and "Diesel Fuel: Average Price Paid by States," for 1980-1983.

1970-1983 Federal Highway Administration, U.S. Department of Transportation. Highway Statistics. Table MF-25 for 1970-1983; this table is not included in the 1976 volume, but is publicly available directly from the Federal Highway Administration.

\subsection{CONVERSION FACTOR}

1970-1983 Energy Information Administration, U.S. Department of Energy. State Energy Data Report. Appendix C, distillate fuel oil.

\subsection{Million Btu per 8arrel}

\subsection{COMPUTATIONAL PROCEDURES}

Physical unit prices for states and the U.S. are calculated using consumption volume data from Highway Statistics to weight the monthly or quarterly Agricultural Prices prices into annual diesel prices for STEPS. Btu prices are then calculated using the completed physical unit price series and the conversion factor. 


\subsubsection{Physical Unit Prices:__1970-1976}

1. Quarterly prices from Agricultural Prices and monthly special fuels volume data from Highway Statistics are collected for states and the U.S.

a. Prices for 1970-1972 are reported in cents per gallon and must be converted to dollars per gallon. Prices for 1973-1976 are al ready reported in dollars per gallon.

b. For 1971-1973, state-level prices are not available for Connecticut, Massachusetts, Maine, New Hampshire, Rhode Island; and Vermont. Each of these states is assigned the New England price for these three years.

c. The third quarter Delaware price is assigned to the missing fourth quarter Delaware price in 1972.

d. The combined Maryland/Delaware prices reported in 1973 are assigned equally and identicaliy to each of these two states.

e. For 1970-1976, no prices are available for Alaska and the District of Columbia. No prices are developed for Alaska, while Maryland (or Maryland/Delaware) prices are assigned to the District of Columbia.

2. The monthly special fuels volumes for each of the years 1970-1976 are converted into quarterly volumes by summing the months for each respective quarter. Since no Alaska prices are developed, the monthly consumption volumes for this state are set equal to zero for all the years 1970-1976.

$$
D L H W X Z Z_{q}=\sum_{m=1}^{3} D^{2} H W Y Z Z_{q, m}
$$

where:

DLHWXZZ = quarterly volume of special fuels used in State $Z Z$ or the U.S. (1000 gal)

OLHWYZZ = monthly volume of special fuels used in State $Z Z$ or the U.S. from Highway Statistics (1000 gal)

$q=$ index for quarters

$m=$ index for months

3. The volume-weighted annual diesel physical unit prices for states and the U.S. are calculated using the quarterly weights and quarterly prices. The equation for 1970-1972 is as follows:

DLACUZZ $=\left(\sum_{q=1}^{4}\left[\left(\right.\right.\right.$ DLAGQZZ $\left.\left.\left._{q} * D_{\text {DLHWXZZ }}\right) / 100\right]\right) / \sum_{q=1}^{4}$ DLHWXZZ $_{q}$ 


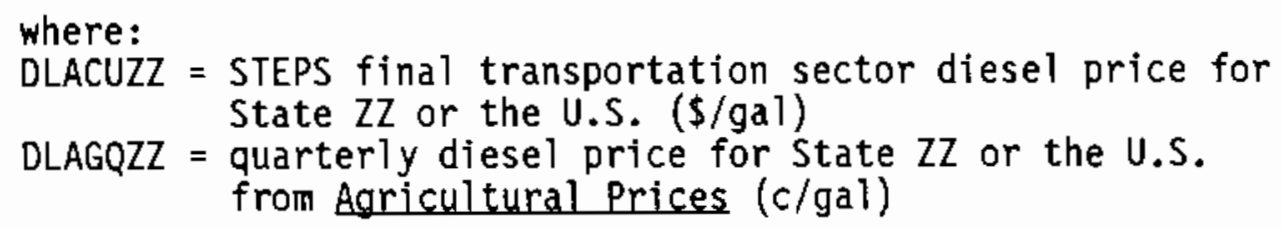

4. The volume-weighted annual diesel prices for 1973-1976 are calculated as follows:

$$
\begin{aligned}
& \text { DLACUZZ }=\left(\sum_{q=1}^{4}\left(\text { DLAGQZZ }_{q} \text { * DLHWXZZ }\right)\right) / \sum_{q=1}^{4} D L H W X Z Z Z_{q} \\
& \text { where: } \\
& \text { DLACUZZ = STEPS final transportation sector diesel price for } \\
& \text { State ZZ or the U.S. ( } \$ / g a l) \\
& \text { DLACQZZ = quarterly diesel price for State } Z Z \text { or the U.S. } \\
& \text { from Agricultural Prices (\$/gal) }
\end{aligned}
$$

\subsubsection{Physical Unit Prices: 1977-1983}

1. Monthly prices from Agricultural Prices and monthly special fuels consumption volume data from Highway Statistics are collected for states and the U.S. No prices are developed for Alaska for any of the years 1977-1983, and Maryland prices are assigned to the District of Columbia. Monthly consumption volumes for Alaska are set equal to zero for all the years 1977-1983 because no prices are developed for these years.

2. The volume-weighted annual diesel physical unit prices for states and the U.S. are calculated using the monthly Agricultural Prices price data and the monthly Highway Statistics volume data:

$$
\text { DLACUZZ }=\left(\sum_{m=1}^{12}\left(D_{1 A G M Z Z_{m}} * D_{\text {DHWYZZ }}\right)\right) / \sum_{m=1}^{12} \text { DLHWYZZ }_{m}
$$

where:

DLACUZZ = STEPS final transportation sector diesel price for State ZZ or the U.S. ( $\$ /$ gal)

DLAGMZZ = monthly diesel price for State $Z Z$ or the U.S. from Agricultural Prices (\$/gal)

DLHWYZZ = consumption volume of special fuels for State $Z Z$ or the U.S. from Highway Statistics (1000 gal)

$m$ = index for months 


\subsubsection{Btu.Prices: 1970-1983}

Btu prices for states and the U.S. are calculated using the completed physical unit price series and the conversion factor:

$$
\text { DLACDZZ }=(\text { DLACUZZ * 42) } / 5.825
$$

where:

OLACDZZ = STEPS final transportation sector diesel price for State ZZ or the U.S. (\$/MMBtu) 


\subsection{KEROSENE AND JET FUEL.}

The STEPS kerosene and jet fuel price series cover the residential, industrial, transportation, and electric utility sectors, with prices in dollars per galion and dollars per million Btu. The residential and industrial sector series are based on prices for kerosene only, the transportation sector is based on prices for jet fuel, and the electric utility sector is based on prices for both kerosene and jet fuel. Since types of prices and computational procedures vary significantly from sector to sector, the development of 1983 prices for each sector is discussed separately below; note, however, that there are no electric utility sector prices developed for 1983, due to a lack of data. Descriptions of data sources and computational procedures for 1970-1982 can be found in State Energy Price System (Volume I) and State Energy Price System: 1982 Update. The kerosene and jet fuel prices reported in Appendices B and C are from previous versions of STEPS and have not been checked for reproducibility.

\subsection{RESIDENTIAL SECTOR}

\subsubsection{Data Sources}

1975-1976 Crop Reporting Board, U.S. Department of Agriculture. Agricultural Prices. Table titled, "Household Supplies: Average Price Paid by Farmers for Lawn Mowers and Petroleum Products."

1975-1976, Bureau of Labor Statistics, U.S. Department of Labor. Producer 1983 Prices and Price Indexes:-Annual Supplement. Commodity code 0572 .

1978-1981 Energy Information Administration, U.S. Department of Energy. Retail Sales and Inventories of Fuel Oil. Table 2.

1983

Energy Information Administration, U.S. Department of Energy. State Energy Data System. Computer tape. Residential sector kerosene consumption data. 


\subsubsection{Conversion Factor}

1983

Energy Information Administration, U.S. Department of Energy. State Energy Data Report. Appendix C, p. 667.

5.670 Million Btu per Barrel

\subsubsection{Computational Procedures}

The STEPS residential sector kerosene price series for 1983 is based on kerosene base prices and indexes from Producer Prices and Indexes (PPI) and an adjustment factor that accounts for the relationship between PPI and Agricultural Prices prices for quarters where the two series overlap (third quarter of "1975 to fourth quarter of 1976). These prices are approximately the retail prices paid by farmers for kerosene and it is not clear whether or not they include taxes. The Agricultural Prices data is used to estimate residential kerosene prices because it is available at the state-level (while PPI data is available only at the Census Division level) and because it includes some residential end use. Once state-level physical unit kerosene prices are developed, physica? unit prices for the U.S. are calculated using the state prices and state residential kerosene consumption data from SEDS. Btu prices for states and the U.S. are calculated from the completed physical unit price series and the conversion factor.

1. The first step in the calculation of prices for 1983 is to compute the adjustment factor relating PPI and Agricultural Prices data. Both of these two data sources report prices beginning with the third quarter of 1975 (1975.3) and ending with the fourth quarter of $1976(1976.4)$. The adjustment factor will be the average of these six quarters.

a. Quarterly physical unit kerosene prices are available directly from Agricultural Prices for 1975.3 through 1976.4. Maryland prices are assigned for the missing District of Columbia prices; no prices are imputed for missing Alaska prices.

b. Since the PPI prices and indexes for 1975.3 through 1976.4 are available only on a monthly basis, quarterly prices must be calculated. This is done using the July 1975 base prices and the respective monthly indexes for those months contained in the 1975.3 to 1976.4 period (July 1975 through December 1976). The PPI prices are calculated for the nine Census Divisions as follows:

$$
\operatorname{KSNCMXX}_{m}=\left(\operatorname{KSNCIXX}_{m} / 100\right) * \mathrm{KSNCJXX}
$$

where:

KSNCMXX = kerosene monthly price for Census Division XX ( $\$ / g a I)$

KSNCIXX = kerosene monthly price index for Census Division $X X$ from PPI

KSNCJXX = kerosene July 1975 base price for Census Division $X X$ from ppI (\$/gal)

$m=$ index for months 
c. The Census Division monthly prices calculated in Equation 11.1 are assigned equally and identically to each state within its respective Census Division:

$$
\mathrm{KSNCMZZ}_{X X, m}=\mathrm{KSNCMXX}_{\mathrm{m}}
$$

where:

$$
\begin{aligned}
\mathrm{KSNCMZZ}= & \text { kerosene monthly price for State } Z Z \text { in Census } \\
& \text { Division } X X(\$ / g a l) \\
m= & \text { index for months }
\end{aligned}
$$

d. In order to combine the monthly PPI-based state-level prices into weighted average annual state prices, monthly quantity weights are calculated from data available in Retail Sales and Inventories of Euel $0 i l$. The "other distillate oil" volumes reported for November 1978 through March of 1981 are simply averaged by month using whatever consumption data are available for each month for each PAD District. The variation in data avaliability results in some months with averages based on three data points while others are based on one or two data points. The Retail Sales data and the resulting monthly averages are shown in Table 11.1. Each month's share of average annual sales (result is a fraction) is calculated by PAD District from the average monthly sales figures shown in Table 11.1. These shares, which are the monthly weights used, are then assigned to each and every state within each respective PAD District.

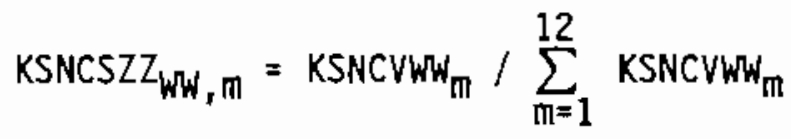

where:

KSNCSZZ = share of average kerosene sales in State ZZ of PAD District WW

KSNCVWW = average monthly retail sales of other distillate fuel oil for PAD District WW from Table 11.1 (1000 bbls) $m=$ index for months

e. Volume-weighted quarterly PPI-based prices for states are calculated using the monthly volume weights developed in Equation 11.3:

$\operatorname{KSNCQZZ}_{\mathrm{q}}=\left(\sum_{m=1}^{3}\left(\operatorname{KSNCMZZ}_{\mathrm{q}, \mathrm{m}} * \operatorname{KSNCSZZ}_{\mathrm{q}, \mathrm{m}}\right)\right) / \sum_{m=1}^{3} \operatorname{KSNCSZZ}_{\mathrm{q}, \mathrm{m}}$

where:

KSNCQZZ = kerosene quarterly price for State $Z Z(\$ / g a l)$

$m=$ index for months 
TABLE 11.1 Other Distillate Sales by PAD Districts and Monthiy Average Sales ( 1000 barrels)

Jan Feb Mar Apr May Jun Jul Aug Sep Oct Nov Dec

PAO la

\begin{tabular}{|c|c|c|c|c|c|c|c|c|c|c|c|c|}
\hline $\begin{array}{l}1978 \\
1070\end{array}$ & 792 & 780 & & & & & & & & & $\begin{array}{l}453 \\
335\end{array}$ & $\begin{array}{l}610 \\
470\end{array}$ \\
\hline 1980 & 631 & 651 & $\begin{array}{l}322 \\
465\end{array}$ & $\begin{array}{l}300 \\
228\end{array}$ & 141 & 105 & 55 & $\begin{array}{r}120 \\
61\end{array}$ & $\begin{array}{l}150 \\
116\end{array}$ & $\begin{array}{l}267 \\
208\end{array}$ & $\begin{array}{l}355 \\
382\end{array}$ & $\begin{array}{l}470 \\
646\end{array}$ \\
\hline 1981 & 774 & 481 & 389 & & & & & & & & & \\
\hline Avg & 732 & 640 & 459 & 289 & 162 & 112 & 66 & 91 & 136 & 218 & 390 & 575 \\
\hline
\end{tabular}

$\underline{\text { PAD } ¥ \mathrm{~b}}$

\begin{tabular}{|c|c|c|c|c|c|c|c|c|c|c|c|c|}
\hline 1978 & & & & & & & & & & & 924 & 1429 \\
\hline $\begin{array}{l}1979 \\
1980\end{array}$ & 2092 & $\begin{array}{l}1898 \\
7508\end{array}$ & $\begin{array}{l}1444 \\
1179\end{array}$ & 897 & $\begin{array}{l}445 \\
466\end{array}$ & $\begin{array}{l}460 \\
276\end{array}$ & $\begin{array}{l}399 \\
231\end{array}$ & $\begin{array}{l}356 \\
275\end{array}$ & $\begin{array}{l}422 \\
309\end{array}$ & $\begin{array}{l}728 \\
632\end{array}$ & $\begin{array}{l}937 \\
845\end{array}$ & 1220 \\
\hline $\begin{array}{l}1980 \\
1981\end{array}$ & $\begin{array}{l}1556 \\
1763\end{array}$ & $\begin{array}{l}1508 \\
1320\end{array}$ & $\begin{array}{l}1179 \\
1145\end{array}$ & 751 & 466 & $2 / 6$ & 237 & 275 & 309 & 633 & & \\
\hline Avg & 1804 & 1575 & 1256 & 824 & 456 & 368 & 315 & 316 & 366 & 681 & 902 & 1328 \\
\hline
\end{tabular}

PAD 1C

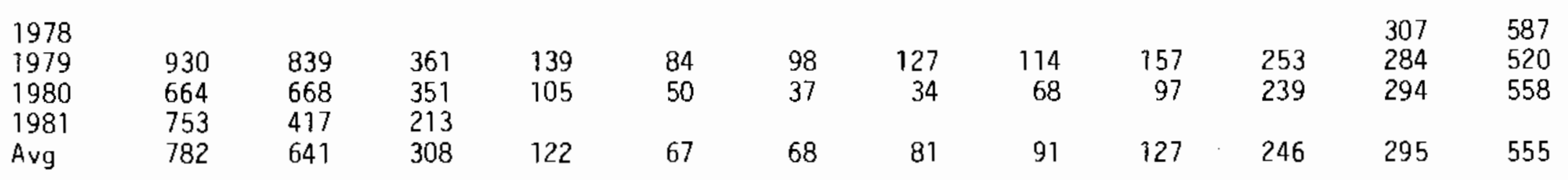

$\underline{P A D} 2$

\begin{tabular}{|c|c|c|c|c|c|c|c|c|c|c|c|c|}
\hline $\begin{array}{l}1978 \\
1979\end{array}$ & & & & & 163 & 135 & 90 & 101 & 142 & 268 & 360 & 475 \\
\hline 1980 & 561 & 518 & 372 & 198 & 103 & 85 & 54 & 70 & 129 & 244 & 281 & 442 \\
\hline 1981 & 516 & 405 & 273 & & & & & & & & & \\
\hline$A \vee g$ & 539 & 462 & 323 & 198 & 133 & 110 & 72 & 86 & 136 & 256 & 325 & 459 \\
\hline
\end{tabular}


TABLE 11.1 (contd.)

$\underline{\operatorname{Jan}} \underline{\text { Feb }}$ Mar Apr May $\underline{\text { Jun }}$ Jul] Aug. Sep Oct $\underline{P A D} 3$

1978

1979
1980

1981

- Avg

1
1
1
1

1
1
1
1

1
1
1
1

0
0
0

PAD 4

1978

1979

1980

1981

Avg

6
7
6.5

6
6
6

4
2
5
3.7

2
2
2

$\begin{array}{llll}2 & 2 & 1 & 1 \\ 1 & 1 & 2 & 2 \\ 1.5 & 1.5 & 1.5 & 1.5\end{array}$

2
2
2

$\begin{array}{ll}3 & 4 \\ 4 & 5\end{array}$

5
8

PAD 5

1978

1979

1980

1981

89
68
79

$\begin{array}{ll}69 & 51 \\ 55 & 41 \\ 62 & 46\end{array}$

$\begin{array}{ll}31 & 21 \\ 31 & 21\end{array}$

22

$\begin{array}{ll}19 & 77 \\ 18 & 21 \\ 19 & 49\end{array}$

31
27
29

37

$\begin{array}{ll}65 & 81 \\ 46 & 79\end{array}$

19

29

41

56

80 
f. The adjustment factor relating PPI and Agricultural Prices data is calculated as follows:

$$
\operatorname{KSRCAZZ}=1 / 6 \sum_{q=1}^{6}\left(\operatorname{KSAGQZZ}_{q} / \mathrm{KSNCQZZ}_{q}\right)
$$

where:

KSRCAZZ = adjustment factor comparing quarterly prices for PPI and Agricultural Prices for State $\mathrm{ZZ}$ (ratio)

$K S A G Q Z Z$ = kerosene quarterly prices for State $Z Z$ from Agricultural Prices ( $\$ /$ gal)

$q=$ index for quarters

2. The next step in the calculation of residential kerosene prices for 1983 is to calculate monthly state-level prices from POI kerosene Census Division data for 1983.

a. Monthly Census Division PPI prices are computed using the July 1975 base prices and the monthly price indexes for 1983:

$$
\operatorname{KSNCMXX}_{m}=\left(\operatorname{KSNCIXX}_{m} / 100\right) * \operatorname{KSNCJXX}
$$

where:

$$
\begin{aligned}
\text { KSNCMXX }= & \text { kerosene monthly price for Census Division } X X(\$ / g a l) \\
\text { KSNCIXX }= & \text { kerosene monthly price index for Census Division } X X \\
& \text { from } P P I \\
\text { KSNCJXX }= & \text { kerosene July } 1975 \text { base price for Census Division } X X \\
& \text { from } P Q I \text { ( } \$ / g a 1) \\
m= & \text { index for months }
\end{aligned}
$$

b. The Census Division monthly prices are assigned equally and identically to each state within the respective Census Division:

$$
\operatorname{KSNCMZZ}_{X X, m}=\operatorname{KSNCMXX}_{m}
$$

where:
KSNCMZZ = kerosene monthiy price for State $Z Z$ in Census Division XX $(\$ / \mathrm{gal})$
$\mathrm{m}=$ index for months

3. The next step is the calculation of annual physical unit state prices.

a. Annual PPI-based physical unit prices for states are computed from the monthly PQI prices (KSNCMZZ) and the monthly volume weights from Equation 11.3 (KSNCSZZ): 
$\operatorname{KSRCNZZ}=\left(\sum_{m=1}^{12}\left(\operatorname{KSNCMZZ}_{m} * \operatorname{KSNCSZZ}_{m}\right)\right) / \sum_{m=1}^{12} \operatorname{KSNCSZZ}_{m}$

where:

KSRCNZZ = kerosene annual price for State ZZ (\$/gal)

KSNCSZZ = share of average kerosene sales in state $Z Z$ from Equation 11.3 (fraction)

$m=$ index for months

b. Final STEPS physical unit residential sector kerosene prices for states are calculated using the adjustment factor (KSRCAZZ) and the annual PPI-based state prices:

$$
\text { KSRCUZZ }=\text { KSRCAZZ } * X S N C N Z Z
$$

where:

$$
\begin{aligned}
\text { KSRCUZZ }= & \text { STEPS final residential sector kerosene price for } \\
& \text { State ZZ }(\$ / \text { gal) } \\
\text { KSRCAZZ }= & \text { adjustment factor (ratio) relating PPI and Agricultural } \\
& \text { Rrices data from Equation } 11.5
\end{aligned}
$$

4. Physical unit prices for the U.S. are calculated using the final state-level physical unit state prices and residential sector kerosene consumption data from SEDS:

$$
\begin{aligned}
& \text { KSRCUUS }=\left(\sum_{Z Z=1}^{51}(K S R C U Z Z * K S R C P Z Z)\right) / \sum_{Z Z=1}^{51} K S R C P Z Z \\
& \text { where: } \\
& \text { XSRCUUS = STEPS final residential sector kerosene price for } \\
& \text { the U.S. ( } \$ / g a l) \\
& \text { XSRCPZZ = residential sector kerosene consumption for State ZZ } \\
& \text { from SEDS (1000 bbls) }
\end{aligned}
$$

5. Btu prices for states and the U.S. are calculated using the completed physical unit price series and the conversion factor:

$$
\text { XSRCDZZ }=(\text { XSRCUZZ * 42) } / 5.670
$$

where:

KSRCDZZ = STEPS final residential sector kerosene price for State ZZ or the U.S. (\$/MMBtu) 


\subsection{INDUSTRIAL SECTOR}

\subsubsection{Data Sources}

1983 Bureau of Labor Statistics, U.S. Department of Labor. Producer Prices and Price Indexes: Annual Supplement. Commodity codes 0572 and 0573 .

1983 STEPS industrial sector distillate price series.

1983 Energy Information Administration, U.S. Department of Energy. State Energy Data. System. Computer tape. Industrial sector kerosene consumption data.

\subsubsection{Conversion Factor}

1983 Energy Information Administration, U.S. Department of Energy. State Energy Data Report. Appendix C, p. 667.

\subsection{Million Btu per Barrel}

\subsubsection{Computational Procedures}

Industrial sector STEPS kerosene prices for 1983 are estimated from PPI base prices and indexes for kerosene and No. 2 distillate oil, and from the STEPS industrial sector distillate price series. It is not clear whether or not these retail prices include taxes. The ratio of PPI kerosene prices to PPI distillate prices is used as an adjustment factor with the STEPS distillate prices to estimate kerosene prices. Physical unit prices for the U.S. are computed using the physical unit state prices and consumption volumes from SEDS. Btu prices for states and the U.S. are calculated using the completed physical unit price series and the conversion factor.

1. Annual wholesale prices are calculated from PPI annual indexes for kerosene and No. 2 distillate fuel $0 i l$ and their respective July 1975 base prices for Census Divisions:

$$
\begin{aligned}
& \text { KSICNXX }=(\text { KSNCIXX } / 100) * \text { KSNCJXX } \\
& \text { DFICNXX }=(\text { DFNCIXX } / 100) * \text { DFNCJXX }
\end{aligned}
$$




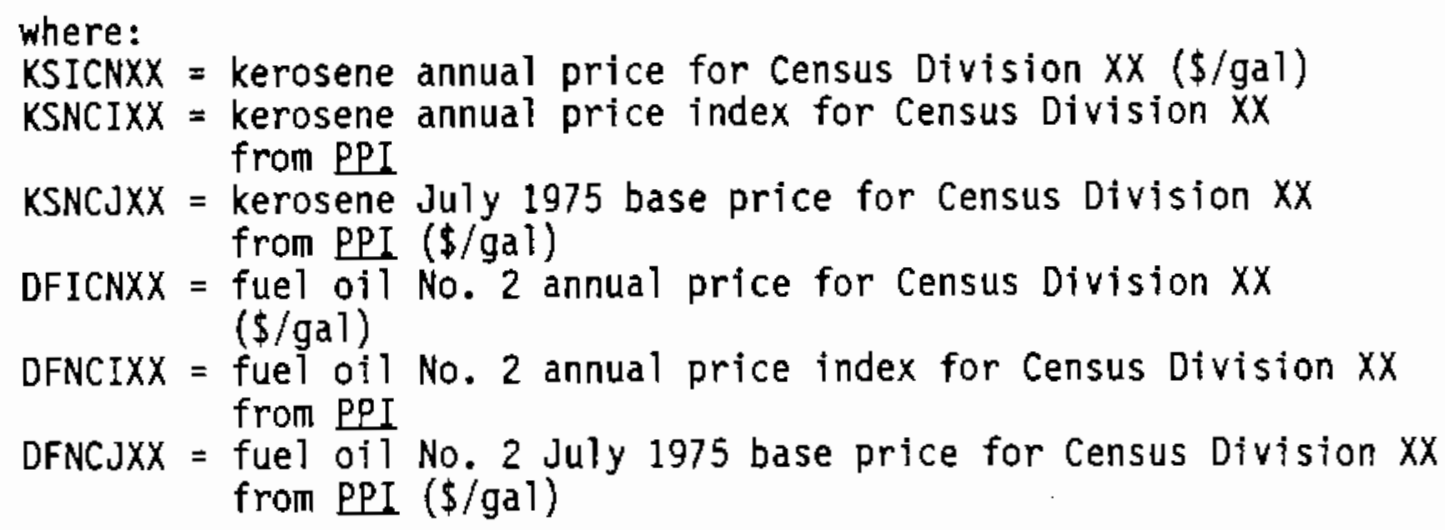

DFNCJXX = fuel oil No. 2 July 1975 base price for Census Division XX from $P P I(\$ / g a l)$

2. Census Division prices for both kerosene and fuel oil No. 2 are assigned equally and identicaliy to each state within its respective Census Division:

$$
\begin{aligned}
& \operatorname{KSICNZZ}_{X X}=\mathrm{KSICNXX} \\
& \text { DFICNZZ }_{X X}=\text { DFICNXX }
\end{aligned}
$$

where:

KSICNZZ = kerosene annual price for State $Z Z$ in Census Division $X X$ $(\$ /$ gal $)$

DFICNZZ = fuel oil No. 2 annual price for State $Z Z$ in Census Division XX (\$/gal)

3. The industrial sector physical unit STEPS kerosene prices for states are computed using the STEPS distillate industrial physical unit price series and the ratio of PPI kerosene prices to PPI fuel oil No. 2 prices:

$$
\text { KSICUZZ }=(\text { KSICNZZ / DFICNZZ }) * \text { DFICUZZ }
$$

where:
KSICUZZ = STEPS final industrial sector kerosene price for State ZZ (\$/gal)
DFICUZZ = STEPS final industrial sector distillate price for State $Z Z(\$ / g a l)$

4. Physical unit U.S. kerosene prices are calculated using the completed kerosene state physical unit prices and SEDS industriai sector kerosene consumption volumes:

$$
\text { KSICUUS }=\left(\sum_{Z \bar{Z}=1}^{51}(\mathrm{KSICUZZ} * \mathrm{KSICPZZ})\right) / \sum_{Z Z=1}^{51} \mathrm{KSICPZZ}
$$




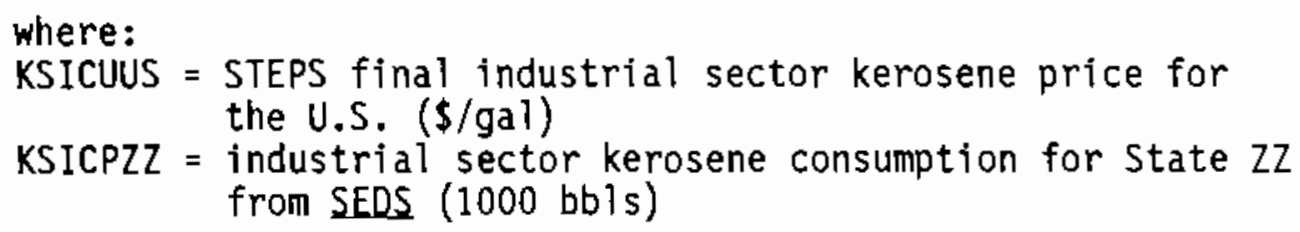

5. Btu prices for states and the U.S. are computed using the completed physical unit price series and the conversion factor:

$$
\text { XSICDZZ }=(\text { XSICUZZ *42) } / 5.670
$$

where:

KSICDZZ = STEPS final industrial sector kerosene price for State $Z Z$ or the U.S. (\$/MMBtu)

\subsection{IRANSPORTAIION SECTOR}

\subsubsection{Data Sources}

1983 Energy Information Administration, U.S. Department of Energy. Petroleum Marketing Monthly. Table 11 (January-October) and Table 14 (November-December).

1983 Energy Information Administration, U.S. Department of Energy. State Energy Data System. Computer tape. Transportation sector jet fuel consumption data.

\subsubsection{Conversion Factor}

1983 Energy Information Administration, U.S. Department of Energy. State Energy Data Beport. Appendix C, p. 667.

\subsection{Million Btu per Barrel}

\subsubsection{Computational Procedures}

The jet fuel transportation sector STEPS series contains PAD District retail prices, excluding taxes, assigned to states. The monthly state-level PAD District prices from Petroleum Marketing Monthly (PMM) are combined into annual prices, which are then assigned to states according to their PAD Districts. Physical unit U.S. prices are calculated from the assigned state prices and jet fuel consumption volumes from SEDS. Btu prices for states and the U.S. are calculated from the completed STEPS physical unit price series and the conversion factor. 
1. Monthly jet fuel prices in cents per gallon excluding taxes, are avajlable from PMM for seven (7) PAD Districts. The monthly prices for each of the PAD Districts (Ia, Ib, Ic, II, III, IV, and V) are assigned equally and identically to each state within a District. The missing January and February prices for PAD District Ia are assumed to be equal to the March price for that District.

$$
\mathrm{JFACMZZ}_{\mathrm{m}}=\mathrm{JFACMWW}_{\mathrm{m}} / 100
$$

where:

JFACMZZ = monthly transportation sector jet fuel price for State ZZ (\$/gal)

JFACMWW = monthly tranportation sector jet fuel price for PAD District WW from PMM (c/gal)

$m=$ index for months

2. Annual jet fuel physical unit prices are computed as the simple average of the state-level prices assigned in Equation 11.19:

$$
\text { JFACUZZ }=1 / 12 \sum_{m=1}^{12} J_{F A C M Z Z}
$$

where:

JFACUZZ = STEPS final transportation sector jet fuel price for State $2 Z$ ( $\$ /$ gal)

$m$ = index for months

3. Physical unit U.S. jet fuel prices are calculated using the completed state prices and jet fuel consumption volumes from SEDS:

$$
\begin{aligned}
& \text { JFACUUS }=\left(\sum_{Z Z=1}^{51}(\text { JFACUZZ } * J F A C P Z Z)\right) / \sum_{Z Z=1}^{51} J F A C P Z Z \\
& \text { where: } \\
& \text { JFACUUS = STEPS final transportation sector jet fuel price for } \\
& \text { JFACPZZ = transportation sector jet fuel consumption volume from } \\
& \text { SEDS (1000 bbls) }
\end{aligned}
$$

4. Btu prices for states and the U.S. are calculated from the completed physical unit price series and the conversion factor:

$$
\text { JFACDZZ }=(\text { JFACUZZ *42) } / 5.670
$$

where:

JFACDZZ = STEPS final transportation sector jet fuel price for State ZZ or the U.S. (\$/MMBtu) 


\subsection{RESIDUAL FUEL}

The STEPS residual fuel price series are developed for the electric ut1lity, industrial, comnercial, and transportation sectors. Physical unit prices in dollars per barrel and Btu prices in dollars per million Btu are calculated for all four sectors. Since the types of prices and computational procedures vary significantly by sector, the construction of the price series is discussed separately for each sector. AIthough STEPS covers the entire period from 1970 to 1983 , only the development of prices for 1983 is discussed below. Descriptions of data sources and computational procedures for residual fuel prices for 1970-1982 can be found in State Energy Price System (Volume I) and State Energy Price System: 1982 Update. The 1970-1982 residual fuel prices reported in Appendices $B$ and $C$ of this report have not yet been verified for reproducibility.

\subsection{ELECTRIC UTILITY}

The STEPS electric utility sector price series for residual fuel contain prices equal to the average delivered cost of receipts at electric utility plants. It is not clear whether or not these prices include any taxes. For 1983, both physical unit and Btu prices are developed directly from the data sources.

\subsubsection{Data_Source}

1983 Energy Information Administration, U.S. Department of Energy. Cost and Quality of Fuels for Electric Utility Plants. Table 51 .

\subsubsection{Conversion Factors}

1983 Since both Btu and physical unit prices are taken directly from the data source, no explicit conversion factors are used. 


\subsubsection{Computational Procedures}

Both physical unit and Btu electric utility sector residual fuel price series are taken from the data source cost and Quality of Fuels for Electric Utility Plants (C\&Q) for 1983. These prices are calculated as the average cost per unit of purchase by electric utilities; it is not clear whether or not taxes are included. The prices for No. 6 fuel oil for states and the U.S. are taken directly from cost and Ouality. while the Btu prices are converted to dollars per million Btu. No imputation is done for states not covered by cost and Quality.

1. Physical unit prices for No. 6 fuel oil are taken directly from the data source for states and the U.S.:

$$
\text { RFEUUZZ }=\text { RFSENZZ }
$$

where:

RFEUUZZ = STEPS final electric utility sector residual fuel price for State $2 Z$ or the U.S. (\$/bbl)

RESENZZ = No. 6 fuel oil price paid by stean-eiectric plants for State $Z Z$ or the U.S. from C\&Q $(\$ / b b l)$

2. Btu prices for states and the U.S. are equal to the Btu prices reported in cost and Quality, converted from cents to dollars per million Btu:

$$
\text { RFEUDZZ }=\text { RFSEFZZ } / 100
$$

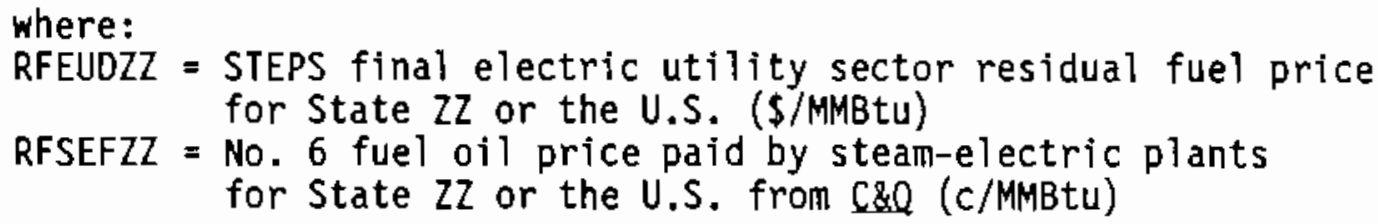

3. The following 22 states do not have physical unit and Btu prices reported by STEPS for 1983: Alaska, Alabama, District of Columbia, Iowa, Idaho, Indiana, Kentucky, Montana, North Carolina, Nebraska, Nevada, Oklahoma, Oregon, South Carolina, South Dakota, Tennessee, Utah, Vermont, Washington, Wisconsin, West Virginia, and Wyoming.

\subsection{INDUSTRIAL SECTOR}

The STEPS industrial sector residual fuel price series contain average cost of residual fuel to manufacturing firms. It is not clear whether or not any of these prices include taxes. Physical unit prices are calculated first, then Btu prices are computed using the physical unit prices and the conversion factor. The 1983 update procedures for the residual fuel industrial sector price series include two steps: 1) finalizing prices for 1982, and 2) generating prices for 1983 . 


\subsubsection{Data Sources}

1978-1980 Bureau of the Census, U.S. Department of Commerce. Annual Survey of Manufactures. Table 3.

1981 Bureau of the Census, U.S. Department of Commerce. Census of Manufactures. Table 3.

1978-1983 McGraw-Hil1, Inc. Platt's Oil Price Handbook and Oilmanac. Refinery and terminal prices for No. 6 fuel oil.

1983

Energy Information Administration, U.S. Department of Energy. State Energy Data System. Computer tape. Industrial sector residual fuel consumption volumes.

\subsubsection{Conversion Factor}

1983 Energy Information Administration, U.S. Department of Energy. State Energy Data Report. Appendix C, p. 668.

6.287 Million Btu per Barrel

\subsubsection{Computational Procedures}

Prior to 1982, the STEPS industrial sector residual fuel price series are based on cost and volume data from the Annual Survey of Manufactures (ASM) and the Census of Manufactures (CM). Since ASM/CM ceased publication of state-level residual fuel data after 1981, prices for 1982 and 1983 in the STEPS series are imputed based on the relationship between Platt's prices and industrial ASM/CM-based prices for the period 1978-1981. These prices are the average cost of residual fue 1 purchased at manufacturing establishments; it is not clear whether or not taxes are included. Physical unit prices for states are calculated, then U.S. physical unit prices are computed using SEDS industrial residual fuel consumption volumes as weights. Btu prices for both states and the U.S. are computed using the completed physical unit price series and the conversion factor.

1. The first step in the estimation of residual fuel industrial prices for 1982 and 1983 is to calculate prices for 1978-1981 from the ASM/CM cost and quantity data for residual fuel.

$$
\text { RFMFNZZ }=(\text { RFMFCZZ / RFMFVZZ) } \star 1000
$$

where:

RFMFNZZ = manufacturing sector residual fuel price for state $Z Z$ $(\$ / \mathrm{bbl})$

RFMFCZZ = cost of residual fuel to manufacturing plants for State ZZ from ASM/CM (\$million)

RFMFVZZ = quantity of residual fuel sold to manufacturing plants for State $Z Z$ from $A S M / C M(1000$ bbls) 
2. A few states are missing ASM/CM data for some of the years from 1978-1981; cost and quantity data for these states are imputed using adjacent state averages given in Table 12.1. Equation 12.4 illustrates the estimation of missing cost data; the calculation of missing quantity data is identical with the substitution of RFMFVZZ for RFMFCZZ. Note that Alaska is the oniy state for which missing data are not imputed. This is explained later. Once the cost and quantity data are estimated for missing states, Equation 12.3 is used to calculate prices.

$$
\text { RFMFNZZ }_{e}=\frac{1}{N} \sum_{a=1}^{N} \operatorname{RFMFNZZ}_{a}
$$

where:

RFMFNZZ = manufacturing sector price for State ZZ (\$/barrel)

$\mathrm{e}=$ index for missing state

$a=$ index for assigned adjacent states with ASM/CM data

$N=$ number of adjacent states assigned to a missing state

3. Residual fuel industrial prices for 1982 and 1983 are based on the average relationship between the ASM/CM-based prices generated for 1978-1981 in Equations 12.3 and 12.4, and assigned Platt's No. 6 fuel oil prices for 1978-1981 (see Table 12.2). These average ratios are calculated at the state-level for all states except Alaska.

IABLE 12.1. Assignment of Adjacent States to be Used in the Imputation of Missing Residual Fuel Industrial Sector Prices, 1978-1981

\begin{tabular}{ll}
$\begin{array}{c}\text { Missing } \\
\text { State }\end{array}$ & Missing Year(s) \\
\cline { 1 - 2 } AK & $1980-1981$ \\
DC & $1979-1981$ \\
MT & $1978-1979$ \\
ND & 1980 \\
NM & $1978-1981$ \\
NV & 1978 \\
OK & 1978,1980 \\
SD & 1981 \\
WY & $1978-1979$ \\
& $1980-1981$
\end{tabular}

Adjacent States
Used in the Imputation
No Imputation
$M D, V A$
$I D, N D, S D, W Y$
$M N, M T, S D$
$A Z, C O, T X$
$A Z, C A, I D, O R, U T$
$A R, C O, K S, M O, T X$
$I A, M N, M T, N D, N E$
$C O, I D, N E, U T$
$C O, I D, M T, N E, U T$

Source: Pacific Northwest Laboratory 
IABLE 12.2. No. 6 Fuel 011 Price Assignments from Platt's: 1978-1983

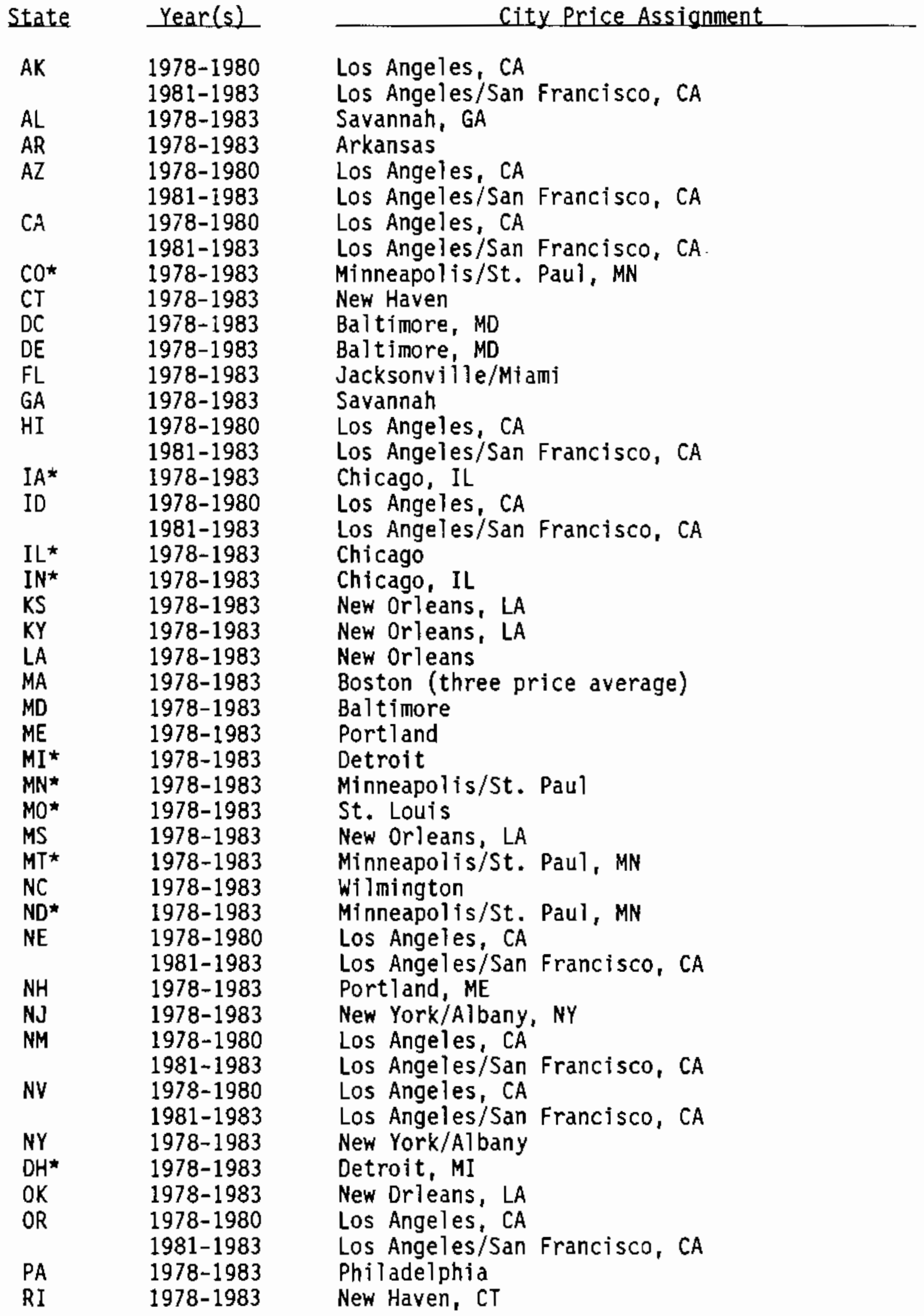


IABLE 12.2 (CONI). No. 6 Fuel 011 Price Assignments from Platt's: 1978-1983

\begin{tabular}{ccc} 
State & Year $(s)$ \\
\cline { 3 - 3 } SC & & $1978-1983$ \\
SD* & $1978-1983$ \\
TN & $1978-1983$ \\
TX & $1978-1983$ \\
UT* & $1978-1983$ \\
VA & $1978-1983$ \\
VT & $1978-1983$ \\
WA & $1978-1979$ \\
& $1980-1983$ \\
$W^{\star}$ & $1978-1983$ \\
$W^{*}$ & $1978-1983$ \\
$W^{\star}$ & $1978-1983$
\end{tabular}

City Price Assignment

Charleston
Minneapolis/st. Paul, MN
New Orleans, LA
New Orleans, LA
Minneapolis/st. Paul, MN
Norfolk
Portland, ME
Los Angeles, CA
Seattle/Tacoma
Chicago, IL
Norfolk, VA
Minneapolis/St. Paul, MN

* Raw data from Platt's must be converted from $c / g a l l o n$ to $\$ /$ barrel. Source: Pacific Northwest Laboratory

$$
\text { RFICRZZ }=\frac{1}{4} \sum_{t=78}^{81}(\text { RFMFNZZ / RFNCNZZ) }
$$

where:

RFICRZZ = average ratio of ASM/CM-based residual fuel prices to Platt's No. 6 fuel oil prices for State $Z Z$ (ratio)

RFNCNZZ $=$ No. 6 fuel oil price assigned to State $Z Z$ from Platt's $(\$ / \mathrm{bb} l)$

$t=$ index for years

4. Physical unit residual fuel industrial prices for 1982 and 1983 are calculated using the assigned Platt's prices for 1982 and 1983 (see Table 12.2) and the state-level average ratios calculated above. Since there is no reported SEDS consumption for the State of Alaska, Alaska prices are not developed for either 1982 or 1983 . All other states have prices reported STEPS prices.

$$
\text { RFICUZZ }=\text { RFICRZZ * RFNCNZZ }
$$

where:

RFICUZZ = STEPS final industrial sector residual fuel price for State $Z Z(\$ / b b l)$

RFNCNZZ = assigned residual fuel price for 1982 or 1983 for State $Z Z$ from Platt's (\$/bbl) 
5. Physical unit U.S. prices for 1982 and 1983 are calculated using the completed physical unit state prices and industrial residual fuel consumption volumes from SEDS.

$$
\begin{aligned}
& \text { RFICUUS }=\left(\sum_{Z Z=1}^{51}(\text { RFICUZZ * RFICPZZ) }) / \sum_{Z Z=1}^{51} R F I C P Z Z\right. \\
& \text { where: } \\
& \text { RFICUUS = STEPS final industrial sector residual fuel price for } \\
& \text { the U.S. }(\$ / \mathrm{bbi}) \\
& \text { RFICPZZ = industrial sector residual fuel consumption for State ZZ } \\
& \text { from SEDS (1000 bbls) }
\end{aligned}
$$

6. Btu prices for states and the U.S. for both 1982 and 1983 are computed using the completed physical unit price series and the conversion factor:

$$
\text { RFICOZZ }=\text { RFICUZZ / } 6.287
$$

where:

RFICDZZ = STEPS final industrial sector residual fuel price for State ZZ or the U.S. (\$/MM8tu)

\subsection{COMMERCIAL SECTOR}

Commerclal sector residual fuel prices for 1983 are imputed for all states from national-level residual fuel prices and the state-level electric utility sector residual fuel prices calculated for STEPS. State-level prices are calculated from U.S. prices that include taxes. Physical unit prices are calculated first, then Btu prices are computed using the physical unit prices and the conversion factor.

\subsubsection{Data Sources}

1983 STEPS 1983 electric utility residual fuel price series.

1983 Bureau of the Census, U.S. Department of Commerce. Statistical Abstract of the United States 1984. Table 472, "General sales and gross receipts (percent)."

1983 Energy Information Administration, U.S. Department of Energy. Monthly Energy Review. Table titled, "Refiner and Gas Plant Operator Sales Prices of Residual Fuel Oil." Average Sales to End Users.

1983 Energy Information Administration, U.S. Department of Energy. State Energy Data System. Computer tape. Commercial sector residual fuel consumption volume data. 


\subsubsection{Conversion Factor}

1983 Energy Information Administration, U.S. Department of Energy. State Energy Data Report. Appendix C, p. 668.

\subsection{Million Btu per Barre1}

\subsubsection{Computational Procedures}

The 1983 commercial sector residual fuel physical unit price series are estimated from the completed electric utility sector residual price series for 1983 and the tax-adjusted U.S. residual fuel price for 1983.

1. The first step in the estimation of the commercial residual fuel physical unit state prices is to convert the state-level excise tax rates reported in Statistical Abstract into a volume-weighted average U.S. sales tax rate. This calculation uses the 1983 commercial residual fuel consumption volume data from SEDS:

$$
\text { RFNCXUS }=\left(\sum_{Z Z=1}^{51}(\text { RFNCXZZ * RFCCPZZ) }) / \sum_{Z Z=1}^{51} \operatorname{RFCCPZZ~}\right.
$$

where:

RFNCXUS = estimated average tax rate on residual fuel for the U.S. (percent)

RFNCXZZ = reported excise tax rate on general sales and gross receipts for State $Z Z$ from Statistical Abstract (percent)

RFCCPZZ = commercial sector residual fuel consumption volume reported for State ZZ from SEDS (1000 bbls)

2. The tax-adjusted U.S. residual fuel oil price is computed using the average U.S. tax rate estimated in Equation 12.9 and the annual average

U.S. residual fuel price to end users from Monthly Energy Review (MER):

$$
\begin{aligned}
\text { RFCCNUS }= & (\text { RFNCNUS } / 100) *[1+(\text { RFNCXUS } / 100)] * 42 \quad(12.10) \\
\text { where: } & \text { RFCCNUS }= \\
& \text { tax-adjusted U.S. residual fue }] \text { price for the commercial } \\
\text { RFNCNUS }= & \text { refiner }(\$ / b b l) \\
& \text { to end users from } M E R(c / g a l)
\end{aligned}
$$

3. Commercial sector physical unit residual fuel prices for states are computed using the 1983 STEPS electric utility sector residual fuel price series. To do this calculation, the relationship between the state-level and U.S. prices in the commercial sector is assumed to be the same as the relationship between state and U.S. prices in the electric utility sector. Some states are missing electric utility prices for 1983; these are imputed using the adjacent state average described in Table 12.3. 
IABLE 12.3. Adjacent State Assignments for Imputing Missing Prices: Residual Fuel Electric Utility Sector, 1983

\begin{tabular}{|c|c|}
\hline Missing State & Adjacent State Assi \\
\hline $\begin{array}{l}A L \\
D C \\
\text { IA } \\
\text { ID } \\
\text { IN } \\
K Y \\
\text { MT } \\
\text { NC } \\
\text { NE } \\
\text { NV } \\
\text { OR } \\
\text { SC } \\
\text { SD } \\
\text { TN } \\
\text { UT } \\
\text { VT } \\
\text { WA } \\
\text { WI } \\
\text { WV } \\
\text { WY }\end{array}$ & $\begin{array}{l}F L, G A, M S \\
M D, V A \\
I L, M N, M O \\
C A, C O \\
I L, M I, O H \\
I L, M O, O H, V A \\
C O, N D \\
G A, V A \\
C O, K S, M O \\
A Z, C A \\
C A \\
G A \\
M N, N D \\
A R, G A, M O, M S, V A \\
A Z, C O \\
M E, N H, N Y \\
C A \\
I L, M I, M N \\
M D, O H, P A, V A \\
C O, N D\end{array}$ \\
\hline
\end{tabular}

Source: Pacific Northwest Laboratory 


$$
\text { RFCCUZZ }=\text { RFEUUZZ * (RFCCNUS } / \text { RFEUUUS })
$$

where:

$$
\begin{aligned}
\text { RFCCUZZ = } & \text { STEPS final commercial sector residual fuel price for } \\
& \text { State ZZ } \$ / \text { bbl) } \\
\text { RFEUUZZ }= & \text { STEPS final electric utility sector residual fuel price } \\
& \text { for State } Z Z \text { ( } \$ / \text { bbl) } \\
\text { RFEUUUS }= & \text { STEPS final electric utility sector residual fuel price } \\
& \text { for the U.S. } \$ / \text { bbl) }
\end{aligned}
$$

4. Physical unit U.S. residual fuel prices for the commercial sector are computed using the completed state-level physical unit prices and commercial sector consumption volume data from SEDS:

$$
\begin{aligned}
& \text { RFCCUUS }=\left(\sum_{Z Z=1}^{51}(\operatorname{RFCCUZZ~*~RFCCPZZ)~}) / \sum_{Z Z=1}^{51} \operatorname{RFCCPZZ}\right. \\
& \text { where: } \\
& \text { RFCCUUS = STEPS final cominercial sector residual fuel price for } \\
& \text { the U.S. ( } \$ / \mathrm{bbl}) \\
& \text { RFCCPZZ = commercial sector consumption volume for State } Z Z \\
& \text { from SEDS (1000 bbls) }
\end{aligned}
$$

5. Btu prices for both states and the U.S. are calculated from the completed physical unit price series and the conversion factor:

$$
\operatorname{RFCCDZZ}=\operatorname{RFCCUZZ} / 6.287
$$

where:

RFCCDZZ = STEPS final commercial sector residual fuel price for State ZZ or the U.S. (\$/MMBtu)

\subsection{IRANSPORTAIION SECTOR}

Transportation sector residual fuel prices in the STEPS data base are developed using different procedures, depending on the primary transportation end-uses for each state. Prices for all years are imputed from the residual fuel commercial sector price series developed above. Physical unit prices are calculated first, then Btu prices are computed using the physical unit prices and the conversion factor.

\subsubsection{Data Sources}

1983 Energy Information Administration, U.S. Department of Energy. Monthly Energy Review. Refiner and gas plant operator sales price of residua] fuel oil with sulfur content greater than one percent; sales to end users excluding tax, 1983 average U.S. price. 
1983 Energy Information Administration, U.S. Department of Energy. Petroleum Supply Annual. Volume I, Table 5.

1983 Energy Information Administration, U.S. Department of Energy. State Energy Data system. Computer tape; transportation sector residua? fuel consumption data.

1983 STEPS commercial sector residual price series.

\subsubsection{Conversion Factor}

1983 Energy Information Administration, U.S. Department of Energy. State Energy Data Report. Appendix C, p. 668.

\subsection{Million Btu per Barrel}

\subsubsection{Computational Procedures}

The primary uses of residual fuel in the transportation sector include vessel bunkering and railroads. Transportation sector residual fuel prices for states in the STEPS serjes are based on the proportion of these two uses of fuel for each state. Once physical unit state prices have been calculated, U.S. physical unit prices are computed using the completed state physical unit prices and transportation sector residual fuel consumption volumes from SEDS. The tax status of these prices appears to be mixed, with some states having prices that include taxes, while others have prices that exclude taxes.

1. In 1983, 26 states consumed residual fuel only for vessel bunkering (see Table 12.4). For these states, the physical STEPS prices are calculated from the U.S. residual fuel oil (sulfur content greater than one percent) price (excluding taxes) and corresponding commercial sector U.S. and state prices. The generated prices are based on the assumption that the state Bunker $C$ prices have the same ratio to the commercial sector state prices that the Bunker C U.S. price (approximated with the residual/sulfur greater than one percent price) has to the commercial sector U.S. price.

$$
\begin{aligned}
& \text { RFACUZZ }=\text { RFCCUZZ * [(RFBKNUS } / 100 * 42) / \text { RFCCUUS }] \\
& \text { where: } \\
& \text { RFACUZZ = STEPS final transportation sector residual fuel price } \\
& \text { RFBKNUS = average U.S. vessel bunkering residual fuel price from } \\
& \text { MER; equal to } 61.6 \mathrm{c} / \mathrm{gal} \text { in } 1983 \text { (c/gal) } \\
& \text { RFCCUZZ = STEPS final transportation sector residual fuel price } \\
& \text { for State } Z Z \text { (\$/bbT) } \\
& \text { RFCCUUS = STEPS final transportation sector residual fuel price } \\
& \text { for the U.S. }(\$ / \mathrm{bbl})
\end{aligned}
$$


IABLE 12.4. Transportation Sector End-Uses for Residual Fuel, by State, 1983

Vessel

Bunkering only

Al abama

California

Connecticut

Delaware

Florida

Georgia

Hawaji

Indiana

Louisiana

Massachusetts

Maryland

Maine

Missouri

North Carolina

New hampshire

New Jersey

New York

Ohio

Oregon

Pennsylvania

Rhode Island

South Carolina

Texas

Virginia

Washington
Vessel

Bunkering and

Railroad Use

Illinois

Michigan

Minnesota

Tennessee

Wisconsin
No Use

ATaska

Arkansas

Arizona

Colorado

District of Columbia

Iowa

Idaho

Kansas

Kentucky

Montana

North Dakota

Nebraska

New Mexico

Nevada

Oklahoma

South Dakota

Utah

Vermont

West Virginia

Wyoming

Source: Petroleum Supply Annual, 1983. 
2. In years prior to 1983, states with residual fuel consumption only in railroads are assigned their respective commercial sector prices. No states have use limited to rajlroads in 1983.

3. Five states in 1983 have roughly equal amounts of vessel bunkering and railroad residual fuel use. Prices for these states are calculated as the weighted average vessel bunkering prices (from Equation 12.14) and railroad prices (assigned commercial sector prices). The weights used for this calculation are taken from Petroleum Supply Annual.

a. First, the vessel bunkering price for each of the five states (IL, MI, MN, TN, and WI) is calculated similarly to Equation 12.14:

RFBKNZZ $=$ RFCCUZZ * [(RFBKNUS $/ 100 * 42) /$ RFCCUUS $]$

where:

RFBKNZZ = vessel bunkering residual fuel price for State $Z Z$ $(\$ /$ bbl $)$

b. Next, the rallroad price for each of the five states is calculated by simply assigning the corresponding commercial sector price:

$$
\text { RFRRNZZ }=\text { RFCCUZZ }
$$

where:

RFRRNZZ = railroad residual fuel price for State $Z Z(\$ / b b i)$

c. The STEPS physical unit state prices are calculated as the weighted average of the vessel bunkering and railroad prices calculated above and the vessel bunkering and rallroad consumption reported in Petroleum Supply Annual:

RFACUZZ $=[($ RFRRNZZ * RFRRVZZ $)+($ RFBKNZZ * RFBKVZZ $)]$

$$
/(\text { RFRRVZZ + RFBKVZZ) }
$$

where:

$$
\begin{aligned}
\text { RFACUZZ = } & \text { STEPS final transportation sector residual fuel price } \\
& \text { for State } 2 Z \text { ( } \$ / \mathrm{bb}]) \\
\text { RFRRVZZ }= & \text { raflroad consumption of residual fuel from for State } Z Z \\
& \text { from Petroleum Supply Annual ( } 1000 \text { bbls) } \\
\text { RFBKVZZ }= & \text { vessel bunkering consumption of residual fuel from } \\
& \text { for State } 2 Z \text { from Petroleum Supply Annual (1000 bbls) }
\end{aligned}
$$

4. No prices for 1983 are developed for the 20 states with no vessel bunkering or railroad use reported in Petroleum Supply Annual (see Table 12.3). 
5. The 1983 physical unit U.S. residual fuel price for the transportation sector is calculated from the completed state physical unit price series and transportation sector residual fuel consumption volumes from SEDS:

$$
\begin{aligned}
\text { RFACUUS }= & \left(\sum_{Z Z=1}^{51}(\text { RFACUZZ * RFACPZZ) }) / \sum_{Z Z=1}^{51}\right. \text { RFACPZZ } \\
\text { where: } & \text { RFACUUS = } \\
\text { STEPS final transportation sector residual fuel price } & \text { for the } U . S \text {. ( } \$ / \text { bb }) \\
\text { RFACPZZ }= & \text { transportation sector residual fuel consumption volume } \\
& \text { for State ZZ from SEDS }(1000 \text { bbls })
\end{aligned}
$$

6. Btu prices for both states and the U.S. are computed from the completed physical unit price series and the conversion factor:

$$
\text { RFACOZZ }=\text { RFACUZZ / } 6.287
$$

where:

RFACDZZ = STEPS final transportation sector residual fuel price for State $Z$ Z or the U.S. (\$/MMBtu) 


\subsection{LIOUEFIED PETROLEUM GAS}

Liquefied petroleum gas (LPG) STEPS price series are developed for the residential and the industrial sectors, with prices in dollars per gallon and in dollars per million Btu. The development of the STEPS liquefied petroleum gas price series is described below only for the year 1983; this is the only year for which data sources and calculations have been verified for reproducibility. Information about the construction of the LPG price series for 1970-1982, can be found in State Energy Price System (Volume I) and state Energy Price System: 1982 Update. Since the data sources and computational procedures are different for the residential and industrial sectors, they are described separately below.

\subsection{RESIDENTIAL SECTOR}

\subsubsection{Data Sources}

1983 American Gas Association. 1984. Gas Househeating Survey: 1983. Appendix 2, "Competitive Fuel Prices."

1983 Energy Information Administration, U.S. Department of Energy. State Energy Data System. Computer tape. Residential sector LPG consumption.

\subsubsection{Conversion Factor}

1983 Energy Information Administration, U.S. Department of Energy. Monthly Energy Review. Table titled, "Approximate Heat Content of Fuels, 1979-1985."

\subsection{Million Btu per Barre]}

\subsubsection{Computational Procedures}

Residential sector LPG Btu prices for STEPS are based on the city-level LPG prices reported in Gas Househeating Survey (GHS). Btu prices for Alaska and Hawa $i$ are imputed and U. S. prices are calculated using the completed state Btu prices and residential sector consumption volumes from SEDS. Physical unit LPG prices are calculated using the completed Btu price series and the conversion factor. These prices are the average delivered prices for propane purchased by residential consumers; it is not clear whether or not taxes are included. 
1. City-level prices from GHS are assigned to their respective states. The STEPS price for a state is equal to the simple average of the city price observations for that state. This equation is executed with hand calculations.

$$
\operatorname{LGRCDZZ}=1 / N \sum_{i=1}^{N} \operatorname{LGRCFZZ}_{i}
$$

where:

LGRCDZZ = STEPS final residential sector $L P G$ price for State ZZ (\$/MMBtu)

LGRCFZZ = residential sector propane price for State $Z Z$ from GHS (\$/MMBtu)

$i=$ index for city observations

$\mathrm{N}=$ number of city observations for State $\mathrm{ZZ}$

2. Alaska and Hawaii are the only states that do not have prices reported in GHS. Missing prices for these two states are imputed by computing the average ratio of state to U.S. prices for years when Alaska or Hawaij data are available, and applying the average ratio to the 1983 U.S. prices to estimate the 1983 prices.

a. To calculate the average ratios (one for Alaska and one for Hawaii), state prices are compared to U.S. prices for the following years: 1972 and 1980 (Alaska); and 1971, 1977, 1978, and 1979 (Hawaii). The U.S. price for this calculation is a simple average of avallable state prices for each year (including states with prices imputed from adfacent state averages).

$$
\text { LGRCRZZ }=1 / N \sum_{t=1}^{N}\left(\text { LGRCFZZ }_{t} / \text { LGRCFUS }_{t}\right)
$$

where:

$$
\begin{aligned}
& \text { LGRCRZZ = average ratio of Alaska (Hawaii) GHS residential sector } \\
& \text { LPG prices to U.S. prices (ratio) } \\
& \text { LGRCFZZ = residential sector LPG price for Alaska (Hawaji) } \\
& \text { from GHS (\$/MMBtu) } \\
& \text { LGRCFUS = residential sector LPG price for the U.S., equal to } \\
& \text { the simple average of state prices other than Alaska and } \\
& \text { Hawai i from GHS ( } \$ / M M B t u) \\
& t=\text { index for years where Alaska (Hawaii) data are available } \\
& N=\text { number of years for which Alaska (Hawaii) data are }
\end{aligned}
$$


b. The average ratio for each state is used with the simple average U. S. price for 1983 to impute the 1983 Alaska and Hawaii prices. Equation 13.3 shows the calculation for Alaska while Equation 13.4 shows the calculation for Hawaii.

$$
\begin{aligned}
& \text { LGRCDAK }=\text { LGRCRAK * LGRCFUS } \\
& \text { LGRCDHI }=\text { LGRCRHI * LGRCFUS }
\end{aligned}
$$

where:

LGRCDAK = STEPS final residential sector LPG price for Alaska (\$/MMBtu)

LGRCFUS = simple average of available GHS state prices for 1983 (\$/MMBtu)

LGRCDHI = STEPS final residential sector LPG price for Hawai $i$ (\$/MMBtu)

3. Final STEPS Btu prices for the U.S. are calculated using the completed Btu state prices and residential sector LPG consumption volumes from SEDS to calculated a weighted average national price:

LGRCDUS $=\left(\sum_{Z Z=1}^{51}(\right.$ LGRCDZZ * LGRCPZZ) $) / \sum_{Z Z=1}^{51}$ LGRCPZZ

where:

LGRCDUS = STEPS final residential sector $L P G$ price for the U.S. (\$/MMBtu)

LGRCPZZ = residential sector $L P G$ consumption volume for State $Z Z$ from SEDS (1000 bbls)

4. Physical unit LPG prices for states and the U.S. are calculated using the completed Btu price series and the conversion factor:

$$
\text { LGRCUZZ }=(\text { LGRCDZZ } \star 3.614) / 42
$$

where:

LGRCUZZ = STEPS final residential sector $L P G$ price for State ZZ or the U.S. (\$/gal) 


\subsection{INDUSTRIAL SECTOR}

\subsubsection{Data Sources}

1978-1981, Crop Reporting Board, U.S. Department of Agriculture. 1983 Agricultural Prices. Table titled, "Household Supplies: Average Price Paid by Farmers" (1978-1979); "L.P. Gas: Average Price Paid by States" (1980); and "L.P. Gas: Average Price Paid by Months by States" (1981, 1983).

1978-1980 Bureau of the Census, U.S. Department of Commerce. Annual Survey of Manufactures. Table 3, state-level quantity and cost of liquefied petroleum gases.

1981

Bureau of the Census, U.S. Department of Commerce. Census of Manufactures. Table 3, state-level quantity and cost of liquefied petroleum gases.

1983

Energy Information Administration, U.S. Department of Energy. State Energy Data System. Industrial sector LPG consumption volumes.

\subsubsection{Conversion Factor}

1983

Energy Information Administration, U.S. Department of Energy. Monthly Energy Review. Table titled, "Approximate Heat content of Fueis, 1979-1985."

\subsection{Million Btu per Barrel}

\subsubsection{Computational Procedures}

The STEPS industrial sector 1983 physical unit price series for LPG is based on 1983 state-level LPG prices from Agricultural Prices and the average ratio of prices from Annual Survey of Manufactures (ASM) or Census of Manufactures (CM) and Agricultural Prices for 1978-1981. Physical unit prices for the U.S. are computed using the state-level prices and industrial sector LPG consumption volumes from SEDS. Btu prices for states and the U.S. are calculated from the completed physical unit price series and the conversion factor. It is not clear whether or not these retail prices include any taxes.

1. Monthly LPG prices for states and the U.S. from Agricultural Prices are first converted into annual state-level prices for the years 1978-1981 and 1983. For all five years, Alaska, the District of Columbia, Hawaii and West Virginia are the only missing states. No prices are imputed for the District of Columbia, Alaska and Hawaij prices are imputed as described later, and West Virginia is assigned the Tennessee prices for 1978-1981. This calculation is done using simple averaging: 
IABLE 13.1. Price Assignments for States Missing ASM/CM Prices, 1978-1981

Missing State

AK

AR

LA

$\mathrm{NM}$

WY
Year(s)

1978

1978

1980

1979-1981

$1978-1981$
Assigned State

LA

AR

$A Z$

CO

Source: Pacific Northwest Laboratory

$$
\text { LGAGNZZ }=1 / 12 \sum_{m=1}^{12} \text { LGAGMZZ }_{m}
$$

where:

LGAGNZZ = annual LPG price based on Agricultural Prices for State ZZ (\$/gal)

LGAGMZZ = monthly LPG price for State ZZ from Agricultural Prices $(\$ /$ gal $)$

$\mathrm{m}=$ index for months

2. The cost and quantity of LPG data from ASM/CM for 1978-1981 are used to calculate state-level industrial sector LPG prices for use in the average ratio calculation (Equation 13.9). Since the quantity data are expressed in pounds rather than gallons, the price per pound must be adjusted to price per gallon with the conversion factor of 4.5 pounds per gallon. This calculation is done for all states (including Alaska and Hawaii), with imputations for missing years as shown in Table 13.1. No prices are imputed for the District of Columbia throughout the period.

$$
\text { LGMFNZZ }=(\text { LGMFCZZ / LGMFVZZ }) * 4.5
$$

where:

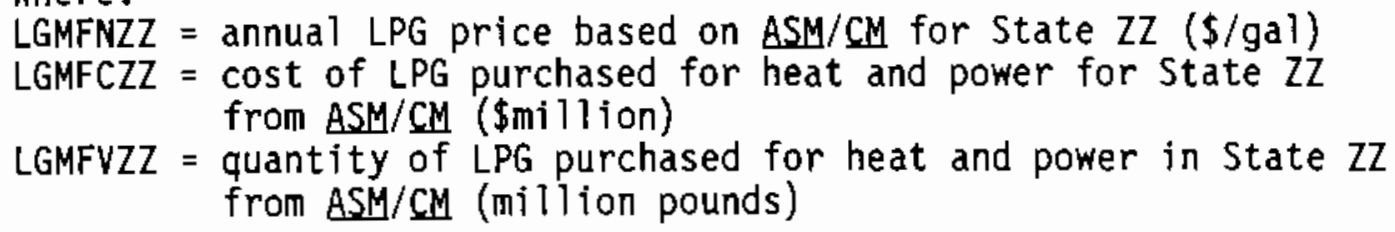


3. The average ratio of ASM/CM prices to Agricultural Prices LPG prices for 1978-1981 is calculated for all states except Alaska and Hawaji as follows:

$$
\text { LGICRZZ }=1 / 4 \sum_{\mathrm{t}=78}^{81} \text { (LGMFNZZ / LGAGNZZ) }
$$

where:

$$
\begin{aligned}
\text { LGICRZZ } & =\begin{array}{l}
\text { average ratio of } \\
\text { prices for } \text { State } Z \text { CM }(\text { ratio) }
\end{array} \\
t & =\text { index for years }
\end{aligned}
$$

4. Industrial sector LPG physical unit prices for 1983, for all states except Alaska and Hawaij, are calculated using the estimated annual Agricultural Prices data for 1983 and the state-level average ratios:

$$
\text { LGICUZZ = LGAGNZZ * LGICRZZ }
$$

where:

LGICUZZ = STEPS final industrial sector LPG price for State ZZ $(\$ /$ gal)

LGAGNZZ = estimated annual LPG price for 1983 for State ZZ from Agricultural Prices ( $\$ / g a l)$

5. Alaska and Hawai i prices are imputed by estimating the relationship between ASM/CM prices for these states (1979-1981 for Alaska and 1978-1981 for Hawai $i$ ) and the U.S. price reported by Agricultural Prices. The average ratio for the available years for each of these two states is calculated and used with the Agricultural Prices U.S. price for 1983 to impute 1983 prices:

Alaska

$$
\begin{aligned}
& \text { LGICRAK }^{=1 / 3} \sum_{t=79}^{81}\left(\text { LGMFNAK }_{t} / \text { LGAGNUS }_{t}\right) \\
& \text { LGICUAK }=\text { LGAGNUS }_{83} \text { * LGICRAK }
\end{aligned}
$$

where:

LGICRAK = average ratio of the ASM/CM LPG price for Alaska to the reported price for the U.S. from Agricultural Prices (ratio)

LGMFNAK = LPG annual price for Alaska from ASM/CM $(\$ / \mathrm{gal})$

LGAGNUS $=L P G$ price for the U.S. from Agricultural Prices $(\$ / g a l)$

LGICUAK = STEPS final industrial sector LPG price for Alaska $(\$ / \mathrm{ga} 1)$ 
Hawaii

$$
\begin{aligned}
& \text { LGICRHI }=1 / 4 \sum_{t=78}^{81}\left(\text { LGMFNHI }_{t} / \text { LGAGNUS }_{t}\right) \\
& \text { LGICUHI }=\text { LGAGNUS }_{83} \text { * LGICRHI }
\end{aligned}
$$

where:

$$
\begin{aligned}
\text { LGICRHI }= & \text { average ratio of the ASM/CM LPG price for Hawaij to the } \\
& \text { reported price for the U.S. from Agricultural Prices (ratio) } \\
\text { LGMFNHI = } & \text { LPG annual price for Hawai from ASM/CM ( } \$ / \text { gal) } \\
\text { LGAGNUS }= & \text { LPG price for the U.S. from Agricultural Prices }(\$ / g a l) \\
\text { LGICUHI }= & \text { STEPS final industrial sector LPG price for Hawait } \\
& (\$ / g a 1)
\end{aligned}
$$

6. The physical unit U.S. price for STEPS is calculated using the completed physical unit state prices and industrial LPG consumption volumes from SEDS:

$$
\begin{aligned}
\text { LGICUUS }=\left(\sum_{Z Z=1}^{51}(\text { LGICUZZ * LGICPZZ) }) / \sum_{Z Z=1}^{51}\right. \text { LGICPZZ } \\
\text { where: } \\
\text { LGICUUS = } \\
\text { STEPS final industrial sector LPG price for the U.S. } \\
\text { LGICPZZ }=\begin{array}{l}
\text { industrial sector } L P G \text { consumption volume for State } Z Z \\
\text { from SEDS }(1000 \text { bb } 1 \mathrm{~s})
\end{array}
\end{aligned}
$$

7. Btu prices for states and the U.S. are calculated using the completed physical unit price series and the conversion factor:

$$
\text { LGICDZZ }=(\text { LGICUZZ *42) } / 3.614
$$

where:

LGICDZZ = STEPS final industrial sector LPG price for state $Z Z$ or the U.S. (\$/MMBtu) 


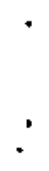

- 


\section{BEFERENCES}

The American Gas Association. 1980. Gas Facts. (1979 data), Arlington, Virginia.

The American Gas Association. 1979. Gas Facts. (1978 data), Arlington, Virginia.

The American Gas Association. 1978. Gas Facts. (1977 data), Arlington, Virginia.

The American Gas Association. 1977. Gas Facts. (1976 data), Arlington, Virginia.

The American Gas Association. 1976. Gas Facts. (1975 data), Arlington, Virginia.

The American Gas Association. 1975. Gas_Facts. (1974 data), Arlington, Virginia.

The American Gas Association. 1974. Gas Facts. (1973 data), Arlington, Virginia.

The American Gas Association. 1973. Gas Facts. (1972 data), Arlington, Virginia.

The American Gas Association. 1970. Gas Facts. (1969 data), Arlington, virginia.

The American Gas Association. 1984, Gas Househeating Survey: 1983. Catalog No. F00084, 36th Annual Survey. Arlington, Virginia.

The American Gas Association. 1979. Gas Househeating Survey: 1978. Catalog No. F00079, 31st Annual Survey. Arlington, Virginia.

The American Gas Association. 1978. Gas Househeating Survey: 1977. Catalog No. F00078, 30th Annual Survey. Arlington, Virginia.

The American Gas Association. 1977. Gas Househeating Survey: 1976. Catalog No. F00077, 29th Annual Survey. Arlington, Virginia.

The American Gas Association. 1976. Gas Househeating Survey: 1975-1978. 28th Annual Survey. Arlington, Virginia.

The American Gas Association. 1975. Gas Househeating Survey: 1974-1977. 27 th Annual Survey. Arlington, Virginia.

The American Gas Association. 1974. Gas Househeating Survey: 1973-1976. 26th Annual Survey. Arlington, Virginia. 
The American Gas Association. 1973. Gas Househeating Survey: 1972-1975. 25th Annual Survey. Arlington, Virginia.

The American Gas Association. 1972. Gas Househeating Survey: 1971-1974. 24th Annual Survey. Arlington, Virginia.

Bureau of the Census, U.S. Department of Commerce. 1982. Annual Survey of Manufactures 1980. M80(AS) -4.2, Fuels and Electric Energy Consumed. Washington, D. C.

Bureau of the Census, U.S. Department of Commerce. 1982. Annual Survey of Manufactures 1979. M79(AS) -4.2, Fuels and Electric Energy Consumed. Washington, D. C.

Bureau of the Census, U.S. Department of Commerce. 1981. Annual Survey of Manufactures 1978. M78(AS)-4.2, Fuels and Electric Energy Consumed. Washington, D. C.

Bureau of the Census, U.S. Department of Commerce. 1978. Annual Survey of Manufactures 1976. M76(AS)-4.2, Fuels and Electric Energy Consumed. Washington, D. C.

Bureau of the Census, U.S. Department of Commerce. Annual Survey of Manufactures 1975. M75(AS) -4.2, Fuels and Electric Energy Consumed. Washington, D. C.

Bureau of the Census, U.S. Department of Commerce. 1976. Annual Survey of Manufactures 1974. M74(AS)-4.2, Fuels and Electric Energy Consumed. Washington, D. C.

Bureau of the Census, U.S. Department of Commerce. 1983. 1982 Census of Manufactures. MC82-S-4, Fuels and Electric Energy Consumed. Washington, D. C.

Bureau of the Census, U.S. Department of Commerce. 1980. 1977 Census of Manufactures. MC77-SR-4(Part 2), Fuels and Electric Energy Consumed. Washington, D. C.

Bureau of the Census, U.S. Department of Commerce. 1976. 1972 Census of Manufactures. Volume I: Subject and Special Statistics, Washington, D. C.

Bureau of the Census, U.S. Department of Commerce. 1984. Statistical Abstract of the United States 1984. 104th edition, Washington, D. C.

Bureau of Labor Statistics, U.S. Department of Labor. 1984. Consumer Prices: Energy. Computer printout, Washington, D. C.

Bureau of Labor Statistics, U.S. Department of Labor. 1984. Supplement to Producer Prices and Price Indexes Data for_1983. Washington, D. C.

Bureau of Labor Statistics, U.S. Department of Labor. 1976. Wholesale Prices and Price Indexes. Data for March 1976, Washington, D. C. 
Bureau of Labor Statistics, U.S. Department of Labor. 1976. Wholesale Prices and Price Indexes. Data for June 1976, Washington, D. C.

Bureau of Labor Statistics, U.S. Department of Labor, 1976. Wholesale Prices and Price_Indexes. Data for September 1976, Washington, D. C.

Bureau of Labor Statistics, U.S. Department of Labor. 1977. Wholesale Prices and Price Indexes. Data for December 1976, Washington, D. C.

Bureau of Mines, U.S. Department of the Interior. 1976. Natural Gas Production and Consumption: 1975. Natural Gas Annual, Mineral Industry Surveys, Washington, D. C.

Bureau of Mines, U.S. Department of the Interior. 1975. Natural Gas Production and Consumption: 1974. Natural Gas Annual, Mineral Industry Surveys, Washington, D. C.

Bureau of Mines, U.S. Department of the Interior. 1974. Natural Gas Production and Consumption: 1973. Natural Gas Annual, Mineral Industry Surveys, Washington, D. C.

Bureau of Mines, U.S. Department of the Interior. 1973. Natural Gas Production and Consumption: 1972. Natural Gas Annual, Hineral Industry Surveys, Washington, D. C.

Bureau of Mines, U.S. Department of the Interior. 1972. Natural Gas Production and Consumption: 1971. Natural Gas Annual, Mineral Industry Surveys, Washington, D. C.

Bureau of Mines, U.S. Department of the Interior. 1971. Natural Gas Production and Consumption: 1970. Natural Gas Annual, Mineral Industry Surveys, Washington, D. C.

Bureau of Power, Federal Power Commission. 1977. Annual Summary of Cost and Quality of Electric Utility Plant Fuels, 1976. Washington, D. C.

Bureau of Power, Federal Power Commission. 1976. Annual Summary of Cost and Quality of Steam-Electric Plant Fuels, 1975. Washington, D. C.

Bureau of Power, Federal Power Commission. 1975. Annual Summary of Cost and Quality of Steam-Electric Plant Fuels, 1973 and 1974. Washington, D. C.

Cantor, Stanley. 1984. Investigate Linking EIA-782 Data to the State Energy Price System (SIEPS). Project briefing presented by Oak Ridge National Laboratory to the Energy Information Administration, U.S. Department of Energy, Washington, D. C.

Crop Reporting Board, U.S. Department of Agriculture. 1984. Agricultural Prices: 1983 Annual Price Summary. Pr 1-3(84), Washington, D. C.

Crop Reporting Board, U.S. Department of Agriculture. 1983. Agricultural Prices: 1982 Annual Price Summary. Pr 1-3(83), Washington, D. C. 
Crop Reporting Board, U.S. Department of Agriculture. 1982. Agricultural Prices: Annual_Summary 1981. Pr 1-3(82), Washington, D. C.

Crop Reporting Board, U.S. Department of Agriculture. 1981. Agricultural Prices: Annual Summary 1980. $\operatorname{Pr} 1-3(81)$, Washington, D. C.

Crop Reporting Board, U.S. Department of Agriculture. 1980. Agricultural Prices: Annual Summary 1979. $\operatorname{Pr}$ 1-3(80), Washington, D. C.

Crop Reporting Board, U.S. Department of Agriculture. 1979. Agricultural Prices: Annual Summary 1978. $\operatorname{Pr} 1-3(79)$, Washington, D. C.

Crop Reporting Board, U.S. Department of Agriculture. 1978. Agricultural Prices: Annual Summary 1977. Pr 1-3(78), Washington, D. C.

Crop Reporting Board, U.S. Department of Agriculture. 1977. Agricultural Prices: Annual Summary 1976. $\operatorname{Pr} 1-3(77)$, Washington, D. C.

Crop Reporting Board, U.S. Department of Agriculture. 1976. Agricultural Prices: Annual Summary 1975. $\operatorname{Pr} 1-3(76)$, washington, D. C.

Crop Reporting Board, U.S. Department of Agriculture. 1975. Agricultural Prices:_Annual Summary 1974. $\operatorname{Pr}$ 1-3(75), washington, D. C.

Crop Reporting Board, U.S. Department of Agriculture. 1974. Agricultural Prices: Annual Summary 1973. Washington, D. C.

Crop Reporting Board, U.S. Department of Agriculture. 1973. Agricultural Prices: Annual Summary 1972. Washington, D. C.

Crop Reporting Board, U.S. Department of Agriculture. 1972. Agricultural Prices: Annual Summary 1971. Washington, D. C.

Crop Reporting Board, U.S. Department of Agriculture. 1971. Agricultural Prices: Annual Summary 1970. Washington, D. C.

Edison Electric Institute. 1984. Statistical Year Book of the Electric Utility Industry 1983. Number 51, Washington, D. C.

Edison Electric Institute. 1983. Statistical Year Book of the Electric Utility Industry 1982. Number 50, Washington, D. C.

Edison Electric Institute. 1982. Statistical Year Book of the Electric Utility Industry 1981. Number 49, Washington, D. C.

Edison Electric Institute. 1981. Statistical Year Book of the Electric Utility Industry 1980. Number 48, Washington, D. C.

Edison Electric Institute. 1980. Statistical Year Book of the Electric Utility Industry 1979. Number 47, Washington, D. C.

Edison Electric Institute. 1979. Statistical Year Book of the Electric utility Industry 1978. Number 46, Washington, D. C. 
Edison Electric Institute. 1978. Statistical Year Book of the Electric Utility Industry 1977. Number 45, Washington, D. C.

Edison Electric Institute. 1977. Statistical Year Book of the Electric Utility Industry 1976. Number 44, New York, New York.

Edison Electric Institute. 1976. Statistical Year Book of the Electric Utility Industry 1975. Number 43, New York, New York.

Edison Electric Institute. 1975. Statistical Year Book of the Electric Utility Industry 1974. Number 42, New York, New York.

Edison Electric Institute. Industry 1973 .

Statistical Year Book of the Electric Utility

Edison Electric Institute. Industry 1972.

Statistical Year Book of the Electric Utility

Edison Electric Institute. Industry 1971.

Statistical Year Book of the Electric Utility

Edison Electric Institute. Industry 1970.

Statistical Year Book of the Electric Utility

Energy Information Administration, U.S. Department of Energy. 1985. Annual Energy Review 1984. DOE/EIA-0384 (84), washington, D. C.

Energy Information Administration, U.S. Department of Energy. 1981. Coke and Coal Chemicals in 1980. DOE/EIA-0120(80), Washington, D.C.

Energy Information Administration, U.S. Department of Energy. 1980. Coke and Coal Chemicals in 1979. DOE/EIA-0120(79), Washington, D. C.

Energy Information Administration, U.S. Department of Energy. 1979. Coke and Coal Chemicals in 1978. DOE/EIA-0120(78), Washington, D. C.

Energy Information Administration, U.S. Department of Energy. 1979. Coke and Coal Chemicals in 1977. DOE/EIA-0120(77), Washington, D. C.

Energy Information Administration, U.S. Department of Energy. 1978. Coke and Coal Chemicals in 1976. DOE/EIA-0120(76), Washington, D. C.

Energy Information Administration, U.S. Department of Energy. coke and Coal Chemicals in 1975. Washington, D. C.

Energy Information Administration, U.S. Department of Energy. Coke and Ceal Chemicals in 1974. Washington, D. C.

Energy Information Administration, U.S. Department of Energy. Coke and Coal Chemicals in 1973. Washington, D. C.

Energy Information Administration, U.S. Department of Energy. Coke and Coal Chemicals in 1972. Washington, D. C. 
Energy Information Administration, U.S. Department of Energy. and coal Chemicals in 1971 . Washington, D. C.

Coke

Energy Information Administration, U.S. Department of Energy. and Coal Chemicals in 1970. Washington, D. C.

coke

Energy Information Administration, U.S. Department of Energy. 1984. Cost and Quality of Fuels for Electric Utility Plants, 1983. DOE/EIA-0191(83), Washington, D. C.

Energy Information Administration, U.S. Department of Energy. 1983. Cost and Quality of Fuels for Electric Utility Plants, 1982 Annual. DOE/EIA-0191(82), Washington, D. C.

Energy Information Administration, U.S. Department of Energy. 1982. Cost and Quality of Fuels for Electric Utility Plants, 1981 Annual. DOE/EIA-0191(81), Washington, D. C.

Energy Information Administration, U.S. Department of Energy. 1981. Cost and Quality of Fuels for Electric Utility Plants, 1980 Annual. DOE/EIA-0191(80), Washington, D. C.

Energy Information Administration, U.S. Department of Energy. 1980. Cost and Quality of Fuels for Electric Utility Plants, 1979. DOE/EIA-0191(79), Washington, D. C.

Energy Information Administration, U.S. Department of Energy, 1979. Cost and Quality of Fuels for Electric Utility Plants, 1978. DOE/EIA-0191(78), Washington, D. C.

Energy Information Administration, U.S. Department of Energy. 1985. Monthly Energy Review. DOE/EIA-0035(85/01), Washington, D. C.

Energy Information Administration, U.S. Department of Energy. 1985. Monthly Energy Review. DOE/EIA-0035(84/12), Washington, D. C.

Energy Information Administration, U.S. Department of Energy. 1983. Monthly Energy Review. DOE/EIA-0035(83/06), Washington, D. C.

Energy Information Administration, U.S. Department of Energy. 1982. Monthly Energy Review. DOE/EIA-0035(82/07), Washington, D. C.

Energy Information Administration, U.S. Department of Energy. 1980. Monthly Energy Review. DOE/EIA-0035/04(80), Washington, D. C.

Energy Information Administration, U.S. Department of Energy. 1978. Monthly Energy Review. DOE/EIA-0035/2, Washington, D. C.

Energy Information Administration, U.S. Department of Energy. 1985. Natural Gas Annua], 1983. D0E/EIA-0131(83)/1, Washington, D. C.

Energy Information Administration, U.S. Department of Energy. 1983. Natural Gas Annual, 1982. DOE/EIA-0131 (82), Washington, D. C. 
Energy Information Administration, U.S. Department of Energy, 1982. Natural Gas Annual, 1981. DOE/EIA-0131(81), Washington, D. C.

Energy Information Administration, U.S. Department of Energy. 1982. Natural Gas Annual, 1980. DOE/EIA-0131(80), Washington, D. C.

Energy Information Administration, U.S. Department of Energy. 1981. Natural Gas Production and Consumption 1979. DOE/EIA-0131(79), Washington, D. C.

Energy Information Administration, U.S. Department of Energy. 1979. Natural Gas Production and Consumption 1978. D0E/EIA-0131(78), Washington, D. C.

Energy Information Administration, U.S. Department of Energy. 1978. Natural Gas Production and Consumption 1977. DOE/EIA-0131/77, washington, D. C.

Energy Information Administration, U.S. Department of Energy. 1978. Natural Gas Production and Consumption 1976. Energy Data Reports, Washington, D. C.

Energy Information Administration, U.S. Department of Energy. 1984. Petroleum Marketing Monthly. DOE/EIA-0380(83/12[3]), Washington, D. C.

Energy Information Administration, U.S. Department of Energy. 1984. Petroleum Marketing Month]y. DOE/EIA-0380(83/12[1]), Washington, D. C.

Energy Information Administration, U.S. Department of Energy. 1983. Petroleum Marketing Monthly. DOE/EIA-0380(83/11), Washington, D. C.

Energy Information Administration, U.S. Department of Energy. 1983. Petroleum Marketing Monthly. DOE/EIA-0380(83/09), Washington, D. C.

Energy Information Administration, U.S. Department of Energy. 1983. Petroleum Marketing Monthly. DOE/EIA-0380(83/08), Washington, D. C.

Energy Information Administration, U.S. Department of Energy. 1983. Petroleum Marketing Monthly. DOE/EIA-0380(83/07), Washington, D. C.

Energy Information Administration, U.S. Department of Energy. 1983. Petroleum Marketing Monthly. DOE/EIA-0380(83/06), Washington, D. C.

Energy Information Administration, U.S. Department of Energy. 1983. Petroleum Marketing Monthly. DOE/EIA-0380(83/04), Washington, D. C.

Energy Information Administration, U.S. Department of Energy. 1984. Petroleum Supply Annual 1983. DOE/EIA-0340(83)/1, Washington, D. C.

Energy Information Administration, U.S. Department of Energy. "Quarterly Coal Consumption Report-Manufacturing Plants: 1983." Form EIA-3, Table 2. Washington, D. C.

Energy Information Administration, U.S. Department of Energy. "Quarterly Coal Consumption Report-Manufacturing Plants: 1982." Form EIA-3, Table 11. Washington, D. C. 
Energy Information Administration, U.S. Department of Energy. "Quarterly Coal Consumption Report-Manufacturing Plants: 1981." Form EIA-3, Table 11. Washington, D. C.

Energy Information Administration, U.S. Department of Energy. "Quarterly Coal Consumption Report-Manufacturing Plants: 1980." Form EIA-3, Table 25. Washington, D. C.

Energy Information Administration, U.S. Department of Energy. 1984. Quarterly Coal_Report. DOE/EIA-0121(83/40), Washington, D. C.

Energy Information Administration, U.S. Department of Energy. 1983. Quarterly Coal Report. DOE/EIA-0121(82/4Q), Washington, D. C.

Energy Information Administration, U.S. Department of Energy. 1981. Retail Sales and Inventories of Fuel 0il. DOE/EIA-0195(81/03), Washington, D. C.

Energy Information Administration, U.S. Department of Energy, 1981. Retail Sales and Inventories of Fuel 0il. DOE/EIA-0195(80/12), Washington, 0 . C.

Energy Information Administration, U.S. Department of Energy. 1980. Retail Sales and Inventories of Fuel Oil. D0E/EIA-0195(80/05), Washington, D. C.

Energy Information Administration, U.S. Department of Energy. 1980. Retail Sales and Inventories of Fuel 0il. DOE/EIA-0195(80/03), Washington, $0 . C$.

Energy Information Administration, U.S. Department of Energy. 1985. State Energy Data Report. DOE/EIA-0214(83), Washington, D. C.

Energy Information Administration, U.S. Department of Energy. 1985. State Energy Data System. Computer tape, Washington, D. C.

Fang, J. M., K. L. Imhoff and L. J. Hood. 1983. State Energy Price System: 1981 Update. PNL-4802, Pacific Northwest Laboratory, Richland, Washington.

Federal Energy Regulatory Commission, U.S. Department of Energy. 1978. Annual Summary of cost and Quality of Electric Utility Plant Fuels, 1977. DOE/FERC-0015, Washington, 0 . C.

Federal Highway Administration, U.S. Department of Transportation. 1984. Highway Statistics 1983. Washington, D. C.

Federal Highway Administration, U.S. Department of Transportation. 1984 . Highway Statistics 1982 . Washington, D. C.

Federal Highway Administration, U.S. Department of Transportation. 1983. Highway Statistics 1981. Washington, D. C.

Federal Highway Administration, U.S. Department of Transportation. 1982. Highway Statistics 1980 . Washington, D. C.

Federal Highway Administration, U.S. Department of Transportation. 1981. Highway Statistics 1979. Washington, D. C. 
Federal Highway Administration, U.S. Department of Transportation. 1980. Highway Statistics 1978. Washington, D. C.

Federal Highway Administration, U.S. Department of Transportation. 1979. Highway Statistics 1977. Report No. FHWA-HP-HS-77, Washington, D. C.

Federal Highway Administration, U.S. Department of Transportation. 1978. Highway Statistics 1976. Report No. FHWA-HP-HS-76, Washington, D. C.

Federal Highway Administration, U.S. Department of Transportation. 1977. Highway Statistics 1975. Report No. FHWA-HP-HS-75, Washington, D. C.

Federal Highway Administration, U.S. Department of Transportation. 1976. Highway Statistics 1974. Washington, D. C.

Federal Highway Administration, U.S. Department of Transportation. 1975. Highway Statistics 1973. Washington, D. C.

Federal Highway Administration, U.S. Department of Transportation. 1974. Highway Statistics 1972. Washington, D. C.

Federa] Highway Administration, U.S. Department of Transportation. 1973. Highway Statistics 1971. Washington, D. C.

Federal Highway Administration, U.S. Department of Transportation. 1972. Hiohway Statistics 1970. Washington, D. C.

Foster and Associates, Inc. 1974. Energy Prices: 1960-73. Ballinger Publishing Company, Cambridge, Massachusetts.

Imhoff, K. L. and J. M. Fang. 1984. State Energy Price System: 1982 Update. PNL-5271, Pacific Northwest Laboratory, Richland, Washington.

McGraw-Hill, Inc. 1984. Platt's 0il Price Handbook and Oilmanac. 60th Edition, New York, New York.

McGraw-Hill, Inc. 1983. Platt's 0il Price Handbook and 0ilmanac. 59th Edition, New York, New York.

McGraw-H111, Inc. 1982. Platt's 0il Price Handbook and Oilmanac. 58th Edition, New York, New York.

McGraw-Hil1, Inc. 1981. Platt's 0jl Price Handbook and Oilmanac. 57 th Edition, New York, New York.

McGraw-Hill, Inc. 1980. Platt's 0il Price Handbook and Oilmanac. 56th Edition, New York, New York.

McGraw-Hill, Inc, 1978. Elatt's Oil Price Handbook and Oilmanac. 54th Edition, New York, New York.

McGraw-Hil1, Inc. 1977. Platt's 0il Price Handbook and 0ilmanac. 53rd Edition, New York, New York. 
McGraw-Hi11, Inc. 1976. Platt's Oil Price Handbook and Oilmanac. 52nd Edition, New York, New York.

McGraw-Hill, Inc. 1975. Platt's Oil Price Handbook and Oilmanac. 51st Edition, New York, New York.

McGraw-Hi11, Inc. 1973. Platt's Oil. Price Handbook and Oilmanac. 49th Edition, New York, New York.

McGraw-Hill, Inc. 1971. Platt's Oil Price Handbook and Oilmanac. 47th Edition, New York, New York.

National Oceanic and Atmospheric Administration, U.S. Department of Commerce. 1983. State, Regional, and National Monthly and Seasonal Heating Degree Days Weighted by Population (1980 Census). Historical Climatology Series 5-1, National Climatic Data Center, Asheville, North Carolina.

Pacific Northwest Laboratory. 1982. State Energy Price System. DOE/N8B-0029, volumes I and II. Prepared for the Energy Information Administration, U.S. Department of Energy, Washington, D. C. 


\section{APPENDIX A}

STEPS Variable Naming Convention

A. 1 
STEPS VARIABLE NAMING CONVENTION

Characters 1 \& $2=$ Fuel Iype

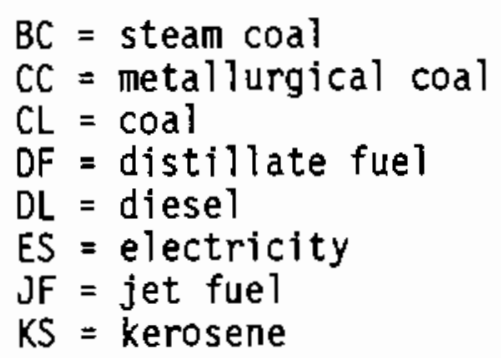

$L G=1$ iquefied petroleum gas

$M G=$ motor gasoline

$\mathrm{ML}=$ leaded motor gasoline

$M U=$ unleaded motor gasoline

$N G=$ natural gas

$\mathrm{OL}=0 \mathrm{iT}$

$\mathrm{RF}=$ residual fue 1

NOTE: Substitutions for the second character are made in two cases: 1) all data files have "D" for the second character (e.g. BD would be a steam coal data file); and 2) files with modifications described in the documentation have "M" for the second character (e.g. RMEU would be a modified version of a residual electric utility file). In addition, the motor gasoline price series has some files with "C" as the second character to denote an intermediate calculated file that does not appear in the written documentation.

\section{Characters $3 \& 4=$ Sector or End Use}

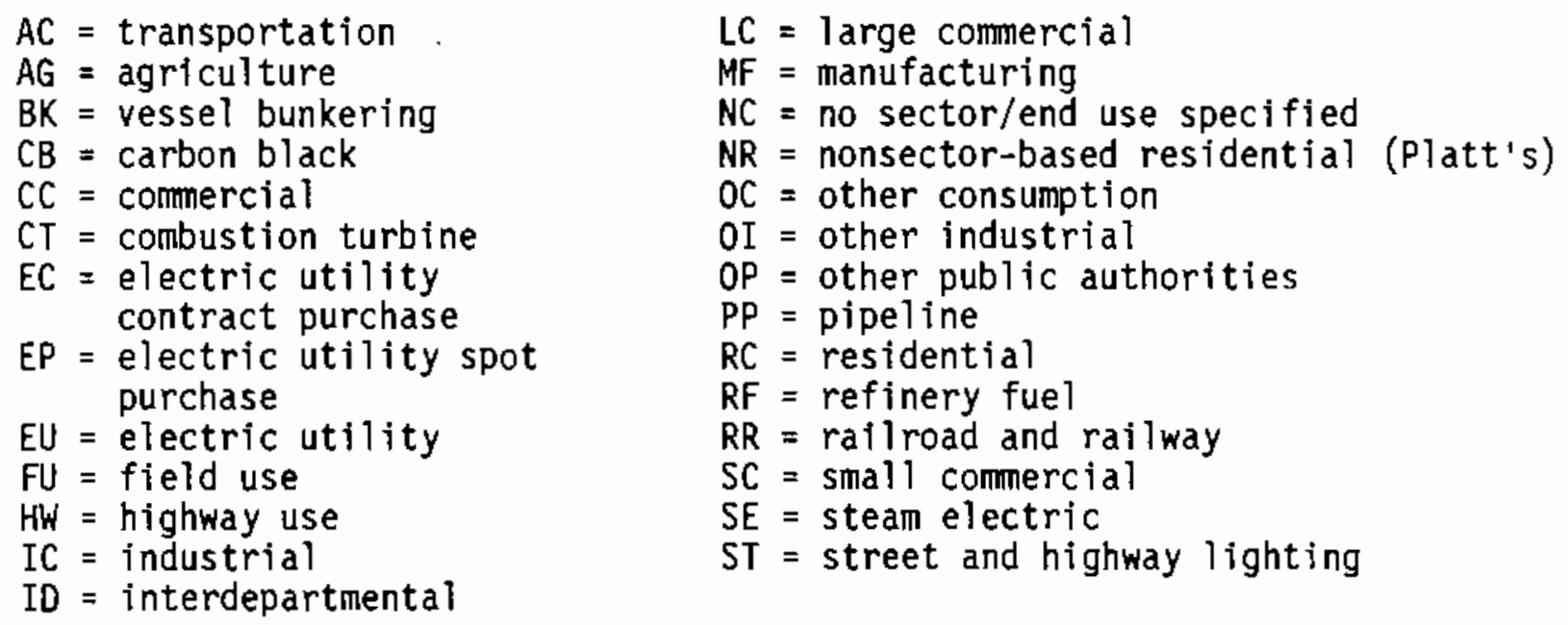

NOTE: The motor gasoline price series has third and fourth character codes that do not conform to this convention. These codes are used only to describe hand-calculations; they are not used in file names that are stored in the computer data library. The code " $\mathrm{CH}$ " is used to designate files that are hand-calculated from CPI data; the code "PH" is used to designate files that are hand-calculated from Platt's data. 
Character $5=$ Type of Data

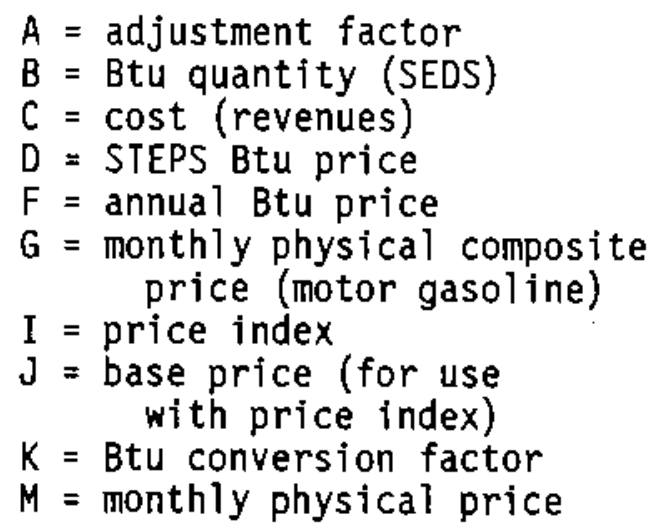

Characters $6 \& 7=$ Geographic Coverage

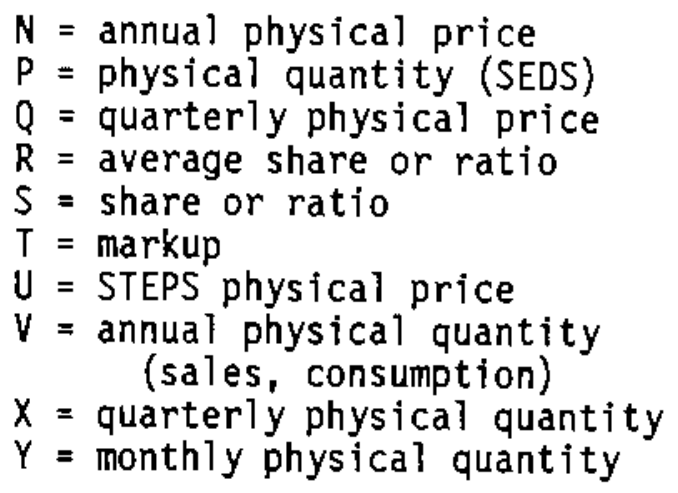

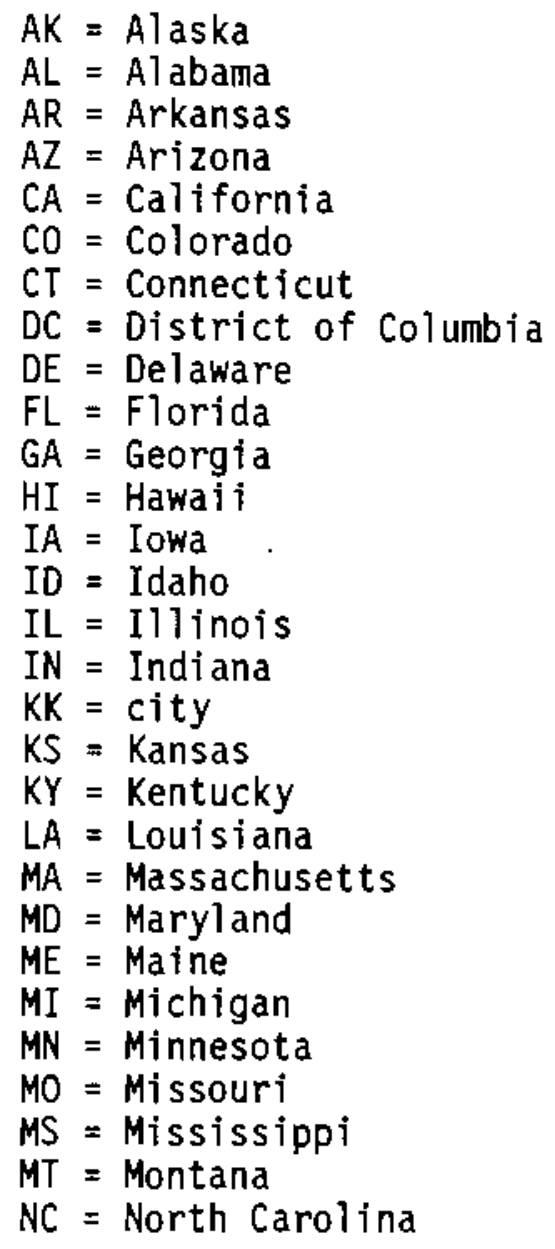

$$
\begin{aligned}
& N D=\text { North Dakota } \\
& \mathrm{NE}=\text { Nebraska } \\
& \mathrm{NH}=\text { New Hampshire } \\
& \text { NJ = New Jersey } \\
& \text { NM }=\text { New Mexico } \\
& \text { NV }=\text { Nevada } \\
& \text { NY }=\text { New York } \\
& \mathrm{OH}=\mathrm{Ohio} \\
& O K=O K] \text { ahoma } \\
& \mathrm{OR}=\text { Oregon } \\
& P A=\text { Pennsylvania } \\
& Q Q=\text { Census Region } \\
& \text { RI }=\text { Rhode Island } \\
& S C=\text { South Carolina } \\
& S D=\text { South Dakota } \\
& \mathrm{TN}=\text { Tennessee } \\
& \mathrm{TX}=\text { Texas } \\
& \text { US = United States } \\
& U T=U \text { tah } \\
& V A=\text { Virginia } \\
& V T=\text { Vermont } \\
& W A=\text { Washington } \\
& W I=W i \text { sconsin } \\
& W V=\text { West Virginia } \\
& W W=P A D \text { District } \\
& W Y=W \text { yoming } \\
& X X=\text { Census Division } \\
& Y Y=\text { Federal Region } \\
& \mathrm{ZZ}=\text { State (and U.S.) }
\end{aligned}
$$

Source: Pacific Northwest Laboratory 


\section{APPENDIX B B}

Final STEPS Physical Unit Prices

E. 1 
TABLE B.1. Electricity Prices: Residential Sector $(\$ / \mathrm{kWh})$

\begin{tabular}{|c|c|c|c|c|c|c|c|c|c|}
\hline YCAK & A & $\mathrm{AL}$ & AF & $A Z$ & $C A$ & $0]$ & $\mathrm{CT}$ & $\mathrm{DC}$ & $D E$ \\
\hline 1970 & 0.032 & 0,016 & 0,023 & 0.024 & 0,072 & 0.027 & $\hat{y}, \mathrm{NE}$ & 0.124 & $0+w$ \\
\hline 1971 & 0.032 & 0.017 & $D, 0 E 4$ & 6,024 & 0.023 & 0.027 & $9.0 \% 7$ & 3,060 & 0.028 \\
\hline 1972 & 0,03 & 0.018 & 0.024 & 0.065 & 0.025 & 0.027 & $0.0 \%$ & $\sqrt[3]{172}$ & 0,02 \\
\hline 197 & 0.033 & $0.02 \mathrm{~d}$ & $\therefore, 0 E 4$ & 01,057 & 0.026 & 0,023 & 5,02 & 0.06 & 0.03 \\
\hline 1974 & 0,034 & 0.023 & 0.029 & 0.032 & 0.034 & 0.030 & 0.044 & 0.03 & $0+1045$ \\
\hline 1975 & 0.035 & 0.028 & 0,082 & 0.040 & 0.036 & 0.034 & $i, 050$ & 3,043 & 0.045 \\
\hline 196 & 0.037 & 0.030 & 0.037 & 0.042 & 0.039 & 0.035 & 0.048 & 0.044 & 0.449 \\
\hline 1977 & 0.042 & 0.036 & $0, \hat{0}+1$ & 0.048 & 0.042 & 0.037 & 0,049 & 0.046 & 0.650 \\
\hline 1978 & 0.045 & 0.037 & 0.042 & 0,051 & 0,045 & 0.059 & 0.350 & $0.05 i$ & 0.057 \\
\hline $197 \%$ & 0.046 & 0.042 & 6.044 & 0.657 & 0.045 & 0,043 & 5,058 & 0,052 & $0,0,0$ \\
\hline 1790 & 0.055 & $\hat{0}+04 \hat{y}$ & 0.053 & 0,003 & 0.059 & 0,051 & $0+39$ & 0.059 & 0.074 \\
\hline 1081 & 0.060 & 0.055 & i.056 & 0.069 & 0,065 & 0.059 & 0,086 & 0.066 & 4.055 \\
\hline 1792 & 0,072 & 0.063 & 0.065 & 0.077 & $0.0 \pi$ & 0.067 & 0.05 & 0,084 & $0.0 \%$ \\
\hline 1983 & 0.085 & 0.066 & 0.072 & 0.078 & 0.071 & 0.067 & $3,06 t$ & in 100 & 0.066 \\
\hline
\end{tabular}

\begin{tabular}{|c|c|c|c|c|c|c|c|c|c|}
\hline IESA $\sqrt{1}$ & FL & $G A$ & HI & IA & ii & IL & 洲 & 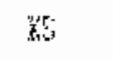 & $\mathrm{K}$ \\
\hline 1970 & 0.021 & 0.418 & 0.028 & $0+30$ & 0.016 & 0.027 & 0.32 & 0,0 & 0,00 \\
\hline $1 \% 71$ & 0.021 & 0.019 & $\dot{y}_{1} 080$ & 0,027 & 0.017 & 0.023 & 0,025 & 0,025 & 0.018 \\
\hline 1372 & 0.022 & 0,020 & 0.030 & 0.028 & 0.017 & 0.030 & 0.324 & $0,0 \%$ & $\hat{0}+019$ \\
\hline 1473 & 0,024 & 0.021 & 0.08 & 0.027 & 0.017 & 0.031 & 0,02 & 0.025 & 0,0 \\
\hline 1974 & 0.031 & 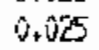 & 0.038 & 0.032 & 0.017 & 0,036 & 0.277 & 0.0727 & 0,124 \\
\hline 1975 & 0.037 & 0.031 & 6,050 & 0.036 & 0.018 & 0.099 & 0.029 & 0.032 & 0.02 \\
\hline 1976 & 0.040 & 0.032 & 0.052 & 0.039 & 0.020 & 0.042 & 0.033 & 0.034 & 0,028 \\
\hline 1977 & 0.041 & 0.037 & 0,056 & 0.043 & 0.021 & 0,044 & $0,0 \mathrm{gj}$ & 0.040 & 0.091 \\
\hline 1978 & 0.044 & 0.041 & 0,040 & 0.044 & 0.022 & 0.049 & 0.341 & 0.043 & 0.04 \\
\hline 1979 & 0.048 & 0.043 & $\pi+0,8$ & 0.049 & 0.025 & 0.053 & $\hat{1}, 044$ & 0,046 & 0.097 \\
\hline 1700 & 0,057 & 0,047 & 0.081 & 0.055 & 0.024 & $0.0 \mathrm{Bi}$ & 0,047 & 0.054 & $1+\sqrt[3]{4} 4$ \\
\hline $1 \% 81$ & 0.072 & 0.051 & $2 .: 21$ & 0.063 & 0.031 & 0,070 & $0,0 \%$ & 0.060 & 0,05 \\
\hline 1782 & 0.075 & 0.061 & 0.132 & 0.068 & $\hat{y}, 034$ & 0.079 & 0.361 & 0.069 & 0.05 \\
\hline 1983 & 0.077 & 0,002 & $\bar{y}_{12}=19$ & 0.071 & 0.034 & 0.095 & $0,0,5$ & 0.076 & 0,0 \\
\hline
\end{tabular}

\begin{tabular}{|c|c|c|c|c|c|c|c|c|c|}
\hline YEAK & LA & $i^{n} \mathrm{~A}$ & 非 & 捉E & MII & 河 & 机 & 粷 & MT \\
\hline$-\cdots$ & ------ & ........ & ........ & $-\cdots$ & $\cdots$ &.- & - & N.t. & \\
\hline 1970 & 0.023 & 0.029 & 0,024 & 0,028 & 0.024 & 0.025 & 0.32 & 0.017 & 0,06 \\
\hline 1971 & 0.023 & 0.031 & $(6,026$ & 0,028 & 0,025 & 0.026 & $n_{1} 067$ & 0,015 & 5.022 \\
\hline 1972 & 0,023 & 0.033 & 0.028 & 0.029 & 0.026 & 0.027 & 0.028 & 0.021 & 0,02 \\
\hline $197 \%$ & 0.024 & 0.034 & 0,029 & 0,080 & 0.027 & 0.027 & $0,06 E$ & 0,020 & 0,6 \\
\hline 1974 & 0.027 & 0.048 & 0,037 & 0.034 & 0.002 & 0.030 & 0.331 & 0,025 & $0+9$ \\
\hline 1975 & $0, \hat{0} 27$ & 0,052 & 0.04 & 0.040 & 0.039 & 0.034 & $\hat{U}, \hat{U} \mathcal{B}_{i}$ & 0.028 & 0.024 \\
\hline 1976 & 0.02 & 0,054 & 0.044 & 0.829 & 0.042 & 0.036 & 0.238 & $0,1 / 34$ & $0, b_{2}$ \\
\hline 1777 & 0.031 & 0.056 & 0.046 & $0,0 \AA_{2}$ & 0.045 & 0,040 & 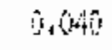 & 5097 & 0.05 \\
\hline 1778 & 0.033 & 0,057 & 0,051 & 0.043 & $0.04 \%$ & 0.042 & 0.344 & 3,009 & 0,120 \\
\hline 1975 & 0.037 & $1,0,2$ & 1. & 0.050 & 0,052 & 0.043 & 0,047 & 0,045 & 0.020 \\
\hline 1730 & 0.047 & 0.076 & 0,15 & 0,103 & 6.057 & 0.055 & $0.5 \%$ & $104\}^{t}$ & $4+131$ \\
\hline 1981 & 0.058 & 0.092 & 0.06 & 0.072 & 0.064 & 0.059 & $0,0 \%$ & 0,05 & 0.036 \\
\hline 1902 & 0,063 & 0.090 & 0.073 & 0.074 & 0,060 & 0.063 & 0.041 & 0,002 & $0+0 x$ \\
\hline $19 \theta^{3}$ & 0.056 & 0.091 & 8,072 & 0.073 & 0.070 & 0,066 & $j_{1}, \Omega^{\sin }$ & 1062 & 0.044 \\
\hline
\end{tabular}


TABLE B. I (CONT). Electricity Prices: Residentiai Sector ( $\$ / \mathrm{kbh})$

\begin{tabular}{|c|c|c|c|c|c|c|c|c|c|}
\hline 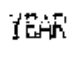 & $+4 C$ & SW & $\mid M E$ & itti & $\mathrm{N}$ & 综物 & $N$ & 河 & 计 \\
\hline$\cdots$ & $\ldots$ & -..- & 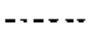 & - & --.-- & - & $-\cdots$ & $-\cdots$ & $\ldots$ \\
\hline 1770 & 0.019 & 0.027 & 0,021 & 0,028 & 0.027 & 0,028 & $0+215$ & $0+130$ & $0, \sqrt{34}$ \\
\hline 1971 & 0.020 & 0.027 & $\hat{0} .0 .22$ & 0,028 & 0.031 & 0.028 & 0.015 & 9,032 & 0,025 \\
\hline $1 \$ 72$ & 0.021 & 0.027 & 0,24 & 0.028 & 0.032 & $0.02 \%$ & 0.016 & 0.034 & 0,05 \\
\hline 1973 & 0,022 & 0.0029 & 0,023 & $0,0=0$ & 0.035 & 0.029 & 0.017 & 0.037 & 0.02 \\
\hline 1974 & 0.027 & 0.029 & 0.025 & 0.040 & 0,048 & 0,052 & 0.321 & 0.051 & $0.0 \%$ \\
\hline 1775 & 0.032 & 0.031 & î.0 & 0.049 & 0.054 & 0.036 & 0.026 & 0.05 & $0,0 \%$ \\
\hline 170 & 0.434 & 0.033 & 0.322 & 0.049 & 0.057 & 0.038 & $0.25:$ & 0.058 & $1+96$ \\
\hline 1977 & 0.038 & 0.036 & 4035 & 0.052 & 0,063 & 0,043 & $i, 0=5$ & $3,0.53$ & 0.043 \\
\hline 1379 & 0,041 & 0.038 & 0.037 & 0.058 & 0.064 & 0.050 & 0.136 & 0.065 & $0+0+7$ \\
\hline 199 & 0.043 & 0.039 & 3,009 & $0,0<1$ & 0.069 & 0.058 & 9036 & 0.072 & 0.051 \\
\hline 1000 & 0.049 & 0.045 & $0_{3}+345$ & 0,072 & 0.082 & 0.025 & $0+i+4$ & 0.479 & 1,05 \\
\hline 1981 & 0,054 & $0+32$ & , o51 & 0.091 & 0.095 & 0.072 & 0,049 & in & 0,0 \\
\hline 1502 & 0,003 & 0.056 & 0.347 & 0.099 & $\hat{0}_{+} \pm 05$ & 0.081 & 0.059 & 0.105 & 0.57 \\
\hline 1495 & 0.066 & 0.061 & 301 & 0.054 & 0.105 & 0.079 & 9,00 & 6109 & n. 67 \\
\hline
\end{tabular}

\begin{tabular}{|c|c|c|c|c|c|c|c|c|c|}
\hline IEAF & or & on & 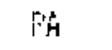 & $\mathrm{Ri}$ & $S C$ & 50 & $T N$ & $\mathrm{~T} x$ & in \\
\hline-- & ......... & .......... & ........ & 然 & ---- & --- & -..-- & $\cdots$ & \\
\hline 1970 & 0.025 & 0.013 & 0.08 & $0.02 \%$ & $0,01 \%$ & 0,027 & $0.0: 1$ & $0+022$ & 0,020 \\
\hline 1971 & 0.026 & 0.013 & $1,02 E$ & 0.029 & 0.021 & 0.027 & 0.013 & 0.02 & 0.024 \\
\hline 1972 & 0.085 & 0.013 & 0.020 & 0.033 & 0.022 & 0.027 & 0.013 & 0.022 & 0,024 \\
\hline 1973 & 0.025 & 0.014 & $(0,091$ & 0.035 & 0.023 & 0.027 & 0.014 & 0.023 & 0.024 \\
\hline 1974 & 0,026 & 0.016 & 0.034 & 0.050 & 0.028 & $0.0 \%$ & 0.017 & 0.026 & $0.4 \%$ \\
\hline 1975 & 0,028 & 0.018 & $0,0.14$ & 0.053 & 0.033 & 0.031 & 0.023 & 0.030 & 0.030 \\
\hline 1976 & 0.032 & 0.020 & 0.245 & 0.652 & 0.034 & 0.034 & 0.05 & 0.034 & $\sqrt[3]{6}+34$ \\
\hline 1977 & 0.036 & 0.024 & 0.048 & 0,058 & 0.039 & 0.035 & 0.025 & 0.035 & 0.037 \\
\hline 1978 & 0.034 & 0.026 & $1, \sqrt{50}$ & $0.05 \%$ & 0.041 & 0.038 & $0.2 \%$ & 0.041 & 0.044 \\
\hline 1979 & 0,041 & 0.026 & 1,053 & 0.067 & 0.043 & 0,040 & 0.095 & 0.045 & 0,045 \\
\hline 1980 & 0.046 & 0.032 & 0.260 & 0.077 & 0.047 & 0.050 & 0,036 & 0.051 & 0.055 \\
\hline 1981 & 0.054 & $0+036$ & 6.067 & 0.095 & 0.054 & 0.056 & 0.044 & 0.062 & 0,03 \\
\hline 1902 & 0.061 & 0.036 & $0+\sqrt{77}$ & 0.092 & $0+000$ & 0.061 & 0.244 & 0.072 & $0,0,7$ \\
\hline 1493 & 0.056 & 0.041 & {$[., 876$} & 0.045 & 0.064 & 0,060 & 5,450 & 0,075 & ij +37 \\
\hline
\end{tabular}

\begin{tabular}{|c|c|c|c|c|c|c|c|}
\hline IEA & $V_{A}$ & UT & WA & WI & $\mathbf{W}$ & $W Y$ & US \\
\hline$\cdots$ & -- - - & --- & $\ldots$ & 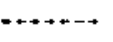 & n & - & \\
\hline 1970 & 0.021 & 0.023 & 0.3 .1 & 0,023 & 0.022 & 0.026 & 0.32 \\
\hline 1971 & 0,021 & 0.023 & 0.011 & 0.024 & 0.023 & 0.026 & $0.0 \mathrm{E}$ \\
\hline 1972 & 0.022 & 0.026 & 0,311 & 0.085 & 0.024 & 0.026 & 0.324 \\
\hline 1973 & 0.024 & 0.028 & 0.011 & 0.087 & 0.025 & 0.025 & 0,025 \\
\hline 1774 & 0.031 & 0.034 & 0.32 & 0,030 & 0.050 & 0.026 & 0.231 \\
\hline 1975 & 0.038 & 0.039 & 0.013 & 0.004 & 0,036 & 0.026 & $0,0 \mathrm{~g}^{\mathrm{E}}$ \\
\hline 1076 & 0.038 & 0.043 & $0,2: 4$ & 0,037 & 0,095 & $0+126$ & 0.337 \\
\hline 197 & 0.043 & 0.044 & $6,0 \mathrm{E}$ & 1.040 & 0.037 & 0.027 & $\hat{y}, \hat{0} 4 \hat{z}$ \\
\hline 1978 & 0,345 & 0.047 & 0.95 & 0.342 & 0.037 & 0,030 & 0,143 \\
\hline $19 \%$ & 0.051 & 0.048 & 0.015 & 0.046 & 0.040 & 0.031 & 0.048 \\
\hline 1.990 & 0.061 & 0,054 & $0.6 \%$ & 0.051 & 0.043 & 0.040 & 0,054 \\
\hline 1981 & 0.062 & 0.062 & 0,02 & 0,058 & 0.050 & 0.044 & 0.02 \\
\hline 1082 & 0,067 & 0.007 & 0,1328 & 0.047 & 0.057 & 0.046 & 0.069 \\
\hline 180 & 0,070 & 0.058 & 0.035 & 0.070 & 0.058 & 0.053 & 0.672 \\
\hline
\end{tabular}


IABLE B.2. Electricity Prices: Commercial Sector ( $\$ / k w h)$

\begin{tabular}{|c|c|c|c|c|c|c|c|c|c|}
\hline IEA & AKK & Ali & $A$ & $A Z$ & $C A$ & $c 0$ & $\mathrm{CI}$ & $\mathrm{in:}$ & $n^{n}$ \\
\hline$\cdots$ & --- & 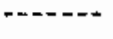 & $\cdots$ & $\cdots$ & * & & - & & \\
\hline 170 & 0.0 .53 & 0,019 & 0,21 & $0.01 \%$ & 0.017 & 0.021 & 0,30 & 6,024 & 1,03 \\
\hline 1971 & 0.033 & 0.020 & 0,022 & 0.020 & 0.018 & 0.021 & 0.028 & 0,026 & $5+\sqrt{4} 4$ \\
\hline $17 / 72$ & 0.036 & 0,020 & 0.02 & 0.021 & 0.019 & 0.021 & 0.228 & 0.027 & 0,000 \\
\hline 107 & 0.034 & 0.023 & 0,023 & 0,023 & 0.021 & 0.021 & 0.030 & 0,028 & 0,025 \\
\hline 1974 & 0.034 & 0.026 & $0.0 Z$ & 0.027 & 0.028 & 0.024 & 0.943 & 0,040 & 0.041 \\
\hline 1975 & 0.037 & 0,031 & {$[1,030$} & 0.035 & 0.030 & 0.027 & $0, \hat{\mathrm{N}} \mathrm{i}$ & 0,043 & $\overline{0}, 04 \hat{0}$ \\
\hline 1776 & 0.037 & 0.033 & 0.035 & 0.038 & 0.033 & 0,030 & 0.047 & 0.046 & $0.0 \% 9$ \\
\hline 1977 & 0.042 & 0.042 & 0.039 & 0,043 & 0.042 & 0.032 & $i, 046$ & 0.052 & 0,456 \\
\hline 1978 & 0.044 & 0.042 & 0.040 & 0.047 & 0,045 & 0.035 & 0.349 & 0,456 & $0+\mathrm{iBS}$ \\
\hline $107 \%$ & 0.046 & 0.048 & $i_{1}, 042$ & 0.053 & 0.045 & 0,040 & 0,057 & 4.657 & 0.042 \\
\hline $1: 80$ & 0.012 & 0.056 & 0.051 & 0.057 & 0.062 & 0.0050 & 0.928 & 0,063 & 0.472 \\
\hline 1981 & 0.067 & 0.061 & 0,048 & 0.062 & 0.006 & 0.056 & 0,05 & $\hat{0}+\hat{0} ; 1$ & 0,07 \\
\hline 1392 & 0.075 & 0.069 & 0.356 & 0,071 & 0.074 & 0.06 .2 & $0.30 \%$ & 6074 & 0.079 \\
\hline 1983 & 0.090 & 0.070 & $i_{1}, 0<2$ & 0.072 & 0.073 & 0.060 & 3,050 & 1000 & 0,08 \\
\hline
\end{tabular}

\begin{tabular}{|c|c|c|c|c|c|c|c|c|c|}
\hline IEST & FL & $G A$ & $\mathrm{HI}$ & 消 & ID & Il & IN & $x^{5}$ & 11 \\
\hline $107 a$ & - nd & $3 r$ & 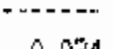 & 0 & 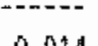 & 0 & 037 & 0,07 & \\
\hline $\begin{array}{l}1.910 \\
1971\end{array}$ & $\begin{array}{l}0.021 \\
0.022\end{array}$ & $\begin{array}{l}3+020 \\
0.021\end{array}$ & $\begin{array}{l}0.034 \\
0.096\end{array}$ & $\begin{array}{l}10+020 \\
0.027\end{array}$ & $\begin{array}{l}0,014 \\
0,015\end{array}$ & $\begin{array}{l}0.023 \\
0.024\end{array}$ & $\begin{array}{r}1463 \\
1,023\end{array}$ & $\begin{array}{l}1,421 \\
0,021\end{array}$ & $\begin{array}{l}0+617 \\
0.017\end{array}$ \\
\hline 1972 & 0.023 & 0.020 & 0.336 & 0.028 & 0.015 & 0.025 & 0.324 & 0.021 & 0.017 \\
\hline $1 \% 73$ & 0.025 & 0.024 & 0.039 & 0.029 & 0.015 & 0.026 & 0.025 & 0.022 & $\hat{0}, 015$ \\
\hline 1774 & 0.033 & 0.024 & 0.044 & 0.031 & 0.015 & 0,031 & 0.327 & 0.024 & 0.016 \\
\hline 1975 & 0.039 & 0,097 & 3,057 & 0,036 & 0.017 & 0.036 & 0,029 & 0.028 & 0.015 \\
\hline 1976 & 0.041 & $\hat{0}, 05 \%$ & 0.059 & 0.040 & 0.019 & 0.037 & 0.032 & 0.032 & $0.01 \%$ \\
\hline 1977 & 0,044 & 0,041 & $\overrightarrow{1}, 064$ & 0.043 & $0.02 \mathrm{t}$ & 0,041 & 0,036 & 0,038 & $0, \hat{0 R}$ \\
\hline 1779 & 0,046 & 0.045 & 0.371 & 0.045 & $\hat{0}_{1}, 021$ & 0.046 & 0,041 & 0.041 & $0+026$ \\
\hline 1979 & 0.051 & 0.048 & 0,076 & 0.050 & 0.023 & 0.045 & 19.04 & $3,0.44$ & {$[, 028$} \\
\hline 1780 & 0,060 & 0,050 & 0,4 & 0.055 & 0,02 & 0,058 & 0.246 & 0,0 & $0+100$ \\
\hline $1 \% \theta 1$ & 0.073 & 0.055 & 0.130 & $\hat{b}+\hat{v}_{3}^{\prime} 3$ & 0,030 & 0.066 & Q +040 & 0,057 & 0.044 \\
\hline 1902 & 0.064 & 0,062 & 0.135 & 0.067 & 0.037 & 0.074 & 0,054 & O. DOE & 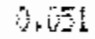 \\
\hline 1983 & 0.068 & 0,062 & 3.122 & 0.071 & 0.098 & 0,077 & $0,05 \%$ & 0,06 & 0,045 \\
\hline
\end{tabular}

\begin{tabular}{|c|c|c|c|c|c|c|c|c|c|}
\hline Y'EAF & IA & $M$ & NW & 昰 & $M I$ & 政 & $\mathrm{j} 9 \mathrm{C}$ & $n$ & $\mathrm{ntT}$ \\
\hline$+\cdots-$ & $\cdots$ & $\ldots$ & $\ldots$ & 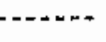 & $\ldots$ & $-1 . . .$. &..$-+\ldots$ & -........ & \\
\hline 1970 & 0.017 & 0,028 & 0.024 & 0.027 & 0.024 & 0.027 & $\hat{0}_{1} x_{24}$ & 0.019 & 0.00 \\
\hline 1971 & 0,018 & 0.030 & {$[1,026$} & 0.027 & 0.025 & 0.027 & 0.025 & 0,020 & 0.020 \\
\hline 1972 & 0.018 & 0.030 & 0.327 & $0.02 \%$ & 0.026 & 0.028 & 0.725 & $0.0 \%$ & 0,020 \\
\hline 193 & 0.019 & 0.031 & $0,02 B$ & 0.029 & 0.028 & $0.02 B$ & $0.02 t_{1}$ & 0.022 & 0.021 \\
\hline 1974 & 0.023 & 0.046 & 0.040 & 0.033 & 0.033 & 0.032 & $0.23^{3}$ & $0+020$ & $0+2$ \\
\hline 1475 & 0.024 & 0.050 & 0.043 & 0.040 & 0.039 & 0.036 & 4,035 & 0.030 & 4.52 \\
\hline 1776 & 0.02 & 0.052 & 0.346 & 0.035 & 0.044 & 0.038 & 0,237 & 0,036 & 0.02 \\
\hline 1177 & 0.029 & 0.056 & 0,05 & 0.043 & 0.047 & 0.040 & $n, 0 z$ & 0.09 & 5.04 \\
\hline 1770 & 0.031 & 0.057 & $0+356$ & 0.045 & 0.051 & 0,041 & 0.341 & 0.01 & 0.02 \\
\hline $1 \% 9$ & 0,035 & 0.062 & 0.057 & 0.053 & 0.054 & 0.043 & 0.044 & 0347 & $0,6 \%$ \\
\hline $1 \% 80$ & 0.042 & 0.076 & 0.063 & 0,064 & 0.061 & $\hat{0}+045$ & 0.045 & 0.45 & $0,4 y$ \\
\hline 1481 & 0.050 & 0.071 & $6.0 \% 1$ & 0.075 & 0.006 & 0.051 & $\mathrm{H}_{1} \mathrm{O}^{\mathrm{E}} \mathrm{S}$ & Sotón & $1,0,04$ \\
\hline 1982 & 0.052 & 0,097 & 0.076 & 0.077 & 0,071 & 0.054 & 0.357 & 0,067 & 0,094 \\
\hline 1483 & 0.055 & $0,0.07$ & 3.075 & 0.071 & 0.073 & 0.058 & 0,06 & 3,066 & 0.040 \\
\hline
\end{tabular}


TABLE B.2 (CONT). Electricity Prices: Commercial Sector $(\$ / \mathrm{kWh})$

\begin{tabular}{|c|c|c|c|c|c|c|c|c|c|}
\hline I & $\mathrm{MC}$ & $\mathrm{MD}$ & 就 & $\mathrm{N}$ & thl & 卜解 & at & में & $\mathrm{OH}$ \\
\hline$\cdots$ & $\cdots$ & & 0,7 & 1200 & 0,026 & Aี & $0 \% 12$ & 0077 & 010 \\
\hline $\begin{array}{l}170 \\
1971\end{array}$ & $\begin{array}{l}0.016 \\
0.017\end{array}$ & $\begin{array}{l}0.023 \\
0.023\end{array}$ & $\begin{array}{l}0.0 .7 \\
0.017\end{array}$ & $\begin{array}{l}0.030 \\
0.031\end{array}$ & $\begin{array}{l}1,+026 \\
0.030\end{array}$ & $\begin{array}{l}1+4,420 \\
0,020\end{array}$ & $\begin{array}{l}1+16 \\
0.017\end{array}$ & 0,031 & $\begin{array}{l}0.125 \\
0.02 S\end{array}$ \\
\hline 197 & 0.018 & 0.023 & $0+3) 8$ & 0.032 & 0.031 & 0.021 & 0.2 .8 & 0,030 & 0,723 \\
\hline 1973 & 0,019 & $0+0 E 3$ & 8.019 & 0.033 & 0.033 & 0.021 & 0.016 & 0,030 & 0.024 \\
\hline 1974 & 0.025 & 0.025 & 0,020 & 0.044 & 0,047 & 0.024 & 0.22 & 0,052 & 0.000 \\
\hline$\$ 45$ & 0.029 & 0.027 & 0.024 & 0.053 & 0.052 & 0.027 & 0.033 & 0.057 & $0.0 \%$ \\
\hline 177 & 0.032 & $0,02 \%$ & 0.028 & 0.055 & 0.054 & 0.030 & 0.032 & 0.060 & 0,03 \\
\hline 1977 & 0.034 & 0.032 & 0.031 & 0.058 & 0,059 & 0.034 & 0,036 & $4+765$ & 0,04 \\
\hline 1978 & 0.037 & 0.034 & 0.233 & 0.065 & $0.0 \mathrm{~B} 1$ & 0.040 & 0.35 & 0,063 & 0.040 \\
\hline 1979 & 0.035 & 0.036 & 0.096 & 0.069 & 0.365 & 0.047 & 0.040 & 0.068 & 1049 \\
\hline 1980 & 0.042 & 0,042 & 0,544 & 0,084 & $0.0 \pi$ & 0.055 & 0.53 & 0,00 & 1.03 \\
\hline 591 & 0.048 & 0.045 & 0,046 & 0,098 & 0.038 & 0,063 & 1.059 & 0.101 & 10.6 \\
\hline 1782 & 0.055 & 0.051 & 0.349 & 0,691 & 0,045 & 0.071 & 0.063 & $0.10 \%$ & anda \\
\hline 1983 & 0.057 & 0.057 & 0,07 & 0.092 & 0.633 & 0.070 & Q.60t & 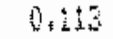 & is \\
\hline
\end{tabular}

\begin{tabular}{|c|c|c|c|c|c|c|c|c|c|}
\hline YEAT & $0 X$ & $O R$ & $F A$ & $\mathrm{RI}$ & 56 & SD & $T$ & $\pi y$ & if \\
\hline --.- & no. & 20 & 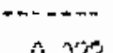 & - & 7 & & & & \\
\hline 1370 & 0.019 & 0.013 & 0.213 & 0.024 & 0.017 & 0.026 & $0+27$ & $\begin{array}{l}010 \\
0,018\end{array}$ & $\begin{array}{l}5+219 \\
0.69\end{array}$ \\
\hline 1971 & 0.019 & 0.014 & 0.056 & 0.025 & 0,018 & $\begin{array}{l}0,020 \\
0,035\end{array}$ & 0.015 & $\begin{array}{r}0+018 \\
0.018\end{array}$ & $\begin{array}{l}4,014 \\
0.019\end{array}$ \\
\hline 1972 & 0,020 & 0.014 & 0,027 & 0.028 & 0.018 & $0+0 \leq 2$ & $3+017$ & $\begin{array}{l}9018 \\
0.018\end{array}$ & $\begin{array}{l}1+\sqrt{12} \\
0,5\end{array}$ \\
\hline 1573 & 0.019 & 0.015 & 0.028 & 0.029 & 0,019 & 0.026 & $0+100$ & W.UYY & 0.124 \\
\hline 1974 & 0.021 & 0.016 & 0.036 & 0.044 & 0.025 & 0,028 & $0+023$ & 0,022 & 0.021 \\
\hline $19 \pi$ & 0.023 & 0.018 & $0,34:$ & 0.048 & $0.02 \%$ & 0.030 & $0,0.04$ & $0,02 \%$ & $0,0 \%$ \\
\hline 1976 & 0.028 & 0.019 & 0.063 & 0.047 & 0.031 & 0.034 & 2.031 & 0.030 & 0.027 \\
\hline 1977 & 0.032 & 0.020 & 0.146 & 0.052 & 0.034 & 0,035 & 0.132 & 0.035 & 0.031 \\
\hline 1979 & 0.035 & 0.022 & $0,0 \leq 0$ & 0.053 & 0.036 & 0.037 & 0.039 & 0.038 & 0.056 \\
\hline 1974 & 0,036 & 0.024 & 0.352 & 0.060 & 0.034 & $0.03 \%$ & 0.843 & 0,040 & 0.04 \\
\hline 1930 & 0.041 & 0.031 & $0,0=7$ & 0.070 & 0.042 & 0.045 & $3,0<6$ & 1,044 & 0.040 \\
\hline 1981 & 0,045 & 0.034 & $0 . \sqrt{65}$ & 0.087 & 0.049 & 0.052 & 0.053 & 6,059 & $0+19$ \\
\hline 1792 & i) $+\hat{0} 50$ & 0.040 & (3,, 174 & 0.082 & 3,054 & 0,052 & 1.04 & 10.097 & $6+47$ \\
\hline 1983 & 0,054 & 0.045 & 0,103 & 0,008 & 0,056 & $0,05.6$ & 0,58 & 0,070 & on \\
\hline
\end{tabular}

\begin{tabular}{|c|c|c|c|c|c|c|c|}
\hline YEAR' & $1 / 4$ & $\mathrm{VT}$ & $W A$ & VI & $W W$ & $w i$ & 16 \\
\hline 1970 & 0.017 & 0.023 & 0.011 & 0.025 & 0.020 & 0.018 & 0.021 \\
\hline 1971 & 0,017 & 0.024 & 0.311 & 0.025 & 0.02 & 0,019 & 0.022 \\
\hline 1472 & 0.018 & 0.026 & 0.012 & 0.027 & 0.023 & 0.019 & 0,023 \\
\hline 1973 & 0.019 & 0.028 & 0.012 & 0.029 & 0.023 & 0.018 & 0,024 \\
\hline 1974 & 0.025 & 0,095 & 0.013 & 0,031 & 0.028 & 0.018 & 3,030 \\
\hline 1975 & $\hat{0}, 030$ & 0,034 & 0.014 & 0.05 & 0.034 & 0.019 & 0.46 \\
\hline 477 & 0.003 & 0,042 & 0.014 & 0.037 & 0,038 & 0.019 & $1,0,37$ \\
\hline 1977 & 0.040 & 0.043 & 0.016 & 0.041 & 0.038 & 0.021 & 0,44 \\
\hline 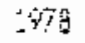 & 0.041 & 0,046 & {$[0.015$} & 0.043 & 0.540 & 0.024 & 0,044 \\
\hline $15 \%$ & 0.04 & $0.04=$ & 0,017 & 0.04 & 0,03 & 0.065 & 0,347 \\
\hline$\%$ & 0.054 & 0.054 & $0, \%$ & 0,053 & 0.043 & 0.039 & $, 1,05$ \\
\hline $198 i$ & 0.055 & 0.067 & 0.024 & 0.059 & 0.049 & 0.043 & 0,460 \\
\hline$\triangle 982$ & 0.059 & 0.072 & 0.029 & 0.066 & $3+055$ & 0.043 & 2,047 \\
\hline 1983 & 0.061 & 0.074 & 0.05 & 0.069 & 0,05 & 0.040 & 0,170 \\
\hline
\end{tabular}


TABLE B.3. Electricity Prices: Industrial Sector ( $\$ / \mathrm{kWh}$ )

\begin{tabular}{|c|c|c|c|c|c|c|c|c|c|}
\hline MAFi & $A K^{\prime}$ & AL & $A F^{\prime}$ & $A Z$ & $C A$ & $\mathrm{CO}$ & $T$ & $\alpha$ & $\mathrm{DE}$ \\
\hline 1070 & 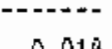 & 0 , & $\therefore$ HA & $80+9$ & 0,010 & 0,010 & $0 \dot{10}=$ & $\therefore 6$ & $\mathrm{AOH}^{2}$ \\
\hline 1707 & $\begin{array}{l}0.018 \\
0.019\end{array}$ & $\begin{array}{l}1+106 \\
0.009\end{array}$ & 0.0 .0 & $\begin{array}{l}0.014 \\
0.012\end{array}$ & 0,010 & 0.012 & $\begin{array}{l}9+23 \\
0+0,6\end{array}$ & 0.014 & 0.015 \\
\hline 1972 & 0.020 & 0.000 & 0,011 & 0,013 & 0.011 & 0,013 & 0.014 & $\hat{1}, \hat{U} 15$ & 0.015 \\
\hline 1973 & 0.021 & 0.010 & 60,8 & $0.0 \pm 5$ & 0.013 & 0.014 & $0.0 \%$ & 0.018 & 0.010 \\
\hline 1974 & 0.022 & 0.013 & 0,017 & 0.019 & 0.020 & 0.016 & 0,031 & 0.025 & 0,028 \\
\hline 1975 & 0.023 & 0.018 & $0,0,8$ & 0.024 & 0.023 & 0.019 & 0.036 & 0.027 & 0,092 \\
\hline 1976 & 0.035 & 0.020 & 0.073 & 0.026 & 0.026 & 0.021 & 0,035 & 0.027 & 0,031 \\
\hline 1477 & 0.035 & 0.023 & 0.025 & 0.030 & $0,03 i$ & 0.022 & 6.037 & 0,024 & 0.04 \\
\hline 1978 & 0.035 & 0.026 & 0.426 & 0.031 & 0.037 & 0.024 & 0.037 & 0.035 & 0.038 \\
\hline $1 \% 9$ & 0.035 & 0,030 & $\mathrm{C}+\mathrm{OH}$ & 0.034 & 0.038 & 0.027 & 0.040 & 0.034 & $0,0,00$ \\
\hline \pm 980 & 0.035 & 0.035 & 0.031 & 0.039 & 0.055 & 0.032 & 0.057 & 0.040 & 2,352 \\
\hline 1481 & 0.0 .44 & 0.041 & 0.038 & $\hat{0}, 042$ & 0.062 & 0.097 & 0.070 & $\hat{0}, 044$ & $0+16$ \\
\hline 1982 & 0.070 & 0,047 & 0.000 & 0,052 & 0.073 & 0.044 & 0.075 & 0.55 & 0,001 \\
\hline $1 / 93$ & 0.099 & 0.050 & 0.041 & 0.053 & $0.0 \mathrm{sen}$ & 0.042 & $0.07 \%$ & 0,64 & $0, b$ \\
\hline
\end{tabular}

\begin{tabular}{|c|c|c|c|c|c|c|c|c|c|}
\hline$Y \mathrm{YAR}^{\prime}$ & FL & HA & HI & İ & iv & IL & $\mathrm{Ih}$ & $\mathrm{NS}$ & $\mathrm{n}$ \\
\hline 1070 & 2 & & 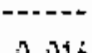 & & 0.006 & $\hat{0} 012$ & 0.97 & 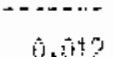 & 4 \\
\hline $\begin{array}{l}1770 \\
167\end{array}$ & $\begin{array}{l}0.012 \\
0.012\end{array}$ & 0.010 & $\begin{array}{l}0.010 \\
0.07\end{array}$ & $\begin{array}{l}0.013 \\
0.014\end{array}$ & $\begin{array}{l}0.006 \\
0.006\end{array}$ & $\begin{array}{l}0.012 \\
0,013\end{array}$ & $\begin{array}{l}0,012 \\
0,012\end{array}$ & $\begin{array}{l}\text { W.1. } \\
0.012\end{array}$ & 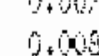 \\
\hline $197 \mathrm{c}$ & 0.014 & 0.012 & 0,017 & 0,014 & 0,007 & 0,014 & 0,013 & 0.01 & 6,40 \\
\hline 1973 & 0.015 & 0.013 & $0+0.9$ & 0.015 & 0.007 & 0.014 & $\hat{0}+0.4$ & 0.015 & 0.009 \\
\hline 1974 & 0.021 & 0.018 & 0.023 & 0,017 & $0,00 \mathrm{~B}$ & 0.018 & $\hat{0}, 010$ & 0.015 & 0.011 \\
\hline 1475 & 0,026 & 0.025 & $0.03 \mathrm{~A}$ & 0.022 & 0.009 & 0.022 & $0,0: 5$ & $0+019$ & 0,010 \\
\hline 1976 & 0.029 & 0,025 & 0.034 & 0.024 & 0.011 & 0.024 & 0.021 & 0.022 & 0,016 \\
\hline 1977 & $0,0.29$ & 0.027 & 0.034 & 0.027 & 0.012 & 0,026 & , o ot & 0.027 & 0.018 \\
\hline 1978 & 0,031 & 0.031 & 0.045 & 0,025 & 0.013 & 0.031 & 0.031 & 0.029 & 0,02 \\
\hline 1979 & 0.035 & 0.032 & $0.04 \xi$ & 0.032 & 0.015 & 0,033 & 0,030 & 0,03 & $0.02 t$ \\
\hline 1980 & 0.046 & 0,036 & 0.064 & 0.036 & 0,019 & 0,040 & 0,038 & 0,070 & 0,030 \\
\hline 1081 & 0.058 & 0.037 & 6.104 & 0.040 & 0.021 & 0.046 & 0.041 & $3+042$ & 0,030 \\
\hline 1982 & 0.057 & 0.047 & 0.109 & 0,044 & 0.025 & 0.053 & $0,04 \mathrm{de}$ & 0.049 & $0,04$. \\
\hline $108 \pi$ & 0.656 & 0.045 & 0.005 & 0.046 & 0.025 & 0.055 & $0,0=K$ & 0,053 & 0.042 \\
\hline
\end{tabular}

\begin{tabular}{|c|c|c|c|c|c|c|c|c|c|}
\hline YGAF & LA & $r A$ & $n$ & 账 & MI & 测 & 此 & No & $\pi i$ \\
\hline--- & - & - & +..- & n......- & $\cdots$ & net+ot & $n$ & -- & \\
\hline 1970 & 0.009 & 0,017 & 0.013 & 0.012 & 0.013 & 0.014 & 0,014 & 0.010 & 0.005 \\
\hline 1971 & 0.009 & 0.018 & 0.0 .4 & 0.012 & 0.014 & 0.015 & 0.0 .4 & 0.011 & 0,05 \\
\hline 1972 & 0.009 & 0.020 & $\hat{0}+015$ & 0.013 & 0,014 & 0.016 & 0.015 & 0.012 & 0,005 \\
\hline 1973 & 0.010 & $0, \hat{0} 21$ & 0.016 & 0.014 & 0.015 & 0.016 & $0.0: 6$ & 0.013 & 0.005 \\
\hline 1974 & 0.014 & 0.034 & 0.025 & 0.020 & 0.021 & 0.019 & 0.019 & $0+018$ & 0.005 \\
\hline 1975 & 0.014 & 0,039 & 0.025 & 0.022 & $0 . \hat{0.27}$ & 0.023 & 0.00 & 0.021 & 0,07 \\
\hline 1976 & 0.014 & 0.040 & 0.027 & 0.021 & 0.029 & 0.025 & 0.025 & 0.025 & 0.007 \\
\hline 1977 & 0.017 & 0.044 & 0,028 & 0.023 & 0.091 & 0.000 & $5+62$ & 0.020 & Ml \\
\hline 1978 & 0,019 & 0.043 & 0.035 & 0,024 & 0.035 & 0,032 & 0,051 & 0,030 & $\therefore 0$ \\
\hline 1979 & 0.023 & 0.048 & 0.034 & 0.031 & 0.038 & 0.033 & $0.0 \%$ & 0.134 & 0,64 \\
\hline 1590 & 0,031 & 0.062 & $0,0.00$ & 0,045 & 0.045 & 0.030 & 0.58 & 0,039 & 0.010 \\
\hline 1481 & 0.065 & 0.075 & 0.044 & 0.051 & 0.051 & 0,042 & 0.040 & 0,048 & 0.014 \\
\hline 1362 & 0.045 & 0.071 & 0,049 & 0.0 .049 & 0,057 & 0,049 & 0,045 & 0,65 & $0+2 z$ \\
\hline 1985 & 0.047 & 0.073 & 0.047 & 0.047 & 0.055 & 0.047 & 0.04 & 0.0 .1 & U. \\
\hline
\end{tabular}


TABLE B.3 (CONT). Electricity Prices: Industrial Sector ( $\$ / \mathrm{kWh})$

\begin{tabular}{|c|c|c|c|c|c|c|c|c|c|}
\hline Fit: & 10 & KD & S & fiti & 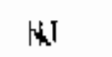 & $|v|$ & 期 & $N Y_{Y}^{Y}$ & H \\
\hline$\cdots$ & $+\ldots+\cdots$ & $\ldots$ & -- & $\cdots \cdot$ & --.-- & $\cdots$ & n....... & $\cdots$ & $\ldots$ \\
\hline 1970 & 0,009 & 0,020 & 0.012 & 0.014 & 0.013 & 0,012 & 0,07 & 0.012 & 0.010 \\
\hline 197 & 0.0010 & 0.021 & 0.012 & 6.0.14 & 0.016 & 0.012 & $0,00 \mathrm{R}$ & 0.013 & 0.011 \\
\hline 1972 & 0.011 & 0,022 & 0,013 & 0,015 & 0.017 & 0,012 & 0,000 & 0.014 & 0.011 \\
\hline $1 \% 73$ & 0,0112 & 0.022 & $6+014$ & $0.01 \mathrm{~B}$ & 0.019 & 0.013 & 0.000 & 0.015 & $0+011$ \\
\hline 1974 & 0.017 & 0.024 & 0.014 & 0.026 & 0.031 & 0,016 & 0.015 & 0.023 & 4.016 \\
\hline 1975 & 0.022 & 0.027 & 0.017 & 0.032 & 0.034 & 0.019 & 0.014 & $0,0, \bar{Z}$ & 0.015 \\
\hline 1976 & 0,023 & 0.029 & 0,020 & 0.632 & 0,035 & 0.022 & 0,121 & 0,07 & 6. \\
\hline 1977 & 0.025 & 0.031 & 0.021 & 6.034 & 0.041 & 0.027 & 0,024 & 0.031 & 0.02 \\
\hline 1979 & 0.027 & 0.032 & 0.022 & 0.039 & 0,042 & 0.034 & 9.025 & 8,032 & 0.025 \\
\hline i 979 & 0.028 & 0.032 & 0.024 & 0.043 & 0.045 & 0.042 & 0.031 & $0+036$ & 0,028 \\
\hline 1790 & 0.032 & $0+034$ & 0.030 & 3.054 & 0.068 & 0,041 & 0.040 & $\sqrt[0]{0,4+1}$ & 0,003 \\
\hline 291 & 0,035 & $0.04 !$ & 6,633 & 0.074 & 0.060 & 0.052 & 0.04 & 0.05 & $3+3$ \\
\hline 1992 & 0.045 & 0.050 & 0,030 & $9+29$ & $0+076$ & $0,0<0$ & $\div 047$ & 0,0 & iे, \\
\hline 1783 & 0.042 & 0.052 & 0.60 & 0.071 & 0.074 & 0.060 & 0.449 & 0,054 & $0+645$ \\
\hline
\end{tabular}

\begin{tabular}{|c|c|c|c|c|c|c|c|c|c|}
\hline HEAR & $a k$ & DR & $P A$ & SI & 35 & 51) & Ti⿱ & $\stackrel{T X}{1 X}$ & $\mathrm{UT}$ \\
\hline$\cdots$ & ....... & - & $+\infty+\infty$ & -- & $\cdots$ & 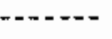 & - & & \\
\hline$\$ 70$ & 0.011 & 0.004 & 0,012 & i). 0117 & $0.00 \mathrm{~B}$ & 0.016 & {$[+6097$} & 0.004 & 0.013 \\
\hline 571 & 0.011 & 0.005 & 0.054 & 0.018 & 0.009 & 0.017 & 0.046 & 0,029 & 0,011 \\
\hline 1472 & 0.011 & 0.005 & 0.015 & 0,020 & 0.009 & 0,017 & $\mathrm{~B}+\mathrm{WWO}$ & $\theta, 60 \%$ & 0,014 \\
\hline 1973 & 0.011 & 0,005 & $0 . \hat{0}] \phi$ & 0.021 & 0,010 & $\hat{0}, 017$ & 0,0109 & 0.010 & 0.014 \\
\hline 1974 & 0.012 & 0.005 & 0.023 & 0,036 & 0.015 & 0,019 & 0,011 & 0,013 & 0,015 \\
\hline .575 & 0,015 & 0,007 & 0.027 & 0.039 & 0.020 & 0.021 & $0.0 \mathrm{j} 7$ & 0.015 & $0.0 \mathrm{it}$ \\
\hline $1976^{\circ}$ & 0.019 & 0.009 & 0.027 & 0.033 & 0.021 & 0.023 & 0.018 & 0.020 & 0,021 \\
\hline 1977 & $\hat{0}+023$ & 0,010 & 0.0 .81 & 0.043 & 0.023 & 0,024 & 0.60 & 0.028 & 0.02 \\
\hline 1579 & 0.085 & 0.011 & $\{0, \hat{1} 3\}$ & 0.044 & 0.020 & 0,027 & 0.025 & $\hat{6}+0,5$ & 0,02 \\
\hline 1579 & 0.026 & 0.013 & 0,036 & 0.050 & 0.027 & 0.028 & 0.050 & 0,028 & 0,030 \\
\hline 1990 & 0.032 & 0.016 & 0.044 & 10,063 & 0.029 & 0.033 & .039 & 0.034 & 0.035 \\
\hline$\$ 981$ & 0.037 & 0.020 & 0.069 & $0.07 \%$ & 0.034 & 0.037 & $0, \hat{0}<\hat{0}$ & 0,042 & , ong \\
\hline 1782 & 0.042 & 0.030 & 4.058 & 0.077 & 0.039 & 0.044 & $130+046$ & 0,01 & 0,045 \\
\hline 1983 & 0.044 & 0.034 & $0.05 \%$ & 0.079 & 0.040 & 0,043 & 0.047 & 0.053 & onto \\
\hline
\end{tabular}

\begin{tabular}{|c|c|c|c|c|c|c|c|}
\hline 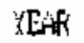 & $V_{A}$ & $V I$ & $\mathrm{H} \dot{\mathrm{A}} \mathrm{A}$ & HI & $W$ & $W Y$ & $\mathrm{US}$ \\
\hline & 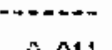 & - & n..... & & a.c. & ans & and \\
\hline 1970 & 0.011 & 0.018 & 0.003 & 0.015 & 0.009 & 0.011 & 5.010 \\
\hline 1971 & 0,011 & 0.016 & 0,0013 & 0.015 & 0.010 & 0.011 & 0.011 \\
\hline 1972 & 0.012 & 0.018 & 0,000 & 10016 & 0,011 & 0.011 & 0,012 \\
\hline$: 973$ & 0.013 & 0.019 & 0.024 & 0.017 & 0.012 & 0,011 & 0.013 \\
\hline 174 & 0.020 & 0.025 & 0.004 & 0,019 & 5.017 & 0,012 & 5,017 \\
\hline .775 & 0,025 & $\hat{0}+02 \dot{0}$ & 0.605 & $\hat{0.020}$ & 0,022 & 0,012 & 0.021 \\
\hline 197 & 0,024 & 0.028 & 0.005 & $\hat{3}+025$ & 0.023 & 0,013 & 0.022 \\
\hline 5977 & 0.029 & 0.028 & 0.015 & 0.028 & 0.023 & 0.014 & 0,025 \\
\hline 198 & 0,031 & 0.030 & 0,005 & 10.029 & 0.026 & 0,017 & 3,026 \\
\hline 1979 & 0.034 & 0.031 & 6,605 & 0.030 & 0.026 & 0.017 & 0.03 \\
\hline 380 & 0,042 & 0.039 & $0.00,5$ & 0.035 & 0.029 & 0.018 & $3+037$ \\
\hline 2981 & 0.042 & 0,048 & 0.011 & 0.034 & 0.033 & 0,025 & 6.043 \\
\hline $1 \div 92$ & 0.047 & 0.054 & 6.017 & 0,045 & 0.040 & 0,032 & $i, 65 j$ \\
\hline 1983 & 0.047 & 0,058 & 0.022 & 0.047 & 0.040 & 0.035 & 0.50 \\
\hline
\end{tabular}


TABLE B.4. Electricity Prices: Transportation Sector ( $\$ / \mathrm{kwh})$

\begin{tabular}{|c|c|c|c|c|c|c|c|c|c|}
\hline YEAF & $A$ & AL & th & $A \bar{Z}$ & $C A$ & $\mathrm{O}$ & {$[T$} & $\mathrm{IC}$ & it: \\
\hline-- & $n$ & - non & - & 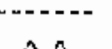 & ה & 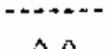 & 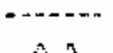 & $x^{2}$ & \\
\hline $\begin{array}{l}1970 \\
1971\end{array}$ & $\begin{array}{l}0.0 \\
0,0\end{array}$ & $\begin{array}{l}0.0 \\
0.0\end{array}$ & $\begin{array}{l}0.012 \\
0.012\end{array}$ & $\begin{array}{l}0+0 \\
0,0\end{array}$ & $\begin{array}{l}0.010 \\
0.010\end{array}$ & $\begin{array}{l}0,0 \\
0.0\end{array}$ & $\begin{array}{l}0+3 \\
0,0\end{array}$ & $\begin{array}{l}3.013 \\
0.015\end{array}$ & $\begin{array}{l}0,11 \\
0,0\end{array}$ \\
\hline 172 & 0,041 & 0.0 & 0.0 .3 & 0.0 & 0.010 & 0.0 & 0.0 & 0.016 & , i. \\
\hline 1970 & 0.071 & 0.0 & 0.015 & 0.0 & 0.011 & 0.0 & 0.0 & 0.017 & 4,0 \\
\hline 1974 & 0.075 & 0.0 & 0.322 & 0.0 & 0.013 & 0,0 & $\hat{v}_{4}, 3$ & $0+126$ & 00 \\
\hline 1975 & 0.032 & 0.0 & $\left(1,0 \mathrm{E}^{\mathrm{E}}\right.$ & 0.0 & 0,015 & $0 . \hat{0}$ & 0.0 & 3,020 & (2) +0 \\
\hline 1976 & 0.031 & 0.0 & 0.227 & 0.0 & 0.017 & 0.0 & 0.3 & 0,026 & 0.0 \\
\hline 1977 & 0.031 & 0,0 & 0,019 & 0.0 & $0.02 \mathrm{E}$ & 0.0 & $\dot{0} .0$ & 0.025 & 0.0 \\
\hline 1978 & 0,030 & 0.0 & 0.0 .4 & 0.0 & 0.031 & 0.0 & 0.0 & 0.03 & 0.4 \\
\hline 1479 & 0.034 & 0.0 & 6.020 & $\hat{0}+\hat{0}$ & 0.025 & 0.0 & 300 & $0,0,30$ & 0.6 \\
\hline 1780 & 0.03 & 0.0 & 0.029 & 0.0 & 0.034 & 0.0 & 0.3 & 0.043 & 0.0 \\
\hline 1981 & 0.026 & $0 . \hat{0}$ & $6+029$ & 0.075 & 0.045 & 0.0 & $\dot{y} .0$ & 0.050 & 0.0 \\
\hline 1982 & 0.030 & 0.0 & 0.929 & 0.250 & 0.063 & 0,0 & 0.3 & 0.063 & 5.0 \\
\hline 1483 & 0.041 & 0.0 & (6) & 0.047 & 0.070 & 0.0 & 0,067 & 0.065 & 0.0 \\
\hline
\end{tabular}

\begin{tabular}{|c|c|c|c|c|c|c|c|c|c|}
\hline YEA & $F L$ & $G \mathrm{~A}$ & $H I$ & $\overline{i A}$ & ID & II & IN & $\mathrm{ks}$ & $T_{i}$ \\
\hline$\cdots$ & n.t. & n. & . & -........ & 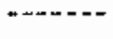 & $\cdots$ & $\cdots$ & $\cdots$ & 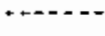 \\
\hline 1370 & 0.0 & 0.0 & 0.0 & 0.0 & 0.0 & 0.014 & 0,228 & 0.0 & 0.1 \\
\hline 1971 & 0.00 & 0.0 & 0.0 & 0.0 & 0.0 & 0,015 & $3,02[t$ & 0.0 & 0,0 \\
\hline 1972 & 0.0 & 0.0 & $\hat{9}+3$ & 0.0 & $0+0$ & 0,016 & 0.209 & 0.0 & $\sqrt[5]{0}$ \\
\hline 1973 & 0.0 & 0.0 & 4.0 & 0.0 & 0.0 & 0.017 & 130.021 & 0,0 & 0.0 \\
\hline 1974 & 0.0 & 0.0 & 0.5 & 0.0 & 0.0 & 0.020 & $0.2 t$ & $0+0$ & $0+\hat{2}$ \\
\hline 1975 & 0.0 & 0.0 & $\pi_{1} 0$ & 0.0 & 0.0 & 0.021 & $0+0 \hat{v i c}$ & 0.0 & $\sqrt[n]{0}$ \\
\hline 1976 & 0.0 & 0.0 & 0.4 & 0.0 & 0.0 & 0.023 & 0.038 & 0.0 & 0.0 \\
\hline 1977 & 0.0 & 0.0 & 0.0 & 0.0 & 0.0 & 0.025 & 0.046 & 0.0 & 0.0 \\
\hline 1978 & 0.0 & 0.0 & 0.5 & 0,0 & 0.0 & 0.028 & 0.053 & 6.0 & $0+\overrightarrow{0}$ \\
\hline 1979 & 0.0 & 0.032 & 0.0 & $0 . \hat{v}$ & 0.0 & 0.032 & 0.056 & 0.0 & 50 \\
\hline 1980 & 0.0 & 0.034 & 0.0 & 0.0 & 0.0 & 0,040 & 0.043 & 0,0 & 0.0 \\
\hline $1 ; 01$ & 0.0 & 0,041 & 0.0 & 0.0 & 0.0 & 0.047 & 0,078 & 0.0 & $5+0$ \\
\hline 1982 & 0.0 & 0.044 & 0.0 & 0,0 & 0.0 & 0,055 & $0.0 \%$ & 0,0 & 0.0 \\
\hline 1483 & 0,0 & 0.042 & 5.0 & 0.0 & 0,0 & 0,060 & 0.096 & 0,0 & 0,0 \\
\hline
\end{tabular}

\begin{tabular}{|c|c|c|c|c|c|c|c|c|c|}
\hline YEAK & IA & $\mathrm{HA}$ & 腛 & $M E$ & $M_{i}$ & 洲 & 㳐 & 证 & 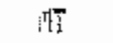 \\
\hline$\cdots$ & (1) & A & & 00 & 00 & & 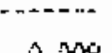 & - & \\
\hline $\begin{array}{l}1970 \\
1 \$ 71\end{array}$ & $\begin{array}{l}0.013 \\
0.0\end{array}$ & $\begin{array}{l}0.019 \\
0.028\end{array}$ & $\begin{array}{l}0.013 \\
3+015\end{array}$ & $\begin{array}{l}0.0 \\
0.0\end{array}$ & $\begin{array}{l}0.0 \\
0.0\end{array}$ & $\begin{array}{l}0.0 \\
0.0\end{array}$ & $\begin{array}{l}0.009 \\
0.010\end{array}$ & $\begin{array}{l}0.0 \\
0,0\end{array}$ & $\begin{array}{l}0.06 \\
0.005\end{array}$ \\
\hline 1972 & 0.014 & 0.030 & 0.5 .6 & 0.0 & 0.0 & 0.0 & 9.311 & 0.0 & $b_{H}$ \\
\hline 1973 & 0.012 & 0.025 & 0.017 & 0.0 & 0.0 & 0.0 & 3,012 & 0,0 & 0.605 \\
\hline 1974 & 0.0 & 0.044 & 0.225 & 0.0 & 0.0 & 0.0 & $0.2: 4$ & 0.0 & $0+005$ \\
\hline 1975 & 0,0 & 0.050 & $\bar{y}+028$ & 0.0 & 0.0 & 0.0 & in, 019 & 0.0 & 0,0 \\
\hline 1976 & 0.0 & 0.062 & 0.026 & 0.0 & 0.0 & 0.0 & 0.024 & 0.0 & $0+0$ \\
\hline 1977 & 0.0 & $\sqrt{1}+064$ & 0,05 & 0,0 & 0,0 & 0.0 & $i_{1}, 0 i$ & 0,0 & 0,4 \\
\hline 1978 & 0,0 & $0.0 \% 2$ & 0.96 & 0.0 & 0.0 & 0.0 & $0+13$ & $0_{\mathrm{i}}$ & 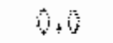 \\
\hline 197 & 0.0 & 0.063 & $A F$ & 0.0 & $0,1)$ & $0 . \hat{0}$ & 500 & 0,0 & 0,6 \\
\hline 1700 & 0.0 & $0+\overrightarrow{0} 7 \overrightarrow{4}$ & 0.343 & 0.0 & 0.0 & 0.0 & 0.036 & 0,0 & 0,0 \\
\hline 1981 & 0,0 & 0.083 & 0.050 & 0,0 & 0.0 & 0,0 & 2.045 & 0,0 & $3+4$ \\
\hline 170 & 0.0 & 0.091 & $0+354$ & 0.0 & 0.0 & 0.0 & 0.042 & 0.0 & 0,0 \\
\hline 1783 & 0.0 & 0.062 & 0,052 & 0.0 & 0.0 & 0.0 & 3,641 & $\omega_{i} 0$ & 0.0 \\
\hline
\end{tabular}


TABLE B.4 (CONT). Electricity Prices: Transporation Sector ( $\$ / \mathrm{kWh})$

\begin{tabular}{|c|c|c|c|c|c|c|c|c|c|}
\hline DEAK & 蜅 & HiD & 谟 & 骕 & ithi & th & 堣 & in & $\mathrm{OH}$ \\
\hline 1970 & 0.0 & 0,0 & $0+j, 1$ & 0.0 & 0,016 & 0.0 & 0,0 & 9.016 & 0,014 \\
\hline 197 & 0,0 & 0.0 & $i, 011$ & 0.0 & 0.020 & 0.0 & 0.0 & 0,019 & a.t: \\
\hline 1972 & 0.0 & 0.0 & 0.3 .3 & 0.0 & 0,017 & 0.0 & 0.0 & 0,04 & 0,110 \\
\hline 1973 & 0.0 & 0.0 & 0,011 & 0.0 & 0.021 & 0.0 & 0.0 & $2: 025$ & 0.917 \\
\hline 1974 & 0.0 & 0.0 & 0.21 & 0.0 & $0+0 Z^{\circ}$ & 0.0 & 0.0 & 0,342 & 0.024 \\
\hline 1975 & 0.0 & 0.0 & 0.014 & 0.0 & 0.039 & 0.0 & 0.0 & 0.047 & 0.020 \\
\hline 1976 & 0.0 & 0.0 & $0.0 \div 5$ & 0.0 & 0.032 & 3.0 & 0,0 & 0.047 & $0+327$ \\
\hline 1977 & 0.0 & $0 . \hat{0}$ & 6,016 & 0,0 & 0.036 & 0.0 & 0,0 & 0.039 & n., \\
\hline 1779 & 0.0 & 0.0 & 0.06 & 0.0 & 0.034 & 0.0 & 0.0 & 0.046 & 0.741 \\
\hline 1979 & 0.0 & 0.0 & 9.016 & 0.0 & 0.041 & 0,0 & 7,0 & 0,052 & 0.045 \\
\hline 1980 & 0.0 & 0.0 & 0.026 & 0.0 & 0.051 & 0.0 & 0.0 & 0.051 & 0.046 \\
\hline 1964 & 0.0 & 0.0 & 0,025 & 0.0 & $0.06 \mathrm{a}$ & 0.0 & 0,0 & 0.059 & 6.058 \\
\hline$\$ 982$ & 0.0 & 0.0 & 6,32 & 0,0 & 0.054 & 0.0 & 0.0 & 9,174 & 0,102 \\
\hline 1903 & 0.0 & 0.0 & 0.0 .39 & 0.0 & 0.065 & 0.0 & 9.0 & 0.98 & 0,07 \\
\hline
\end{tabular}

\begin{tabular}{|c|c|c|c|c|c|c|c|c|c|}
\hline YEAF & GR & DK & $\mathrm{FH}$ & RI & $x$ & 5II & $T \mathrm{~T}$ & 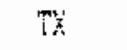 & $j i$ \\
\hline$\cdots$ & ----- & - & 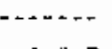 & - & - & $2+\infty$ & $\cdots-$ & $\cdots$ & ... \\
\hline 1970 & 0.0 & 0.0 & 0.322 & 0.0 & 0.0 & 0.0 & $\hat{0}+0$ & 0,0 & 0,0 \\
\hline 1771 & 0.0 & 0.0 & 0.015 & 0.0 & 0.0 & $\hat{0}, \hat{0}$ & 3.0 & 300 & 0.0 \\
\hline 1772 & $\hat{0}+0$ & 0,0 & 0.07 & 0.0 & 0.0 & 0.0 & 0,0 & $0+3$ & 0.0 \\
\hline 1973 & 0.0 & 0.0 & 0.018 & 0.0 & 0.0 & 0.0 & $5: 0$ & 0,0 & 0.0 \\
\hline 1974 & 0.0 & 0.0 & 0.026 & 0.0 & $\hat{0}+0$ & 0,0 & 0,0 & 0.0 & 0.0 \\
\hline 1975 & 0.0 & 0.0 & 0.029 & 0.0 & $0 . \hat{0}$ & 0.0 & 0.0 & 0,0 & 0.0 \\
\hline 1976 & 0.0 & 0.0 & 0,127 & 0.0 & 0.0 & 0.0 & 0,0 & 0.0 & 30 \\
\hline 147 & 0.0 & 0.0 & 0.032 & 0.0 & $\hat{U}+\hat{0}$ & 0.0 & 3,0 & $i, 0$ & 5,0 \\
\hline 1378 & 0.0 & 0.0 & 0.332 & 0.0 & 0.0 & 0.0 & 0.0 & 0.0 & on \\
\hline 1979 & 0.0 & 0.0 & $0,0=5$ & 0.0 & 0.0 & 0,0 & 9,0 & 0,0 & 0.0 \\
\hline 1700 & 0.0 & 0.0 & 0.052 & 0.0 & 0,0 & 0.0 & $\hat{\theta}+\hat{0}$ & 0.0 & 0.4 \\
\hline 1781 & 0.0 & 0.0 & 0,06 & 0.0 & 0.0 & 0,0 & 4.00 & $\hat{3}, 0$ & 0.6 \\
\hline 1902 & 0.0 & $0+0$ & 0.08 & 0.0 & $0+0$ & 0,0 & $0+3$ & $0 . \overline{10}$ & +4 \\
\hline 1983 & 0,0 & 0.0 & 5,045 & 0.0 & 0,0 & $\hat{v}+\hat{v}$ & 0.0 & 50 & 0.0 \\
\hline
\end{tabular}

\begin{tabular}{|c|c|c|c|c|c|c|c|}
\hline IEAK & $V_{A}$ & 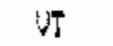 & WA & WI & $\mathbb{N}$ & لي & US \\
\hline$\cdots$ & mancos- & $-\cdots,-$ & $-\ldots . . .$. & - & ---..- & $\cdots+\infty$ & $\cdots$ \\
\hline 1970 & 0.0 & 0.0 & 0.207 & 0.0 & 0.0 & 0,0 & 0.315 \\
\hline 1971 & 0.0 & 0.0 & 0.087 & 0,0 & 0.0 & 0.0 & 0,017 \\
\hline 1972 & 0.0 & 0.0 & 0,008 & 0.0 & 0.0 & 0.0 & 0.019 \\
\hline 1973 & 0.0 & $0+0$ & 0.009 & 0.0 & 0.0 & 0.0 & 0.022 \\
\hline 1974 & 0.0 & 0.0 & 0.010 & 0.0 & 0,0 & 0.0 & 0,034 \\
\hline 1975 & 0.0 & 0.0 & $\tilde{0}, 011$ & 0,0 & 0.0 & $0 . \hat{0}$ & $0,03 i$ \\
\hline 1976 & 0,0 & 0,0 & 0.011 & $0,1]$ & $\hat{b}+\ddot{u}$ & 0.0 & 0.030 \\
\hline$\$ 97$ & 0.0 & 0.0 & $0.01 \%$ & 0,0 & 0.0 & 0.0 & 0,03 \\
\hline 178 & 0,050 & 0.0 & $0.0 \pm 3$ & 0.0 & 0.0 & 0.0 & 0.034 \\
\hline 1979 & 0.051 & 0.0 & Gots & 0.0 & 0.6 & 0.0 & 0.045 \\
\hline 1980 & 0.050 & 0.0 & 0.015 & $\hat{0}, \hat{0}$ & $0+0$ & 0.0 & 0.047 \\
\hline 1901 & 0.0 .00 & 0.0 & 0.067 & 0.0 & 0.0 & 0.0 & 0.046 \\
\hline 1702 & 0.061 & 0.0 & 0,019 & 0.0 & $0+0$ & 0.0 & 0.068 \\
\hline 1903 & 0.062 & 0.0 & 0.021 & 0,0 & 0.0 & $0 . \hat{0}$ & 0.075 \\
\hline
\end{tabular}


TABLE B.5. Natural Gas Prices: Residentia) Sector $(\$ / 1000 \mathrm{cu} f \mathrm{t})$

\begin{tabular}{|c|c|c|c|c|c|c|c|c|c|}
\hline IEAR & $A K$ & AL & 保 & $A Z$ & $C A$ & $C 0$ & at & $\mathrm{IC}$ & DE \\
\hline$-\cdots$ & ........ & 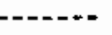 & 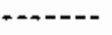 & 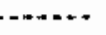 & -- & n.... & $\cdots$ & - & \\
\hline 1700 & $2+519$ & 1.150 & 0.754 & $1.1 \%$ & 0.985 & 0,719 & 1.712 & 1.455 & \pm .58 \\
\hline 1971 & 1.531 & 1,186 & 0.797 & 1,226 & 1.034 & 0.746 & 2,064 & 1.511 & 1,627 \\
\hline 1372 & 1,553 & 1.266 & 0.327 & 1.244 & $1,07 \%$ & 0.782 & 2.34 & 1.649 & 1,700 \\
\hline 197 & 1.574 & 1.348 & 3.972 & $1+368$ & $1+161$ & 0.825 & 2.247 & $1, n B_{1}$ & 1,65 \\
\hline $17 \% 4$ & 1,580 & 1.550 & 1.00 & 1.500 & 1.390 & 1.000 & 2.750 & $1+707$ & 2.110 \\
\hline 1975 & 1.627 & 1.568 & 1.116 & 1.534 & 1.574 & \pm .157 & 3.25 & 2302 & 2,426 \\
\hline 1976 & 1.653 & 1.989 & 1.227 & 2.117 & 1.771 & 1.268 & $3+4 \mathrm{i1}$ & 2.574 & $2+6+47$ \\
\hline 1977 & 1,710 & 2.309 & 1. & 2,612 & 1.987 & $1+625$ & 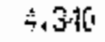 & 3,28 & 3.24 \\
\hline 1379 & $1.7 \omega$ & 2.706 & 1.960 & 3.070 & 1,985 & 1,408 & 4.473 & 3,400 & 4,600 \\
\hline $147 \%$ & $1.70 \mathrm{~B}$ & 3.651 & $1,5 \times 5$ & 3.504 & 2.469 & $2+436$ & 4746 & 3.764 & 4,025 \\
\hline 1980 & $1.7 \%$ & 4.046 & 2.474 & 4.052 & 3.517 & $3.23 y$ & $5.95 \%$ & 4.574 & 4.300 \\
\hline 1981 & 1.454 & 4.774 & 3.044 & 4,622 & 3.735 & 4.175 & 8.851 & 5.499 & 5. \\
\hline 1982 & 1.797 & $5, \overline{3} 3$ & 3.30 & 5.925 & 4,430 & 4.899 & $8+515$ & Srót5 & $8+347$ \\
\hline 1983 & 2,336 & 6.224 & $5_{1}+46$ & 6,409 & 5.413 & 5.516 & $9.7 \mathrm{EE}$ & $3: \sqrt{0}$ & $0,5 \%$ \\
\hline
\end{tabular}

\begin{tabular}{|c|c|c|c|c|c|c|c|c|c|}
\hline TEAK & $\mathrm{Fl}$ & $G$ & $\mathrm{HI}$ & $\mathrm{IH}$ & ID & il & IN & $\mathrm{K}_{\mathrm{K}}$ & $\overline{K I}$ \\
\hline 1970 & 2.514 & 1.048 & 0.5 & 0,946 & 1.391 & 1.046 & +50 & 0.685 & 0.99 \\
\hline 1971 & 2.597 & $1+133$ & $i, 0$ & 1.027 & 1.494 & 1.072 & 1,056 & 0.717 & $4,4 \times 0$ \\
\hline 1772 & $2.65 \mathrm{~B}$ & 1.257 & 0.0 & 1.106 & 1.507 & 1,135 & 1.130 & $0, \pi$ & 0,95 \\
\hline $197 \%$ & 2.702 & 1.303 & {$[1,0$} & 1.30 & 1.521 & $1+213$ & 1.285 & (1):74 & 9,489 \\
\hline 1574 & 2.850 & 1.400 & 0.0 & 1.220 & 1.800 & 1.350 & 1.280 & 0,900 & $1+100$ \\
\hline $1 \% 5$ & 2.739 & 1.497 & 0 & 1.427 & 2.181 & 1,613 & 1.455 & 1.09 & 1.07 \\
\hline 1976 & $2+813$ & 1.655 & 0.0 & $1+b+2$ & 2.241 & 1.098 & $1.6 \%$ & 1.482 & 1.320 \\
\hline 1977 & 3.529 & 1.966 & 6.0 & 1.495 & 2,857 & $2+213$ & 2,022 & 1.734 & $1.70 \mathrm{~g}$ \\
\hline 1578 & 3.540 & 2.330 & 0.0 & $2+252$ & 3.407 & 2.503 & 2.138 & 1.770 & $\therefore 97$ \\
\hline 179 & 3,700 & $2+877$ & $\therefore .0$ & $2+684$ & 3.725 & 3.006 & $2, m+2$ & 1.952 & 2.355 \\
\hline 1780 & 4.802 & $3+679$ & 12.997 & $3.1 \% 2$ & 4,979 & 3.612 & 3.155 & 2.347 & 3.725 \\
\hline 1081 & 5.307 & $4+342$ & 15.572 & $3+895$ & 5.570 & 4.046 & 3,07 & 3004 & 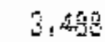 \\
\hline 1002 & 6.598 & 5,334 & 15.708 & 4.695 & 6.927 & 4.733 & 4.384 & 4,061 & 4.467 \\
\hline 1083 & 6.957 & 6.105 & 16,49 & 5.523 & 7,393 & 5.467 & $54 \%$ & $4,60:$ & 5,303 \\
\hline
\end{tabular}

\begin{tabular}{|c|c|c|c|c|c|c|c|c|c|}
\hline 泟 & LA & inA & Mi & 测 & MI & 训 & 酒 & 性 & AT \\
\hline$\cdots$ & ...e.n. & - & - n. & -- & $\cdots-$ & & & & \\
\hline 1970 & 0.774 & 1.919 & 1.455 & 1.980 & 1.015 & 1.096 & 0.364 & 0.394 & $0+900$ \\
\hline 141 & 0.711 & 2.119 & 1.511 & $2+053$ & 1.063 & 1.183 & 1.016 & 0,944 & $0 . \% 9$ \\
\hline 1772 & 0.915 & 2,290 & 1.649 & 2,140 & 1.049 & 1,231 & 1.097 & 1.085 & $\hat{D}_{+} \bar{Y} \mathrm{H}$ \\
\hline 1973 & 0.973 & 2,401 & 1,681 & 2,174 & 1.182 & 1.304 & 1.161 & 1,009 & i.08t \\
\hline 1974 & 1.120 & 2,710 & 1.707 & 2.37 & 1.370 & 1.410 & 1.270 & 1.230 & $\therefore+120$ \\
\hline 1475 & 1.360 & $3+152$ & 2.395 & 2.648 & $1,62 \mathrm{i}$ & 1.509 & 1,495 & 1,408 & $1.2 \%$ \\
\hline 1976 & $\$ .571$ & 3.642 & 2.574 & 2.880 & 1,894 & 1.738 & 1.697 & 1.712 & $4-32 A$ \\
\hline 1977 & 1.973 & 3.750 & $3,2 \mathbb{1}$ & 3.623 & 2.225 & 2.132 & 2.184 & $2: 19$ & 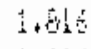 \\
\hline 178 & 2,470 & 4,167 & 3,400 & $3.5 / 2$ & $2,30.9$ & 2,406 & 2.204 & $2+348$ & $1+3 \% 4$ \\
\hline 1979 & 2.705 & 4.554 & 3,766 & 4,100 & 2.644 & 2.35 & $2 \pi T^{2}$ & 2.601 & $2+2 i=$ \\
\hline 1790 & 3.403 & 5.421 & 4,477 & 6.350 & 3.191 & $3+228$ & 3.286 & $3+479$ & 3.053 \\
\hline 1781 & 4.149 & 6.372 & $=045$ & 7,449 & 3.945 & 4.080 & 4.021 & 3,40 & $3.72^{4}$ \\
\hline 1702 & 5.325 & 7.542 & $6+127$ & 8.638 & 4.750 & 4.962 & $5+202$ & 4.91 & 4,480 \\
\hline 1983 & 6.120 & 8.327 & $7+432$ & 4.835 & 5.946 & 5.906 & 6.53 & 5.307 & 4,67 \\
\hline
\end{tabular}

B. 11 
TABLE B. 5 (CONT). Natural Gas Prices: Residential Sector $(\$ / 1000 \mathrm{cu} \mathrm{ft}$ )

\begin{tabular}{|c|c|c|c|c|c|c|c|c|c|}
\hline 'BGÁ' & $3 \mathrm{C}$ & $S D$ & $N E$ & トH & Wi & $1+3$ & iv & 刘 & $\mathrm{OH}$ \\
\hline$\cdots$ & - & $\cdots$ & - & . & - & 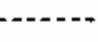 & $\cdots$ & $\cdots$ & \\
\hline 1770 & $1+300$ & 1,024 & 0.851 & 1.386 & 1.808 & 0.928 & 1.507 & 1.379 & 0.900 \\
\hline 1971 & 1,338 & 1.059 & 5,422 & 2.053 & 1.946 & 0.95 & 1.512 & i. $49 \%$ & 0.484 \\
\hline 1772 & 1,407 & 1.132 & $0, w_{1}$ & 2.140 & 2,018 & 0.973 & $1,3_{4}$ & 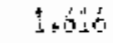 & $\therefore+15=$ \\
\hline 1973 & 1.505 & 1.144 & $1.0 \mathrm{Al}$ & 2,174 & 2.083 & 1,003 & 1.536 & 1.741 & 1.110 \\
\hline 1974 & 1.650 & 1.190 & 1,140 & $2+3 \pi$ & 2,250 & 1.240 & 1,720 & 2,000 & 1.245 \\
\hline 1975 & 2,024 & 1.509 & 5.281 & $2+648$ & $2+692$ & 1.330 & 1.750 & 2,536 & 1.504 \\
\hline lith & 2.130 & 1.750 & 1,360 & $2+580$ & 3.140 & 1.363 & 2.043 & 2.870 & 1.773 \\
\hline 1977 & 2,312 & 2.106 & \pm .79 & $5,+23$ & 3.423 & 2.115 & $\because 782$ & 3.241 & 2.212 \\
\hline 1978 & 2.990 & 2.328 & 1,908 & $3.5 / 2$ & 3.533 & 2.486 & $2+800$ & 3.67 & 2,42 \\
\hline 197 & 3.516 & 2.879 & 2,304 & 4,103 & 4,300 & 2.732 & 2.832 & 4.124 & 2.30 \\
\hline $1 \% 80$ & $4+110$ & 3.351 & 2,724 & $4+6 \div 3$ & 5,065 & 3.323 & $4,3<0$ & 4.756 & 3.54 \\
\hline 1881 & 5.172 & $4+27$ & 345 & 5,476 & 5.973 & 3.084 & 4.85 & 5.00 & $3+76$ \\
\hline 192 & 5.731 & 4.612 & 4,157 & 6.952 & 7.032 & 4.748 & 5.34 & 4.517 & 4.965 \\
\hline 69 & 6.657 & 5.570 & $4+\$ 57$ & 7.476 & 7.435 & 5.500 & 6.816 & 7.374 & B. $\mathrm{WH}^{7}$ \\
\hline
\end{tabular}

\begin{tabular}{|c|c|c|c|c|c|c|c|c|c|}
\hline IPAR & ㅈ. & $O R$ & $F^{\prime} A$ & FII & 50 & SD & TN & $T X$ & ЦiT \\
\hline 1970 & 0,341 & 1.511 & $1+237$ & $1.8 \widetilde{3} 2$ & 1.353 & 1.040 & 0.72 & $0+92$ & 0.85 \\
\hline 1971 & 0.874 & $1+600$ & 1,280 & 1.932 & 1,470 & 1.102 & 0.476 & $0,9 \% 3$ & 0.873 \\
\hline 1772 & 0.898 & $1+673$ & 1,356 & 2,053 & 1.615 & 1.132 & $1+\sqrt{2}+4$ & 1.314 & 6.901 \\
\hline 1973 & 0.919 & 1.764 & $1+481$ & 2,373 & 1.652 & 1.194 & 1,077 & 1,00 & 4. \\
\hline 1974 & 1,050 & 2,000 & 1.600 & 2.550 & 1,970 & $1+290$ & 1.170 & 1.170 & $1+070$ \\
\hline 1975 & $1+21 B$ & $2+190^{\circ}$ & $1,9 \mathrm{~A}$ & $3+085$ & $2+130$ & 1,397 & $1,2 \% 1$ & 1.523 & 1,215 \\
\hline 1974 & 1.497 & 2.682 & 2.139 & 3.320 & $2+291$ & 1.501 & $1+611$ & 1,807 & 1.379 \\
\hline 1977 & 1,793 & 3.432 & 2.506 & $4+223$ & 2.974 & 1,828 & 2,094 & $2 \times 32$ & 1,637 \\
\hline 1778 & 1,930 & 3.827 & $2+633$ & 4.130 & 3.004 & $\left.2+10^{0}\right)$ & $2+140$ & 2,731 & $1, \sqrt{25}$ \\
\hline 1979 & $2+198$ & 4.122 & $3 .: 72$ & 3.686 & 3.501 & $2+615$ & 2.35 & 3.214 & 2.22 \\
\hline 1760 & 2,461 & 5,604 & $3,90 \%$ & 5.692 & $4+192$ & 3.132 & $2+391$ & $3+407$ & 2,741 \\
\hline 1981 & 2.945 & 6.063 & 4.509 & B.bó & 4.902 & 3.912 & 3.40 & 4.997 & 3.20 \\
\hline 1,782 & $3.5,44$ & 6.72 & 5.424 & 7.900 & 5.515 & 4.711 & $4+320$ & 5.312 & $3+410$ \\
\hline 1489 & 4,335 & 7.239 & $6.4+3$ & 8.600 & 6.380 & 5.551 & $5+21$ & 5.509 & 4,26 \\
\hline
\end{tabular}

\begin{tabular}{|c|c|c|c|c|c|c|c|}
\hline IEF: & VA & $\operatorname{Vi}$ & 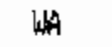 & HI & 组 & th & $\mathrm{U}_{i}$ \\
\hline$x_{0 \rightarrow x}$ & 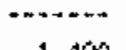 & - & 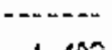 & $\cdots+\infty$ & $-\overline{-1}$ & 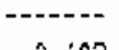 & \\
\hline 1970 & 1.450 & 1.986 & 1,403 & 1,247 & 0.891 & 0.682 & 1.090 \\
\hline $1 \% / 1$ & 1.522 & 2.053 & 1.434 & 1.264 & 0.738 & 0.707 & 1.149 \\
\hline 1972 & 1.559 & 2.140 & 1.407 & 1.339 & 0.964 & 0.740 & 1,214 \\
\hline 1973 & 1,679 & 2.174 & 1,552 & 1.429 & 0.974 & 0.765 & $1.2 \mathrm{gi}$ \\
\hline 1574 & 1.370 & 2.377 & 1.770 & 1.500 & 1.100 & 0.850 & 1,431 \\
\hline$\{97\}$ & 2.244 & $2+648$ & 2.274 & 1.746 & 1,453 & $1.0 \mathrm{i} 7$ & $1.70 \mathrm{~g}$ \\
\hline 1976 & 2.535 & 2,680 & 2.695 & 2.110 & $1, \sin$ & 1.194 & $1+778$ \\
\hline 197 & 3.028 & $3+2.23$ & 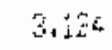 & 2,495 & 2.547 & 1,585 & $2.3+5$ \\
\hline 1.379 & 3.26 & 3,572 & 3.482 & $2+283$ & 2.610 & 1.911 & $2+\pi / 3$ \\
\hline 147 & 3.720 & $4+103$ & 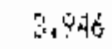 & 3,60 & 2,955 & 2.513 & $2+9$ \\
\hline 1780 & 4,265 & $6+231$ & $5+313$ & $3+340$ & 3.545 & $2+820$ & $3+692$ \\
\hline 1981 & 4,659 & 6.599 & $3.06 \%$ & $4, \pi 71$ & 4,241 & 3.511 & 4.290 \\
\hline 1702 & 6,030 & 7.245 & 4.870 & 5.643 & 5.209 & 4.539 & 5.177 \\
\hline \multirow[t]{2}{*}{148} & 7.031 & 6.798 & $6.87 \%$ & 6.427 & 6.003 & 5.131 & $600 \mathrm{~s}$ \\
\hline & \multicolumn{7}{|c|}{ B. 12} \\
\hline
\end{tabular}


TABLE B.6. Natural Gas Prices: Commercial Sector $(\$ / 1000 \mathrm{cl} f \mathrm{ft})$

\begin{tabular}{|c|c|c|c|c|c|c|c|c|c|}
\hline IEA & $A K$ & Al & $A R$ & $\mathrm{~A} \ddot{\mathbb{Z}}$ & $C A$ & $C 0$ & $C T$ & $\mathrm{DC}$ & $\mathrm{ISE}$ \\
\hline 2070 & 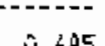 & $4<0$ & $0=26$ & 000 & 4770 & 570 & 17 & 117 & 1745 \\
\hline $14 \% 1$ & $\begin{array}{l}0.000 \\
0.732\end{array}$ & $\begin{array}{l}0+006 \\
0,656\end{array}$ & $i, 3=0$ & $\begin{array}{l}0.025 \\
0 ., 395\end{array}$ & $\begin{array}{l}v_{1} / 28 \\
6759\end{array}$ & $\begin{array}{l}0+50 \\
0.503\end{array}$ & $\begin{array}{l}1,4,2 \\
1,52\end{array}$ & $\begin{array}{l}1+112 \\
i \quad 47\end{array}$ & $\begin{array}{l}1+4 \\
+1,2\end{array}$ \\
\hline 1972 & 0.818 & 0.732 & 0.300 & 0,783 & $0 . \overline{8} .13$ & 0.644 & $1+50$ & 1,223 & 1.355 \\
\hline 1973 & 0.776 & 0.737 & 0.617 & 0.766 & 0.851 & 0.583 & 1,822 & 1,259 & 1,35 \\
\hline 1974 & 0.874 & 0.875 & 0.756 & 0.830 & 0.992 & 0.823 & 2.228 & 1.430 & 1.63 \\
\hline 1975 & 0.974 & 1.079 & 0.891 & 1.159 & 1.289 & 0.890 & 2,65 & $6 \% 57$ & 1,901 \\
\hline 1976 & 1.038 & 1.596 & $1,3.8$ & 1.427 & 1.560 & $1.087^{\circ}$ & $3+\alpha$ & $2,+56$ & $\{975$ \\
\hline 1977 & 1.345 & 1.827 & 1,513 & 1.757 & 2.073 & 1.403 & $3+5,33$ & 2,72 & 2847 \\
\hline 1978 & $1+35$ & 2,092 & 1.65 & $2+202$ & 2.245 & 1.725 & $3,7: 8$ & 2.983 & 3.951 \\
\hline 1975 & 1.031 & 2.778 & 2.25 & 2,644 & 2.733 & 2.290 & 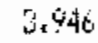 & 3.170 & 3.74 \\
\hline 1980 & 1,059 & 3.393 & 2.276 & 3.135 & 3.982 & 3.015 & 4,70 & 4.220 & 4,045 \\
\hline 1401 & 1,405 & 4.072 & $2+816$ & 3.535 & 4,378 & 3.537 & 5,000 & $5: 24$ & 5.179 \\
\hline 1782 & 1.542 & 4.824 & 3.528 & 4.398 & 5,318 & 4.58 & 5.762 & 5.276 & 5.54 \\
\hline 93 & 1.840 & 5,418 & 477 & 5.552 & 8.332 & 5.043 & 7,454 & 7 & $B 6$ \\
\hline
\end{tabular}

\begin{tabular}{|c|c|c|c|c|c|c|c|c|c|}
\hline YEAE: & $\mathrm{FL}$ & $G$ & HI & IA & il & Il & IN & wi & $n$ \\
\hline$\cdots$ & -....... & - & 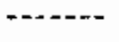 & 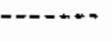 & -........ & …… & . & $\cdots$ & $\cdots$ \\
\hline 1970 & 0.927 & 0.740 & 0.0 & 0,688 & 1.014 & 0.744 & $0+B 32$ & 0.454 & $1+10$ \\
\hline 1971 & 1.063 & 0.350 & 6.0 & 0.734 & 1,010 & 0.779 & i), 801 & 9447 & 0,706 \\
\hline 1772 & $1+204$ & 0.387 & 0.3 & 0.333 & 1.030 & 0.843 & 0.925 & $6+510$ & 0.751 \\
\hline 1973 & 1.292 & 0.455 & 0.0 & 0.899 & 1.070 & 0.899 & 0,795 & 3,53 & 0,804 \\
\hline 1374 & 1.643 & 1.015 & 0.0 & 0,931 & 1.212 & 1.016 & 1.256 & 0.545 & 0.40 \\
\hline 1975 & 1.699 & $1+096$ & {$[1+0$} & 1.063 & 1.548 & 1.313 & 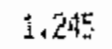 & 0.671 & 1.061 \\
\hline 1976 & 1.720 & 1,382 & 0.3 & 1.275 & 2,060 & 1,640 & $1+497$ & 1.098 & 1.149 \\
\hline 1977 & $2+010$ & 1.754 & 0.0 & 1,647 & 2,420 & 1,70 & $-8 y$ & $1,194^{\circ}$ & 1,65 \\
\hline 1978 & 2.032 & 2.05 & 0.0 & 1.984 & 3.075 & 2,248 & 2,009 & 1.171 & 1.331 \\
\hline 1979 & 2.735 & 2.524 & 0.0 & 2.390 & 3.456 & 2,807 & 2.459 & 1,607 & 2.205 \\
\hline 1000 & 3.433 & 3.219 & 12.277 & 2.946 & $4+5 \% 2$ & 3.339 & 2.654 & $1+397$ & $2+90$ \\
\hline 1981 & 3.752 & 3,980 & $1-4.742$ & 3.56 & 5,602 & 3.742 & 2.39. & 2.406 & 394 \\
\hline 1782 & 4,675 & 4.743 & $14+2: 3$ & $4.3+3$ & $6+123$ & 4.439 & $4+173$ & $3+2 s$ & $4,39.4$ \\
\hline $1 \% 83$ & 5.044 & 5.417 & $1 \leq 704$ & 5.043 & 6.230 & 4,756 & 5.71 & $4,55 \%$ & $5+5$ \\
\hline
\end{tabular}

\begin{tabular}{|c|c|c|c|c|c|c|c|c|c|}
\hline YEA & LA & THA & PD & NWE & inI & 啉 & $M 0$ & 知 & 政 \\
\hline$\cdots$ & -...-- & - & 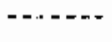 & $-\ldots+\ldots$ & $\cdots$ & & -...... & & \\
\hline 1770 & 0.379 & 1.417 & $1,1: 2$ & 1.436 & 0.837 & 0.645 & 0.627 & 0.582 & 0.610 \\
\hline 1971 & 0.410 & 1.596 & $1+14 \bar{i}$ & 1,495 & 0.969 & 0.759 & 0,651 & 0.625 & 0.65 \\
\hline 1372 & 0.462 & 1.713 & 1,223 & 1.634 & 0.903 & 0.834 & 0.754 & 0.67 & 0.663 \\
\hline $14 \%$ & 0.511 & 1,811 & $1,25 \%$ & 1.704 & $0 . \dot{4} 60$ & 0.850 & $0,78 \hat{0}$ & 0.723 & 0,775 \\
\hline 174 & 0.601 & 2.145 & 1.430 & 1.894 & 1.130 & 0.979 & 0.396 & 0.753 & 0.997 \\
\hline 1975 & 0.798 & 2,647 & 1.987 & 2.116 & 1.483 & 1.162 & $1+154$ & $1,4,43$ & 1,95 \\
\hline 1976 & $1.0 \%$ & 3.077 & 2,156 & $2+652$ & $1+\sqrt{22}$ & $1+410$ & 1,354 & $\therefore .290$ & 1.185 \\
\hline 1977 & 1.396 & 3.425 & 2729 & $3, z=1$ & 2.117 & 1.724 & 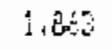 & $i: 75$ & $1.59 \%$ \\
\hline $197 \dot{a}$ & 1,442 & $3+537$ & 2.98 & 3.267 & $2+229$ & 3.123 & 2.002 & 2.025 & $1+69$ \\
\hline 1979 & 2.280 & 3.539 & 3.70 & $3,60 B$ & 2.578 & 2.557 & $2,5 \%$ & 2,457 & $1+27$ \\
\hline 1500 & $2+694$ & 4,723 & 3.5 & $5+124$ & $3+198$ & $2+879$ & 2,98 & $3+450$ & $3+14$ \\
\hline $1 \% 81$ & $3+693$ & 5.725 & 4,453 & $8+1 E 8$ & 3.826 & $3+630$ & 3.592 & 3.572 & 4.50 \\
\hline 1782 & 4,927 & 6.415 & 5.554 & 7.324 & 4.658 & 4,551 & 4,766 & $4+532$ & $4: 874$ \\
\hline 1983 & 5.715 & 7.422 & 6.710 & 8.997 & $5+633$ & 5,268 & $5+608$ & 5.473 & 5.064 \\
\hline
\end{tabular}


TABLE B. 6 (CONT). Natura1 Gas Prices: Commercial Sector $(\$ / 1000 \mathrm{cu} f \mathrm{t})$

\begin{tabular}{|c|c|c|c|c|c|c|c|c|c|}
\hline$I^{\prime} F A+K^{\prime}$ & $h \mathrm{hC}$ & NII & PHE & NH & Mi & $M$ & $H+v$ & 47 & OH \\
\hline 1970 & 0.962 & 0.693 & 0.528 & $1.4 \%$ & 1,418 & 0,476 & 0.756 & 1.190 & 0,763 \\
\hline 1971 & 0.983 & 0.765 & 6,587 & 1.495 & 1.456 & 0.500 & $\lambda_{1} 7 \sigma_{0}$ & 1,265 & 0.825 \\
\hline 1972 & 1.048 & 0.807 & 0.583 & 1.634 & $1.480^{\circ}$ & 0.526 & $0, B O O$ & 1.302 & $0+87$ \\
\hline 1973 & 1.137 & 0,873 & 0.758 & 1.704 & 1.553 & 0.524 & $0,87 z$ & 1.370 & Q6, 625 \\
\hline 1374 & 1.276 & $1+000$ & $0.9-2$ & 1,884 & 1.862 & 0.716 & 1.358 & $1+70$ & 1.67 \\
\hline 1975 & 1.745 & $1+106$ & $i_{1}$ & 2.118 & 2,328 & 0.797 & $1.54 E$ & 2,002 & 1.344 \\
\hline 1976 & 2.040 & 1,353 & 1.154 & 2.652 & 2.768 & 1.071 & 1.773 & $2+345$ & 1,62 \\
\hline 1977 & 3.046 & 1.67 & 1.34 & $3+231$ & 3.098 & 1.676 & 2.190 & 2.855 & $2+070$ \\
\hline 1778 & 2.796 & 1.939 & 1.537 & 3.267 & 3.374 & 2,001 & 2,405 & 3.052 & 2,240 \\
\hline 1979 & 3.092 & 2.472 & $2, \hat{0} 4$ & 3,608 & 3.594 & 2.304 & 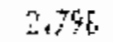 & $3 \times 4$ & 2.601 \\
\hline 1780 & 3.711 & $3+432$ & $2.28 \mathrm{~B}$ & 4,128 & 4.596 & 2.90 & 3.25 & 4.217 & 3.315 \\
\hline 178 & 4.719 & 3.654 & 2,801 & 5,106 & 5,482 & 3,388 & 4.579 & 4.795 & $3+21$ \\
\hline 1392 & 5.240 & 4.096 & $3 . 4 \longdiv { 2 }$ & 6.08 & $6+360$ & 4.455 & 5.544 & 5.453 & $\frac{A}{4}+\frac{6}{4}+4$ \\
\hline 1993 & 6.0009 & 5.060 & 4.216 & 6.790 & 6,690 & 4.805 & 6.054 & 6,47 & $5+71$ \\
\hline
\end{tabular}

\begin{tabular}{|c|c|c|c|c|c|c|c|c|c|}
\hline IEAR & Gk & of & $F^{\prime} A$ & RI & $x$. & SII & $T \mathrm{~W}$ & $\pi$ & it \\
\hline$\cdots$ & -....... & -....- & -...- & - n.t. & $-\cdots, \ldots$ & ---o-s & $m a n-\cdots$ & & \\
\hline 1370 & 0.522 & 1.278 & 0.965 & 1.474 & 0.889 & 0.636 & 0.713 & 0.454 & 0.51 \\
\hline 1971 & 0.534 & 1.312 & 1.001 & 1.615 & 0.485 & 0.669 & 0.76 & 0.496 & 0.84 \\
\hline 1472 & 0.565 & 1,432 & 1.086 & 1,822 & $1+00 \bar{y}$ & 0.643 & 0.854 & $0+3 \%$ & $070 \%$ \\
\hline 197 & $0+640$ & 1,452 & 1.52 & 1.885 & 1,017 & 0.766 & $0+410$ & 0.55 & $0.7 \% 5$ \\
\hline 1774 & $0.75 t$ & 1.710 & 1.279 & 2.131 & $t+12 i$ & 1.135 & 0.979 & 0.709 & 0.70 \\
\hline 1975 & 0,935 & $1+863$ & 1,705 & 2,746 & 1.253 & 0.993 & $1+127$ & 1.050 & $1.51 \%$ \\
\hline 1976 & 1.16 & 2.373 & 1.721 & 3.387 & $1,48 ?$ & 1.132 & $1+431$ & $1+42$ & 1.527 \\
\hline 1477 & 1.525 & 3.077 & 2.307 & 3.461 & 2,115 & 1.444 & 2.674 & 1.797 & +790 \\
\hline 1978 & 1.685 & 3.397 & $2.37)$ & 3.260 & 2,457 & 1.725 & 2.070 & 2.196 & $\therefore 465$ \\
\hline 1979 & 3.418 & 3.719 & $2+551$ & 3,089 & 2.784 & 2.230 & $2+464$ & 2.64 & 2.38 \\
\hline+910 & 2.300 & 5.110 & 3.569 & 5.105 & 3.210 & 2.720 & 3.000 & 2.19 & 5974 \\
\hline 1981 & 2.857 & 5.430 & $4+217$ & 5.83 & 3.962 & 3.412 & 3.537 & 3,691 & $5+353$ \\
\hline $9 R_{2}^{2}$ & 3.454 & 6.294 & 5.043 & 6.861 & $4+3 \pm 1$ & 4.092 & 4.426 & 4,486 & 3.45 \\
\hline 1983 & $4+127$ & 6.488 & 6.075 & 7.103 & 5.534 & 4.876 & 5,153 & 5.046 & 4318 \\
\hline
\end{tabular}

\begin{tabular}{|c|c|c|c|c|c|c|c|}
\hline YFAk & VA & $V T$ & 14 & $\sqrt{\vdots}$ & $W U$ & 明 & 5 \\
\hline$\cdots$ & $-\cdots$ & $--\cdot$ & $=-6$ & 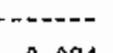 & 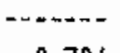 & 0.5 & \\
\hline 5970 & 0.862 & 1,436 & 1.105 & 0.834 & 0,706 & 0,436 & 0.759 \\
\hline 1071 & $0.9 \% 6$ & 1.495 & $\therefore 128$ & 0.952 & 0.734 & $0.4 \pi$ & $\hat{0}+\hat{i}+21$ \\
\hline 4972 & $1+103$ & 1.634 & \pm .152 & 1.998 & 0.746 & 0.498 & 0.478 \\
\hline 1973 & $1+128$ & 1.704 & $\therefore 246$ & 1,100 & 0.762 & $0.52 \%$ & 0.944 \\
\hline 1974 & 1.304 & 1,964 & 1,391 & 1,153 & 0,992 & 0.592 & 1.672 \\
\hline 1575 & 1,717 & $2+116$ & 1,814 & $1+312$ & 1.20 & 0.673 & 1.350 \\
\hline 175 & 1.595 & 2,652 & 2.30 & 1.712 & 1.503 & 0,792 & 1,1 \\
\hline 157 & 2.42 & 3.231 & 2.674 & 2.097 & 2,253 & 1.190 & 2.037 \\
\hline 190 & 2.442 & 3.267 & $2+929$ & 2.348 & 2.153 & 1,655 & 3.54 \\
\hline 1979 & 3.134 & 3.608 & 3,463 & $2+690$ & 2.650 & 2.374 & 2.725 \\
\hline $1 \%$ & 3.767 & 6.151 & 4.814 & 3.46 .1 & 3,340 & 2.653 & 3.373 \\
\hline 1981 & 4,183 & 6.851 & 5.346 & 4,377 & $3+95 \hat{2}$ & 3.271 & 4,002 \\
\hline 1982 & 5.373 & $7+061$ & $5+21.2$ & 4,951 & $4+\% 44$ & 4.627 & 4.82 \\
\hline \multirow[t]{2}{*}{1983} & $6+236$ & 6.513 & 6.076 & 5.313 & 5.72 & 5.369 & 5.572 \\
\hline & & & & B. 1 & & & \\
\hline
\end{tabular}


TABLE B.7. Natural Gas Prices: Industrial Sector $(\$ / 1000 \mathrm{cu} f t)$

\begin{tabular}{|c|c|c|c|c|c|c|c|c|c|}
\hline YEA & $A K$ & $\mathrm{AL}$ & 活: & $A Z$ & $\mathrm{CA}$ & $C O$ & $\mathrm{Tt}$ & Ji: & $\mathrm{iE}$ \\
\hline- & n...- & $\cdots$ & $\ldots$ & $1 .$. & --- & 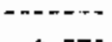 & $\cdots$ & $\rightarrow+\cdots$ & \\
\hline 1970 & 0.428 & 0.335 & $0+205$ & 0.437 & 0.405 & 0.278 & 1.044 & 0,604 & 0,54 \\
\hline 1471 & 0.635 & 0.391 & $0,3 C E$ & 0.467 & 0.430 & 0.302 & $1: 57$ & 0.719 & $0+630$ \\
\hline 1772 & $\hat{0}+6 B 4$ & 0.424 & $0.34 \div$ & $0.47 \mathrm{~A}$ & 0,471 & $\hat{0}, 331$ & 1.173 & 0.750 & 0,75 \\
\hline 1973 & 0.725 & 0.476 & 0.395 & 0.491 & 0.533 & 0.375 & 1.259 & 0.775 & 0.83 \\
\hline 1774 & 0.750 & 0.500 & 0.400 & 0.580 & 0.690 & 0.480 & 1.730 & 1,181 & $1+040$ \\
\hline 1975 & 0.811 & 0.746 & 0,672 & 0.757 & 1.111 & 0,645 & 2.247 & 1,372 & $1.3 \%$ \\
\hline 1976 & $0, B \in B$ & 1.102 & $0.9=3$ & 0.919 & 1.464 & 0.795 & 2.674 & 1.621 & $i, 461$ \\
\hline $1 \% 7$ & 1.011 & 1.328 & $\cdot 1,217$ & 1.305 & $1 . \dot{4} 49$ & 1.097 & $2,+71$ & 2.97 & $2+47$ \\
\hline 1778 & $0.9 \leq 0$ & 1,352 & $1+155$ & 1.603 & 2.149 & 1.322 & 3.743 & $2+624$ & $2+510$ \\
\hline ¿4979 & 1.048 & 2.334 & 1.252 & 2.150 & 2.731 & 1.544 & 3,273 & 2,193 & $2+607$ \\
\hline 1480 & 0.389 & 2.545 & 2.223 & 2.685 & 3.801 & 2,632 & $4+\frac{1}{1}>1$ & 2,45 & 2,800 \\
\hline 1931 & 0.359 & 3.153 & 2.78 & 3.172 & 4,054 & 3.401 & 50 & 3,005 & 3.65 \\
\hline $17 \mathrm{AR}$ & 0.581 & $4.23 \%$ & 3.244 & 4.339 & 4.879 & 3.983 & 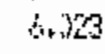 & 0.0 & $4+57$ \\
\hline 1983 & $0,0 \in 7$ & 4.5003 & 3,69 & 4.139 & 5.490 & 4.283 & $5 \%$ & $4+6$ & $4+20$ \\
\hline
\end{tabular}

\begin{tabular}{|c|c|c|c|c|c|c|c|c|c|}
\hline YEAR & $\mathrm{FL}$ & $\mathrm{GA}$ & $\mathrm{HI}$ & IA & ID & IL & IN & $\mathrm{X}$ & $\mathrm{KY}$ \\
\hline 1970 & 0.350 & 0,413 & 0.0 & 0.367 & 0.444 & 0.502 & 0.474 & 0.273 & $0+48$ \\
\hline 1471 & 0.442 & 0.517 & 0.0 & 0.393 & 0.489 & 0.541 & 0.511 & 3,26 & 0.54 \\
\hline 1972 & 0.450 & 0.535 & 0.0 & 0.464 & 0,534 & 0.637 & 0.577 & 0.393 & $6+5$ \\
\hline 1973 & 0.581 & 0,612 & $i . \hat{0}$ & 0.518 & 0.585 & 0,492 & $0.55 t$ & 0.340 & 0.574 \\
\hline 1974 & 0.750 & 0,700 & 0.0 & 0,600 & $0,7 \pm 0$ & 0.810 & 0,700 & 0.400 & $0+600$ \\
\hline 1975 & 1,026 & 0.843 & 0,0 & 0.779 & 1.171 & 1.223 & $\overline{2}, 80 ?$ & 0.540 & 5.75 \\
\hline 1976 & 1,057 & 1.105 & 0.0 & 1.009 & 1.545 & 1.464 & 1,000 & 0.812 & 1,074 \\
\hline 1977 & 1.146 & 1.412 & $\hat{i}, \hat{v}$ & 1.351 & 1.885 & 1.852 & 1,476 & 0,495 & $1, * 1,5$ \\
\hline 1378 & 1.187 & 1.757 & 0.0 & 1.659 & 2.242 & 2.124 & 1.600 & $1+151$ & $\therefore+574$ \\
\hline 1979 & 2.165 & 2.235 & $\pi_{0} 0$ & 1.450 & 2.534 & 2,625 & 2469 & 1,64 & 39 \\
\hline 1700 & 2.790 & 2,842 & 0.3 & 2.516 & 3.767 & 3.171 & 2,604 & 5.331 & 2.691 \\
\hline $1 \% 01$ & 3.271 & 3.693 & $\vec{v}, \hat{0}$ & 3.104 & $3,+93$ & 3.612 & 3.041 & 3,022 & 3.134 \\
\hline 1782 & $4,0.6$ & 4.172 & 0.0 & 3.742 & $4.80 z$ & 4.262 & 3.755 & 2.934 & 4 \\
\hline 1483 & 4,103 & 4.516 & $0, \hat{0}$ & $4+103$ & 5.120 & 4.832 & 4,2 & 3.394 & 4.580 \\
\hline
\end{tabular}

\begin{tabular}{|c|c|c|c|c|c|c|c|c|c|}
\hline THA & LA & W & $M 0$ & $M \mathbb{E}$ & MI & 汭 & 海 & $\mathrm{FS}$ & 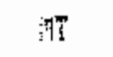 \\
\hline$\ldots$ & 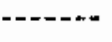 & - & ........ & -..-- & -...- & ... & …… & $\cdots+\cdots$ & \\
\hline 1570 & 0.241 & 1.040 & 0.684 & 0.853 & 0.535 & 0.418 & 0.403 & $0+30^{n}$ & 0,33 \\
\hline$\$ 971$ & 0.272 & 1.070 & 0.719 & 0.935 & 0.565 & 0.447 & $j, 434$ & 0,330 & 0,5 \\
\hline 1772 & 0.326 & 1.234 & $0, \pi 30$ & 1,011 & 0.632 & 0,485 & 0.444 & 0.342 & 0.342 \\
\hline 1973 & 0.378 & 1.290 & 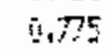 & 1,107 & 0.694 & 0.544 & $\overline{0}, 4=1$ & $\hat{1}, 435$ & 0.420 \\
\hline 1974 & 0.630 & 1.710 & $1+181$ & 1,198 & 0.910 & 0,640 & 0.580 & 0.570 & 0.500 \\
\hline 1975 & 0.761 & 2.292 & 1.372 & 1.457 & 1,254 & 0.836 & $0,8 C 2$ & $0.72 \mathrm{i}$ & 0.945 \\
\hline 1076 & 0.444 & $2+500$ & 1.521 & 2.267 & 1.548 & 1.129 & 0.794 & 1.749 & 0,957 \\
\hline 1977 & 1.183 & 2.596 & 2.97 & 2,841 & 1.841 & 1,123 & $1,45 i$ & 1,457 & 1.58 \\
\hline 198 & 0.910 & 3.008 & 2,024 & $2+776$ & 1.930 & 1.236 & 1,461 & $1+5$ & 1.64 \\
\hline 1479 & 0.421 & 3.234 & 2493 & 3,262 & 2.310 & 1,453 & $1,4=$ & 277 & 1,74 \\
\hline $1 ; 00$ & 1,283 & $4+154$ & 3.251 & $4+290$ & 2,727 & 2.479 & 2.56 & 2.75 & $3,: 43$ \\
\hline $1 \div 81$ & 1.877 & 5,090 & $3+52$ & $5+216$ & 3.545 & 3.183 & 5,3 & 3.316 & $4+5$ \\
\hline 1982 & 3,159 & 5.673 & 5.041 & 6.630 & 4.315 & 4.877 & 4.414 & 4,15 & $5+489$ \\
\hline $19 \mathrm{HO}^{2}$ & $3+133$ & 5.674 & 6,017 & 7,459 & 5,127 & 4,465 & 5,009 & 4,299 & $3,7=0$ \\
\hline
\end{tabular}


TABLE B.7 (CONT). Natural Gas Prices: Industrial Sector $(\$ / 1000 \mathrm{cu} f \mathrm{ft})$

\begin{tabular}{|c|c|c|c|c|c|c|c|c|c|}
\hline YEAK & $\mathrm{NC}$ & $W \mathbb{D}$ & $\mathrm{NE}$ & $H$ & 级 & 나며 & $\mathrm{EN}$ & $\mathrm{H}$ & $\mathrm{JH}$ \\
\hline$\cdots$ & - & - & 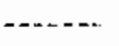 & - & 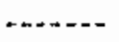 & - & - & $-\ldots$. & \\
\hline 1970 & 0.512 & 0.393 & 0.320 & 0.853 & 0.696 & 0.266 & 0.562 & $0+675$ & $0+5$ \\
\hline 1971 & 0.535 & 0.443 & 0.306 & 0.955 & 0.739 & 0.323 & 0.54 & 3.771 & 0.2 .17 \\
\hline 1972 & 0.557 & 0.435 & 0.488 & 1.011 & 0.811 & 0.337 & 0,715 & $0+356$ & \\
\hline $19 \% 3$ & 0.682 & 0.543 & 0.440 & $1+107$ & 0.970 & 0.381 & $0_{1}, 7 \varsigma_{3}$ & arivg & \\
\hline 1,774 & 0.870 & 0.640 & 0.540 & 1.148 & 1.110 & 0.550 & 0.890 & $1.110 \hat{~}$ & \\
\hline 1075 & 1.363 & 1,002 & 0.685 & 1.457 & 1,699 & 0.621 & $1 .: 54$ & 1,494 & \\
\hline 1776 & $1+\hat{B} B 4$ & 1.333 & $\hat{0}+34 \hat{4}$ & $2+267$ & 2,178 & 0.697 & 1.427 & 1.575 & \\
\hline 1977 & 2,368 & 1.711 & 1,024 & 2.653 & $2+419$ &, \pm 477 & $1+\alpha 6$ & 1. & \\
\hline 1779 & 1.96 .1 & 1.961 & 1,112 & 2.776 & $3+384$ & 1.722 & 1.780 & 2.371 & \\
\hline 1979 & 2,636 & 2,505 & 1,252 & 3.262 & 3.187 & 2.115 & $2+321$ & 3734 & \\
\hline 1700 & 3.340 & 2.719 & $2+164$ & 3.431 & 3.748 & 2.576 & 2.990 & 3.504 & \\
\hline $19 Q_{1}^{\prime}$ & $4,41 \pi$ & 4.098 & 2781 & $4+6=1$ & 4,722 & 2.791 & $3+k 5$ & 3760 & \\
\hline $\mathrm{i} H \hat{Z}$ & 4.642 & $4.31 \%$ & 3.547 & 5.504 & 5,241 & 3.654 & 4,414 & $\frac{ \pm}{3}+970$ & \\
\hline 1983 & 5.171 & $4+765$ & $3 \% 4$ & $5+494$ & 5.446 & 3.953 & ب. & $5, h \quad z$ & $5+1$ \\
\hline
\end{tabular}

\begin{tabular}{|c|c|c|c|c|c|c|c|c|c|}
\hline ZEAS & ok & G & $F A$ & $\mathrm{RI}$ & $x$ & $\mathrm{GD}$ & $\mathrm{TN}$ & i) & it? \\
\hline.- & o & ......... & ---- & $\cdots$ & - & - & - & n...u- & 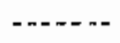 \\
\hline 1970 & 0.253 & $\sqrt{5}+494$ & 0.586 & $0.8+4$ & 0,463 & 0.326 & 0.390 & 0.200 & $3+24$ \\
\hline 1971 & 0.271 & 0.513 & 1. 651 & $0, \% 58$ & 0.494 & 0.351 & 0,446 & 0,247 & 0,24 \\
\hline 1972 & 0.293 & 0.545 & 0.721 & 1.148 & 0.548 & 19382 & 0.446 & 0,260 & 5.364 \\
\hline $197 \%$ & 0.362 & 0.699 & $\dot{0}, 7{ }^{\prime} 1$ & 1,337 & 0.648 & 0,407 & $i j, 497$ & 13.313 & 0.394 \\
\hline 1774 & 0.440 & 0.890 & 0.940 & 1.730 & 0.720 & 0.720 & 0.610 & $\sqrt{4} 530$ & 0.460 \\
\hline 1975 & 0.717 & 0.961 & 1.057 & 2.129 & 1.028 & 0,602 & 0,751 & 0.947 & 0.693 \\
\hline 199 & 0.891 & 1.768 & 1.354 & 2.291 & 1.294 & 0,726 & 1.174 & 5.311 & 0.76 \\
\hline 1977 & 1.326 & 2,110 & 1.917 & 2.947 & 1.597 & 0.964 & $1+495$ & 1,269 & 1,170 \\
\hline $19 \% 8$ & 1.486 & 2,516 & 2.020 & 2.300 & $1,84 \%$ & 1.598 & $1+5 i 4$ & 1.903 & 1.40 \\
\hline 1979 & 1.796 & 2.902 & $2.54 i$ & 2,649 & 2.458 & 2,037 & $2.1 C^{5}$ & 1.896 & 1,735 \\
\hline 1700 & 2.110 & 4,394 & $3.0 k 4$ & $4+542$ & 2.950 & 2.344 & 2.578 & $2+30 \%$ & $2+26$ \\
\hline 1981 & 2.553 & 4.622 & $2+699$ & 5,354 & 3.839 & $3+024$ & 345 & 2,006 & 2.581 \\
\hline 1992 & 2.943 & 5.594 & 4,499 & $4+193$ & 4,374 & 3.397 & $3+960$ & 3.406 & 2.453 \\
\hline 1983 & 3.351 & 5.343 & 5.070 & 6.189 & 4.856 & 4,456 & 4315 & 3,450 & 3.14 \\
\hline
\end{tabular}

\begin{tabular}{|c|c|c|c|c|c|c|c|}
\hline TEAR' & VA & $\mathrm{vI}$ & WA & WI & WN & $w^{4}$ & LS \\
\hline & & & & & & & \\
\hline 1.770 & 0.507 & 0.953 & 0.401 & 0.552 & 0.459 & 0.247 & 0.371 \\
\hline 1971 & $0.5 \times 8$ & 0.735 & 0.441 & 0.577 & 0.520 & 0.272 & 0.409 \\
\hline 1712 & 0.55 & 1.011 & 0,472 & 0.046 & 0.558 & 0,301 & 0.451 \\
\hline 1973 & 0.658 & 1.107 & 0.531 & 0.679 & 0.634 & 0.314 & 0.501 \\
\hline 1974 & 0.930 & 1.198 & 0.3 .0 & 0.770 & 0.750 & 0.370 & 0,$5 ;$ \\
\hline 1975 & 1.100 & 1,457 & 5.344 & 1.053 & 1.013 & 0.518 & 0.65 \\
\hline 170 & 1.453 & $2+267$ & $1+142$ & 1.396 & $2+293$ & $0+6 \%$ & 1.240 \\
\hline 147 & 1.932 & $2+671$ & $2+153$ & $1+701$ & $2+\hat{021}$ & 0.943 & 1.495 \\
\hline 178 & 2.144 & 2.776 & 3.54 & 2.055 & 1.875 & 1,280 & 1,704 \\
\hline 1979 & 2.325 & 3.262 & 2,29 & 2.48 & $\dot{\partial}, 454$ & $1 . \%$ & 1,97 \\
\hline 1780 & 3.055 & 4.823 & 4,302 & 3.144 & 2.548 & 2.405 & $2, \overrightarrow{3}+3$ \\
\hline 1981 & 3.567 & 5,613 & 4.625 & $3.7 / n$ & 3.519 & 3.074 & $3+13 t$ \\
\hline 1,732 & 4.386 & 5.46 & 5.303 & $4,4: 7$ & 4.384 & 3.421 & 3.478 \\
\hline 1983 & 5.038 & 5,015 & 5.257 & $4+630$ & 5.078 & $3+67$ & 4.184 \\
\hline
\end{tabular}


TABLE B.8. Natura] Gas Prices: Electric Utility Sector $(\$ / 1000 \mathrm{cu} \mathrm{ft})$

\begin{tabular}{|c|c|c|c|c|c|c|c|c|c|}
\hline YEAS & ARK & PH & A & $A \bar{I}$ & $C A$ & $\mathrm{CO}$ & $\mathrm{CT}$ & $\mathrm{Di}$ & DE \\
\hline$\cdots$ & $\cdots$ & $-\cdots$ & -...- & -...4- & -..encos & $\cdots$ & 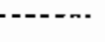 & -....... & \\
\hline 1870 & $0.3 / 3$ & 0.273 & 0.255 & 0.369 & 0.546 & 0.234 & 0.347 & 0,329 & $0,3 \%$ \\
\hline 1971 & 0.427 & 0.322 & (0.283 & 0.418 & 0.364 & 0.263 & 0.391 & 0,35 & 0,477 \\
\hline 172 & 0,420 & 0.352 & 0.307 & 0.419 & 0.400 & 0.305 & 0.473 & $0+3.5$ & 9.404 \\
\hline 1973 & 0.400 & 0.370 & 4,350 & 0,440 & 0.450 & $0.2 \% 0$ & i) 0 & 0.0 & $0.7 \mathrm{Ga}$ \\
\hline 1774 & $\hat{0}+5 \hat{w}$ & $0.8 \%$ & 0.410 & 0.570 & 0.600 & 0.400 & 0.3 & $0+0$ & \pm 000 \\
\hline 1975 & 0.514 & 1.110 & $5, \$ 20$ & 0,783 & 1.110 & 0.586 & 0.0 & $0, \hat{0}$ & $1,1 \hat{0}$ \\
\hline 1776 & 0.661 & 1,900 & 0.300 & 0.37 & $1+650$ & 0,768 & 0.3 & $0 . j$ & $i+30$ \\
\hline 1977 & 0,761 & 2,070 & 1.020 & $1+150$ & 2.220 & $1+031$ & 1,0 & 1). 0 & 2.00 \\
\hline 1970 & 0.830 & 2.350 & 1.160 & 1.420 & 2.311 & 1.285 & 0.0 & 0.0 & 1.950 \\
\hline $1 \% 9$ & 0,865 & 2.560 & 1.760 & $2+196$ & 2.582 & 1.850 & 0,0 & 0.0 & 2,700 \\
\hline 1760 & $12+480$ & 2.960 & 2,20 & 2.550 & 3.710 & $2+5 \% 0$ & $0+3$ & $0+0$ & $3+420$ \\
\hline 1081 & 0.550 & 3.240 & $2, \sqrt{50}$ & 2,790 & 4.210 & 3.170 & 0.0 & 0.0 & 4,340 \\
\hline 1382 & 0.710 & 3.3890 & 3.90 & 3.930 & 5,290 & 3,480 & 0.3 & 0,0 & 4.260 \\
\hline 1083 & 1.050 & 3,450 & 3,30 & 4,300 & 5.320 & 4.170 & 0.0 & 50 & 4.321 \\
\hline
\end{tabular}

\begin{tabular}{|c|c|c|c|c|c|c|c|c|c|}
\hline IESF' & $\mathrm{FL}$ & GA & $\mathrm{HI}$ & IA & if & II & $I N$ & $\mathrm{KS}$ & $\mathrm{Ni}$ \\
\hline 1970 & $0.3 \therefore 5$ & 0.294 & 0.2 & 0.276 & 0.0 & 0.360 & $0.34 \%$ & 0,25 & 026 \\
\hline 141 & 0,399 & 0.322 & 0,0 & 0.319 & 0,0 & 0,390 & 0,397 & 0,322 & 0,334 \\
\hline 1972 & 0.403 & 0.358 & 0.0 & 0.380 & $\hat{v}+0$ & 0,43 & $0.42 \%$ & 0.377 & 0,35 \\
\hline 1973 & 0,460 & 0.480 & 90 & 0.420 & 0.0 & 0,810 & {$[0,4 ? 6$} & 3,290 & 0,300 \\
\hline 197 & $\hat{v}+600$ & 0,600 & 0.0 & 0.500 & 0.0 & 0.790 & 0,360 & 0.350 & $0+40$ \\
\hline 1975 & 0.729 & 0.731 & 0,0 & $b_{1}, 682$ & 1,450 & 1.158 & {$[1,8 \mathrm{i} 9$} & 3,49 & 0.693 \\
\hline 1376 & 0.838 & 1.012 & 0.0 & 0.924 & 1.600 & 1.407 & $1.0 B 7$ & 0.702 & 0.347 \\
\hline 1977 & 0.892 & 1.370 & $\bar{i} .0$ & 1.309 & 2,040 & 1.843 & 1,37 & $\hat{0}, \otimes 1$ & 1,100 \\
\hline 1979 & 1,052 & 1.740 & 0.0 & $1+3 \% 1$ & 2.230 & 2.807 & 1,660 & 1.182 & 1,073 \\
\hline 1979 & 1.292 & 2,830 & 9.0 & 2.016 & 2.920 & 2.743 & $2.1 \% 2$ & 1,380 & 1,717 \\
\hline 1700 & 1.550 & 2,650 & 0.7 & 2,430 & 3.900 & $3+260$ & 2.520 & 1.710 & $3+210$ \\
\hline 1981 & 1,970 & 3.530 & 0.0 & 2,90 & 4.580 & 4.230 & 3,000 & 2,110 & 2,540 \\
\hline 1982 & 2.220 & 4.180 & 0.0 & 3.640 & 5.740 & 4.700 & 3.360 & 2.380 & $3+470$ \\
\hline 1993 & 2,560 & 4.280 & {$[1,0$} & 3.850 & 0,0 & 5.440 & $4+290$ & 2,910 & $3.3 \mathrm{~s}$ \\
\hline
\end{tabular}

\begin{tabular}{|c|c|c|c|c|c|c|c|c|c|}
\hline IEAR & LA & $M A$ & Mi & 性 & 怔 & 懒 & 1 性 & $\mathrm{NR}_{\mathrm{i}}$ & $9 \%$ \\
\hline 130 & $-\cdots$ & $0 .----$ & 0.320 & 0,0 & 0.49 & 0.258 & A & 0,274 & 0 \\
\hline $1 \uplus 1$ & 0.241 & 0.436 & 0,353 & 0,459 & 0.474 & 0.295 & 3,306 & 0,306 & 0,30 \\
\hline 1972 & 0.274 & 0,452 & $0.3 \mathrm{cB}$ & 0.449 & 0.486 & 0.397 & 0.308 & 0.321 & $0+343$ \\
\hline 1973 & 0.320 & 0.540 & 6,0 & 0.0 & 0.440 & 0,430 & 0.300 & 9.420 & 0.340 \\
\hline 1974 & 0.440 & 1.440 & 0.3 & 0.0 & 0.730 & 0.470 & 0.430 & 0.580 & 0,340 \\
\hline 1975 & 0.676 & 1.330 & 1.040 & 0.0 & 1.076 & 0,630 & $0+272$ & $0.85 e$ & 0.45 \\
\hline 1976 & 0.831 & 1.530 & 1,530 & 0.0 & 1.227 & 0.802 & 0.752 & $1+294$ & 0.490 \\
\hline 1977 & 0.962 & 1.880 & 2,080 & 0.0 & 1,326 & 1.080 & 1.085 & $1.3 \%$ & 0,78 \\
\hline 1780 & $1+17 t$ & 1.870 & $1+760$ & 0.0 & $1+594$ & 1.350 & $1+109$ & 1,425 & 0,920 \\
\hline 1979 & 1.540 & 2.692 & 1.890 & 0,0 & $1.65 \%$ & 1.711 & 1.490 & 1.95 & $2+7$ \\
\hline $1 \% 0$ & $2+990$ & 34400 & 3.30 & 0.0 & 2.020 & 1.970 & 2.170 & 2,150 & a \\
\hline $1 \div 81$ & 2.920 & 3.740 & CABi: & 0,0 & 2,150 & 2.590 & 2,3 & 2,55 & $4, Z$ \\
\hline 1082 & 3.230 & $4+220$ & $4+200$ & 0,0 & 2.540 & 3.750 & $3.7 \%$ & $3+240$ & 2.010 \\
\hline 1983 & 3.300 & 4.100 & 160 & 0.0 & 4,930 & 3.840 & $\frac{6}{4} \cdot 4$ & $3,42 \mathrm{~L}^{\mathrm{n}}$ & 0.50 \\
\hline
\end{tabular}


TABLE B.8 (CONT). Natural Gas Prices: Electric Utility Sector $(\$ / 1000 \mathrm{cu} \mathrm{ft})$

\begin{tabular}{|c|c|c|c|c|c|c|c|c|c|}
\hline IPAT & $\mathrm{NHC}$ & 1.TD & 怔E & WH & ד & topl & | & $\| 4$ & Ch \\
\hline$\cdots$ & ------ & - & n...... & C.t. & an. & --.- & $\cdots$ & & \\
\hline 1370 & 0.381 & 0.315 & 0.208 & 0.0 & 0.401 & 0.323 & 0.413 & 0,385 & $0,40 ?$ \\
\hline 1971 & 0.480 & 0.400 & 0.312 & 0.459 & 0.474 & 0.345 & 4.45 & $0,44_{3}^{2}$ & $\tilde{y}_{4}, \bar{y} ;$ \\
\hline 1972 & 0.502 & 0.402 & $0.37 \hat{\mathrm{v}}$ & 0.444 & 0,484 & $0.36 \%$ & 0.471 & 0,472 & 0.32 \\
\hline 1973 & 0.520 & 0.0 & $0, \$ 10$ & $0+\hat{v}$ & 0.550 & 0.350 & 0.5 & 0.100 & 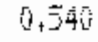 \\
\hline 1974 & 0.450 & 0.0 & 0,480 & 0.0 & 0,730 & 0.500 & 0,700 & 0.710 & $0+670$ \\
\hline 1075 & 1.445 & 0,700 & $0, \dot{\infty} 00$ & 1.0010 & 0.974 & 0.720 & $1: 266$ & $\hat{j}, \div 01$ & 1.003 \\
\hline 1974 & $3.4 \%$ & 0.0 & $0.7 \% 1$ & 1.300 & $1.47 \%$ & 0.984 & 1.50 & $1+1000$ & 1.025 \\
\hline 1977 & 4.260 & 0.0 & 0.540 & 0.0 & 1.937 & 1.484 & $\perp: 840$ & 1.445 & 0.935 \\
\hline 1978 & 3.110 & 0.0 & 1.560 & 0.0 & 2,032 & 1.704 & 1.680 & 1,539 & 5.024 \\
\hline 1979 & 3.040 & $0, \hat{0}$ & 1,392 & 2.450 & 2,659 & $2+140$ & 2.450 & 2.35 & $1, \pi 5$ \\
\hline $1 \div 80$ & 3.2 .20 & 0.0 & 1,730 & 0.0 & 3.120 & $2.54 \hat{0}$ & $2+76$ & $2+700$ & 8.900 \\
\hline 1401 & 4,530 & $0 . \hat{0}$ & 2830 & 3.530 & 4,140 & 2.910 & 3.390 & 3.00 & 351 \\
\hline 1782 & 4,600 & $0+0$ & 2,700 & 0.0 & $4.4 \hat{0} \hat{0}$ & $3.2 \%$ & $4+180$ & 4,20 & 4.30 \\
\hline 1483 & 0.0 & 0.0 & 3,050 & 0.0 & 4.200 & 3.560 & 4.800 & $\rightarrow: \div 0$ & 5,250 \\
\hline
\end{tabular}

\begin{tabular}{|c|c|c|c|c|c|c|c|c|c|}
\hline IEAK & OX & $\mathrm{O}$ & F'A & FiI & 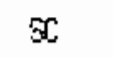 & Si & TN & $I y$ & $\mathrm{iji}$ \\
\hline$\cdots$ & - & --N-- & - n...... & n....... & +...t. & - & $\cdots$ & & \\
\hline 1070 & 0.199 & 0.384 & 0.428 & 0.398 & 0.374 & 0.334 & 0.255 & 0.281 & 0.200 \\
\hline $1 \% 7$ & 0.214 & 0.435 & $i+447$ & 0.502 & 0.445 & 0.355 & 3.275 & 0.260 & 4,33 \\
\hline 1972 & 0.249 & 0.451 & 0,494 & 0.514 & 0.487 & 0.362 & 0.328 & $0+208$ & 0,324 \\
\hline 1973 & 0.280 & 0.570 & {$[1,0$} & 0.590 & 0.540 & 0.400 & 而, 3010 & 078 & $i, 30$ \\
\hline 1974 & 0.410 & 0.770 & $\pm .5 \%$ & 0.920 & 0.700 & 0,470 & 0.3 & 0.450 & 0.350 \\
\hline 1975 & 0.629 & 1.310 & $1,4>0$ & 1,200 & 0.735 & 0.640 & $\hat{\mathfrak{g}}, \hat{\mathrm{v}}$ & 13770 & 0.500 \\
\hline 1976 & 1.050 & 1.700 & 1.640 & 0.0 & 1.042 & 0.850 & 0.0 & $1+45$ & 0.590 \\
\hline $19 \% \bar{t}$ & 1.359 & 2,022 & 2,070 & $0, \hat{0}$ & 0.0 & $1.1 \%$ & 0.0 & $1,25 n$ & 1.030 \\
\hline 1778 & 1,480 & 2.391 & 2.530 & 0.0 & 1.820 & $1+430$ & 0,0 & 1.422 & 1.250 \\
\hline 1979 & 1.619 & 3.429 & 3.010 & 2,580 & 2.391 & 1.970 & 0.0 & 1,69 & $\dot{1}+50$ \\
\hline 1000 & 1.320 & 4.220 & 3.670 & 0.0 & 2.460 & 1.940 & $0 . \hat{3}$ & $1+410$ & 10710 \\
\hline $1 \% 91$ & 2.010 & 4,600 & $=, 080$ & 3.340 & 3.370 & 2.240 & 0,0 & 2,500 & 2.130 \\
\hline 1982 & 2.170 & 5.320 & 4,150 & $4+104 \hat{0}$ & 4.050 & 3.570 & 0.0 & $3+240$ & $2+25$ \\
\hline 1963 & 2.520 & 0.0 & 5.100 & 3.900 & 4,400 & 0.0 & 0.0 & 3,20 & 2,250 \\
\hline
\end{tabular}

\begin{tabular}{|c|c|c|c|c|c|c|c|}
\hline Y'EAR' & 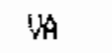 & $\mathrm{VT}$ & $W A$ & WI & WV & Wy & US \\
\hline -... & 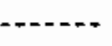 & 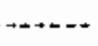 & & - & . n.t. & & \\
\hline 1970 & 0.298 & 0.0 & 0.0 & 0.428 & 0,329 & 0.228 & 0.32 \\
\hline 1971 & 0.371 & 0.459 & 0.0 & 0.498 & 0.345 & 0.298 & 0,323 \\
\hline 1772 & 0.417 & 0.449 & 0.0 & 0.445 & 0.383 & 0,301 & 0,340 \\
\hline 197 & 0,410 & 0.440 & 0.0 & 0.470 & 0.160 & 0.0 & 0,351 \\
\hline 1774 & 0.570 & 0.510 & 0.0 & 0.570 & 0.150 & 0.920 & 0.440 \\
\hline 1975 & $1.080^{\circ}$ & 1.170 & $0, \hat{0}$ & 0,89 & 0.460 & 0.0 & 0,750 \\
\hline 196 & 1.249 & 1.700 & 0.0 & 1.207 & 0.680 & 1.970 & 1.050 \\
\hline 197 & 1.421 & $2+010$ & 0.0 & 1.775 & 1.970 & 1,700 & 3.234 \\
\hline 1970 & $2+200$ & $2+220$ & $i_{+}$ & $1+992$ & $1+750$ & 2.100 & 1.474 \\
\hline $197 \%$ & 2.463 & 2.630 & $2.7+20$ & 2,27 & 2.770 & 2,710 & 1,907 \\
\hline 1900 & 3.190 & 4.500 & 3.540 & 2.860 & 2.950 & $3+900$ & 2.280 \\
\hline 1981 & 3.890 & 4.820 & 3.940 & 3.680 & 4.430 & 3.420 & $2+714$ \\
\hline 1982 & 4.260 & 5.000 & $5,9: 0$ & $4+230$ & 4.150 & 4.370 & 3.30 \\
\hline 1483 & 4,390 & 0.0 & 0.0 & 4,240 & 4.550 & 4.970 & 3.580 \\
\hline
\end{tabular}

B. 18 
TABLE B.9. Coking Coal Prices: Industrial Sector (\$/ton)

\begin{tabular}{|c|c|c|c|c|c|c|c|c|c|}
\hline YEAK & $\mathrm{AK}$ & $\mathrm{AL}$ & AF & $A Z$ & $C A$ & $C 0$ & $G T$ & $x$ & $\mathrm{DE}$ \\
\hline 1900 & 0.0 & \pm \pm .360 & 0,0 & 0,0 & 11,40 & $1 \pm .610$ & 0,0 & 0,0 & 0.5 \\
\hline 1971 & $0 . \hat{U}$ & 12,460 & 6.0 & 0.0 & $12+30$ & $12+500$ & $6+0$ & 0,0 & 0.0 \\
\hline 1972 & $\hat{0} .0$ & 14,150 & 0,0 & 0.0 & 12.820 & 13.820 & 0.5 & 0,0 & 0.0 \\
\hline 1973 & 0.0 & $17+240$ & $0 . \hat{0}$ & $\hat{0}+0$ & 16.260 & 16.26 & 0.0 & 0.6 & 0.0 \\
\hline 1974 & 0.0 & $33.740 \hat{~}$ & 0.0 & 0,0 & 34,650 & 34.650 & 0,5 & 0.0 & $a+j$ \\
\hline 1975 & 0.0 & 40.270 & $\hat{v}+\hat{V}$ & $0, \hat{0}$ & $37+110$ & $37+110$ & 0.0 & 0.0 & $\overrightarrow{0}+\hat{0}$ \\
\hline 1976 & 0.0 & 40,050 & 0.0 & 0.0 & 40.550 & 40.550 & $\hat{0}, \hat{\mathrm{j}}$ & $\hat{0}+0$ & $0 . \mathrm{V}$ \\
\hline 1977 & 0,0 & 55.230 & 0.0 & $0 . \hat{0}$ & 42.380 & 42,390 & 0.0 & 0.0 & 0.0 \\
\hline 198 & $\hat{0}, 0$ & 48,690 & 0.0 & 0.0 & $45+670$ & 45,570 & 0.0 & 0.0 & $0+3$ \\
\hline 1979 & 0.0 & 48.200 & $\hat{\imath} .0$ & 0.0 & 46.50 & $46+800$ & 0.0 & 0.0 & $\hat{0}=0$ \\
\hline 1930 & 0.0 & $52+560$ & 0.0 & 0.0 & 52.880 & 52.890 & 0,0 & 0.0 & 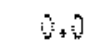 \\
\hline 1481 & 0.0 & 55.370 & 0,0 & 0.0 & 60.510 & 80.510 & 0.0 & 0.0 & 0.0 \\
\hline 1982 & 0.0 & 58.440 & $0,0.0$ & 0.0 & 55.600 & 50.600 & 0,0 & 0.0 & $0+i$ \\
\hline 1983 & $\hat{0}+\hat{0}$ & $54+490$ & $8+0$ & $0+0$ & 0.0 & 0.0 & 0,0 & 0,0 & 00 \\
\hline
\end{tabular}

\begin{tabular}{|c|c|c|c|c|c|c|c|c|c|}
\hline YeAs: & $\mathrm{H}$ & $G$ & HI & $\mathrm{IA}$ & ID & IL & ind & $\mathrm{KS}$ & 11 \\
\hline-- & $\cdots$ & $\cdots$ & anan & 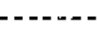 & - & N & $-\ldots+\cdots+$ & $\cdots$ & \\
\hline 1570 & 0,0 & 0.0 & 0.0 & 0.0 & 0.0 & 11.160 & 1: & 0,0 & $\pm 0,220$ \\
\hline 1971 & 0,0 & 0.0 & 0.0 & 0.0 & 0.0 & 13,410 & $\{4,076$ & 0,0 & $1+73$ \\
\hline 1972 & 0,0 & 0.0 & 0.0 & 0.0 & 0.0 & 14.940 & 15,730 & 0.0 & $=200$ \\
\hline 1973 & 0.0 & 0.0 & $0+\hat{0}$ & 0.0 & 0.0 & $16+\frac{1}{1} 40$ & $18+340$ & 0.0 & 17.710 \\
\hline 1974 & 0.0 & 0.0 & 0.0 & 0.0 & 0.0 & 32.830 & $3 ;, 030$ & 0.0 & 22,830 \\
\hline 1975 & 0.0 & 0.0 & 0,0 & 0.0 & 0.0 & 39,800 & 47,20 & 0.0 & $4 \hat{A}+970$ \\
\hline 1976 & 0.0 & 0.0 & 0.0 & 0,0 & 0,0 & 38.480 & 40,340 & 0.0 & 44,670 \\
\hline 1977 & 0.0 & 0.0 & 0.0 & 0.0 & 0.0 & $42+240$ & $45+190$ & 0.0 & 47,040 \\
\hline 1978 & $\hat{0}+0$ & 0,0 & 0,0 & 0.0 & 0,0 & 49.710 & 54,150 & 0,0 & $50+820$ \\
\hline 1979 & 0.0 & 0,0 & 0.0 & 0.0 & 0.0 & 48.460 & 50.250 & 0.0 & $47+020$ \\
\hline 1980 & 0.0 & 0,0 & 0,0 & 0.0 & 0.0 & 51.750 & 3.1050 & 0,0 & 48,520 \\
\hline 1981 & 0.0 & 0.0 & 0.0 & 0.0 & 0.0 & $56+100$ & $B+000$ & 0.0 & 54,510 \\
\hline 1982 & $\hat{v}_{+} 0$ & 0.0 & 0.0 & 0.0 & 0,0 & 59.790 & 67,400 & 0.0 & 54,77 \\
\hline 1983 & 0.0 & 0.0 & $\hat{v}+\hat{0}$ & 0.0 & 0.0 & $5 x+30$ & $65.5 x$ & 40 & 42,250 \\
\hline
\end{tabular}

\begin{tabular}{|c|c|c|c|c|c|c|c|c|c|}
\hline TSE & $L A$ & itA & $T D$ & 和 & : YI & intis & 舟0 & 185 & $\pi$ \\
\hline$\ldots . .$. & - & -.-- & ----- & $-\ldots$ & 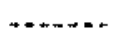 & n....... & - & - & $\cdots \cdots$ \\
\hline \pm 970 & 0,0 & 0.0 & 15,630 & 0.0 & 14,680 & 14.150 & 10,220 & 0.0 & 0.0 \\
\hline 1971 & 0.0 & 0,0 & 16.940 & 0.0 & 17,710 & 18.570 & 11.73 & 0.0 & 0.0 \\
\hline 1772 & 0.0 & 0.0 & 20.520 & 0,0 & 19.380 & 18.160 & 15.280 & 0.0 & 0.0 \\
\hline 1473 & 0.0 & 0.0 & 22.590 & 0.0 & 21.300 & 21.270 & $27,7 \ldots$ & $0 . \hat{0}$ & 0,0 \\
\hline 1974 & 0,0 & 0.0 & 42.700 & 0,0 & 44.290 & 36.680 & 32.030 & 0.0 & 0,0 \\
\hline 1575 & 0.0 & 0.0 & 57.270 & $0 . \hat{0}$ & 55.430 & 48.370 & 42.670 & 0.0 & 0.0 \\
\hline 1976 & 0.0 & 0.0 & 56.350 & 0,0 & 53.460 & 48.700 & 44,60 & 0.0 & 0.0 \\
\hline 107 & 0.0 & 0.0 & 9.210 & $0 . \hat{U}$ & 53.760 & 48.410 & $47+44$ & 0.0 & 0.0 \\
\hline 1978 & $0+0$ & 0.0 & 52,50 & 0.0 & 50.220 & 65,290 & 50.520 & 0.0 & 0,0 \\
\hline $1.7 \%$ & 0.0 & 0.0 & $5=200$ & $\hat{0}+\hat{0}$ & 5000 & $59+020$ & $4: 6 x$ & $i_{i} i_{0}^{0}$ & 0,0 \\
\hline 1590 & 0.0 & $0.0]$ & 53.500 & 0.0 & 30,740 & 0,0 & $40=20$ & N. & 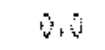 \\
\hline 1481 & 0.0 & 0.0 & 45,480 & 0.0 & 64,700 & $0 . \hat{0}$ & 54.510 & 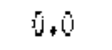 & 0.0 \\
\hline 1982 & 0.0 & 0.0 & 73.150 & i) +0 & 66.210 & 0.0 & 54,770 & 0.0 & 0,0 \\
\hline 1498 & $0 . \hat{0}$ & 0.0 & 0.0 & 0.0 & 59.770 & 0,0 & $42+25 x$ & 0.0 & 0.0 \\
\hline
\end{tabular}


TABLE B.9 (CONT). Coking Coal Prices: Industrial jector (\$/ton)

\begin{tabular}{|c|c|c|c|c|c|c|c|c|c|}
\hline YAPF & $\mathrm{in}$ & 145 & $\mathrm{HE}$ & 洲 & $x$ & Nin & $1 \mathrm{H}$ & Hit & 政 \\
\hline 1970 & 0.0 & 0.0 & 0.0 & 0.0 & $15+330$ & 0.0 & 0,13 & $15.6,30$ & $1+350$ \\
\hline 1971 & 0.0 & $0 . \hat{0}$ & 0.0 & $0 . \hat{0}$ & 18.540 & 0.0 & 0.0 & $18+540$ & $13+560$ \\
\hline 1972 & 0.0 & 0.0 & 0,5 & 0,0 & 0.0 & 0,0 & 0,0 & 20.520 & 15,490 \\
\hline 1973 & 0.0 & 0.0 & 0.0 & $0 . \hat{0}$ & 0.0 & 0.0 & 0.0 & $20.5 \%$ & 17,30 \\
\hline 974 & 0.0 & 0.0 & 0,0 & 0,0 & 0,0 & 0,0 & 0.0 & $42+700$ & 34.980 \\
\hline 1975 & 0.0 & 0.0 & 0,0 & $0 . \hat{0}$ & 0.0 & 0.0 & 0.0 & 57.270 & 42,120 \\
\hline 1976 & 0.0 & $\hat{0}, \hat{0}$ & 0,0 & 0.0 & 0.0 & 0.0 & 0.0 & 5,550 & 40,900 \\
\hline 197 & 0.0 & $0, \hat{0}$ & 0.0 & 0.0 & $0, \hat{0}$ & 0.0 & 0.0 & $77+210$ & 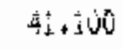 \\
\hline 1978 & 0,0 & 0.0 & 0.6 & 0.0 & 0.0 & 0.0 & 0,0 & 32,670 & 47.170 \\
\hline 1079 & 0.0 & 0.0 & 0.0 & 0.0 & 0.0 & 0.0 & 0.0 & $62+200$ & $47+300$ \\
\hline 1780 & 0.0 & 0.0 & 0,0 & 0.0 & 0.0 & 0.0 & $0 . \overline{3}$ & $03+500$ & 5050 \\
\hline 1901 & 0.0 & 0.0 & 0.0 & 0.0 & 0.0 & 0.0 & $\hat{B} . \hat{0}$ & 40.400 & $40+30$ \\
\hline 742 & 0,0 & 0.3 & 0,0 & 0.0 & 0.0 & 0.0 & (4) & $7 a 150$ & 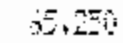 \\
\hline 483 & 0.0 & 0,0 & 0.0 & 0.0 & 0.0 & 0.0 & 0.0 & 0.6 & 5,5 \\
\hline
\end{tabular}

\begin{tabular}{|c|c|c|c|c|c|c|c|c|c|}
\hline TEA & DX & CR & $\mathrm{FA}$ & RI & 50 & 50 & Tit & 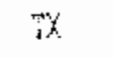 & $w_{i}^{m}$ \\
\hline 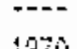 & 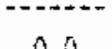 & 0 & 1.7 & 0 & $\therefore$ & 10 & & & \\
\hline $\begin{array}{l}1770 \\
1471\end{array}$ & $\begin{array}{l}0.0 \\
0.0\end{array}$ & $\begin{array}{l}0.0 \\
0.0\end{array}$ & $\begin{array}{l}1.760 \\
12,370\end{array}$ & $\begin{array}{l}0.0 \\
0.0\end{array}$ & $\begin{array}{l}0.0 \\
0.0\end{array}$ & $\begin{array}{l}0.0 \\
0.0\end{array}$ & $\begin{array}{l}10,220 \\
11,730\end{array}$ & $\begin{array}{l}50+20 \\
11,750\end{array}$ & $\begin{array}{l}11,620 \\
12,=0\end{array}$ \\
\hline $1 \% 72$ & 0.0 & 0.0 & $14.8 B 0$ & 0.0 & 0.0 & 0.0 & 15,290 & $15+290$ & 2.20 \\
\hline 1473 & 0.0 & 0.0 & 17.550 & 0.0 & 0.0 & 0.0 & $17, \pi 0$ & $17+710$ & $+2,20$ \\
\hline 1974 & 0.0 & 0,0 & 36.740 & 0.0 & 0.0 & 0.0 & 32,530 & 32,430 & 34,60 \\
\hline 1475 & 0.0 & 0.0 & 40.690 & 0.0 & 0.0 & 0.0 & 42.870 & $42+870$ & $3+110$ \\
\hline 1976 & 0.0 & 0.0 & 43.450 & 0.0 & 0.0 & 0.0 & 44,670 & 44,670 & 40.50 \\
\hline 1077 & 0.0 & 0.0 & 43.430 & $0 . \hat{v}$ & 0,0 & 0.0 & $47+\hat{0} 4 \hat{\imath}$ & 47,040 & 42,030 \\
\hline 1978 & 0.0 & 0.0 & 52,960 & 0,0 & 0.0 & 0.0 & 50.620 & 50,60 & 45,670 \\
\hline 1579 & 0.0 & 0.0 & 50.370 & 0.0 & 0.0 & $\hat{y}+\hat{0}$ & $47+025$ & 47.020 & $4 i, 5$ \\
\hline 1990 & 0.0 & 0.0 & 58.930 & 0.0 & 0.0 & 0.0 & 48.520 & 48.520 & 2.360 \\
\hline $1 \div 81$ & 0.0 & 0.0 & 63.500 & 0.0 & $0 . \hat{0}$ & 0.0 & $54.5: 6$ & 54,510 & $6+510$ \\
\hline 1982 & 0.0 & 0.0 & 67.670 & 0,0 & 0.0 & 0.0 & 54,700 & 54,770 & $5+600$ \\
\hline $148=$ & $0 . \hat{0}$ & 0.0 & 57.580 & $0+\hat{v}$ & $\hat{0}+\hat{v}$ & 0.0 & 42.20 & 42.200 & 6.0 \\
\hline
\end{tabular}

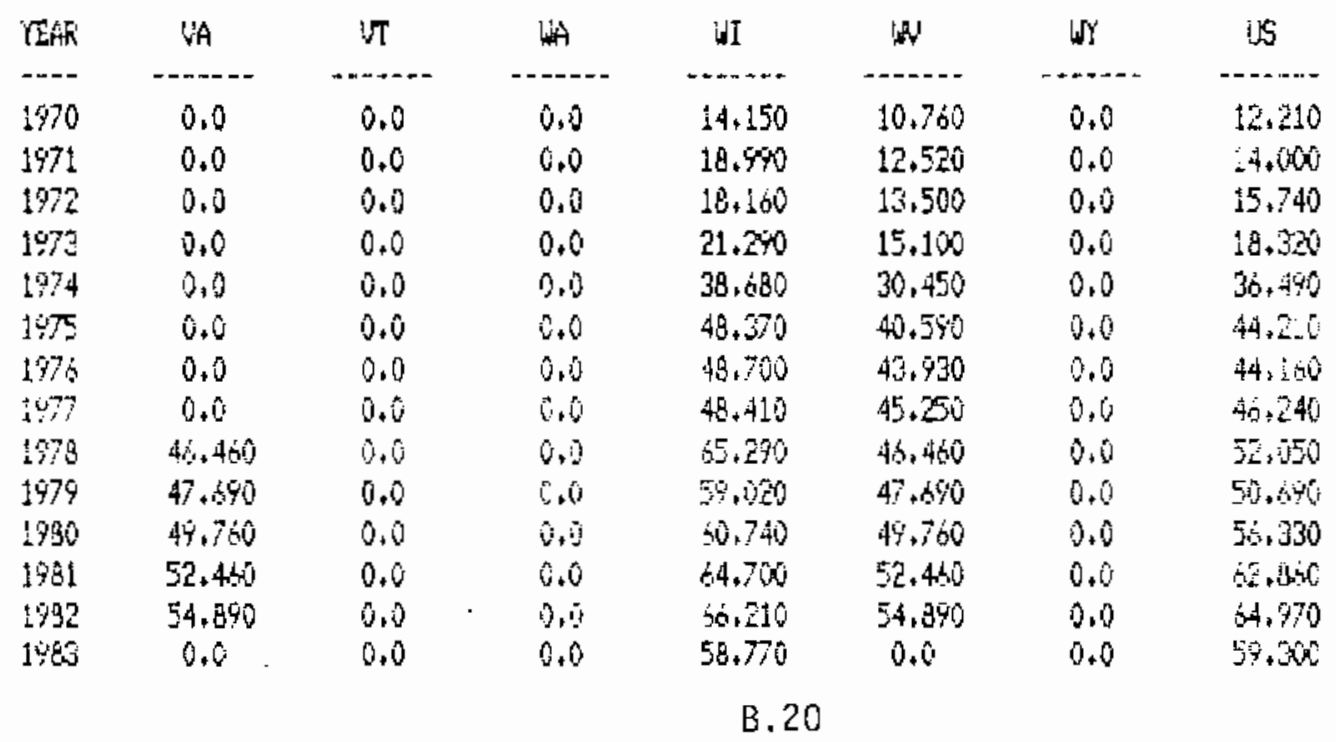


TABLE B.10. Steam Coal Prices: Residential Sector ( $\$ /$ ton)

\begin{tabular}{|c|c|c|c|c|c|c|c|c|c|}
\hline TEAK & $A K$ & AIL & Af' & $\mathrm{A} Z$ & $C A$ & 00 & $C T$ & $\mathrm{DC}$ & 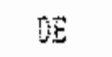 \\
\hline 1970 & 0.0 & 18.756 & $0+i j$ & 0.0 & 0.0 & 20,892 & 27.908 & 24,151 & 20,000 \\
\hline 1971 & 0.0 & $23+377$ & 0,0 & 0,0 & 0.0 & $15+315$ & 37.325 & $30+012$ & $\mathrm{~W}+\mathrm{OH}$ \\
\hline 1872 & 0.0 & 23.844 & $0, \bar{j}$ & 0.0 & 0.0 & 21.466 & 37.675 & 35,000 & 35,000 \\
\hline 1475 & 0.0 & 25.301 & 0.0 & 0.0 & 0.0 & 33.919 & $41+729$ & $31.7 \%$ & 35,45 \\
\hline 1974 & 0.0 & 41,938 & 0.0 & 0.0 & 0,0 & $24+190$ & $4 \overline{1}, 213$ & 51.127 & $3+12$ \\
\hline $14 \%$ & 0.0 & 40.599 & 0.0 & 0.0 & 0.0 & 35.101 & $58+3 x$ & 38.5077 & $60+80$ \\
\hline 1076 & 0.0 & 43.356 & 0,0 & 0.0 & 0.0 & 32,084 & 30,265 & $37+568$ & 34,80 \\
\hline 1977 & 0.0 & 45.414 & 0.0 & 0.0 & 0.0 & 36.376 & 70.530 & $60+32$ & $60+325$ \\
\hline 1978 & 0,0 & 64,137 & 0.0 & 0.0 & 0.0 & 37,753 & $3:+335$ & 62,722 & 55.51 \\
\hline $1 \% 79$ & 0.0 & 50.378 & 0,0 & 0.0 & 0.0 & 64,908 & $P S_{+}+\hat{A}_{-} 4$ & $63+682$ & 5 \\
\hline 1780 & 0.0 & 66,789 & 0.0 & 0.0 & 0.0 & 57,030 & 100.431 & 7.444 & 75,719 \\
\hline 1981 & 0.0 & 82.240 & 0.0 & 0.0 & 0.0 & 75.940 & $119, \overline{2} 31$ & $83+344$ & $12 \div 270$ \\
\hline 1982 & 0.0 & 73.976 & 0,3 & 0.0 & 0.0 & 71.034 & 122,089 & 85.465 & 94,369 \\
\hline 1993 & 0.0 & 81.576 & $a+6$ & 0,0 & 0.0 & do. & 15.00 & $77=248$ & 35 \\
\hline
\end{tabular}

\begin{tabular}{|c|c|c|c|c|c|c|c|c|c|}
\hline YEAF & $F$ & CA & $\mathrm{HI}$ & $I A$ & ID & $\mathrm{I} \mathrm{L}$ & in & 16 & in \\
\hline 1970 & 0,0 & 22.134 & 0,01 & 29.443 & 22,787 & 23.687 & $25.39 \%$ & 20.762 & 5,90 \\
\hline 1471 & $\hat{0}+0$ & $22+540$ & $6+0$ & 24.853 & $23+546$ & 30. & 23.615 & 20,474 & 19, we \\
\hline 1972 & 0.0 & 25,810 & 0.0 & 24,994 & 25,010 & 31.502 & $26,0 \hat{B} 5$ & 22,129 & 21,99 \\
\hline $1 \% 7 \mathrm{~s}$ & $\hat{v}, 0$ & $22+178$ & 0.0 & 26.526 & 13.264 & 25.542 & 26.846 & 26,361 & 75.895 \\
\hline 1974 & 0.0 & 24,956 & $0, \overline{1}$ & 39.911 & 31.239 & $38+244$ & 51.510 & 25.670 & 42,36 \\
\hline 1975 & 0.0 & 71.843 & 0.0 & 82,043 & 39.552 & 46.875 & 58,001 & $3,02 t$ & 4h.58 \\
\hline 1976 & 0.0 & 34.685 & $0, j$ & 30,995 & 43.698 & 50.521 & $5,5,527$ & 30.349 & 42.979 \\
\hline कात & $0+0$ & 51.514 & 0.0 & 51,153 & 30.796 & $51+655$ & $55+378$ & 40.330 & $54+284$ \\
\hline 1778 & 0.0 & 64,357 & $0, i)$ & $71+312$ & 55,195 & $52+435$ & 56.674 & 41,948 & 54.020 \\
\hline 1979 & 0.0 & 63.273 & 0.0 & $71+561$ & 50.289 & 50.049 & 50,482 & $48+366$ & 47.79 \\
\hline 1980 & 0,0 & 70.140 & 0.0 & 74,525 & 57.479 & $48+304$ & 34,694 & 48.417 & 51,700 \\
\hline 1981 & 0,0 & 79.777 & 0.0 & $\pi . \$ 13$ & $63+311$ & 54,079 & 81,02 & 59.206 & 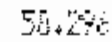 \\
\hline 1982 & 0.0 & 33.245 & 0.0 & 95.868 & 65,535 & 51,973 & $52,5 i 7$ & 4799 & $37.87 \%$ \\
\hline 1403 & 0,0 & 76.875 & 0.0 & 84,145 & 46.831 & $58+665$ & 62.47 & $68+0 a$ & 55,244 \\
\hline
\end{tabular}

\begin{tabular}{|c|c|c|c|c|c|c|c|c|c|}
\hline TiAR & EA & 134 & ND & 河 & MI & 楼 & 物 & $i n$ & in \\
\hline$\cdots$ & - & $\ldots+\infty$ & $+\cdots+\infty$ & - - & 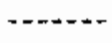 & , n... & $\cdots$ & $\cdots$ & ( \\
\hline 1970 & 0.0 & 24,243 & $24,13+$ & 24,859 & 32,979 & 35.753 & $1 \%, 006$ & 0.0 & 18.555 \\
\hline 1971 & 0.0 & 37,325 & 3,011 & 37.35 & 33.840 & 23.844 & 2.65 & 0.0 & 23.225 \\
\hline 1972 & 0.0 & 37.675 & 35.000 & 37.675 & 39.001 & 21.655 & $29.7 \% 2$ & 0.0 & 19.203 \\
\hline 1973 & 0.0 & 41.504 & $31.7 \%$ & 41.729 & $31 . \mathrm{Be} 2$ & 25.085 & $7+62$ & $\dot{v}_{0} \hat{0}$ & 20.25 \\
\hline 1974 & 0.0 & 49.213 & 5,127 & 49.213 & 61,871 & 7.749 & 3,300 & $0+0$ & 23.964 \\
\hline $1 \% 5$ & 0.0 & 58.340 & 39.507 & 58.360 & 60.221 & 67.753 & 39.284 & 0.0 & $23+63$ \\
\hline 1976 & 0.0 & 60.265 & 34.388 & 50.265 & $65+194$ & 68.046 & 3.241 & 0.0 & 47.25 \\
\hline 1977 & 0.0 & 70.538 & 60.56 & 70.538 & 75,690 & $6 \theta+\cos \theta$ & $45+188$ & 0.0 & 26,64 \\
\hline 1978 & 0.0 & 81.395 & $62+72$ & 81.335 & 73,917 & 95.663 & 44,973 & 0.0 & 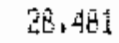 \\
\hline 1979 & $0 . \hat{0}$ & 78.614 & is & 79.614 & 76.616 & 71.300 & 41,120 & 6.0 & $2+50$ \\
\hline 1900 & 0.0 & 100.431 & 71,444 & 87.793 & 93.185 & $97+216$ & 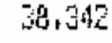 & 0.0 & 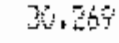 \\
\hline $1 \% 81$ & 0.0 & $119+831$ & $80+34$ & $107+981$ & 91,35 & 79.42 & 32.346 & 0,0 & $3=460$ \\
\hline 1982 & 0.00 & 122.084 & 85.465 & 99.001 & 94,900 & 115,020 & $37,11^{2}$ & 0.0 & 42.464 \\
\hline 1983 & 0.0 & 115.037 & $77+289$ & 43.020 & 41.323 & 1003.937 & $49.0 \%$ & $0+0$ & $15+465$ \\
\hline
\end{tabular}


TABLE B. 10 (CONT). Steam Coal Prices: Residential Sector ( $\$ /$ ton)

\begin{tabular}{|c|c|c|c|c|c|c|c|c|c|}
\hline TEth' & 战 & $\mathrm{ND}$ & $\mathrm{kE}$ & 性 & 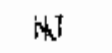 & F蚹 & FN & WY & 计 \\
\hline$\cdots$ & $\cdots$ & - & - & - & --- & 等 & 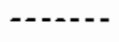 & - & \\
\hline 1970 & 26.370 & 35.984 & 24.983 & 24.859 & 26.023 & 0.0 & 30.345 & 5,118 & 24,382 \\
\hline 1971 & 22.744 & 30.011 & $2 v+634$ & 37.325 & $32+248$ & 0.0 & 20.497 & $42+172$ & $20+202$ \\
\hline $1 \% 2$ & 28,75 & 33.034 & 23,924 & 37,675 & 31.777 & $0+0$ & $21, A B 9$ & $33+41$ & 27.54 \\
\hline 1973 & 30.966 & $32+095$ & 26.526 & 41.429 & 31.538 & 0.0 & $17.96 \mathrm{ts}$ & 34,112 & 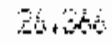 \\
\hline 1974 & 56.375 & 58.492 & 34.235 & 49.213 & 49.348 & 0,0 & 34.335 & 45,769 & $57+317$ \\
\hline 1975 & $45+807$ & 68.733 & 47.46 & 58.360 & 46.519 & 0.0 & 34.589 & $\sin 760$ & 58.314 \\
\hline 1976 & 45,563 & 83,061 & 50.727 & 50.265 & 78.041 & 0.0 & $64+167$ & 63.762 & 57,49 \\
\hline 1977 & 62.811 & 36.828 & 57.54 & 70.538 & 60.778 & 0.0 & 75.236 & 68.973 & 64 6 \\
\hline 1975 & 38.352 & 34.078 & 75.507 & $\$ 1.335$ & 62,061 & 0.0 & $75+507$ & 66.124 & 60,27 \\
\hline 1979 & 53,453 & 39.654 & 80.53 & $79, \dot{114}$ & 64.120 & 0.0 & 106.541 & $67+34$ & 61,01 \\
\hline 1980 & 60.628 & 44.144 & 30.934 & $\$ 7.793$ & 71.354 & 0.0 & 115.980 & 73,198 & 00,76 \\
\hline 1981 & 73.741 & 26.052 & $83+305$ & 107.481 & 79.288 & 0.0 & 120.452 & $81+08$ & $74+19$ \\
\hline 1992 & 34.949 & 62,242 & 95,504 & 49.001 & 79.290 & 0.0 & 12,146 & 42,472 & 70.99 \\
\hline 198 & 63,344 & $49+813$ & $4 \%, \angle B O$ & 93.020 & $69+582$ & 0.0 & 105.06 & $34+329$ & $70+7=1$ \\
\hline
\end{tabular}

\begin{tabular}{|c|c|c|c|c|c|c|c|c|c|}
\hline risti & OK & C & $F^{\prime} A$ & $k_{l}^{\prime}$ & $S C$ & SD & 74 & $x$ & $\pi$ \\
\hline$\cdots$ & $-\cdots$ & +....... & - & -...- & ......... & $\cdots$ & $-\ldots . .$. & n. & $\cdots$ \\
\hline $1 \% 0$ & 0.0 & 0.0 & $23,76:$ & 22.718 & 37.826 & 40.467 & 17.00 & 0.0 & 17,495 \\
\hline 1971 & 0,0 & 0.0 & 35.059 & 37.35 & 22.744 & 21.276 & 2.377 & $i, 0$ & 17.40 \\
\hline 1972 & 0.0 & 0.0 & 26.362 & 37.675 & 28.759 & 21.645 & 24.927 & 0.6 & 17,702 \\
\hline 1973 & 0.0 & 0.0 & 24.810 & 41,929 & 26.526 & $39+267$ & 23.574 & 0,0 & $16+524$ \\
\hline 1974 & 0.0 & 0.0 & 50,325 & 49.213 & 44,933 & 78,740 & $41,7: 28$ & 0.0 & 27.725 \\
\hline $14 \pi$ & 0.0 & 0.0 & 57.20 & 58.360 & 54,577 & $80+351$ & 38.240 & 0.0 & $2+6)$ \\
\hline 1976 & 0.0 & 0.0 & 51,958 & 60.265 & 66.129 & 30.204 & 39.505 & 0.0 & 34.685 \\
\hline 1977 & 0.0 & 0,0 & 53,412 & 70.538 & $67+699$ & 67.850 & 44.849 & 0.0 & 34,56 \\
\hline 1978 & 0.0 & 0.0 & 54,687 & 81.335 & 67.197 & 72.592 & $4: 661$ & 0,0 & $4 A_{0}+550$ \\
\hline 1979 & 0,0 & 0,0 & $55+673$ & 79.614 & 65.415 & 72.674 & $33+067$ & $0+0$ & $7+720$ \\
\hline 1980 & 0,0 & 0.0 & $60, \sin 8$ & 120.431 & 71.714 & 78.281 & 44,914 & 0.0 & 68.026 \\
\hline 1981 & 0.0 & $0 . \hat{0}$ & 71.200 & 119.831 & 5.212 & 59.735 & $52+80 i$ & 0,0 & 90431 \\
\hline $1>B Z$ & 0.0 & $0+0$ & 71.526 & 122.089 & 82.512 & 76,204 & $35+153$ & 0 & 45.174 \\
\hline 1980 & 0.0 & 0.0 & KE. .098 & 115.037 & 84.079 & 94.626 & 3,786 & 0.0 & $7:+30$ \\
\hline
\end{tabular}

\begin{tabular}{|c|c|c|c|c|c|c|c|}
\hline YEAR & VA & UT & WA & DII & 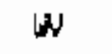 & $W Y$ & 15 \\
\hline & -.. & & & & . & - & \\
\hline 1970 & $30+876$ & 31,662 & 22.386 & 37.625 & 15.207 & 15.230 & 26,023 \\
\hline 1971 & 30,011 & 37.325 & $2.99 \%$ & $3+.566$ & $25+449$ & 16.641 & 27,75 \\
\hline 1572 & 36.509 & 37.675 & 25.010 & 36.075 & 24.651 & 13.397 & 20,305 \\
\hline 1973 & 35.406 & $41 .+529$ & $2 t .343$ & 38.450 & 21.537 & 21,102 & $27+121$ \\
\hline 1974 & 54,506 & 49.213 & $3 \div 399$ & 54,709 & 32.951 & 21.262 & 49,758 \\
\hline 1975 & 60.764 & $58+360$ & $25,3^{7} ;$ & $49+9 B$ & 27.64 & 21.591 & 55,025 \\
\hline 1976 & 70.921 & $60+365$ & 43,35 & 55.856 & $27,7+4$ & 32.220 & 54,606 \\
\hline $1 \% 7$ & 77,271 & 70.530 & $30.7 \%$ & 71.201 & 40.845 & $27+113$ & $50+14$ \\
\hline 1978 & 42,600 & 31,335 & 50,290 & $79+680$ & 33.559 & $25.72 \pm$ & 36.64 \\
\hline 1979 & 80.971 & $102+373$ & $87+0,02$ & 80,489 & $31+155$ & 16,238 & 58.102 \\
\hline 150 & $36+69$ & 90,442 & 95,02, & 58.153 & 35.756 & 19.475 & $3: 944$ \\
\hline $1 \% 01$ & 97.36 & $119.49 \%$ & 101,147 & $4+093$ & $47+422$ & 27.251 & $71+50$ \\
\hline $1 \% 82$ & 94.660 & 117.749 & $107.68+$ & 91.953 & 45.690 & 58.841 & 74.532 \\
\hline 1483 & $84,6-49$ & 104.923 & $85+41$ & 45.804 & 37.726 & $54+147$ & 67,240 \\
\hline
\end{tabular}


IABLE B.11. Steam Coal Prices: Industrial Sector ( $\$ /$ ton)

\begin{tabular}{|c|c|c|c|c|c|c|c|c|c|}
\hline 'Tién' & $A K$ & AL & Afi & $A I$ & $\mathrm{CA}$ & 50 & ET' & $\mathrm{i}$ & $\mathrm{OE}$ \\
\hline & 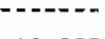 & 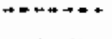 & & & & & & & \\
\hline 1770 & \pm 8.393 & $6+480$ & 0.0 & 12,726 & $15,32 \%$ & 8.649 & 190108 & 2,695 & 6.57 \\
\hline 1971 & 16.005 & $9.1 \%$ & 0.0 & $11+226$ & $12+150$ & 8.702 & 18.809 & 11.135 & 209 \\
\hline 1472 & 13,800 & $B .519$ & 0,0 & 14,727 & 14,486 & 9,249 & 21,419 & $5+500$ & 7.405 \\
\hline $19 \% 3$ & 19.567 & $9+173$ & 14.55 & $14,6-1$ & 14,178 & 9.146 & 2.929 & 7.797 & 10.014 \\
\hline 1974 & 20.364 & 19.143 & 21.572 & 20.747 & 24.209 & 16,197 & $33, \ldots$ & 24,791 & 21,459 \\
\hline 1975 & 27.200 & 24.5002 & 26.101 & 19.302 & 21,168 & 17.300 & 47,345 & 29.737 & 56,27 \\
\hline 1976 & 25.859 & 28.367 & 31.553 & 23.611 & 25.616 & 22.150 & 38.097 & 26.504 & 24,233 \\
\hline 147 & 27.281 & 30,489 & 28.302 & 26.054 & 28.298 & 22.759 & 40.438 & 27.79 & 31,74 \\
\hline 1978 & 27,652 & 35.014 & 36.609 & $\vec{Z}+\mathrm{AB}$ & 31,108 & 26.424 & 39.147 & 3,704 & 20.736 \\
\hline 1979 & 30.296 & 37.483 & 39.894 & 32,63 & $34+008$ & 20,630 & 37.406 & $3+283$ & $30.5 \%$ \\
\hline 1980 & 0.0 & 41.840 & $40 . * 30$ & 32,090 & 40.300 & $26+160$ & 0.0 & 0.0 & 24.260 \\
\hline 1981 & 0.0 & 47.840 & 44.550 & 32.687 & $45+800$ & $25+100$ & 0.0 & 0.0 & 30.740 \\
\hline 1982 & 0.0 & 48.820 & 45.640 & 43,440 & 51.010 & 30.350 & 0.13 & 0.0 & 33.460 \\
\hline 1709 & 0.0 & 46.490 & 46.450 & 44.410 & 52.0130 & $2 \% 470$ & 0.0 & 60 & 5 \\
\hline
\end{tabular}

\begin{tabular}{|c|c|c|c|c|c|c|c|c|c|}
\hline YSifi & Fl & GA & $\mathrm{HI}$ & $\mathrm{IA}$ & ID & 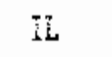 & $\mathrm{HA}$ & 16 & it \\
\hline 1970 & 0,0 & 11.789 & 0,4 & 3,289 & 30.573 & 10.270 & $1+540$ & $9+517$ & $10+260$ \\
\hline 1971 & 0.0 & 10.913 & 0.0 & 9,805 & $10+349$ & 9.617 & $9,5 \%$ & 10,30 & $5+7$ A \\
\hline 1972 & 0.0 & 12.927 & 0,0 & 10,086 & 10.957 & 11,501 & 12.724 & $10+207$ & 11,344 \\
\hline 1973 & 0.0 & $12+876$ & 0.0 & 11.303 & 10.908 & $11,44 c$ & 13.037 & 9.38 & 11,747 \\
\hline 1974 & 0,0 & 23.954 & 0.0 & 17,509 & 16,122 & 18,542 & 21.403 & $1 \%, 093$ & 18.606 \\
\hline $19 \% 5$ & 12.516 & 30.711 & 0.0 & 26.296 & $17+437$ & 25,909 & 29.696 & 18.719 & $2 \%+04$ \\
\hline 1976 & $28 .: 21$ & 28.737 & $0,1)$ & 2,190 & 21.607 & 28.044 & $25.37 \%$ & 24,967 & 27.454 \\
\hline 1977 & 32.324 & 31.373 & 0.0 & $27+68$ & 23.810 & 30.472 & 28.044 & $2 i, 25$ & 20.44 \\
\hline 1978 & 36,605 & 36.010 & 0,0 & 30,084 & 24,664 & 34.348 & $31 ; 517$ & 2,289 & $3+45$ \\
\hline 1979 & $37+065$ & 36.647 & $\hat{4}+\hat{y}$ & 31.769 & 33.537 & 35.315 & 32.370 & 32.766 & $35+519$ \\
\hline $1 \% 00$ & 40,435 & 39.030 & 0.0 & 34,270 & 30,000 & 38.140 & 35,360 & 28.440 & $42+20$ \\
\hline 1981 & 47.180 & $42+800$ & 0.0 & 39.180 & 32,880 & 41.090 & $37+8 \div 0$ & 32,80 & 4470 \\
\hline 1982 & 49,750 & 44.560 & 0,0 & 40,360 & 34.980 & $43+100$ & 33,260 & 36.710 & 46.190 \\
\hline 1983 & 48.430 & $4 \hat{i}+040$ & 0.0 & 37.300 & 37.180 & $40+240$ & 31.780 & $3+5 n$ & $4 h, 70$ \\
\hline
\end{tabular}

\begin{tabular}{|c|c|c|c|c|c|c|c|c|c|}
\hline DAF & $\mathrm{iA}$ & 海 & (TD) & ME & 洲i & 淋 & 舟 & NE & $\pi$ \\
\hline--- & n...... & -....-- & $-\ldots . . .$. & n...... & $\cdots$ & ......... & - & $\ldots . . .$. & $\cdots$ \\
\hline 1970 & 0.0 & $21+649$ & $\therefore 626$ & 23.654 & 12.310 & 0,625 & 10.713 & $3,02 B$ & 10,325 \\
\hline 1471 & 0.0 & 14.970 & $G+629$ & 20,0000 & 13.000 & $12 . \pi 7$ & 9.405 & 5.430 & 13.348 \\
\hline 1972 & 0.0 & 24.975 & +.441 & 25,956 & 13.984 & 4.167 & $11,41 \hat{v}$ & 9,890 & 10.604 \\
\hline 1973 & 0.0 & 30.314 & 4.558 & $2 \dot{2}+278$ & 14.363 & 8.75 & 12.018 & 10.506 & 10.6 \\
\hline 1974 & 0.0 & 41.237 & 18. & 36.437 & 23,722 & 13.593 & 17,606 & 21,840 & 14,044 \\
\hline $14 \pi 5$ & 0.0 & 62.500 & $2 ๘, 03 \%$ & $62+500$ & 34.176 & $16.420 \hat{0}$ & 25.110 & 75.796 & 16.47 \\
\hline 1976 & 0.0 & 43.796 & $2 x+11$ & 43,796 & 32,081 & 20.954 & 26.774 & 27,745 & 20.914 \\
\hline 1977 & 30,303 & $4 \hat{9}+080$ & 25.300 & 49,0000 & $32+519$ & 23.975 & 27.606 & 28.55 & tis. \\
\hline 1773 & 36,568 & 43.011 & 26,037 & 43,011 & 37.251 & 20.099 & 30.734 & 34,143 & $2+332$ \\
\hline 1979 & 36.412 & 37.506 & 26.030 & $37+906$ & 40.816 & $2 E+15 \theta$ & $32+96$ & $34+840$ & 25,58 \\
\hline 5750 & 27.490 & 41,090 & $2 \pi+200$ & 41,090 & 43,730 & 30,170 & 34,600 & 30.40 & $30+900$ \\
\hline 1961 & 34.140 & 40,040 & 3.740 & 46.060 & 51.140 & $34+370$ & $37+40$ & 45,413 & $36+100$ \\
\hline 1932 & $37.1 \%$ & 49,710 & 33.460 & 49,710 & 54,430 & 36.030 & 37,650 & 45,62 & 35.50 \\
\hline 1ues & $36+225$ & 40,730 & $3 i, 500$ & $4 \overline{4}+730$ & 49,730 & 39.50 & 35,450 & $43+806$ & 31,0 \\
\hline
\end{tabular}


TABLE B.11 (CONT). Steam Coal Prices: Industrial Sector (\$/ton)

\begin{tabular}{|c|c|c|c|c|c|c|c|c|c|}
\hline YEAK & 配 & 340 & 恮 & 献 & $|k|$ & Nat & bev & $14 y^{\prime \prime}$ & {$[1+1$} \\
\hline$\cdots$ & $\ldots$ & $\cdots$ & - & - & . & $\ldots . .$. & - & - & \\
\hline 1770 & 12.658 & 10,277 & 3.345 & 0.0 & 5.550 & 12,104 & 12,513 & $11,+600$ & 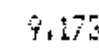 \\
\hline 1971 & 14.030 & $8,5=97$ & 8.372 & 0.0 & $12.3 \mathrm{kn}$ & $11+309$ & $1 \hat{2}+\hat{0} 85$ & 13.215 & $\%$ \\
\hline 192 & 13.237 & 10.409 & 4,415 & $0, i$ & 7,303 & 12,257 & $12,0] \mathrm{d}$ & $12,29 \%$ & 10.6 \\
\hline 1473 & 14.109 & 9.324 & 4.897 & 0,0 & 10,051 & 12.279 & $11.70 \mathrm{~d}$ & 12.215 & 11. \\
\hline 177 & 30.588 & 13.583 & $1 ;, 413$ & 0.0 & 25,575 & 18.584 & $19+317$ & 5,545 & 22,4 \\
\hline 1075 & $35.45 \%$ & 16.420 & 15.527 & 0.0 & 30.457 & 0,0 & 19,302 & $32+198$ & $y+1$ \\
\hline 1776 & $30,78 \mathrm{C}$ & 20.959 & $19+97$ & 0,0 & 22.798 & 23.297 & 23,451 & $32+394$ & \\
\hline 197 & 33.822 & 23.975 & 2,191 & 0.0 & 45.455 & $23+042$ & $2 s, 054$ & $3 x_{2}, y$ & $\div$ \\
\hline 1979 & 34.236 & 20,094 & 27,333 & 0.0 & 31,250 & 25,974 & 27.98 & 35.20 & $31+7$ \\
\hline 1979 & 39.554 & 22.158 & 32,364 & 0.0 & 34.483 & 28,134 & 32,321 & 37.906 & 34. \\
\hline 1980 & 71.660 & 34,530 & 32,453 & 0,0 & 34.690 & 19.215 & 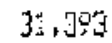 & $4 \therefore, 790$ & 31. \\
\hline 1981 & $45+280$ & 35.525 & $36,70.5$ & 0.0 & 41.985 & 20.317 & $35+200$ & 42060 & 3 \\
\hline 1812 & 4,400 & 35,300 & 33.734 & $0 . \hat{0}$ & 45,700 & 34,795 & 49,560 & $49+710$ & 34 \\
\hline $1 \% 93$ & 44.250 & 39.550 & $32+474$ & 0,0 & 43.285 & 34.743 & 41.790 & $40+750$ & \\
\hline
\end{tabular}

\begin{tabular}{|c|c|c|c|c|c|c|c|c|c|}
\hline TEFK & UK & U & $\mathrm{FAH}$ & EII & $x$ & $S D$ & 3it & $7 x$ & : \\
\hline 170 & $0 . \tilde{v}$ & 7,514 & 7,73 & 0,0 & 11.915 & 0,0 & 4,15 & $\dot{1}=33$ & 7.000 \\
\hline 1971 & 15.873 & $9+317$ & 10.075 & 0.0 & 13.110 & 0.0 & $10+073$ & 1.72 & 8,6 \\
\hline 1972 & 10.534 & $7+514$ & 9.321 & 0,0 & 13.185 & 0.0 & 10.211 & $13 \times 676$ & 8.004 \\
\hline 1973 & 7.051 & 12.132 & $7.17 \%$ & $0 . \hat{v}$ & $14+\mathrm{OLA}^{4}$ & 0.0 & $10+622$ & 12.774 & 8.34 \\
\hline 1974 & 18,740 & $14+957$ & 20.726 & 0,0 & 33.615 & 0.0 & 24,537 & $19+590$ & 17.2106 \\
\hline 1975 & 22.014 & 21.168 & 20,321 & 0.0 & 36.036 & 19.428 & $2+0+1$ & 18.919 & 17,43 \\
\hline 1976 & 27.765 & $25+616$ & 27.000 & 0.0 & 31.990 & 22,677 & 23.914 & 28.260 & $21+607$ \\
\hline 1977 & 26.042 & $28.2 \%$ & 20.044 & 0.0 & 32.659 & 24,615 & 26.604 & $25.29 \%$ & 23.010 \\
\hline 1978 & 31,553 & 31.108 & 26.921 & $\hat{0}+\hat{U}$ & 38,314 & 25.840 & 3.046 & 31.979 & 24,664 \\
\hline 1979 & 34,609 & 37.224 & $31.2 \%$ & 0.0 & $37+270$ & 26.964 & $32+30=$ & 30,412 & $25+34$ \\
\hline 1980 & 29.525 & $3 \% .680$ & 32,200 & 0.0 & 41,550 & 34,443 & 33,530 & $14 .=50$ & 23.480 \\
\hline 1,81 & 33.0400 & 44.353 & 3.70 & 0.0 & 45.750 & $36+483$ & 37.83 & 2.810 & $7+16$ \\
\hline 1892 & $37+450$ & 47.513 & 41,710 & 0.0 & $\$ 8.730$ & 33.850 & 40,610 & 20,740 & $33+390$ \\
\hline $1 \% 63$ & 38.60 & 45.470 & 30,040 & 0.0 & 46,040 & 3.600 & $38+1100$ & $26+400$ & 3.52 \\
\hline
\end{tabular}

\begin{tabular}{|c|c|c|c|c|c|c|c|}
\hline YEAE & $V A$ & $V T$ & W4 & WI & W & WY & 15 \\
\hline & ....... & - & $\ldots$ & & - & $\cdots$ & \\
\hline 1770 & $10+084$ & 0.0 & 12,673 & 15.233 & 8.317 & 8.066 & 11,2 \\
\hline 1971 & 12.640 & 0,0 & 12,945 & 12.456 & $9+791$ & $4 .+44$ & 10.7 \\
\hline $\operatorname{tin} 2$ & 11.042 & 0.0 & 11.757 & 16.641 & 10.135 & 8.440 & 12.4 \\
\hline 1973 & 11.467 & 0.0 & 13.501 & 37.022 & $10+37 \hat{V}$ & 8,207 & 22,6 \\
\hline 1974 & $31+105$ & 0.0 & 17583 & 24,106 & 21.627 & 14.349 & $2+3$ \\
\hline $14 \%$ & 34.434 & $\hat{v}+\hat{0}$ & 21.168 & 3.159 & $31+345$ & $16.50 \mathrm{~g}$ & 23.34 \\
\hline 157 & $30+297$ & 0.0 & 25.456 & 32.550 & 27,962 & 20,742 & 29.057 \\
\hline 1977 & $32+220$ & 0.0 & $2 \mathrm{z}+2 \mathrm{\theta}$ & 34.281 & $89+86$ & 23.000 & 61.5 \\
\hline 1973 & 37,371 & 0.0 & 3...56 & 3457 & 31 , $A B A$ & 25,599 & 3,7 \\
\hline $197 \%$ & 38.537 & 0,0 & $32+44 i$ & 40.755 & 32,712 & 28.634 & $34.7 \%$ \\
\hline 1990 & 40,150 & 0,0 & 48.740 & 33.440 & 5.056 & 30.723 & 35.140 \\
\hline 1581 & $46+150$ & 0.0 & 5्र4, $\operatorname{sen}$ & $47,6+1$ & 36,690 & 31.700 & 34.460 \\
\hline 1132 & 47.360 & 0,0 & 55.400 & 50.290 & 38.790 & 23.600 & $4 \div, 110$ \\
\hline 1993 & $4_{2}^{\prime \prime}+710$ & 0,0 & $47+200$ & 48,010 & 37.590 & 24.450 & 39.32 \\
\hline
\end{tabular}


TABLE B.12. Steam Coal Prices: Electric Utility Sector (\$/ton)

\begin{tabular}{|c|c|c|c|c|c|c|c|c|c|}
\hline Cati & $A K^{\prime}$ & Ă & $A f^{\prime}$ & $B 7$ & $C A$ & 0 & $T$ & {$\left[\mathrm{H}^{n}\right.$} & $\mathrm{DE}$ \\
\hline 100 & 70 & $\ldots$ & -- & $\ldots$ & 10 & $\ldots$ & rentar. & $\therefore 0$ & \\
\hline $\begin{array}{l}1970 \\
1971\end{array}$ & 11,570 & 6,030 & 0,7 & $3, \hat{4} 90$ & 0.0 & $5+570$ & 20,500 & $9+620$ & 9.620 \\
\hline 1971 & $12+213$ & 7.920 & 0.0 & 4.760 & $0 . \hat{0}$ & 6.040 & $22+230$ & $12+810$ & $2 E+4 j$ \\
\hline $1 \% 7$ & 13.740 & 9.900 & $0,1]$ & 6,620 & 0.0 & $6+390$ & 14,130 & $13+460$ & 13.460 \\
\hline 10 & 13.415 & 9.720 & $\hat{0}+i j$ & $6+530$ & 0.0 & 6.80 & $29+910$ & 16480 & $14+290$ \\
\hline 1974 & $14+200$ & 17.140 & 0.0 & 3.540 & 0.0 & $\gamma+420$ & 26.420 & 4,30 & 26,770 \\
\hline $1 \% 5$ & 16.727 & 21.240 & 0.0 & 4.340 & 0.0 & 9.550 & 0.0 & 30.310 & 20,28 \\
\hline 1976 & 16.940 & 23.240 & 0,0 & 4,730 & 0,0 & 7,660 & 0,0 & 0,0 & 25.430 \\
\hline 197 & 18.830 & 26.20 & 0.0 & 20,030 & 0.0 & $12+260$ & 0,0 & $0 . \hat{0}$ & $26+400$ \\
\hline 1978 & 20.082 & 31.490 & 16,380 & 10.370 & 0.0 & 13.270 & $\hat{0}, 5$ & 3.6 & 31.300 \\
\hline 1979 & 27.770 & 35.350 & $19+1.0$ & $16+670$ & 0.0 & 15.180 & 0.0 & 0.0 & 3,460 \\
\hline 1980 & $30+630$ & 38.550 & 22,720 & 20,730 & 0.0 & $17+110$ & 0,0 & 0.0 & $40+460$ \\
\hline 1981 & $30+60$ & 45.260 & 26.250 & 22,000 & $\hat{4}+\hat{0}$ & 19.340 & $0 . \hat{0}$ & 0.0 & 50.710 \\
\hline 1982 & 20,300 & 48.830 & 24.740 & 24,930 & 0.0 & 21.970 & 0.8 & 0.0 & 54,000 \\
\hline 160 & $27+240$ & $48+440$ & 30,020 & $z+310$ & 0.0 & $21.5 \%$ & 0.0 & 0.0 & $8+9 t$ \\
\hline
\end{tabular}

\begin{tabular}{|c|c|c|c|c|c|c|c|c|c|}
\hline YARR & Fl & IA & HI & In & ID & IL & ind & 10 & $\pi$ \\
\hline$\ldots$ & $\cdots$ & r r & & $\ldots . .$. & & - & & + & \\
\hline 1970 & 6.980 & 9.020 & 0.0 & 6.680 & 0.0 & 6.260 & $5,4+10$ & 6.730 & $4+600$ \\
\hline 1971 & 7.720 & 10.130 & $6+0$ & 7,730 & 0.0 & 7.100 & 5.160 & 7.450 & $5+70$ \\
\hline 1972 & 9.610 & 10.560 & 0.0 & 8.040 & 0.0 & 7.940 & 6.670 & 7.790 & 6.130 \\
\hline 1473 & 11.720 & 10,490 & 0.0 & $\$ .700$ & 0.0 & 8,610 & $7+300$ & 8.550 & $6+6 n$ \\
\hline 177 & 16.920 & 13.670 & $0 . i$ & 13.080 & 0,0 & 11,220 & 7,330 & 7,250 & 11.760 \\
\hline $19 \pi$ & 23.390 & 22,150 & 0.0 & $17.220 \mathrm{v}$ & 0.0 & 15.280 & 12.57 & $13+400$ & $15+20$ \\
\hline 1976 & 25.520 & 23,190 & 0,0 & 18.050 & 0.0 & $17+380$ & 14,520 & 15,130 & 34990 \\
\hline 147 & $29+380$ & 26.020 & 0.0 & 20.450 & 0,0 & 21.080 & 2,300 & $14+27 \mathrm{Jj}$ & $107 \%$ \\
\hline 1778 & 34,630 & 29.700 & 0.0 & 23.350 & 0.0 & 25.750 & 23,600 & 10.400 & 24,390 \\
\hline 1979 & 39.430 & 32.780 & 0.6 & $23+090$ & 0.0 & $29+880$ & 25.200 & $18+51$ & $25.5 \%$ \\
\hline 1930 & $42+640$ & 35.710 & 0.0 & 25.850 & 0.0 & $33+240$ & $Z 30$ & $15+680$ & $27+970$ \\
\hline \pm 81 & $47+850$ & $40^{\circ}+670$ & $n_{+0}^{n} 0$ & 27.250 & 0.0 & 38.630 & $31+320$ & $21+470$ & 3,130 \\
\hline 1782 & 51,720 & 44.640 & 0.0 & 28.600 & 0.0 & 41.370 & 34,920 & $3+500$ & +300 \\
\hline 1983 & 53.170 & 45.800 & 0.0 & 29,530 & 0,0 & 42.370 & 34.300 & $24+710$ & $3+m$ \\
\hline
\end{tabular}

\begin{tabular}{|c|c|c|c|c|c|c|c|c|c|}
\hline 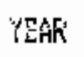 & LA & in & $W$ & $\mathrm{HE}$ & 江 & sind & $\mathrm{N}$ & ing & $7^{7}$ \\
\hline$\cdots$ & $-\cdots$ & n....... & --- & ........ & 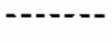 & $\cdots$ & nan. & .......... & 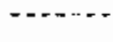 \\
\hline 1970 & $\hat{v}+\hat{0}$ & 8.750 & $\$, 620$ & 0.0 & 9.600 & 6.870 & 5.460 & 180 & 3.000 \\
\hline 1971 & 0.0 & $9.6 \%$ & $1 \hat{i}, \hat{B} \dot{i}$ & 0.0 & 10.110 & 7.250 & $\therefore+140$ & 6.420 & $3+20$ \\
\hline 1972 & 0.0 & 13.150 & 13,460 & 0.0 & 10,980 & 7.810 & 6.410 & $9+720$ & $3+390$ \\
\hline 1973 & $0 . \hat{v}$ & $20.5 / 0$ & 13.622 & 0.0 & $11+3400$ & 7.050 & 7,240 & 9.50 & 3.450 \\
\hline 1974 & 0.0 & $31+800$ & 27,900 & 0.0 & 19.510 & 8.760 & 3,070 & $13+910$ & 4,230 \\
\hline 1975 & 0.0 & 31.800 & $31+680$ & 0.0 & 21.040 & 11.180 & 11.590 & $1 \gamma_{+} 010$ & $4.7,00$ \\
\hline $177 b$ & 0.0 & 0,0 & 28,190 & 0.0 & 24,020 & 12.220 & 13,50 & $23+860$ & 4,940 \\
\hline 1977 & 0.0 & 0,0 & 29.240 & 0.0 & 25,240 & $12+100$ & 20.40 & 24.870 & $4+3$ \\
\hline 1978 & 0,0 & 0.0 & 33,030 & 0.5 & 29,720 & 14.090 & $2: 600$ & 34,00 & 3450 \\
\hline$\$ 09$ & 0.0 & $b 2+780$ & 35,300 & 0.0 & $34+550$ & 17,040 & $2+7 x$ & 3.06 & 6440 \\
\hline 1900 & 0.0 & 52.060 & $3 B, 000$ & 0,0 & 37,570 & 13.310 & 25,320 & 14,00 & $\therefore=4$ \\
\hline 1891 & 34,400 & 64.230 & 44.350 & $0+\hat{0}$ & 41.60 & 19.400 & 20.520 & $5 . \mathrm{Ve}$ & 576 \\
\hline$: 782$ & $37+900$ & 35,350 & $4 \%, 60$ & $0+0$ & 46.340 & 22,780 & 30,60 & 58,70 & 9,790 \\
\hline 198 & $38+840$ & 59,900 & 44.240 & 0.0 & 44.200 & $24+4010$ & 31,50 & 60,450 & 12,6 \\
\hline
\end{tabular}


IABLE B. 12 (CONT). Steam Coal Prices: Electric Utility Sector (\$/ton)

\begin{tabular}{|c|c|c|c|c|c|c|c|c|c|}
\hline YEA & int: & itu & 㙁 & 闯 & 什 & 训杪 & (I) & $M i$ & 애 \\
\hline$+5 \%$ & 0 & $7 \mathrm{~N} 70$ & A & $\therefore 900$ & 14 & $=55 \hat{A}$ & $7: 30$ & +4 & \\
\hline 1071 & $\begin{array}{r}7+010 \\
10.700\end{array}$ & $\begin{array}{l}3+4 / 0 \\
3,900\end{array}$ & $\begin{array}{l}6,410 \\
5+4 \pi\end{array}$ & $\begin{array}{l}9,990 \\
9,890\end{array}$ & $\begin{array}{l}11+140 \\
13.416\end{array}$ & $\begin{array}{l}6.200 \\
2770\end{array}$ & 7360 & $\begin{array}{lll}x+400 \\
x+800\end{array}$ & \\
\hline $19 / 2$ & 10,600 & 3.650 & 7,50 & 13.030 & 16.360 & 2,760 & 6,670 & 12,600 & D.t. \\
\hline 1973 & $11+790$ & 2,170 & 10.530 & 13.470 & 17,290 & 2,740 & 0.250 & 12,450 & $i^{z}=$ \\
\hline 1974 & 25.550 & 2,360 & 12.310 & 21.710 & 32,780 & 3.430 & 6,320 & 24.970 & $\because$ \\
\hline 1575 & 25.550 & 3.520 & 18.280 & 32.240 & 40,330 & 4.040 & $7+690$ & $25+310$ & $\left(1+t^{2}\right.$ \\
\hline 176 & 26,560 & $3+940$ & 19,230 & 33.740 & 37,910 & $4+630$ & 11.020 & 27,60 & 3, \\
\hline 147 & $29+30$ & 5.120 & $2 \div, 370$ & 34.770 & $36+840$ & 5.270 & $12,0 \%$ & 20,400 & 25 \\
\hline 1978 & $33+280$ & $5,206 \mathrm{v}$ & 22.070 & 38.410 & 40,820 & 7,590 & $17+340$ & 31.100 & $2 \pi$ \\
\hline 1979 & 35.470 & 6.60 & 21,410 & 40.940 & 43,520 & 8.510 & 23.5840 & 33.430 & $M$ \\
\hline 590 & 38,460 & 7,360 & 23.360 & 42,860 & $47+200$ & 9.880 & $23.17^{0}$ & $36+260$ & $\therefore$ \\
\hline 1981 & 42.250 & $9 \div 020$ & 20,60 & 40.230 & $54+220$ & $1 \hat{2}, 7^{90}$ & 24,240 & 41,72 & $\because$ \\
\hline 1792 & 40.040 & 10.730 & 20.370 & 30,940 & 56,450 & 14.350 & 25,960 & 45,40 & \\
\hline 1483 & $47+020$ & 10.890 & 21.300 & 52.500 & 52,100 & 15.230 & $20+300$ & 44.5 & \\
\hline
\end{tabular}

\begin{tabular}{|c|c|c|c|c|c|c|c|c|c|}
\hline CAAR & $\alpha x$ & $a k$ & $F A$ & $\overrightarrow{k i}$ & 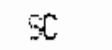 & $5 j$ & $T H$ & 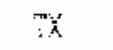 & iT \\
\hline$+\cdots$ & 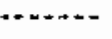 & - n---- & --..-- & $\cdots$ & & & - & & \\
\hline $1 \% 0$ & 9,710 & 0.0 & 7,300 & 0.0 & 8.590 & 5.300 & 5.400 & $\dot{0} .0$ & 5.750 \\
\hline 1471 & 4,910 & 0.0 & $8+230$ & 0.0 & 11.960 & 6.420 & 7.180 & 3000 & $8, \%$ \\
\hline 1772 & 4.920 & 0.0 & 9.890 & 0,3 & 11.460 & 7,270 & 3,750 & 3.020 & 7.100 \\
\hline 103 & 0.0 & 0.0 & 16.590 & 0.0 & 12.590 & 6.220 & 8.510 & $i, 750$ & $8+5$ \\
\hline 1974 & 0.0 & 0.0 & 18.420 & 0,0 & $31+360$ & $7.7 \pm 0$ & 10.870 & 2.370 & $\hat{3}+4+4$ \\
\hline 1075 & 0.0 & 0.0 & 26.450 & 0.0 & 27.470 & 0.090 & $19+000$ & $3+976$ & 11.250 \\
\hline 1978 & 16,180 & 0.0 & 23,410 & 0.0 & 25.270 & 6.700 & $20,5 \pm 0$ & 4,500 & 14,840 \\
\hline 1977 & 18.070 & 0.0 & 24.140 & 0.0 & 29.630 & 6.570 & $22+880$ & $8.1 \% 0$ & $17+180$ \\
\hline 1978 & 10.190 & 0.0 & 27,900 & $\hat{0}, 0$ & 33,450 & 7.570 & 26.700 & 4,610 & 10.810 \\
\hline 1979 & 20,020 & 0.0 & 28.930 & 0.0 & 36.000 & 8.300 & 31.250 & 14.130 & 84,60 \\
\hline $1 \% 90$ & 21.460 & $23+150$ & 32.100 & 0,0 & 38.690 & 9,650 & 36.210 & 17,910 & $B, B D D$ \\
\hline 1581 & 24,870 & $26+250$ & $37+450$ & 0.0 & 44.320 & 11.900 & $4 \hat{\mathrm{j}}+2 \mathrm{~F}$ & 21,820 & $240+9$ \\
\hline $1 \% 82$ & 28.080 & 28.500 & 39.660 & 0,0 & $47+250$ & 14530 & $4=\pi 0$ & 23,900 & $32+50$ \\
\hline 1783 & 29,730 & 0,0 & $37+300$ & $\hat{0}+\hat{0}$ & $45+110$ & 14.520 & $40+5: 0$ & 24,790 & $30,7 x_{\mathrm{o}}$ \\
\hline
\end{tabular}

\begin{tabular}{|c|c|c|c|c|c|c|c|}
\hline VAAK & VA & $V T$ & ias & UI & WN & 輀 & 16 \\
\hline-- & 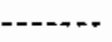 & 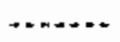 & ...... & 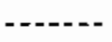 & - - & .... & $\ldots \ldots$ \\
\hline $1 \% 0$ & 9,560 & 12.250 & 0,0 & 8.920 & 5.820 & 2.310 & $7,0,00$ \\
\hline 1971 & 11.140 & 15.370 & 0.0 & $9+800$ & 7.330 & 2.440 & 8.180 \\
\hline $197 \%$ & 10.960 & \pm 8.180 & 0.0 & 10.740 & 8.300 & 2.320 & 8,590 \\
\hline $1 \% 73$ & 11.440 & 19.220 & 8.300 & $11+260$ & 8.620 & 3.320 & $9+0.6$ \\
\hline 1974 & $2 B+670$ & 38.770 & 5.790 & 55.920 & $1 \$, 590$ & 3.930 & 15,430 \\
\hline 1075 & 27,380 & 52.750 & 9.100 & 28.365 & 20.240 & $4+100$ & 3.45 \\
\hline 570 & 27.940 & 0,0 & 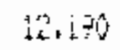 & 10.070 & 21,550 & 5.650 & 28,380 \\
\hline $107 \%$ & $33+120$ & 0.0 & $11+720$ & 20.520 & 24.040 & $i_{1}+110$ & $20+36$ \\
\hline 1978 & 30.640 & 0.0 & 12,400 & 24.900 & 29.030 & $6,59 v^{x}$ & 8.750 \\
\hline 1979 & 41.540 & 45.550 & 10.50 & $2 b+450$ & 30.490 & 8.210 & 26.156 \\
\hline 1500 & 42,650 & 3.0 & $15, \equiv 90$ & $29,0 \% 0$ & 34,130 & 9.990 & 20,760 \\
\hline 1581 & 47,850 & 54.560 & $17+900$ & 30,600 & $34+100$ & 12.000 & 32.310 \\
\hline 1982 & 48.160 & 53.740 & 22.550 & 34,490 & 41.900 & 13.680 & 34,400 \\
\hline 1480 & $43+030$ & $0, \hat{0}$ & $2 t: 2 u$ & $34+25$ & $42+120$ & $16.6 \%$ & $3+4+2$ \\
\hline
\end{tabular}


TABLE B.13. Distillate Fuel Prices: Residential Sector ( $\$ / g a 1)$

\begin{tabular}{|c|c|c|c|c|c|c|c|c|c|}
\hline 'EAR' & $\mathrm{AK}$ & $\mathrm{AL}$ & $A F^{\prime}$ & $\overrightarrow{A \vec{Z}}$ & CA & $\infty$ & {$[T$} & $D C$ & $\mathrm{DE}$ \\
\hline 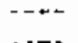 & - & - & 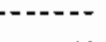 & & - & & $\cdots$ & $\cdots$ & \\
\hline $\begin{array}{l}1970 \\
1971\end{array}$ & $\begin{array}{l}0.194 \\
0.205\end{array}$ & $\begin{array}{l}0.172 \\
0.189\end{array}$ & $\begin{array}{l}0.130 \\
0.140\end{array}$ & $\begin{array}{l}0.176 \\
0.185\end{array}$ & $\begin{array}{l}0,176 \\
0.186\end{array}$ & $\begin{array}{l}0.177 \\
0.188\end{array}$ & $\begin{array}{l}0.205 \\
0.2 \% 6\end{array}$ & $\begin{array}{l}0.1 \% \\
0.200\end{array}$ & $\begin{array}{l}0,1 \% \\
0,20\end{array}$ \\
\hline $17 \%$ & 0.200 & 0.191 & 0.112 & 0.187 & 0,187 & 0.139 & 0,217 & 0,201 & 0,201 \\
\hline 1473 & 0.237 & 0.210 & 0.183 & 0.28 & 0.218 & 0.219 & 0.246 & 0.234 & $0+254$ \\
\hline 1974 & 0.365 & 0.313 & 0.310 & 0.340 & 0.346 & 0,340 & $0,=90$ & 0.558 & 0,05 \\
\hline 1975 & 0.398 & 0.351 & $\operatorname{c.32} 2$ & 0.391 & 0.389 & 0,344 & 6. Jis & 0.376 & 0,96 \\
\hline 1976 & 0.431 & 0,387 & 0.33 & 0.420 & 0.431 & 0.408 & $0,42$. & 0.403 & 0.463 \\
\hline 1977 & $0,4 i 3$ & 0.455 & 0.403 & 0.435 & 0.446 & $0.45 i$ & 0.471 & $0,4,00$ & $0+40$ \\
\hline 1978 & 0.532 & 0.473 & $0,-=11$ & 0.472 & 0.453 & 0.455 & 0,531 & 0.507 & 0.473 \\
\hline $1 \% 9$ & 0.682 & 0.034 & 0.634 & 0.613 & 0.621 & 0.642 & 0.720 & 0.742 & 0.65 \\
\hline 1980 & 0,978 & 0.948 & 0.967 & 1.009 & 0.954 & 0.965 & 0.780 & $\div 026$ & 0.754 \\
\hline 1981 & 1.190 & 1.185 & 1.118 & 1.103 & $1.0 \% 6$ & 1,153 & 1.277 & 1.274 & $1+17$ \\
\hline 1992 & 1.174 & 1.1 .32 & 1,055 & $1+124$ & 1,088 & \pm .102 & \pm .193 & $\therefore 345$ & 2,113 \\
\hline 198 & 1,008 & 0,584 & 0.407 & 1.056 & 1.010 & 0,930 & 1,091 & 1.170 & 1,40 \\
\hline
\end{tabular}

\begin{tabular}{|c|c|c|c|c|c|c|c|c|c|}
\hline SAR' & $\mathrm{FL}$ & GA & Hi & Iǹ & 10 & il & 23 & to & $\mathrm{NY}$ \\
\hline$\cdots$ & …‥-- & - - & $\cdots$ & $\cdots-\cdot$ & ........ & & - & & \\
\hline 1970 & 0.174 & $\hat{0}+172$ & 0.176 & 0.169 & 0.194 & 0,167 & 0,167 & 0.165 & $0+163$ \\
\hline$\$ 071$ & 0.192 & 0.189 & 0.186 & 0.177 & 0.205 & 0.179 & $0.17 \%$ & 0.47 & $0+14$ \\
\hline 1972 & 0.193 & 0.191 & 0.197 & 0,178 & $\hat{0}+2 n$ & 0.180 & 0.130 & 0.190 & OBtis \\
\hline 1,73 & 0.213 & 0.20 & 0.218 & 0.220 & 0,237 & 0.231 & 0.231 & $0.19 \%$ & 0,215 \\
\hline 1974 & 0.344 & 0,341 & 0.346 & 0.338 & 0.365 & 0.358 & 0,358 & 0.037 & 0,334 \\
\hline 1975 & 0.363 & 0.362 & 0,380 & 0.356 & $0.3 \% 1$ & 0.35 & $0.35 k$ & 0.343 & 0.35 \\
\hline 1976 & 0,403 & 0.401 & 0.431 & 0.383 & 0,420 & 0.390 & 0.390 & 0.397 & 0.384 \\
\hline 1977 & 0.447 & 0.455 & 0.446 & 0.443 & 0.452 & 0.446 & 0.446 & 0.447 & 0,45 \\
\hline 1978 & 0.482 & 0.484 & 0.953 & 0.458 & 0.436 & 0.465 & $\hat{0}, \pm 85$ & 0.458 & 0.467 \\
\hline 1979 & 0.632 & 0.040 & 0.021 & 0,615 & $0.62 \mathrm{I}$ & 0.688 & 0.727 & 0.692 & $0 .+42$ \\
\hline 1990 & 0,960 & 0.960 & 0.959 & 0.942 & $0.91 \mathrm{~s}$ & $0.45 \mathrm{~A}$ & 0.996 & 0.95 & 0,955 \\
\hline 1981 & 1.205 & 1.195 & 1.096 & 1.118 & 1.104 & 1.149 & 1,185 & 1,126 & 1.185 \\
\hline 1992 & 1.162 & $\$ .158$ & 1,138 & 1,096 & 1.104 & 1.109 & $\therefore 143$ & 1,068 & 1,135 \\
\hline $198=$ & 1.104 & $1,0.52$ & 1.040 & 1.027 & 1.018 & 1.004 & $1, \omega$ & 1.016 & 0.59 \\
\hline
\end{tabular}

\begin{tabular}{|c|c|c|c|c|c|c|c|c|c|}
\hline YSAR' & $L A$ & $M$ & $\mathrm{IJ}$ & ME & HI & inty & $\mathrm{HO}$ & , 喓 & $\pi !$ \\
\hline$\cdots$ & ---- & $--n+x+a$ & - & ...... & -........ & nomenter & - & $\cdots+\cdots+\infty$ & 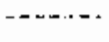 \\
\hline 1970 & 0.134 & 0.207 & 0.1948 & 0.208 & $0,1.71$ & 0.175 & $0,1 \leq 5$ & 0,172 & 0.277 \\
\hline 1971 & 0.147 & 0.218 & $0+200$ & 0.219 & 0.181 & 0.190 & 0.179 & 0.197 & $0.18 \bar{c}$ \\
\hline 1972 & 0,148 & $\hat{0} .219$ & 0.201 & 0.220 & $0+182$ & 0.180 & 0.180 & 0.199 & 0.189 \\
\hline 1973 & $0.1 \% 2$ & 0.251 & 0.234 & 0.248 & 0.186 & 0.224 & 0.196 & 0.210 & 0.210 \\
\hline 1974 & 0.294 & 0.370 & 0.358 & 0.377 & 0.327 & 0.349 & 0.337 & 0.334 & 0.340 \\
\hline $1 \% \pi$ & 0.310 & $0+355$ & 0.376 & 0.349 & 0.349 & 0.354 & 0.35 & 0.345 & $0+344$ \\
\hline 1970 & 0.353 & 0.421 & 0.493 & $\hat{0}, 424$ & 0.385 & 0.389 & 0.377 & 0,304 & $0.450 \hat{2}$ \\
\hline 1977 & 0,342 & 0.473 & 0.460 & 0.475 & 0.446 & 0.444 & 0.437 & 0.543 & $0+48$ \\
\hline $1 \% 8$ & 3.411 & 0.488 & 0,402 & 0,486 & $0.47 \%$ & 0.478 & $0 .-50$ & $0+467$ & $3+461$ \\
\hline 179 & $0+240$ & 0.709 & 6,701 & 0.288 & 0.709 & 0.724 & $0, \ldots E$ & 0,4 & $\ddot{v}+\vec{i}+\overrightarrow{4} \bar{j}$ \\
\hline 1980 & 0.922 & 0,479 & 0.979 & 0.763 & 0.978 & 0.999 & 0.951 & 0.455 & $6+40$ \\
\hline 1081 & 1.143 & $1+213$ & 1.214 & $1+204$ & 1.183 & 1.184 & $1.12 i$ & $1+105$ & 2.147 \\
\hline 1992 & 1,055 & 1.176 & 5.17 & 1,155 & $1+13 \%$ & $\$ .151$ & +798 & $1+125$ & $i+3 i$ \\
\hline 1903 & $0.7 / 24$ & 1.071 & 1.103 & 1,028 & 1.064 & 1.031 & $1,0 \mathrm{ie}$ & 0.724 & $0+769$ \\
\hline
\end{tabular}


TABLE B.13 (CONT). Distillate Fuel Prices: Residential Sector ( $\$ /$ gal)

\begin{tabular}{|c|c|c|c|c|c|c|c|c|c|}
\hline mot & $x$ & Ho & $\mathrm{HE}$ & 㓔 & NH & N1 & 洲 & kit & [- \\
\hline$\ldots$ & …… & Anon+a- & $+n+\cdots+*$ & $\cdots+\cdots$ & - & $-\ldots$ & --N-- & & 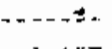 \\
\hline 1970 & $0.13 t$ & 0,177 & 0.165 & 0.209 & $0+19 \%$ & $0+136$ & 0,176 & 0.299 & 0.195 \\
\hline $1 \% 1$ & 0.171 & 0.188 & $\mathrm{C}+17 \mathrm{~F}$ & 0.219 & 0.209 & 0.147 & 0.195 & $0.20 \%$ & 0.211 \\
\hline 1972 & 0.191 & 0.169 & 0.160 & 0.220 & 0.210 & 0.148 & 0.137 & 0,210 & 3.72 \\
\hline 1073 & 0.221 & 0.219 & 0.196 & 0.248 & 0.240 & 0.178 & $0.2 \% 8$ & 0.240 & $n+9$ \\
\hline 1974 & 0.352 & 0.348 & 0.337 & 0.377 & 0.369 & 0.335 & 0,346 & 0.369 & 0.327 \\
\hline 1075 & 0.376 & 0.354 & 0.363 & 0.398 & 0.369 & 0.341 & 0.371 & 0.309 & 5,4 \\
\hline 1376 & 0.407 & 0.389 & 0.397 & 0.424 & 0,411 & 0.420 & 0,420 & 0,451 & i) $+3 E$ \\
\hline 1977 & 0.455 & 0.444 & 0.447 & 0.475 & 0.467 & 0.449 & $0.43^{5}$ & 0.467 & $5+4,46$ \\
\hline 1970 & 0.487 & 0.468 & 0.458 & 0,503 & $0.49 \mathrm{~A}$ & 0.412 & 0.453 & 0,501 & 1,474 \\
\hline 1979 & 0.643 & 0.669 & 0.602 & 0.725 & 0.710 & 0.331 & 0.621 & 0.712 & $\sqrt{1}, 45$ \\
\hline 1980 & 0.964 & 0.950 & 0.751 & 1,004 & 0.979 & 0.942 & 0.659 & 0.982 & $0.71 \%$ \\
\hline 1081 & 1.198 & 1.151 & $1+126$ & 1.237 & $1+215$ & $1+\$ 19$ & $1+096$ & 1.232 & $\therefore 13$ \\
\hline 1986 & $1,1,6$ & $1 . \$ 19$ & 1.080 & 1.174 & $1: 174$ & 1.074 & $1,0 \mathrm{~s}$ & 1.0 & 1.10 \\
\hline 298 & 1.070 & 1.030 & 1, tib & 1.041 & 1.079 & 0.936 & 1.610 & 1,121 & 100 \\
\hline
\end{tabular}

\begin{tabular}{|c|c|c|c|c|c|c|c|c|c|}
\hline $\mathrm{IEAK}$ & ok & GiF & $\mathrm{PA}$ & RI & 5 & GD & $\mathrm{I}$ 到 & $\overline{I X}$ & iI \\
\hline-- & - & n. & $\cdots$ & Natenes & $\cdots$ & $\cdots$ & -- & 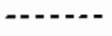 & \\
\hline 1970 & 0.124 & 0.196 & 0.197 & 0.207 & 0.180 & 0.177 & 0.171 & $0+136$ & 1,57 \\
\hline$\$ 971$ & 0.126 & 0.205 & 0.200 & $\hat{v}+218$ & 0.190 & 0.188 & 0,189 & 0.147 & $0+130$ \\
\hline 1972 & 0.126 & 0.206 & $5+201$ & 0.219 & $0.1 \% 0$ & 5.189 & $a_{+}+1$ & $0+149$ & 0.135 \\
\hline 1973 & 0.156 & 0.237 & 0.232 & 0.246 & 0,224 & $0+214$ & $\hat{0}, 215$ & 0.172 & $0.21 \%$ \\
\hline 1974 & 0.303 & 0.365 & 0.323 & 0.375 & 0.352 & 0.340 & 1.334 & $0+2 \gamma_{4}^{4}$ & $5+348$ \\
\hline 1975 & 0.306 & 0.388 & 0.390 & 0.395 & 0.373 & 0.354 & 0.345 & 0.219 & 0.944 \\
\hline 1976 & 0.345 & 0.431 & 0.407 & 0.421 & 0.406 & 0.399 & 0.384 & 4,95 & 0,400 \\
\hline 197 & 0.385 & 0.463 & 0.461 & 0,471 & 0,456 & 0,444 & $0,44,3$ & 0,39 & 0.455 \\
\hline 1979 & 0.404 & 0.458 & 0.485 & 0.507 & 0.488 & 0.468 & 0.47 & 0,411 & 0.485 \\
\hline 1979 & 0.642 & 0,680 & $0, E Q 8 \theta$ & 0.726 & 0.645 & 0.664 & $0, \sin$ & 0.600 & 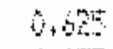 \\
\hline 1980 & 0.415 & 0.973 & $0,96 \mathrm{i}$ & $1.0 \hat{1} 1$ & 0.964 & 0.950 & $3+755$ & {$[0,503$} & 0.955 \\
\hline SEE & 1.110 & 1.114 & $1+181$ & $1+238$ & 1.202 & J.151 & 1.165 & 1,114 & 4,159 \\
\hline 1792 & 1.046 & 1.116 & $1 . \pm 37$ & 1.201 & 1,160 & $1+119$ & 1.29 & 1.044 & $1+1+5$ \\
\hline 1983 & 0.996 & 1.034 & $1+058$ & $1.10 \overline{5}$ & 1.006 & 1,030 & 0.959 & 0,70 & $\mathrm{~b}, \mathrm{a}$ \\
\hline
\end{tabular}

\begin{tabular}{|c|c|c|c|c|c|c|c|}
\hline YESA & UA & VT & 焕 & HI & 舸 & WY & US \\
\hline$-\cdots--$ & - & 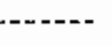 & $\cdots$ & -...- & 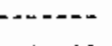 & 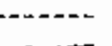 & \\
\hline 1970 & 0.150 & 0.209 & 0.194 & 0,147 & 0.190 & 0.177 & 0.885 \\
\hline$\$ 971$ & 0.203 & 0.219 & 0,205 & 0.174 & 0.203 & 0.188 & 0.196 \\
\hline 1972 & 0.204 & 0.220 & 0.206 & $0 \div 80$ & 0.204 & 0.189 & $i+97$ \\
\hline 1973 & 0.227 & 0.248 & 0.257 & 0.231 & 0.227 & 0.219 & 0.220 \\
\hline 1974 & 0.352 & 0.377 & 0.365 & 0.358 & 0.352 & 0.348 & 5,340 \\
\hline 1975 & 0.373 & 0.398 & 0.368 & 0.356 & 0.373 & 0.394 & 0.377 \\
\hline 1074 & 0.403 & 0.424 & 1.431 & $9+50$ & $9+403$ & 0.408 & $5+406$ \\
\hline 5977 & $\hat{0} .45{ }^{\circ}$ & 0.475 & 0.463 & 0,446 & 0.459 & 0.451 & $\hat{0}+4 \dot{\Delta L}$ \\
\hline 179 & $0,4 \% 1$ & $0+508$ & $1+48$ & 0.447 & 6.46 & 0.453 & $\overline{1}+4+4$ \\
\hline$\$ 97$ & 0.704 & 0.725 & 0.57 & 0.673 & 0.651 & $\hat{0}, b+4$ & $6.7 \mathrm{it}$ \\
\hline 1790 & 0.785 & 1.015 & $1,00 \mathrm{~s}$ & 0.815 & 0.922 & $0,4,52$ & $\pi, 7 t$ \\
\hline 2985 & $1+205$ & 1.254 & 1.165 & 1.091 & 1.150 & 1.145 & 1.154 \\
\hline $17 / 82$ & 1.177 & 1.201 & 1.176 & 1.079 & 1.043 & $1+127$ & $1+\infty 0$ \\
\hline 1953 & 1.087. & 1.129 & 1.090 & 1,012 & 1.010 & 0.961 & 1.678 \\
\hline
\end{tabular}


TABLE B.14. Distillate Fuel Prices: Commercial Sector ( $\$ /$ gal)

\begin{tabular}{|c|c|c|c|c|c|c|c|c|c|}
\hline TEAR & AR & HL & $A F$ & $A Z$ & $\mathrm{CA}$ & $\mathrm{CO}$ & $C T$ & 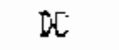 & $D F$ \\
\hline 1970 & 0,168 & 0.134 & $0.11 \%$ & 0.155 & 0.155 & 0.146 & 0,152 & 0.155 & 0.155 \\
\hline 51 & 0.177 & 0.146 & 0.128 & 0,563 & $0,1+3$ & 0.152 & 0.150 & 0.158 & 0.158 \\
\hline 972 & 0.178 & 0,146 & 0.129 & 0.164 & 0.164 & 0.152 & 0.150 & 0,158 & 0.158 \\
\hline 1573 & $0+210$ & 0.161 & 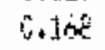 & 0.196 & 0.196 & 0.184 & $0.1 \%$ & 0.193 & 6.108 \\
\hline 1974 & 0.343 & 0.263 & $0.2,6$ & 0.329 & 0.329 & 0.315 & 0.340 & 0.350 & 5.310 \\
\hline 1075 & 0.3 .51 & 0.308 & $0+318$ & 0.363 & 0,361 & 0.345 & 0.33 & 0.332 & 0,33 \\
\hline 1976 & 0.403 & 0.341 & 0.335 & 0.395 & 0.403 & 0.365 & 0.363 & 0.357 & 0.357 \\
\hline $1 \% 7 /$ & 0.433 & 0.397 & 0.397 & 0.409 & 0.417 & 0.404 & $0,4: 1$ & 0.413 & 0.413 \\
\hline 1978 & 0,482 & 0,414 & 0.393 & 0.440 & 0.422 & 0.413 & 0.432 & i) 443 & 0.429 \\
\hline 1979 & 0.646 & 0.589 & 0.606 & 0,601 & 0,608 & 0.604 & 0,437 & 0,246 & 0,67 \\
\hline 1980 & 0.936 & 0.863 & 0.367 & 0.964 & 0.916 & 0.900 & 0.383 & 0,700 & 0.074 \\
\hline 3981 & 1.119 & 1.080 & 1,069 & 1.054 & 1.047 & 1.0 .85 & 1.1 .5 & $1+149$ & 1.100 \\
\hline 1962 & $1+112$ & 1.015 & 1.004 & 1.073 & 1.038 & $1.01 \%$ & $\therefore, 08$ & 1.102 & 1.336 \\
\hline 1986 & 1.007 & $0+84]$ & $0+833$ & 1.607 & 0.443 & $0.87 \%$ & 0.974 & 0.975 & 0,40 \\
\hline
\end{tabular}

\begin{tabular}{|c|c|c|c|c|c|c|c|c|c|}
\hline reta & $\mathrm{FL}$ & $\mathrm{GA}$ & $\mathrm{HI}$ & IA & II) & IL & $+i$ 计 & IS & 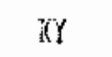 \\
\hline$\cdots$ & ----- & --- & +..ente- & ……"- & $+\ldots+n+\infty$ & $\cdots+\infty$ & 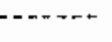 & $-\ldots . . .$. & 然 \\
\hline 1970 & 0.136 & 0,134 & 0.155 & 0.146 & 0.168 & 0.144 & 0,144 & $\hat{0}+14 a$ & 0,142 \\
\hline 1471 & 0.140 & 0.146 & $6+1 B$ & $\hat{0}+152$ & 0.177 & 0.153 & $0.15 \%$ & 0.154 & 0,154 \\
\hline $1 \% 12$ & 0.148 & 0,146 & 0.154 & 0.153 & 0.178 & 0.153 & 0.153 & 0,155 & 0,155 \\
\hline $19 \%$ & 0,163 & 0.172 & 0.196 & 0.194 & 0.210 & 0.200 & 0.200 & 0.173 & 0.105 \\
\hline 1974 & 0.298 & 0.286 & 0.324 & 0.318 & 0.343 & 0.330 & 0.330 & 0.317 & 0.300 \\
\hline 145 & 0.313 & 0.312 & 0.361 & 0.332 & 0.343 & 0.332 & 0.356 & 0.33 & 0.318 \\
\hline $1 \% 6$ & 0.350 & $0.3 A B$ & 0,413 & $\hat{0}+357$ & Q. .395 & $0.36 \hat{0}$ & 0.360 & 0,370 & 0.355 \\
\hline $14 \pi$ & 0.394 & 0,401 & 0.417 & 0.414 & 0.425 & 0,415 & $0.4: 5$ & 0.418 & 0.407 \\
\hline 1978 & 0,417 & 0.419 & $0 . \pm 22$ & 0,426 & 0.412 & 0.427 & 0,441 & $0,42 \%$ & $0+427$ \\
\hline 1079 & 0.587 & 0.594 & 0.600 & $0,(x) 1$ & 0,604 & 0.645 & $0+699$ & 0,60 & 0.312 \\
\hline 1980 & 0.874 & 0,075 & 0.716 & 0,892 & 0.889 & 0,900 & 0,924 & 0,001 & 5,900 \\
\hline 1981 & 1.097 & 1.008 & 1,047 & 1,074 & 1.059 & 1,0011 & 1.123 & 1.,QE! & $1+117$ \\
\hline 1492 & $1+041$ & 1.038 & $1+038$ & 1.042 & 1.056 & 1.045 & $\mathrm{t}+0.5$ & 1,035 & 1,050 \\
\hline 156,3 & 0,945 & 0.907 & 0.963 & 0.934 & 0.912 & 0.895 & $0.87 \%$ & 0.95 & 0.77 \\
\hline
\end{tabular}

\begin{tabular}{|c|c|c|c|c|c|c|c|c|c|}
\hline$Y$ YEAF & LA & NA & $M D$ & $M E$ & $M I$ & 倩 & HO & 45 & til \\
\hline$\cdots$ & $\cdots-$ & - & 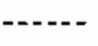 & ...- & 1.. & A & $\cdots$ & $\cdots$ & $\ldots$ \\
\hline 1970 & 0.123 & 0.153 & 0.155 & 0.174 & 0.146 & 0,145 & $5+143$ & 0.134 & 0.14 \\
\hline 1971 & 0.134 & 0.162 & 0.158 & 0,162 & 0.153 & 0.148 & 0.154 & 0.152 & 0.152 \\
\hline 1972 & 0.135 & 0.162 & 0.53 & 0.183 & 0.153 & 0.147 & Ij. & 20.153 & i) .152 \\
\hline 1973 & 0.158 & 0.196 & 0,183 & 0.213 & 0.168 & 0.187 & 0.173 & 0.167 & 0,184 \\
\hline 1174 & 0.276 & 0.315 & 0.310 & 0.341 & 0.300 & 0.31 .6 & 0.317 & 0.290 & 0.315 \\
\hline 1575 & 0.297 & 0.339 & 0.332 & 0.361 & 0.323 & $\hat{v}, 324$ & 0,335 & $0.30 \%$ & $0.34=$ \\
\hline 1975 & 0.336 & 0.363 & 0.55 & 0.386 & $0+354$ & 0.355 & 3.370 & 1) 3338 & 0.345 \\
\hline.$\$ 77$ & 0.375 & 0.413 & 0.413 & 0.436 & 0.413 & 0.407 & 6,418 & 0,367 & 0.406 \\
\hline $1 \% t_{j}$ & $0.3 \%$ & 0.428 & $5+436$ & 0.449 & 0.436 & $0+430$ & 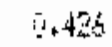 & 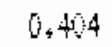 & $\hat{0}+41 \mathrm{E}$ \\
\hline $57 \%$ & 0.612 & 0.632 & 0.226 & $\hat{v}+641$ & 0.661 & 0.558 & 0,66 & $0.5 \%$ & 6,604 \\
\hline 1780 & 0.982 & 0.881 & 0.836 & 0.507 & 0.505 & 0.715 & $1+00 \mathrm{i}$ & $0 . \hat{0} 70$ & 0 \\
\hline $9 \tilde{\delta}^{-1}$ & 1.093 & 1.113 & 1.120 & 3.145 & 1.11 & \pm .100 & $1+051$ & $1,0 \%$ & i. 09 \\
\hline 882 & $1+009$ & 1.077 & 1,0004 & 1.099 & 1.066 & 1.052 & 1.065 & $1+09$ & $1+3 / 8$ \\
\hline 983 & 0.831 & 0.991 & 0.92 & 0.970 & 0.925 & 0.74 & $0,8,5$ & 0,231 & $0.7 \mathrm{~A}$ \\
\hline
\end{tabular}


TABLE B.14 (CONT). Distillate Fuel Prices: Commercial Sector ( $\$ /$ gal)

\begin{tabular}{|c|c|c|c|c|c|c|c|c|c|}
\hline IEAT: & in: & juD & 㤌 & WH & $\$ 4 !$ & 1 胡 & 140 & $\mathrm{HI}^{\prime}$ & $\mathrm{OH}$ \\
\hline 1570 & a 101 & & & & & & & & \\
\hline $\begin{array}{l}1971 \\
1571\end{array}$ & $\begin{array}{l}1.641 \\
0.147\end{array}$ & $\begin{array}{l}0.146 \\
0.152\end{array}$ & $\begin{array}{l}0.145 \\
i, 454\end{array}$ & $\begin{array}{l}0.154 \\
0 . \pm 63\end{array}$ & $\begin{array}{l}0.159 \\
0.167\end{array}$ & $\begin{array}{l}0.128 \\
0.138\end{array}$ & $\begin{array}{l}0.152 \\
0.165\end{array}$ & $\begin{array}{l}0.159 \\
0,1,67\end{array}$ & $\begin{array}{l}0,100 \\
0.170\end{array}$ \\
\hline 1972 & 0.147 & 0.152 & 0.155 & 0.1 .33 & 0.168 & 0.138 & 0,164 & 0.168 & $\hat{0}+17 \hat{9}$ \\
\hline 1973 & $0+169$ & 0.194 & 0.173 & 0.193 & 0.196 & 0.167 & $9+29$ & 0.196 & Bind \\
\hline 1974 & $0.29 \%$ & 0.315 & $0.3 \% 7$ & 0.321 & 0.32 & 0.324 & 0.324 & 0.325 & $\hat{0}_{3} 300$ \\
\hline 1075 & 0.324 & 0.324 & 0.339 & 0.341 & 0.344 & 0.363 & 0.363 & 0,344 & 0.32 \\
\hline 197 & 0.353 & 0.355 & 0.370 & $0.3 \mathrm{BS}$ & 0.364 & 0.345 & $0+345$ & 0.36 & $0.35-4$ \\
\hline 1977 & 0.401 & 0.407 & $0.41 \mathrm{~L}$ & 0.414 & 0.424 & 0,422 & 0,409 & 0,424 & 0,413 \\
\hline 1578 & 0.421 & 0.425 & 0.426 & 0,436 & 0.444 & 0.344 & 0,422 & 0,447 & 0.43 \\
\hline 1975 & 0.597 & 0.630 & 0.666 & 0.61 & 0.643 & $0.6 \mathrm{is}$ & 0,608 & 0,644 & 0,648 \\
\hline 1700 & 0.378 & 0.395 & 0,901 & 0.843 & 0.897 & 0.912 & $0.7 \leq 6$ & 0.879 & $3+371$ \\
\hline 1981 & 1.091 & $1+083$ & 1.081 & 1.157 & 1.128 & 1.083 & 1,047 & $1: 537$ & 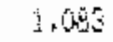 \\
\hline 1802 & $\therefore .242$ & 1.035 & 1.335 & $1.07 \mathrm{t}$ & 1.087 & $1+\hat{U} 42$ & 1.020 & $1+103$ & 1.045 \\
\hline 196 & 0.716 & 0.925 & 0.723 & 0.945 & 0.899 & 0.842 & 0,963 & $\sqrt{144}$ & 0.88 \\
\hline
\end{tabular}

\begin{tabular}{|c|c|c|c|c|c|c|c|c|c|}
\hline HEA & $O x$ & OR & $F A$ & FI & $5 \mathrm{C}$ & 50 & IN & $\mathrm{D}$ & it \\
\hline 1470 & 0.114 & 0.170 & 0,151 & 0.153 & $0.14 \hat{0}$ & 0.144 & $0.14 \pi$ & 0.125 & 0.14 \\
\hline 1971 & 0.115 & 0.177 & 0.161 & 0.16 & 0.146 & 0,152 & ind & 0,134 & 0,15 \\
\hline 1572 & 0,115 & 0.178 & 0,101 & 0.162 & $0.14 k$ & 0.152 & 0.162 & $\hat{a}+15$ & 0,52 \\
\hline 1973 & 0.143 & 0.210 & 0.165 & 0.192 & 0.175 & 0.184 & $\bar{y}+1 \hat{E}$ & 0.55 & 0.154 \\
\hline 1774 & 0.294 & 0.343 & 0.3 .8 & $0.31 \%$ & 0.265 & 0.315 & 0,300 & $0+27 s$ & 0.35 \\
\hline 1975 & 0.295 & 0.361 & 0.344 & 0.399 & 0.322 & 0.324 & 0.316 & 0,29 & 0.34 \\
\hline 1976 & 0.328 & 0,403 & 0.362 & 0.363 & 0.352 & 0.355 & 0.355 & 0,354 & 0.345 \\
\hline 1977 & 0.373 & 0,433 & 0,418 & 0,411 & 0,402 & 0.407 & 0.407 & $0,37 t$ & 0,404 \\
\hline 1978 & 0.384 & 0,428 & 0,438 & 0.435 & 0.423 & 0.476 & 0.427 & 0.343 & 0,41 \\
\hline 1979 & 0.614 & 0.647 & 0,634 & 0.640 & 0.597 & 0.630 & $6+612$ & $0,6]$ & is \\
\hline 1780 & 0.075 & 0.931 & 0.917 & $0.3 \%$ & 0,878 & 0.855 & $0, \infty 0$ & 0,340 & 0.890 \\
\hline 1981 & $i+0, i$ & 1.066 & 1,112 & 5.124 & 1.094 & 1,083 & 1.117 & 1,06 & 1,02 \\
\hline 1982 & 1.000 & 1.065 & 1.062 & 1,088 & 1.040 & $1+05$ & 1.050 & 0,998 & 1,07 \\
\hline 1993 & 0.904 & 0,459 & 0.455 & 1,050 & 0,112 & 0,935 & 0.97 & ) & 0,507 \\
\hline
\end{tabular}

\begin{tabular}{|c|c|c|c|c|c|c|c|}
\hline YEAK & VA & VT & H & آلس & Vل & $\mathrm{dit}$ & 15 \\
\hline - & $\cdots$ & - & $\ldots+\cdots$ & $\cdots$ & & & \\
\hline 1970 & 0.150 & 0.154 & 0.168 & 0,144 & 0.150 & $0.146^{\prime}$ & 0.153 \\
\hline 1971 & 0.160 & 0.163 & 0.1 .177 & 0.153 & 0.180 & 0.152 & 0.161 \\
\hline 1372 & 0.160 & 0.133 & 0.178 & 0.153 & 0.160 & 0.152 & 0.161 \\
\hline 1975 & 0.177 & 0.193 & 9.210 & 0.200 & 0,177 & 0.134 & 0,190 \\
\hline 1974 & 0.305 & 0.321 & 0.343 & 0.330 & 0.305 & 0.315 & 0.319 \\
\hline 1975 & 0.329 & 0.341 & $0,3 t 5$ & 0,52 & 0.329 & 0.345 & 0,337 \\
\hline 1976 & 0.357 & 0.366 & 0,405 & 0,360 & $0+357$ & $0+365$ & 0.3003 \\
\hline 197 & 0.412 & 0.414 & 0.493 & 0.415 & 0.412 & 0.404 & 0,414 \\
\hline 1779 & 0.434 & 0.430 & 0.445 & 0.4 .8 & $n+421$ & 0.411 & 0,432 \\
\hline 1979 & 0,633 & 0.631 & $\{1,857$ & 0.86 & 0.607 & 0.606 & 0.435 \\
\hline 1320 & 0.546 & 0.898 & 0,450 & 0.174 & 0.966 & 0.947 & 0,395 \\
\hline $1 \% 81$ & 1.111 & 1,134 & $1+260$ & 1,05 & 1.085 & 1.077 & $1+10_{0}^{\mathrm{t}}$ \\
\hline 178 & 2.007 & 1.087 & $1+113$ & 1.026 & 1.027 & 1.044 & 1.004 \\
\hline 93 & 0.722 & 1.076 & 0,847 & 0.946 & 0.855 & 0.408 & 0,456 \\
\hline
\end{tabular}

B. 30 
TABLE B.15. Distillate Fuel Prices: Industrial Sector (\$/gal)

\begin{tabular}{|c|c|c|c|c|c|c|c|c|c|}
\hline 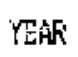 & $A X$ & $\mathrm{AL}$ & An & $A Z$ & $C A$ & $\mathrm{CO}$ & $C T$ & $\mathrm{DC}$ & $\mathrm{DE}$ \\
\hline--- & andert & , n... & 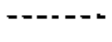 & $\cdots$ & -- & & & & \\
\hline 170 & $\hat{0}, 0)$ & $0.0 \%$ & 0,573 & 0.099 & 0.094 & 0.115 & 0.124 & 0.169 & $3+100$ \\
\hline 1971 & $0,0,4$ & 0.103 & 0,045 & 0.102 & 0.007 & 0.114 & 0.107 & $0,17 j$ & $6+100$ \\
\hline $197 \%$ & 0.096 & 0.103 & 0,399 & 0.103 & 0.098 & 0.113 & 0.127 & 0,170 & 0.109 \\
\hline 1973 & 0.127 & $0 . \pm 13$ & 0.131 & 0.136 & 0.131 & 0.147 & 0.137 & $0.1 \%$ & w. \\
\hline 1774 & 0.3 .38 & 0.239 & 0.232 & 0.221 & $\hat{0}+272$ & 0.250 & 0.310 & 0.322 & $0+274$ \\
\hline 195 & 0.371 & 0.283 & $0.2 \%$ & 0.303 & 0.507 & $0.0 \mathrm{I}$ & 0.334 & 0.346 & 0,30 \\
\hline 1976 & 0.393 & 0,309 & 0.284 & 0,330 & 0,340 & 0.301 & 0,344 & 0.364 & 0.32 \\
\hline 1977 & 0.443 & 0.370 & 0.300 & 0.344 & 0.340 & 0.306 & 0.385 & 0,445 & 0.35 \\
\hline 1979 & $0,48 \vec{i}$ & 0.397 & 0.388 & 0.362 & 0.369 & 0.330 & 0,400 & $0+\ldots$ & .394 \\
\hline 1979 & 0.691 & 0.506 & 0.491 & 0,461 & 0.528 & 0,341 & 0.55 & 0.515 & $0.5=$ \\
\hline 1940 & 0.869 & 0.733 & 0.575 & 0.714 & 0,762 & 0.737 & 0.799 & $1+058$ & 0,771 \\
\hline 1981 & 0.968 & 0.906 & $\hat{0} .808$ & 0.062 & 0.890 & 0.805 & 0.461 & $0]+864$ & 5,747 \\
\hline 1302 & 1.120 & 0.890 & 0,399 & 0.852 & 0.870 & 0.624 & $\therefore .973$ & 1.047 & 0.785 \\
\hline $5 \%$ & 0.987 & 0.834 & 0.827 & 0.851 & 0.043 & 0.85 & 0.933 & 0.396 & $0+45$ \\
\hline
\end{tabular}

\begin{tabular}{|c|c|c|c|c|c|c|c|c|c|}
\hline Wák & FL & G & $\mathrm{HI}$ & $\mathrm{JH}$ & ID & $\mathrm{IL}$ & 34 & 15 & K \\
\hline$\cdots$ & $+\ldots+$ & --.-- & 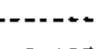 & n...... & 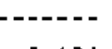 & - & $\cdots+\cdots+-$ & & \\
\hline 1970 & 0.078 & 0.080 & 0.132 & 0.504 & 0.106 & 0.105 & 0,105 & 0.089 & $0+101$ \\
\hline 101 & 0.084 & 0.096 & 0.105 & 0.108 & 0.109 & 0.109 & $0+106$ & 0,45 & 0.59 \\
\hline $1 \% 2$ & 0.084 & 0.086 & 0.100 & 0.108 & 0.110 & 0.109 & 0.106 & 0.095 & 0,109 \\
\hline 1972 & $0.0 \% 2$ & 0,101 & 0.142 & .0 .146 & 0.147 & 0.147 & 0.144 & 0.113 & 0,129 \\
\hline 1974 & 0.279 & 0.235 & 0.30 & 0.284 & 0.317 & 0.299 & 0.302 & 0,234 & 0,236 \\
\hline $1 \% 5$ & 0.355 & 0.295 & 0.300 & 6.279 & 0,333 & 0.323 & 0.31 & $0.2 \%$ & 0.510 \\
\hline 1976 & 0.324 & 0.304 & 0.289 & $0.32 \%$ & 0,355 & 0.342 & 0,316 & 0.317 & 0.305 \\
\hline $1 \% \pi$ & 0.374 & 0.372 & 0.372 & 0.388 & 0.361 & 0.385 & $0.3 \mathrm{~B}$ & 0.356 & 0.30 \\
\hline 1978 & 0,406 & 0.410 & 0.310 & $0.38 \%$ & 0.405 & 0.407 & 0.384 & 0.387 & 0,406 \\
\hline 1079 & 0.530 & 0.504 & 0.520 & 0.528 & 0.545 & 0.533 & 0.528 & $0.47 \%$ & $b_{4} 501$ \\
\hline 1790 & 0.797 & 0,754 & $\hat{v}_{1} 7 \div 2$ & 0.732 & 0,835 & 0.745 & 0.772 & 0.642 & 0.75 \\
\hline 1981 & 0.551 & 0.873 & 0.850 & 0.813 & 1.024 & 0.884 & 0.67 & $\hat{x}+802$ & 0.679 \\
\hline 1792 & 0,960 & 0,927 & 3.125 & 0,808 & 0,017 & 0,951 & $0,5,4$ & 0.800 & $0,7 n$ \\
\hline 1405 & 0.840 & 0.855 & $6+643$ & 0.292 & $0 . \$ 49$ & 0.894 & 0.868 & 0.871 & 0.48 \\
\hline
\end{tabular}

\begin{tabular}{|c|c|c|c|c|c|c|c|c|c|}
\hline TEAF' & {$[A$} & MA & $H E$ & 听 & 用 & it & 速 & its & $\mathrm{T}$ \\
\hline .... & - & - & not.t. & n...... & 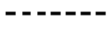 & ......... & & & \\
\hline$: 970$ & 0.071 & 0.103 & 0.112 & 0,087 & 0.055 & 0.115 & $\hat{v}, 106$ & 0.102 & 0,121 \\
\hline 1971 & 0.076 & 0.109 & 0.1 .4 & 0.092 & 0.097 & 0.114 & 0.114 & 0.115 & $0+120$ \\
\hline 1972 & 0.076 & 0.109 & 0.113 & 0.092 & 0.097 & 0,113 & 0.114 & $0,1.15$ & $5+119$ \\
\hline 1973 & 0.070 & 0.141 & 0.130 & 0.117 & 0.110 & 0.149 & $0+135$ & 0.125 & $0+157$ \\
\hline 1974 & 0.207 & 0.310 & $0+218$ & 0.267 & 0,285 & 0.290 & 0.25 & 0,240 & 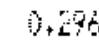 \\
\hline 1955 & 0.251 & 0,327 & 0.325 & 0.319 & 0.315 & 0.331 & $0+3: E$ & 0.235 & 10.87 \\
\hline 1976 & 0.287 & 0.344 & 0.348 & 0.354 & 0.320 & 0.343 & 0.53 & 0.299 & 0.314 \\
\hline$\$ \hat{977}$ & 0.302 & 0.392 & 0.383 & 0.402 & 0.379 & $0.39 \bar{c}$ & 9.37 & 0.377 & 0.34 \\
\hline 179 & 0.280 & 0.404 & $0,+40$ & 0,423 & 0.408 & $0.4 \pm 1$ & 0.344 & 0.402 & 3.37 \\
\hline $197 \%$ & 0.46 & 0.511 & $c+53$ & 0.67 & 0.521 & 0.556 & 0.482 & $0,5+4$ & 0,514 \\
\hline 17800 & $\hat{y}, b / B$ & 0.776 & 0.777 & 0,024 & 0.772 & 0.785 & 0, की & 0,770 & 6.720 \\
\hline 1981 & $0+899$ & 0,522 & 0.745 & 0.842 & 0.855 & $0.89 \mathrm{i}$ & 6,78 & $0.4=$ & $0, \%$ \\
\hline 1982 & 0.907 & 0,540 & 0.739 & 0.979 & 0.925 & j. 014 & 5,36 & 0.946 & 4.317 \\
\hline 1983 & 0.824 & 0.501 & 0.891 & 0.547 & 0.5013 & 0.841 & $0+87$ & 0,824 & 0,72 \\
\hline
\end{tabular}


TABLE 8.15 (CONT). Distillate Fuel Prices: Industrial Sector ( $\$ /$ gal)

\begin{tabular}{|c|c|c|c|c|c|c|c|c|c|}
\hline IEAF & $\mathrm{NC}$ & $\mathrm{id}$ & E & W & $i k l$ & 懒 & ity & $\mathrm{W}$ & ए̈H \\
\hline$\ldots$ & anana & n........ & n...... & - & ---e- &.- & ancenter & -- & \\
\hline 1970 & 0.098 & 0.109 & 0.102 & 0,055 & 0.105 & 0,131 & $0,1.33$ & 0.097 & 0.107 \\
\hline 1971 & 0.101 & $0+109$ & $0.10 \%$ & 0.101 & 0.112 & 0.138 & 0.137 & 5,104 & 0,112 \\
\hline 1972 & 0,100 & 0.108 & 0,109 & 0.101 & 0.112 & 0,138 & 0.134 & 0,103 & $0,1,12$ \\
\hline 1973 & 0,115 & 0.142 & $6+130$ & 0.128 & 0.136 & 0.171 & 0.185 & 0.126 & 0.105 \\
\hline 1974 & 0.275 & 0.304 & 0.257 & 0.304 & 0.301 & 0,250 & 0,273 & $0+302$ & 0,308 \\
\hline 1975 & 0.304 & 0.378 & 0.311 & 0.318 & 0.32 & 0.286 & 0.310 & 0.328 & 0,320 \\
\hline 1976 & 0,333 & 0.415 & 0.332 & 0,324 & $0+333$ & 0.331 & 0,340 & 0.397 & 15,341 \\
\hline Iैन & 0,378 & 0.381 & 0.351 & 0.376 & 0.382 & 0.358 & $0+362$ & 5,387 & $0+582$ \\
\hline 1978 & 0.397 & 0.414 & 0,592 & $0,4 \hat{j} 2$ & 0.397 & 0.375 & $0,0,4$ & 0.400 & 0,400 \\
\hline 1979 & 0.517 & 0.563 & $6.4 \div$ & 0.401 & 0.544 & 0.533 & $0.5 \%$ & 0.544 & 0.53 \\
\hline 1980 & 0.762 & 0.771 & 0.455 & 0,795 & 0.759 & 0.895 & 0,757 & 0.743 & 0.756 \\
\hline 1901 & 6.704 & 0.506 & 0.880 & 0,978 & 0.415 & 1.103 & A 380 & 0.912 & 616 \\
\hline 152 & 0.739 & 0.955 & $0,7 \pm 4$ & 0.352 & 0.922 & 0.947 & 0,724 & ग & $\therefore, 007$ \\
\hline 1998 & 0.871 & 0.883 & 0.971 & 0.432 & 0.863 & 0.835 & 0.843 & $0 . \% 10$ & 0,64 \\
\hline
\end{tabular}

\begin{tabular}{|c|c|c|c|c|c|c|c|c|c|}
\hline TEx & $0 x$ & W & $\mathrm{PA}$ & $\mathrm{kiI}$ & $\hat{x}$ & 50 & 科 & $x$ & 51 \\
\hline 1370 & 0.075 & 0.112 & 0.048 & 0.099 & $0.0 B 0$ & 0.101 & 0.100 & $0.0 \%$ & 5,3 \\
\hline 1971 & 0.075 & 0.114 & 0.104 & 0.105 & 0.002 & 0.100 & 0.108 & $0.0 \%$ & 0.01 \\
\hline 1972 & 0.074 & 0.115 & 0.503 & 0.105 & 0,092 & 0.099 & $i+0,0$ & 0.097 & 0.000 \\
\hline 1973 & 0,054 & 0.153 & 0.118 & 0.133 & 0.098 & 0.131 & 0.11 & 0,115 & $6+14$ \\
\hline 1974 & 0.262 & 0.281 & 0.301 & 0.28 & 0.286 & 0.323 & 9,27 & 0.261 & $0.27 \%$ \\
\hline 1975 & 0.296 & 0.317 & 0.330 & 0.324 & 0.294 & 0.357 & 0.253 & 0.279 & 0.302 \\
\hline 1976 & 0.317 & 0,341 & 0.535 & 5.309 & 0.322 & 0.376 & ij +313 & $0.54 j$ & 0,30 \\
\hline $19 \pi$ & 0.365 & 0.383 & 0.387 & 0.391 & 0.375 & 0,391 & 0.381 & $6+36$ & 0,973 \\
\hline 1978 & 0.393 & 0.389 & 0.33 & 0,415 & 0.403 & 0.438 & {$\left[1,40^{\circ}\right.$} & $0+54$ & 0.340 \\
\hline 1979 & 0.595 & 0.518 & 0.50 & $0+576$ & 0.506 & 0.604 & 0.500 & 0.587 & 0.505 \\
\hline $1 \% 00$ & 0.788 & 0.780 & 0.785 & 0.783 & 0.640 & 0.794 & 0,763 & 0,344 & 07,2 \\
\hline 1981 & 0.666 & 0.875 & 0.517 & $1,00 \%$ & 0.928 & 0,913 & 0.918 & $0,54 \mathrm{i}$ & 0.50 \\
\hline 4982 & 0.844 & 5.894 & 0.953 & 1.073 & 0.892 & 0.894 & 1.057 & $1.45 \%$ & 0.50 \\
\hline 1983 & 0.854 & $\hat{0} .812$ & 0.873 & 0.991 & 0.968 & 0.883 & 0,857 & 0.821 & 0.92 \\
\hline
\end{tabular}

\begin{tabular}{|c|c|c|c|c|c|c|c|}
\hline IEAR & $W A$ & VT & WA & WI & LWV & WY & US \\
\hline$\cdots$ & n & "n. & nacente- & $n+\infty+\ldots$ & 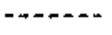 & --.-- & \\
\hline 1970 & 0.093 & 0.117 & $0 .+01$ & 0,100 & 0.078 & 0.111 & D. $=00$ \\
\hline 1971 & $0.0 \mathrm{BB}$ & 0.124 & 0.1614 & 0.109 & $0+104$ & 0.110 & 0.104 \\
\hline 1472 & 0.089 & 0.124 & 0,05 & 0.109 & 0.104 & 0.109 & $j_{*}=04$ \\
\hline 1973 & 0.096 & 0.157 & 0,140 & 0,148 & 0.114 & 0.143 & 0.197 \\
\hline 1974 & 0,259 & i) +308 & 0.226 & 0.275 & 0.276 & 0.291 & ] +290 \\
\hline 1975 & 0,303 & 0,331 & $0,26.4$ & 0,310 & 0,315 & 0.311 & 0,909 \\
\hline 1976 & 0.315 & 0,371 & 6,314 & 0,837 & $0+3033$ & 0.333 & $0+60$ \\
\hline 1977 & 0.370 & 0,403 & 0.360 & 0.381 & 0.398 & 0.348 & 0.371 \\
\hline $177 \%$ & $0.3 \% 1$ & 0.417 & $\hat{0}+407$ & $1+3 \%$ & $6+40$ & 0.376 & $8+37^{n}$ \\
\hline 257 & 0.458 & 0.612 & 0.561 & 0.590 & 0.530 & 0.487 & 0.534 \\
\hline 1980 & 0.734 & 0.810 & 0.34 & 0.718 & 0.853 & 0.739 & $\vec{b}_{4}, \vec{k}$ \\
\hline 2981 & 0.926 & 0,905 & 0.933 & 0.956 & 0.940 & 0.894 & 0.914 \\
\hline 1982 & 0.410 & $0+780$ & 1,25 & 1.016 & 1.443 & $0+7 \% 5$ & $\hat{0.718}$ \\
\hline 1982 & 0.854 & 0.921 & 0.859 & $0.845^{\circ}$ & 0.846 & 0.913 & $0+361$ \\
\hline
\end{tabular}


TABLE B.16. Distihlate Fuel Prices: Electric Utility Sector (\$/ga])

\begin{tabular}{|c|c|c|c|c|c|c|c|c|c|}
\hline Dan & $A k^{k}$ & $\hat{A} \mathbf{L}$ & $A F$ & $A_{2}^{\vec{Z}}$ & CA & $\infty$ & 0 & $\mathrm{DE}$ & $\overline{D E}$ \\
\hline 1970 & $0+0$ & 0,111 & 0,365 & $0+100$ & 0.051 & 0.066 & 0.052 & 0.064 & 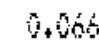 \\
\hline $1 \% 1$ & $0 . \hat{0}$ & 0.125 & 604 & $0.0 \% 0$ & 0.082 & 0.048 & 0.076 & $0.6 \%$ & $\mathrm{~V}, \mathrm{MO}$ \\
\hline 1972 & 0.0 & 0.128 & $0+104$ & 0.139 & 0.106 & 0,098 & 0.091 & 0.092 & $0, \sqrt[n]{34}$ \\
\hline 1973 & 0.0 & 0.123 & 0.149 & 0.142 & 0.150 & 0.218 & 0.124 & 0.114 & 0,112 \\
\hline 194 & 0.0 & $0.28 \mathrm{z}$ & 0.280 & 0.293 & 0.258 & 0.320 & 0.316 & 0.262 & $0+280$ \\
\hline $10 \%$ & 0.0 & 0.248 & 0.307 & 0.313 & 0.529 & 0.352 & 0.316 & 0.289 & $6,3 E$ \\
\hline 176 & 0,0 & 0.324 & 0.345 & 0.338 & 0.364 & 0.328 & 0.336 & 0,311 & 0.390 \\
\hline 1977 & 0.0 & 0.369 & 0.302 & $0.3 \% 2$ & 0.373 & 0.369 & 0.33 & 0,341 & $10+44$ \\
\hline 1978 & 0.0 & 0.381 & 0.463 & 0,384 & 0.389 & 0.390 & 0.293 & 0.973 & $\sqrt[3]{3} 341$ \\
\hline 199 & 0.0 & 0.568 & 0.407 & 0.612 & 0.492 & 0.316 & 0.541 & 0.50 & 0,53 \\
\hline 1990 & 0,0 & 0.872 & 0.520 & 0.905 & 0,745 & 0,990 & 0,336 & 9.48 & $0.86 \hat{v}$ \\
\hline 1981 & 0.0 & 1.070 & 0.889 & 1.023 & 0.499 & 1,007 & 1.041 & 1.004 & $1.03 \mathrm{t}$ \\
\hline 1992 & 0.0 & 0,982 & 0,938 & 1,024 & 0.982 & 0.302 & 1,005 & 0,976 & $0+78 \mathrm{I}$ \\
\hline 1483 & 0.0 & $0.6,5$ & 0.097 & 0.671 & 0.0 & 0,343 & $1+86$ & 0.305 & 0,342 \\
\hline
\end{tabular}

\begin{tabular}{|c|c|c|c|c|c|c|c|c|c|}
\hline VAf & FL & GA & $H I$ & IA & ID & IL & IN & 30 & in \\
\hline 190 & 0.0051 & $0,05 \alpha$ & (1) & untos & 0.0 & 0.097 & 0,107 & 0,490 & 343 \\
\hline 1971 & $\begin{array}{l}0.031 \\
0.0 .57\end{array}$ & $\begin{array}{l}1028 \\
0.098\end{array}$ & $\begin{array}{l}0.064 \\
0.075\end{array}$ & 0.119 & $0+0$ & 0.076 & $\begin{array}{l}4,1, i \\
0.112\end{array}$ & $\begin{array}{l}0.609 \\
0.116 \\
0.16\end{array}$ & $\begin{array}{l}1 \\
0.134\end{array}$ \\
\hline 1972 & 0.080 & 0.091 & 0,085 & 0.123 & 0.0 & 0.101 & $0+113$ & 0.112 & $6+134$ \\
\hline 1973 & 0.124 & 0.104 & 0.109 & 0.159 & 0.0 & 0.135 & 0.140 & $0.1 B$ & $0.11^{2}$ \\
\hline 1974 & 0,255 & 0.288 & 0.142 & 0,334 & 0.0 & 0.254 & 0.241 & 0.230 & $6+365$ \\
\hline 1975 & $0+304$ & 0.312 & $c+241$ & 0.289 & 0.297 & 0.279 & 0.283 & $0+206$ & 0.316 \\
\hline 1976 & 0.323 & 0.337 & 0.266 & $0+323$ & 0.0 & 0.333 & 0.277 & $0+308$ & 0,336 \\
\hline 1477 & 0,358 & 0.379 & $0+318$ & 0.369 & 0.36 & 0.395 & 0.375 & 0.359 & 0.287 \\
\hline 1978 & 0.369 & 0.387 & 0.386 & 0.372 & 0,445 & 0,392 & 0.364 & 0.363 & $0.3 \%$ \\
\hline 1979 & 0.667 & 0.533 & $0.4 \% 5$ & 0.506 & 0.451 & 0.541 & 6.534 & $\sqrt[0]{4} 48$ & 0.618 \\
\hline 1980 & 0.790 & 0.858 & 0.726 & 0.838 & 0.0 & 0.863 & 0.330 & 0,785 & 0,905 \\
\hline 1981 & 0.996 & 1.073 & $1.2 x$ & 1.020 & 0.0 & $1, \hat{6} 0$ & $\frac{1}{2}, 049$ & . & $2+125$ \\
\hline 1982 & 0.993 & 1.003 & 3.260 & $0+861$ & 0,0 & 5.027 & 0,750 & 0.941 & 1,050 \\
\hline 1483 & 0.872 & 0.850 & 0.472 & $0.85-4$ & 0.0 & 0.875 & $6+86$ & $6+434$ & 0.07 \\
\hline
\end{tabular}

\begin{tabular}{|c|c|c|c|c|c|c|c|c|c|}
\hline $\cosh$ & LA & 法 & FID & 证 & MI & 锊 & i40 & 145 & 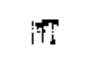 \\
\hline$\cdots$ & $\cdots$ & ---- & $\cdots$ & & ---- & $\cdots$ & - & $\ldots$ & . \\
\hline 1970 & 0.083 & 0.059 & 0.067 & 0.059 & 0.091 & 0.090 & 0,098 & $0.08 \mathrm{~B}$ & 0,061 \\
\hline 1971 & 0.089 & 0.105 & 0.090 & 0.067 & 0.107 & 0.137 & 0.117 & $0+127$ & 0,02 \\
\hline 1972 & 0.114 & 0.110 & 0.1995 & 0.065 & 0.112 & 0.127 & 0.10. & 0,123 & 0,040 \\
\hline 1973 & 0,200 & 0.155 & 0.118 & 0.068 & 0.131 & 0.181 & 0,180 & 0.145 & 0.208 \\
\hline 1974 & 0.445 & 0.293 & 0.269 & 0.0 & 0.268 & 0.304 & 0,309 & 0.290 & 0,0 \\
\hline 1975 & 0.05 & 0.295 & 0.28 & 0.347 & 0.279 & 0.316 & $0.3: 1$ & 0.289 & 0.0 \\
\hline 1976 & 0.296 & 0.335 & 0.318 & 0.357 & 0.323 & 0.314 & 0.314 & 0.309 & A. 340 \\
\hline 1977 & 0.340 & 0.374 & $0 . \sin$ & 0.390 & 0.344 & $0.3 \%$ & $0+36$ & 0,35 & 0.6 \\
\hline 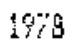 & 0.352 & 0.389 & 0.381 & 0.415 & 0.383 & 0,368 & 0,357 & 0.350 & $\hat{1}, 400$ \\
\hline 1579 & 0.405 & 0.583 & 6.560 & 0,30 & 0.552 & 0.470 & $0_{1}+\omega_{1}$ & $5+20$ & $5 \cdot 47 \%$ \\
\hline 1580 & 0.638 & 0.930 & $0,3 c_{2}$ & 0.53 & 0.936 & 5,510 & 4.27 & 0.751 & bُ \\
\hline 1981 & 0.890 & 1.036 & 1.000 & 1.09 & 1.026 & 1.103 & $0,0 \% 9$ & 0,481 & $\hat{W}, 7 i$ \\
\hline 1792 & 0.900 & 0.783 & 0,700 & 1,044 & 0.972 & 0.795 & 0,55 & 0,515 & $3+715$ \\
\hline 198 & 0.855 & 0.872 & 0.814 & 0.853 & 0.237 & 0.870 & 0.83 & 0.43 & 0.0 \\
\hline
\end{tabular}


TABLE B.16 (CONT). Distillate Fuel Prices: Electric Utility Sector $(\$ / g a l)$

\begin{tabular}{|c|c|c|c|c|c|c|c|c|c|}
\hline 'TEAf' & $14 \mathrm{C}$ & $\mathrm{ND}$ & 纱E & 情 & WXT & 詶任 & 軸 & 放Y & $\mathrm{D} H \mathrm{H}$ \\
\hline$\cdots$ & - & 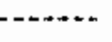 & 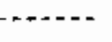 & $\ldots$ & 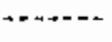 & & - & & \\
\hline 1970 & 0.113 & 0.169 & 0.089 & 0.056 & 0.063 & 0.040 & 0,182 & 0.06 & 0.102 \\
\hline 1971 & 0.123 & 0.165 & 0.16 & 0.057 & 0.101 & 0.076 & $0.12 t$ & $0.07 \%$ & 0.169 \\
\hline 172 & 0.094 & 0.179 & $0.1 \exists \pm$ & 0.067 & 0.103 & 0.107 & 0,137 & 0,093 & villa \\
\hline 1973 & 0.120 & 0.130 & 0.150 & 0.109 & 0.129 & 0.249 & 0.195 & $0.12 \%$ & 0,15 \\
\hline 1974 & 0.317 & 0.285 & 0.202 & 0.0 & 0.0 & $0+290$ & 0.309 & 0.307 & $3+295$ \\
\hline 1975 & 0.308 & $0.2 \% 5$ & $5+261$ & 0.304 & 0.288 & 0.258 & 0.343 & $0+2 \%$ & $4+23$ \\
\hline 1976 & 0.334 & 0.345 & 0.313 & 0.326 & 0.315 & 0.331 & 0,318 & 0.318 & 0.336 \\
\hline 1977 & 0.378 & 0.392 & 0.355 & 0.369 & 0.348 & 0.355 & $0.35 \%$ & 0.364 & $0+3 E$ \\
\hline 1978 & 0.387 & 0,400 & 0.393 & 0.389 & 0.385 & 0.387 & 0.358 & 0.367 & 0,400 \\
\hline 1979 & 0.525 & 0.552 & $6+605$ & 0.580 & 0.573 & 0.576 & 0.679 & $0.5 \mathrm{EL}$ & 0.513 \\
\hline 1380 & 0.804 & 0,844 & $0.5 \% 5$ & 0.517 & 0.8000 & 0.983 & 0.602 & 0.775 & 0,791 \\
\hline $1 \div 81$ & 1.017 & 1.045 & $6+287$ & 1.028 & 0.997 & 1.025 & 0,40 & 0.785 & 074 \\
\hline 19ga & 0.77 & 0.997 & 0.710 & 0.959 & 0.461 & 0.955 & 0,780 & $0.55 \%$ & 1.936 \\
\hline 1483 & 0.826 & 0.796 & 0.810 & 0.043 & 0.870 & 0.837 & 0.54 & 0.672 & 0,2 \\
\hline
\end{tabular}

\begin{tabular}{|c|c|c|c|c|c|c|c|c|c|}
\hline YEifi & IXK & 的 & $F^{\prime} A$ & $\mathrm{RI}$ & 5 & 50 & $\mathrm{TN}$ & $x$ & iT \\
\hline-- & ---- & $\ldots$ & 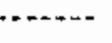 & - & & $\ldots$ & & & \\
\hline 1970 & 0,080 & 0.122 & 0.068 & 0.059 & 0.096 & 0.114 & 0,0 & 0,068 & $\hat{1}_{1}, \sqrt{\mathrm{n}} 4 \mathrm{\theta}$ \\
\hline 191 & 0.074 & 0.126 & 0.107 & 0.072 & 0.144 & 0,142 & 0.140 & $0.06 t$ & $0.04 \%$ \\
\hline 1972 & 0.094 & 0.152 & 0.119 & 0.092 & 0.150 & 0.141 & 0,122 & $0+126$ & 0.050 \\
\hline 1973 & 0.179 & 0.167 & 0.160 & 0.181 & 0.167 & 0.146 & 0.168 & $\tilde{y}+1 \hat{q}$ & 0,32 \\
\hline 1974 & 0.230 & 0.307 & 0.318 & 0.300 & 0.319 & 0.0 & 0.366 & 0.260 & 0.313 \\
\hline 1975 & 0.267 & 0.316 & 0.322 & 0.284 & 0.334 & 0.320 & 0.304 & 0.28 & $U_{*}$ \\
\hline 1976 & $0.29 \%$ & 0.303 & 0,307 & 0.0 & 0.333 & 0.360 & 0.324 & 0.337 & 0.337 \\
\hline 1077 & 0.372 & 0.365 & 0.357 & 0.0 & 0.380 & 0.409 & $0+365$ & 0,352 & 0.344 \\
\hline 1978 & 0.360 & 0.347 & 0.389 & $0, \hat{v}$ & 0.391 & 0,411 & 0.368 & 0.355 & 0.352 \\
\hline $14 \%$ & 0.644 & $0, \pi 9$ & 0.532 & 6.0 & 0.520 & 0.577 & 0,45 & 0,69 & $5+6$ \\
\hline 1780 & 0.752 & 0.894 & 0,304 & 0.0 & 0.801 & $0,8 B d$ & 0,258 & 0.530 & 0.97 \\
\hline $198 \mathrm{i}$ & 0.978 & $0 . \$ 18$ & 1.006 & 0.0 & 1,021 & 1,070 & 1.140 & $0,0,0$ & 1.02 \\
\hline 1982 & 0.926 & 0,990 & 0,990 & 0.0 & 0,951 & 0.922 & $\therefore 123$ & $0+480$ & 0.72 \\
\hline $198 \%$ & 0.800 & 0.832 & 6.85 & $\hat{0} . \hat{0}$ & 0.13 & 0.755 & 0.90 & 0.717 & $3 . B 5$ \\
\hline
\end{tabular}

\begin{tabular}{|c|c|c|c|c|c|c|c|}
\hline Maf & WA & $V T$ & WA & $\mathrm{HI}$ & $i N$ & WY & US \\
\hline .... & 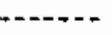 & ----- & - & 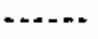 & - & & \\
\hline 1770 & 0.050 & 0.127 & 0.0 & 0.096 & 0.129 & 0.106 & 0.074 \\
\hline 1971 & 0.0 .64 & 0.136 & 0.0 & 0,126 & 0.118 & 0,086 & $0.0 \% 5$ \\
\hline 1972 & 0,075 & 0.144 & 0,072 & 0.113 & 0,131 & 0.148 & 0.100 \\
\hline 1473 & 0.121 & 0.157 & $0.1 \%$ & 0.178 & 0.175 & 0.159 & 0.13 \\
\hline 1974 & 0.291 & 0.0 & 0.0 & 0.284 & 0.316 & 0.328 & $0.30:$ \\
\hline 1975 & 0.305 & 0.303 & 60 & 0.318 & 0.324 & 0.341 & 0.301 \\
\hline 1976 & 0.394 & $0.31 \%$ & $0, \theta$ & 0,319 & 0,351 & 0.350 & 0.325 \\
\hline 1977 & 0.395 & 0.395 & 0.0 & $0.3 \mathrm{hos}$ & 0.572 & $0.45 \%$ & $0+34$ \\
\hline 1978 & $0+335$ & 0.0 & $0,46-1$ & 0.367 & 0.405 & 0.479 & 0.37 \\
\hline 1979 & 0.557 & 0.704 & $6+48$ & 0.485 & 0,545 & 0.526 & ij. 55 \\
\hline $1 \% 90$ & 0.819 & 0.555 & 0,39 & 0.772 & 0.883 & 0.972 & 0,75 \\
\hline 1981 & 0.985 & $0+7,4$ & $0.8 \% 0$ & 0.901 & 1.046 & 1.062 & 0.000 \\
\hline 1982 & 0.970 & $1.02^{\circ}$ & 1.097 & 0,946 & 0.690 & 1.008 & 0.956 \\
\hline 83 & 0,812 & $\hat{v}, 0$ & 0.740 & $0+821$ & 0.365 & 0.974 & 0.844 \\
\hline
\end{tabular}


IABLE B.17. Motor Gasoline Prices: Transportation Sector ( $\$ / \mathrm{gal}$ )

\begin{tabular}{|c|c|c|c|c|c|c|c|c|c|}
\hline TEFR & AK & AL & $\mathrm{AF}$ & $A Z$ & $\mathrm{CA}$ & $C 0$ & $\mathrm{CI}$ & $\mathrm{IC}$ & NE \\
\hline$\cdots$ & .r..... & 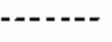 & $\cdots+\infty$ & $-\cdots$ & m...... & $\cdots$ & note- & $\ldots . . .-$ & \\
\hline 1970 & $0,3 y$ & $0+38$ & 0.343 & 55 & 0,350 & 0.340 & $\bar{j}+37 i$ & $\sqrt[n a]{0}$ & $0+48$ \\
\hline 1971 & 0.407 & 0.356 & 0,35 & 0.359 & 0.355 & 0.367 & 0.978 & 0.367 & 0,35 \\
\hline 1972 & 0.402 & 0.369 & 6.347 & 0.354 & 0.349 & 0.351 & 0.375 & $0+377$ & 0.37 \\
\hline 1073 & 0,434 & 0.386 & 0,370 & 0.33 & 0.38 & 0.399 & 0.410 & 0.310 & $0,3 \overline{0}$ \\
\hline 197 & 0.597 & 0.518 & v. 512 & $\hat{j}+515$ & 0.557 & 0.525 & 0.540 & $0.54 i$ & 0.51 .3 \\
\hline 1975 & 0,647 & $\hat{U} .533$ & 0.575 & 0.578 & 0.605 & 0.584 & $0.5 \%$ & 0.507 & 0,567 \\
\hline 196 & 0.670 & 0.588 & 0.604 & 6,605 & 0.631 & 0,613 & 0,10 & 0,433 & 0.573 \\
\hline $19 \pi$ & 0,711 & 0,641 & 0,645 & 0.637 & 0.667 & 0.642 & $0+69$ & $\dot{0} ., 57$ & $0.50 \mathrm{~s}$ \\
\hline 1974 & 0,744 & 0.659 & 0.260 & 0.678 & $0.67 d$ & 0.632 & $5+64$ & 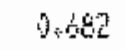 & 0,617 \\
\hline 1979 & 0.974 & 0.86 & 0.957 & 0.805 & 0,770 & 0.857 & $0.89 \%$ & 0.570 & 0.87 \\
\hline 1980 & 1.276 & $1+210$ & 1.206 & $1 . \pm 94$ & $i+271$ & 1,171 & 1.244 & 1,247 & 1,24 \\
\hline 1981 & 1.448 & $1+388$ & 1,341 & 1.327 & 1.398 & $i+305$ & 1. A 41 & 1.403 & 1,405 \\
\hline$\$ 49 \%$ & 1.419 & 1.319 & $1.2 \% 2$ & $1.2 \%$ & $1 .+39 \%$ & 1.268 & $1+242$ & +325 & $1+45$ \\
\hline 1983 & 1.309 & 1.054 & 1.054 & $1+0 D$ & 5.046 & $\stackrel{1}{1} 055$ & 1.143 & $130 \hat{0}$ & 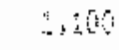 \\
\hline
\end{tabular}

\begin{tabular}{|c|c|c|c|c|c|c|c|c|c|}
\hline SEA & $F L$ & $G A$ & $\mathrm{HI}$ & IA & ID & it. & $\bar{i} i$ & $\mathrm{KO}$ & $\mathrm{Yu}$ \\
\hline$\cdots$ & $+\infty+--$ & $\ldots$ & - & $\ldots$ & $=-$ & $\cdots$ & - & & \\
\hline 1770 & 0.51 & 0,350 & 0.412 & 0.354 & 0,51 & $0+38$ & $5.67 \%$ & $0+30$ & 1,367 \\
\hline 1971 & 0,347 & 0.363 & 0,420 & 0.353 & 0.350 & $0.37 \%$ & $0.37 \%$ & 0.53 & $0,3 \pi$ \\
\hline 1772 & 0.30 & 0.341 & $0 . \$ 16$ & $0+3 / 3$ & 0,352 & 0,344 & 5.35 & $0.2 z$ & 5.73 \\
\hline 1973 & 0.381 & $0.3 B S$ & 0.448 & 0.390 & 0.400 & 0.406 & $0.3 \%$ & $0.37 \%$ & 0.496 \\
\hline 197 & $0.50 \%$ & 0.549 & 0.597 & 0.513 & 0.537 & 0,560 & 539 & 0.524 & $0+73$ \\
\hline 1975 & 0.548 & 0.592 & 0.981 & 0.575 & 0.601 & 0.591 & 0.55 & 0.56 & $0,5 \%$ \\
\hline 196 & 0.571 & 0.606 & 0.709 & 0.604 & 0,623 & 0,600 & {$[+607$} & 0,567 & $0+103$ \\
\hline 1977 & 0.588 & 0,644 & 0.740 & 0.648 & 0.656 & 0,646 & $\hat{0}, 646$ & 0.225 & 0.640 \\
\hline 1978 & 0,648 & 0.559 & 0.777 & 0.678 & 0.697 & 0,666 & 0,67 & 0 ents & 0.65 \\
\hline 1979 & 0.875 & 0.882 & 0.574 & 0.536 & 0.892 & 0.904 & $0.8 \mathrm{ig}$ & 0.550 & $0+860$ \\
\hline 1490 & 1.214 & 1.234 & $1+352$ & 1.224 & $1+205$ & 1.20 & 1.235 & 1,40 & 1.71 \\
\hline $\pm 98 \pm$ & $1.35 \mathrm{E}$ & 1,385 & 1.560 & 1.362 & 1,375 & $1.96 \mathrm{i}$ & $1,3(x)$ & 1.265 & +30 \\
\hline $198_{2}^{2}$ & $1+315$ & $1+304$ & 1.536 & 1.322 & 1.37 & 1,280 & 1.301 & 107 & $\therefore 285$ \\
\hline 1983 & 1.067 & 1.037 & $1,46 t$ & 1.122 & $1.10 \%$ & 1.072 & 1,079 & 1.057 & 1.090 \\
\hline
\end{tabular}

\begin{tabular}{|c|c|c|c|c|c|c|c|c|c|}
\hline VEAt & LA & $M A$ & 阳 & 测 & $\mathrm{Ml}_{\mathrm{i}}$ & 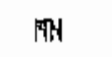 & MI & $m 5$ & $\pi ?$ \\
\hline & & & . & $\ldots$ & $\ldots$ & - & & $-\cdots$ & \\
\hline 1970 & 0.358 & 0.350 & 0.357 & 0.378 & 0.39 & 0.372 & 0,341 & 0,355 & 0,345 \\
\hline 1971 & 0,356 & 0.366 & 0.361 & 0.391 & 0.345 & 0.371 & 0.362 & 0.375 & 0.36 \\
\hline 1972 & 0.341 & 0.359 & 0.377 & 0.391 & 0,342 & 0,371 & 0.358 & 0.375 & 0.53 \\
\hline 1973 & 0.365 & 0,391 & $0.3 \% 2$ & 0,402 & 0.396 & 0.391 & 0.392 & 0.35 & 0.36 \\
\hline 1974 & 0.500 & 0.548 & 0.565 & 6.544 & 0.559 & 0.541 & 3.541 & 0.522 & 0.53 \\
\hline 1975 & 0.562 & 0.592 & 0.608 & 0.571 & 0.591 & 0.579 & 0.569 & 0.542 & 0.59 \\
\hline 1976 & 0,304 & 0.602 & 0,620 & 0,548 & 0.601 & 0 & 5,582 & 0 & $0,6 y$ \\
\hline 1977 & 0.630 & 0.645 & 0.654 & 0.624 & 0.642 & 0.632 & 0.616 & 0.64 & 0,6 \\
\hline 1970 & 0,65 & 0,044 & 0,46 & $5+62$ & 0,068 & 0,033 & 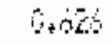 & $n_{1}, 4,47$ & 0 \\
\hline $197 \%$ & 0.475 & 0.674 & 0.670 & $0.9 E_{2}$ & 0.912 & 0,596 & $b, 86$ & 0.91 & 0,0 \\
\hline 1990 & 1,219 & 1,212 & 1.242 & 1.222 & $\{1+2 \leqslant\}$ & $1+195$ & $1+1+4$ & 121 & $\because 47$ \\
\hline $1 \% 1$ & 1.364 & $1+354$ & 1.376 & 1.35 & 1,396 & 1.347 & 1.501 & 1407 & 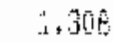 \\
\hline $1982^{\circ}$ & $1+282$ & 1,261 & 1.310 & 1.259 & 1.320 & $1+31 i$ & $1+227$ & 1,37 & $1+24$ \\
\hline 1983 & 1.055 & 1,085 & 1.104 & 1.108 & 1.102 & $1+114$ & 1.054 & 1.037 & 1065 \\
\hline
\end{tabular}


IABLE B.17 (CONT). Motor Gasoline Prices: Transportation Sector ( $\$ / g a l)$

\begin{tabular}{|c|c|c|c|c|c|c|c|c|c|}
\hline YEAT & W & 50 & NE & $\mathrm{NH}$ & 间 & 䞎 & 就 & $\mathrm{NH}$ & Sil \\
\hline .... & n... & . & $\cdots$ & $\cdots$ & - & ... & 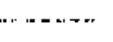 & , n & - \\
\hline $19 \%$ & 0.353 & 0.354 & 0.378 & 0,345 & 0,374 & 0.348 & $4+383$ & 0.365 & 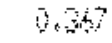 \\
\hline 1971 & 0.373 & 0.371 & 0.375 & $\hat{0}, 3 \hat{B} \mathrm{~B}$ & 0.381 & 0.370 & 0.374 & 0.377 & $0.37 \%$ \\
\hline $1 \% \mathrm{~L}$ & 0.073 & 0.325 & 0.775 & 0.376 & $0+343$ & 0,344 & 0.370 & D. 374 & 0.97 \\
\hline 2973 & 0.393 & 0.392 & 0.401 & 0.401 & 0.386 & 0.382 & 0,415 & 0.420 & 0.0 \\
\hline 1974 & 0.522 & 0.528 & 6.534 & 0.547 & 0.569 & 0.530 & 0.5 .45 & 0.544 & 0.55 \\
\hline 1975 & 0.564 & 0.587 & $0.59 \%$ & 0.567 & 0.594 & 0.591 & $0.5 \%$ & 0.601 & 0,541 \\
\hline 1976 & 0.605 & 0.625 & 0,632 & $0.5 \%$ & 0.611 & $0.5 \% 5$ & $0.5 \% 2$ & 1), 19 & 0.59 \\
\hline 1977 & 0.020 & 0.665 & 0.662 & 0.631 & 0,642 & 0.637 & $0+6=0$ & 0.647 & 0.45 \\
\hline 1978 & $0,+40$ & 0.60 & 0,608 & 0.655 & $0.2+4$ & 0.64 & 0.681 & $30 \sin \theta$ & $t_{10}$ \\
\hline 179 & 0,854 & 0.894 & 0.932 & 0.992 & 0.895 & 0.844 & 0.917 & 0.519 & 0,46 \\
\hline $1 \% 80$ & $1+214$ & $1+209$ & 1,327 & 1.243 & $1+243$ & 1.176 & 1.236 & 1.26 & $1.15 z$ \\
\hline 1981 & 1,365 & 1.337 & 1,372 & 1.79 & 1,356 & 1.344 & 3.45 & 순.7영 & 1.6 \\
\hline 1992 & 1.311 & 1.37 & 1,331 & $1.31 \%$ & $1+269$ & $1+\pi \mathbb{Z} 1$ & 1.386 & 137 & $\therefore$ \\
\hline 1963 & 1,077 & $1+144$ & 1.131 & 1.115 & 1.045 & , & 1.075 & a. $67 \%$ & $1,1, t$ \\
\hline
\end{tabular}

\begin{tabular}{|c|c|c|c|c|c|c|c|c|c|}
\hline TES & ax & $\mathrm{OF}$ & $P A$ & KII & $5 C$ & 50 & T: & $\mathrm{Y}$ & $d T$ \\
\hline$\cdots$ & - & - & 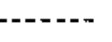 & -- & & & &.- & \\
\hline 1970 & 0,33 & $0+34$ & $0+345$ & 0.362 & (6) +54 & 0.372 & 0.354 & 0.50 & $0+244$ \\
\hline 1971 & $0.35 t$ & 0.358 & 0.372 & 0,369 & 0.057 & 0.340 & 0.35 & 0.348 & 0.50 \\
\hline 1972 & $0+3 A B$ & 0,353 & $5+367$ & 0.361 & to & 0.30 & 0.355 & {$[10$} & 0.55 \\
\hline 1973 & 0.375 & 0.384 & $0.37 \%$ & $0,3 \% 3$ & 0.384 & 0.367 & 0.375 & 0.349 & 0,774 \\
\hline 1974 & 0.5055 & 0.500 & 0.550 & 0.527 & 0.531 & 0.525 & 0.504 & 01,497 & 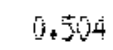 \\
\hline 1975 & 0,565 & 0.555 & 0.570 & 0.562 & 0.544 & 0,587 & 0.573 & $15+545$ & 0,565 \\
\hline 1975 & 0.595 & 0.573 & 0.692 & 0.586 & 0.580 & $0+611$ & 0.597 & 0.565 & 0.586 \\
\hline $19 \pi$ & 0,638 & 0.616 & 0.640 & 0,622 & 0.613 & 0,640 & 0.641 & 0.600 & 0.60 \\
\hline 1978 & 0,668 & 0,061 & {$[1+609$} & 0.030 & $1+27$ & 0,668 & 0.049 & 0,610 & $0, \pi$ \\
\hline 1974 & $0.85 \%$ & 0.903 & $0+87 \%$ & 0.890 & 0.865 & 0.985 & 0.875 & 0.516 & $0.8 B$ \\
\hline 19010 & 1.205 & $1+20$ & $1,2 \pm 5$ & 1.239 & 1.218 & 1.209 & 1.0213 & $t=5 i$ & कo \\
\hline$\$ 981$ & 1.341 & 1.351 & $1+357$ & \pm .376 & 1.355 & 1,336 & 1.357 & 1.294 & 1,348 \\
\hline 1982 & $1+275$ & 1.312 & $1+277$ & $1+267$ & 1.320 & $1+327$ & $1,2 \%$ & 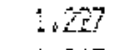 & $4=57$ \\
\hline 1989 & 1.022 & 1.016 & 1.674 & $1.10 \%$ & 1.094 & $\pm .17 \pm$ & $1.05 \%$ & 1.07 & $1,0 \mathrm{~B}$ \\
\hline
\end{tabular}

\begin{tabular}{|c|c|c|c|c|c|c|c|}
\hline YEAR & VA & VT & $\forall \hat{~}$ & WI & $W$ & $d Y$ & 15 \\
\hline$\cdots$ & nowenter & $\cos +\cos$ & $\cdots+\cdots$ & $\cdots-$ & -- & --- & --- \\
\hline 1970 & 0.356 & 0.387 & $5+6$ & 0.332 & 0.357 & 0.346 & 1) +35 \\
\hline 1971 & 0.350 & 0.401 & 0.367 & 0.346 & 0.370 & 0.371 & 0.363 \\
\hline $197 /$ & 0.367 & 0.401 & 0,30 & 0.336 & 0.384 & $0.3+5$ & 0.361 \\
\hline 1973 & 0.395 & 0,417 & 0,353 & 0.354 & 0.392 & 0.394 & 0.386 \\
\hline 174 & 0.551 & 0.559 & $5+537$ & 0.539 & 0.515 & 0.537 & $0,5+40$ \\
\hline 1975 & 0.596 & 0.586 & 0.577 & 0.560 & 0.577 & $0,5 \%$ & 0.501 \\
\hline 1776 & $0, ., 0$ & 0.64 & 0,001 & $0+58$ & 0.541 & 0.617 & $1+40 t$ \\
\hline 197 & 0.667 & 0,620 & 0.646 & 0.614 & 0.632 & 0,660 & 0.67 \\
\hline 577 & 0.675 & 0,442 & $n+6=$ & 0.623 & $0,44 \mathrm{i}$ & $0, \Delta, 1$ & 0.65 \\
\hline $197 \%$ & $0.860^{\circ}$ & 0,904 & 0.837 & 0.850 & 0.51 & 0.845 & $0,8 \overline{2}$ \\
\hline iptoj & $1+235$ & $1+55$ & $2+231$ & 1.179 & $1+253$ & 1.049 & 1.25 \\
\hline 1981 & 1.384 & 1.392 & 1.374 & 1.399 & 1.394 & 1.336 & 1.35 \\
\hline 1982 & 1,317 & 1,316 & 1.305 & $1.2 \% 4$ & $1, \ldots 2$ & $1+396$ & 1.296 \\
\hline \multirow[t]{2}{*}{1983} & 1.082 & 1.155 & 1.063 & 1.105 & $1+145$ & 1.071 & 1.067 \\
\hline & & & & B. 36 & & & \\
\hline
\end{tabular}


IABLE. B.18. Diesel Fuel Prices: Transportation Sector ( $\$ / g a 1)$

\begin{tabular}{|c|c|c|c|c|c|c|c|c|c|}
\hline YT:AK' & $A x$ & AL & $A \mathbb{R}$ & $B Z$ & {$[\mathrm{~A}$} & $\infty$ & $\mathrm{CT}$ & $\mathrm{IC}$ & $D E$ \\
\hline 1970 & 0.0 & $0+18-1$ & 0,160 & 0.174 & 0.197 & 0.167 & $0,1 \%$ & 0.183 & 0.170 \\
\hline 151 & 0.0 & 0.187 & $6+169$ & $0+181$ & 0,216 & 0.172 & 0.207 & $0.1 \% \hat{3}$ & $6+19$ \\
\hline 1972 & 0.0 & 0.197 & 0,17 & 0.184 & 0.206 & 0.171 & 0.216 & $0+195$ & 0.05 \\
\hline 1973 & 0.0 & 0.243 & $0+149$ & 0.205 & 0.247 & $0,20 \mathrm{~N}$ & 0,250 & 0.244 & $0+2 \frac{24}{24}$ \\
\hline 1974 & 0,0 & 0,378 & 0.326 & 0.952 & 0.406 & 0.339 & 0.17 & 0.385 & B. \\
\hline lyte & 0.0 & 0,405 & 0.351 & 0.50 & 0.447 & 0.346 & 0.408 & 0.370 & 0.340 \\
\hline 1976 & 0,0 & 0,429 & 0,274 & 0.394 & 0.460 & 0.374 & $\hat{v}_{2}=30$ & 0.417 & 0.417 \\
\hline 1977 & 0.0 & 0.463 & $4+429$ & 0.457 & 0.455 & 0.428 & 0.501 & $0+40$ & $0,4+0$ \\
\hline 1978 & 0,0 & 0.457 & 0.438 & 0,472 & 0.458 & 0.446 & 0,526 & 0.515 & 6.515 \\
\hline 1579 & 0.0 & 0,30 & 0.656 & 0.65 & 0,683 & 0.689 & 0.73 & $0, \sqrt{30}$ & 8.761 \\
\hline 1990 & 0.0 & $0,96 \%$ & 0.924 & 1.019 & 0.980 & 0,988 & $\therefore, 127$ & 1.068 & 1.01 \\
\hline 1981 & 0.0 & 1.187 & $1.12 \mathrm{a}$ & 1.173 & 1.127 & 1.140 & 1.250 & $1.18 \bar{z}$ & 1.18 \\
\hline 1982 & 0,0 & 1.124 & 1,068 & 1.112 & 1.105 & 1.075 & 1,28 & 1.100 & $1: 101$ \\
\hline $198=$ & 0.0 & 0.977 & $0, \% 4 c$ & 0,580 & 0,784 & 0.5477 & $1+124$ & 1.084 & 1.035 \\
\hline
\end{tabular}

\begin{tabular}{|c|c|c|c|c|c|c|c|c|c|}
\hline YEA & $\mathrm{FI}$ & $\mathrm{GA}$ & 泣 & $I A$ & $I D$ & IL & $\mathrm{in}$ & 16 & $\mathrm{Hi}$ \\
\hline--- & --- & nara & - & 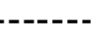 & $\cdots$ & ----- & $\cdots$ & ++ & \\
\hline 1970 & 0.200 & 0.183 & 0.149 & 0,177 & 0.182 & 0.173 & 0.170 & 0.104 & o, nits \\
\hline 1071 & 0.209 & 0.200 & $0.2 \hat{v e}$ & 0.178 & 0.199 & 0.198 & 0.171 & 0.164 & $011+4$ \\
\hline 1972 & $0.21 \%$ & 0.209 & 0.203 & 0.132 & 0.194 & $0+201$ & 0.178 & 0.170 & $3+56$ \\
\hline $19 \%$ & 0.256 & 0.243 & $0.22 x$ & 0.214 & 0.275 & 0.249 & 0.274 & 0.216 & 0.22 \\
\hline 1974 & 0.358 & 0.371 & $\hat{0}+326$ & 0.348 & 0.358 & 0.373 & 0.358 & 0.357 & 0.370 \\
\hline 1975 & 0.401 & 0.419 & 0.345 & 0.367 & 0.372 & 0.373 & 0,37 & 6.65 & 0.398 \\
\hline 1978 & 0.440 & 0.434 & 0,395 & 0.394 & 0.399 & 0.415 & 0,990 & 0.388 & 0.415 \\
\hline $19 \pi$ & 0,490 & 0.489 & 6.434 & 0.459 & 0.435 & 0.479 & 0.46 & 0,435 & $0,4,9$ \\
\hline 1979 & 0.522 & 0.500 & 0.474 & $\therefore \Leftrightarrow$ & 0.149 & 0.502 & 0,468 & 0.456 & 0,467 \\
\hline 1974 & 0.769 & 0.722 & $c+0.9$ & 0.700 & 0.674 & 0.748 & $0, B=7$ & $0.6 \%$ & 0.86 \\
\hline 1980 & 1,070 & $\$ .038$ & 1375 & 0.96 & 0.764 & 1.033 & 0,75 & 0,772 & 0,951 \\
\hline 1 & 1.271 & 1,213 & $1+201$ & 1.148 & 1.131 & $1.2 Z_{2}$ & 1.197 & 1.135 & 1,14 \\
\hline 1982 & 1.146 & 1.098 & $1+\therefore 8 i$ & 1.105 & 1.103 & $1+181$ & $1 .-51$ & 1.095 & 1,084 \\
\hline 1963 & 1.041 & 0,970 & 1.213 & 0.985 & 0.975 & $1+065$ & 1.034 & 0.560 & 0.740 \\
\hline
\end{tabular}

\begin{tabular}{|c|c|c|c|c|c|c|c|c|c|}
\hline FEAR & LA & $\mathrm{mA}$ & MD & ME & MI & MN & 相 & 溚 & MIT \\
\hline 1070 & 0 & 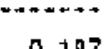 & 0 & 0 & 0 & & $\therefore 71$ & 8790 & $5+77$ \\
\hline $\begin{array}{l}1970 \\
1971\end{array}$ & $\begin{array}{l}0.150 \\
0.162\end{array}$ & $\begin{array}{l}0.187 \\
0.206\end{array}$ & $\begin{array}{l}0.283 \\
0.193\end{array}$ & $\begin{array}{l}0.192 \\
0.207\end{array}$ & $\begin{array}{l}0.176 \\
0.181\end{array}$ & $\begin{array}{l}0.1 / 2 \\
0.177\end{array}$ & $\begin{array}{l}9 . .71 \\
0.176\end{array}$ & $\begin{array}{l}1,240 \\
0,244\end{array}$ & $\begin{array}{l}\sqrt{41 / 2} \\
0.178\end{array}$ \\
\hline 1772 & 0.164 & 0.200 & $0 . .45$ & 0.208 & 0.179 & 0.173 & $\dot{y}+7 \hat{j}$ & 0.215 & $0.17 \mathrm{~g}$ \\
\hline 1973 & 0.197 & 0.250 & $0.2=8$ & 0.250 & 0.229 & 0.224 & 0,215 & $0+245$ & $0,21 \%$ \\
\hline 1974 & 0.373 & 0.379 & 0.395 & 0.379 & 0.369 & 0.354 & jojo & 4.367 & 0,36 \\
\hline 1975 & 0.352 & 0,403 & 0.30 & 0.402 & 0.384 & 0,370 & 0.37 & 0.381 & 0,30 \\
\hline 1976 & 0.371 & 0.430 & {$[1+417$} & 0,430 & 0.401 & 0.309 & $1+400]$ & 5.440 & 0,35 \\
\hline $5 \%$ & 0.445 & 0.501 & 0.491 & 0.502 & 0.468 & 0,461 & 0.436 & 0,522 & 0,430 \\
\hline 1978 & 0.429 & 0.526 & 4.515 & 13,526 & 0.433 & 0.43 & 3.459 & 0.535 & $\hat{3}+4=0$ \\
\hline $2 \$ 7 \%$ & 0.656 & 0.741 & 0,72 & 0.735 & 0.718 & 0.704 & 0.600 & 0.74 & $8+9$ \\
\hline 1780 & $0.94 \overline{9}$ & $1+02$ & 1.067 & 1.028 & 0,877 & $0.5 \% 3$ & $3+47$ & 1,64 & 19 \\
\hline 1981 & 1.195 & 1,256 & $1,1,5$ & 1.255 & 1,194 & 1,150 & 1.140 & $1,2 \%$ & $\therefore 15 \%$ \\
\hline 1782 & 1,055 & $1+213$ & 1,009 & $1+210$ & 1.157 & 1.126 & $1, \ldots 04$ & 1.20 & 1.10 \\
\hline 1983 & 0.923 & 1.125 & 1.034 & $1+115$ & 1.052 & 0.597 & 0.985 & 1,043 & 0.97 \\
\hline
\end{tabular}


TABLE B. 18 (CONT). Diesel Fuel Prices: Transportation Sector ( $\$ /$ gal)

\begin{tabular}{|c|c|c|c|c|c|c|c|c|c|}
\hline YEAT & IHC & WVI & $\sqrt{4} \vec{a}$ & 哺 & tht & 洲 & LAV & 到 & $\mathrm{gi}$ \\
\hline 1570 & 0.40 & 0.104 & 0.45 & 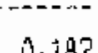 & ia & in & 0.200 & 00 & 611 \\
\hline 1971 & 0.285 & 0,183 & $\begin{array}{l}0.58 \\
0.160\end{array}$ & 0.207 & 0.243 & $\begin{array}{l}0.160 \\
0.181\end{array}$ & $\begin{array}{l}0+208 \\
0,221\end{array}$ & $\begin{array}{l}+\infty \\
6+202\end{array}$ & $\begin{array}{l}1.16 \\
1.194\end{array}$ \\
\hline 1772 & 0.190 & 0.184 & $0,1 \rightarrow 0$ & 0,200 & 0.278 & 0.107 & 0,21 & $0+150$ & $0+19$ \\
\hline 1973 & 0.244 & 0.222 & $1+211$ & 0.250 & 0.297 & 0.205 & $0.25 t$ & i) 243 & $0,3 t 4$ \\
\hline 1974 & $0.40 \dot{\theta}$ & 0.354 & $0.3 * 0$ & 0.377 & 0.411 & 0.346 & 0.400 & 0.375 & 0.362 \\
\hline 1475 & 0.433 & 0.370 & 0.347 & 0.403 & 0.445 & 0.363 & $0.41 \bar{f}$ & $0,3 \%$ & 0.393 \\
\hline 1976 & 0,460 & 0.405 & 0.387 & 0.430 & $0+440$ & 0.387 & 0.45 & 0.420 & $0+410$ \\
\hline 1977 & 0.516 & 0.453 & 0.438 & 0.502 & 0.476 & 0.431 & 0.456 & 0.481 & 0.48 \\
\hline 179 & $0.5 \%$ & 0.471 & 0.453 & 0.526 & 0.506 & 0,454 & 0,400 & 350 & 0.490 \\
\hline 1979 & $0.728 \mathrm{~B}$ & 0.706 & 1636 & 0,746 & 0.712 & 0,669 & 3.690 & 0.726 & 0.75 \\
\hline 1980 & 1.017 & 1,003 & 0.779 & 1.023 & t.019 & 0,93 & 1.021 & 1.034 & 0.984 \\
\hline 1981 & 1.232 & 1,189 & 1.163 & 1.249 & 1.215 & 1.151 & 1.210 & 1.310 & 1,104 \\
\hline 192 & 1,189 & 1,143 & 1.393 & 1.204 & $\frac{1}{1} 150$ & 2.104 & $\therefore+1(0)$ & 1,242 & $1+1+4 \hat{y}$ \\
\hline 1983 & 1,087 & 1.010 & 0,85 & 1,132 & 1.082 & 1.007 & 1.052 & 1,141 & 1.034 \\
\hline
\end{tabular}

\begin{tabular}{|c|c|c|c|c|c|c|c|c|c|}
\hline YEAF & ok & GF & $F A$ & $\mathrm{kII}$ & $x$ & 50 & $\mathrm{TN}$ & $T$ & $r$ \\
\hline & & & & & & & & & \\
\hline 1970 & 0.155 & 0.186 & 0,187 & 0.189 & $0+183$ & 0.183 & 0.178 & $9+146$ & $0+ \pm A 3$ \\
\hline 1971 & 0.150 & 0.197 & .190 & $0+20 \%$ & 0.214 & 0.182 & บे.183 & 0.160 & $\hat{1}+1+1 \% 4$ \\
\hline 1972 & 0.157 & 0.193 & 0.196 & 0.209 & 0.216 & 0.197 & 0.170 & 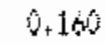 & 1.10 \\
\hline 1973 & 0.206 & 0.220 & 3.250 & 0.256 & 0.261 & 0.229 & 0.236 & 3,194 & 0,25 \\
\hline 1974 & 0.343 & 0.344 & $0.3 \mathrm{~s}-1$ & 0.379 & 0,405 & 0.360 & 0.375 & $\sqrt[n]{3} \mathbf{3} 4$ & 0,351 \\
\hline 175 & 0.362 & 0.373 & 0.366 & 0.403 & 0.418 & 0.377 & $0.41 \%$ & $i_{2} 346$ & 0.412 \\
\hline 1976 & 0.389 & 0.35 & 0.407 & 0,430 & 0,445 & 0.404 & 0.125 & 0.371 & 0.35 \\
\hline 1977 & 0.450 & 0.427 & $j, 473$ & 0.501 & 0.493 & 0.469 & 0,455 & 0.413 & $0,4,4 \frac{15}{3}$ \\
\hline 1978 & 0,468 & 0.442 & 0.474 & 0.526 & 0.520 & 0.489 & 0,432 & 0.426 & $0,4 \%$ \\
\hline 1979 & 0.730 & 0.657 & 6.720 & 0.740 & 0.694 & 0.700 & $0.6 \%$ & 0.664 & 0,691 \\
\hline 1980 & $4+013$ & 0.965 & 0.778 & 1.028 & 1.058 & 0.937 & 1.305 & 0.983 & 9. \\
\hline 1981 & $1+194$ & 1.101 & $1+201$ & 1,235 & 1.252 & 1.168 & 1.176 & 1.155 & 1.19 \\
\hline 1982 & $1+131$ & 1.084 & 1.168 & 1.208 & 1.172 & 1.115 & 1.093 & 1.641 & 1.877 \\
\hline 1993 & 1.005 & 0.450 & 1.055 & 1.125 & 1,007 & 0.564 & 0,45 & 4.940 & $1+40$ \\
\hline
\end{tabular}

\begin{tabular}{|c|c|c|c|c|c|c|c|}
\hline YEAAF' & WA & UT & $W$ & WI & WN & $W^{\prime}$ & L \\
\hline$-\cdots$ & ....... & I. & & 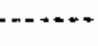 & 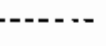 & - ne- & \\
\hline 1970 & 0.173 & 0.198 & 0.103 & 0.134 & 0.239 & 0.181 & 0. \\
\hline $17 / 1$ & 0.185 & 0.207 & 0.452 & 0,186 & 0.265 & 0.184 & 0.2 \\
\hline 1072 & 0.184 & 0.208 & $0+14 y$ & 0.185 & $0+2 B B$ & 0.181 & 0.1 \\
\hline 1973 & 0.220 & 0.251 & 0,223 & 0.25 & 0.346 & 0.205 & 0.2 \\
\hline $1 / 74$ & 0.359 & 0.378 & 0.347 & 0.341 & 0.506 & 0.355 & 0.3 \\
\hline 1975 & 0,378 & 0.403 & 01,368 & 0.363 & $0.55 i$ & 0.375 & $\sqrt{3}$ \\
\hline 1076 & 0,403 & 0,430 & 0,401 & $0,3 \%$ & 0.507 & 0.401 & 0.4 \\
\hline $1 \% 7$ & 0.462 & 0.512 & 0.433 & 0,445 & $0.55 \%$ & 0.436 & 0.4 \\
\hline 178 & 0.487 & 0.526 & $0+44 ?$ & 0,475 & 0,600 & 0.46 & 0,4 \\
\hline 179 & 0.40 & 0.745 & 0,50 & 0.714 & 0.826 & 0.693 & 3.6 \\
\hline $1 \div 00$ & $1.00 \%$ & 1.00 & $0, \pi 2$ & $\therefore+10$ & 1.100 & 1.028 & 0.7 \\
\hline $1 \div$ & $1+225$ & 1.251 & $1,1]^{E}$ & $1+172$ & 1.412 & $1+165$ & $1, i$ \\
\hline 1702 & 1,176 & 1.210 & $1.1 \pm 8$ & $1+130$ & 1.365 & 1.117 & $1+1 . .4$ \\
\hline 83 & 1,066 & 1.120 & 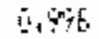 & 1.01 .5 & 1.227 & 0.999 &, 0 \\
\hline
\end{tabular}

B. 38 
TABLE B.19. Kerosene Prices: Residential Sector (\$/gal)

\begin{tabular}{|c|c|c|c|c|c|c|c|c|c|}
\hline $\mathrm{IBAK}$ & Ak & AL & $R$ & $A \vec{Z}$ & $C A$ & $\mathrm{CO}$ & {$[T$} & $i c$ & $\mathrm{DE}$ \\
\hline .... & 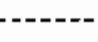 & n...... & -.--- & 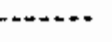 & -- & $\cdots$ & 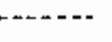 & $-\cdots$ & \\
\hline 1970 & 0.0 & 0.217 & 0,189 & 0.391 & 0.347 & $0.2 \times 4$ & $0 . z_{24}^{24}$ & 0.203 & $0+101$ \\
\hline 197 & 0.0 & 0.225 & 0,191 & 0.363 & 0.371 & 0.200 & i) 225 & 0.248 & $0.1 \% 4$ \\
\hline 1972 & $0, \overline{0}$ & 0.228 & 0.200 & 0.330 & 0.404 & 0.210 & 0.228 & 0.27 & 0.205 \\
\hline $1 \% 3$ & 0.0 & 0.262 & 4,27 & 0.346 & 0.479 & 0,246 & $i s, 26$ & 0,257 & 0.25 \\
\hline$[374$ & 0.0 & 0.399 & 0.371 & 0.535 & 0.721 & 0.387 & 0.407 & 0397 & $0.37 \%$ \\
\hline 1975 & 0,0 & 0.447 & 0.378 & 0.628 & 0,695 & 0.399 & $j_{4} 447$ & 0.454 & 0.454 \\
\hline 1776 & 0.0 & 0.480 & 0,371 & 0.54 & $\hat{0} .701$ & 0,431 & 0.452 & 0.443 & 0.443 \\
\hline 1077 & 0.0 & 0.521 & 1]. 463 & 0,704 & 0.773 & 0.493 & 4,506 & 0.520 & 0.50 \\
\hline 1779 & 0.0 & 0.576 & 0.487 & 0,749 & 0.814 & 0.514 & $0 . \overrightarrow{3} 41$ & 0.552 & $0.55 \%$ \\
\hline 1979 & 0.0 & 0.943 & 0,40 & 0.853 & $1+163$ & 0.571 & $i x, 719$ & 0.746 & 1.746 \\
\hline 1700 & $\hat{0}+0$ & 0.811 & 1.244 & 1.976 & 1.756 & 1.077 & 1.100 & 1.154 & 1,154 \\
\hline 1981 & 0.0 & 1.507 & 1.270 & 1.927 & $2, \hat{v} 65$ & 1.320 & 1,422 & 1,453 & 1,458 \\
\hline 1902 & 0.0 & $1+458$ & 1.251 & 1.934 & $2+04$ & 1.326 & 1.156 & 1.426 & $\therefore, A 2$ \\
\hline 1993 & 0.0 & 1,316 & 1.116 & 1.793 & 1.704 & 1,237 & 1,26 & 2,240 & 20 \\
\hline
\end{tabular}

\begin{tabular}{|c|c|c|c|c|c|c|c|c|c|}
\hline İEAR' & FL & GA & HI & IA & in & IL & IN & $\mathrm{K}$ & $\mathrm{m}$ \\
\hline ---. & - & - & -...+. & - & $\cdots$ & $\cdots+\infty$ & 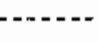 & $\cdots+\cdots+$ & 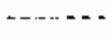 \\
\hline 1770 & 0.220 & $0.1 \%$ & 0.396 & 0.212 & 0.337 & 0.220 & 0.25 & 0.10 & 0.24 \\
\hline $1 \$ 1$ & 0.216 & 0.207 & $\overrightarrow{0}, 457$ & 0.215 & 0.326 & 0.227 & 0.205 & 1.190 & 0.215 \\
\hline 1772 & 0.216 & 0,222 & 0.460 & 0,254 & 0.417 & 0.25 & $\hat{U}_{1} 187$ & $0+1 \frac{17}{4}$ & 0.817 \\
\hline 197 & 0.248 & 0.254 & 0.497 & 0.251 & 0.434 & 0.254 & 0,238 & 0.235 & $1,+25$ \\
\hline 1974 & 0.400 & 0.401 & 0.5 .4 & 0.375 & 0.536 & 0.396 & 0.382 & 0,365 & $0,3 \%$ \\
\hline 1975 & 0.442 & 0.452 & 0.700 & 0.403 & 0.550 & 0.425 & 0.450 & 0,344 & $0,42 E$ \\
\hline 1976 & $0.4 B O$ & 0.454 & 0,700 & 0.440 & 0.588 & 0.452 & $0,4 h$ & 0.407 & 0,446 \\
\hline 1977 & 0.546 & 0.537 & 0.849 & 0.503 & 0.245 & 0.526 & 0.516 & 0.477 & 0.485 \\
\hline 1378 & 0.584 & 0.574 & $0.8 \% 4$ & 0.535 & 0.687 & 0.551 & $0 . \overline{3} 41$ & 0.507 & 0.524 \\
\hline 1979 & 0.791 & $0.7 \vec{T} 9$ & 1.27 & 0.737 & 0.763 & 0.796 & $0,7 / 2$ & 0.699 & 0.436 \\
\hline 1.790 & 1.203 & 1.184 & 1.748 & 1.093 & 1,437 & $1+1 / 5$ & 1.154 & 1,136 & 0.625 \\
\hline 1981 & 1,515 & 1.491 & 2.26 & 1,337 & 1.764 & 1.443 & 1.417 & 1,269 & 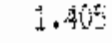 \\
\hline 1902 & 1.502 & 1.478 & 2.304 & 1,298 & 1.772 & 1.402 & 1,377 & $1+231$ & 1.355 \\
\hline 1483 & 1,349 & 1,328 & 2,090 & 1,217 & 1.652 & 1,288 & 1.255 & $1+154$ & $1+29$ \\
\hline
\end{tabular}

\begin{tabular}{|c|c|c|c|c|c|c|c|c|c|}
\hline IEAK & $I A$ & HA & 淜 & 泟 & MI & int & 湴 & $\mathrm{m}$ & th \\
\hline$\cdots$ & 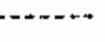 & 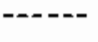 & - & $+\cdots$ & $\cdots$ & $\cdots+\infty$ & 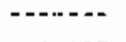 & $\ldots$ & \\
\hline 1770 & 0.216 & 0.215 & 0.203 & 0.214 & 0.211 & 0.205 & 0.193 & 0.278 & 0,75 \\
\hline 1971 & 0,220 & 0.225 & $D_{1} 248$ & 0.225 & $0.20 \mathrm{e}$ & 0.208 & 0,211 & 0.280 & $0,94 \mathrm{i}$ \\
\hline 1772 & 0.237 & 0.228 & 0.227 & 0.228 & 0.212 & 0.212 & $10+2.3$ & 0.25 & 0.244 \\
\hline 1973 & 0.274 & 0.262 & 0.87 & 0.262 & 0.256 & 0.242 & $n, 247$ & 0.306 & 0.271 \\
\hline 154 & 0.437 & 0.407 & 0.397 & 0.407 & 0.405 & 0.374 & 0.375 & $0.4 \%$ & 3,415 \\
\hline 1975 & 0.461 & 0.427 & i..454 & 0.427 & 0.421 & 0.393 & 1.349 & 0.513 & 0.427 \\
\hline 196 & 0.511 & $0.45 ?$ & 0,443 & 0.452 & $0.4 \%$ & 0.426 & 0,45 & 0.50 & $0,4 \%$ \\
\hline $19 \%$ & 0.597 & 0.506 & 0.520 & 0.506 & 0.509 & 0.498 & 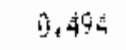 & 0,598 & 0.501 \\
\hline 1778 & 0.67 & 0.541 & 0.52 & 0.341 & 0.536 & 0.530 & 0,75 & 0,61 & 0.53 \\
\hline 1979 & 0.700 & 0.719 & 0.746 & 0.715 & 0,761 & 0.730 & B.7ES & 1,083 & 0.50 \\
\hline 1980 & 1.345 & 1.100 & 1.454 & 1.100 & 1.138 & 1.082 & 1.373 & $0,3,3$ & $1+117$ \\
\hline $1 \% 91$ & 1.30 & 1.422 & $1: 4: E$ & 1,422 & 1,397 & $5+35$ & 1.315 & $\therefore: 30$ & s. \\
\hline 1782 & 1.611 & $1+456$ & 1.426 & 1,456 & 1.357 & 1,286 & \pm .275 & 1.674 & $2 \div 375$ \\
\hline 1908 & 1,441 & 1.264 & 1,286 & 1.264 & 1.246 & 1.206 & $1,25 E$ & 1.511 & 1,286 \\
\hline
\end{tabular}


TABLE B.19 (CONT). Kerosene Prices: Residential Sector ( $\$ /$ gal)

\begin{tabular}{|c|c|c|c|c|c|c|c|c|c|}
\hline YGAF & 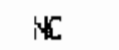 & HIJ & ME & $H$ & 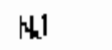 & 14 & (kn) & $4 Y^{\prime}$ & $\mathrm{OH}$ \\
\hline$\cdots$ & $\ldots+\ldots$ & - & $-\cdots \cdot-$ & .... & . & --..- & -- & - & \\
\hline 1970 & $0.18 \%$ & 0.223 & 0,137 & 0.213 & $0.2 \%$ & 0.201 & 0.451 & 0,211 & 0.99 \\
\hline 1971 & 0.196 & 0.220 & $\bar{y}_{4}$ & 0.225 & 0.239 & 0.201 & 3,45 & 2.224 & $1+30^{1}$ \\
\hline 1972 & 0.200 & 0.220 & 0.189 & 0,28 & 0.244 & 0.206 & 0,443 & $0.2 \%$ & 0.200 \\
\hline 1873 & $0.23 B$ & 0.259 & $0.2: 44$ & 0.262 & 0.293 & 0.241 & 0,480 & 0.273 & 0.236 \\
\hline 1974 & 4.368 & 0.361 & 0.356 & 0,407 & 0.445 & 0.389 & 0.623 & 0.410 & 0.379 \\
\hline 1970 & 0.399 & 0.363 & 5375 & 0,457 & 0.474 & 0.411 & 0.477 & 0.442 & 0,31 \\
\hline 1573 & 0.432 & 0.403 & $0,4,0$ & 0.452 & 0.510 & 0.420 & $\hat{0}_{+644}$ & 0,463 & $6+40$ \\
\hline 1977 & 0.487 & 0.455 & 9.459 & 0.506 & 0.569 & 0,482 & $0.7 \mathrm{Gm}$ & 0.521 & 0,707 \\
\hline 1778 & 0.521 & $0,4 B S$ & $0+4 \% 8$ & $\hat{\mathrm{V}}+541$ & $\hat{0}+604$ & 0.512 & 0.774 & 0.52 & 0,510 \\
\hline 1979 & 0.706 & 0.672 & 0.697 & 0.719 & 0.820 & 0.598 & 5.808 & 0.750 & $\sqrt{17}, \mathrm{~L}^{0}$ \\
\hline $1 ; 30$, & 1.074 & 0.997 & $1.3 . .8$ & 1,100 & 1.252 & 1.075 & 1.640 & 1,146 & 1.089 \\
\hline 1981 & 1.353 & 1.220 & 1,247 & 1.422 & $1.60 !$ & $1+324$ & 2,00 & 1,45 & $\therefore$ \\
\hline 1392 & 1,341 & $1+58$ & +20 & $2+456$ & 1.601 & 1.327 & $3+363$ & 1,46 & +200 \\
\hline 1993 & 1.204 & $1+\$ 10$ & 1.134 & 1,264 & 1.429 & 1.229 & $1, \dot{s} 56$ & ane & 舟 \\
\hline
\end{tabular}

\begin{tabular}{|c|c|c|c|c|c|c|c|c|c|}
\hline HEA & OK & OF & $F^{\prime} A$ & $\mathrm{KI}$ & $x$ & SD & $\mathrm{TN}$ & $\pi i$ & IT \\
\hline & contons & & & & & & & & \\
\hline $\begin{array}{l}1770 \\
1971\end{array}$ & $\begin{array}{l}0.191 \\
0.195\end{array}$ & $\begin{array}{l}0.377 \\
0.403\end{array}$ & $\begin{array}{l}0.2 .1 \\
0.219\end{array}$ & $\begin{array}{l}0.250 \\
0.225\end{array}$ & $\begin{array}{l}0.213 \\
0.216\end{array}$ & $\begin{array}{l}0.211 \\
0.212\end{array}$ & $\begin{array}{l}\hat{y}+2+9 \\
\hat{0}+21 \hat{0}\end{array}$ & $\begin{array}{l}0,175 \\
9,458\end{array}$ & $\begin{array}{l}0.35-4 \\
0.405\end{array}$ \\
\hline 1772 & 0.191 & 0.440 & 0.24 & 0.228 & 0.218 & 0.218 & 0.26 & 0,190 & $0+4+2 i$ \\
\hline $19 \%$ & 0.226 & 0.454 & 0.246 & 0.262 & 0.256 & 0.243 & 0.256 & 0.216 & 6.492 \\
\hline 1974 & 0.375 & 0.506 & 0.30 & 0.407 & 0,403 & 0.355 & 0.427 & 0.364 & 0.621 \\
\hline 1975 & 0.388 & 0.515 & 0,421 & 0.427 & 0.426 & 0.392 & $i, 457$ & 0,406 & 0.48 \\
\hline 146 & $\hat{0}, 417$ & 0.522 & 0.440 & 0.452 & 0.447 & 0,424 & 0,468 & 0,424 & 0.644 \\
\hline 1977 & 0.477 & 0.581 & {$[, 454$} & 0.506 & 0.506 & 0.497 & $\overline{4}, 51 ?$ & 0.501 & 0.743 \\
\hline 1779 & $0.5 \hat{4}$ & 0,612 & 0.524 & 0.541 & 0.541 & 0.517 & 0.572 & 0.526 & 0.791 \\
\hline 1979 & 0.708 & 0,874 & 0.712 & 0.719 & 0.734 & 0.713 & $0,8 \%$ & 3.756 & $0.97 \%$ \\
\hline 1980 & 1,074 & 1.320 & $1, R Q$ & 1.100 & 1.15 & 1.057 & 0.900 & $1+200$ & 1.67 \\
\hline 1981 & 1.311 & 1,551 & 1.389 & 1.422 & 1.405 & 1.294 & 1.500 & 1.34 & 2,192 \\
\hline 1982 & 1.273 & 1.577 & 1,30 & 1.456 & 1.38 & $1,25,6$ & 1.446 & 1.353 & 2.045 \\
\hline 1983 & 1.156 & $1+430$ & 1.240 & 1,264 & $1 . x_{i}$ & 1,178 & 1,311 & 1.210 & 1,17 \\
\hline
\end{tabular}

\begin{tabular}{|c|c|c|c|c|c|c|c|}
\hline $\mathrm{IHAF}$ & WA & $\mathrm{VI}$ & WA & $\mathrm{HI}$ & WN & $W Y^{\prime}$ & US \\
\hline & & 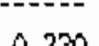 & לויר & & & & $\wedge$ 3ी \\
\hline 140 & 0.194 & 0.220 & 0.3 .5 & 0.179 & 0.221 & 0.230 & $U+2 U /$ \\
\hline 1971 & 0.203 & 0.225 & 0.357 & 0.205 & 0.229 & 0.231 & 0.215 \\
\hline 1772 & 0.204 & 0.228 & 0.375 & 0.214 & 0.232 & 0.266 & 0.25 \\
\hline 1973 & 0.241 & 0.262 & 0,403 & 0.249 & 0.260 & 0.285 & 0.253 \\
\hline 1974 & 0.372 & 0,407 & 0.469 & $0+3 \%$ & $0.3 \mathrm{FT}$ & 0.416 & 0.304 \\
\hline 1975 & 0,404 & 0.407 & 0.488 & 0.400 & $0.4 \overline{C B}$ & 0,428 & 0,42 \\
\hline 178 & 0.400 & 0,452 & 0.543 & 0.419 & 0,483 & 0.457 & 0.149 \\
\hline 1977 & 0.497 & 0.506 & 580 & 0,470 & 0.519 & 0,451 & 0.509 \\
\hline 1973 & 0.521 & 0.541 & 0.5 .1 & $5+513$ & 0,545 & 0.53 & 0.544 \\
\hline 1979 & 0.707 & 0.719 & $11+873$ & 6.32 & 0.753 & 0.581 & 0.776 \\
\hline 1900 & $1+0 \%$ & 1.100 & 1.3 .8 & 1.095 & 1.145 & 1.055 & 1.377 \\
\hline 1491 & 1.354 & $1+422$ & 1.550 & $1+344$ & 1,442 & 1.343 & 1.422 \\
\hline 1982 & 1.342 & 1.454 & \pm .35 & 1.307 & 1.429 & 1.349 & 1,000 \\
\hline \multirow[t]{2}{*}{1903} & $\$ .205$ & $1+264$ & 1.429 & $1+200$ & 1.294 & 1.257 & $1+255$ \\
\hline & & & & B. & & & \\
\hline
\end{tabular}


TABLE B.20. Kerosene Prices: Industrial Sector ( $\$ /$ ga 1$)$

\begin{tabular}{|c|c|c|c|c|c|c|c|c|c|}
\hline TEAT & $A K$ & Al & $A F$ & $\dot{A} 7$ & $C A$ & $\infty$ & CT & $7 d:$ & $\mathrm{D} \Gamma$ \\
\hline$+\infty$ & -----"- & 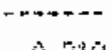 & 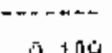 & 4 & 02 & 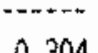 & & 4702 & $B+81$ \\
\hline $\begin{array}{l}1970 \\
1971\end{array}$ & $\begin{array}{l}0.0 \\
0.0\end{array}$ & $0.11 \%$ & $\begin{array}{l}0+104 \\
5.181\end{array}$ & $\begin{array}{l}0.391 \\
0.365\end{array}$ & $\begin{array}{l}0.348 \\
0.371\end{array}$ & $\begin{array}{l}0.204 \\
0.200\end{array}$ & $\begin{array}{l}0,24 \\
0,25\end{array}$ & $\begin{array}{l}0.25 \\
0.240\end{array}$ & $\begin{array}{l}0,181 \\
0,104\end{array}$ \\
\hline 1972 & 0.0 & 0.220 & $0+760$ & 0.330 & 0.400 & 0.210 & 0.228 & 0.20 & 0.20 \\
\hline 1973 & 0.0 & 0.262 & $G_{1} 227$ & 0,346 & 0.479 & 0.246 & 4.262 & $0,2 \%$ & 1,25 \\
\hline 1774 & 0,0 & 0,34 & 0.371 & 0.555 & 0.721 & 0.367 & 0.407 & 0.397 & 0.345 \\
\hline 1975 & 0.0 & 0.447 & 0,378 & 0.628 & 0.685 & 0.399 & 0.427 & 1,454 & 0,454 \\
\hline 1376 & 0.0 & 0.480 & $0.3 \div 1$ & 0.519 & 0.701 & 0,431 & 0.452 & 0.443 & 0,443 \\
\hline 1977 & 0.0 & 0.520 & {$\left[1,4 \sigma_{0}^{2}\right.$} & 0,705 & $0.7 / 3$ & 0.484 & 0.507 & 0.521 & 0.521 \\
\hline 1978 & 0,0 & 0.576 & 5,406 & 0.749 & 0.014 & 0.515 & $0 . .3 \mathrm{~d} 2$ & 0,553 & 0,53 \\
\hline 1979 & 0.0 & $0, \$ 43$ & 0 & $1+006$ & 1.163 & 0.691 & 0.721 & 0,747 & 0.747 \\
\hline 190 & 0.0 & 1,245 & 1,343 & 1.578 & 1.756 & 1.079 & 1.102 & 1.156 & $1+152$ \\
\hline 1981 & 0.0 & 1.528 & $1+i g 1$ & 1,727 & 2.054 & $1+324$ & 1.426 & $\therefore 447$ & 1,447 \\
\hline 1722 & 1.317 & 0.767 & 0.497 & 0.949 & 1.055 & 0.873 & $1+151$ & $1+194$ & $2+450$ \\
\hline 1483 & 1.060 & 0.890 & 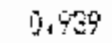 & 0,966 & 0.705 & 0,760 & $1+099$ & 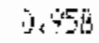 & 1,40 \\
\hline
\end{tabular}

\begin{tabular}{|c|c|c|c|c|c|c|c|c|c|}
\hline PEAK & $F$ & CAA & HI & IA & ID & IL & IN & $\mathrm{IS}$ & $W$ \\
\hline - & 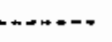 & ----.. & - & 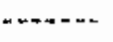 & $\cdots$ & ------- & -nate- & $-\cdots-$ & 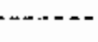 \\
\hline 1970 & 0.220 & 0,200 & $10.3 \%$ & $0.2 \mathrm{i} 2$ & 0.337 & 0,222 & $0.2 \% 5$ & $0+15$ & 0,234 \\
\hline 1971 & 0.216 & 0.207 & $i, 4 E 7$ & 0.219 & 0.326 & 0.227 & 0,205 & 0.193 & 0,215 \\
\hline 1976 & 0.216 & 0.222 & 0,488 & 0.219 & 0,477 & 0.225 & 0.107 & $9+19 y$ & $6+217$ \\
\hline 1973 & 0.248 & 0.254 & $\pi, 487$ & 0.251 & 0.434 & 0.259 & $0.23 \mathrm{E}$ & 0,235 & $0, Z^{2}$ \\
\hline 1974 & 0,400 & 0,401 & 0.5 .9 & 0.375 & 0.536 & 0.386 & 0.302 & $0+345$ & 0.39 \\
\hline 1975 & 0,442 & 0,452 & in 70 & 0.403 & 0.551 & 0.429 & $0,4=0$ & 0,354 & $a+42$ \\
\hline 1976 & 0.480 & 0,454 & 0,760 & $0,44^{0}$ & 0.588 & 0.452 & 0,434 & 0.407 & 0.446 \\
\hline 1977 & 0.547 & 0.538 & $6,8=9$ & 0.504 & 0.646 & 0.527 & 0.517 & 0,478 & 0.466 \\
\hline 1978 & 0.585 & 0.576 & $0+3 \% 4$ & 0.536 & 0.689 & 0.552 & $\hat{0}+342$ & 0.565 & $0+539$ \\
\hline 1479 & 0.793 & 0.781 & 1.277 & $0+738$ & $0 ., 09$ & 0.788 & $U_{1}:$ & 0.700 & 0.397 \\
\hline 1980 & 1.206 & 1.187 & 1,728 & 1.095 & 1,441 & 1.178 & $1+157$ & 2,138 & 1,16 \\
\hline $1 \div 91$ & 1.526 & $1.5 \times 2$ & 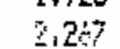 & 1.421 & 1,769 & 1,446 & 1,420 & $1,34 \mathrm{E}$ & 1,430 \\
\hline 1782 & 1.061 & $1+052$ & 1.357 & 0.972 & 1,101 & 0.957 & 0,713 & 0,915 & .007 \\
\hline 1483 & 0,97 & 0.936 & 5,5 & W., & 1.040 & 0.978 & i. 444 & 0.709 & 10,2 \\
\hline
\end{tabular}

\begin{tabular}{|c|c|c|c|c|c|c|c|c|c|}
\hline IHAK & LA & THA & ins & 邽 & $|x|$ & $\mathrm{N}$ & 浿 & 滥; & $T T$ \\
\hline 1070 & 0.716 & & & 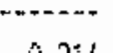 & 91 & & 4 & 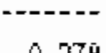 & 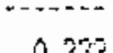 \\
\hline $\begin{array}{l}7719 \\
1 \% 71\end{array}$ & $\begin{array}{l}0.216 \\
0.228\end{array}$ & $\begin{array}{l}0.214 \\
0.225\end{array}$ & $\begin{array}{l}0.203 \\
i .240\end{array}$ & $\begin{array}{l}0.226 \\
0.225\end{array}$ & $\begin{array}{l}0.211 \\
0.208\end{array}$ & $\begin{array}{l}0.205 \\
0.208\end{array}$ & $\begin{array}{l}0,1,3 \\
0,211\end{array}$ & $\begin{array}{l}0.274 \\
0.288\end{array}$ & $\begin{array}{l}0.212 \\
0.241\end{array}$ \\
\hline 1972 & 0.237 & 0.228 & 0.227 & 0.228 & 0.212 & 0.212 & $0.2: 3$ & 0.295 & 0.245 \\
\hline 1073 & 0.274 & 0.262 & {$[, 2,7]$} & 0.262 & 0.257 & 0.242 & $0.24 \pi$ & 0,306 & 0.291 \\
\hline 1974 & 0.437 & 0.407 & 0.397 & 0,407 & 0,405 & 0.374 & 0.375 & 0.427 & 0.416 \\
\hline 1975 & 0.461 & 0.427 & $\overline{1}, 454$ & 0.427 & 0.421 & 0.373 & 0.249 & 0.513 & 0.427 \\
\hline 1076 & 0.511 & $\hat{0}, 452$ & 0.443 & 0.452 & 0.435 & $0+424$ & 0.425 & 0.553 & 0,450 \\
\hline 1977 & 0.596 & 0.507 & 0.551 & 0.507 & 0.510 & 0.449 & 0 & 0.59 & 4.5 \\
\hline 1778 & $0.62 k$ & 0.542 & 0.753 & 0,542 & $0.5 \mathrm{~s}$ & 0.531 & 0.526 & 0,61 & 1) 6 \\
\hline 1979 & $0.6 \%$ & 0.721 & 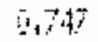 & S.7FE & 0.763 & 0.731 & 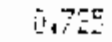 & Who & 9 \\
\hline 1380 & 1.344 & 1.102 & 1.156 & $\therefore 10 \%$ & $1+140$ & 1,004 & 1.075 & 1,49 & 1.1 .80 \\
\hline 1981 & 1.522 & 1.426 & $1,4+17$ & 1,426 & 1.400 & 1.408 & $1: 3 \%$ & 1,75 & 1,32 \\
\hline 1722 & 0.828 & 1.187 & 1,60 & \pm .196 & 0.964 & 1.017 & 0.708 & 0.945 & 5,072 \\
\hline 1983 & 0.436 & 1.004 & {$[1,98$} & 1,055 & 0.987 & 0,898 & 0,909 & 1.867 & 1,000 \\
\hline
\end{tabular}


TABLE B.20 (CONT). Kerosene Prices: Industrial Sector ( $\$ / g a 7)$

\begin{tabular}{|c|c|c|c|c|c|c|c|c|c|}
\hline YOAK & $H C$ & WII & $\mathrm{XNE}$ & 㖄 & $\mid+k 1$ & 㸱 & hy & $\mathrm{MH}$ & UH \\
\hline 1970 & 0,189 & 0.223 & 0.107 & 0.213 & 0,232 & 0.201 & 0.451 & $0+21$ & $0+19$ \\
\hline 1971 & 0.196 & 0.220 & 0,188 & 0.225 & 0.239 & 0.201 & 0.468 & 0,225 & 0.001 \\
\hline 1772 & 0.200 & 0.220 & $4+187^{\circ}$ & 0,228 & 0.245 & $0.20 \times$ & 0.443 & 0,223 & 0,200 \\
\hline 1475 & 0.239 & 0.255 & $\sqrt{1}, 254$ & $0,2 \mathrm{~N}^{2}$ & 0.293 & 0,241 & $\tilde{0}+46$ & 1,273 & 0.230 \\
\hline 1974 & 0.369 & 0,361 & 0.356 & 0,407 & 0.445 & 0.388 & 0.623 & 0.410 & 0.379 \\
\hline 1975 & 0.399 & 0.363 & $19+370$ & 0.487 & 0.474 & $\hat{0}, 411$ & 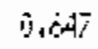 & $\hat{0}_{1}, 44_{2}$ & 1.391 \\
\hline 1976 & 0.432 & 0.403 & 0,410 & 0,452 & $0.51 \hat{0}$ & 0.430 & 0.544 & 0,463 & 0,420 \\
\hline 1477 & 0.488 & 0.460 & {$[470$} & 3,507 & 0.57 & 0.492 & 3.734 & 0.522 & 4,403 \\
\hline 1979 & 0.522 & 0.487 & 0.490 & 0.542 & 0,605 & 0.513 & 0,700 & 0.554 & 6.512 \\
\hline 199 & 0,708 & 0.673 & 0,480 & $0,7 \pm 1$ & 0.822 & 0,694 & 1,004 & $\sqrt{1}+3_{2}$ & 3,700 \\
\hline $1 ; 80$ & 1.077 & 0.980 & 1,020 & $i+102$ & $1+254$ & 1.076 & 1,542 & 1.148 & 1.493 \\
\hline $19 \mathrm{at}$ & 1.362 & 1.277 & 1,35 & 1,486 & 1.604 & 1,320 & 2.006 & 1.460 & 1,340 \\
\hline$i=02$ & 1.028 & $1+163$ & 0.724 & $1 . \div 8$ & $i+111$ & 1,27 & $1+143$ & $1.1+4$ & $9+5$ \\
\hline 1983 & 0.742 & $0 . \% 21$ & 0,96 & $1.02 B$ & $0+727$ & 0.415 & $0, \%$ & 5.977 & 0,64 \\
\hline
\end{tabular}

\begin{tabular}{|c|c|c|c|c|c|c|c|c|c|}
\hline IESAF' & ok & $\mathrm{OK}$ & $F ' A$ & Rit & $\mathrm{SC}$ & SD & $\mathrm{TH}$ & $T i$ & $\mathrm{iT}$ \\
\hline$\cdots$ & - & - & n...n-s & - & . & - non- & - & 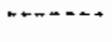 & $\cdots$ \\
\hline 1970 & 0.191 & $0.37 \pi$ & 0,212 & 0,230 & 0.213 & 0.211 & 0,84 & $3+178$ & 0.35 \\
\hline 1971 & 0.195 & 0,403 & 0.219 & 0.225 & 0.216 & 0.213 & $0,2 \mathrm{k}$ & D. 180 & 0.40 \\
\hline 1572 & 0.191 & 0.440 & $0.2 \%$ & 0.228 & 0.218 & 0.218 & 0.26 & $9+190$ & 0,40 \\
\hline $\pm 9 \% 3$ & 0.226 & 0.454 & 0.246 & 0.262 & 0.256 & 0.243 & 0.25 & 0.216 & 0.402 \\
\hline 1874 & 0.376 & 0.506 & $0.3 \%$ & 0.407 & 0,403 & 0.375 & 0.427 & 0.364 & 0.321 \\
\hline 1075 & $0.38 B$ & 0.516 & 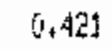 & 0.457 & 0.426 & 0.393 & 0,457 & 5,458 & 0.496 \\
\hline 1976 & 0.417 & 0.522 & $\hat{n}+440$ & 0.452 & 0.447 & 0,424 & 0.465 & 0.424 & 0.644 \\
\hline $1 \% 7$ & 0.479 & 0.581 & 0.499 & $0.5 \times 7$ & 0.507 & 0.498 & 0.515 & $\mathrm{j}, 501$ & 1.744 \\
\hline 1078 & $0.50 \mathrm{H}$ & 0.612 & $0,5,5$ & 0.542 & 0.542 & 0.518 & $\hat{0} .574$ & 0.526 & $9+7 \%$ \\
\hline 1979 & 0.710 & 0.874 & 5,713 & 0.721 & 0.736 & 0.714 & 0,995 & 0.755 & 2.047 \\
\hline $1 \geqslant 80$ & 1.077 & $1+317$ & 1.009 & 1.102 & $i+11 \bar{y}$ & 1.054 & $1+2+4$ & $1,12 \%$ & $\therefore .550$ \\
\hline 1981 & 1.227 & 1.551 & $1,3 i_{i}$ & $1+426$ & 1.415 & 1.375 & 1.526 & 1.278 & 2,00 \\
\hline $1 \% 02$ & 0.955 & 1,096 & $1+9 \%$ & 1.199 & 1.009 & 1,083 & 0.792 & 1.703 & $1+255$ \\
\hline log & 0.970 & 0.972 & 0,457 & $1+104$ & 0.939 & 0.921 & $B, 20$ & 3,98 & 1,600 \\
\hline
\end{tabular}

\begin{tabular}{|c|c|c|c|c|c|c|c|}
\hline $\mathrm{YEAH}$ & VA & $V T$ & WA & WI & WN & $w i$ & U5 \\
\hline- & 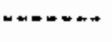 & -...... & - & - & name & - & 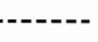 \\
\hline 1970 & 0.145 & 0.220 & 0.333 & 0.199 & 0.221 & 0.230 & 0.209 \\
\hline 1971 & 0.203 & 0.225 & {$[1,357$} & 0.205 & 0.229 & 0.291 & 3,216 \\
\hline 1772 & 0.204 & 0.228 & 0.375 & 0.244 & 0.232 & 0.266 & 0.218 \\
\hline $\pm 97 \%$ & 0.241 & 0.262 & 0.403 & 0.249 & 0.260 & 0.285 & 0.254 \\
\hline 1974 & 0.372 & 0.407 & 0.4 .8 & 0.374 & 0.35 & 0.416 & 0.400 \\
\hline 175 & 0.404 & 4,427 & D. 498 & 0.460 & 0,428 & 0,428 & 0.428 \\
\hline 175 & 0.430 & $0+452$ & 0.344 & $3+4 \pm 5$ & 0.40 & 0,48 & $6+454$ \\
\hline $17 \%$ & 0,599 & 4.507 & 0.580 & 0.451 & 0.521 & 0.492 & 1..5.j \\
\hline$i \div 7 \mathrm{~g}$ & 0.522 & 0,542 & 0,31 & vi $5 \pm 4$ & 0.67 & 0.523 & $\hat{0}+37$ \\
\hline 1975 & 0.709 & $0,7 / 21$ & 0.972 & 0.734 & 0.755 & 0.48 & $0.75 i$ \\
\hline $1 \% 0$ & 1.073 & 1.102 & $1+3.8$ & 1.097 & $i+149$ & 1.097 & 1.127 \\
\hline 1901 & $1+363$ & 1.426 & 1.540 & 1.347 & 1.452 & 1.346 & 1, A 是 \\
\hline 1787 & 1,016 & $1+225$ & 1.108 & 0.960 & $1+005$ & 1,283 & $\hat{y}+994$ \\
\hline \multirow[t]{2}{*}{1983} & 0.924 & $1+026$ & 0.422 & 0.678 & 0.917 & 1.001 & $0.9+1$ \\
\hline & & & & B & & & \\
\hline
\end{tabular}


IABLE B.21. Jet Fuel Prices: Transportation Sector (\$/gal)

\begin{tabular}{|c|c|c|c|c|c|c|c|c|c|}
\hline Ie & AK & Ai & 佔 & $A^{7}$ & $C A$ & $\infty$ & $\mathrm{CH}_{\mathrm{i}}^{\mathrm{m}}$ & If & $\mathrm{TE}$ \\
\hline 1.370 & $\hat{0}+104$ & 0.092 & $0.1: 0$ & 0.109 & 0.104 & 0.100 & $\hat{0}+10$ & $0+100$ & 0.108 \\
\hline $1 \% 71$ & 0.109 & 0.096 & $5+116$ & 0.113 & 0.109 & 0.113 & 0.111 & $0, \leq 13$ & $0.11 \frac{15}{13}$ \\
\hline 1072 & 0.109 & 0.096 & $0.1 \cdot 5$ & $0.1: 3$ & 0.109 & 0.113 & $0.1: 1$ & 0.113 & $0.1 \pm 3$ \\
\hline 1973 & 0.129 & 0.114 & $4+297$ & 0.134 & 0.129 & 0,134 & 0,431 & 9,134 & 0.1 .54 \\
\hline 1974 & 0.222 & 0.196 & $0.2 \%$ & 0.232 & 0,522 & 0.231 & 0.226 & $0,2\}$ & 0.201 \\
\hline 1975 & 0.289 & 0.256 & 0.308 & 0.301 & 0.289 & 0.301 & 1,245 & 3.301 & 0.301 \\
\hline 1776 & 0.32 & 0.276 & 0,35 & 0.331 & 0.327 & 0,331 & 0,322 & 0.30 & 0.320 \\
\hline 1977 & 0.370 & 0.32 & 5,379 & 0.394 & 0.370 & 0.394 & {$\left[\begin{array}{ll}371 \\
7\end{array}\right.$} & 0,378 & 0.37 \\
\hline 1778 & 0.404 & 0.362 & 0.437 & 0.413 & 0,404 & 0.413 & 0.418 & 0,417 & 0.49 \\
\hline 1979 & 0.536 & 0.490 & Th & 0.578 & 0.536 & 0.576 & $3,5=0$ & 0,385 & 0.585 \\
\hline 1780 & 0.978 & 0.804 & 0.771 & 0.932 & 0.878 & 0.932 & 0.756 & $\hat{v} .957$ & 0.557 \\
\hline 1981 & 1.020 & 1.008 & $1+\mathrm{N}=\mathrm{t}$ & 1,095 & 1.020 & $1+035$ & 1.053 & $1,0,0$ & $1,9 \mathrm{E}$ \\
\hline 1982 & 0.946 & $1+002$ & 0.77 & $0.94 \%$ & 0.996 & 0.946 & 1.913 & 0.969 & 0.969 \\
\hline 5792 & 0.903 & 0.851 & 4.851 & 0,703 & 0.703 & $3+494$ & Whe & 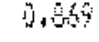 & $3+28$ \\
\hline
\end{tabular}

\begin{tabular}{|c|c|c|c|c|c|c|c|c|c|}
\hline YEAF' & FL & $G A$ & $H I$ & IA & ID & iL & iN & 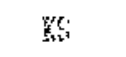 & $\mathrm{rif}$ \\
\hline$+\infty$ & - & ---- & $\cdots$ & N+N- & --- & $\ldots+\ldots$ & $\cdots+\cdots$ & - & $\cdots$ \\
\hline 1970 & 0.100 & 0.108 & 0.104 & 0.109 & $0+108$ & 0.165 & 0.105 & 0.109 & 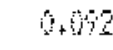 \\
\hline 1971 & 0.113 & 0.113 & 0.109 & 0.114 & 0.113 & 0.110 & $\hat{y}+10$ & i).114 & $0.0 \%$ \\
\hline 1972 & 0.113 & 0.113 & $10+108$ & 0.114 & 0.113 & 0.104 & 0,109 & 0.114 & $0.9 \%$ \\
\hline 1973 & 0.134 & 0.134 & $i_{1} .299$ & 0.155 & 0.134 & 0,130 & 0.150 & 5.35 & 0.114 \\
\hline 1974 & 0.231 & 0.231 & 0.222 & 0.233 & 0.231 & 0.224 & 0.224 & 0.26 & 0.196 \\
\hline 1975 & 0.301 & 0.301 & 0,285 & 0.304 & 0.301 & 0.272 & 0.292 & $\sqrt{4}, 34$ & $i, 25$ \\
\hline 1775 & 0.320 & 0.320 & 0.30 & 0.332 & 0.331 & 0.330 & 0.330 & 0.332 & 0.276 \\
\hline 1977 & 0.378 & 0.378 & 0.370 & 0.389 & 0.384 & 0.373 & 4.35 & 3,389 & 0.31 \\
\hline 179 & $0.41 \%$ & 0.419 & 0.404 & 0.420 & 0.433 & 0.402 & 0.402 & 0.420 & 0.362 \\
\hline 1979 & 0.585 & 0.585 & 0.536 & 0.583 & 0.578 & 0.549 & 0.549 & i. .5 .3 & $0.4 \%$ \\
\hline 1.700 & 0,957 & 0.757 & 0.978 & 0.933 & 0.932 & 0.893 & 0.993 & $\hat{x}+73$ & $6+404$ \\
\hline 1481 & 1.028 & $1.02 \mathrm{~B}$ & 1,020 & 1.075 & 1.035 & 1.019 & 1.019 & 1.096 & +1000 \\
\hline 1982 & $\hat{0}+960$ & 0.969 & $0.5 \% 6$ & $\hat{0} .571$ & 0.986 & 0.975 & 0.975 & 0.971 & $1+102$ \\
\hline 1483 & 0.863 & 0.863 & 5,403 & $0,88_{2}^{2}$ & 0.899 & $0.8 \mathrm{BC}$ & $0,2 \mathrm{BZ}$ & $0,98 z$ & 5,402 \\
\hline
\end{tabular}

\begin{tabular}{|c|c|c|c|c|c|c|c|c|c|}
\hline YEAF & IA & Wh & 10 & "TE & 邽 & $\mathrm{IN}$ & 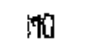 & ins & : \\
\hline$\cdots$ & ....... & -...-- & ------ & n....... & m.n. & -- & & $m+$. & \\
\hline 1970 & 0.110 & 0.106 & 0.108 & 0.106 & 0.105 & 0.109 & 0.104 & $0.0 \% 2$ & 0.108 \\
\hline 1971 & 0.116 & 0,111 & 6.113 & $0+111$ & 0,110 & 0.114 & 0.114 & 0,096 & $0.0+5$ \\
\hline 1972 & 0,115 & 0.111 & 0.1 .3 & 0.111 & 0.107 & 0.114 & 0.114 & 0.096 & 0.113 \\
\hline $1 \% 7$ & 0.137 & 0.131 & 0.134 & 0.131 & 0.130 & 0.135 & 0.135 & 0.114 & 0.134 \\
\hline 1974 & 0.236 & $0+226$ & 0.231 & 0.226 & 0.224 & 0.233 & 0.230 & $0.1 \%$ & 0,231 \\
\hline 1975 & 0.308 & 0.295 & 0.305 & 0.295 & 0.282 & 0.304 & 0.392 & 0.256 & 0.301 \\
\hline 1976 & 0.325 & 0.322 & 0.320 & 0.322 & 0.330 & 0.332 & 0,372 & 0.276 & 0,35 \\
\hline 1977 & 0,379 & 0.371 & 0.378 & 0.371 & 0.373 & 0.389 & 0,345 & 5.32 & (1. \\
\hline 1978 & 0.437 & 0.418 & 0,419 & 0.419 & 0.402 & 0.420 & 0.420 & 0,342 & 0,113 \\
\hline $17 \%$ & 0,605 & 0.560 & $0,5 \mathrm{~F}$ & 0,560 & 0.549 & 0.593 & $7+2 g^{\circ}$ & 5,490 & $0+78$ \\
\hline 1960 & 0,971 & 0.916 & 0.957 & $0.9 \mathrm{jh}$ & 0.993 & 0,953 & $0+33$ & 0,204 & $i_{1}, \bar{Q}$ \\
\hline $108 !$ & 1,026 & 1.053 & 1,$0 ; \varepsilon$ & 1.053 & 1.019 & 1.036 & 1.080 & 1,008 & 1.09 \\
\hline 1782 & 0.957 & $1+013$ & $0.96 \%$ & 1.013 & 0.475 & 0.971 & 0.77 & $1+002$ & 0.94. \\
\hline 1983 & 0.851 & 0,129 & 1,45 & 0.929 & 0.882 & 0.882 & $1.08 i$ & 0.351 & 0.67 \\
\hline
\end{tabular}


TABLE B.21 (CONT). Jet Fuel Prices: Transportation Sector ( $\$ /$ gal)

\begin{tabular}{|c|c|c|c|c|c|c|c|c|c|}
\hline YEAF & $\mathrm{NC}$ & HWD & WE & $\mathrm{KH}$ & 成了 & 州 & 洲 & $\mathrm{MI}$ & $\mathrm{HH}$ \\
\hline$\cdots$ & $\cdots$ & -....... & ........ & 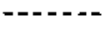 & $\cdots$ & $\cdots$ & -- & -...... & \\
\hline 1770 & $0+109$ & 0.109 & 0.109 & 0.106 & 0.10 .3 & 0.108 & 0.108 & 0,103 & 0.105 \\
\hline $1 \% 1$ & 0.113 & 0.114 & $4+114$ & 0.111 & 0.108 & 0.113 & 0.2its & iv: 408 & 1110 \\
\hline 1772 & 0.113 & 0,114 & 0.114 & 0.111 & 0,108 & 0.113 & 0.113 & $0+105$ & $0.10 \%$ \\
\hline 1973 & 0,134 & 0.135 & 0.135 & 0.151 & 0.128 & 0.134 & $0.12 c$ & 0.29 & 0.130 \\
\hline 1074 & 0.231 & 0.239 & 0.253 & 0.226 & 0.221 & 0.231 & 0.231 & $0+221$ & 0.224 \\
\hline 1975 & 0.301 & 0.304 & 0,36 & 0.295 & 0.288 & 0.301 & 0,301 & 3235 & $0.2 \%$ \\
\hline 1976 & 0.320 & 0.332 & 0.332 & 0.322 & $\sqrt[0]{4} 312$ & 0.331 & 0.391 & 0.312 & 0,30 \\
\hline 1977 & $0.37 \mathrm{a}$ & 0.399 & 5399 & $0,37 i$ & 0.359 & 0.394 & $\bar{v} .384$ & 0,35 & 0.373 \\
\hline 1779 & $0.41 \%$ & 0.400 & $0+420$ & 0.418 & 0.408 & 0.413 & 0.413 & $\hat{0}+408$ & 0.402 \\
\hline 199 & 0.585 & 0.583 & 0,583 & 0.560 & 0.551 & 0.578 & 3.56 & 5.55 & U. \\
\hline 1000 & 0.957 & 0.939 & $0.7,3$ & 0.956 & 0.397 & 0.932 & 0,732 & 0.947 & 0.40 \\
\hline 1481 & $1.02 B$ & 1.006 & 1.006 & 3.053 & 1.011 & 1.035 & 1,05 & 201 & 2,61 \\
\hline 1902 & $3+769$ & 0.771 & 0.978 & $\therefore+413$ & 2,747 & 0,746 & 0,70 & og & 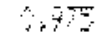 \\
\hline 183 & 0.063 & 0.892 & î, & $0,7 \%$ & 0.869 & $0,4=1$ & 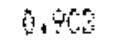 & 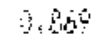 & id. \\
\hline
\end{tabular}

\begin{tabular}{|c|c|c|c|c|c|c|c|c|c|}
\hline TEAK & ax & iR & $P A$ & $\mathrm{Kt}$ & SC & SD & $\mathrm{TN}$ & $D$ & !t \\
\hline 1970 & $0.1 \pm 0$ & 0.104 & 0.103 & 0.105 & 0.108 & 0.199 & 0,32 & 0.110 & मी० \\
\hline 1971 & 0.116 & 0.109 & 0.06 & 0.11 & 0.113 & 0.114 & 5,076 & 0.116 & 0,115 \\
\hline 1772 & 0.115 & 0.108 & 0.108 & 0.111 & 0.113 & 0.114 & $0.09 \%$ & $0+15$ & 0.113 \\
\hline 1973 & 0.137 & 0.129 & 5.56 & 0.131 & 0.134 & 0.135 & 0.214 & $0.13 \%$ & 0.134 \\
\hline 1974 & 0.236 & 0,222 & 0.221 & 0.226 & 0.231 & 0.253 & 0.196 & 0.235 & 0.251 \\
\hline 1475 & $0.30 \mathrm{~B}$ & 0.289 & 0.288 & 0.275 & 0.301 & 0.304 & $0 . \approx 6$ & 0,300 & 0,31 \\
\hline 1976 & 0.325 & $0,3 \alpha \gamma$ & 0.3 .2 & 0.322 & 0.320 & 0.332 & 0.276 & 0.35 & 0.331 \\
\hline 1977 & 0.379 & 0.370 & $i, 359$ & 0.371 & 0.378 & 0.339 & $0,32 \mathrm{i}$ & 4.379 & 0.394 \\
\hline 1778 & 0,43 & 0.404 & 0.408 & 0.418 & 0.419 & 0.420 & 0.362 & $\hat{0}+437$ & 0.413 \\
\hline 1979 & 0.605 & 0.536 & 0.551 & 0.560 & 0.585 & 0.533 & 0.490 & 0,60 & 0.978 \\
\hline 1980 & 0.971 & 0.878 & $0.8 \%$ & 0.916 & 0.957 & 0.933 & 0.304 & $0 \% 1$ & 0.96 \\
\hline 1481 & 1.026 & 1.020 & 1.011 & 1.053 & $1,02 B$ & 1.036 & i. $00 \mathrm{~W}$ & 1.026 & 1,05 \\
\hline$\triangle 7 B 2$ & 0.957 & 0,596 & 0.947 & 1,013 & 0.969 & 0,771 & $1+02$ & 0.857 & 0,46 \\
\hline $1 \% 63$ & 0.882 & 0.403 & 609 & 0.95 & 0.463 & 0.882 & 0,89 & $j: 8 \%$ & 0,90 \\
\hline
\end{tabular}

\begin{tabular}{|c|c|c|c|c|c|c|c|}
\hline YEA & VA & $v$ & WA & WI & $W$ & Híl & US \\
\hline & & & & & & & \\
\hline 1770 & 0.108 & 0.106 & 0.104 & 0.105 & 0.108 & $0+108$ & 0.105 \\
\hline 1971 & 0.113 & 0.111 & $0.10 \%$ & 0.110 & 0.113 & 0.113 & $0 . \$ 10$ \\
\hline 1772 & 0.113 & 0.111 & 0.108 & 0.107 & 0.113 & 0.113 & $\hat{0}+110$ \\
\hline 197 & 0.134 & 0.131 & 0.29 & 0.130 & 0.134 & 0.134 & 0.131 \\
\hline 1974 & 0.231 & 0.226 & $0.2 \%$ & 0.224 & 0.231 & 0.231 & 0.225 \\
\hline 1975 & 0.301 & 0.25 & 0.24 & 0.32 & 0,301 & 0.301 & $0,2 \% 4$ \\
\hline 675 & $0+320$ & 0.322 & $0.35 \%$ & 3,300 & 0.320 & $0+35$ & 0.328 \\
\hline 197 & 4.37 & 0.371 & 1,50 & 3,3 & $0.37 \mathrm{~B}$ & 0,304 & $0,3 j$ \\
\hline 198 & $0.41 \%$ & 0.458 & 0,404 & 0,402 & 0.417 & 0.413 & $\hat{0}+4 \dot{1} 1$ \\
\hline 1979 & 0.585 & 0.500 & 0.536 & 0.549 & 0.585 & 0.578 & 3.56 \\
\hline 1780 & 0,457 & $10+316$ & 0.875 & $\hat{0}, 395$ & 0.757 & 0,43 & 0.913 \\
\hline $1 \% 91$ & $1.02 \mathrm{~B}$ & 1.053 & 1.030 & 1.019 & 1.028 & 1.0035 & 1,024 \\
\hline 1702 & 0.969 & 1,013 & 0.996 & 0.775 & $0.98 \%$ & 0.896 & 0.976 \\
\hline 1963 & 0.663 & 0,32 & 1,903 & 0.892 & 0.863 & 0.899 & 0.975 \\
\hline
\end{tabular}


TABLE B.22. Residual Fuel Prices: Commercial Sector ( $\$ / b b 1)$

\begin{tabular}{|c|c|c|c|c|c|c|c|c|c|}
\hline 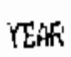 & $A{ }^{2}$ & $A L$ & $A H^{\prime}$ & $A \bar{Z}$ & CA & {$[\bar{j}$} & $\mathrm{CT}$ & $B C$ & DE \\
\hline$\cdots$ & - & $\cdots$ & $\cdots$ & $\cdots$ & 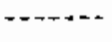 & 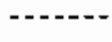 & ......... & $\cdots$ & \\
\hline 1970 & 2.806 & 3,344 & 2.366 & 2.563 & 2.841 & 2.415 & 2,793 & 4,202 & 3.247 \\
\hline 1971 & 3.749 & 4,23 & 37722 & 3.753 & $3+8 j 1$ & 3.384 & $3+646$ & 5,481 & $4+2.24$ \\
\hline 1972 & 4,064 & 4.489 & 3,957 & $3+836$ & 3.952 & 3.590 & 4,318 & 5.927 & 4.525 \\
\hline 1973 & 4.898 & 5.278 & $4,7 \pm 2$ & 4.707 & 4.716 & 4.570 & 5.39 & $7+4 \overline{4}$ & 5.40 \\
\hline 1974 & 9,715 & 11.105 & 9,796 & 8.487 & 10.604 & 10.011 & 13.007 & 14,715 & 12,117 \\
\hline 1975 & $11+892$ & 11.197 & 10.481 & $12+, 005$ & $10+245$ & 9.193 & $13+631$ & 16.5015 & $11+95$ \\
\hline 1976 & 12,182 & 11.015 & 10.5 .55 & 12,132 & 10,130 & 11.474 & 13,223 & 15.966 & 11,54 \\
\hline 197 & $12+242$ & 12.757 & 11.747 & 12.706 & 12.149 & $11+881$ & 14,443 & $154 \%$ & 13454 \\
\hline 1978 & 12.104 & 12.498 & $1 \hat{3}+680$ & 13.518 & 11.327 & 12.407 & $\$ 4,560$ & 20,321 & 13.204 \\
\hline 1979 & 16.850 & 16.719 & 10.057 & 16.322 & 15.809 & 19.345 & $23+3 \%$ & $2 \bar{Y}+54$ & $20+30$ \\
\hline 1980 & 30.403 & 22,308 & 21.535 & 28.904 & 23.100 & 27.937 & $3 j+244$ & 30.064 & 30.614 \\
\hline$\$ 81$ & 37.375 & $31+879$ & $30+675$ & $32+322$ & $30,20 \times 5$ & $24+894$ & 40.227 & $54+165$ & $34.41 \%$ \\
\hline \pm 982 & 31.774 & 27.133 & 20,419 & 30,854 & 28,305 & 24,680 & 32,454 & $4+5003$ & 29,410 \\
\hline $1 ; 8$ & 0.0 & $25,9 \mathrm{gl}$ & $Z_{H}+A_{Z i}$ & 32,082 & $37+312$ & $28+210$ & $2 B+247$ & 28.120 & 27.72 \\
\hline
\end{tabular}

\begin{tabular}{|c|c|c|c|c|c|c|c|c|c|}
\hline YEAK' & $F I$ & GA & $H I$ & IA & ID & iL & Ij & IS & $\mathrm{Ii}$ \\
\hline & & & & & & - & $\cdots$ & - n...... & \\
\hline 1970 & 2.112 & 2.289 & 3.350 & 3.358 & 2.455 & $3+585$ & 2,739 & 2.75 & 2.513 \\
\hline 1971 & 3.211 & 3.283 & 4.386 & 4,346 & 3.518 & 4.540 & 3.804 & $3711 E$ & $3+45$ \\
\hline 1972 & 3.365 & 3,587 & 4.630 & 4,674 & 3.929 & 5.012 & 4,100 & 5,84 & 4,030 \\
\hline 1973 & 4.224 & 4.474 & 5.505 & $5+572$ & 4,929 & 5.489 & 5.018 & 4,785 & 5.06 \\
\hline 1974 & 4.254 & 11.300 & 10.762 & 11.259 & 13.549 & 13.621 & $1 \pm, 749$ & 9,725 & $+5+415$ \\
\hline 1975 & 11.259 & 10.870 & $12+322$ & 12.312 & 12.895 & 13.723 & 51,744 & 12.01 & 10500 \\
\hline 1976 & 10,928 & $\$ 1.080$ & 12.667 & $13+456$ & 10.595 & 13.203 & $1: A 34$ & 11,747 & +20165 \\
\hline 1977 & 12,901 & 13.406 & 13.468 & 13.645 & $13+633$ & 14.766 & $1.3+2 \%$ & 12,70 & $15,9 B$ \\
\hline 1978 & 11.811 & 12.124 & 13.741 & 13,942 & 15.264 & $14+658$ & 14,123 & $5: 993$ & 14,570 \\
\hline 1979 & 17.819 & 16.576 & 20.492 & $17+840$ & 17.500 & 20.553 & $19+354$ & 16.045 & 19,467 \\
\hline 1780 & 25.12 & $25+125$ & 27,948 & 21.046 & 27,476 & $27+640$ & 25,067 & 29,295 & $70,+50$ \\
\hline 1981 & 30.207 & 31,454 & 35.486 & 31,644 & 36.278 & $34+826$ & $31.2 \mathrm{H1}$ & $36.5 \mathrm{in}$ & $3+2$ \\
\hline 1982 & 26.564 & 20.107 & 39.205 & 5.735 & 33.457 & 29,461 & 26.772 & 25,060 & $32+144$ \\
\hline 1983 & $26.81 \mathrm{i}$ & 27.603 & $34+410$ & $2 \%, 347$ & 32.805 & 30.859 & 32,05 & 20,644 & 30,315 \\
\hline
\end{tabular}

\begin{tabular}{|c|c|c|c|c|c|c|c|c|c|}
\hline IEAF & I.A & $M A$ & 910 & $M E$ & MI & 挑 & MD & 45 & 㹥 \\
\hline ---- & ......- & -- & -- & $\cdots$ & 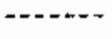 & & $\cdots$ & & \\
\hline 1970 & 3.612 & 3.062 & $2+552$ & 2.275 & 3.043 & 2.852 & 2.711 & $1+68$ & 3,62 \\
\hline$\$ 71$ & 4,305 & $4,35 t$ & 3,998 & 3.364 & 4.172 & 3,927 & 4,000 & 3.597 & 3.242 \\
\hline 1772 & $4+696$ & 4.479 & 4,349 & 3.265 & 4.367 & 4,096 & $4, \because 94$ & 3.831 & 4,479 \\
\hline$: 573$ & 5,445 & 5,443 & 5.360 & 4.611 & 5,271 & 4,948 & 5.055 & 4,651 & 5,443 \\
\hline 1974 & 11,714 & 12.303 & 12.762 & 11.749 & 11,075 & 10.717 & 10.277 & 10,350 & $1=+34$ \\
\hline 9975 & 11.054 & 13.212 & 13.375 & 11.668 & 12.721 & 5.1 .177 & 11.598 & 11,351 & 3,206 \\
\hline 1176 & 11.212 & $12+657$ & $12+627$ & 11,414 & $11+757$ & 11.070 & $11+306$ & 10.474 & 12.774 \\
\hline 1977 & 12,825 & 14.468 & 14,518 & $13+994$ & $\$ 4.107$ & 13.200 & 13.901 & 12,496 & $1,4,60$ \\
\hline 1979 & $11,0.44$ & $13+159$ & +3. 830 & 15.113 & $13+679$ & $13.35 b$ & $13+2 \%$ & 1: & $: 5,34$ \\
\hline 1979 & 17.707 & 21.305 & $23+153$ & 14.848 & 15,362 & 18,181 & 17,517 & $A h_{1}+100$ & 19.62 \\
\hline 1790 & $2 n, 018$ & $30+257$ & $31+31$ & 23.042 & $20.5 \% 6$ & 21,699 & $z_{x}+0 \mathrm{Q}$ & $30+61$ & 2,1 \\
\hline 1981 & 32,120 & 38.39 & 37.206 & 36.384 & 3.320 & 26.521 & $31.6 \mathrm{~W}$ & $5+190$ & 29,604 \\
\hline 192 & $29+774$ & 33.543 & 31.683 & 34,211 & 27,041 & 24,992 & 23.227 & 27.000 & $27+402$ \\
\hline 983 & $21.30 \mathrm{t}$ & 26.355 & 28.267 & 23.020 & $2 \%, 080$ & 22,807 & 26,295 & 25,501 & 20,137 \\
\hline
\end{tabular}


TABLE B.22 (CONT). Residual Fuel Prices: Commercial Sector ( $\$ / b b 1)$

\begin{tabular}{|c|c|c|c|c|c|c|c|c|c|}
\hline YEAT & $B C$ & 149 & NE & 州 & $\mathrm{Nij}$ & Hir & W & 畩 & $\mathrm{gi}$ \\
\hline H. & - & - & $\ldots$ & 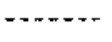 & $\ldots .$. & $\cdots$ & 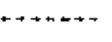 & - & \\
\hline 5970 & 2,405 & 6,050 & $2+453$ & 2,862 & $\overline{3} .288$ & 3.042 & 3,062 & 3.034 & $3+110$ \\
\hline 9971 & 3.722 & 6.729 & $4+162$ & 3.975 & 4.377 & 4,103 & $5.1 \mathrm{LS}$ & $4,1+1$ & 4,244 \\
\hline 1972 & $4+604$ & $3+851$ & $3+413$ & 4.153 & 4,779 & 4,474 & $4: 479$ & 4.453 & 4,590 \\
\hline 1973 & 4,950 & 7.418 & 4,760 & 5,030 & 5.790 & 5.443 & 5.443 & 5415 & 5.594 \\
\hline 1974 & 11.453 & 10.522 & 7.352 & 10.931 & 13.35 & 12,434 & $12+434$ & 11,372 & 12,974 \\
\hline 1975 & 12.353 & 12,445 & 11,197 & $11,9+3$ & 13.795 & $13+20 t$ & 13.206 & 12,920 & $13,92 B$ \\
\hline 1974 & 12.313 & 11.585 & 12.263 & 11,343 & $13,+66$ & 12.774 & 12.774 & 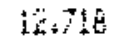 & $2+586$ \\
\hline 197 & 14.344 & 12,417 & 14,736 & 13.432 & 15.385 & 14,330 & $14+230$ & 14,622 & 14,352 \\
\hline 1970 & $13+426$ & 12.760 & $12,87 \mathrm{t}$ & $13+144$ & 14,779 & 13.844 & 13.844 & 14.436 & 15,011 \\
\hline 1979 & 18.814 & 17,715 & 15,936 & 19,442 & 23.459 & 23.564 & 17.500 & 19.699 & $37+242$ \\
\hline 1980 & $27+202$ & $26+176$ & 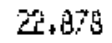 & $38.20 \hat{0}$ & $34+304$ & 35.977 & 27.379 & $7+6 z$ & 24.184 \\
\hline 361 & 34.450 & $30+980$ & 31.900 & 3.415 & 40,341 & 44.227 & $36+54$ & 37.060 & $33.8 \mathrm{~K}$ \\
\hline $1 \% a z$ & $\not, 7 \not 21$ & 24.377 & $30+0 \% 0$ & 31,091 & 34.656 & $37+721$ & $3+\overline{7} 400$ & 31,74 & $0+6$ \\
\hline 1983 & 27.792 & $24+\mathrm{v} 56$ & 2.719 & 20.286 & 29.430 & 0,0 & 34.737 & $20.10 \%$ & 7 \\
\hline
\end{tabular}

\begin{tabular}{|c|c|c|c|c|c|c|c|c|c|}
\hline YEAR & ink & DK & $P \hat{A}$ & $\mathrm{~B} I$ & {[} & SD & $T N$ & $T$ & iT \\
\hline & - & ---.-- & - & & & & & & \\
\hline 1970 & $j+06 i$ & 2.530 & $3+285$ & $2+641$ & 2,066 & $3+99$ & 2.447 & $1+377$ & $3+7: 4$ \\
\hline 1971 & 3.743 & 3.467 & $4+74$ & 3.804 & 3.262 & 5,011 & 3.160 & 3.097 & 4.285 \\
\hline 1972 & 4.474 & 3.774 & $4.70 \mathrm{~L}$ & $4 . j 54$ & 3.430 & 5.193 & 3.50 & $3+117$ & $4.77 \%$ \\
\hline 1975 & 5.443 & 4.626 & 5,665 & 5.179 & $4+372$ & 6.015 & $4.51 \%$ & 3,107 & 5.57 \\
\hline 1974 & 12.434 & $10+246$ & $13+314$ & 12.363 & 10.154 & 11.013 & 11.320 & 5.418 & 12,560 \\
\hline$\$ 975$. & 13.206 & $11.8 \mathrm{BZ}$ & $13+294$ & 13.181 & 11,678 & $12+960$ & 12.160 & 4,728 & 11.455 \\
\hline 1975 & $12 . \pi / 4$ & 11,212 & 12.545 & $12+97$ & $11+036$ & $12+051$ & $17+\ldots 2$ & 11.445 & 11,101 \\
\hline 9977 & 14,630 & 12.469 & 14.653 & 14.694 & 13,901 & 13.860 & 13.272 & 12.4007 & $\frac{4}{3}+221$ \\
\hline 1978 & 13.384 & 12.25 & $14+244$ & 14,441 & 12.770 & 13,589 & $13+255$ & $12+3$ & 9,41 \\
\hline $57 \%$ & 18,920 & 10.061 & 20.969 & $21+484$ & 17,211 & $15+803$ & $17.6,6$ & 18,117 & 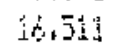 \\
\hline 1900 & 37.75 & 24,799 & 29.753 & 31,018 & 25.797 & (44.37 & $24,5,1$ & 2644 & 77,124 \\
\hline 1951 & 48.364 & 33.695 & 38.669 & 38.861 & 32,095 & 27.548 & $33.5 \%$ & 30.843 & $25,6]$ \\
\hline $1 \% 92$ & $36+149$ & $2 \%, 351$ & $3 E+46$ & 30.790 & $27 . \dot{4}+4_{2}^{2}$ & 25.744 & $7+6 E$ & 27.581 & $35+41$ \\
\hline Luts & 0.0 & 37.392 & 29.346 & 27.167 & 27.603 & 23,472 & $x, 760$ & $20+14$ & 3,50 \\
\hline
\end{tabular}

\begin{tabular}{|c|c|c|c|c|c|c|c|}
\hline YEAF & $\sqrt{A}$ & VT & WA & Wi & $W$ & $W Y$ & 15 \\
\hline$\cdots$ & $\ldots$ & "--- & & -- & 4 & $\cdots$ & \\
\hline 1970 & 1.749 & 3.062 & 2,016 & $3+222$ & 3.289 & 3.062 & 3.38 \\
\hline 1971 & 2.894 & 4,141 & 3.467 & 4,346 & 4.111 & 4.103 & 4,176 \\
\hline 1972 & $3+162$ & 4,474 & 3.775 & 4.577 & $4+369$ & 4.479 & 4,43 \\
\hline 2973 & $4+123$ & 5,434 & 4,572 & 5.500 & 5,444 & 5.443 & $5+446$ \\
\hline 1774 & 10.614 & 12,782 & 9.927 & $11+229$ & 13.0 .49 & 12,434 & $12+1 \%$ \\
\hline 1975 & 11.672 & 12.394 & 10.453 & $13+253$ & 12.35 & 13.200 & 12,751 \\
\hline 176 & 11,474 & 12,485 & $10.7+4$ & 12.506 & 11.242 & $12,7 / 4$ & 12,445 \\
\hline 1577 & 13.561 & 24.750 & 14.005 & 14,365 & 15.30 & 14,630 & 14.89 \\
\hline $19 \%$ & $12+841$ & 14.254 & $\$ 1.7 \mathrm{bL}$ & $19+82$ & 15.255 & 13.344 & $10 \% 6$ \\
\hline $19 \%$ & 18.420 & 20,025 & 16.212 & $\frac{117}{17}+40$ & 15.360 & 14,623 & $19+490$ \\
\hline 1990 & 26,160 & $24+319$ & 24,577 & $24+187$ & 24.308 & 29.254 & $27+911$ \\
\hline 1981 & 32.471 & 38.854 & 32,431 & 32,177 & 33.367 & 34,633 & $34+460$ \\
\hline $1 \% 82$ & 27.765 & 32.712 & 30.046 & 26.458 & $25+166$ & 28.803 & 30,032 \\
\hline 1983 & 27,960 & $27+805$ & 37.392 & 30.275 & $28+183$ & $20+137$ & 20.05 \\
\hline
\end{tabular}


TABLE B.23. Residua? Fuel Prices: Industrial Sector (\$/bbT)

\begin{tabular}{|c|c|c|c|c|c|c|c|c|c|}
\hline YEA & AK & $\mathrm{AL}$ & inf & $\hat{A} \vec{Z}$ & $\mathrm{CA}$ & $\infty$ & $G$ & IC & $\mathrm{DE}$ \\
\hline 1570 & & & & & & & & & 37 \\
\hline $\begin{array}{l}19.0 \\
1971\end{array}$ & $\begin{array}{l}2,803 \\
3,660\end{array}$ & $\begin{array}{l}3.270 \\
4.130\end{array}$ & $\begin{array}{l}2.902 \\
3.640\end{array}$ & $\begin{array}{l}2.505 \\
3.670\end{array}$ & $\begin{array}{l}2+777 \\
3.590\end{array}$ & $\begin{array}{l}2.360 \\
3.260\end{array}$ & $\begin{array}{l}2,722 \\
3,810\end{array}$ & $\begin{array}{l}4,109 \\
5,360\end{array}$ & $\begin{array}{l}3.72 \\
4,146\end{array}$ \\
\hline 1972 & 3.955 & $4+390$ & $3.9 i 0$ & 3.751 & 3.864 & 3.511 & $4+202$ & 5.79 & $\frac{B}{3}+4$ \\
\hline 1973 & 4.780 & 5.162 & 4,606 & 4,603 & 4,614 & 4,301 & ${ }_{-2} 239$ & 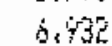 & 52,200 \\
\hline 1974 & 4,500 & 10,860 & 9.380 & 8,300 & 10,370 & 9.750 & 12,720 & $\pm \$ .390$ & 11,340 \\
\hline 1975 & 11.620 & 10.950 & 10,200 & 11.740 & 10,410 & 8.590 & 15.330 & 16,136 & 11,70 \\
\hline 1976 & 12,050 & 10.900 & 10,450 & $\pm 2,050$ & 10.030 & 11,350 & $=3.000$ & 35.793 & 31,40 \\
\hline 1977 & 11.880 & 12,390 & 11,400 & 12.330 & 11.790 & 11.530 & 14,550 & 15.5t & 13,56 \\
\hline 1774 & 11.990 & 12,380 & $11,5,0$ & $\pm 3.4 \%$ & 11.220 & $12.2 \%$ & $-4,720$ & $20+130$ & 13.000 \\
\hline 1979 & 15.136 & $15.01 B$ & 14.423 & 14.602 & 14.201 & 16.479 & 21,460 & 26,544 & 15.240 \\
\hline$\$ 980$ & 26.151 & 19.188 & 18.524 & 24.362 & $1 \bar{y}+80 \dot{y}$ & 24.000 & 26.344 & 43.604 & 36.333 \\
\hline 1781 & 34,090 & 25.372 & $23.2 A$ & 24,242 & 25.252 & 20.675 & 36.074 & $4 \overline{4}, 302$ & $32+326$ \\
\hline 1982 & 30.465 & 25.977 & $2.2 \% 4$ & 29.162 & 27.097 & 20.634 & 31.077 & $3 \%, 384$ & $20+349$ \\
\hline 1983 & 90 & 24.207 & {$[4,649$} & 30,091 & 76.864 & $2 h, B 12$ & 24,300 & 9,5 & 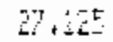 \\
\hline
\end{tabular}

\begin{tabular}{|c|c|c|c|c|c|c|c|c|c|}
\hline IEAK & FL & GA & $H I$ & In & ID & IL & IN & $\mathbb{K}_{\mathrm{B}}^{T}$ & 11 \\
\hline$\ldots$ & 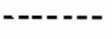 & - & n. & $\ldots$ & $=$ & $\cdots$ & - & - & 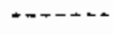 \\
\hline$\llcorner .97 \hat{V}$ & 2,060 & 2.238 & 3.276 & 3.284 & 2,400 & 3.506 & 2,708 & 2.658 & 2.457 \\
\hline 1971 & 3.140 & 3.210 & $4+270$ & 4,250 & 3.440 & 4,440 & 3,720 & 3,630 & 376 \\
\hline 1972 & 3.291 & 3.509 & 4,528 & 4,571 & 3.842 & 4.902 & $4,3.5$ & 3.856 & $3+7+1$ \\
\hline 1973 & 4,131 & $4.37^{5}$ & 5,384 & 5,449 & $4+821$ & 5.951 & 4,507 & 4,678 & $4+946$ \\
\hline 1974 & 9.050 & $11+050$ & 10.720 & 11.020 & 13.250 & 13.320 & 11.490 & 7.510 & 10,500 \\
\hline 1975 & 11.010 & 10,630 & 12.050 & 12,040 & 12,610 & 13,420 & 11,600 & 11.560 & 13,25 \\
\hline 1976 & 10.810 & 10,960 & 12.530 & 3.310 & 10.480 & 13.060 & $11+3 \div 0$ & 11.620 & 13.020 \\
\hline 1977 & 12.520 & $\$ 3.010$ & $13+070$ & 13.290 & $13+290$ & 14.330 & 12.880 & 12.580 & 24,430 \\
\hline 1978 & 11.700 & 12.010 & $13+9: 0$ & $13.8 \times 0$ & 15.120 & 14.520 & 13.790 & 11.580 & 14.730 \\
\hline 1979 & 16.006 & 15.249 & 18,400 & 16.026 & 15.720 & 18.462 & 17,307 & 14,412 & 17,936 \\
\hline 980 & 21.613 & 21.611 & 24,287 & $\$ 8.102$ & 23.634 & 23.775 & $21+31$ & $25+199$ & 2.501 \\
\hline 1991 & 28.840 & 29.567 & $2 E .484$ & 20.314 & 27.455 & 28.804 & 2791 & $25+381$ & 29,443 \\
\hline 1982 & 2.453 & 26,910 & $31+7 / 1$ & 24.639 & 32.053 & $28+206$ & 3,531 & 26.971 & 30,77 \\
\hline 1983 & 24.306 & 25.747 & 32,650 & $33+141$ & 32.099 & 25,061 & $26+36$ & 24,454 & $30+76$ \\
\hline
\end{tabular}

\begin{tabular}{|c|c|c|c|c|c|c|c|c|c|}
\hline IEAK & $i A$ & NA & 4 & ME & 楛I & N & In] & $n$ & $m$ \\
\hline$\cdots$ & - & ---- & -..-- & - & $\ldots+\cdots+$ & 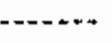 & 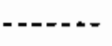 & -.-. & \\
\hline 1770 & 3.532 & 2.945 & 2.397 & $2+225$ & 2.375 & 2,798 & 2.54 & 2,50 & $2+975$ \\
\hline 1971 & 4,210 & $4+260$ & 3.910 & 3.290 & 4,080 & 3.940 & 3.490 & 3.430 & $3,17 \%$ \\
\hline 1972 & 4,542 & 4,380 & 4.301 & 3.584 & 4.270 & 4.006 & 4.041 & 3.747 & $4+380$ \\
\hline 1973 & 5.325 & 5,323 & $5+261$ & 4.509 & 5.154 & 4.839 & 4.943 & 4.548 & $5+325$ \\
\hline 1574 & 11.460 & 12.520 & 12.400 & 1,490 & 10.330 & 10.400 & $=0.250$ & $10+610$ & $12+180$ \\
\hline $19 \%$ & 10.810 & 12.920 & 13.000 & 11.410 & $12+440$ & 10.430 & $11.44 i$ & $11: 4000$ & 12.414 \\
\hline 1976 & 11,050 & 12.520 & $12+450$ & $\$ 1.290$ & $11+630$ & $10+750$ & $-1,450$ & $100+380$ & 12.63 \\
\hline 1977 & 12.450 & 14.040 & $1+4380$ & 13.590 & 13.690 & $1 \tilde{c} .810$ & $13,4 \div 0$ & 12.130 & $24+19$ \\
\hline 178 & 10.760 & $53+600$ & 13.700 & 2.970 & 13,550 & 13.230 & $3+170$ & 1.500 & 13.73 \\
\hline 1975 & 15.906 & $19+139$ & 20,672 & 17,839 & 14.670 & $16+3 i$ & $15+7]^{2}$ & 14.316 & $7, b_{2}$ \\
\hline 1920 & 23.154 & $26+48$ & 27,165 & 24.120 & 20.246 & 18.604 & $-7,441$ & 17.720 & $3+64$ \\
\hline 1781 & 28.824 & 31.151 & $3=049$ & 31.434 & 25,712 & 26,930 & $E_{A} B A H$ & 27.115 & 64.316 \\
\hline 1982 & 27.548 & 32.115 & 30,354 & $29.38 \hat{c}$ & 26.655 & 23.519 & $27+120$ & $25,85.9$ & $26+20$ \\
\hline $\operatorname{lig} 3$ & 27.451 & 28,705 & 23.752 & 23.520 & $25+243$ & 25.000 & 25.820 & 25,24 & 2.719 \\
\hline
\end{tabular}


TABLE B.23 (CONT). Residual Fuel Prices: Industrial Sector ( $\$ /$ bbi)

\begin{tabular}{|c|c|c|c|c|c|c|c|c|c|}
\hline$\left[1,4 R^{2}\right.$ & $\sqrt{1}$ & ND & WWE & PHA & $\mathrm{N}_{\mathrm{T}} \mathrm{T}$ & 料 & N & MiY & H \\
\hline & $\cdots$ & $\cdots$ & & & $\cdots$ & - & $\cdots$ & & \\
\hline 1970 & 2.548 & 5.416 & $2.5 \% 9$ & $2.74+$ & 3.215 & 2,995 & $2+375$ & $2+772$ & $3+041$ \\
\hline 191 & 3.640 & 6.580 & 4.070 & $5+890$ & 4,280 & 4,012 & 5,000 & 4.600 & 4,150 \\
\hline 1972 & 3.916 & $6+649$ & 3.924 & $4+362$ & $4+673$ & 4.390 & 4.380 & $4+355$ & +489 \\
\hline 1973 & 4,947 & 7.255 & 2,663 & $4+725$ & 5,662 & 5,323 & 5,328 & $5.2 \%$ & $5.4 \%$ \\
\hline 1974 & 11,200 & 10,290 & $7+170$ & 50,600 & 12,960 & 12.160 & 12.100 & 11,610 & 2,50 \\
\hline 1975 & 12.080 & 12.170 & 10.750 & 11.650 & 13.490 & 12,714 & $12,71<$ & 12.040 & $23+62 \mathrm{~L}$ \\
\hline 1976 & 12.180 & 11,400 & 12,130 & 11.200 & 13.300 & 12.636 & 2,636 & $5+500$ & $12+450$ \\
\hline 1477 & 13,420 & 12.050 & $14+300$ & 13.520 & 14.990 & 14.198 & 14.190 & 14,190 & 14,50 \\
\hline 1978 & 13.300 & $12+640$ & 12,770 & $: 3.020$ & 14.640 & 13.733 & 13.733 & 14,300 & 5.4 .670 \\
\hline 1979 & 16.900 & 15,913 & 14,315 & 17.464 & 21.073 & 21,167 & 15,720 & $17 \times 495$ & 17,24 \\
\hline 1780 & 23.398 & 22,515 & 40,579 & 24.841 & 24,507 & 30,945 & 23,700 & 23.754 & 30.301 \\
\hline 1981 & 30.261 & $23 . \dot{4} 45$ & 35,688 & 32.069 & 30.697 & 40.340 & 50,302 & 3,37 & Et: \\
\hline 502 & 28.455 & 23.339 & 24,303 & 20,707 & 33.180 & 36.114 & $32,=33$ & 3,601 & 24.794 \\
\hline $1 \% 83$ & $27+480$ & 24.033 & 25.074 & 80.745 & 30,724 & $30+659$ & 50.755 & 2765 & 2,60 \\
\hline
\end{tabular}

\begin{tabular}{|c|c|c|c|c|c|c|c|c|c|}
\hline $\mathrm{OEF}$ & OR & OK & FA & KII & 5 & SD & TN & $1 \%$ & $\mathrm{LIT}$ \\
\hline$\cdots$ & & 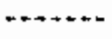 & ( & & & 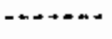 & $\ldots$ & - & \\
\hline 1970 & 2.945 & 2,474 & $3.2 \mathrm{i3}$ & 2.583 & 2.020 & 3,910 & $2+100$ & $i .93$ & 3.62 \\
\hline 1971 & 3.560 & 3.390 & 4.80 & $3+720$ & 3.190 & 4,900 & Setort & 2,970 & $4+5$ \\
\hline 1072 & 4,380 & 3.640 & 4,548 & 4,062 & 3.362 & 5,078 & 3.490 & $3+i 48$ & $4,6+4$ \\
\hline 1973 & 5.323 & 4.523 & 5,540 & 5.064 & 4,276 & 5.880 & 4.419 & 3.879 & 5.345 \\
\hline 1974 & 12.160 & 10.020 & 13.920 & 12.090 & 7.930 & 10.770 & $-1+070$ & 3.230 & $12,0 \%$ \\
\hline 1975 & 12.914 & 11,620 & $13+000$ & 12.890 & 11.420 & 12,690 & 11.500 & 4,510 & ti. 500 \\
\hline 1774 & 12.636 & 11.040 & $12+4=0$ & $\div 2.830$ & 11,510 & 11.920 & $\$ 2+0 \leqslant 0$ & $11+37 \hat{0}$ & $\pm 1,010$ \\
\hline 177 & 14.198 & 12,100 & $16+220$ & $14+260$ & 13.490 & 13.450 & 12,860 & 12,040 & 22.930 \\
\hline 1979 & $13+733$ & $12+110$ & $14,1 \leq 0$ & 14,600 & $(2+65)$ & 13.460 & 3.130 & {$[2,201]$} & $\bar{y}=60$ \\
\hline 1979 & 15,204 & 14.427 & 18.836 & 19,290 & 15.460 & 14,250 & $15,8=9$ & 10,993 & $14+53$ \\
\hline 1780 & 32.492 & 21.331 & 25,372 & $26+680$ & 22.189 & 20,568 & 21,126 & 23,179 & $2+3$ \\
\hline $1 \dot{9} 81$ & 27.264 & 24.285 & $31+30$ & 31,219 & 30.120 & 25.126 & 27,042 & 25,052 & 30,030 \\
\hline 1482 & 34,609 & 23.101 & 31.256 & $29+469$ & 26.752 & $24.6+8$ & 7,723 & 26,358 & $2+37$ \\
\hline 1793 & 30.589 & 27.834 & 27.780 & 27,213 & 20.462 & 25.053 & 27.898 & 23,044 & 25 \\
\hline
\end{tabular}

\begin{tabular}{|c|c|c|c|c|c|c|c|}
\hline TEAF & VA & $\sqrt{T}$ & WA & $W$ & WW & $山 Y^{\prime}$ & 49 \\
\hline -... & - & $\cdots$ & ........ & - & $-\cdots+\infty$ & $\cdots$ & $\cdots-\cdots$ \\
\hline 1970 & 1.710 & 2,994 & $2+358$ & 3.151 & 3.217 & 2,955 & 2.884 \\
\hline 171 & 2.930 & 4.050 & 5,30 & 4,250 & 4,020 & 4.012 & $3.8^{2}$ \\
\hline 1972 & 3.048 & $4+375$ & $3.6 \% 1$ & 4.476 & 4.468 & 4,380 & 4.122 \\
\hline 1873 & 4.032 & 5,314 & 4.471 & 5.379 & 5,324 & 5.323 & 5.00 \\
\hline 1974 & 10.390 & 12.500 & 9,50 & 10,980 & 12.780 & 12,160 & $11,4,30$ \\
\hline 175 & 11.370 & 12,120 & 11,200 & 12.86 & 12.080 & 12.91 .4 & $14+7 t$ \\
\hline 1976 & $11,35.2$ & 12.350 & 10,530 & 2.370 & $11.1 \mathrm{~m}$ & 12,80 & \pm 904 \\
\hline 57 & $13+160$ & 14.320 & $\mathrm{~L}+3 \mathrm{H}$ & 13.440 & 12,910 & $14+190$ & $13.3 \mathrm{i}$ \\
\hline 1978 & $12+720$ & $14+120$ & 11.350 & 13,860 & $13+160$ & 13.730 & 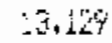 \\
\hline 1975 & 16.547 & 17.708 & 14,563 & $15+84$ & 13.905 & 17.67 & 17.422 \\
\hline i>0 & $22+501$ & $5+219$ & 21.140 & 20.805 & 20,900 & 2.162 & 23.385 \\
\hline $1 \% 81$ & 29.920 & 31.164 & 25,435 & 26.237 & 29.438 & 31.589 & $28+42$ \\
\hline 1982 & 26.777 & $51+520$ & $28.7 \mathrm{~s}$ & $25,8+0$ & 23.960 & 27.576 & 28.377 \\
\hline \multirow[t]{2}{*}{1983} & $26.82 \mathrm{E}$ & 29.519 & $20 \div 444$ & $25.25 \%$ & 25.473 & 36.027 & 27.5 \\
\hline & \multicolumn{7}{|c|}{ B. 43} \\
\hline
\end{tabular}


TABLE B.24. Residual Fuel Prices: Transportation Sector (\$/bbl)

\begin{tabular}{|c|c|c|c|c|c|c|c|c|c|}
\hline YCAR & $A K$ & AL & $A F^{\prime}$ & $A Z$ & $\mathrm{CH}$ & 60 & 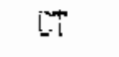 & $\mathrm{DC}$ & iE \\
\hline$\cdots$ & 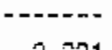 & 9 & n+... & 00 & 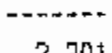 & 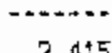 & 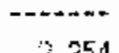 & & \\
\hline 1570 & 2,321 & 2.708 & 0.0 & 0.0 & 2.301 & 2.415 & 2.254 & 0,0 & $\therefore 67$ \\
\hline 1971 & $\hat{3}+\hat{0} 31$ & 3.420 & 0.0 & 0.0 & 2.973 & 3.34 & $3+155$ & 0 & $3 \div 428$ \\
\hline 1772 & $3+291$ & 3.635 & 0.0 & $0+0$ & 3.200 & 3.580 & 3.80 & $0, \hat{0}$ & 3644 \\
\hline 1973 & 3.458 & 4.274 & 0.0 & 0.0 & 3.820 & 4.398 & 4.338 & $0+\hat{\theta}$ & 4,72 \\
\hline 1974 & 7.966 & 8.792 & 0.0 & 0.0 & 8.587 & 10.011 & 10,535 & 0.0 & $\dot{7} .504$ \\
\hline 1975 & 9.613 & 9.059 & $0, \hat{0}$ & $\hat{0}+\hat{0}$ & $8, \$ 12$ & $9.1 \% 3$ & 11,028 & $0+0$ & $9+704$ \\
\hline 1976 & 10.194 & 4,221 & 0,0 & 0.0 & 3.477 & 11.474 & $1: .965$ & 0.0 & $7+661$ \\
\hline 1977 & 9.572 & 10,372 & $0 . \hat{0}$ & 0.0 & 9.847 & $11+381$ & 12.214 & 0.0 & $11+3+0$ \\
\hline 1978 & 9,392 & 8.698 & $0+0$ & 0,0 & 8.789 & 12.407 & 1,531 & 0.0 & 10.240 \\
\hline $1 \% 9$ & 23.549 & 13.840 & 0.0 & 0.0 & 13,097 & 18.345 & 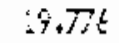 & 0.0 & $10.20 \%$ \\
\hline 1980 & 23.452 & $17+208$ & 0.0 & 0.0 & $17+619$ & 27.937 & 25,643 & 0,0 & 20,35 \\
\hline 1981 & 29.739 & 25,366 & 0.0 & 0.0 & $24+106$ & 24.849 & 3.000 & 0 & 27.381 \\
\hline 1992 & 0.0 & 22,525 & 0.0 & 0.0 & 23,498 & 0.0 & $2 i n+547$ & $\hat{0}, \hat{0}$ & $24+38$ \\
\hline 1983 & $0, \hat{0}$ & $\hat{0}, \hat{0}$ & 6.0 & 0.0 & $37+912$ & 0.0 & $2 x+640$ & $\dot{0} \cdot \dot{0}$ & $2 \mathrm{E}$ \\
\hline
\end{tabular}

\begin{tabular}{|c|c|c|c|c|c|c|c|c|c|}
\hline YEAK' & FL & GA & $\mathrm{HI}$ & IA & ID & II. & Int & is & $\mathrm{I}$ \\
\hline--- & - & ......-- & - & $-\cdots+\cdots$ & - - - - & --- & $\cdots$ & & \\
\hline 1970 & 1.710 & 1.853 & 2.712 & 3.350 & 0.0 & 3.133 & 2.242 & 2.713 & 0.0 \\
\hline 1971 & 2.600 & $2+458$ & 5.536 & 4.345 & 0.0 & 4.031 & $3+\hat{v} \theta 0$ & 3.712 & 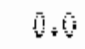 \\
\hline 1972 & 2.725 & 2.905 & 3.749 & $4+674$ & 0.0 & 4,450 & 3.325 & 3,743 & 0.0 \\
\hline 1973 & 3.420 & 3.623 & 4,458 & 5.572 & 0.0 & 5.312 & 4.064 & 4,785 & 0.0 \\
\hline 1974 & 7.494 & 9.150 & 8.876 & 11.269 & 0,0 & 12,093 & 9,14 & 7.725 & 0,0 \\
\hline 1575 & 9.108 & 8.794 & $9+469$ & 12.312 & 0.0 & 12.178 & 9,48 & $11+21$ & 0.0 \\
\hline $197:$ & 9.145 & 9,272 & 10,600 & $13+456$ & 0.0 & 11.733 & $\overline{4}, 568$ & $1: .747$ & $0, n$ \\
\hline 1977 & 10.510 & 10.921 & 10.971 & 13.695 & 0.0 & 13.152 & $10.8 .2 ?$ & $12+463$ & 0.0 \\
\hline 1978 & 9.165 & $4+408$ & 10.018 & 13,992 & 0,0 & 12.722 & 10.959 & $1: 993$ & 0.0 \\
\hline 1979 & $14 . \sqrt{5} !$ & 14.053 & 16.404 & 17.840 & 0.0 & 20.553 & $b, \hat{005}$ & 16.045 & 0,0 \\
\hline 19 BัB० & 19.382 & 19,381 & 21.554 & 21.046 & 0.5 & 27,640 & 18,33 h & 27.295 & 0,0 \\
\hline 1481 & 24.051 & $Z, A 61$ & 28,236 & $31+44$ & $0, \hat{0}$ & 34,826 & 24.098 & 36.54 & 0.0 \\
\hline 1982 & 22.053 & 23.334 & 27.566 & 0.0 & 0.0 & 28.147 & 22,215 & 0,0 & $0, \pi$ \\
\hline 1985 & 27.184 & 27.987 & 34,889 & 0.0 & 0.0 & $3+129$ & 0.0 & $0+0$ & 0,0 \\
\hline
\end{tabular}

\begin{tabular}{|c|c|c|c|c|c|c|c|c|c|}
\hline TEAR & LA & WA & 洴D & 恇 & i月I & 些 & 10 & 㭴 & $\pi$ \\
\hline 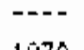 & and & a... & 20 & 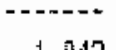 & 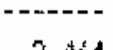 & & & & \\
\hline 1970 & 2.925 & 2,480 & 2,340 & 1.842 & $\begin{array}{r}2,464 \\
7.578\end{array}$ & $\begin{array}{l}2.309 \\
3.180\end{array}$ & $\begin{array}{l}2,911 \\
4,080\end{array}$ & $\begin{array}{l}2,136 \\
2.840\end{array}$ & 0.0 \\
\hline 1971 & $3+48 \%$ & 3.527 & $a+236$ & $2+724$ & 3.378 & 3.180 & $\begin{array}{r}4+080 \\
4+19 d\end{array}$ & 2.840 & 0 \\
\hline 1972 & 3.802 & 3.627 & 3,561 & 2.967 & 3.536 & 3,317 & 4,184 & $3+102$ & $0+0$ \\
\hline $1 \% 3$ & $4+409$ & 4.407 & $4+35$ & 3.734 & 4.268 & $4+007$ & 5.055 & 3.766 & 0.0 \\
\hline 1974 & 9.489 & 10.367 & 10.334 & $\$ 1514$ & $8+\dot{y} \leqslant B$ & 8.679 & 10.277 & 3.785 & 3.0 \\
\hline 1975 & 8.943 & $10+689$ & 10.821 & 9.434 & $10.2 \%$ & 9.042 & 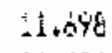 & $\bar{y}+193$ & 00 \\
\hline $197 \mathrm{~s}$ & 4,382 & 10.592 & 10.566 & 9.551 & 4,839 & 4.263 & 11.005 & 9.79 & 0.0 \\
\hline 1477 & 20.451 & 11.785 & $1 E+071$ & $11.3 \% 9$ & $11.4 \% 2$ & 10.753 & $4+501$ & 10,182 & 0,0 \\
\hline 1979 & 8.585 & 10.653 & 10.732 & \pm 00.176 & 10.614 & 10,364 & 13,245 & 9.64 & 30 \\
\hline 1979 & 14.658 & 17.637 & 19,051 & $18+430$ & 13.545 & 15.050 & $27+57$ & 13.377 & 0.0 \\
\hline 190 & 20.764 & 23.339 & 24,631 & 21.531 & 18.202 & 16.738 & 22,602 & 45.591 & 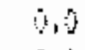 \\
\hline 1981 & 2.556 & $30+54$ & 25,604 & 28.450 & 24.521 & 21.10 & 31,605 & $24+812$ & 0.0 \\
\hline 1982 & 23.887 & 27.947 & $26+303$ & 25,810 & 23.996 & 21.031 & 23.516 & $22+421$ & 0,0 \\
\hline 1983 & 21.548 & 26.722 & $22+680$ & $29+424$ & 29.324 & 23,151 & 26,601 & 23.099 & $0+0$ \\
\hline
\end{tabular}


TABLE B.24 (CONT). Residual Fuel Prices: Transportation Sector ( $\$ / b b 1)$

\begin{tabular}{|c|c|c|c|c|c|c|c|c|c|}
\hline YEAR & $M C$ & (10 & 试 & $i+1$ & 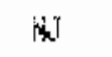 & 粷 & 沼 & $M$ & OH \\
\hline-- & -- & 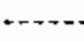 & & - & - & - & $\cdots$ & + & \\
\hline 1970 & 2.110 & 0.0 & 2.559 & 0.0 & 2.662 & 0,0 & 0,0 & $2+461$ & $=518$ \\
\hline 1971 & 3.014 & 0.0 & 4.162 & 0.0 & 3.544 & 0.0 & 0.0 & 5,367 & $3+40$ \\
\hline 1972 & 3.242 & 0.0 & 3.910 & 0.0 & 3.269 & 0.0 & 0,0 & 3,606 & 3.717 \\
\hline 1973 & 4,013 & 0.0 & $4,7 \% 8$ & 0.0 & $4+\cos 9$ & 0.0 & 0.0 & 4,355 & 4.50 \\
\hline 1974 & 9.274 & 0.0 & 7,352 & 0.0 & 10,731 & 0.0 & 0.0 & 7,613 & 10 , 极 \\
\hline 145 & 9,944 & 0.0 & 11.197 & 0.0 & 11.150 & 0.0 & 0.0 & $10.45 \%$ & $11+268$ \\
\hline 1978 & 10,304 & 0,0 & 12,263 & 0,0 & 11.268 & 0.0 & 0,0 & 10,642 & 10.53 \\
\hline $19 \pi$ & 11.685 & 0.0 & 14.736 & 0.0 & 12.533 & 0,0 & 0.0 & $11+\$ 11$ & $12+100$ \\
\hline 1978 & 10,418 & 0.0 & 12,291 & 0.0 & 11.468 & 0.0 & 0,0 & $1 \div 202$ & 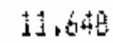 \\
\hline 1979 & 15.575 & 0.0 & 15.736 & 0.0 & 19.420 & $\hat{\mathrm{v}} \cdot \hat{\mathrm{v}}$ & 0.0 & 16.397 & 15,48 \\
\hline 1930 & 20,903 & 0,0 & 26,378 & 0.0 & 26.462 & 0.0 & 0,0 & 25.307 & 13.65 \\
\hline 1981 & $27+410$ & $0 . \hat{0}$ & 31,800 & 0.0 & $32+\sqrt{45}$ & 0.0 & 0.0 & 29,14 & $78+84$ \\
\hline $19 B 2$ & 24,673 & 0,0 & 0,0 & 25,811 & 20.770 & 0.0 & 0,0 & $26, \Xi 60$ & 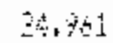 \\
\hline 1483 & 0.0 & 0,0 & 0.0 & 26.652 & 24,845 & 0,0 & 0.0 & 20.500 & 250 \\
\hline
\end{tabular}

\begin{tabular}{|c|c|c|c|c|c|c|c|c|c|}
\hline YTAE: & $0 x$ & CF & $F A$ & $\mathrm{ki}$ & $x$ & SD & $\mathrm{TH}$ & $\mathrm{T}$ & $\pi T$ \\
\hline--- & $-\cdots$, & $+\cdots+c-1$ & $\cdots$ & n.t. & ---.-- & 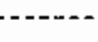 & $\cdots+\cdots+$ & -- & $\cdots$ \\
\hline $1 \% 0$ & 0,0 & 2.049 & 2.660 & 2.130 & 1.673 & 0.0 & $0, j$ & +.50 & 0.0 \\
\hline 1071 & 0.0 & 2,807 & $\therefore+4$ & 3.080 & 2,641 & 0.0 & $\sqrt{0}+0$ & 2.457 & $\hat{0} 0,0$ \\
\hline 1972 & 0.0 & $3+056$ & 3.507 & $3+363$ & 2.784 & 0.0 & 0,0 & 2,24 & 90 \\
\hline $19 \%$ & 0.0 & 3,746 & 4.587 & 4.193 & 3.540 & 0.0 & $0+0$ & $3+212$ & 0.0 \\
\hline 1974 & 0,0 & 8.297 & 10.781 & 10.011 & $8+222$ & 0.0 & 0,5 & 2,85 & $\vec{j}+\vec{j}$ \\
\hline 1575 & 0.0 & $9,6,13$ & 10.755 & $10+104$ & 9.448 & 0.0 & 0.0 & 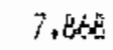 & 0,0 \\
\hline 1976 & 0.0 & 9.382 & 10.299 & 10.854 & 9.737 & 0.0 & 0.0 & 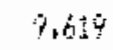 & 0.5 \\
\hline 147 & 0.0 & 10.157 & 11.407 & 11,470 & 11.324 & 0.0 & 0.0 & $10+307$ & 0.0 \\
\hline 1978 & 0,0 & 4.486 & $1 \div+053$ & 11,593 & 9.909 & $0+0$ & 0.0 & 9.64 & 0.0 \\
\hline 1979 & 0.0 & 13.246 & 17.350 & 17,705 & 14.247 & 0.0 & 0.0 & $15 \times 00$ & 0.0 \\
\hline 1980 & 0,0 & 19.129 & $2.9 \overline{51}$ & $23+426$ & $19+999$ & 0.0 & 0.0 & 20.797 & 0,0 \\
\hline 1981 & 0,0 & 26.811 & $3 x+700$ & 30,422 & $25.53 \mathrm{~h}$ & 0.0 & $0 . \hat{0}$ & 24.542 & $\hat{0}+0$ \\
\hline 1982 & 0,0 & 24.356 & 27.132 & 25,553 & 23.147 & 0.0 & 79.165 & $2 \mathrm{~s}+45$ & 0,0 \\
\hline 190 & 0.0 & 0.0 & 22.740 & 27.545 & 0.0 & 0.0 & 0.0 & 20,420 & 00 \\
\hline
\end{tabular}

\begin{tabular}{|c|c|c|c|c|c|c|c|}
\hline rafin & HA & $\sqrt{T}$ & HA & WI & 汭 & WY & $1 \mathrm{BS}$ \\
\hline$\cdots$ & - n.... & - & -........ & --..- & n........ & & \\
\hline 1970 & 1.416 & 0.0 & 2.118 & 2.604 & 0.0 & 3.062 & 2,152 \\
\hline 1971 & 2.343 & 0.0 & 2.807 & 3.519 & 0.0 & 4.103 & 3.075 \\
\hline $1 \% 72$ & 2.580 & 0.0 & $3.65 \mathrm{~h}$ & 3.706 & 0.0 & 4.479 & 3.304 \\
\hline 1973 & 3.59 & 0.0 & $E+702$ & 4.454 & 0.0 & 5.443 & 4.010 \\
\hline 1974 & 9.545 & 0,0 & 3.957 & 4,092 & 0,0 & 12,434 & 3.972 \\
\hline $1 \div 5$ & 9.40. & 0.0 & 5.266 & 10.722 & 0,0 & 13.206 & $4.13 \mathrm{~L}$ \\
\hline 175 & +.602 & $0+0$ & 8.993 & 10,465 & 0,0 & 12.774 & 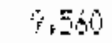 \\
\hline $197 ?$ & 11.047 & 0.0 & 9.58 & 11.702 & 0.0 & 14,030 & $: 50.50$ \\
\hline 1973 & 7,864 & 0.0 & $A, i 2 b$ & 10.857 & 0.0 & 13.864 & $9,+97$ \\
\hline 1479 & $15+249$ & 0.0 & $i=421$ & 14.003 & 0.0 & 19,023 & $\therefore 4+41$ \\
\hline 1900 & $20.17 \%$ & 0.0 & $13.95 \dot{8}$ & $\$ 8.658$ & 0.0 & 26,254 & 9,990 \\
\hline 1981 & $25+837$ & 0.0 & 25.805 & {$[+103$} & 0.0 & 34.635 & 25.64 \\
\hline 1982 & 23.218 & $0, j$ & 24,700 & 23.039 & 0.0 & 28.903 & 24,152 \\
\hline \multirow[t]{2}{*}{1980} & 28.249 & $0+\hat{0}$ & 0.0 & 0.0 & 0.0 & 0.0 & $20.54 \pi$ \\
\hline & & & & B. 50 & & & \\
\hline
\end{tabular}


IABLE B, 25. Residual Fuel Prices: Electric Utility Sector (\$/bbl)

\begin{tabular}{|c|c|c|c|c|c|c|c|c|c|}
\hline YEAR & AK & AL & $\mathrm{AF}$ & $A Z$ & $C A$ & 00 & $\mathrm{CT}$ & $\mathrm{DC}$ & $D E$ \\
\hline$\cdots$ & ---.- & $\cdots$ & -..-- & 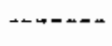 & - & - n...... & $\cdots$ & 2. & \\
\hline 1970 & 0.0 & 0.0 & $2,6+0$ & 4.033 & 2.479 & $2+30$ & 2,340 & $2,0, b_{2}$ & 2.850 \\
\hline 1971 & 0.0 & 0.0 & 3.734 & 3.671 & 3.88 .1 & 3.390 & 3.330 & 4.134 & 4,110 \\
\hline 1972 & 0.0 & 0.0 & $4, \pm 16$ & 5.476 & 4.893 & 3.392 & 3.945 & 3.95 & 3,559 \\
\hline 1973 & 0.0 & 0.0 & 4.520 & $6.36 \%$ & 5.774 & 5,245 & 5.178 & 4.704 & $5.43 \%$ \\
\hline 1974 & 0.0 & 0,0 & 10,53 & 11,173 & 12.320 & 11.387 & $12+48$ & tकish & $(2+5 i j$ \\
\hline 1975 & 0.0 & 0,0 & 11.560 & $13+030$ & $15.2 B 9$ & 12.054 & $12+365$ & $12.38 \%$ & 12,122 \\
\hline 1976 & 0.0 & 0.0 & $12,0+\sin 2$ & 13,452 & 14.339 & 10,170 & $11+842$ & 11,397 & 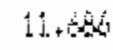 \\
\hline 1977 & 0.0 & 0.0 & 12,560 & 14.211 & 14.526 & 11,741 & 13.741 & 13. $82 \mathrm{~A}$ & 13.49 \\
\hline 1978 & 0.0 & 0.0 & 12.076 & $13+865$ & 15.856 & $11+16 t$ & 13.077 & $13+013$ & 12.731 \\
\hline$: 979$ & 0.0 & 0.0 & 15.769 & 18.020 & 19,316 & 15,311 & 20.50 & $20.27 \hat{i}$ & $20+273$ \\
\hline 1980 & $\hat{v}+\hat{\theta}$ & 0.0 & 21,021 & 27.506 & 30.441 & 27.493 & $2 \vec{b}+97$ & $27,40 \%$ & 20.799 \\
\hline 1981 & 0.0 & 0.0 & 2.474 & 31,664 & 40.795 & 27,451 & $34+499$ & 30.995 & 3,30 \\
\hline 1982 & $\hat{0}+\hat{v}$ & 0.0 & 25.150 & 32.319 & 42,044 & 0.0 & 29.694 & 0.0 & $2 \%+45$ \\
\hline 1983 & 0.0 & 0.0 & 23,0 & 32.380 & 37.74 & $28 .+80$ & 28.510 & $\hat{0} \cdot r_{i}^{r}$ & 27,50 \\
\hline
\end{tabular}

\begin{tabular}{|c|c|c|c|c|c|c|c|c|c|}
\hline YEA & FL & GA & $\mathrm{HI}$ & Is & 10 & IL & Iit & 15 & $\pi$ \\
\hline ---- & - +......- & naten- & -....... & -... & ...... & - & $\cdots$ & $\cdots-$ & $-\ldots+\ldots$ \\
\hline $1 \% 70$ & 2.054 & 1.554 & 2.523 & 3.343 & 0.0 & 3.719 & 0.0 & $9+239$ & 5,0 \\
\hline 1971 & 2.634 & 3.317 & 2,941 & 3.767 & 0.0 & $3+378$ & 0.0 & 4.124 & 0,0 \\
\hline$\$ 47^{\circ}$ & $3,1+0$ & 3.087 & $3+301$ & 3.60 & 0,0 & 4,054 & 0,0 & 4,017 & 6,0 \\
\hline 1973 & 4,217 & 3.510 & 4,010 & 5,043 & 0.0 & 4,248 & 0.0 & 5.065 & 00 \\
\hline 1974 & $11+153$ & 9.801 & 4.713 & 0,0 & 0.0 & 7,798 & 0.0 & 5.879 & 0,0 \\
\hline 1975 & 11.526 & $10.8 \%$ & 9.359 & 0.0 & 0.0 & 8.391 & 0.0 & $10+ \pm 22$ & $0+\overline{0}$ \\
\hline 1976 & 11.281 & 10,980 & $9.8 \%$ & 0.0 & 0.0 & 12.755 & 100 & 1,231 & $0+0$ \\
\hline 197 & 13.206 & 12,727 & 11.680 & 0.0 & 0.0 & 15.230 & 0,0 & $12-45$ & 0.0 \\
\hline 1978 & 12.300 & 12,095 & 13.858 & 0.0 & 0.0 & 15.673 & 0.0 & 11,379 & 5.6 \\
\hline 1979 & 18.059 & 17.279 & 16,136 & 0.0 & 0,0 & 23.722 & 0.0 & 13.266 & 0.0 \\
\hline 1480 & 23.406 & 21.734 & 23.505 & 0.0 & 0.0 & 34.764 & 3.0 & $27+853$ & $5+\hat{0}$ \\
\hline 1981 & 29.816 & 26.607 & 41.021 & 0.0 & 0.0 & $46,04 \hat{0}$ & 0.0 & $20.73 n$ & $\hat{0}_{1} 0$ \\
\hline 1982 & 27.145 & 23.482 & 41,425 & 0.0 & 0.0 & $44+850$ & 0,0 & $23.45 i$ & $\hat{v}+0$ \\
\hline 1983 & 20.060 & 27.860 & 34,730 & 0.0 & 0.0 & 34.220 & 0.0 & 20.710 & 10 \\
\hline
\end{tabular}

\begin{tabular}{|c|c|c|c|c|c|c|c|c|c|}
\hline YES & LA & $M_{A}$ & ito & 眐 & $M I$ & $M N$ & Mo & 45 & $\mathrm{n}^{\prime}$ \\
\hline$\ldots$ & - & - & -... & $\cdots$ & ... & & $\cdots$ & . & \\
\hline 1970 & 3.071 & 2.299 & $2+281$ & $2+35$ & $3+755$ & 3.593 & 3.55 & 3,013 & $\ddot{z}+2 y$ \\
\hline 1971 & 3.264 & 3.931 & 3.872 & 2,412 & 4,599 & 5.307 & 4,10 & 4.327 & $\stackrel{i}{i} i 1$ \\
\hline 1972 & 4,127 & 4,093 & 3,724 & 2.339 & 4.802 & 4.553 & 3.645 & $4,8 \%$ & 3.58 \\
\hline 1973 & 4,607 & 4,446 & 4.482 & 2,424 & 4.897 & 5.563 & 4.840 & 5.605 & 6.245 \\
\hline 1974 & 10.232 & 11.942 & $11+330$ & 10.058 & 10.819 & $11+558$ & $1 \mathrm{t}, 15 \mathrm{t}$ & 10,200 & 7.157 \\
\hline$\$ 975$ & 10,775 & $1 \pm .823$ & $11+404$ & $\$ 1.066$ & $12,31 \%$ & $12+328$ & 11,070 & $10.70 t$ & 0.0 \\
\hline 1976 & 10,814 & 11.144 & 11.124 & 10.459 & 13.535 & $11,0 \leqslant 2$ & 10.843 & 10.731. & $1 \% 0$ \\
\hline 1977 & 11.730 & 13,054 & 13.197 & 12.785 & 16.350 & 12.926 & $12+532$ & $\$ 1.175$ & 15,40 \\
\hline 1978 & 11,246 & 11.797 & $12+27$ & $18+328$ & 16.256 & 2,515 & $12 .+1$ & 10,00 & 0.0 \\
\hline 1979 & 16,772 & 17.477 & 18.705 & 17.841 & 19.367 & 16.160 & 15.4\%? & 30.72 & $3, n$ \\
\hline 1789 & 22.433 & 24,053 & $24,2 h d$ & 27,324 & 25.057 & $20,11 \dot{4}$ & $21+75$ & 19.080 & $0 \%$ \\
\hline 198.1 & 27,514 & $25.66 \%$ & $31.46 k$ & 33.205 & 34.550 & 33.907 & 28,2, & 24,097 & , d \\
\hline 1982 & 24,793 & 26.422 & $20+750$ & $30+301$ & $30+517$ & $29+430$ & $97+2+1$ & 24,21 & $+i$ \\
\hline 1983 & 21.500 & 26.600 & 28.550 & 24.240 & $2 \hat{y}, 350$ & 23.100 & $2 h, 540$ & 23.780 & $0+i$ \\
\hline
\end{tabular}


IABLE B.25 (CONI). Residual Fuel Prices: Electric Utility Sector ( $\$ / \mathrm{bb} 1)$

\begin{tabular}{|c|c|c|c|c|c|c|c|c|c|}
\hline IDAR & $N C$ & $\mathrm{~N} B$ & $\overrightarrow{H E}$ & $\mathrm{NH}$ & WJ & $N H$ & 秘 & $\mathrm{Ni}$ & 대 \\
\hline$\cdots$ & -- & -.--- & $m+\ldots$ & $\cdots$ & & $\cdots$ & 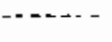 & 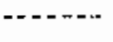 & \\
\hline 1970 & 4.228 & 0.0 & $3+119$ & $2.0 \% 3$ & 2.797 & 1.544 & $3+345$ & 2.38 & $4+2$ \\
\hline 1971 & 4.555 & 0.0 & 3.662 & 2.134 & $4.31 \%$ & 2.910 & 4,682 & 3.265 & 4.552 \\
\hline 1972 & $3.5,45$ & 0.0 & $4+47$ & 2,481 & $4+377$ & 4.022 & 5.0 .67 & 3,772 & $4,6,5$ \\
\hline 1973 & 3.746 & 0.0 & $4+097$ & 3.63 & 5.342 & 4,879 & 7,172 & $4.80 \%$ & $5+4$ \\
\hline 147 & 10.896 & 0.0 & 10,428 & 11.897 & 12,064 & 9.871 & $12+113$ & कू? & $14.2 \%$ \\
\hline 1975 & 10,993 & 0.0 & 10.937 & 11.353 & $12+710$ & 10.431 & 12.418 & \pm 1.082 & $\frac{4}{4}+7$ \\
\hline 1976 & 0.0 & 0.0 & 15.940 & 10.804 & $12+28$ & 11.138 & $12+597$ & $11: 735$ & 12,0 \\
\hline 1977 & 0,0 & 0.0 & 11.320 & 12.843 & 14.173 & 12.325 & 13.190 & 53.487 & 1 \\
\hline $17 \%$ & 11.889 & $0+\hat{v}$ & 16.65 & 11,073 & 13.475 & 13.223 & 12,497 & 12,54 & 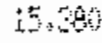 \\
\hline 1974 & 0.0 & 0,0 & $14+2 B 4$ & 16.799 & 20.686 & 15.182 & $\operatorname{Is}, 4(A)$ & $\mathrm{i} 8.977$ & 48.63 \\
\hline 1980 & $0+0$ & 0 & 20.324 & 23,731 & $29+446$ & $2 b .0 .38$ & $2 \vec{x}+274$ & 20,361 & $2+\cdots$ \\
\hline 1981 & 0,0 & 0,0 & 34.450 & 29,207 & 34,436 & $35+80 \%$ & $2 \% 110$ & 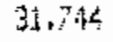 & 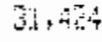 \\
\hline 1082 & 0.0 & $\Delta \div 0$ & 100 & 25,96 & 31.75 & 34.67 & $25+415$ & 274 & $\therefore$ \\
\hline 193 & 0.0 & $24+200$ & 0,0 & 6.530 & 27.716 & $25+470$ & 0.0 & 6.370 & \\
\hline
\end{tabular}

\begin{tabular}{|c|c|c|c|c|c|c|c|c|c|}
\hline YEA & $\mathrm{OK}$ & 吸 & $\mathrm{FA}$ & RI & $\mathrm{SC}$ & 90 & $\pi$ & $i=$ & 13 \\
\hline$\cdots$ & $n$ & $\cdots$ & - - & m...- & naten & ----.. & $\cdots$ & $\cdots$ & $\cdots$ \\
\hline 1970 & $2+41$ & 0,0 & $2.8 \%$ & 2.896 & $2+832$ & 4.079 & 0.0 & $3+2+8$ & $1.6 \%$ \\
\hline 1971 & 2.795 & 0.0 & 4,385 & 4,060 & $4.17 \dot{0}$ & 4.793 & 0.0 & 3.515 & 1,715 \\
\hline 1972 & 3,462 & 0,0 & 4,405 & 4.041 & $4+497$ & $4,7 / 3$ & 0.0 & $4+541$ & $1: 744$ \\
\hline 1973 & 4,430 & 0.0 & $5+2 t_{2}^{\prime 2}$ & 4,340 & 3.319 & 5.062 & 0,0 & $5.2 \%$ & 340 \\
\hline 1974 & 10.171 & 0.0 & $12+302$ & 11,861 & 7.057 & 10.543 & $v_{0} \hat{0}$ & $7+51.1$ & 4 \\
\hline 1975 & 9,204 & 0.0 & 12,588 & 11.302 & $7+126$ & 13,884 & 0.0 & 11.578 & 5,79 \\
\hline 1976 & 9.464 & 0.0 & $12+152$ & 11,328 & 0.830 & 10,724 & 0.0 & 10.76 & $7 \times 4.44$ \\
\hline 1977 & 12,190 & 0.0 & 14.046 & 12.802 & 10,828 & 11.636 & 0,0 & 11.938 & $15+24$ \\
\hline 1976 & 0,0 & 0.0 & 13.490 & 12.553 & $11+866$ & 12.742 & 0,0 & $11, i 4 \bar{\pi}$ & $10+59$ \\
\hline$\$ 779$ & 13.990 & 0,0 & 20,021 & 19.793 & 12,305 & 14,067 & 0,0 & 14,430 & 56,110 \\
\hline 1800 & $0+0$ & 0.0 & 27.956 & 24.964 & $2 l .534$ & 19.459 & 0,0 & $23+24$ & 23,268 \\
\hline 1981 & 24,715 & 0.0 & $33,6 z$ & 30,085 & 27.304 & 36,144 & 0.0 & 27.57 & 25,76 \\
\hline 1982 & 0.0 & 0.0 & $31+235$ & 23.917 & 26.053 & 0.0 & $\hat{10.0}$ & 28.434 & 10 \\
\hline 1923 & 0.0 & 0.0 & 28.610 & 27,420 & 0.0 & $\hat{0} .0$ & 0,0 & 20,330 & $\hat{H}, 4$ \\
\hline
\end{tabular}

\begin{tabular}{|c|c|c|c|c|c|c|c|}
\hline YEAR & $V A$ & $V_{T}$ & WA & WI & $W V$ & $W Y$ & 15 \\
\hline --- & $\cdots$ & -- & -. & היניניני & 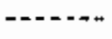 & & $\cdots$ \\
\hline 1970 & 1.553 & 0.0 & 0.0 & 3.649 & 0.0 & 0.0 & 2.505 \\
\hline 1971 & 2,472 & 0.0 & 0.0 & 4,665 & 0.0 & 0.0 & 3.511 \\
\hline 1972 & 2.857 & 0.0 & 2,149 & 4.220 & 0.0 & $\hat{0}+\hat{0}$ & 3.874 \\
\hline 1973 & 3.417 & 0.0 & 4,486 & 4,965 & 0.0 & 0.0 & 4.305 \\
\hline $\pm \% 74$ & 10.286 & $0, \hat{0}$ & 4,477 & 5.550 & 0.0 & 0.0 & 11.559 \\
\hline 1975 & 11.567 & 0,0 & 0.0 & 10.360 & 0.0 & 0.0 & $12+3 b^{2}$ \\
\hline 1576 & $11+079$ & 0.0 & 0.0 & $10+\therefore 85$ & 10.0 & 0.0 & 12.03 \\
\hline 1977 & 13.324 & 0.0 & 0,0 & $12,7 \mathrm{E}$ & 0.0 & 0.0 & 13.57 \\
\hline \pm 178 & $12+402$ & 0.0 & 0.0 & 32,870 & $16+25$ & 0.0 & 13.114 \\
\hline 1979 & 18,533 & 0.0 & 16,611 & 15.599 & 0.0 & 0.0 & 105 \\
\hline $1 \div 90$ & 24.709 & $0+0$ & 20.311 & 27,202 & 0.0 & $\sqrt{3}+1)$ & 26.54 \\
\hline 1981 & 31,597 & 0.0 & 0.0 & 34,167 & 0.0 & 0.0 & 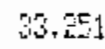 \\
\hline $1 \% 92$ & 28.921 & 0.0 & 0.0 & 0.0 & $0+0$ & 0.0 & $30.2 \%$ \\
\hline \multirow[t]{2}{*}{1983} & 28.220 & 0.0 & 0.0 & 0.0 & 0.0 & 0,0 & 28.720 \\
\hline & & & & B. 5 & & & \\
\hline
\end{tabular}


TABLE B.26. LPG Prices: Residential Sector ( $\$ / g a l$ )

\begin{tabular}{|c|c|c|c|c|c|c|c|c|c|}
\hline IVAS & $A K$ & Al & GAR & $\hat{A z}$ & $\mathrm{BA}$ & CO & $C \mathrm{~T}$ & $\mathrm{IX}:$ & $\mathrm{DE}$ \\
\hline 190 & $0.2 \% 1$ & 0,216 & 0.101 & 0.174 & 0,214 & 0.164 & 0.250 & 0.216 & 6246 \\
\hline $1 \% 1$ & 0.296 & 0.200 & 0.175 & 0.276 & 0.234 & 0.15 & (1:25 & 0,250 & 9.203 \\
\hline 1972 & 0.300 & 0,200 & 0.180 & 0.254 & 0.250 & 0.166 & 0.254 & 0.223 & $0,2,6$ \\
\hline 1973 & 0.504 & 0,31 & $i+240$ & 0.321 & 0.340 & 0.356 & $i, 3 x$ & 1306 & 1, \\
\hline 174 & $0.51 \hat{Y}$ & 0.365 & 0.700 & 0.318 & 0.400 & 0.255 & 0.301 & 0.334 & 0.345 \\
\hline 1975 & 0.559 & 0.393 & 0,320 & 0,505 & 0.405 & 0.303 & $\mathrm{i}, 455$ & 0.410 & $0 ., 731$ \\
\hline 1976 & 0.610 & 0.380 & 0.400 & 0.514 & $0.4 \angle \mathrm{Z}$ & 0.350 & 0,486 & 0.431 & 0,444 \\
\hline 1977 & 0,643 & 0.435 & $0,41 E$ & 0.655 & 0.498 & 0.371 & $0,5 \geqslant 0$ & 0.431 & $0.4 \mathrm{in}$ \\
\hline 1978 & 0.663 & 0.457 & 0.343 & 0.504 & $\hat{0}_{*} 461$ & 0.400 & 0,364 & 0,510 & 0,600 \\
\hline 1979 & 0.914 & 0.550 & $0,6 E$ & 0,623 & 0.617 & 0.554 & 0,60 & i).776 & 0.500 \\
\hline 1900 & 1.120 & 0.710 & 0,803 & 0.775 & 0.747 & 0.61 & 0.844 & 0,813 & 0,781 \\
\hline 1981 & 1.832 & 0.735 & 0.657 & $0 .+50$ & 0,690 & 0.703 & $0,4, i 6$ & 090 & 0.823 \\
\hline 1982 & 1,106 & 0.782 & $0.75 \%$ & 1.027 & 0.807 & 0.801 & 1.064 & $1+100$ & 0.394 \\
\hline 1483 & 1.204 & 0.797 & $0,7,5$ & 1.010 & 0.447 & 0.720 & 6 & A: & iक \\
\hline
\end{tabular}

\begin{tabular}{|c|c|c|c|c|c|c|c|c|c|}
\hline U & $\mathrm{FL}$ & GA & $\mathrm{HI}$ & IA & II & Il & IN & $k i$ & $\mathrm{il}$ \\
\hline-- & $\cdots++\cdots$ & $\cdots$ & -...- & -4 & ---- & 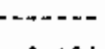 & $n+\ldots+$ & $-\cdot \cdot-\cdot$ & \\
\hline 1970 & 0.221 & 0.2274 & 0.296 & 0.171 & 0.213 & 0,198 & 0.193 & 0.144 & $0+217$ \\
\hline 1971 & 0,270 & 0.216 & {$[4,400$} & 0.359 & 0.250 & 0.177 & $\dot{j}_{i} ; \mathbb{R}_{i}$ & $\hat{4}: 134$ & $0.20=$ \\
\hline 1972 & 0.291 & 0.207 & 0.305 & 0.175 & 0.262 & 0.188 & $0+15$ & 9.142 & 0.24 \\
\hline 1973 & 0,410 & 0.336 & 0.513 & 0.313 & 0.532 & 0.311 & 5.39 & 0.273 & 6,368 \\
\hline 1374 & 0.497 & 0,352 & 0.528 & $0.3 \pm 7$ & 0.285 & 0.339 & 0.301 & 0.290 & 0,375 \\
\hline 1975 & 0.575 & 0.401 & 0.599 & 0.323 & 0.390 & 0.339 & 0,357 & 0.300 & $0,3 \%$ \\
\hline 1978 & 0.553 & 0,48 & 0.521 & 0,362 & 0.342 & 0.381 & $\hat{0}+30 \hat{0}$ & 0.320 & $0+428$ \\
\hline 1977 & 0.644 & 0.435 & 0.650 & 0.411 & 0,479 & 0.438 & b. $4 i^{i} i$ & 0.372 & 0.463 \\
\hline 1978 & 0.638 & 0.436 & 0.652 & 0,410 & 0.490 & 0.410 & 0.42 & 0,35 & $0,47=$ \\
\hline 1979 & 0.712 & 0.485 & 0.070 & 0.570 & $0,0,14$ & 0.583 & is 59 & 0.600 & $0.5 \mathrm{H}$ \\
\hline 1380 & 0.947 & 0.700 & 1.128 & 0.628 & $0.71 \%$ & 0.648 & 0.55 & 0.626 & 0.751 \\
\hline $1 \% 81$ & 1.047 & 0.757 & 1.166 & 0.593 & 0.977 & 0.677 & $0.7 \mathrm{mi}$ & 3628 & 0.789 \\
\hline 1782 & 1,136 & 0.757 & 1.255 & 0.66 & 0.805 & $0+6 \sqrt{5}$ & 0.768 & 0,651 & 0.908 \\
\hline 1993 & 1.108 & 0.783 & 1.256 & 0,69 & 0.850 & $0 . \overrightarrow{7} \perp 2$ & 4.775 & 0,00 & 0,53 \\
\hline
\end{tabular}

\begin{tabular}{|c|c|c|c|c|c|c|c|c|c|}
\hline YEAT' & LA & $M A$ & $M D$ & ME & $M$ & 咻 & ing & in & $\mathrm{itt}$ \\
\hline- & -..... & ---s- & .......... & ....... & $\cdots$ & - & $\cdots+. . .+4$ & $\cdots$ & \\
\hline 100 & 0.174 & 0.274 & $0+2=6$ & 0.237 & 0.211 & 0.195 & 0.179 & 0,203 & 0.202 \\
\hline 1971 & 0.195 & 0.272 & 0.237 & 0.195 & 0.133 & 0.175 & 0.173 & 0.193 & 0.215 \\
\hline 1.972 & 0.232 & 0.280 & 0.25 & 10.350 & 0.196 & 0.186 & 0.179 & 0.200 & 0.210 \\
\hline 1973 & 0.359 & 0.407 & {$[1+360$} & 0.376 & 0.342 & 0,336 & $i, 304$ & 1). 340 & 0.34 \\
\hline 1974 & 0.500 & 0.423 & $0+3.3$ & 0.46 .4 & 0.341 & 0.318 & 0,271 & 0.350 & $0.37 \%$ \\
\hline 1975 & 0.400 & 0,448 & 0.420 & 0.436 & 0.391 & 0.385 & $0.2 x_{9}$ & 0.373 & 0.35 \\
\hline 197,6 & 0.550 & 0.475 & 0.440 & 0.443 & 0.365 & 0.48 & $0,3+4$ & $0+401$ & $0.3 \%$ \\
\hline 1977 & 0.431 & 0.499 & 1.412 & 0.516 & 0.460 & 0,430 & $\pi, 305$ & 2,430 & $0.9 \%$ \\
\hline$i \geqslant 8$ & 0.415 & $0.52 \%$ & 0,46 & 0.555 & 0.413 & 0.436 & 0.367 & 0.400 & $3+42 \mathrm{~K}$ \\
\hline 1179 & 0.545 & 0.764 & 0.623 & $0.8 \times 0$ & 0,670 & 0.546 & 0,59 & 2580 & $\mathrm{AO} \mathrm{i}$ \\
\hline 1.900 & 0,732 & 0,824 & $0.3 \%$ & 0,920 & 0.740 & 0.672 & 10.477 & 0,76 & 0.60 \\
\hline 1481 & 0.735 & 0.902 & 0.75 & 1.000 & 0.755 & 0.475 & $0,0.45$ & 4.725 & 0.756 \\
\hline 1502 & 0.829 & 0.933 & 0.750 & $1+1042$ & 0,811 & 0,77 & $0,7: 2$ & 0.35 & $0,7,79$ \\
\hline $1+83$ & 0.915 & 0.995 & G. 48 & 1,052 & 0.814 & 0,750 & $a_{1}+9$ & 0.50 & 0,717 \\
\hline
\end{tabular}


TABLE B.26 (CONT). LPG Prices: Residential Sector ( $\$ / g a 1)$

\begin{tabular}{|c|c|c|c|c|c|c|c|c|c|}
\hline ZEAK & $1+C$ & 17 & ME & 唀 & $M$ & th & H. & $\mathrm{Mi}$ & $\mathrm{HH}$ \\
\hline 1070 & 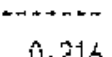 & 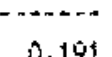 & $0+5$ & $03 \mathrm{~d}^{2}$ & 079 & 56 & $t$ & a & $A+5$ \\
\hline $\begin{array}{l}140 \\
1 \% ? 1\end{array}$ & $\begin{array}{l}0+\angle 16 \\
0.199\end{array}$ & $\begin{array}{l}0.171 \\
0.193\end{array}$ & 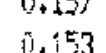 & $\begin{array}{l}0+14 i \\
0.731\end{array}$ & $\begin{array}{l}0.22 \\
0.264\end{array}$ & $\begin{array}{l}0.120 \\
0.114 ?\end{array}$ & $\begin{array}{l}0+C N 1 \\
10,377\end{array}$ & $\begin{array}{l}0.24 / \\
i 1.74\end{array}$ & $\begin{array}{l}0+192 \\
0.18\end{array}$ \\
\hline 1972 & 0.214 & 0.185 & 0.153 & 0.238 & 0.275 & 0.150 & 0.307 & 0.243 & G+18 \\
\hline 1473 & 0.334 & 0.326 & 6.29 & 0.390 & 0.427 & 0.293 & $1,3 \%$ & 2,340 & 0,326 \\
\hline 1974 & 0.538 & 0.324 & 0.303 & 0,430 & 0,485 & 0.312 & $0+400$ & 0.376 & 0,376 \\
\hline 195 & 0.377 & 0.320 & $0.3 E$ & 0,428 & 0.450 & 0.374 & 0,434 & i) +400 & 0.412 \\
\hline 196 & 0.437 & 0.376 & 0.331 & 0.405 & 0.400 & 0.388 & 0.427 & 0.447 & 0.406 \\
\hline 1977 & 0,475 & 0.429 & $9+419$ & 0.59 & 0.534 & 0,417 & 0,566 & 1,524 & 0.475 \\
\hline 1978 & 0.497 & 0.420 & 0.352 & 0.507 & 0.620 & 0.459 & 0,305 & 0.326 & 6) \\
\hline 1079 & 0,642 & 0.570 & 8,50 & 0.720 & 0.695 & 0.474 & $\therefore .658$ & $i_{1}, 265$ & 0.564 \\
\hline 1980 & 0,703 & 0,685 & 0.625 & 0.845 & $4+900$ & 0.651 & 0.350 & 0.755 & 5,702 \\
\hline 1001 & 0.795 & 0.491 & प) & 0.914 & 1.050 & 0,750 & 0,951 & 9,403 & 0.778 \\
\hline 1782 & 0.345 & 0.686 & 0,665 & 0.725 & 0.705 & $0,4 \approx 8$ & 0.762 & $9+3 \hat{E}$ & 3. 1004 \\
\hline $1 \div 83$ & 0.968 & 13,681 & 9,642 & 3.756 & 1.010 & 0.761 & 1052 & $D_{1} \div B$ & 0,926 \\
\hline
\end{tabular}

\begin{tabular}{|c|c|c|c|c|c|c|c|c|c|}
\hline YEAF: & $\bar{O} \mathrm{k}$ & OF & $P A$ & FI & $x$ & SD & TN & $T$ & $\| T$ \\
\hline-- & 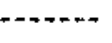 & n....... & n.t. & - & - & $-\cdots--$ & $-\cdots+\cdots$ & ……- & \\
\hline 1770 & 0.151 & 0.214 & 0.221 & 0.237 & 0,232 & 0.180 & $0.2=1$ & $0+153$ & $0+204$ \\
\hline 1971 & 0.148 & 0.239 & $0,21:$ & 0,253 & 0.210 & 0.170 & 0,190 & $0: 456$ & 0.165 \\
\hline 1972 & 0.143 & 0.243 & 0.264 & 0.207 & 0.227 & 0.172 & 0,208 & 0.154 & $0.24 \%$ \\
\hline 1973 & 0.253 & 0.336 & 0.317 & 0.340 & 0.333 & 0.302 & 0,35 & 9.316 & 0.446 \\
\hline 1974 & 0.293 & 0.386 & 0.374 & $0.340^{\circ}$ & 0.366 & 0.289 & 0.39 & 8.234 & 0.33 \\
\hline 1975 & 0.285 & 0,480 & 0.403 & 0.500 & $0.3 \% 0$ & 0.311 & $(0,3551$ & 4. 31 ? & 0,45 \\
\hline 107 & 0.374 & 0.405 & 0.483 & 0.515 & 0.483 & $0.32 \mathrm{~J}$ & 0,376 & 0.300 & 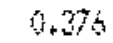 \\
\hline 1977 & 0.396 & 0.540 & 0.518 & 0,505 & 0.475 & 0.402 & 0.451 & 3,424 & 0.455 \\
\hline 1979 & 0.400 & 0.485 & 0.497 & 0,485 & $0.4 \leqslant 8$ & 0.371 & 0.424 & 0.373 & 0.45 \\
\hline 1979 & 0.510 & 0,680 & 0.692 & 0,700 & 0.650 & 0.559 & $0.5 \mathrm{Nt}$ & $0,5 \mathrm{~s}$ & $0.6 \mathrm{1} 7$ \\
\hline 1780 & 0.668 & 0.824 & 0.824 & 0.785 & $\hat{y}+684$ & 0.628 & 0,701 & 0.67 & 0.745 \\
\hline 1981 & 0.677 & 0,935 & $0.8 \%$ & 0,50 & 0,831 & 0.642 & b.86 & 0.749 & 0.710 \\
\hline 1792 & 0.73 & 0.934 & 0.844 & 0.334 & 0.830 & 0.640 & 0,35 & 0.011 & 077 \\
\hline $1 \div 83$ & 0.750 & 0.992 & 7,470 & 6.840 & 0.062 & 0.666 & 0.778 & 1936 & 5,60 \\
\hline
\end{tabular}

\begin{tabular}{|c|c|c|c|c|c|c|c|}
\hline I'EAK & VA & $\sqrt{1}$ & $W A$ & $\mathrm{WI}$ & $\lfloor, N$ & $W Y$ & US \\
\hline$\ldots$ & "-- & - & & & 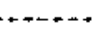 & - & \\
\hline 1970 & 0.215 & 0.259 & 0.2 .4 & 0.157 & 0.213 & $0.1 \% 0$ & 0.150 \\
\hline 1971 & 0.213 & 0.235 & 0.301 & 0.177 & 0.215 & 0.173 & 0.187 \\
\hline 172 & 0.213 & 0.228 & 0.271 & $0.19 \%$ & 0.233 & 0.181 & $\hat{0}+1 \%$ \\
\hline 1973 & 0.347 & 0.330 & $\overline{0.417}$ & 0.394 & 0.374 & $0.26 t$ & $0+309$ \\
\hline 1974 & 0.351 & 0.540 & 0.370 & 0.333 & 0.357 & 0.303 & $10+334$ \\
\hline 1975 & 0.404 & 0.430 & 0.522 & 0.378 & 0.453 & 0.383 & 0.35 \\
\hline 1776 & 0.422 & 0,450 & $3+300$ & 0.392 & 0.427 & 0.386 & $0.7 \%$ \\
\hline 1977 & 0,461 & 0.547 & is. 540 & {$[1,452$} & 0,497 & 0.401 & 0.447 \\
\hline 172 & 0.45 & 0,500 & 0.725 & 0.412 & 0.510 & 0.389 & 0.434 \\
\hline 179 & $0.60 \mathrm{i}$ & 0.716 & $\dot{3}, 680$ & 0,620 & 0.614 & 0.535 & 0.505 \\
\hline 1980 & 0.734 & 0.450 & $0,7+4$ & 0.704 & $0.81 \%$ & 0.664 & $0,7.4$ \\
\hline $1 \% 91$ & 0.803 & 0.730 & 0.470 & 0.799 & 0.845 & 0.687 & 0.725 \\
\hline 1902 & 0.843 & 0,834 & 0,334 & $0.7 \pi$ & 0.843 & $0+362$ & 0,304 \\
\hline \multirow[t]{2}{*}{1983} & 0.723 & 1.080 & {$[1,800$} & 6.772 & 0,866 & 0.662 & 0.814 \\
\hline & & & & B. & & & \\
\hline
\end{tabular}


TABLE B.27. LPG Prices: Industrial Sector (\$/gal)

\begin{tabular}{|c|c|c|c|c|c|c|c|c|c|}
\hline 1EA & $A K$ & AL & HF & $\mathrm{A} I$ & $\mathrm{CA}$ & 60 & $G$ & $x$ & $\mathrm{DE}$ \\
\hline--- & $0 . \pm 19$ & 0.144 & 0,12 & 0.096 & $0,+130$ & 0.113 & 0.172 & 0,128 & 0,100 \\
\hline 171 & 0.123 & 0.154 & 4.200 & 0.102 & 0.139 & 0.117 & 0,127 & $0: 32$ & $0+13$ \\
\hline 1772 & 0.123 & 0.154 & 0.122 & 0.102 & $\hat{0}, 143$ & 0.121 & $0.12 \%$ & 0,133 & 0.154 \\
\hline 1973 & 0.131 & 0.162 & 0.99 & 0,116 & 0.154 & $0.13 \mathrm{E}$ & 0.237 & 0.342 & 0.144 \\
\hline 1574 & 0.225 & 0.276 & 0,244 & 0,205 & 0.234 & 0.251 & $0.2 \pm 2$ & 0,248 & $0+251$ \\
\hline 1975 & 0.243 & 0.280 & 0.236 & 0.229 & 0.250 & 0.242 & $0,2 \varepsilon$ & 1) 204 & 0.325 \\
\hline 1776 & 0.269 & 0.304 & 0.85 & 0.260 & 0.282 & 0.268 & 0.20 & 0.321 & 0.35 \\
\hline $1 \% 7$ & 0.303 & 0.354 & 0,280 & 0.305 & 0.339 & 0.313 & i).31E & 0.307 & 0.341 \\
\hline 1778 & $0.3 \pm 6$ & 0.330 & $0.2 \%$ & 0.400 & 0,362 & 0.334 & 0.337 & 0.483 & i) 432 \\
\hline 1779 & 0.346 & 0,305 & 0,393 & 0.321 & 0.366 & 0.349 & 0,30 & 0,342 & $3+342$ \\
\hline 1780 & 0.346 & 0.462 & 0.485 & 0.500 & 0.456 & 0.419 & $0.4-4$ & 0.458 & 0,413 \\
\hline $1 \div 81$ & 0.474 & 0,536 & 0.527 & 0.595 & 0.529 & 0.556 & $\overline{1}, 5,5$ & 9,512 & 0.39 \\
\hline 1082 & 0.485 & 0.530 & 0.34 & 0.610 & 0.609 & 0.543 & 0.345 & 0.54 & 1). 54 \\
\hline 1983 & 0.520 & 0.593 & $\bar{v}, 112$ & $n+b 3$ & 0,625 & 1.584 & $\bar{b}_{4}$ & 3,6 & 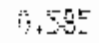 \\
\hline
\end{tabular}

\begin{tabular}{|c|c|c|c|c|c|c|c|c|c|}
\hline PEAE: & 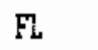 & $G A$ & $\mathrm{HII}$ & IA & ID & IL & I & $\mathrm{MF}$ & 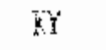 \\
\hline$\cdots$ & 7 & 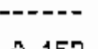 & 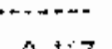 & n. & na & - & $10 a$ & $\because$ & \\
\hline 1770 & 0.117 & 0.153 & $0.1: 7$ & $0.10 \%$ & 0.138 & 0,098 & 0.128 & 6.077 & $0+135$ \\
\hline 1971 & 0.117 & 0.159 & 0,122 & 0.117 & 0.144 & 0.104 & $3+36$ & טิ:025 & $y+144$ \\
\hline 1972 & 0.120 & 0.163 & 10.122 & $\hat{0}, \$ 15$ & 0.148 & 0.104 & 0,136 & $5+102$ & 0,148 \\
\hline 1973 & 0.130 & 0.171 & पू. & 0.127 & 0.152 & 0.113 & 0.42 & 0.092 & 0,155 \\
\hline 1974 & 0.222 & $\hat{0}+2 \pi$ & 0.223 & 0.230 & 0.226 & 0.197 & 0.251 & 0.185 & $0+244$ \\
\hline 1975 & 0.228 & 0.269 & 3.240 & 0.226 & 0.285 & 0.197 & 3,25 & $0,97 \mathrm{H}$ & 0,266 \\
\hline 1776 & 0.250 & 0,302 & 0.235 & $0.24 \mathrm{~h}$ & 0.281 & 0,217 & 0.272 & 0,200 & $0+295$ \\
\hline 1977 & 0,256 & 0.347 & $0+300$ & 0.278 & 0,332 & 0.261 & 0.332 & 0.244 & 0,321 \\
\hline 1978 & 0.242 & 0,353 & 0.265 & 0.36 & 0.360 & 0.272 & 0.346 & 0.244 & $0+337$ \\
\hline $19 \%$ & 0,427 & 0.373 & 0.360 & 0.314 & 0.343 & 0.310 & ט. 34 년 & 0.272 & 0.360 \\
\hline $1 \% 00$ & 0,478 & 0.461 & 0.330 & 0,40 & 0.5000 & 0.431 & 0.446 & $0+3+3$ & 0.457 \\
\hline 1981 & 0.530 & 0.532 & $\because 200$ & 0,482 & 0,608 & 0.457 & $\hat{n} \cdot 4 \hat{\pi}^{2}$ & 0.445 & 6.773 \\
\hline $1 ; 02$ & 0.571 & 0.559 & 0.428 & 0.460 & 0,611 & 0.465 & 0.35 & 0.407 & 0.621 \\
\hline 1983 & 0.607 & 0.316 & $\pi_{1} 426$ & 0.542 & 0.659 & 0.526 & 0.572 & 0.422 & $5+684$ \\
\hline
\end{tabular}

\begin{tabular}{|c|c|c|c|c|c|c|c|c|c|}
\hline IEA & IA & MA & 怔 & ME & IIII & W & ins & 梅 & TT \\
\hline-- & $\cdots$ & - & & ....... & ----- & - & 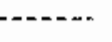 & $\cdots$ & \\
\hline 1770 & 0,104 & 0.149 & 0.1 .3 & $0 . \pm 24$ & $0.12 \%$ & 0.112 & 0.112 & 0.126 & 0.12 \\
\hline 1971 & 0.104 & 0.135 & $0+117$ & 0.122 & 0.129 & $0+120$ & 4,400 & 1.:35 & 6.130 \\
\hline 172 & 0.104 & 0,136 & $0.1: 7$ & 0.133 & 0.133 & 0.120 & $0.1: \dot{2}$ & 0.1 .35 & $0.12 \%$ \\
\hline 1973 & 0.114 & 0.135 & 0.175 & 0.131 & 0.140 & 0.123 & $6+254$ & D.1特 & 0.142 \\
\hline 1374 & 0.214 & 0.225 & 0.2 .9 & 0.220 & 0.225 & 0.232 & 0.232 & 0.247 & $6+20$ \\
\hline 1975 & 0.236 & 0.270 & 4.243 & 0.291 & 0.228 & 0.239 & 3.217 & 0.247 & 1,25 \\
\hline 1976 & 0.257 & 0.330 & $0.2+1$ & 0.32 & 0.258 & 0,265 & 0,244 & 0.264 & 0,754 \\
\hline 1977 & 0.282 & 0.330 & 0.296 & 0,330 & $0.30 \mathrm{~B}$ & 0.296 & 9.272 & 1,314 & 1,25 \\
\hline 178 & 0.316 & 0.345 & 0.347 & 0.355 & 0.289 & 0.324 & 0.317 & 0.317 & 0.25 \\
\hline 1979 & 0.346 & $0,40 \mathrm{~s}$ & 13031 & $0,3 \%$ & 0.350 & 0.314 & 0.3 & 5,337 & 0,36 \\
\hline 100 & 0,503 & 0.483 & 0.448 & 0.530 & 0.451 & 0.426 & 0,774 & 0,40 & of \\
\hline 1481 & 0,433 & 0.508 & 9.512 & 0.556 & 0.844 & 0.477 & 3,554 & 11549 & 0.595 \\
\hline $1 \geqslant 82$ & 0,550 & 0,604 & 0.58 & 0.624 & 0.517 & 0.514 & 0.334 & 0.52 & 0,35 \\
\hline 1983 & 0.573 & 0.643 & 4,553 & 0.604 & 0.564 & 0.570 & 0.585 & 0,600 & $0.57 n$ \\
\hline
\end{tabular}


TABLE B. 27 (CONT). LPG Prices: Industrial Sector (\$/gal)

\begin{tabular}{|c|c|c|c|c|c|c|c|c|c|}
\hline YEAF' & $N C$ & ND & NE & $\mathrm{H} H$ & $1+21$ & MPI & N & $\mathrm{Ml}^{2}$ & $\mathrm{OjH}$ \\
\hline$\ldots$ & $=$ & - & - & & & & - & $\cdots \cdot$ & \\
\hline 1570 & 0,126 & 0.113 & 0.99 & 0.133 & 0.143 & 0.109 & $0.0 \%$ & 0,135 & 0,134 \\
\hline 1971 & 0.126 & 0.120 & 9107 & 0.136 & 0.143 & 0.116 & $0.16 \mathrm{i}^{\mathrm{i}}$ & $3: 132$ & 0.197 \\
\hline 1972 & 0.126 & 0,120 & $0,5 \hat{\gamma}$ & $0+137$ & $0+137$ & 0.117 & $0, \sqrt{6}$ & 0.124 & $0+17$ \\
\hline 197 & 0.137 & 0.124 & 0.216 & 0.135 & 0.147 & 0.132 & D.210 & 0.135 & 0.143 \\
\hline 1774 & $0+217$ & 0.214 & $0.2 \% 6$ & 0.226 & 0.304 & 0.243 & 0.173 & 0.228 & 0.252 \\
\hline 1975 & 0.235 & 0.225 & 0.200 & 0.252 & 0.332 & 0.247 & $\sqrt[8]{4} 97$ & 0,293 & 0.26 \\
\hline 1776 & 0.235 & 0.254 & 0.240 & 0.349 & 0.358 & 0.778 & 0.704 & $0.2 \mathrm{~g}$ & 0,0 \\
\hline 1977 & 0.285 & 0.271 & 0.240 & 0,328 & 0.332 & 0.320 & 0,21 & 1344 & 0.33 \\
\hline 1978 & 0,320 & $0,2.17$ & 0.293 & 0.400 & 0.337 & 0.325 & 0.250 & 0,344 & $0.3 \%$ \\
\hline 1979 & 0.311 & 0.367 & $(1,295$ & 0,329 & 0,351 & 0.376 & 0,346 & {$[1,376$} & 0,301 \\
\hline 1980 & 0.459 & 0,458 & 0.454 & 0,418 & 0.451 & 0.527 & 0.437 & 0.504 & 0.467 \\
\hline $1 \% 81$ & 0.557 & 0.493 & {$[1,454$} & 0.56 & 0.510 & $0.5 \%$ & $\mathrm{j}_{\mathrm{A}} \mathrm{x}$ & $2 t$ & 1,012 \\
\hline 1982 & 0.540 & 0.423 & 0.46 & 0.603 & 0.42 & 0.612 & 0,54 & 0.67 & 0.50 \\
\hline 1983 & 0.567 & 0.505 & $0 . \overline{5} 1 \overline{7}$ & $n_{1}, \dot{B} 2$ & $0,4,3$ & 0,653 & $\dot{4}=35$ & 000 & 4 \\
\hline
\end{tabular}

\begin{tabular}{|c|c|c|c|c|c|c|c|c|c|}
\hline HEA & $0 \mathrm{X}$ & OR & FA & FiI & $5 x$ & $\mathrm{SD}$ & TW & $T X$ & UT \\
\hline$\cdots$ & n....... & n...... & …… & $\cdots$ & $-\cdots$ & $-\cdots-$ & --.-- & - & $\cdots$ \\
\hline 1770 & 0.103 & 0.118 & 0,102 & 0.107 & 0.137 & 0.1 .15 & $0,1.5$ & 0,60 & 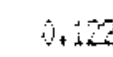 \\
\hline $1 \% 1$ & 0.113 & 0,125 & $\overline{1}_{2}: \pm 2$ & 0,114 & 0.144 & 0.118 & 0.125 & 0,044 & 5.15 \\
\hline 1772 & 0.109 & 0.128 & 0.172 & 0.10 & 0.149 & 0.120 & 0.123 & $0+097$ & $0+12$ \\
\hline 19,73 & 0.122 & 0.135 & 0.39 & 0.113 & 0.155 & 0.126 & $0_{1}$ & 0,110 & 0,126 \\
\hline 1974 & 0.243 & 0.202 & 0.225 & 0,189 & $\hat{U}+246$ & 0.224 & 0.223 & 0.204 & $0+\frac{1}{15}$ \\
\hline 1975 & 0.230 & 0.256 & 0,203 & 0.231 & 0.260 & 0.228 & 0.213 & i) 2045 & 0,258 \\
\hline 5776 & 0.257 & 0.279 & $0.2 \times$ & 0.272 & 0.281 & 0.244 & 0.240 & 0.20 & $0+25$ \\
\hline 1977 & 0.324 & 0.330 & 0.352 & 0.284 & 0.290 & 0,301 & 0,251 & D. 206 & 0,305 \\
\hline 1978 & 0.346 & 0.351 & 0.336 & 0.302 & 0.316 & 0.244 & 0.303 & 0.218 & 1). 305 \\
\hline 1979 & 0.355 & 0,379 & 0,371 & 0.321 & 0.329 & 0.357 & 0,346 & 0.373 & 0.304 \\
\hline 1700 & 0.500 & 0.472 & 0,469 & $\hat{0}, 4 k 2$ & 0.371 & 0.381 & 0.434 & 0.456 & 9.341 \\
\hline 1984 & 0.545 & 0.541 & $0,5=5$ & 0.538 & 0.495 & 0,375 & 0,537 & i) 514 & $0, \frac{115}{7}$ \\
\hline$\{P B 2$ & 0.577 & 0.511 & 0.103 & 0.554 & 0,541 & 0.445 & 0.540 & 0.721 & 0.512 \\
\hline 1783 & 0.623 & 0.525 & 0.474 & $0.5 \%$ & 0.565 & 0.488 & $0+52^{2}$ & 0.55 & 5.5 \\
\hline
\end{tabular}

\begin{tabular}{|c|c|c|c|c|c|c|c|}
\hline YEAF & VA & VI & 始 & $W I$ & WV & WY & US \\
\hline$\ldots$ & 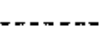 & ------ & -...- & $\cdots$ & $\cdots$ & --- & \\
\hline 170 & 0.134 & 0.120 & 0.121 & 0.131 & 0.128 & 0.117 & 0.100 \\
\hline $1 \$ 71$ & 0.140 & 0.116 & 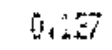 & 0.139 & 0.133 & 0.125 & 0.105 \\
\hline 1972 & 0.141 & 0.117 & $\hat{0}+1,1$ & $0.13 \%$ & 0.133 & 0.120 & 0.106 \\
\hline 1973 & 0.150 & 0.116 & 8625 & 0.147 & 0.145 & 0.132 & $0, \pm 18$ \\
\hline 1974 & 0.243 & 0.194 & 0.203 & 0.854 & 0,232 & 0.207 & 0.28 \\
\hline 1975 & 0.269 & 0.251 & $1 ; 28$ & $0+250$ & 0.239 & 0,293 & $0.22 t$ \\
\hline 1986 & 0.276 & 0.299 & 0.259 & 0.254 & 0.272 & 0.267 & 0.242 \\
\hline 197 & 0.325 & $0+270$ & 0.312 & 0.201 & 0.317 & 0,295 & $0,2 \%$ \\
\hline 1779 & 0.313 & 0.316 & $0+207$ & $0+344$ & 0.323 & 0.309 & 0.270 \\
\hline 1979 & 0.372 & 0.321 & 0.35 & 0,36 & $\hat{v}+370$ & 0,348 & 0.257 \\
\hline 1780 & 0.402 & 0.489 & 0,000 & 0,46 & 0.507 & $0.45 \%$ & 0.454 \\
\hline 1401 & 0.506 & 0.563 & 0.535 & 0.492 & 0.543 & $0+5 \times 1$ & 0.500 \\
\hline 1902 & 0.545 & 0.575 & 0.548 & $0.5 \times 2$ & 0.581 & 0.540 & 0,735 \\
\hline \multirow[t]{2}{*}{1783} & 0.568 & 0.612 & 0.652 & 0.49 & 0.603 & 0.531 & 0.5 \\
\hline & & & & & & & \\
\hline
\end{tabular}




\section{DISTRIBUTION}

No, of

Copies

OFFSIIE

Charles A. Allen, EI-642

Office of Energy Markets and End Use

Energy Information Administration 1000 Independence Avenue, S.W.

Washington, DC 20585

Arthur T. Andersen, EI-64

Statistics 8ranch

Office of Energy Markets and End Use

Energy Information Administration 1000 Independence Avenue, S.W.

Washington, DC 20585

Richard Bavier, SFJ-1

Office of Energy Assistance

B-448, 2100 Second Street, S.W.

washington, DC 20201

Byung Doo Hong, EI-522

Data Analysis and Forecasting Branch

Office of Coal, Nuclear, Electric and Alternate Fuels

Energy Information Administration 1000 Independence Avenue, S.W.

washington, DC 20585

Coy Lay, EI-642

Statistics Branch

Office of Energy Markets and End Use

Energy Information Administration 1000 Independence Avenue, S.W. Washington, DC 20585

W. David Montgomery, EI-60

Office of Energy Markets and End Use

Energy Information Administration 1000 Independence Avenue, S.W. Washington, DC 20585
No. of

copies

OEFSIIE

Katherine E. Seiferlein, EI-642

Statistics Branch

Office of Energy Markets and End Use

Energy Information Administration 1000 Independence Avenue, S.W. Washington, DC 20585

Richard Sto11, EI-642

Statistics Branch

Office of Energy Markets and End Use

Energy Information Administration 1000 Independence Avenue, S.W. Washington, DC 20585

30 DOE Technical Information Center

ONSIIE

DOE Richland Operations Office JJ Sutey/KR Absher

12 Pacific Northwest Laboratory

RC Adams

JM Fang

KL Imhoff

LG McWethy

RJ Moe

Publishing Coordination (2)

Technical Information (5) 
